University of Montana

ScholarWorks at University of Montana

Graduate Student Theses, Dissertations, \&

Professional Papers

\title{
Legitimacy and the Use of Natural Resources in Kruger National Park, South Africa
}

Randy Tanner

The University of Montana

Follow this and additional works at: https://scholarworks.umt.edu/etd Let us know how access to this document benefits you.

\section{Recommended Citation}

Tanner, Randy, "Legitimacy and the Use of Natural Resources in Kruger National Park, South Africa" (2007). Graduate Student Theses, Dissertations, \& Professional Papers. 619.

https://scholarworks.umt.edu/etd/619

This Dissertation is brought to you for free and open access by the Graduate School at ScholarWorks at University of Montana. It has been accepted for inclusion in Graduate Student Theses, Dissertations, \& Professional Papers by an authorized administrator of ScholarWorks at University of Montana. For more information, please contact

scholarworks@mso.umt.edu. 


\section{LEGITIMACY AND THE USE OF NATURAL RESOURCES}

IN KRUGER NATIONAL PARK, SOUTH AFRICA

By

Randy Tanner

M.S., Resource Conservation, The University of Montana, Missoula, Montana, 2004

B.S., Mathematics, Southern Illinois University, Carbondale, Illinois, 2001

Dissertation

presented in partial fulfillment of the requirements

for the degree of

Doctor of Philosophy

in Forestry

The University of Montana

Missoula, MT

Autumn 2007

Approved by:

Dr. David A. Strobel, Dean

Graduate School

Wayne Freimund, Chair

Department of Society and Conservation

Perry Brown

College of Forestry and Conservation

Mike Patterson

Department of Society and Conservation

Doug Dalenberg

Department of Economics

Karen Adams

Department of Political Science 
Legitimacy and the Use of Natural Resources in Kruger National Park, South Africa

Chairperson: Wayne Freimund

Around the globe, protected area managers confront an increasingly complex web of interests and demands, expressed by a variety parties, that often compete or conflict. When an action concerning the governance and management of a protected area is infused with such complexity, decision-making requires an evaluation of that action's legitimacy. Most often, this evaluation is implicitly made rather than expressly articulated. The purpose of this dissertation was both to illustrate the importance and utility of explicitly evaluating legitimacy and to provide a conceptual framework for understanding how the legitimacy of protected area governance and management may be understood.

To better understand the concept of legitimacy, I conducted a case-study of subsistencebased resource use in Kruger National Park, South Africa. The collection of firewood, medicinal plants, thatching grass, and meat by local residents living outside Kruger has long been a contentious issue. Since the Park's establishment in 1926, resource use among local residents has been almost entirely prohibited. With South Africa's democratization in 1994, though, Kruger became a park-in-transition. In the interest of equity and benefit provision, the current management regime is exploring the possibility of providing local residents some level of access to resources in the Park. Despite these interests, providing such access to resources is by no means considered a universally legitimate action.

As part of the case study, I conducted in-depth qualitative interviews with local residents, Kruger staff, and Kruger visitors, as well as a survey of Kruger visitors. Analysis revealed both common and varying conceptualizations of the legitimacy of resource use in Kruger among local residents. Procedurally speaking, all three groups largely believed that a consultative (rather than a co-management) approach to deciding how and what resources might be utilized would be the most legitimate approach. Substantively speaking, resource use was legitimated and illegitimated on a variety of dimensions including the morality, pragmatism, conventionality, and rationality of resource use. This study demonstrated that legitimacy is a multi-dimensional concept that, if explicitly evaluated, provides considerable insight into the governance and management of protected areas and may reveal previously unforeseen resolutions to complex issues. 


\section{ACKNOWLEDGMENTS}

It is a myth to think that one undertakes a dissertation on their own. Since the first day I arrived in Missoula after moving from southern Illinois, I have been surrounded by topnotch researchers, teachers, graduate students, and staff. All have contributed to this dissertation in very important ways. Wayne Freimund, my dissertation Committee Chair and Advisor, was there at every step to offer guidance on everything from framing my research questions to organizing the final draft of my dissertation. Perhaps just as important, though, Wayne was always willing to offer professional and personal advice, and I'm lucky to have made such a good friend along the way. Thanks, Wayne - I wouldn't have changed a thing!

My dissertation committee - Perry Brown, Mike Patterson, Doug Dalenberg, and Karen Adams - provided extraordinary support and exceeded any expectations that I had before I began this dissertation. From independent studies to in-depth discussions of the data, they were always accommodating and anxious to help.

Beyond my committee, our Department's faculty was always willing to assist in whatever way possible and took the extra steps to make us graduate students feel like their colleagues rather than their students. I owe special thanks, too, to all of the CFC staff, especially Shonna Trowbridge, Jodi Todd, Lynn Gruszie, Robert Logan, Gary Decker, and Sherri McWilliams who tolerated what must have seemed like an incessant stream of administrative, accounting, and computer questions.

One of the strongest features of our College and Department is the collegial environment our graduate students have created. I've made friends that I'll remember the rest of my life and received a lot of good advice from a number of graduate students - in particular, Chad Dear and Paul Lachapelle.

While conducting my research, I had the good fortune to be a part of the Treehouse Research Program for People and Conservation - a working group of professors and students from the University of Montana and the Centre for Environment, Agriculture and Development at the University of KwaZulu Natal. My participation in this program allowed me to travel to southern Africa on a number of occasions. In the course of that experience, I've made life-long friends that I would not have otherwise made and seen a world I would not have otherwise known. I would like to especially thank Wayne Freimund, Steve McCool, and Charles Breen for all of their guidance, advice, and making this opportunity possible.

South Africa National Parks and the United States Forest Service International Programs both provided substantial support for my research. The latter being the principal funding agent for this research and the former providing technical support and much of the data I collected and analyzed. Both were indispensible to the success of this research.

Nearly 400 individuals contributed data to this study through interviews or surveys. I appreciate the time they took out of their lives, their visits to Kruger, and their workday to speak with me about such an important issue.

I owe a special thanks to my parents, Margaret and Stephen Tanner. Throughout my life, they've taught me patience and determination, two traits that are absolutely necessary for any graduate student.

Finally, no one has offered more support than my wife, Jamie (and our dog, Rogan!). Jamie and I have been together throughout the entirety of this adventure, and I could always count on her love and confidence in me. This dissertation is dedicated to her.

Thank you to everyone who made this research possible, I hope the work I have put into it adequately reflects the time, energy, and encouragement you have provided me. 


\section{TABLE OF CONTENTS}

Chapter 1 - Introduction: The legitimacy of protected area governance and management

The complex and (sometimes) conflicted nature of protected areas

Protected areas and legitimacy

Resource use in protected areas

The study site: Kruger National Park, South Africa

Research questions and objectives

Outline of the dissertation

Chapter 2 - Protected Areas and the Call for Legitimacy

The evolving governance and management of Kruger National Park

The management of Kruger National Park before democratization

Early protection of Kruger National Park

"Management by intervention" in Kruger National Park

$\underline{\text { Towards decentralization }}$

The management of Kruger after democratization

$\underline{\text { Protected areas as adaptive systems in South Africa }}$

Protected areas and the call for legitimacy

Objectives and research questions for the study

Resource use and legitimacy

Conclusion

Chapter 3 - Conceptualizing "Legitimacy"

Social and behavioral conceptualizations of "legitimacy"

Weber and "legitimacy" 
Normative conceptualizations of "legitimacy" $\quad 57$

Habermas' response to Weber $\quad 57$

Contemporary normative conceptualizations of legitimacy 63

Deliberative democracy as legitimacy $\quad 64$

Instrumentalism and pragmatism as legitimacy $\quad 66$

$\begin{array}{ll}\text { Constitutionality and the law as legitimacy } & 68\end{array}$

$\begin{array}{ll}\text { A synthetic framework for understanding and exploring legitimacy } & 71\end{array}$

A synthetic definition of "legitimacy"

Normative criteria for legitimacy $\quad 76$

$\begin{array}{ll}\text { A synthetic conceptual framework } & 79\end{array}$

$\begin{array}{lr}\text { Conclusion } & 84\end{array}$

$\begin{array}{ll}\text { Chapter } 4 \text { - Research Design } & 86\end{array}$

$\begin{array}{ll}\text { Critical theory as a research tradition } & 87\end{array}$

$\begin{array}{lr}\text { Critical theory and legitimacy } & 90\end{array}$

A case-study and mixed-method approach to research 92

$\begin{array}{ll}\text { A mixed-method approach } & 94\end{array}$

Data: instruments, collection, and analysis $\quad 96$

$\begin{array}{ll}\text { Interview data } & 98\end{array}$

$\begin{array}{ll}\text { Sampling } & 104\end{array}$

1. Sampling Park staff and local residents - snowball 104 sampling

2. Sampling Park visitors - systematic random sampling 106

$\begin{array}{ll}\text { A brief description of the samples } & 107\end{array}$

$\begin{array}{ll}\text { Analysis - a grounded theory approach } & 109\end{array}$

$\begin{array}{ll}\text { Survey data } & 111\end{array}$

$\begin{array}{ll}\text { The questionnaire } & 112\end{array}$ 
A brief description of the questionnaire sample

$\underline{\text { Analysis - multivariate statistical analyses }}$

Testing logic: connecting the data and theory

The abductive logic of a critical theory approach

The function of the interview data

The function of the survey data

Summary

Limitations to the research design

Limitations associated with the interview data

Limitations associated with the survey data

Conclusion

Chapter 5 - Insight into the Context: Local Resident Perspectives on the Evolving Park-People Relationship

Historic populations in the Park

"Skukuza": the forced removal of Park inhabitants

Before and after Apartheid

Conclusion

\section{Chapter 6 - Contemporary Resource Use in Kruger National Park and} Resources in Demand among Local Residents

Resources currently of interest to local residents

Wood 
Chapter 7 - Conceptualizing the Legitimacy of Resource Use in Kruger National Park - Park Staff

Kruger staff and the legitimacy of resource use

A brief look at Kruger's integrated conservation values

Kruger staff and the substantive legitimacy of resource use among local residents

Resource use as legitimate

Fulfilling Kruger's mandate

A moral responsibility to provide benefits

$\underline{\text { A strategic tool }}$

Resource use as illegitimate

Moral responsibilities and the rationale for protected areas

The need for precaution in the face of uncertainty

The inability to meet demands for resources

Kruger staff and the procedural legitimacy of resource use among local residents

An overview of Park staff conceptualizations of the legitimacy of

resource use

\section{Chapter 8 - Conceptualizing the Legitimacy of Resource Use in Kruger National Park - Local Residents}

Local residents and the legitimacy of resource use

Local resident thoughts on the importance of Kruger National Park 
The resource gradient 243

Resource use as illegitimate $\quad 245$

Local residents and the procedural legitimacy of resource use 248

An overview of local residents' conceptualization of the legitimacy

of resource use

Chapter 9 - Conceptualizing the Legitimacy of Resource Use in Kruger National Park - Park Visitors

The values visitors assign to Kruger National Park 258

$\begin{array}{ll}\text { Interview data } & 259\end{array}$

Survey data 262

Park visitors and the substantive legitimacy of resource use 265

Interview data and qualitative survey data 265

$\begin{array}{ll}\text { Survey data } & 268\end{array}$

A synthesis of the interview and survey data 280

Park visitors and the procedural legitimacy of resource use 280

An overview of Park visitor conceptualizations of the legitimacy 285

of resource use

Resource use within the broader collection of local residents'

interests 
Contemporary relationships with surrounding private game $\underline{\text { reserves }}$

Community levy and financial benefits: an example of a supplementary approach

Conclusion

\section{Chapter 11 - Contributions to a Framework for Understanding Legitimacy in Protected Area Governance and Management}

A framework for understanding legitimacy

Legitimacy and context

Dimensions of legitimacy

Legitimacy and the resolution of protected area issues

Deciding which legitimations matter

Reconciling multiple legitimations: "legitimacy spaces"

\section{Appendices}

Appendix A - Visitor questionnaire with summary statistics

Appendix B - Visitor questionnaire cover letter

Appendix C - Sustainable Use - Statement of Intent (from the Kruger

National Park Management Plan) 


\section{LIST OF TABLES, FIGURES, \& BOXES}

\section{Tables}

Table 1-1: Threats from the loss of natural capital

Table 4-1: Links between concepts, research questions, interview questions, and survey questions

Table 4-2: The Grounded Theory approach

Table 4-3: Survey distribution at entry gates

Table 4-4: Survey distribution at rest camps

Table 6-1: Primary resources of interest to local residents

Table 7-1: SANParks corporate and conservation values

Table 9-1: Descriptive statistics for values scale items (visitor survey question 7) 263

Table 9-2: Should resource use be allowed in Kruger? (survey question 11(a)) 273

Table 9-3: Descriptive statistics for resource-use scale items (survey question 9) 274

Table 9-4: Logistic regression results for resource-use scale items (survey question

9) with question 11(a) as dependent variable

Table 9-5: Correlation for resource use scale items

Table 9-6: Restricted logistic regression model for resource use scale with question 11(a) as the dependent variable

Table 9-7: Who should decide how and what resources will be gathered? (survey question 11(b))

Table 10-1: Conceptualizing the legitimacy of resource use - a summary 289

Table 10-2: Should the Park provide other benefits to local residents? 291

Table 10-3: Access to resources and a community levy - responses from Park visitors who felt benefits should be provided

\section{Figures}

Figure 1-1: Kruger National Park, South Africa 13

Figure 2-1: South Africa $\quad 22$ 
Figure 2-2: The Adaptive Management Process

Figure 3-1: A synthetic and systemic conceptual framework for understanding and exploring legitimacy

Figure 4-1: Research trajectory

Figure 7-1: A model of Park staff conceptualizations of the legitimacy of resource use

Figure 8-1: A map of local resident conceptualizations of the legitimacy of resource use

Figure 9-1: A map of Park visitor conceptualizations of the legitimacy of resource use

Figure 11-1: A synthetic, conceptual framework for understanding legitimacy

Figure 11-2: Park staff and animal rights activists' conceptualization of the legitimacy of elephant population control

Figure 11-3: The intersecting legitimacy spaces of Park staff and animal rights activists concerning elephant population control

Figure 11-4: Scenarios for shared perceptions of legitimacy

\section{Boxes}

Box 2-1: "Centralized Protectionism" 26

Box 2-2: "Decentralization"

Box 2-3: "Systems Thinking” and "Adaptive Management” 35 


\section{CHAPTER 1}

INTRODUCTION:

THE LEGITIMACY OF PROTECTED AREA GOVERNANCE AND MANAGEMENT

On the morning of July 8, 2007, I sat in an airport café in Johannesburg reading a complimentary copy of The Sunday Independent provided to me while en route to South Africa's Kruger National Park. On the front page was a feature of the twenty-four-hourlong "Live Earth" concert held the previous day in 7 cities across 7 continents as a means to raise awareness of a "climate in crisis." That the concert was held on 7-7-07 was, perhaps, not merely a matter of circumstance but a recognition that it just might take a little luck to solve our most pressing environmental challenges. What was somewhat surprising about the Independent's coverage of the concert was that it made no attempt to highlight the army of entertainers or the ubiquitously lamented perils of global warming. Instead, the article presented a poignant analysis of findings from the South African government's recently released 2006 South Africa Environment Outlook (SAEO) report that, among other things, suggested the country was spending its "natural capital" at an alarming rate. Among the findings of the report were a number of resultant threats to both the natural world and the livelihoods of the "many rural dwellers" who are the most vulnerable to a deteriorating environment (see, e.g., Table 1-1).

Whether or not it was the author's intent, the article revealed to the mainstream both the important link between natural resources and rural livelihoods and, perhaps more fundamentally, one of the most vexing tensions that protected areas are confronted with. Namely, how protected areas - as critical reserves of natural resources - can and should contribute (if at all) to improving the rural livelihoods of their neighbors without further 
Table 1- 1: Threats from the loss of natural capital

Threats to the natural world Threats to livelihoods

Biodiversity loss is increasing with almost 10 percent of South Africa's birds and frogs and 20 percent of its mammals threatened.

Natural resources are being exploited in an unsustainable way threatening the functioning of ecosystems
Food production has been decreasing since 1975.

South Africa's poverty index increased from $16.4 \%$ (one year after democratization) to $31.7 \%$ in 2002 , representing an increase of 1.7 million people living on less than $\$ 1$ a day.

Source: The Sunday Independent, July 8, 2007, page 1

endangering natural resources that are already threatened? If, as the SAEO report suggested, food production in South Africa is decreasing as poverty seems to be increasing, is it legitimate to turn to protected areas for the resources that rural people need to survive, or will further exploitation of protected areas only exacerbate poverty and result in the irreversible loss of biodiversity? The question is essentially one concerning the legitimacy of the multiple demands or expectations that are increasingly placed on protected areas.

With this dissertation, I sought to explore this nexus of legitimacy, protected areas, and rural livelihoods through a case study of "resource use" in Kruger National Park, South Africa, from the perspectives of local residents, the staff of Kruger National Park, and visitors to Kruger National Park. Three primary research questions framed this study: 
Research question \#1: What are the resources in demand among residents living near the western boundary of Kruger National Park?

Research question \#2: How do different groups - i.e., Park managers, local residents, and visitors - conceptualize the legitimacy of resource use?

Research question \#3: Are there possible strategies for resolving competing or conflicting conceptualizations of legitimacy?

As this dissertation demonstrates, questions concerning the legitimacy of how society relates to protected areas are far from trivial. But, they are, nonetheless, fundamental, and explorations of such questions are necessary if societies elect to ensure their continual existence.

\section{The complex and (sometimes) conflicted nature of protected areas}

One of the most challenging questions that protected areas have been faced with over the past several years is for whom and why do they exist? In 1872 Yellowstone National Park - the world's first national park - was established in order to preserve a landscape rich in wildlife, geological, and aesthetic features. Since then, the establishment of protected areas has been rationalized as a mechanism to both preserve and conserve genetic and biological diversity, to drive economic development through tourism, to provide recreational opportunities, to meet the needs of subsistence-based lifestyles, to facilitate the realization of spiritual and other values, and to provide environmental services (e.g., clean air and water) among others.

While it is clear that protected areas have been established to meet multiple demands, it is also true that many of these demands are viewed as incommensurate. Some scholars, for instance, argue that the fundamental goal of protected areas is to 
preserve the diversity and richness of natural resources, lest the human hand destroy our last remaining natural areas and species (Redford and Sanderson 2000; Robinson 1993; Terborgh 1999; Terborgh 2000; Brandon, Redford, and Sanderson 1998; Kramer, van Schaik, and Johnson 1997). Humans, then, are viewed as separate from the natural environment and human activities such as resource utilization for subsistence purposes are viewed as illegitimate. Conversely, others have argued that protected areas rather serve as institutions for the conservation of natural resources and may also provide for more consumptive benefits including the utilization of resources (e.g., timber, hydropower, medicinal plants, etc.) and economic development (e.g., eco-tourism) (West and Brechin 1991; Wells, Brandon, and Hannah 1992; Ellis 1998; Lehmkuhl, Upreti, and Sharma 1988; Wilshusen, West, and Fortwangler 2003; Dixon and Sherman 1990; Stevens 1997). The assumption, in this instance, is that humans have always been both a part of and dependent upon landscapes that are now demarcated as protected areas and that there is often little evidence to suggest that human interaction with and direct consumption of protected area resources necessarily leads to resource degradation (Wilshusen and others 2002; Lado 1999; Lado 2004; Mistry and others 2004; Spaargaren 2003).

Not only has the substantive nature of protected areas evolved in response to a broad array of emerging interests and demands, but so, too, has the process by which they are governed and managed. Considered by many to be outmoded, the "fences and fines" or "centralized protectionist" approach to management and governance - characterized by an expert-driven and, at times, exclusionary philosophy - has, in many circumstances, given way to "collaborative" or "community-based" management and governance that 
champions inclusiveness and consensus-building (see, e.g., Child 2004, 22; Terborgh 1999; Agrawal and Clark Gibson 1999; Kellert 2000; Chambers 1997; Holt 2005; Huff 2005; Barrow and Murphree 2001; Belsky 1999;).

In truth, seldom are either of these approaches and the multitude of interests realized in their purest forms. The management and governance of protected areas is typically an amalgamation of centralized and deliberative approaches, depending upon the substantive issue in question. Wildlife management might be controlled by governmental agencies, whereas eco-tourism and concessions management might be largely administered by the private sector. In this manner, the evolving demands and expectations that are placed on protected areas, coupled with the changing way in which they are managed and governed, have given rise to complex public debates that sometimes seem to foster a deeply conflicted or confused assessment of why protected areas exist and who should make that determination.

\section{Protected areas and legitimacy}

One of the most important contributions that social science has made in terms of the way protected areas are understood is that it has brought to the forefront the importance of context. As a matter of philosophy, the existence and purpose of protected areas is increasingly portrayed not as a function of universal norms but of organic values and beliefs borne of the historical and contemporary context within which individual protected areas exist. Stated quite frankly, there is a recognition that what works in one time and place might not always work in another. Consequently, as some scholars have recently argued, protected area management and governance might be less a matter of 
abstractly choosing between centralization and decentralization or the protection of biodiversity and the improvement of livelihoods and more a matter of identifying and constantly re-negotiating the combination of strategies that engender a widely shared belief that management and governance are legitimate (see, esp., Brechin and others 2002; Wilshusen and others 2003; Murphree 2004).

Society's belief that the management and governance of protected areas is legitimate (within whatever context that assessment might be made) is, perhaps, the surest guarantor that protected areas will continue to exist in democratic societies. This is particularly true in transitional societies, such as South Africa, where historic protected area regimes symbolize the former marginalization of emerging, dominant classes (e.g., black South Africans). In such settings, organizations administering protected areas are re-casting their objectives and purposes in order to legitimize the existence of those areas among the new powers (Mabunda, Pienaar, and Verhoef 2003). Moreover, from an instrumental perspective and within the context of both established and transitional societies, the belief that management and governance are legitimate engenders a sense of ownership among constituencies that galvanizes their deference to or observance of protected area objectives (Brechin and others 2002).

Despite the cardinal, but admittedly veiled, significance of the concept of legitimacy as it relates to protected areas, only a handful of studies and writings have directly addressed the topic. McGuire and Sanyal (2006) offer an analysis of the legitimacy of watershed management on National Forests. Mascarenhas and Scarce (2004) address the concept within the context of forest planning in British Columbia. Johnston and Soulsby (2002) discuss legitimacy and social justice as they relate to 
environmental policies in northern Scotland. Kull (2002) presents a study of the legitimacy of community-based natural resource management in Madagascar. And, Brechin and others (2002) and Murphree (2004) describe legitimacy as a key consideration in protected area management and governance. While all of these studies and writings address the concept of legitimacy, not all define or offer a conceptual description of legitimacy, and where the concept has been defined, it has been done so inconsistently across studies. Some (see, e.g., Mascarenhas and Scarce 2004), for instance, equate legitimacy with the degree to which objectives or goals are successfully met. Others, such as McGuire and Sanyal (2006), adopt a decidedly procedural definition where legitimacy is tantamount to deliberative democracy.

As demonstrated in this study, it is, perhaps, true that all of these conceptualizations are correct within particular contexts - different combinations of procedural factors (e.g., whether or not a decision-making process is consistent with deliberative democracy) and substantive factors (e.g., whether or not particular interests are served by an action) produce different perceptions of legitimacy in different settings. Within current protected area scholarship, though, a holistic analysis of the concept of legitimacy - that incorporates the way in which the concept is understood across a broad array of disciplines (e.g., political philosophy, communication studies, sociology, etc.) has yet to be articulated. It is my opinion that in the absence of such an analysis and notwithstanding the emerging interest in legitimacy, the concept remains under-theorized and under-appreciated within the context of protected area management and governance. By understanding the variety of ways in which legitimacy is conceptualized, there are 
greater opportunities for resolving the most challenging issues that protected areas are confronted with.

A fundamental purpose of this study was to respond to this knowledge gap. Legitimacy has been put forward as a concept central to the management and governance of protected areas, but to date, it has arguably received only a superficial theoretical treatment. Through this study, I have attempted to contribute to the growing body of scholarship concerning legitimacy and protected areas by holistically exploring the concept as it is constructed through the eyes of a number of different groups and individuals. Moreover, while I believe this study offers philosophical and conceptual insights, I also had the good fortune to explore the concept of legitimacy through the lens of an important, practical issue that has relevance across a number of protected areas worldwide.

\section{Resource use in protected areas}

"Resource use" within protected areas may be thought of in a number of different ways. It may be defined, for instance, in terms of subsistence, which is the traditional or customary use of natural resources for personal or family consumption (Lado 2004; Smith and Wishnie 2000). Or, it may also be defined more broadly as "uses or impacts on the scenery, soils, water and nutrient cycles, habitats, flora and fauna, and the balance between trophic levels, in ecosystems" (South Africa National Parks 2002). Perhaps most commonly, though, resource use is defined as the collection, transportation, and utilization of natural resources for either personal, household, or commercial purposes (Holmes 2003; De Boer and Baquete 1998; Lado 2004; Kajembe and others 2003; 
Moleele and Mainah 2003; Smith and Wishnie 2000; Stewart and Weidema 2005; Spaargaren 2003).

The use of resources has historically been an important and, at times, controversial issue that protected areas have been confronted with. As local residents who stand to benefit from those resources have gained increasing power and decision-making authority through the decentralization of protected area management, their demands for access to resources in protected areas utilization have become increasingly legitimized. Nevertheless, proponents of the historical, centralized approach to management and governance still hold considerable power within South Africa and many fear that by allowing resource use within protected areas, the flora and fauna will be irreversibly degraded. As a result, resource use within many protected areas in South Africa has either been prohibited or heavily restricted. The tides are turning in significant ways, though, as new legislation (e.g., the Protected Areas Act of 2004) explicitly sanctions resource use in protected areas as a means to provide human benefits. And, while the Act states that resource use "may" (rather than "shall") be provided, agencies, such as South Africa National Parks, which administers Kruger National Park, are committing considerable time and effort to understanding how access to resources may be provided to local residents in a manner that is viewed as legitimate by its constituents (e.g., including Park visitors, as well as the broader society).

South Africa, then, as a transitional society on many different levels, might be faced with what Habermas termed a "legitimation crisis" where the actions of a government (in this case the prohibition or heavy restriction of resource use) might no longer be viewed as legitimate by one or more of its constituencies that now has the 
power to challenge those actions (Habermas 1975, 68-75). Resource use is perhaps not at the "crisis level" in the common use of the phrase, but South Africa National Parks has expressed a clear and immediate need to understand how the provision of access to resources among local residents can be legitimately implemented (if at all) within the context of other Park objectives and mandates. This need, coupled with the opportunity to expound upon a concept of paramount importance to protected area management and governance, is the fundamental motivation for this dissertation. Through this dissertation - with Kruger National Park as a case study - I aimed to (1) describe the current demands and interests among local residents pertaining to resource use in the Park, (2) explore how Park staff, local residents, and Park visitors conceptualize the legitimacy of resource use, and (3) identify possible resolutions to the resource use issue in the face of competing or conflicting conceptualizations of its legitimacy.

For those with an interest in legitimacy and conservation, resource use is certainly not the only issue meriting an examination. Issues such as human-wildlife conflict, ecotourism, sustainable development, and transboundary conservation all have the potential to contribute to a more complete understanding of legitimacy. I chose, though, resource use as the substantive frame of reference for this dissertation for two primary reasons. First, resource use - particularly in the context of poverty alleviation and sustainable development - is a dominant social issue in many protected areas around the world (Mulongoy and Chape 2005; Wilshusen and others 2002; Negi and Nautiyal 2003). As such, protected area managers, decision-makers, and constituencies worldwide stand to benefit more from an examination of legitimacy in the context of resource use rather than ancillary issues or localized issues. 
Second, resource use is an issue that strikes at the very heart of a protected area's existence. In fact, in the course of preliminary interviews with Kruger staff, resource use was identified by many of the interviewees as the \#1 social issue they are currently confronted with. How, some might ask, can a protected area legitimately be set apart and protected from poverty-stricken societies whose livelihoods might dramatically improve should they be allowed to utilize resources within the area - particularly in areas such as those adjacent to Kruger National Park where resources outside of the Park are dramatically degraded (Pollard, Shackleton, and Carruthers 2003, 434)? That question, many would argue, is a naïve appeal to the heartstrings of decision-makers and organizations with a zeal for social justice and does not take into account the interests of and benefits provided to national and international protected area constituencies (e.g., environmental services, genetic banking, etc) (Redford and Sanderson 2000; Terborgh 1999; Terborgh 2000; Brandon, Redford, and Sanderson 1998; Kramer, van Schaik, and Johnson 1997). The validity of both viewpoints, and everything found between, is contingent upon what it means for an action to be legitimate within a protected area. Consequently, not only does this study of resource use provide insight into the conceptualization of legitimacy, but I am also hopeful that it will result in a useful way to frame a debate - i.e., what constitutes legitimacy in protected areas - that arguably has as much history as protected areas themselves. And, nowhere is this debate more relevant than Kruger National Park, South Africa. 


\section{The study site: Kruger National Park, South Africa}

Kruger National Park - one of the world's largest protected areas at more than 2 million hectares - is situated in the far northeastern corner of South Africa (see Figure 11). With Mozambique's Limpopo National Park immediately to the east and Zimbabwe's Gonarezhou National Park immediately to the north, the three contiguous parks joined efforts in 2000 to create the Great Limpopo Transfrontier Park. Kruger is divided into six ecosystems that are home to 517 species of birds, 1,982 plants and 147 mammals, many of which are either endemic to Kruger or are endangered. Kruger is also a land with a rich cultural heritage marked by bushman rock paintings and a number of other archaeological sites found in the Park. Today, humans do not inhabit the Park (other than Park staff), but more than 2 million people live along or near the Park's western boundary (far fewer people inhabit the Park's eastern boundary shared with Mozambique). Aside from the private game reserves, most of those living near the Park's western boundary are indigenous Vhavhenda, Tsonga, Pedi, and Swazi peoples who live on rural or disbursed urban communal lands. Poverty and HIV/AIDS are rampant among those living along the boundary and there is a heavy dependency on basic natural resources, such as wood used for firewood, that are becoming increasingly exhausted.

Over the past two decades, South Africa has undergone a transition - in politics, demography, and economics - of massive proportions. At the beginning of the twentieth century, the entire region was under the control of colonial powers that conventionalized the disenfranchisement of indigenous peoples. In terms of protected areas, indigenous 
peoples were dislocated from lands they traditionally occupied in order to establish protected areas (including Kruger), prohibited from utilizing the resources

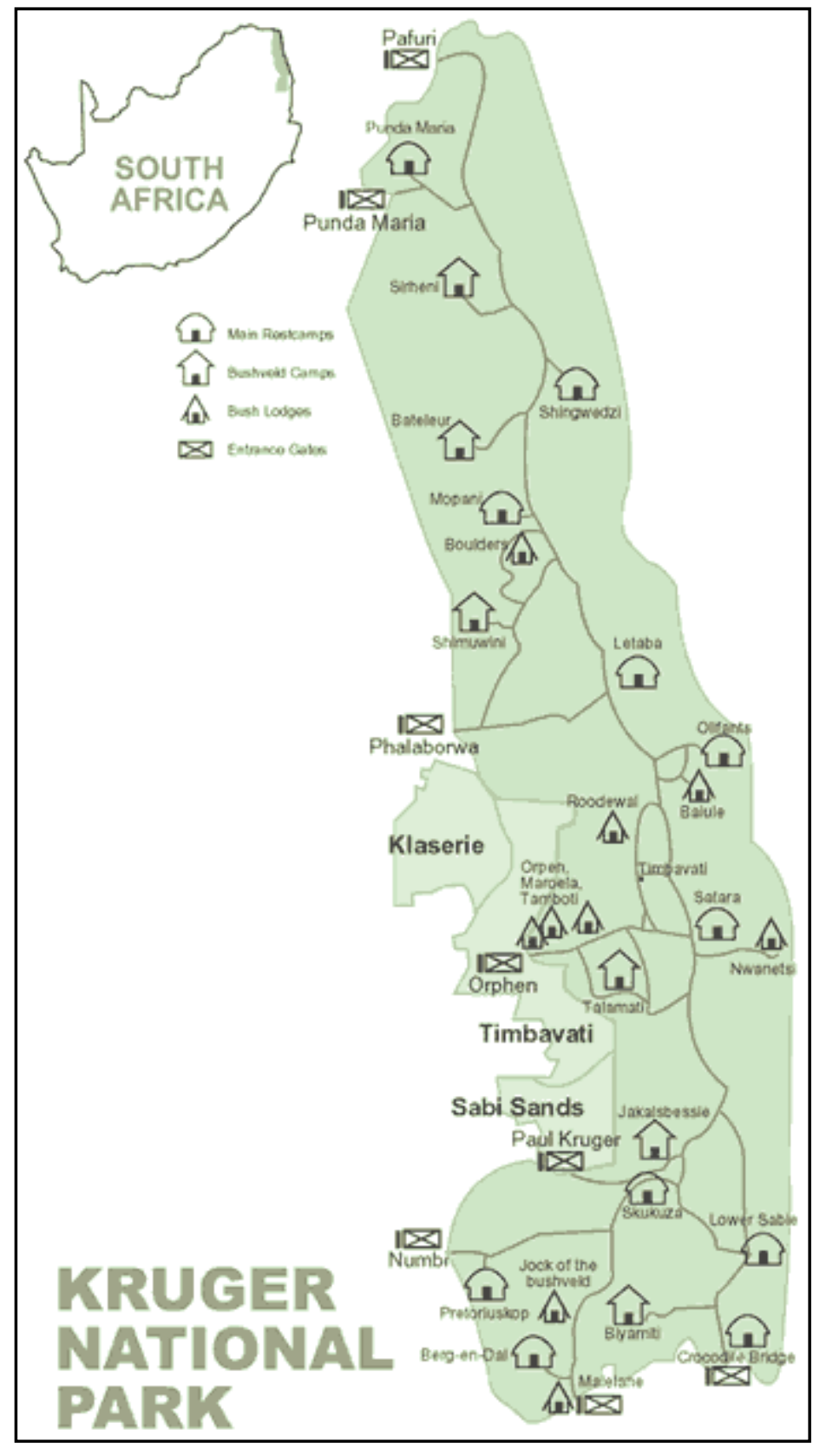

Figure 1- 1: Kruger National Park, South Africa

from those areas for subsistence (or any other purpose), and economically marginalized to the extent that it was virtually impossible for them to even visit the areas (Carruthers 1995).

With the democratic transition throughout southern Africa at the end of the twentieth century, though, the empowerment of indigenous peoples was institutionalized and, consequently, their relationship with parks and protected areas was predicted to change in very fundamental ways (Murphree 2004). First, in countries such as South Africa and Zimbabwe, radical initiatives were undertaken to both redistribute traditional lands back to indigenous peoples and/or 
provide them with restitution for forced removals. Second, indigenous peoples were expected to gain a voice in the protected area planning and policy process that would call for decentralized management strategies and a recognition that, in addition, to preserving biodiversity, protected areas could also facilitate poverty alleviation resulting from colonial repression (Sinha and Bushell 2002; Bell 1999; Berkes and Folke 1998; Foggin et al. 2000). Third, the emergence of a black middle class would translate to increased protected area visitation by blacks and other indigenous peoples. In short, the region was and continues to witness the birth of a new and potentially very powerful constituency.

These changes, though, have been met with mixed success. Many mechanisms targeted at empowering indigenous constituencies - e.g., community-based natural resource management initiatives, eco-tourism, integrated conservation and development programs, etc. - have not met the expectations of donor organizations funding the programs or governments and indigenous constituencies implementing them (Lane and McDonald 2005; Campbell 2001; Fakir 2001). As noted in Table 1-1, the poverty index in South Africa has actually risen following democratization. Moreover, the ecological systems in communal lands within which local residents live are increasingly vulnerable and exhausted of the natural resources that local residents are dependent upon (Pollard, Shackleton, and Carruthers 2003).

It has been argued that the perceived failure of these community-empowerment initiatives can be attributed to a lack of intellectual and economic capacity among implementing parties (particularly indigenous constituencies) (see, e.g., Sagar and VanDeveer 2005; Dzigirai and Breen 2005; Jones and Murphree 2004). However, and perhaps more fundamentally, an equally plausible explanation may be that government 
agencies and departments, donor organizations, and indigenous constituencies do not view the initiatives as contextually legitimate and, consequently, there is a lack of will to implement them (see, e.g., Kull 2002). Why, for instance, would communities situated in and around protected areas adopt an imposed eco-tourism initiative when what they might actually desire is access to protected area resources for subsistence purposes - is eco-tourism the most legitimate framework within which empowerment and the devolution of governing and managing power may occur?

The historically centralized protected area regime is giving way to devolution and an emphasis on the provision of human benefits, but the legitimacy of those efforts has yet to be thoroughly explored (Carruthers 1995). This knowledge gap, combined with the large population of indigenous peoples living immediately adjacent to the Park (numbering in the millions) makes Kruger an ideal study site to explore the role of legitimacy in protected area policy, planning, and management. This is particularly true in the context of resource use for subsistence purposes which, at present, is prohibited within the Park but has been described by some Park staff as the most pressing social issue they face. Recognizing that new acts and policies provide for the sustainable utilization of natural resources and that resource degradation is rampant on the lands inhabited by indigenous constituencies adjacent to the Park, there is a growing interest among policy- and decision makers to understand the demands of surrounding communities related to resource use, as well as the most legitimate ways to incorporate those demands and interests into Park policies and management. 


\section{Research questions and objectives}

Like many social science studies related to protected areas, this study contains both conceptual and applied themes. On one hand, contributing to the theoretical understanding of legitimacy was a fundamental objective of this study. But, on the other hand, this study was also undertaken to inform South Africa National Parks and its constituencies as they confront an important, complex issue. I attempted to achieve these two objectives by responding to three fundamental questions:

Research question \#1: What are the resources in demand among residents living near the western boundary of Kruger National Park?

Research question \#2: How do different groups - i.e., Park managers, local residents, and visitors - conceptualize the legitimacy of resource use?

Research question \#3: Are there possible strategies for resolving competing or conflicting conceptualizations of legitimacy?

From a practical standpoint, at the time this research was undertaken, little was known of the specific types of resources that were of interest to local residents. The first research question was posed in order to identify the resources that local residents were most interested in accessing. As I explored this question, it was evident that the historical relationship between the Park and local residents, as well as their current livelihoods, were important factors that shaped the resources (and benefits more broadly defined) of interest.

Through the second research question, I attempted to identify the variety of ways that Park managers, local residents, and visitors conceptualize the legitimacy of resource use in Kruger. As the findings in this dissertation demonstrate, the way in which individuals from these three groups framed the legitimacy of resource use was driven by 
contextual factors, as well as more specific substantive and procedural considerations that were expressed in terms of moral, rational, pragmatic, and conventional dimensions. Taken together, the variety of ways in which legitimacy was conceptualized provided insight into a more general framework for understanding the legitimacy of protected area management and governance that I introduce in Chapter 2 and discuss more thoroughly in Chapter 11.

The exploration of the various ways that the legitimacy of resource use was conceptualized was not only instructive from a theoretical perspective, but it also provided insight into how the resource use issue might be resolved (see research question 3). Resource use proved to be a contested issue among local residents, Park staff, and visitors and there was no clear indication of a single, direct response to the resource use issue that would be universally viewed as legitimate. However, by recognizing (1) that other actions (such as the provision of developmental assistance) are responsive to many of the underlying interests that have given rise to the expressed interest in resource use and (2) those actions are more widely held to be legitimate than providing access to resources (including among local residents), there are possible resolutions to the issue that might engender a shared belief of legitimacy.

\section{Outline of this dissertation}

Throughout the course of this research, I relied and drew upon a number of conceptual, methodological, and analytic frameworks and approaches including normative and social/behavioral conceptualizations of "legitimacy," critical theory, grounded theory, and multivariate statistical analysis. Figure 1-2 illustrates how all of 
these frameworks and approaches come together in this dissertation as I respond to the fundamental research questions.

I begin the body of this dissertation in Chapter 2 by discussing the evolving way in which Kruger National Park has been managed and governed since it was established and how this evolution - as it has manifested similarly in numerous other contexts - has given rise to the need for a more refined understanding of legitimacy.

Taking this knowledge gap as a point of departure, in Chapter 3 I present a synthetic review of how legitimacy has been conceptualized across a diverse array of disciplines including political philosophy, social psychology, and communications studies, to name a few. In the latter part of the chapter, I argue that it is likely that none of these approaches to understanding legitimacy is "wrong" or exclusively "right" and that a synthetic framework (which I then present) that capitalizes on insights from a range of theories and approaches can facilitate a more holistic (and, perhaps, more useful) understanding of the legitimacy of protected area governance and management.

In Chapter 4, I discuss the research design for this study. Normatively speaking, this exploration of legitimacy is loosely grounded in the critical theory research tradition that is oriented towards resolving what is intersubjectively desired based on norms, values, beliefs, and definitions (e.g., a legitimate policy for resource use among local residents) and what manifestly exists (e.g., a resource use policy that local residents might likely view as illegitimate). More directly, I discuss in this chapter the case study approach I adopted, as well as the methods of data collection I employed, which included semi-structured interviews with Park staff, local residents, and Park visitors and a survey distributed to Park visitors. 
In Chapters 5 through 9, I present and discuss the results of my analysis of the data. In Chapter 5, I provide a look at local residents' perspectives on their relationship with Kruger. In Chapter 6, I then discuss the current state of affairs with respect to resource use in Kruger and the interests that local residents have in collecting resources from the Park. In Chapters 7 through 9, I present an analysis of how Park staff, local residents, and Park visitors conceptualize the legitimacy of resource, respectively. Finally, in Chapter 10, I then identify how the various conceptualizations of legitimacy give rise to possible ways in which the resource use issue might be resolved.

Having presented and discussed the results of my analysis of the data, in Chapter 11 I offer my perspective on how the findings of this study can contribute to a framework for understanding the legitimacy of protected area governance and management. In Chapter 12, I conclude by briefly reflecting on the strengths and limitations of this study, as well as suggesting a way forward for future research. 


\section{CHAPTER 2}

\section{PROTECTED AREAS AND THE CALL FOR LEGITIMACY}

\section{Introduction}

While it is true that protected areas serve a variety of interests, it is also true that there are often competing views regarding the legitimacy of those interests. In South Africa, for instance, protected areas were historically established to preserve dwindling populations of hunted game. Over the course of that time, though, interests have emerged in tourism, the preservation of aesthetically appealing landscapes, sustaining less charismatic biota, and more recently, employing protected areas to facilitate sustainable development and livelihood improvement. The evolving demands placed on protected areas are by no means unique to South Africa. In the last couple decades global democratization and greater attention to human rights has led to more decentralized approaches to protected area governance, and in many settings, the protectionist, "fortress conservation" philosophy has given way to more utilitarian approaches that allow for or encourage the sustainable utilization of protected area resources (e.g., firewood, medicinal plants, wildlife, etc.).

The philosophic transitions that have taken place have by no means been absolute, nor have they gone unchallenged. Instead, contemporary protected area scholarship, governance, and management may be characterized in terms of a variety of thematic approaches that translate to often very different objectives for protected areas. The resultant tensions between these approaches has, in turn, given rise to the contested legitimacy of actions ranging from community conservation and elephant culling to, as is 
the case for this dissertation, resource utilization. The conflicting or competing views regarding the legitimacy of actions within protected areas (and in some case the legitimacy of protected areas themselves) has facilitated the emergence of a growing interest among protected area scholars in the conceptualization and exploration of legitimacy as a socio-political phenomenon. The purpose of this chapter is to illustrate why the call for an understanding and exploration of legitimacy and protected areas has emerged by highlighting the historical transition in protected area thought - particularly within the context of South Africa - and to illustrate how the resultant themes in protected area governance and management have given rise to a growing interest in understanding the legitimacy of protected areas.

\section{The evolving governance and management of Kruger National Park}

In 1872, Yellowstone National Park was established by the United States Government "as a public park or pleasuring ground for the benefit and enjoyment of the people" (United States Congress 1872). While Yellowstone enjoys the status as the world's first national park, it is preceded by a long history of protected areas. Some historical records, for instance, indicate that areas of land were set aside in India more than two millennia ago for the purposes of protecting natural resources (Holdgate 1999). Moreover, despite protected areas being popularly conceived as public areas, European kings of the Renaissance frequently proclaimed "royal hunting reserves" in order to protect their wildlife from the peasantry (Williams 2005).

Societies have long set aside special areas for the purposes of protecting cultural or natural resources, but the movement to formalize the establishment of and create 
public access to these areas first materialized in the late nineteenth and early twentieth centuries. The series of dialogues, processes, and events through which societies came to terms with instituting protected areas as truly cultural artifacts were incredibly formative, as many of the themes that emerged in that era continue to either directly or indirectly dominate the contemporary protected area discourse. Historical and contemporary perspectives on Kruger National Park provide a particularly rich illustration of this phenomenon, as well as a demonstration of how protected areas can be both a cause and effect of societal change.

\section{The management of Kruger National Park before democratization}

The first region of South Africa to be colonized by Europeans was the Cape near present-day Cape Town (see Figure 2-1). The Cape Colony was established by the Dutch in 1652 primarily as a stopover for ships trading with the Dutch East India Company (the world's first multinational company), but was later seized by the British in 1797 to serve their own trading interests.

The colonization of the

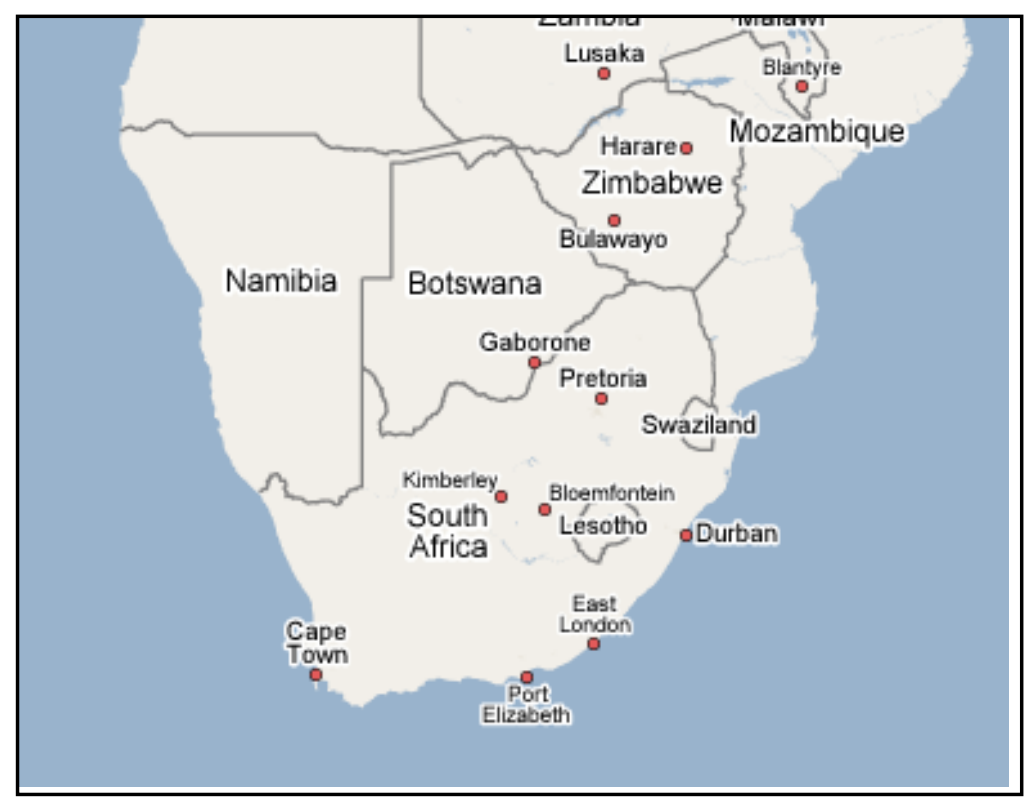

Figure 2- 1: South Africa (courtesy Google Maps (2007))

Cape by the Dutch and later the British introduced both a strong market economy and firearms, which in turn led to the over-exploitation of many natural resources including, 
in particular, the wildlife of the region (Carruthers 1995, 4). In fact, as early as 1654, Jan van Riebeeck, the Cape's founder and then Governor, was forced to introduce measures to squelch the extermination of penguins on Robben Island (Carruthers 1995, 4).

More expansive conservation legislation was introduced in the Cape after it was seized by the British in the late eighteenth century, but as the Dutch left the Cape in response to their dissatisfaction with British rule, the Cape became less of an area of concern in terms of conservation than did the Transvaal ${ }^{1}$ where Dutch settlers were migrating through. The Dutch settlers' "Great Trek" from the Cape through present-day Kruger and into Mozambique brought with it unfettered hunting for meat, skins, and ivory. Not only was there a need for these resources among the "voortrekkers," (many of whom did not survive the journey) but, as with the Protestant expansion in the United States, their Christian beliefs instilled a responsibility to conquer the "wild" and tame the "untamed" (including indigenous peoples) (Grove 1989). As settlements were established through the interior of South Africa north of the Orange and Vaal rivers (present-day KwaZulu-Natal), so too were trading networks for meat, skins, and ivory (Carruthers 1995, 5; Carruthers 2005).

It did not take long for the consequences of unrestricted hunting and commercial harvesting of wildlife in the Transvaal to become evident, and as a result, the regional parliament passed a resolution in 1846 to protect the dwindling herds. The 1846 legislation was very rudimentary in comparison to wildlife-related laws and regulations in the Cape at the same time, but it did mark a first step in establishing control over

\footnotetext{
${ }^{1}$ The Transvaal was an early province in South Africa that consisted of the present-day provinces of Gauteng, Limpopo, and Mpumalanga. It was within this region where the voortrekkers settled after leaving the Cape.

${ }^{2}$ In Dutch, voortrekker literally means "those who move ahead."
} 
wildlife in the Transvaal (Carruthers 1995). Ultimately, though, this and other legislation of that era suffered from the settler mentality that violating wildlife-related laws and regulations was not a serious offense (Grove 1989).

As the Voortrekkers established more permanent settlements, agriculture and industry prospered, and an urbanized elite emerged in the region (Grove 1989). More important to this group than commercial harvesting of wildlife were opportunities for recreational hunting. Many recognized the financial rewards of protecting wildlife in order to provide hunting opportunities for foreign travelers and the urban elite, and as a result, private game reserves began to dot the South African landscape. The first of these Reserves was the Pongola Game Reserve, established in 1889, but which was later abolished in 1921 as a result of ambiguity concerning its administration (Carruthers 2005). The Sabi and Shingwedsi Reserves followed in 1902 and 1903, respectively, and transformed into the lynch pin for the South African protected area system.

\section{Early protection of Kruger National Park}

With the realization that poaching and use of natural resources within the Sabi and Shingwedsi Reserves could not be controlled in the absence of a resident authority, Colonel James Stevenson-Hamilton was appointed warden of both Reserves, but he received, however, only vague directions that essentially amounted to a mandate to stop hunting activities in the area (Mabunda, Pineaar, and Verhoef 2003, 7). StevensonHamilton, assisted by black "game scouts," worked diligently to enforce the locally unpopular mandate, but enforcement was difficult, given the Reserves' large size and lack of infrastructure (Mabunda, Pineaar, and Verhoef 2003, 7). Exacerbating this challenge 
were the many isolated black families who were not employed by the Reserves but were living in the Reserves. Stevenson-Hamilton confronted this challenge by forcefully removing the families, thus earning him the nickname "Skukuza," which literally translates as "he who sweeps clean" (Carruthers 1995, 92).

Before these efforts were complete, the policy was reversed after Colonial authorities recognized that these families might be able to assist by providing labor and funding in the form of rent (Carruthers 1995, 92). Still yet, enforcement was a challenge, and Stevenson-Hamilton petitioned to have the the Sabi and Shingwitsi Game Reserves proclaimed as national parks with the hope that the proclamation would bring with it tighter restrictions and more adequate protection (Mabunda, Pineaar, and Verhoef 2003). His lobbying was eventually successful after the Nationalist party came into power in 1924. The National Parks Act was passed in 1926, and the Sabi and Shingwitsi Game Reserves were jointly declared the Kruger National Park - the country's first National Park. $^{3}$

The new legislation not only resulted in an increase in protection, but also a redistribution of power. Stevenson-Hamilton's autonomy was augmented with with oversight by a Board of Trustees and later an administrative organization - South African National Parks. As the central authority shifted from a single person to an organization, the rationale for protection morphed, as well. Whereas wildlife had principally been protected in an effort to preserve species for the later enjoyment of sportsmen, post-legislation protection became a matter of preserving Kruger National

\footnotetext{
${ }^{3}$ The Park's namesake is Paul Kruger, who Stevenson-Hamilton described as the first South African leader to call for setting aside land for game (Stevenson-Hamilton 1937). Interestingly, there are no accounts of Kruger having any interest in protecting wildlife. In fact, in 1884, the former hunter voiced his opinion against tighter controls aimed at protecting wildlife (Carruthers 1995, 15).
} 


\section{Box 2-1: "Centralized Protectionism"}

"Protection" has always been a key theme in protected area management and governance (the very term "protected area" implies this), but the object of protection and the way in which protection is effectuated has varied throughout history, both in South Africa and globally. Dramatic landscapes and unique geological features were central to the protection of the United States' first national parks, whereas wildlife was a defining object of early protection efforts in South Africa. In both cases, protection was a response to the perception that these resources, or opportunities to enjoy and utilize these resources, were diminishing or may potentially diminish (Jones 2006; Sellars 1997). According to the logic of centralized protectionism, which figured strongly in the establishment of protected areas in South Africa, resource degradation and scarcity requires the establishment of a central authority to guard and protect resources and/or biological diversity from human impacts.

Despite critiques based on democratic- or human-rights-based arguments, the logic of centralized protectionism has, by no means, become outmoded. Some contemporary scholars charge that opportunities for setting aside lands rich in natural resources are declining exponentially across the globe, and that societies should be compelled to protected what is already set aside and seek protection for those "last remaining bastions" that have yet to be set aside (Terborgh 1999, 59-92; Oksanen 2004, 18; Brandon, Redford, and Sanderson 1998, 1-23; Heckenberger and others 2007; Sarkar 2005; Oates 1997). As some have further argued, and as was the case with the establishment of some South African protected areas, implementing this protection may require dislocation of indigenous peoples and militant guarding (Terborgh 1999, 55-57).

While, perhaps an extreme view, those who subscribe to this approach maintain that the "ecologically noble savage" does not exist and that science must be favored over traditional or indigenous ecological knowledge when it comes to the management and governance of protected areas (Heckenberger and others 2007; Redford 1991). As discussed in this section, the logic of centralized protectionism played a key role in the establishment of South Africa's protected areas and, while in Kruger it has ostensibly given way to decentralized and "adaptive" approaches, elements of centralized protectionism remain as key features in contemporary management and governance.

Park as a symbol of "national heritage" to be enjoyed by the South African public

(Carruthers 1994). During the era of Apartheid, the South African "public" consisted of 
only white South Africans, and the Park's mission resonated primarily with Afrikaaner Nationalists ${ }^{4}$ (Meskell 2006).

For the most part, Stevenson-Hamilton, under the watchful eye of the Board of Trustees, assumed a protective approach to management that favored natural processes over scientific intervention. As he described in a "General Report" on the Park,

It pays best to trust nature in all matters pertaining to wild life. In the course of many millions of years she has evolved a system which has continued to work... [Scientists have]... developed a feeling that man can by his own efforts improve upon nature... science with its classical approaches and verbose jargon... can be very dangerous. (Carruthers 1995, 113 citing Stevenson-Hamilton 1946)

The management philosophy of the early Kruger National Park was not aimed at engineering a particular setting or manipulating the Park to provide certain opportunities, but was instead marked by protecting the integrity of the Park (sometimes by force when dealing with poaching) against human interference. In no way did this mean, though, that tourists were not welcome in the Park or were unable to learn about nature while in the Park. It was instead a matter of the Park itself, rather than "science," providing the instrument of instruction (Carruthers 1995, 113). This management philosophy gave rise to a very limited decision-space where essentially any human action - especially scientific activities - was off the table (Carruthers 1995, 113).

As Stevenson-Hamilton neared retirement in the mid-twentieth century, he came under increasing pressure from the Board of Trustees to accommodate the growing interests biologists and other scientists had in the Park. By the time he retired in 1946, scientific wildlife management had become modus operandi in African protected areas,

\footnotetext{
4 "Afrikaaner Nationalists" refers to the white descendants of Dutch Voortrekkers who would later institute Apartheid in 1948.
} 
and the South African National Parks Board began to tout scientific research as a means to fulfill their "educational responsibility" (Jones 2006; Carruthers 1995, 114). As a result of the emerging importance of research and its application, the Park's new motto became "management by intervention" (Steyn 1957).

\section{"Management by intervention" in Kruger National Park}

If "letting nature be what it is" was the mantra of the previous era of management, the scientific/interventionist approach initiated in the mid-twentieth century could be best characterized as a centralized effort to "manage nature for what it should be." The shift was an important one because the object of protection was no longer a landscape left to carry out "natural processes" but was, rather, a set of values identified with scientific protection of biodiversity and tourism/recreation (Moore and Masuku van Damme 2002). Research and management, for instance, was undertaken in an effort to re-introduce species previously extinct in Kruger, and veterinary services were introduced in the Park aimed at maintaining the health of those species that were threatened or that could transmit diseases to livestock living outside the Park (Mabunda, Pienaar, and Verhoef 2003, 11).

In terms of tourism and recreation, a vast road network was built, as well as "rest camps," complete with lodging and dining opportunities, that catered to the mobile, affluent visitors (Moore and Masuku van Damme 2002). Dictating, in no small part, these undertakings were the efforts by the Apartheid-instituting National Party to use national parks - in particular, Kruger - as a means to build a national identity and sense of unity among Afrikaans-speaking white South Africans (Mabunda, Pienaar, and 
Verhoef 2003, 13). Black indigenous populations were effectively prohibited from utilizing the Park in any way, which by design, precluded the opportunity to establish a sense of park-ownership among black South Africans.

The set of values that Kruger came to represent - scientific protection of biodiversity and tourism/recreation - materialized through corporate, technocratic, and insular management (Mabunda, Pienaar, and Verhoef 2003, 10-14; Moore and Masuku van Damme 2002). Research in the Park, for instance, was conducted by what some labeled an "inbred" scientific services department that did not interact with outside researchers or consider the impact of management on surrounding areas (Biggs 2004). In terms of infrastructure development, rather than tendering construction and maintenance to outside laborers, these tasks were accomplished almost exclusively by a corporate technical services department (Mabunda, Pienaar, and Verhoef 2003, 10). And, commercial services in the Park were run by corporate staff in lieu of the use of concessionaires. In all instances, black South Africans were relegated to temporary menial positions, whereas white (principally Afrikaaner) South Africans held the most influential positions. Irrespective of the merits or pitfalls of centralization as a governance and management philosophy, it resulted in the recognition of only a limited set of values, which as Moore and Masuku van Damme (2002) discuss was, tantamount to environmental racism.

\section{$\underline{\text { Towards decentralization }}$}

As evident from Kruger's history, even in eras of highly centralized control whether by a park warden or by an administering organization - the Park's purpose and 
essential character has never been static. While the Park was first established in order to protect dwindling game populations, Kruger later came to effectively represent a broader nationalist identity among the Afrikaaner society, a repository for scientific research and education, as well as a refuge for "wilderness experiences." In many respects, the goals associated with these purposes was successfully achieved precisely because the Park was administered by a relatively autonomous, central authority that enjoyed the luxury of being able to ignore large sectors of the South African population who might have potentially expressed discordant opinions regarding the purpose and goals of the Park (Moore and Masuku van Damme 2002). With the social transformation that followed the fall of Apartheid, though, the Park began to decentralize its authority and embrace an entirely new constituency - i.e., black South Africans - that would bring with it a set of norms, values, and beliefs that in some cases were viewed as incommensurate with the historical purposes of the Park. Notwithstanding incommensurabilities and the legacy of centralized protection, the inclusion of the concerns of previously marginalized groups has been a defining feature of governance and management in Kruger National Park over the past decade.

\section{The management of Kruger after democratization}

Democratization in South Africa facilitated the emergence of a new constituency for Kruger, but because of forced removals and a failure to establish a sense of Park ownership among black South Africans, the new constituency has not always assigned significant value to Kruger (Mabunda, Pienaar, and Verhoef 2003, 14). When land reform was institutionalized in 1994 - bringing with it the opportunity for those who had 
been removed from national parks to reclaim the land they had historically inhabited park managers feared the demise of the Park. ${ }^{5}$ Since the black community did not necessarily share the same sense of endearment towards parks that white South Africans had come to hold, some believed that development priorities would supercede conservation needs among claimants if lands in the Park were successfully re-claimed (Ramutsindela 2002). ${ }^{6}$

Nelson Mandela's comments at Kruger's centenary celebration ${ }^{7}$ suggest, though, that the interests of local communities (including those who were removed from Park) had less to do with land acquisition than benefits broadly defined:

In commemorating this historic day, we do not forget those who had to surrender their local land to make it possible, often through forcible removal, nor those who for generations were denied access to their heritage except as poorly rewarded labour. We recall these threads in our history not to decry the foresight of those who established the park, nor to diminish our enjoyment of it. We do so rather to reaffirm our commitment that the rural communities in and around our parks should also benefit from our natural heritage, and find in it an opportunity for their development. (Mandela 1998)

Moreover, the managers of Kruger came to recognize that,

The future survival of national parks such as Kruger will be guaranteed only by unconditional support of the black majority of South Africa's population. The challenge to managers is to make national parks relevant to the daily lives of all South Africans. (Mabunda, Pienaar, and Verhoef 2003, 17)

\footnotetext{
${ }^{5}$ For a comprehensive overview of land reform in South Africa, see Ramutsindela (2003), Levin and Winer (1997), and de Beer (2006).

${ }^{6}$ Beyond regaining title to land, though, there were and still are a number of options for black South Africans within the land reform framework. Restitution, in the form of monetary compensation or alternative land, is the most exercised option for claims based on forced removals and is the most applicable avenue for land reform in national parks (African National Congress 1994). To date a few successful claims have been made within the park - the most well-known being the Makuleke claim of 1998. Currently, a little more than $50 \%$ of the Park is claimed.

${ }^{7}$ The centenary celebration marked the 100 years from when there was first interests in establishing the game reserves that would become Kruger National Park rather than the designation of the National Park as such.
} 
The insular and autocratic decision-making organization could no longer function unchanged under the new sociopolitical system. Significant changes in administration and external partnerships necessitated that choices be justified in terms of explored options, forcing reconsideration of entrenched policies. (Biggs and Rogers 2003, 61)

To say the least, a new era of management had emerged (at least in principle) in Kruger. Ostensibly gone was the supremacy of centralized scientific management and set in its place were objectives aimed at decentralizing management and providing benefits to historically disenfranchised populations. As provided in the Protected Areas Act of 2003, protected areas ${ }^{8}$ - including Kruger National Park - were to serve a number of objectives including, but not limited to,

- providing opportunities for "cooperative governance in the declaration and management of protected areas" (Ch. 1 §2(b)),

- promoting "sustainable utilisation of protected areas for the benefit of people, in a manner that would preserve the ecological character of such areas" (Ch. $1 \S 2(\mathrm{e}))$, and

- promoting "participation of local communities in the management of protected areas, where appropriate" (Ch. $1 \S 2(\mathrm{f}))$

In order to address these objectives, a Social Ecology unit (which would later become the "People and Conservation" department) was created in 1995 to foster "mutually beneficial dialogues and partnerships" with surrounding communities. To date, the principal products of their efforts include (1) seven "community forums" put in place in 2005 to serve as medium through which local residents could provide input to Park managers, (2) limited economic benefits provided through business opportunities for

8 The definition of "Protected areas" includes National Parks (Ch. 2 §9(a)) 


\section{Box 2-2: "Decentralization"}

Decentralization - the separation and distribution of power and resources - in protected area governance and management has become increasingly important to the practice of conservation over the past few decades (Huff 2005; Chambers 1997; Colchester 2000; Dobson 1998; Anaya 2000, 86). In 1980 the World Conservation Union (IUCN) published a World Conservation Strategy, which held that the management of natural resources was not possible if conservation did not contribute to development and livelihood improvement of those living near or around protected areas. Combined with this pragmatic perspective were emerging moral arguments for the recognition of fundamental human rights and the self-determination of indigenous populations (including those living near protected areas) (Anaya 2000, 45-47). ${ }^{1}$

As a result of these considerations and others, "community conservation" - "those principles and practices that argue conservation goals should be pursued by strategies that emphasize the role of local residents in decision-making about natural resources" (Adams and Hulme 2001, 13) - materialized as a paradigm that challenged the centralized protectionist approach. In the late twentieth century, "integrated conservation and development projects" were launched and organizations administering protected areas began to undertake more collaborative or consultative approaches to governance whereby local communities helped shape Park management (Doyle 1998; Twyman 1998; World Commission on Environment and Development 1987; Barrett and Arcese 1998; Jones and Murphree 2004; Agrawal and Gibson 1999; Barrow and Murphree 2001; McAllister 1999; Murphree 1991; Ribot 2002).

The community conservation movement came to head in South Africa with democratization and land reform, but as with other similar efforts around the globe, it has experienced challenges as a result of the legacy of centralized protection and disenfranchisement of those who are now sought to be involved. Nevertheless, decentralized approaches to governance and the variety of demands and goals articulated through these approaches by various constituencies represents a different (but not always competing or conflicting) perspective on how the legitimacy of a protected area is established.

local artists and traders, (3) integration of certain cultural issues into the Parks, and (4)

environmental education offered to students in surrounding communities. 


\section{$\underline{\text { Protected areas as adaptive systems in South Africa }}$}

If anything can be said for certain of the transformation that Kruger has

undergone since democratization, it is that governance and management has become very complex. Attentiveness to social dimensions and numerous emerging constituencies has introduced a multitude of considerations, demands, and interests that make governance and management uncertain enterprises at best. As a result, Kruger - like many protected areas throughout the world - has adopted a systemic "adaptive" approach to governance and management (see Box 2-3) that embraces change, complexity, and uncertainty. At its most basic level, "adaptive management" is rooted in the philosophy that governance and management actions should be implemented on small-scale, experimental bases that allow managers to identify how those actions influence and are influenced by the broader social-ecological system before implementing them broadly.

As adaptive management has risen in popularity among theorists and practitioners, its conceptualization has become increasingly nuanced. While still true to Leopold's plea that management should involve "giving [ideas] a trial" (see Box 2-3) this general philosophy has morphed into a systematic framework. In Kruger, adaptive management has been implemented in accordance with Figure 2-2. With this approach, managers identify goals and a desired future state and then operationalize those into more well-defined management objectives. Different options are then explored to achieve those objectives, and the approach deemed to be the most appropriate is implemented. Fundamental to this approach is the practice of monitoring to evaluate whether the objectives and broader goals are being achieved, as well as whether the ecosystem and societal results are desirable. Moreover, there is an acknowledgment that 


\section{Box 2-3: "Systems Thinking" and "Adaptive Management"}

There are adherents to the centralized and decentralized approaches regardless of context, but increasingly, protected areas (including Kruger National Park) are being conceptualized as systems embedded within larger social systems where management and governance are driven more by contextual and systemic factors than a single ideology. From this vantage point, protected areas are inextricably linked with broader social, economic, and political systems and function as a result of demands placed through those systems (Stankey, Clark, and Borman 2005). Common demands include requests for greater public participation in decision-making, access to resources for subsistence purposes, and pressure to protect biodiversity.

Some theorists have taken the "systems conceptualization" of protected areas further than others. While some acknowledge the system characteristics of protected areas without developing a formal "systems theory" for protected areas (e.g., Stankey, Clark, and Borman 2005), others, such as Anderies, Janseen, and Ostrom (2004); Walker and others (2002); Janssen, Anderies, and Ostrom (2007); and Gunderson and Holling (2001) have formalized the conceptualization into frameworks and hypotheses in order to better describe and explain how protected areas function from a systems theory perspective. The most prevalent frameworks and hypotheses borrow heavily from ecosystem science and have introduced concepts such as "system robustness" and "system resilience" into the contemporary protected area discourse in order to highlight:

- "The amount of change the system can undergo and still retain the same controls on function and structure

- The degree to which the system is capable of self-organization

- The ability to build and increase the capacity for learning and adaptation." (Resilience Alliance 2005)

Many of the terms employed by protected area systems theorists - including "robustness," "resilience," "adaptiveness," "self-organization," and "dynamism" to name a few - do not have commonly agreed upon definitions, which arguably inhibits their utility for practitioners, at least for the time being. Nevertheless, the broader impact of this body of research - that protected areas can be conceived as systems embedded within larger social, political, and economic systems - has had important implications for management. One of the most significant outgrowths of the systems conceptualization of protected areas has been the advent of "adaptive management."

At its most basic level, adaptive management is an exceedingly intuitive concept that consists of four major components: (1) planning, (2) taking action, (3) monitoring that action, (4) evaluating that action, and then re-planning on the basis of that evaluation (Stankey, Clark, and Borman 2005, 4). The formalization of the adaptive management approach is often attributed to the early work of Holling (1978) and the later work of Lee (1993), but as Norton $(2005,88)$ argues, the concept may actually owe its birth to Aldo Leopold who somewhat desperately asked why conservationists always talk about ideas, "instead of going out on the land and giving them a trial" (Leopold quoted in Meine and Knight 1999). Adaptive management has, perhaps, been informally practiced for several decades now, but the formal adoption of adaptive management as a management approach is a relatively new phenomenon. The approach has only been instituted in Kruger National Park, for instance, over the past seven to eight years (Kruger National Park 2006) and adopted system-wide in the United States Forest Service over the past two (United States Forest Service 2005). 


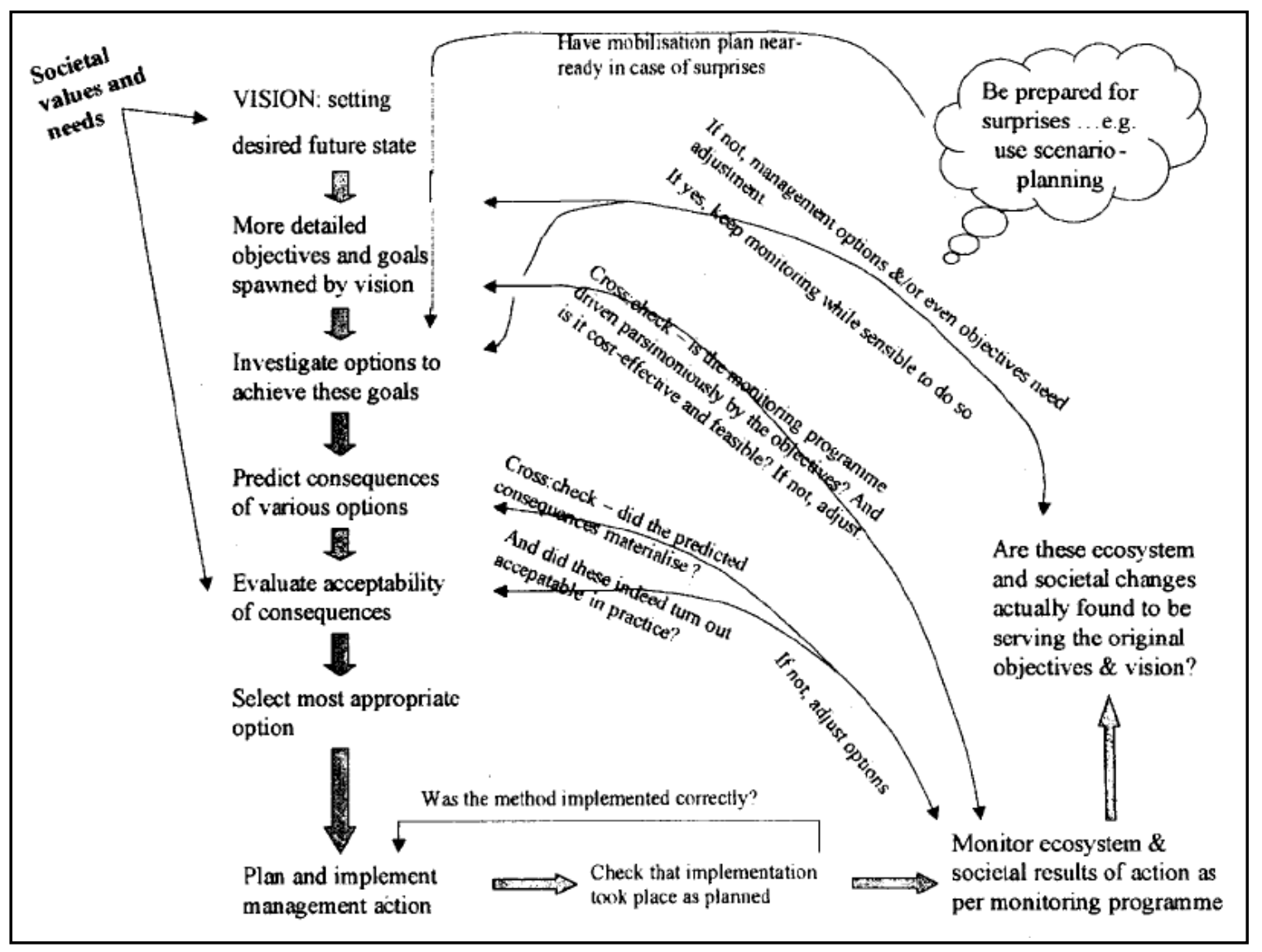

Figure 2- 2: The Adaptive Management Process (from Biggs and Rogers (2003), p. 67)

as ecosystems and societies change, so too may the objectives and implementation strategies. In Kruger, this approach has been applied to management issues ranging from elephant culling to tourism. (Biggs and Rogers 2003, 59-80)

\section{Protected areas and the call for legitimacy}

It is, perhaps, true that the substantive principle of adaptive management does not necessarily constitute a revolution for protected areas - even under centralized protectionist regimes, protected area managers exercise purposive trial-and-error 
experimentation. But, the formalization and adoption of adaptive management as a process is a mark of notable transition. Most significantly, the adaptive management process, as adopted by Kruger and other protected areas worldwide, explicitly acknowledges and embraces the tapestry of social, economic, and political values that, in turn, define the protected area system. In accordance with adaptive management, managers are directed to monitor, evaluate, and adapt not only to biophysical change but to social change, as well. As discussed earlier, for instance, the most important social change that Kruger has faced (and is adapting to) over the past decade-and-a-half is the nation's democratization and the emergence of a new constituency - previously marginalized black South Africans (particularly those living near the border of the Park).

In no small part due to the democratization and decentralization of protected areas - coupled with the attendant increased complexity of governance and management - the concept of "legitimacy" is increasingly put forward as a critical attribute of the protected area system that must be assessed and monitored (see, e.g., Brechin and others 2002; Jones and Murphree 2004; Brechin and others 2003, xi, 14; Brosius 2004; van Houtan 2006). Despite the recognized importance of the concept in other areas of social and political inquiry (e.g., political science, sociology, communications, etc.) the concept has only recently begun to receive attention among protected area scholars. Tuler and Webler (1999), for instance, in their study of the forest policymaking process in the United States commented that, "It soon became clear that everything about the process could be seen as being related to legitimacy." In their critique of the centralized protectionist paradigm, Brechin and others $(2003$, xii) posit that, "In order for biodiversity conservation efforts to be successful over time, among other concerns, those 
actions must be viewed as legitimate." There have been a number of rationales put forward to justify the study of legitimacy in protected area settings, but most of them are put forward on moral and pragmatic grounds.

Morally speaking, a protected area may realize its objectives through unethical or unjust means (e.g., the protection of biodiversity through forced removal of indigenous populations). But, as the evolution of Kruger's management and governance illustrates the robustness and long-term interests concerning protected areas are likely to be more firmly established if the governance and management of those areas is perceived to be legitimate. ${ }^{9}$ Among other things, attentiveness to the concept of legitimacy forces scholars and practitioners to assess protected area systems from an important, moral perspective with a sensitivity to social, political, and economic outcomes (Johnston and Soulsby 2002).

Second, assessments of legitimacy are also important from a pragmatic perspective. As discussed earlier, because black South Africans were historically excluded from the governance and management of protected areas, some argue that they now have little or no sense of ownership for those areas (Mabunda, Pienaar, and Verhoef 2003, 12). Consequently, nature conservation in South Africa has been an uphill battle following democratization and the rise of blacks to the political elite (Mabunda, Pienaar, and Verhoef 2003, 12). It may be reasonably asked, for instance, why a societal group would elect to protect what had been a symbol of oppression and illegitimacy for many years. As Kull (2003) and Brechin and others (2002) have argued, when groups or individuals perceive the governance and management of a protected area to be legitimate,

\footnotetext{
${ }^{9}$ Consider, for instance, what many perceive to be a lacking sense of ownership and commitment to protected areas among black South Africans, who are now the politically dominant social group in South Africa. Because of this perceived lack of ownership, some fear that that protected areas are jeopardized.
} 
they develop a sense of ownership for that area and they "buy into" its associated objectives, which ultimately translates to less conflict and more robust management and governance. Moreover, as Brechin and others (2002) note, protected area managers will never likely have enough resources to adequately enforce resource protection, so it behooves managers to "negotiate agreements" that protected area constituencies "view as legitimate and feasible." The assumption in doing so is that policies and actions viewed as legitimate are more frequently obeyed and enforceable.

It is certainly true that calls for greater attention to issues such as social justice, equity, and increased opportunities for public participation are not new to protected area management (see, e.g., Bell 1987 and UNCE 1972). What might be commonly conceived as elements of legitimacy - e.g., public participation, social justice, social appropriateness, etc. - have been studied for some time now. Nevertheless, these elements (and others) have yet to be holistically conceptualized and explored from a protected area perspective. Indeed, the handful of studies concerning legitimacy and protected areas have tended to equate legitimacy with a narrow set normative criteria and have exhibited inconsistent definitions of the concept. Mascarenhas and Scarce (2004), for example, in their study of forest planning in British Columbia equate legitimacy with a process that has "fair representation, appropriate government resources, and [is] consensus-driven." Johnston and Soulsby (2002) discuss the concept of "ecological legitimacy" in their study of an environmental dispute in Scotland and describe it as the link between "environmental and social justice." Employing examples from communitybased natural resource management in Madagascar, Kull (2002) broadly defines legitimacy as "popular acceptance" - irrespective of whether such acceptance is gained by 
force, acquiescence, or the will of society. Finally, McGuire and Sanyal (2006) adopt the conceptualization of legitimacy put forward by the German philosopher Jürgen Habermas in their study of watershed management in the United States - "legitimacy means a political order's worthiness to be recognized" that is ultimately established through procedural means aligned with deliberative democracy (citing Habermas 1976, 178).

\section{Objectives and research questions for the study}

While protected area scholars have, indeed, offered limited conceptual definitions of legitimacy, the concept has not been operationalized to the extent that it may be monitored, evaluated, and adapted. Finally, little knowledge exists regarding the consequences of differing perceptions of legitimacy - what for instance should happen when different constituency groups perceive the legitimacy of a particular action in different ways? Through this dissertation, I attempted to contribute to these knowledge gaps by having

1. synthesized the legitimacy-related scholarship that exists across a wide range of disciplines in order to craft a framework for understanding legitimacy in protected area settings,

2. explored the concept of legitimacy in the context of resource use within Kruger National Park to understand how legitimacy is conceptualized within that particular setting, and then

3. identified the consequences of different perceptions of legitimacy among those parties with an interest in a particular issue (i.e., resource use in Kruger National Park.)

Taken together, these three items constituted the broad objectives of this dissertation. 


\section{Resource use and legitimacy}

As discussed in Chapter 1, the subsistence-based utilization of resources, such as firewood, medicinal plants, and thatching grass, has historically been prohibited in the Park (except in rare circumstances). The Protected Areas Act of 1994, though, explicitly states that Parks may consider allowing sustainable use of natural resources within their boundaries, and as a result, Kruger managers feel that there are increasing demands for access to resources. The potential for resource use has not been welcomed by all within the Kruger organization - based on both moral reservations of utilizing resources within a park and because of the added layer of complexity that resource use would introduce.

In 2005 I conducted a number of informal, exploratory interviews with the staff of Kruger National Park and resource use was described as ranking high on everyone's list of intractable issues that they were currently dealing with. This perception of intractability was attributed to a number of factors including

1. lack of knowledge concerning the consequences of resource use for the biodiversity of the Park (and the corresponding fear that resource use would be tantamount to resource degradation),

2. the fear that subsistence-based use, if it were allowed, would inevitably transform into commercial use, and

3. the perception that resource use is inconsistent with the park ideal and would interfere with Park objectives related to biodiversity conservation and tourism, among others.

Not all of the Kruger staff members felt that resource use was inherently a "bad" thing. Many viewed the provision of access to resources as the morally right thing to do, given that many of the residents that might have an interest in accessing the resources were forcefully removed (or descendants of those removed) from the Park. For this subset of the staff, though, the issue was still considered a difficult one since the provision of 
resource use would require (1) persuading the remainder of the staff who felt that it was an undesirable policy and (2) the assessment of the types of resources that were in demand and the levels of resource use that would be "sustainable" and not infringe upon the biodiversity of the Park. As the findings and discussion in later chapters will show, differing perceptions of legitimacy exist not only among the staff, but also between and among different social groups living near the border of the Park, as well as visitors to the Park.

\section{Conclusion}

In this chapter, I have attempted to demonstrate that, far from being a straightforward enterprise, protected area governance and management necessitates complex, contextual and value-laden decisions that can profoundly shape the purposes of protected areas. Depending on these values and beliefs, protected areas may serve a number interests, such as biodiversity conservation and subsistence. As the history of South Africa's protected areas demonstrates, the legitimacy of these interests and the way in which these interests are governed and managed varies over time. The democratization of South Africa in the mid-1990s, for instance, facilitated a challenge to the traditional protectionist approach and ostensibly gave rise to a more devolved form of governance and responsiveness to demands for resource utilization in protected areas. As new constituencies for protected areas have been recognized and incorporated into the management of protected areas, the corresponding and increasing complexity has given rise to adaptive approaches to management and governance. An important, implied consideration is whether the manner in which protected area governance and management responds or adapts to complexity and change is, in fact, legitimate in the 
eyes of various constituencies. Recognizing the importance of legitimacy to protected area management and governance, in the next chapter, I present a review of the various ways in which legitimacy has been conceptualized across a broad array of disciplines, and I offer a synthetic framework for understanding the legitimacy of protected area governance and management. 


\section{CHAPTER 3}

\section{CONCEPTUALIZING “LEGITIMACY”}

\section{Introduction}

Before exploring various conceptualizations of legitimacy, it is instructive to first understand where legitimacy itself is situated within the broader socio-political framework. As Weber argues, "legitimacy" is a typology of "authority," which he defines as "the probability that a command with a specific content will be obeyed by a given group of persons" $(1947,152)$. In most societies authority is typically understood in terms of a government or state that makes a claim to wielding authority and the citizenry who is subject to that authority. When commands or actions are deemed to be "legitimate," they are assigned a higher degree of authority to the extent that the commands or actions are obeyed voluntarily $(1986,31)$. Consequently, every political system, according to Weber, "attempts to establish and cultivate the belief in legitimacy," since legitimacy carries with it the highest probability that a command or action will be obeyed $(325,1947)$.

It is true, however, that not every group in the citizenry (or even a majority) of a political system will view a command or action as legitimate. In such an instance, the expression of authority becomes a function of coercive power, which may be defined as "the ability to influence the outcomes or behaviors of others" based on "the capacity to control and to dominate” (Hollander 1992; van Knippenberg, van Knippenberg, and de Cremer 2007). For instance, the Apartheid-instituting Nationalist Party, despite being 
viewed as illegitimate among black South Africans, was able to establish authority as a result of its considerable coercive power over black South Africans. With sufficient power, then, authority can be wielded irrespective of perceptions of legitimacy. Illegitimate perceptions of authority, though, might eventually diminish the power of a given group. The fall of Apartheid, as a case in point, was brought on in no small part by the increasing power of black South Africans and the power exerted by the international community, both of whom viewed Apartheid as illegitimate.

In this way, power, authority, coercion, and legitimacy form a complex and connected system. The authority of actions or commands - the probability that they will be obeyed - is a function of legitimacy, but not entirely dependent on legitimacy. While it is more efficient for authority wielding groups to be viewed as legitimate and enjoy voluntary obedience to their commands, authority may still be established through the coercive exercise of power. And, as long as those groups requiring coercion are small enough or weak enough to not challenge that power, a governing body's authority can be maintained. Nevertheless, as the fall of Apartheid demonstrates, powerful coalitions can arise from what was at one time a collection of weak or disinterested groups, and the acquisition of this power can give rise to an effective revolution. Consequently, the coercive exercise of power is less resilient than the legitimate exercise of power, and it is to a governing body's advantage to pursue its interests in a legitimate way (Weber 1986, 31). As I will discuss throughout this chapter, though, there are a variety of views related to what exactly constitutes "legitimacy" and how it is established. 
In this chapter, I present a synthetic review of "legitimacy" that not only reveals how the concept is understood across a wide array of disciplines but that also provides a number of insights into how a framework for understanding the legitimacy of protected area governance and management might be crafted. As I will discuss, there are wellestablished traditions in legitimacy-related scholarship. The two most significant traditions are the "social and behavioral" and "normative" conceptualizations. The social and behavioral conceptualization of legitimacy, first articulated by Weber, maintains that legitimacy is a perception, belief, or cognitive phenomenon ascribed to an authority that, as defined by some, is not necessarily a function of an authority's "rightness." While, perhaps, useful from an empirical perspective, some political philosophers counter that such a conceptualization has very little utility from a normative perspective. As a result, these scholars have put forward normative conceptualizations of legitimacy that identify the concept with a set of normative criteria, such as deliberative democracy or instrumental utility.

After presenting a discussion of the social and behavioral and normative conceptualizations of legitimacy, I argue that the two traditions need not be conceived as incommensurable, as they often are. Instead, I offer a synthetic framework for understanding legitimacy - based, in part, on the work of scholars from these two traditions - that I believe to be of utility from both empirical and normative perspectives. I close the chapter by marking the way forward to the methodological approach I adopted for studying the legitimacy of resource use in Kruger. 


\section{Social and behavioral conceptualizations of "legitimacy"}

The concept "legitimacy" is, indeed, fundamental to both social and political theory, but while the concept is implicitly addressed in the philosophies of Plato, Aristotle, and later Rousseau (Barnard 2001, 8-9, 27, 52; Stillman 1974; Merquior 1980), it was first formalized by Weber with the 1924 publication of The Theory of Social and Economic Organization. Weber's conceptualization of legitimacy differs markedly from the implicit conceptualizations of earlier scholars in that Weber was concerned with the why of legitimacy rather than the what. Weber, for instance, did not offer a universal and normative set of characteristics that identify an entity or action as legitimate, but instead posited that legitimacy is a perception or belief held by a social group (e.g., society-atlarge) that voluntarily compels or engenders the obedience of that group to another group (e.g., the state). As long as a social group feels that an authority is legitimate, then, it is, in fact, legitimate. Weber's conceptualization is not without critics (see, e.g., Rehfeld 2005, 15-16; Grafstein 1981), but his theory of legitimacy laid the foundation for the social and behavioral explorations of the concept. In this section, I briefly present Weber's conceptualization, as well as contributions from subsequent social and behavioral explorations of legitimacy.

\section{Weber and "legitimacy"}

One of Weber's most significant contributions to the sociology of politics and government was his treatment of the concept of legitimacy, which he characterized as a perception or judgment held by a social group towards an authority that engenders 
compliance with and obedience to that authority (Weber 1986, 31). Weber's interest in legitimacy stemmed from his critique of the bureaucratization of society and his interest in characterizing the state and its exercise of power over society. ${ }^{10}$ In his well-known essay Politics as a Vocation (1921), Weber defines the state as "a human community that (successfully) claims the monopoly of the legitimate use of physical force within a given territory" [emphasis original]. In the same essay, he defines politics as any activity in which the state engages in to influence the relative distribution of "physical force." Politics, then, is fundamentally an enterprise of power, and according to Weber, the politician must somehow harmonize ultimate ends and the ethic of responsibility (Marlin 2002, 155). Weber distinguished, though, obedience to commands through coercion and legitimation. When the exercise of power is legitimated, society - the object of power considers that power "valid" and social order is more stable and securely guaranteed (Weber 1986, 31; Stryber 2001).

Weber was less concerned with what legitimacy is than how or why legitimacy is acquired, or in his words, why or how a social order "enjoys the prestige of being considered binding" (Weber 1986, 31). The perception or belief of legitimacy, he argued, could be traced to three "ideal"11 avenues of legitimation:

1) tradition - "the belief in the sanctity of immemorial traditions and the legitimacy of those exercising authority under them" (Weber 1986, 212),

2) charisma - "devotion to the specific or exceptional sanctity, heroism, or

\footnotetext{
${ }^{10}$ Both themes are dominant in The Theory of Economic and Social Organization (1924) and Economy and Society

${ }^{11}$ By ideal, Weber was referring to constructions based on a one-sided accentuation of certain features of social reality. The simplified ideal constructions, he argued, were necessary to understand the complexity of social reality, even if reality did not necessarily correspond to the ideal constructions. (Weber 1949, 9093)
} 
exemplary character of an individual person, and of the normative patterns or order revealed or ordained by them" (Weber 1997, 328), and

3) rational-legal/value-rational - "a belief in the legality of patterns of normative rules and the right of those elevated to authority under such rules to issue commands" or a belief in the rationality of an authority's absolute value (Weber 1997, 130, 328). ${ }^{12}$

Weber's conceptualization is often criticized for being a-moral (see, e.g., Beetham 1994) in so far that Weber fails to define normative criteria for legitimacy, but he does place higher value on certain types of legitimacy. Most importantly, he argues that legitimation is often an evolutionary process whereby an authority is initially legitimized through either traditional or charismatic means, but later acquires a more desirable legitimacy when that legitimacy is established through rational-legal means (Matheson 1987). As Ansell $(2001,8705)$ discusses, Weber's account of modernity in the West illustrates how traditional and charismatic authority is supplanted by rational-legal authority, and that, ultimately, this evolution is what has brought about the stability of the West.

As an example on a smaller scale, Weber's tripartite account of legitimacy might also serve as an explanation of how or why the exclusion of local people (particularly blacks) from governance and management of Kruger was legitimated. As a number of authors have discussed, the most formative element of the historical relationship between the Park and its neighbors has been the legacy of Apartheid (Meskell 2006; Moore and

\footnotetext{
${ }^{12}$ Weber distinguishes between rational-legal and value-rational types of legitimacy, but does not include value-rational in his typology. Barker $(1990,49)$ has argued that Weber implied value-rational legitimacy to be distinct, but coupled with rational-legal legitimacy.
} 
Masuku van Damme 2002; Carruthers 1995; Mabunda 2003). As discussed in Chapter 2, Kruger was employed as a vehicle for building traditions and identity among those with allegiance to the Apartheid-instituting National Party (Carruthers 1995). Discrimination and segregation were fundamental to this legacy, and as a result, the removal and exclusion of blacks was viewed as legitimate. The traditional views that gave rise to removal and exclusion were buttressed by the romanticism of the charismatic game ranger who was portrayed as defending those traditions against those who would threaten it. The game ranger's defense against the activities of local peoples such as "illegal poaching" or "trespassing" were viewed as acts of heroism and of honor. These traditional and charismatic elements became so enshrined in the Afrikaaner psyche that the exclusion of local peoples, if not legally sanctioned, was never called into question by a large sector of the South African society until land reform was instituted in 1994.

Consistent with Weber, the combination of traditional, charismatic, and rationallegal legitimation fostered a relatively stable policy of exclusion and removal that was effectively instituted for more than ninety years. Nevertheless, despite the power of Weber's account in explaining how or why exclusion and removal were legitimated, his conceptualization fails to offer evaluative criteria against which those actions may be judged. Because exclusion and removal had attained legitimacy among a social group with the capacity to enforce it, does that render it right or desirable? Moreover, what explains the illegitimation of such actions, as evidenced with the fall of Apartheid? Indeed, Weber made important contributions to understanding the sources and processes of legitimation, but as critics and scholars who would follow in his tradition have 
demonstrated, there were aspects of his theory that would benefit from further development.

\section{Post-Weberian social and behavioral conceptions of legitimacy}

Weber offered an unprecedented and thorough account of how and why the perception of legitimacy might be established, but his contribution has been criticized for (1) distorting or failing to directly and precisely define what legitimacy is (see, e.g., Habermas 1975, 97-102; Beetham 1994, 11) and (2) offering circular characterizations when the definition is implied (Grafstein 1981). Beetham $(1994,8)$ goes as far to regard Weber's approach as "an unqualified disaster," and Grafstein (1981) comments that, "In Weber's hands ... legitimacy no longer represents an evaluation of a regime; indeed, it no longer refers directly to the regime itself. Rather it is defined as the belief of citizens that the regime is, to speak in circles, legitimate." The legitimacy-based scholarship that followed Weber suggests that the critiques leveled against Weber contributed to two movements - the efforts by political philosophers to attach normative criteria to legitimacy and the attempts by some social scientists to sharpen Weber's belief-oriented definition of legitimacy. Setting aside the former for the time being, I turn to the latter to illustrate some contemporary social conceptualizations of legitimacy.

Among classic social scientists and theorists, Friedrich, Lipset, and Easton are perhaps the most well-known and oft-cited scholars who have attempted to augment and expand upon Weber's conceptualization (whether explicitly or implicitly). According to Friedrich $(1963,234)$ legitimacy is "the question of fact whether a given rulership is 
believed to be based on good title by most men subject to it.” Similarly, Lipset (1988, 64) characterized legitimacy as the "capacity of the system to engender and maintain the belief that the existing political institutions are the most appropriate ones for the society." Finally, systems theorist Easton $(1979,278)$ described legitimacy as the "conviction on the part of the member that it is right and proper ... to accept and obey the authorities." While all three definitions, in the Weberian tradition, share the belief-oriented characterization of legitimacy, Easton's and Lipset's definitions in particular have been criticized for being even more under-theorized and problematic than Weber's, based on their espoused relativity and circularity (Beetham 1994, 9-10, 136-7; Rehfeld 2005, 15). Friedrich's treatment of legitimacy, however, has arguably received less criticism within social science circles as a result of its subtle, but defined, evaluative component.

In contradistinction to Weber, Lipset, and Easton, Friedrich's conceptualization of legitimacy contains a number of evaluative, but still belief-oriented, criteria for legitimacy. ${ }^{13}$ First, Friedrich argues that the justifications for government and its actions (referred to as the "rulership") must be "believed to be based on good title by most men." Here, Friedrich introduces the concept of "congruence" - that legitimacy, in part, is determined by whether or not a government and its actions comport with the system of values and beliefs held and assigned by "most men" (Stillman 1974). Second, the use of the phrase "men subject [to the rulership]" highlights Friedrich's supposition that the assessment of legitimacy belongs to the governed and not, for instance, inhabitants of other countries under the rule of other governments. Third, by claiming that legitimacy is a judgment made by "most men," Friedrich implies that legitimate government and action

\footnotetext{
${ }^{13}$ Stillman (1974) offers an extensive discussion of all of the evaluative criteria discussed here.
} 
may not be viewed as such by all of the governed, since values and beliefs will invariably differ among them. Finally, and perhaps most significantly, while recognizing that values and beliefs will vary among the governed, Friedrichs conceptualization of legitimacy is essentially value-free. As Stillman (1974) describes, "For Friedrich, a government does not have to be good, just, constitutional, peaceful, etc., in order to be legitimate; any rulership needs only belief in its good title by most of its subjects to be legitimate." True to Weber, then, Friedrich maintained the belief-oriented charcterization of legitimacy, but he blazed a new trail in the legitimacy scholarship by introducing evaluative components.

Friedrich's conceptualization of legitimacy, as well as his philosophies of administrative discretion and reason remain influential, though his ideas have been refined and filtered through the lenses of a number of more contemporary scholars. For instance, in his contemporary classic, "Managing Legitimacy: Strategic and Institutional Responses" (1995), Suchman defines legitimacy as "a generalized perception or assumption that the actions of an entity are desirable, proper, or appropriate within some socially constructed system of norms, values, beliefs, and definitions." Here, Suchman adopts some of the evaluative criteria introduced by Friedrich (e.g., congruence), but modifies the evaluative framework to identify the power of normative (but not necessarily universal) beliefs held not only by the governed, but those beyond the jurisdiction of the entity exercising authority. Moreover, Suchman acknowledges that the perception of legitimacy may vary based on the perspective against which it is evaluated. He delineates, for example, pragmatic legitimacy (based on interests), moral legitimacy 
(based on perceptions of what is right and just), and cognitive legitimacy (based on an authority's taken-for-grantedness or lawfulness). Other scholars offer relatively similar definitions of legitimacy (see, e.g., Zelditch 2001, 33; Berger and others 1998, 350; Meyer and Scott 1983, 201; Friedman 1981; Douglas 1986, 45-46) and even different delineations (see, e.g., Aldrich 1999 and Dobrev 2001), but as Johnson, Dowd, and Ridgeway (2006) discuss, there are several common themes to almost all contemporary social and behavioral conceptualizations of legitimacy:

a) "legitimacy is a problem in the construction of social reality;"

b) "[legitimacy]' is fundamentally a collective process;"

c) "legitimacy depends on apparent, though not necessarily actual, consensus among actors in the local situation that most people accept the object as legitimate;" and

d) "as a collective construction of social reality, legitimacy has both a cognitive dimension that constitutes the object for actors as a valid, objective social feature and a normative, prescriptive dimension that represents the social object as right."

The emerging convergence in the definitional character of legitimacy has resulted in a shift of emphasis for social and behavioral scholars of legitimacy in at least two important ways. First, many social and behavioral scholars - increasingly comfortable with what legitimacy is (e.g., see the four points above) - are re-visiting how legitimacy is acquired, a project originally established by Weber. Some continue to analyze the acquisition of legitimacy within Weber's tripartite source-based framework (see, e.g., Eddy 2005), but others have taken Weber's evolutionary conception of legitimation (i.e., the transition from traditional and charismatic legitimacy to rational-legal legitimacy) as a point of departure in highlighting the processes associated with legitimation (see, e.g., Walker 2004, Zelditch 2001, and Zelditch and Walker 2004). Johnson, Dowd, and 
Ridgeway (2006), for instance, characterize the legitimation process in terms of four stages,

1. social innovation - an action is created in order to address some "need, purpose, goal or desire at the local level of actors;"

2. local validation - "local actors must construe [the action] as consonant with and linked to the existing, widely accepted cultural framework of beliefs, values, and norms;"

3. diffusion - once the new, prototype action and associated processes are locally validated, "it may be diffused into other new, local situations;" and

4. general validation - "as a result of the diffusion of the new social object across contexts, actors eventually take on the belief that most actors believe that the innovation is acceptable."

Contemporary social and behavioral studies of legitimacy are often concerned with how these stages (or similar theoretical constructions) manifest within particular contextual settings (see, e.g., McGuire and Sanyal 2005; Gibson, Caldeira, and Spence 2005; Johnston and Soulsby 2002; Kull 2002; Mascarenhas 2004 and Scarce; and Muldoon 2003).

That social and behavioral definitions of legitimacy and the process of legitimation put forward by social and behavioral scholars might be more empirically instrumental than normative conceptualizations does not imply they are more valid. Considering again, for instance, the historical relationship between Kruger and those that have lived in or near the Park, the social and behavioral conceptualizations of legitimacy provide a very useful framework to understand how the historic exclusion and removal of local peoples from Kruger were legitimized. For instance, Weber, as well as contemporary social and behavioral theorists, provide insight into how and why 
underlying beliefs concerning local peoples (and blacks, in general) legitimated their removal and exclusion from Kruger. But, while illustrating how beliefs transform to legitimacy, the social and behavioral account fails to offer an evaluative framework for assessing the rightness of those beliefs. According to Friedrich's conceptualization, prior to the fall of Apartheid, the policy of forced removal and exclusion would be viewed as legitimate simply because most of those who constituted the recognized South African citizenry would have viewed that policy as appropriate. Clearly, though, with the fall of Apartheid, the beliefs that gave rise to that policy were later viewed as illegitimate. At some point, then, the beliefs underlying the Apartheid regime were viewed as not being "right," but the social and behavioral account offers little insight into the evaluative criteria or basis from which this judgment was made.

An important element of legitimacy, then - but missing from the social and behavioral account - is a discussion of specific norms that are viewed as "right" or "appropriate" and will give rise to legitimate authority. Some social and behavioral accounts of legitimacy do recognize the role of norms (see, e.g., Suchman (1995)), but most do not offer specific norms (e.g., deliberative democratic decision-making procedures) that engender legitimacy. As a result, political philosophers have maintained that the belief-oriented conceptualization of legitimacy is little more than an assessment of public approval and is of little utility (except, perhaps, to public opinion researchers) (Rehfeld 2005, 15-16). 


\section{Normative conceptualizations of "legitimacy"}

Broadly speaking, the history of the normative conceptualization of legitimacy is as old as the history of philosophy itself. The concept of legitimacy strikes at the heart of the question as to how power and authority should be appropriately exercised over society - a question that has been tackled by a number of political philosophers from Plato, Aristotle, and onward. Rigorous and explicit treatments of legitimacy from a normative perspective, though, emerged only within the past few decades - initially, as a response to Weber. Just as theorists in the tradition of Weber have attempted to sharpen his conceptualization of legitimacy, critics of his belief-oriented definition have more thoroughly developed their normative conceptualization. In this section, I discuss Habermas' response to Weber, as well as recent normative perspectives of legitimacy.

\section{Habermas' response to Weber}

Jürgen Habermas' theory of legitimacy is borne of his broader critical-theory philosophy. As a critical theorist, Habermas contributed to the philosophical project founded by Horkheimer and Adorno in the mid-1930's and later expounded by the "Frankfurt School."14 In essence, early critical theorists endeavored to salvage the normative philosophy of Marx, that as the Frankfurt School believed, had been inappropriately applied and misunderstood. Early Frankfurt School philosophers posited that Marxism was never intended to be applied as an empirical science (Roderick 1986, 22-32). Rather, it was to serve as a critique with practical intent aimed at exposing the

\footnotetext{
${ }^{14}$ For a detailed history of the Frankfurt School and its attendant philosophy, see Wiggershaus (1994).
} 
inconsistencies between ideology and reality, theory and praxis (Roderick 1986, 24-27).

In this way, critical theorists were and are concerned with the mechanics of moving and transforming society from the factual, material "is" to the normative "should be."

Habermas' first detailed discussion of legitimacy appeared in Legitimation Crisis, where he attempted to identify the crisis ${ }^{15}$ points within advanced capitalist societies and how the modern state manages those crises and maintains its legitimacy $(1975,2)$.

Legitimacy, which Habermas defined as "a political orders' worthiness to be recognized," is not established by rational-legal means alone, as Weber suggests, though. According to Habermas,

"If belief in legitimacy is conceived as an empirical phenomenon without an immanent relation to truth, the grounds upon which it is explicitly based have only psychological significance. Whether such grounds can sufficiently stabilize a given belief in legitimacy depends on the institutionalized prejudices and observable behavioral dispositions of the group in question. If, on the other hand, every effective belief in legitimacy is assumed to have an immanent relation to truth, the grounds on which it is explicitly based contain a rational validity claim that can be tested and criticized independently of the psychological effect of these grounds." (Habermas 1975, 97)

For Habermas, then, legitimacy is not contingent on held beliefs among particular social groups - it is, to the contrary, dependent on alignment with a broader, universal truth against which a group's "validity claim" is tested. The rational-legal legitimacy put forward by Weber, Habermas argued, is an insufficient guarantor of congruence with truth and does not inherently possess a "rational validity claim" (Habermas 1975, 98).

\footnotetext{
${ }^{15}$ Habermas describes a crisis as a a state of strain within society where societal collapse is imminent.
} 
The idea of a rational validity claim is central to Habermas' conceptualization of legitimacy and can be best described as a rational or logical claim to the truthfulness and/or rightfulness of a action (Habermas 1985, 302-309). Multiple claims to validity or truth (whether fallible or infallible) may exist for a given action throughout a diverse society, but a validity claim is only considered "rational" if it satisfies three basic criterions:

1. a presupposition or explication that the state of affairs in question are true and not misconstrued,

2. the claim conforms to accepted normative expectations, and

3. there are no doubts concerning the intentions or sincerity of the entity making the claim. (Habermas 1985, 17, 302-309; Cooke 1994)

To illustrate these points and their role in judgments of legitimacy, consider the following example. As discussed in Chapter 2, some protected area scholars with a strong interest in preserving biodiversity have claimed that protected areas must be militantly guarded against surrounding populations in order to protect the biodiversity that exists within those areas. To that set of scholars, the claim is "valid" or is representative of their vision of truth. Critics of this claim might counter that it is not a rational validity claim because, in accordance with Habermas' criteria for rational validity claims,

1. the state of affairs described is not accurate - biodiversity is not really in danger or in need of protection,

2. militantly guarding protected areas against surrounding populations is immoral and does not conform with accepted norms, and/or

3. there are interests other than the preservation of biodiversity that are driving the desire for militant protection of the areas in question. 
As a consequence, critics might argue that the grounds upon which a decision to militantly guard a protected area are based contain no rational validity claims and are, therefore, deemed illegitimate. ${ }^{16}$

After conceptually aligning legitimacy with "rational validity," Habermas has devoted a substantial portion of his philosophical project to articulating how the rational validity of claims are established and determined. Generally speaking, Habermas has adopted a communicative and procedural theory approach. He argues that discourses where rationality will take shape and that legitimacy depends on communicative arrangements. The centerpiece of his "theory of communicative action" is what he initially termed the "ideal speech situation," which, as he continued to develop the concept, would later closely resemble "deliberative democracy" (Kelly 2004). Habermas describes the ideal speech situation as a communicative arrangement that maintains an "orientation for truth" and meets the following criteria:

1) everyone with competence to speak and act is allowed to take part in discourse;

2) everyone is allowed to question any assertion, introduce any assertion into discourse, and express attitudes, desires and needs; and

3) no speaker may be prevented by either internal or external coercion from exercising his rights as laid down in 1) or 2). (Habermas 1985, 25; McCarthy 1984, 308)

\footnotetext{
${ }^{16}$ As an aside, it is equally true that a similarly constructed argument could be manufactured for claims to the validity of community conservation or resource use, for example.
} 
Moreover, for any given action, the arrival at rational validity claims related to that action requires both unlimited discussion and discussion free from distorting influences (McCarthy 1984, 306).

In summary, Habermas conceptualization of legitimacy can be described in the following way: legitimacy - a political orders' worthiness to be recognized - requires rational validity claims for a particular issue that can only be generated and then debated within the ideal speech situation (or a perfect form of "deliberative democracy"). Critics of Habermas have highlighted that the "ideal speech situation" is just that - an ideal (Harrington 2000, Kohn 2000). As Gosling (2000) discusses, the "ideal speech situation" is almost always unattainable, and even if it were attainable, it would be impossible to know whether or not it had truly been reached - how, for instance, could it ever be known whether a speaker was truly free from all types of internal or external coercion? While a speaker may claim they were free from coercion, that claim itself may be a result of coercion. Moreover, a speaker may be coerced without even knowing they are being coerced. ${ }^{17}$ In short, the ideal speech situation is a commendable goal, but because of its imperfect realization, Habermas' equating of legitimacy with rational validity that can only emerge from the ideal speech situation implies that legitimacy can never be reached. Delanty (1997) and Harrington (2000) also comment that, beyond the impossibility of realizing the ideal speech situation, Habermas' theory of legitimacy and communicative action reflect an occidental bias in so far that he universally associates legitimacy with popular or deliberative democracy - practices that might not be considered legitimate

\footnotetext{
${ }^{17}$ Schmookler (1993) presents a compelling argument demonstrating how the free market, which, in theory, expands the choices and actions available to an individual actually constrains choice and action. Most people, he argues, though, are not aware of such constraints.
} 
within non-western societies (consider, for instance, the chieftainships of South Africa where decisions are made almost exclusively by a chief and a select group of ndunas or "headmen").

Finally, critics such as Valadez (2000, 61-63) have insightfully noted that, while procedurally speaking, Habermas' theory of legitimacy and communicative action may be attractive (its western bias and Utopian nature notwithstanding), Habermas offers no guidance regarding the substantive moral or cognitive incommensurability of actions in question. What, for instance, is a society to do when all relevant thoughts have been expressed free from coercion, all thoughts have been thoroughly considered by decisionmakers without prejudice, yet there remains disagreement over the substantive rightness of the action? Such a situation is, perhaps, very possible, for instance, in Kruger with respect to resource use. In 2005, "community forums" were established in order to facilitate deliberative dialogue between Park staff and local residents concerning Parkcommunity issues, such as resource use. In conversations that I had with some staff who had participated in those forums, those staff commented that participating parties were almost always afforded ample discussion time, but that sometimes different groups (including different groups within the broader local-resident group) held very different views concerning what was appropriate in the Park. Whereas, for instance, some traditional healers felt that medicinal plants must come from inside the Park in a "natural," "undisturbed" setting in order to contain healing powers, others felt that it was sufficient to be provided with plants that came from a nursery. There was no way to logically reason which view was right; the competing views were simply 
incommensurable and rooted in different worldviews. In this case, Habermas' deliberative-democracy account of legitimacy offers little further guidance. The process by which an issue is discussed - in the example, the use of medicinal plants - might be perfectly sound, but still not lead to a resolution.

The Habermasian conceptualization of legitimacy, then - like Weber - is not free from critique. Whereas Weber is chided for his relativism, Habermas is critiqued for his overly prescriptive and unattainable universalism. Just as Weber laid the foundation for the belief-oriented approach to understanding legitimacy, though, it is also true that Habermas - in his response to Weber - played a significant role in laying the groundwork for a normative philosophy of legitimacy.

\section{Contemporary normative conceptualizations of legitimacy}

Following Habermas' theory of legitimacy to its logical conclusion suggests that legitimacy requires a particular type of democracy (namely, deliberative democracy). As discussed above, though, critics contend that his unqualified brand of legitimacy is likely to never be achieved, because it requires consensus building and impartial neutrality to identify legitimizing claims with which all participants agree. These requirements, in their purest form, render Habermas' legitimacy as largely unachievable, since most social and political debates of any significance (including those concerning protected areas) consist of incommensurable - but perfectly rational and valid - claims. Whether or not in response to Habermas and his critics, contemporary conceptualizations reflect a loosening of the normative bindings of legitimacy in order to offer a more practical and 
realistic conceptualization of legitimacy. The relaxing of normative principles that define legitimacy are rationalized by differentiating democracy as a concept and a theory. Beetham (1992), for instance, differentiates between the concept of democracy, which is widely accepted, and the theories of democracy, "which involve contestable claims" regarding what is "desirable or practicable and how it might be realized in sustainable institutional form. ${ }^{, 18}$ Normatively speaking, contemporary conceptualizations of legitimacy almost universally champion the concept of democracy, but split in terms of how democracy should be realized (Arneson 2003; Griffin 2003).

\section{Deliberative democracy as legitimacy}

Bohman maintains that democracy, indeed - at the conceptual level - is tantamount to legitimacy, and like Habermas, he argues that democracy is best effectuated through deliberative means $(1996,183)$. Unlike Habermas, though, Bohman points out that no neutral or impartial standpoint exists from which unanimity can be achieved $(1996,183)$. He does not dismiss deliberative democracy, but only recants it to be deemed successful when "agents are sufficiently convinced to continue their ongoing cooperation" $(1996,33)$. The outcome of an action or decision, then, is legitimate when the reasons or rationale behind it are sufficient to motivate cooperation of all those deliberating. Legitimacy is expressed not as rationally-valid unanimity, but as (1) a belief among participants that they have contributed to and influenced an outcome or action, even if they disagree with it and (2) recognition and consideration by all

\footnotetext{
${ }^{18}$ Barnard (2001, 178-9) refers to the same observation by Beetham and discusses this distinction in more depth.
} 
participants of the moral framework from which other participants are operating (1996, 33).

Bohman's conceptualization of legitimacy is particularly attractive to scholars of multicultural societies who are well aware of the incommensurability of values and beliefs. But as one such scholar, Valadez, comments, deliberation and justice are not enough,

In order for a state to rightly demand recognition of its legitimacy, ... it is also necessary that it answer to the injustices of the procedures through which it incorporated the cultural groups within its boundaries $(2001,9)$.

The forms of redress that Valadez offers are contextually dependent, but at a minimum, states must guarantee the self-determination of cultural groups, equal access to knowledge upon which decisions are based, and recognition as a political community (2001, 6-10). In many respects, for instance, it would seem that the South African government subscribed to just such a view of legitimacy with the fall of Apartheid. Land reform was instituted with the new democracy, bringing with it reparations for groups who had been forcefully removed from their land, and those same groups not only came to be recognized as a political community, but drive many of the decision-making processes and are the dominant political community in the country.

While Valadez's conceptualization might be tenable at the multicultural scale, it is arguably contradictory when applied to proximately homogenous cultural groups within a multicultural society - guaranteeing the self-determination of cultural groups ensures that authority structures will be maintained, many of which might run counter to democratic principles (e.g., chieftanships in South Africa). In this way, at the multicultural societal 
scale, procedurally prescribing deliberative democracy, while at the same time substantively prescribing principles of self-determination, equality, and justice might resolve issues of legitimacy at that scale, but they cannot necessarily be applied to subscales without rendering the overarching conceptualization untenable.

\section{Instrumentalism and pragmatism as legitimacy}

Arneson (2003) avoids the challenges associated with equating legitimacy and deliberative democracy by adopting a purely substantive and instrumental account of legitimacy. Arneson holds that the concept of democracy forms the basis of legitimacy, but that,

what renders the democratic form of government for a nation morally legitimate (when it is) is that its operation over time produces better consequences for people than any feasible alternative mode of governance (2003).

Arneson bases his instrumental conceptualization on two "accounts" of legitimacy - the "correctness account" and the "best results account." He argues that most accounts of legitimacy can be classified as the former - the assumption in most being that given a portfolio of possible actions or policies for a given need, "a political decision procedure is morally legitimate just in case it reaches the morally best decisions as to which policies to enact". With this account, Arneson asserts, it is conceivable that autocratic procedures could produce "morally superior political decisions" that lead to a more "just order" [emphasis added]. But, while giving rise to a just order, this account fails to "render citizens more virtuous." The virtuosity of citizens (rather than justice), he claims, is necessary in order to produce the best possible outcome. And, the best possible outcomes 
are ensured through a "best results account" legitimacy, where a "political decision procedure is morally legitimate just in case over the long haul it gives rise to results that are morally superior to the results that any feasible alternative procedures would produce." As critics have countered, Arneson's distinction between the "correctness" and "best results" accounts are a bit cloudy (Griffin 2003). But, fundamentally, Arneson advances a conceptualization that places a priority on the substantive outcome associated with a policy or action rather than the procedures that guide the decision-making process. In this way, Arneson has clearly departed from the, arguably more popular, deliberative democracy account of legitimacy.

This should not imply, though, that practices such as deliberative democracy might not serve a groups interest. As discussed in the previous chapter, for example, managers of Kruger National Park came to realize that if the interests of biodiversity were to be served after democratization, then black South Africans would need to be involved in decision-making processes related to protected areas to the extent that they would see the benefits of biodiversity conservation. Should blacks have remained excluded from decision-making processes, they would have held little value in conservation and, being the dominant political community, might have instituted policies that were counter to biodiversity values.

Arneson's pragmatic conceptualization is, perhaps, in the minority as far as theories of legitimacy are concerned, but he is not the only theorist to champion an outcomes-oriented account of legitimacy. Suchman (1995) offers a delineation of legitimacy that includes what he calls pragmatic legitimacy, whereby an action or policy 
is legitimate if it is in the "self-interested calculations of an organization's most immediate audiences." Pragmatic legitimacy, he argues may not always be rooted in the direct satisfaction of interests, but also the indirect or larger interests that a group may have. With this phenomena, which he labels influence legitimacy, constituents support an organization not necessarily because they provide for specific, favorable outcomes, but because the authority is responsive to their overall goals or interests. For instance, while some residents living near Kruger will have a direct, pragmatic interest in utilizing resources (e.g., traditional healers who need access to medicinal plants), it is also true that some may be less concerned about the direct utility of resource use than the broader precedent of decision-making involvement that the issue might give rise to.

\section{Constitutionality and the law as legitimacy}

For better or worse, laws serve as an expression of values. In democratic societies, the values expressed are ostensibly that of the citizenry, whereas in autocratic societies, the values expressed may be that of the autocrat. Irrespective of the origin of expressed values, a democratic society's legal framework - typically founded on a constitution or charter - often serves as the basis from which a society is compelled to act. In terms of legitimacy and law, a substantial amount of scholarship is devoted to the legitimacy of specific laws or bodies of law. In fact, it may even be said that the discipline of law itself is consigned to indirectly or directly analyzing the legitimacy of specific laws, including how they are legitimately crafted, interpreted, and applied. The exploration of the "legitimacy of law," though, is much different than the statement of "legitimacy as law" (i.e., equating legitimacy with law). 
The validity of questioning or analyzing the legitimacy of law faces little theoretical threat as an enterprise in and of itself. History has certainly demonstrated, for instance, that as societal values, norms, and beliefs change over time, the social framework that gave rise to a particular law morphs into a new framework that might or might not call that law into question and potentially render that law illegitimate (consider, e.g., the rise and fall of Apartheid). It is, perhaps, more difficult, though, to argue that legitimacy may be validly equated with the establishment of a legal order. If for example this argument were true, then the legitimacy of old orders - e.g., Apartheid in South Africa - could or would never be called into question. Nevertheless, as Rawls and others have demonstrated, it is possible to articulate qualified conceptualizations of legitimacy as law.

In A Theory of Justice (1971), Rawls employs a variant of the social contract to better understand how goods and services within a society can be more justly distributed. As a consequence of his "Justice as Fairness" theory, he arrives at two important principles of justice,

1. the liberty principle - "each person is to have an equal right to the most extensive scheme of equal basic liberties compatible with a similar scheme of liberties for others;" $(1971,60)$ and

2. the difference principle - "social and economic inequalities are to be arranged so that:

a. offices and positions must be open to everyone under conditions of fair equality of opportunity, and

b. they are to be of the greatest benefit to the least-advantaged members of society $(1971,303)$.

Rawls later argued that his theory was not to serve as a "comprehensive conception of the good" (2005, xliv) but that instead, it was compatible with a liberal conceptualization of 
justice. In Political Liberalism (2005), he further elaborated upon the concept of liberal justice and offered a conceptualization of legitimacy vis-à-vis "the liberal principle of legitimacy":

Our exercise of political power is fully proper only when it is exercised in accordance with a constitution the essentials of which all citizens as free and equal may reasonably be expected to endorse in light of principles and ideals acceptable to their common human reason $(2005,137)$.

For Rawls, then, the exercise of authority or power over society is legitimate if it comports with a constitution - the foundational essence of a legal order - but only if that constitution reflects the beliefs, values, and norms held by that society.

Rawls' conceptualization of legitimacy identifies consistency with a constitution as a sufficient guarantor of legitimacy, but as Fallon (2005) argues, legitimacy may be tantamount to the rule of law without substantive constitutionality being a necessary condition. Citing Bush v. Gore ${ }^{19}$, Fallon (2005) describes how substantively-speaking, an action may be conceived as illegitimate within a constitutional framework, but because of the legitimacy conferred to the decision-making authority (in this case, the United States Supreme Court) through a constitution, the legitimacy of the decision is established. In other words, if the process through which an action or decision is undertaken is consistent with a society's constitution, that alone may be sufficient rather than substantive consistency - to render the action legitimate. In no small part, such occurrences may be a result of the substance of a constitution and legal order being

\footnotetext{
${ }^{19}$ Bush v. Gore (531 U.S. 98) was a 2000 United States Supreme Court decision which confirmed the controversial (and perceived by some to be illegitimate) United States presidential election.
} 
more open to interpretation and sensitive to changing societal values than the procedural prescriptions (Fallon 2005).

Abstractly, both Rawls and Fallon argue that constitutionality translates to legitimacy. But, they also qualify their conceptualizations in important ways. First, consistency with a legal order is a function of changing values, norms, and beliefs $-\mathrm{a}$ legal order gives rise to legitimacy only to the extent that society can be expected to “endorse" order (Rawls 1971, 137). Second, the substantive congruence between a legal order and societal values, norms, and beliefs may be sufficient to guarantee the legitimacy of that order, but it may not be necessary if an action is taken in such a way that is consistent with the decision-making processes sanctioned by that order (Fallon 2005; see also Barnett 2003). In short, a legal order may serve as a defining, normative principle of legitimacy, but as an expression of values, a legal order must not be aggrandized at the cost of the underlying social framework that gave rise to it.

\section{A synthetic framework for understanding and exploring legitimacy}

Each account of legitimacy presented above is useful in its own right when explaining certain dimensions of the legitimacy of Park-related actions that affect or involve local residents. In terms of the broader, historic relationship between the Park and local residents, the social and behavioral account of legitimacy offers an explanation for how policies sanctioning forced removal and exclusion from the Park were legitimated on the basis of predominant beliefs of the time. However, that account fails to offer an understanding of how and why, based on underlying norms, beliefs pertaining 
to the legitimacy of actions change over time. For instance, as a result of racial discrimination, the involvement of local residents in decision-making processes during the Apartheid era never occurred. Now, though, with the fall of Apartheid and South Africa's interest in "empowering" rural communities, involving local residents in decision-making processes is deemed necessary for a variety of normative reasons. To understand this transition, it's necessary to more thoroughly explore those normative dimensions of legitimacy and the evaluative criteria that dimension offers.

As with the social and behavioral account, the normative account alone, though, offers an insufficient framework for understanding legitimacy. Norms, for instance, which are philosophically put forward as universal guarantors of legitimacy might be readily refuted on the basis of contextual beliefs (e.g., deliberative democracy might be very illegitimate in traditional South African societies). More fundamentally, it is arguably true that norms purported to give rise to legitimacy (e.g., constitutionality or pragmatic, outcome-oriented decision-making) matter little if societies do not believe those norms to be right or appropriate.

Fundamentally, then, I argue that a synthetic conceptualization is needed to fully appreciate the legitimacy of a particular action. Suchman (1995), I believe, offers the closest approximation to this synthesis by recognizing the importance of both beliefs and norms, but he and others leave room for further development and synthesis. For instance, while Suchman discusses the importance of moral, pragmatic, and rational norms, he does not account for the role of laws and conventions in his framework (see, e.g., Rawls 
2005 and Fallon 2005), nor does he discuss how these norms manifest through either procedural or substantive avenues (see, e.g., Barnard 2001).

While it is true that most of the elements for this synthesis have already been introduced by other theorists (albeit disjointedly) there are dimensions of legitimacy that have not been thoroughly discussed. Most significantly, I believe, there is little if any discussion in the literature concerning how multiple legitimate actions may exist for a group that are pursuant to a particular issue and how the existence of multiple legitimate actions can facilitate the resolution of conflicts related to a particular issue. ${ }^{20}$ For instance, it is feasible that there might be a number of policies for resource use that are viewed as legitimate by most people living near Kruger. Likewise, a number of legitimate policies might exist for the Park staff and Park visitors, as well. In this way and for a particular issue, I argue that each interested group - based on contextual factors, as well as specific procedural and substantive considerations - has an associated "legitimacy space" that defines the bounds for what that group deems to be legitimate actions pursuant to that issue. When those spaces overlap (envision a Venn diagram), there is an opportunity for resolving an issue in a way that is viewed legitimate by all or some of those parties involved.

In this section, I provide a synthetic framework that employs both social and behavioral and normative perspectives on legitimacy. I begin by describing how Suchman's (1995) definition provides a useful starting point for this synthesis. I then

\footnotetext{
${ }^{20}$ The conflict resolution literature does discuss how groups or individuals craft "viable alternatives" in decision-making processes, but these alternatives are typically viewed from an interested-oriented perspective and there is little theoretical treatment concerning the legitimacy of multiple alternatives (see, e.g., McKinney and Harmon (2005)).
} 
provide a brief overview of normative criteria for assessing legitimacy that have been offered by protected area scholars and others alike. Finally, based on the scholarship presented in this chapter, I provide a synthetic framework for understanding and exploring the legitimacy of protected area governance and management.

\section{A synthetic definition of "legitimacy"}

While often portrayed as competing theories of legitimacy (see, esp. Beetham 1994), I believe that it is not necessarily true that social-behavioral and normative conceptualizations must be at odds with one another. I draw this conclusion by first considering Suchman's (1995) oft-cited definition of legitimacy,

legitimacy is a generalized perception or assumption that the actions of an entity are desirable, proper, or appropriate within some socially constructed system of norms, values, beliefs, and definitions.

Suchman's conceptualization - and the contemporary belief-oriented conceptualization, in general - does not preclude or discount the important role of norms or societal prescriptions in the determination of legitimacy. On the contrary, the conceptualization merely posits that "norms, values, beliefs, and definitions" must be considered within the context of a "socially constructed system." Nothing in Suchman's conceptualization (within his definition or beyond) precludes normative prescriptions to ensure legitimacy within a socially constructed system. In fact, Suchman, and other social and behavioral scholars, identify a number of normative considerations that may engender legitimacy (e.g., instrumentalism, conventionality or adherence with law, morality, etc.). Indeed, 
normative scholars have articulated similar prescriptions, although primarily within the context of democratic societies.

The opportunity for a synthetic framework of legitimacy exists if we acknowledge that different cultures and societies do not always share the same norms, values, beliefs, and definitions. A culture, in fact, may be defined as a social group with a particular set of norms, values, beliefs, and definitions. If we assume this to be true, then without imposing alien norms upon a culture or society, a normative and universal conceptualization of legitimacy cannot be said to exist. As such, Suchman's contextual "socially constructed system" dimension of legitimacy must be accepted. Nevertheless, within particular cultures or societies, there are likely to be definitive normative criteria for legitimacy. In democratic societies, for instance, the "one-person-one-vote" philosophy is a central normative tenet of legitimacy, just as is "equality before the law". In other socieities, though, such as the chieftanships of South Africa, this is not necessarily be true.

As the concept of legitimacy receives increasing attention in protected area scholarship, Suchman's conceptual definition of legitimacy is especially useful for at least three reasons. First, Suchman's definition espouses that legitimacy varies across socially constructed systems. Given that the socially constructed system within which protected areas and surrounding areas are embedded might differ sharply from the system to which most normative conceptualizations of legitimacy are attuned (i.e., democratic systems), Suchman's definition does not preclude the emergence of dimensions of legitimacy that are inconsistent with some occidental or democratic conceptualizations. 
Second, as an emerging area of interest, the normative dimensions of legitimacy, as related to protected areas, have yet to be thoroughly explored. Suchman's definition accommodates this exploration of legitimacy rather than limiting inquiry to deductive testing of specific normative criteria. Certainly, the normative criteria offered by some scholars (e.g., instrumentalism, morality, rationality, conventionality or adherence to the law, etc.) serves as a valuable starting point, but within the relatively unexplored context of protected areas it is reasonable to expect that other normative criteria will emerge. This is not said with the intent to discredit deductive testing of normative criteria, but to rather highlight that within an exploratory context, it might be just as valuable to capture the landscape of legitimacy as to focus on a specific feature of that landscape. Finally, to an extent, empirical studies of legitimacy, such as this one, must be grounded on a belieforiented conceptualization if legitimacy is to be measured in some way. By assuming that, for instance, deliberative democracy is a universal guarantor of legitimacy, (1) there is no point in measuring to see if that is, in fact, true (lest the assumption be violated) and (2) even if the legitimacy of deliberative democracy could be measured, it would still involve measuring beliefs about legitimacy. For these reasons and reasons discussed throughout this chapter, I elected to adopt Suchman's definition of legitimacy for the purposes of this study.

\section{Normative criteria for legitimacy}

Calls for an understanding of legitimacy have only recently begun to emerge in protected area scholarship. Those studies that have offered conceptualizations of 
legitimacy in terms of protected area governance and management vary widely in their normative offerings. McGuire and Sanyal (2006), in their study of watershed management on National Forests, adopt Habermas' conceptual framework of legitimacy and, consequently, align legitimacy with a process that closely resembles deliberative democracy. Mascarenhas and Scarce (2004) adopted a more pragmatic or instrumental approach in their research on forest planning in British Columbia by describing how participants in the planning process felt that forest planning was legitimate if and only if it successfully achieved its goals. Three criteria they found to most significantly contribute to this success were "representativeness, government mandate and influence, and the consensus decision-making approach.” Johnston and Soulsby (2002) loosely identify legitimacy with the nexus binding social and environmental justice in their study of environmental policies in northern Scotland. Kull (2002) and Brechin and others (2002) offer Weberian belief-oriented definitions of legitimacy, but stop short of offering any normative criteria that might give rise to beliefs of legitimacy. While an important contribution in its own right, the emerging research and scholarship pertaining to the legitimacy of protected area governance and management has focused only on particular dimensions of legitimacy rather than adopting a more holistic conceptualization.

The danger in adopting a conceptualization of legitimacy based on, for instance, pragmatism alone, while failing to recognize or consider the importance of other normative criteria, is that actions conceived to be instrumentally sound (and, hence, legitimate) might, in fact, be viewed by society to be very illegitimate from a moral, rational, or conventional standpoint. Theory and practice proceed, though, equating 
legitimacy with pragmatic outcomes without recognizing the potential illegitimacies from other perspectives. For example, annexing private lands surrounding a protected area in order to increase the size of that protected might meet certain pragmatic interests associated with biodiversity protection, but such an action would likely be conceived as illegitimate from a moral and legal perspective. Moreover, what might be considered legitimate for one entity (e.g., those with an interest in biodiversity protection) could very well be considered illegitimate to another entity (e.g., those whose land would be annexed). A sound conceptualization of legitimacy, then, must consider a range of normative criteria and allow for the emergence of contested criteria that might not be initially considered.

The varying normative conceptualizations of legitimacy offer a wide array of considerations for criteria of legitimacy, and theorists have synthesized these criteria through a variety of delineations (see, e.g., Suchman 1995; Aldrich 1999; and Dobrev 2001). As I have discussed above, and based in part on these delineations, most normative conceptualizations of legitimacy can be categorized as,

- moral - whether or not an action is "right" or "just" (Buchanan 2002; Valadez 2000; Bohman 2003; Suchman 1995; Johnston and Soulsby 2002),

- rational - whether or not an action is logically sound and it can be feasibly achieved (Weatherford 1992; Weber 1920; Habermas 1996; Suchman 1995),

- pragmatic - whether or not an action meets a specific interest (Arneson 2003; Suchman 1995), or

- conventional - whether or not an action comports with laws, policies, or other formal or informal guidelines (Rawls 1993; Rohr 1986; Fallon 2005; Barnett 2003). 
Each of these criterions may then be further expressed through either procedural or substantive terms. ${ }^{21}$ For instance, it may be the case that for a given action, it must not only be substantively, morally legitimate, but the process, as well, must be morally sound. So, too, may an action - beyond meeting the substantive interests of concerned parties - also need to meet procedural goals or interests (e.g., inclusiveness, representativeness, etc.).

A synthetic conceptual framework

Summarily stated, the synthetic and systemic conceptual framework that I adopted for understanding the legitimacy of resource use in Kruger National Park can be stated in terms of five components and represented, in part, in Figure 3-1.

\section{Summary:}

\section{A synthetic framework for understanding and exploring legitimacy}

- Component 1 - Definition of legitimacy: Adopting Suchman's definition, legitimacy may be defined as "a generalized perception or assumption that the actions of an entity are desirable, proper, or appropriate within some socially constructed system of norms, values, beliefs, and definitions." The object of legitimacy is an action taken in response to a given societal issue or need (e.g. the provision of access to resources). Institutions, governments, or organizations may be the object of legitimacy, since their existence is an action in response to some societal issue or need.

- Component 2 - Contextual norms, values, beliefs, and definitions: The variety of contextual norms, values, beliefs, and definitions (as articulated in Suchman's definition of legitimacy) associated with different groups or individuals form the basis of their varying conceptualizations of legitimacy and give rise to more specific procedural and substantive considerations.

\footnotetext{
${ }^{21}$ Barnard (2001, 27-30) offers a detailed account of the importance of distinguishing between substantive and procedural legitimacy.
} 


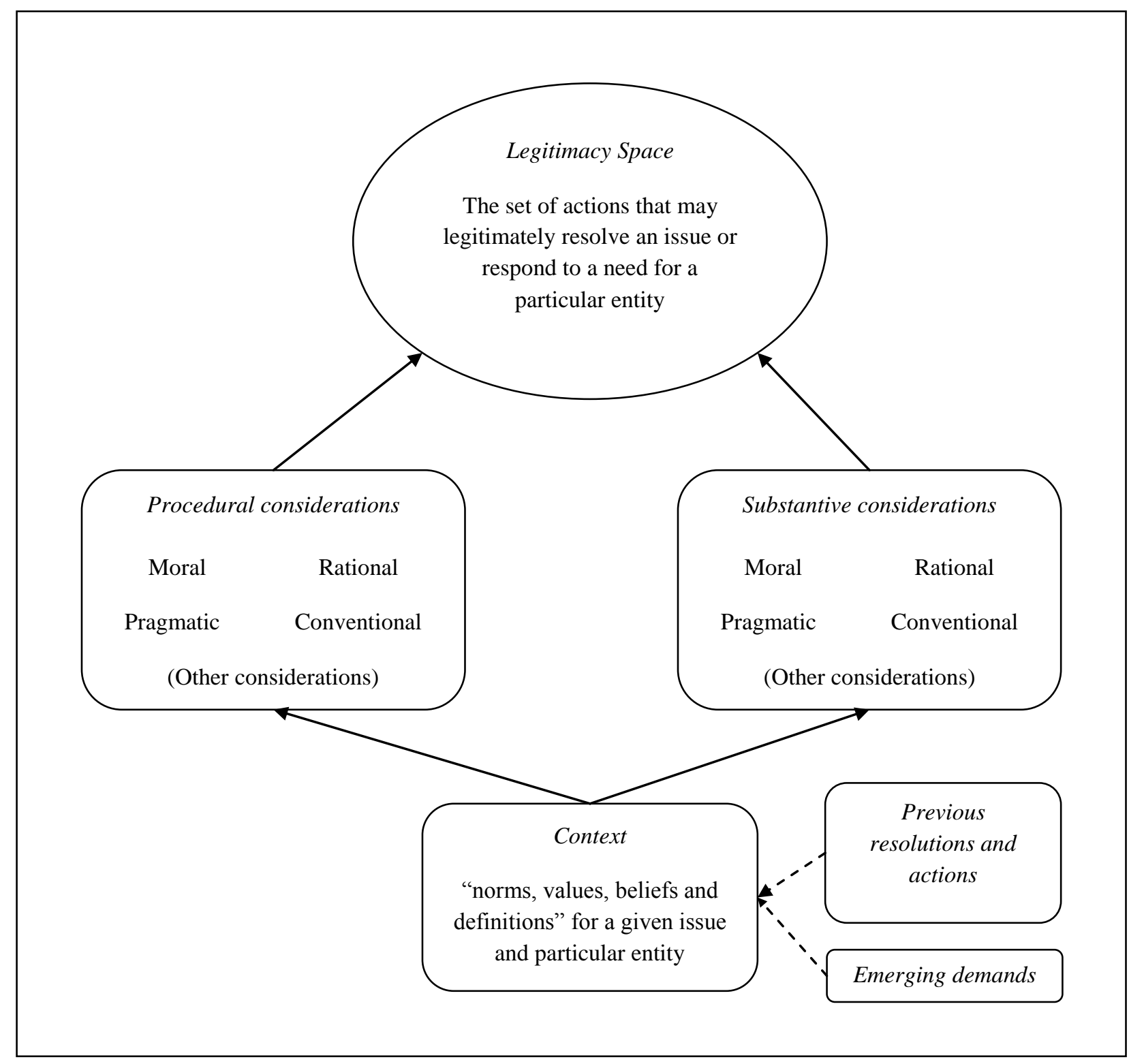

Figure 3-1: A synthetic and systemic conceptual framework for understanding and exploring legitimacy

- Component 3 - Procedural and substantive considerations: Assessments of legitimacy may be understood in terms of both procedural and substantive considerations related to a specific issue and action. These considerations may be further delineated in terms of dimensions such as morality, pragmatism, rationality, conventionality, or others. 
- Component 4-Legitimacy spaces: A legitimacy space is the set of all actions that are legitimately responsive to a given issue for a particular group or individual. For a given issue, there may be (1) no legitimate actions, (2) a single legitimate action, or (3) multiple legitimate actions that define the legitimacy space. Different social groups will likely have different legitimacy spaces.

- Component 5 - Recursive dimensions of legitimacy: Previous actions and resolutions, legitimate or not, frequently impact the context in a way that influences assessments of legitimacy for subsequent issues. Moreover, the legitimacy of actions or resolutions for a particular action, as well as emerging demands, must be re-evaluated as contextual factors change.

The foundation of legitimacy, as suggested by the adopted definition, is the norms, values, beliefs, and definitions for a given issue associated with the various groups or individuals. In terms of this study, the historic relationship between Kruger and surrounding residents is one contextual factor that has substantially shaped local residents' beliefs concerning how and what benefits they should derive from the Park. These contextual factors, in turn, define the procedural and substantive considerations by which the legitimacy of actions responsive to a societal issue or need are evaluated (i.e., morality, rationality, pragmatism, conventionality, or other normative criteria). In terms of Park staff, for instance, their underlying values have led them to subscribe to the adaptive management process, which implies that if they are to view a resource use policy as procedurally legitimate, it must follow the adaptive management process.

The suite of procedural and substantive considerations give rise to a "legitimacy space" for each group or individual within which legitimate actions that are responsive to a societal issue or need can be crafted. If an individual, for example, believes that procedurally speaking, only managers should make decisions concerning resource use and that, substantively speaking, resource use is a morally inappropriate activity in a 
Park, then that individual's legitimacy space might be very narrowly defined (e.g., it could contain only one legitimate action - the prohibition of resource use). If, on the other hand, one believes that, procedurally speaking, it's okay for either managers alone to make decisions concerning resource use or that local residents can assist in that process and, substantively speaking, resource use is an acceptable, but not necessary, activity, then there are a variety of actions that individual would view as legitimate (thus, their legitimacy space would be broader than that of the previous example).

It's important to note that legitimacy spaces may be empty, consist of a single action, or many possible actions depending on the context and issue or need in question. Moreover, this space could be defined in very different ways across or within social groups. If all legitimacy spaces of interest intersect in some fashion, then the possibility exists that the perception of legitimacy might be shared. However, as is perhaps the case with many issues, not all legitimacy spaces for all groups (or within all groups, for that matter) will intersect. Thus, either (1) some legitimacy spaces will have to be re-defined (which may entail compromises or trade-offs) or (2) some legitimacy spaces will have to be marginalized.

Once a legitimate course of action is taken, there are recursive considerations. First, societal change implies that the contextual framework (i.e., the underlying norms, values, beliefs, and definitions) will change, as well. Consequently, the legitimacy of a particular action must be re-evaluated. Second, and conversely, as Johnson and others (2006) assert, the perception or assumption of legitimacy associated with an action for a particular social issue or need may create, maintain, or change the contextual framework 
in that setting or in another setting. If, for instance, creating community nurseries in response to the demand for medicinal plants in protected areas in Malawi is perceived as legitimate, it might be the case that protected area management organizations in South Africa will perceive that action as legitimate and institute a similar action in South African protected areas. Moreover, if the creation of a community nursery was achieved through "community involvement" practices, and those practices were perceived as legitimate, then the same type of involvement might be employed for different issues or needs. In this way, the actions of an entity can be strategic in so far that if an entity wishes to advance a particular action for a complex issue, it may be advantageous to first implement that action within a setting where the action will be readily legitimated. Once legitimated, a more convincing case can be made for applying a similar action to a more complex setting. Community conservation is an excellent example of this phenomenon; advocates for community involvement or those who are at least interested in its implementation have recognized that its large-scale systemic legitimacy is, to an extent, dependent on illustrating its legitimacy on smaller project-by-project scales.

The framework that I have outlined above is by no means the only possible manner in which legitimacy may be understood or explored. Instead, this framework represents my synthetic understanding of legitimacy based on the myriad theories and conceptualizations that preceded this study. Rather than a hypothesis per se, this framework offers one way of organizing my thoughts on the legitimacy of protected area governance and management and defining the bounds of this study. As will be evident in the next chapter and throughout the remainder of this dissertation, this framework - to a 
certain extent - guided the questions I asked when interviewing and surveying Park staff, local residents, and Park visitors. "Context" and "procedural and substantive considerations" were important features of both the interviews and surveys that I will discuss in more depth in the next chapter. However, there were elements of the framework that I allowed to emerge rather than deductively test. For instance, I did not ask those that I surveyed or interviewed to address dimensions such as "morality," "rationality," "pragmatism," or "conventionality." Instead, recognizing the exploratory nature of this study, I elected to allow those elements - or any others - to emerge from the data. As it turns out, though, the dimensions listed above did figure strongly in the various conceptualizations of legitimacy. In Chapter 11, after presenting and discussing the results of this study, I return to this framework to discuss how this study might offer an original contribution to the broader understanding of legitimacy vis-à-vis this framework.

\section{Conclusion}

In this chapter, I have attempted to lay a conceptual foundation for understanding legitimacy. As discussed, legitimacy has been conceived in a number of different ways ranging from the abstract, belief-oriented conceptualization of social and behavioral theorists to the prescriptive, normative conceptualizations of other scholars. There is no

reason to conclude, though, that these conceptualizations must necessarily be at odds with one another. With the synthetic framework that I have presented, I believe it is possible to appreciate both the cognitive and normative dimensions of legitimacy at no cost to 
either. Having offered a conceptual framework, in the next chapter - "Research Design" - I present my specific research questions, the operationalization of my conceptual framework in terms of resource use within Kruger National Park, and the testing logic by which the "legitimacy" of this research can be evaluated. 


\section{CHAPTER 4}

\section{RESEARCH DESIGN}

\section{Introduction}

As discussed in the previous chapters, there are multiple approaches to understanding complex concepts such as legitimacy and its relationship to protected area governance and management. A distinguishing feature of this approach was that it was designed to be a scientific study. According to Patterson and Williams $(2001,6)$, "science is:

1. a rigorous and systematic set of empirical activities for constructing, representing and analyzing knowledge about phenomena being studied (Brunner 1982; Nespor and Barylske, 1991) that is guided by

2. a set of normative commitments shared by a community of scholars."

Consequently, the description of a scientific study consists of an articulation of "normative commitments" along with a "testing logic" that describes the rigorous, systematic, and empirical activities and "explains the manner in which data function as a test of ideas" (Shrader-Frechette and McCoy 1994).

To illustrate the scientific design of this research, this chapter is divided into four parts. In the first part, I discuss the critical theory research tradition, which formed the basis of the normative research commitments I adopted for this research. As I will discuss, attentiveness to these commitments provided a framework that allowed me to sharpen my research questions and identify the types of data that would be responsive to those questions. In the second part, I present the data collection instruments, sampling 
frameworks, a brief description of the samples, and analytic methods. Next, by articulating the testing logic I adopted, I discuss how the data served as a test of those ideas rooted in the normative commitments and research questions. In the fourth and final part, I offer an overview of the primary limitations to this research. The research design discussed in this chapter, while complex, provides the fundamental basis upon which the contributions of this study may be evaluated.

Figure 4-1 provides an overview of the research design. I began this research by identifying important areas of protected area governance and management that both the literature and managers in Kruger identified as needing further study. Having identified the concept of legitimacy and the issue of resource use as two such domains, explored and synthesized the literature relating to Kruger National Park and legitimacy. In mnay respects, this review and synthesis was grounded in the principles of Critical Theory. This discussion can be found in Chapters $2 \& 3$. The remainder of the dissertation is focused on the questions I asked, my analysis of those questions, and how I went about doing so. As I will discuss in this Chapter, I've adopted a Grounded Theory approach to analyzing and asking the interview questions and a multivariate statistical approach to designing and analyzing the visitor survey.

\section{Critical theory as a research tradition}

Whether implicitly or explicitly, researchers adopt a number of normative commitments that shape every aspect of their research from fundamental beliefs concerning the nature of reality and what constitutes knowledge to methods and modes of 
analyzing and interpreting data. ${ }^{22}$ As protected area scholarship increasingly embraces a "critical pluralistic" worldview, whereby multiple approaches (embracing very diverse normative commitments) may be legitimately employed when studying protected areas, the explicit articulation of these normative commitments becomes increasingly important if the logical utility of different approaches are to be evaluated against one another (Patterson and Williams 1998; Hunt 1991, 41). For instance, as discussed in Chapter 3, the study of legitimacy reflects at least two broad approaches - the "social and behavioral" and "normative" approaches - that are based on very different assumptions concerning how legitimacy may be understood and measured. Whereas the social and behavioral approach is empirically grounded, the normative approach is more firmly rooted in philosophy.

Because I have adopted a synthetic conceptualization of legitimacy, neither of the two broad approaches alone sufficiently capture the underlying norms that shaped the research design for this study. Instead, because of the synthetic nature of my conceptualization (that draws from both empirical and normative approaches), I adopt somewhat of a synthetic approach to research, as well, that may be loosely characterized as a "critical theory" approach to understanding legitimacy. As a research tradition, critical theory is fundamentally concerned with distortions or inconsistencies between what is intersubjectively desired based on the norms, values, and beliefs of a society and the empirically existent reality (Murray and Ozanne 1991). A critical theory approach to understanding legitimacy, then - consistent with my conceptualization and research

\footnotetext{
${ }^{22}$ See Patterson and Williams (1998 and 2005) who, based in part on the work of Laudan, discuss the "macrostructure of science" and the importance of articulating normative commitments associated with that structure's elements
} 


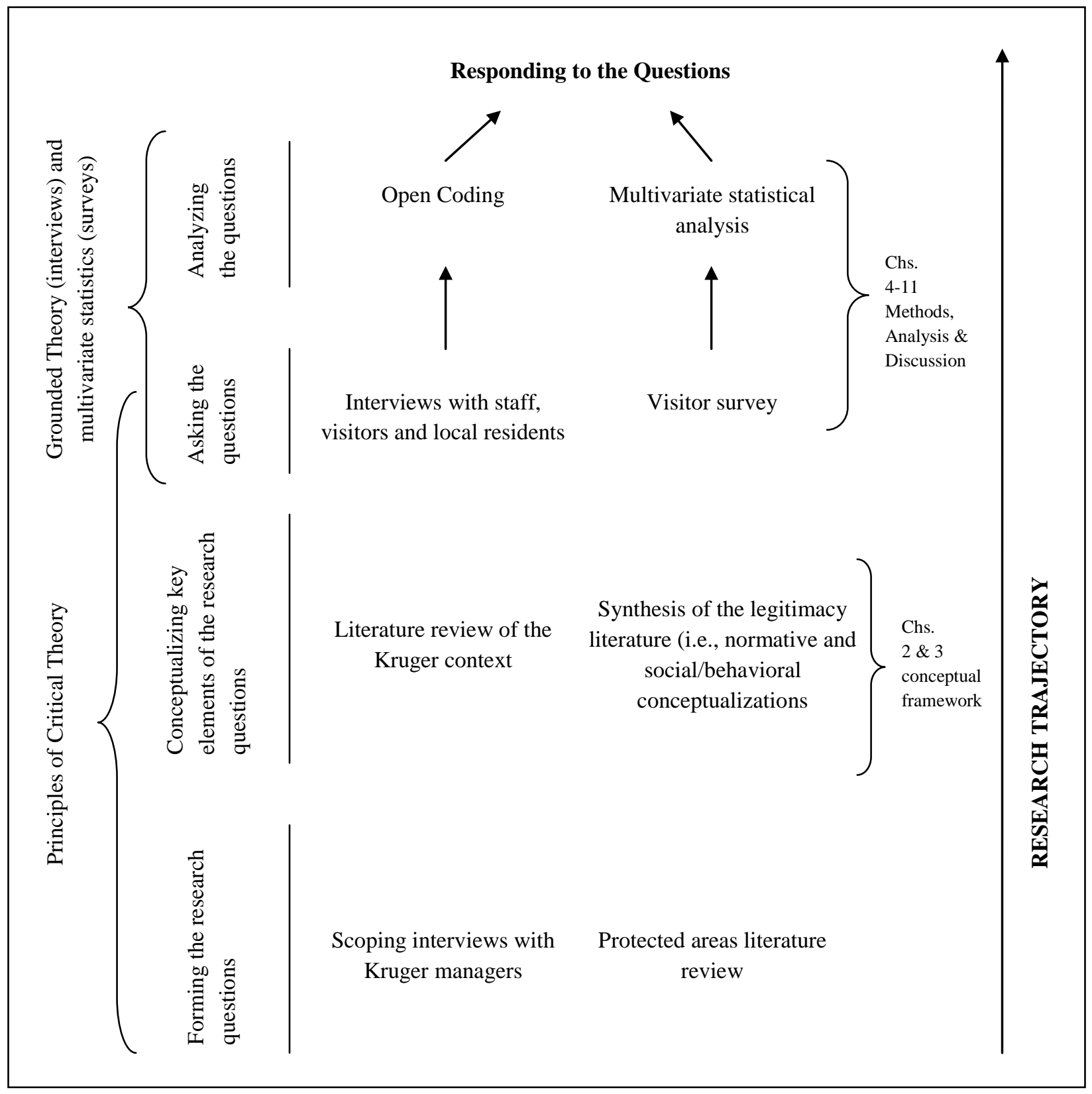

Figure 4-1: Research trajectory

questions - seeks to (a) understand how different societal groups construct views of legitimacy based on their norms, values, and beliefs and (b) identify ways in which those perceptions of legitimacy might be reconciled against the material reality of a given issue 
(in this case, resource use). In this section, I briefly discuss critical theory as a research tradition, as well as the utility of a mixed-method and case-study approach

\section{Critical theory and legitimacy}

Perhaps more so than any other research tradition, "critical theory" embraces the concept of legitimacy, as I have defined it. The centrality of legitimacy to critical theory is apparent when considering its overarching purpose - to help people envision a better society and emancipate human freedom and potential (Roderick 1986, 20-23). As a school of thought, critical theory originated with the reinterpretations of Marx by scholars such as Georg Lukacs, Karl Korsch, Antonio Gramsci, and Karl Mannheim, but began to coalesce into a definable paradigm with the 1923 founding of the Institute of Social Research in Frankfurt, Germany. Scholars associated with this Institute, who came to be collectively known as the Frankfurt School, sought to salvage the normative philosophy of Marx while calling into question the empiricist, and perhaps deterministic, foundations of his theory of historical materialism (Wiggershaus 1994). The Frankfurt School ended its 50-year history in 1973 with the death of its founders Max Horkheimer and Theodor Adorno. Nevertheless, students of the scholars who comprised the Frankfurt School including Habermas, who wrote extensively on the subject of legitimacy - carried on the tradition of critical theory, albeit from a variety of slightly different perspectives.

While critical theory manifests in a number of forms (e.g., Feminism, Social Ecology, Queer Theory, etc.), there are certain dimensions of the approach that are common to nearly all. First, critical theorists call into question extreme positivist and 
interpretivists accounts (Habermas 1988, 549; McCluskie 2003; Murray and Ozanne 1991). Because it precludes the material structure of reality, the subjective ontology of interpretivists denies the possibility that a constructed social reality exists and may influence individuals (Dews 1999) Conversely, positivists who believe in the existence of an objective reality ignore historical and contextual factors that shape our world (Habermas 1988b, 549). Critical theorists, then, hold that reality is socially constructed, but once constructed, it acts upon society (Murray and Ozanne 1991).

In terms of legitimacy, the question then becomes to what extent is that social construction and the interests that have given rise to it legitimate across a set of actors (Habermas 1975, 73-75)? And, more importantly, if the existent reality is illegitimate, how may legitimacy be established (Habermas 1975, 73-75; Habermas 1971, 313)? ${ }^{23}$ These thematic questions are closely aligned with the research questions for this study identified in Chapter 2, and as illustrated in the sub-questions below, attentiveness to broad themes of critical theory facilitate a refinement and sharpening of the questions:

Research question \#1: What are the resources in demand among residents living near the western boundary of Kruger National Park?

Sub-question: How have the historical and current relationships between the Park and local residents shaped the nature of requests for resources or benefits, in general?

Research question \#2: How do different groups - i.e., Park managers, local residents, and visitors - conceptualize the legitimacy of resource use?

\footnotetext{
${ }^{23}$ Many critical theorists argue that this legitimation corresponds to the "emancipation" of the actor experiencing the inconsistent reality (Marcuse 1964, x; McCarthy 1978, 126; Fuhrman 1979)
} 
Sub-question: Is the manifest reality of resource use in Kruger consistent with different groups' beliefs concerning the legitimacy of resource use?

Research question \#3: Are there possible strategies for resolving competing or conflicting conceptualizations of legitimacy?

Sub-question: Notwithstanding differing perceptions of legitimacy concerning resource use between groups, within social groups, are there ways to resolve inconsistencies between the current resource use policy in Kruger and what are perceived to be legitimate, desired policies among that group?

\section{A case-study and mixed-method approach to research}

Relative to other research traditions, research organized (at least in part) around a critical theory approach is typically pragmatic and contextually- or issue-driven. That is, rather than broad or abstract research explicitly designed to be generalizable across a broad array of circumstances, critical theorists typically orient their research around a specific "questionable or unclear situation" (Roderick 1986, 58) or "concrete practical problem" (Murry and Ozanne 1991) where there is an opportunity to connect theory and practice.

The pragmatic nature of critical theory by no means precludes the applicability of lessons learned within a specific context to other contexts - it is rather the case that the goals of critical theory are immediately oriented to a particular issue within a particular setting (Gerring 2004, Morrow 1994). For instance, while a critical theory approach to understanding legitimacy might very well inform a broader philosophy of legitimacy, it does so through a contextual lens. This case study approach is particularly well-suited for establishing a direct link between social science and decision-making - a task which 
broad-scale and experimental approaches are often ill-suited for, due to their failure to consider contextual variables (Gerring 2004).

Two important considerations illuminate the logic of the case study approach. First, unlike classical-experimental methods that involve manipulation, control, and replicated observations, the case-study approach is "quasi-experimental" in that,

1. in addition to the exploration and description of a particular variable of interest (e.g., legitimacy), there is an effort to explore that variable in order to specify cause-and-effect relationships, but

2. "the control of these variables is difficult, if not impossible." (Shrader-Frechette and McCoy 1994).

Second, because of the complexity associated with case studies and the inability to control specific variables, it is often the case that the researcher does not know what the relevant variables are or whether the findings may apply in other contexts (Gerring 2004; Shrader-Frechette and McCoy 1994). Hypotheses, then, concerning causal relationships must be "working" hypotheses and, according to Yin (1984, $16 \mathrm{ff}$; cited in ShraderFrechette and McCoy 1994)), the case-study analyst has two primary objectives: (1) "to pose and to assess competing explanations for the same phenomenon or set of events" and (2) "to discover whether (and if so, how) such explanations might apply to other situations.”

In terms of this study, these considerations feature strongly in the research design. For instance, not knowing what factors would contribute to perceptions concerning the legitimacy of resource use in Kruger, I posed a synthetic framework that incorporated a broad array of contributing factors, while also recognizing that additional factors might materialize throughout the course of the study. Moreover, no assumptions were made 
regarding the generalizability of how legitimacy is constructed across different groups. In other words, I did not assume that because a particular group viewed the legitimacy of resource use in a particular way that a similar group in another contextual setting will hold similar views, nor will a group's construction of legitimacy be the same across issues (e.g., a contributing factor might figure strongly in some issues and weakly in others). In short, the case-study approach I employed for this study - consistent with my broader normative research commitments - was designed to provide intensive insight into a particular issue for a specific context and to contribute to a broader conceptual discussion concerning legitimacy through that insight.

\section{A mixed method approach}

Patterson and Williams (2005) argue that, rather than representing a troubling inconsistency, the multitude and diversity of approaches associated with a particular research domain (e.g., the study of legitimacy) can offer insight into a phenomenon from a variety of perspectives. Conceptually speaking, and consistent with the critical theory research tradition, I have adopted a similar philosophy for this study. For the purposes of this study, I employed both qualitative (i.e., interviews with Park staff, local residents, and Park visitors) and quantitative (i.e., a visitor survey) approaches. Whereas some have historically regarded quantitative and qualitative approaches as inherently

conflicting or qualitative approaches as inferior, social scientists have increasingly argued that the schism is a false one and that each approach offers a perspective that the other cannot (see, e.g., Corner 1991; Bryman 2006; Onwuegbuzie and Leech 2005; Brannen 
2005; Sale, Lohfeld, and Brazil 2002). For reasons discussed in the next section, a mixed-method approach offered more complete research design.

Despite the benefits associated with mixed-method approaches, there are also potential pitfalls. More than twenty years ago, Mitchell (1986) identified possible problems such as confused units of analysis, the need for more time and money to perform different analyses, the need for proficiency in multiple methodological approaches, and challenges associated with comparing results from different data sources. In addition to these pragmatic challenges, there are also logical quandaries associated with mixed-method approaches - in particular, whether the adopted worldview or paradigmatic commitments preclude the use of mixed methods (e.g., a purely rationalistpositivist approach might not logically embrace idiographic qualitative data).

Critical theorists, though, eschewing pure positivism and interpretivism, maintain that the combination of quantitative and qualitative methods is consistent with critical theory's ontological commitments that identify reality as the interplay between objective social structures (positivism) and the subjective individual (interpretivism) (Morrow 1964, 207). Responding to critics who argue that quantitative methods do not comport with critical theory's normative commitments, Braybrooke $(1987,60)$ argues that

Simply put, nothing about qualitative research, regardless of the form it takes, necessarily precludes the use of quantitative representations or nonquantitative formal methods ... Moreover, the activities of research design, data collection, and analysis in quantitative social research necessarily are based on the interplay of constructed meanings.

Habermas $(1988,73)$ goes even further by directing that, 
"While the natural sciences and the humanities are able to live side by side, in mutual indifference if not in mutual admiration, the social sciences must resolve the tension between the two approaches and bring them under one roof. Here the research practice itself forces us to reflect on the relationship between analytic and hermeneutic procedures"

\section{Data: instruments, collection, and analysis}

The approach outlined above, including in particular as it relates to a mixedmethod and case study approach, was adopted to provide in-depth insight into the legitimacy of resource use in Kruger National Park from a variety of perspectives. While, indeed, I believe this approach permits a more holistic and complete account of the issue, it is also true that the data - including its collection and analysis - is necessarily complex. In this section, I describe the types of data that were collected, how they were collected, general descriptions of the samples, and the methods of data analysis I employed.

In order to respond to the fundamental research questions, two forms of data were collected and analyzed - (1) digitally recorded and transcribed semi-structured interviews conducted with the staff of Kruger National Park, residents living along the western boundary of the Park, and Park visitors and (2) surveys distributed to Park visitors. The fieldwork for this research began in the summer of 2005 when I traveled to South Africa in order to, among other things, speak with staff members at Kruger National Park to identify the most important Park-related issues that social science research could contribute to. A number of issues were discussed including land claims in the Park, damage-causing animals, elephant culling, and resource use. In terms of resource use, 
many staff at the Park discussed their frustrations with serving the interests of "many masters" - the mandate to protect biodiversity, the demands of visitors, and the increasingly vocalized demands of local residents. How, some staff asked, could a resource use policy for Kruger be developed that is simultaneously viewed as appropriate among such different social groups?

After returning to Missoula and reviewing the nearly twenty interviews I conducted with the staff, I began to develop the conceptual framework and research questions laid out in Chapters 2 and 3 and - pursuant to the framework, research questions and normative commitments I adopted for this research - I crafted an interview guide that I would utilize in semi-structured interviews with the three social groups that the staff of Kruger identified as being fundamentally important in terms of the resource use issue: local residents (including private game reserve owners adjoining the park), Park visitors, and the Park staff themselves. I conducted the semi-structured interviews during June-August, 2006 - a little more than a year after first meeting with the Park staff.

Because of the extraordinary diversity of visitors to Kruger National Park, I concluded that semi-structured interviewing would insufficiently capture the diversity of views that visitors held regarding resource use and the Park, in general (to a larger degree, anyway, compared to Park staff and local residents). Consequently, based in large part on the qualitative data I obtained during June-August 2006, I developed a visitor questionnaire aimed at identifying their broad values and beliefs concerning Kruger National Park, as well as their specific beliefs concerning resource use among 
local residents. Consistent with my conceptual framework discussed in Chapters 2 and 3, this information facilitated an analysis whereby I explored the relationships between fundamental beliefs held by visitors concerning the Park and the specific, normative beliefs regarding the procedural and substantive dimensions of resource use in the Park. All questionnaires were distributed and collected from November 2006-January 2007.

\begin{tabular}{|l|l|}
\hline $\begin{array}{l}\text { Phase 1 } \\
\text { May 2005 }\end{array}$ & Scoping interviews with Park staff \\
\hline $\begin{array}{l}\text { Phase 2 } \\
\text { June 2005-May 2006 }\end{array}$ & $\begin{array}{l}\text { Theoretical preparation, developing } \\
\text { research questions and interview guides }\end{array}$ \\
\hline $\begin{array}{l}\text { Phase 3 } \\
\text { June-August 2006 }\end{array}$ & Conducting semi-structured interviews \\
\hline $\begin{array}{l}\text { Phase 4 } \\
\text { September-October 2006 }\end{array}$ & $\begin{array}{l}\text { Initial analysis of interviews and } \\
\text { questionnaire development }\end{array}$ \\
\hline $\begin{array}{l}\text { Phase 5 } \\
\text { November 2006-January 2007 }\end{array}$ & Administration of questionnaire \\
\hline $\begin{array}{l}\text { Phase 6 } \\
\text { February 2007- May 2007 }\end{array}$ & Analysis of interview and survey data \\
\hline
\end{tabular}

Interview data

Semi-structured interviews were conducted with Park staff, local residents, and Park visitors in an effort to respond to all three fundamental research questions. The qualitative data gathered through semi-structured interviews proved to be a particularly useful source of data responsive to these questions for at least three reasons. First, relatively little is known concerning resource use in Kruger, including desired levels of use and perceptions regarding resource use among staff, local residents, and visitors. As such, in addition to being descriptive and explanatory in nature, this study is 
fundamentally exploratory. Babbie $(2003,245)$ argues that when conducting research in an area that is unfamiliar to the researcher, or that is not well-documented through other research, open-ended or semi-structured interviews are typically a necessary and central source of data. Through the use of semi-structured interviews, ideas, themes, and tangential (but relevant) thoughts are allowed to emerge that might not have manifested through an ex ante, closed-ended questionnaire. Second, the very nature of the meaningbased research questions implies the need for nuanced and idiographic responses. As Strauss and Corbin $(1998,11)$ argue, qualitative data - such as that collected through semi-structured interviews - is the type of data best suited for revealing the "meaning or nature of experience and action." Third, the hermeneutic understanding that Habermas calls for $(1988,173)$, which is most readily revealed through qualitative data, is necessary in order to insure the ontological consistency with the normative commitments I have adopted for the purposes of this study.

Because Park staff, local residents, and visitors play such different roles in the issue of resource use in Kruger, interview questions were necessarily phrased or delivered in different ways. In fact, three different interview guides were utilized, one for each group. The questions posed in these three interview guides were the result of a synthetic operationalization rooted in the ideas and conceptualizations discussed in the first two chapters and directly derived from the three fundamental research questions (see Table 4-1).

\section{Interview guide for Park staff}

1. Could you describe your involvement with the issue of resource use in the Park? [If you have never been involved with the issue, that's o.k. - I'd still like to hear 
your thoughts].

2. Have you been involved in any decision-making processes related to resource use? In what way?

3. What is your understanding of the current policy for local-resident resource use in the Park?

4. Are there appropriate types and levels of resource use by local residents? Why?

5. As I understand, a policy for resource use is being drafted to accompany the management plan. What do you think are the most likely policy outcomes related to resource use?

6. From the perspective of the position you hold at Kruger, what do you think is the most appropriate policy for resource use? Why?

Table 4- 1: Links between concepts, research questions, interview questions, and survey questions

\begin{tabular}{|c|c|c|c|}
\hline Concept & Research Question & Interview Question & Survey Question \\
\hline $\begin{array}{l}\text { Resource use and } \\
\text { context }\end{array}$ & $\begin{array}{l}\text { Research Question 1: } \\
\text { What are the resources } \\
\text { in demand among } \\
\text { residents living near the } \\
\text { western boundary of } \\
\text { Kruger National Park? }\end{array}$ & $\begin{array}{l}\text { PS*: } 3 \\
\text { LR: } 4,5\end{array}$ & None \\
\hline $\begin{array}{l}\text { Procedural and } \\
\text { substantive } \\
\text { considerations } \\
\text { (including the various } \\
\text { dimensions of each) }\end{array}$ & $\begin{array}{l}\text { Research Question 2: } \\
\text { How do different groups } \\
\text { - i.e., Park managers, } \\
\text { local residents, and } \\
\text { visitors - conceptualize } \\
\text { the legitimacy of } \\
\text { resource use? }\end{array}$ & $\begin{array}{l}\text { PS: 4-9 } \\
\text { LR: 1-3, 6- } 9 \\
\text { PV: } 1,3,4,5\end{array}$ & PV: $7-11$ \\
\hline $\begin{array}{l}\text { Inconsistencies between } \\
\text { the manifest reality and } \\
\text { what is desired } \\
\text { Legitimacy spaces }\end{array}$ & $\begin{array}{l}\text { Research Question 3: } \\
\text { How are competing or } \\
\text { conflicting perceptions } \\
\text { of the legitimacy of } \\
\text { resource use resolved? }\end{array}$ & PS: 10 & PV: 11 \\
\hline
\end{tabular}


* PS = Park staff; LR = Local residents; PV=Park visitors

7. What values or beliefs - either personal or derived from SANParks - contribute to that judgment?

8. What do you think is the most appropriate way to develop a policy for resource use in the Park? What are the factors that would make such a policy appropriate?

9. When you think about management actions or policies in general, what do you think are the most important factors that make a decision or appropriate?

10. If we assume that different groups will perceive the appropriateness of a given resource use policy differently, what do you think is the best way to resolve those differences?

11. Can you recommend anyone else I might want to speak with?

\section{Interview guide for local residents}

1. Is the Kruger important to you? Why or why not?

2. Could you tell me a little about the historical relationship you and your community have had with the Park? What about the current relationship?

3. Do you think the use of resources in Kruger among local residents is appropriate? Why or why not?

4. What type of resources would you want to utilize or collect from inside the Park?

5. Why would it be important to you to utilize or collect those resources?

6. Have you been involved in processes where these demands or desires were expressed to Park managers? If you've been involved in such processes, what were your impressions of that process? Was it appropriate or inappropriate?

7. What is your understanding of the current policy for resource use in the Park?

8. Are you satisfied with the current resource use policy? Why? 
9. If you could change the policy, how would you do it?

\section{Interview guide for Park visitors}

1. Would you say that Kruger National Park is important to you? Why?

2. What do you think of when you hear the phrase "resource use" or the word "subsistence" as related to Kruger National Park? (If the respondent says "I do not know," I will provide a brief explanation of the term)

3. Do you think resource use among local residents should be allowed in Kruger National Park? Why?

4. If you think resource use should be allowed at some level, what do you think would be the most appropriate way to manage it?

5. Do you think resource use would affect your experience in the Park? How?

A couple of observations concerning the way in which the questions were operationalized are worth noting. First, it's readily apparent that the word "legitimacy" is never used in any of the questions. Instead, I operationalized legitimacy in terms of the conceptual definition I adopted:

Legitimacy is "a generalized perception or assumption that the actions of an entity are desirable, proper, or appropriate within some socially constructed system of norms, values, beliefs, and definitions." (Suchman 1995)

Operationalizing "legitimacy," as conceptualized here, gives rise to questions of desirability, properness, or appropriateness of resource use within Kruger within a social group's particular context (including its attendant norms, values, beliefs, and definitions). The framework I adopted, then, served as a guide for constructing the interview questions in so far that "legitimacy" - as an abstraction - was clarified or refined for the respondent 
in terms of "appropriateness," which is, arguably, a less abstract concept. Of course, "appropriateness" is not tantamount to "legitimacy," the definition suggests that appropriateness coupled with a "socially constructed system" is equivalent to legitimacy. As a result, in all three interview guides, I pose questions concerning the social group's underlying values and beliefs concerning Kruger National Park in an effort to understand how those contextual considerations influence perceptions of legitimacy.

Second, the synthetic framework discussed in the latter part Chapter 3 and illustrated in Figure 3-1 (p. 80) served as a guiding framework for this study. As such, rather than deductively test the specific elements of this framework through the interviews (e.g., asking whether or not "morality" was the most important contributing factor to a respondent's perception of the legitimacy of resource use), I chose to ask questions in such a way that the elements of legitimacy would emerge from the data and enrich the framework. As with the choice of collecting qualitative data more generally, the exploratory nature of this research, as well as my assumption that legitimacy is a contextually-driven concept, requires that meaning be allowed to emerge rather than superimposed ex ante. The questions presented in the interview guides, then, were crafted in such a way that respondents would be in a position to elaborate on the concept of legitimacy - in particular the broadly defined dimensions that I discuss in Chapters 2 and 3 - but would not be pigeon-holed into discussing a limited set of dimensions. Nevertheless, as will be discussed later in terms of the survey data, the qualitative data collected through the interviews facilitated the development of a questionnaire that 
provided for a deductive test of certain specific, emergent elements Park visitors' conceptualizations of legitimacy.

\section{Sampling}

In the third phase of this study, three diverse populations were sampled for the purpose of gathering qualitative data - Park managers, local residents, and Park visitors. Being directly involved with the issue of resource use, the motivation for collecting data from Park managers and local residents is self-evident at this point - local residents have an interest in utilizing resources in the Park, and Park managers will ultimately act in response to that interest. The importance of visitor's views concerning resource use is, perhaps, less obvious. As discussed in the Kruger Management Plan, though, visitors are an exceedingly important constituency - the views of whom Park managers must consider in all issues and decisions concerning the Park. Park visitors are so important to the management of the Park that visitor-related activities - under the auspices of tourism

- constitute one of three "pillars" upon which the management of Kruger stands (the other two being "biodiversity conservation" and "constituency building") (Kruger National Park 2006).

1. Sampling Park staff and local residents - snowball sampling The sampling of Park managers and local residents was performed vis-à-vis a "snowball sampling" design. Snowball sampling is the location of one or more key informants who will, in turn, provide the researcher with the names of other likely informants that can provide a diversity of views rather than a necessarily representative 
set of views (Bernard 2002, 185-186). As illustrated in the classic research of Richardson (1988), Kadushin (1968), and Ostrander (1980), snowball sampling is particularly appropriate for populations where

- not all members are suitable informants or have the background to provide meaningful data,

- where members know many other members of the population, as well as which members will be able to provide a meaningful diversity of views,

- members are difficult to locate in the absence of assistance from another member of that population. (Bernard 2002)

The Park staff and, to a greater extent, local resident populations fit this criteria well. While a substantial and diverse portion of the Park staff were well-equipped to discuss resource use (and sampled, as a result), discussions with a few, initial key informants allowed me to gather the contact information for a number of other valuable informants who could provide a wide range of perspectives. For instance, discussions with senior managers facilitated the identification of a subset of in-the-field game rangers who had extensive experience with resource use and were able to provide very meaningful and diverse insights. In terms of local residents, discussions with Kruger's Community Facilitator, as well as my participation in three Kruger Community Forum meetings outside the Park $^{24}$, gave rise to a list of initial community members - all along the western boundary - whom I attempted to interview. Those that I interviewed during this initial round were able to then provide me with contact information for a wide variety of other local residents who I then attempted to interview.

\footnotetext{
${ }^{24}$ The Community Forums were established in 2005 to serve as a venue for stakeholder and local resident participation in decision-making processes.
} 
2. Sampling Park visitors - systematic random sampling

Unlike as was the case with Park staff and local residents, the Park visitor population did not fit the snowball sampling criteria described above. Park visitors are transient, they rarely know one another outside of a group they might be with, and there is no reason to assume that one visitor's perceptions of resource use are any more valuable than another's. With such large, diverse populations where members do not know one another, random sampling is more appropriate.

For the purposes of collecting interview data from Park visitors, I employed a "multi-stage cluster sampling design." As described by Babbie $(2003,208)$, multistage cluster sampling is "the process by which natural groups (clusters) are sampled initially, with the members of each selected group being subsampled afterwards." The multistage design for this study began with the selection of four different "rest camps" within the Park where I would sample visitors. ${ }^{25}$ In total there are 13 major rest camps throughout the Park, and the four selected - Lower Sabie, Skukuza, Letaba, \& Punda Maria - were selected on the basis of their geographic diversity and the perceived differences among staff in the type of visitors that frequent those camps. For instance, Skukuza is a large camp in the south presumably visited by a very wide range of visitors, whereas Punda Maria in the far north is a much smaller camp where staff felt that visitors were more specialized (e.g., multiple-day campers, bird watchers, photographers, etc.). Rest camps were chosen as the intercept point - in opposition to entry gates - because I felt that

\footnotetext{
${ }^{25}$ Because the sampling design involved the random selection of
} 106 
rushed visitors at the gates would be less receptive to participating in an interview than relatively relaxed visitors lounging in the rest camps.

After deciding on the four camps to sample, each camp was assigned a randomly selected day (between June $14^{\text {th }}$ and August $15^{\text {th }}, 2006$ ) and time (either 10 am or 2 pm) to be sampled. Skukuza was sampled on June $16^{\text {th }}$ at $10 \mathrm{am}$; Punda Maria on June $27^{\text {th }}$ at $2 \mathrm{pm}$; Letaba on July $5^{\text {th }}$ at $2 \mathrm{pm}$; and Lower Sabie on August $2^{\text {nd }}$ at 10 am. Once at the camp, I stationed myself at the most centrally-active location in the camp (which, in all cases, was the Park shop), and - employing a "systematic random sampling" design ${ }^{26}$ asked every third exiting visitor if they would be interested in participating in the interview. $^{27}$

\section{A brief description of the samples}

A total of 111 interviews with Park staff, local residents, and Park visitors were conducted during the sampling period, resulting in more than 1,200 pages of transcribed data. Of interviews, 28 (25.25\%) were with Park staff, 44 (39.63\%) were with local residents, and 39 (35.13\%) were with Park visitors. I was able to interview all Park staff that were selected through the sampling procedure, all but one local resident selected, and 4 visitors whom I sampled to interview elected to not participate. Park staff from four main groups were interviewed - the Scientific Services department (39.28\% of the

\footnotetext{
${ }^{26}$ Systematic random sampling is a type of probability sampling in which every $k$ th unit in a list is selected for inclusion in the sample (Babbie 2003, 203)

${ }^{27}$ The interval at which members of a sample are systematically selected (in this case three) is typically based on a "sampling interval," which is the population size divided by the sample size. However, because of the lack of data concerning the population (i.e., the total number of visitors leaving a particular park shop for a particular day), a reasonable interval of three was selected.
} 
interviewees), the People and Conservation department (14.28\%), the Conservation Services department (14.28\%), Park rangers (28.57\%), and other staff (3.57\%). Most of the staff interviewed (57.14\%) were stationed at the Park headquarters in Skukuza, while the remaining interviewees were stationed at various other locations throughout the Park.

Of the 44 local residents interviewed, 14 (31.82\%) were from the northern half of the western boundary region, while $30(68.18 \%)$ lived in the southern region along the western boundary of the Park. Almost all local residents that were interviewed were black South Africans (89\%), the only exception being 4 white game reserve owners and 1 white non-governmental organization (NGO) director. Community leaders - including chiefs and ndunas (a local leader within a larger chieftanship) - constituted $15.91 \%(\mathrm{n}=7)$ of the local residents interviewed; $11.36 \%(\mathrm{n}=5)$ of the sample were sangomas (i.e., traditional healers); $9.1 \%(n=4)$ were rangers, owners, or chief wardens at game reserves adjacent to Kruger; $22.72 \%(\mathrm{n}=10)$ interviewed were employed in various occupations, including school teachers, tour guides, and NGO personnel; and $40.91 \%(\mathrm{n}=18)$ were unemployed. A translator provided assistance in interviews with 2 of the community leaders, 3 of the sangomas, and 13 of the unemployed residents ( $40.91 \%$ of the local resident interviews).

I attempted to interview 43 visitors during the sampling period, however 4 chose to not participate on account of language barriers, thus providing me with 39 completed visitor interviews (90.70\% response rate). Of the completed visitor interviews, 32 $(82.05 \%)$ of the interviewees were South African, and 7 (17.95\%) were international 
visitors from United States ( $\mathrm{n}=2$ ), Germany ( $\mathrm{n}=2$ ), France, Australia, and the Netherlands.

\section{Analysis - a grounded theory approach}

One of the most powerful and frequently employed means of analyzing interviews is through "grounded-theory." The grounded-theory approach, first articulated by Glaser and Strauss in the late 1960s, is a set of techniques for (1) identifying "categories" and "properties" that emerge from the texts (most typically interview transcripts), (2) recognizing relationships between and among categories and properties and (3) formulating those relationships into theories (Glaser and Strauss 1967; Russell 2002). Grounded-theory differs from other methods of text analysis, such as content analysis, in that it allows hypotheses and theories to emerge rather than testing the data against $a$ priori hypotheses or theories. The use of grounded-theory is especially valuable in studying issues that have not been previously studied, as was the case with this research. Using strictly deductive methods of analysis for emerging areas of research, for instance, constrains theory, and, often, the a priori hypotheses or theories are speculative at best (Glaser and Strauss 1967; Strauss and Corbin 1998). This is not to say that with grounded theory research questions and propositions are not postulated beforehand. In fact, the research questions, framework, and principles of critical theory that I have discussed were adopted beforehand to serve as a guiding framework that set the bounds for the research. In essence, and consistent with my normative commitments for this research, the value of grounded-theory is that it allows the researcher to explore concepts 
and meanings of interest while permitting the emergence of theory related to those concepts and meanings.

The first component of the grounded-theory method (see Table 4-2) is the process of "coding" where categories - or "concepts that stand for phenomena" - as well as the properties -or "characteristics of those categories" - are identified (Strauss and Corbin 1997, 101). This process usually begins with simply reading through interview transcripts and underlining or highlighting dominant ideas or themes as one goes along. After the researcher has become familiar with the nature of the texts, the interview transcripts are then typically imported into a qualitative data analysis software package, such as NVivo, which was used for this study. Using this software, a researcher then codes or labels passages of transcripts in terms of the meaning that the text conveys.

Table 4- 2: The Grounded Theory approach to analysis

\begin{tabular}{|l|l|}
\hline Component 1: preparing the data & $\begin{array}{l}\text { Produce transcripts of interviews and read through } \\
\text { the texts }\end{array}$ \\
\hline Component 2: coding & $\begin{array}{l}\text { Identify categories and properties that arise from the } \\
\text { texts }\end{array}$ \\
\hline Component 3: generating theory & $\begin{array}{l}\text { Use the relationships among categories and properties } \\
\text { to generate theory, constantly checking the theory } \\
\text { against the data }\end{array}$ \\
\hline Component 4: presenting theory & $\begin{array}{l}\text { Present the results using quotes from interviews that } \\
\text { illustrate the theory }\end{array}$ \\
\hline
\end{tabular}


As the coding proceeds, the researcher will likely find that certain codes are conceptually related to one another. For instance, the codes "medicinal plants," "firewood," "meat," "thatch grass" that might be identified with different passages are conceptually related in so far that they constitute types of resources in demand among local residents. In this case, "resources in demand" might serve as a category, whereas "medicinal plants," "firewood," "meat," and "thatch grass" are properties of that category.

The establishment of categories and properties then allows the researcher to develop theories regarding how different concepts relate to one another. For instance, in terms of the "resources in demand" category and its properties mentioned above, it might be possible, based on the data and the way the properties relate to the category, to theorize which properties (i.e., resources of interest) are the highest in demand. After such theories are uncovered, excerpts from the transcript are provided in the research results to illustrate the theories.

Because the theories are immediately generated from the data, they are "grounded" in the data and - substantively and contextually speaking - exhibit a high degree of validity. Of course, different theories might emerge in different contexts with different data, such that reliability might be called into question. Nevertheless, given the importance of contextual understanding that I have assumed in terms of my conceptualization of legitimacy and my broader normative commitments, the grounded theory approach to analysis provided a very useful analytic approach. 


\section{Survey data}

The second data component was a visitor survey administered to Park visitors during late November 2006 to mid-January 2007. Broadly speaking, the survey was designed to elicit data concerning visitors' values related to Kruger National Park and how those values related to procedural and substantive dimensions of resource use in the Park. Consistent with my conceptualization of legitimacy, this data was analyzed to understand how underlying values relate to perspectives on resource use, as well as the most important factors that contribute to perceptions of legitimacy.

The packet offered to visitors included a ten-page questionnaire (Appendix 1), a cover letter explaining the nature of the research (see Appendix 2), and a postcard that they were asked to complete on-site as a tool to identify any non-response bias. Once presented with the survey, visitors were asked to deposit completed surveys at the registration desks at any of ten major rest camps throughout the Park. Ten days after the sampling period ended, I traveled to all of the camps to retrieve the completed surveys. In this section, I discuss the questionnaire itself, the sampling framework I employed, and the methods of data analysis I utilized.

\section{The questionnaire}

Development of the visitor questionnaire began in September 2006 after I had returned from collecting interview data in Kruger during June-August 2006. The substantive content of the questionnaire was based on my informal analysis and review of the interview transcripts while I was in South Africa and after I had returned to Missoula. 
Several important themes emerged through this analysis (some of which were unexpected) that allowed me to ask direct and detailed questions concerning Kruger and resource use. Once drafted, the survey was proofed by a number of graduate students and faculty in the Department of Society and Conservation, staff from Kruger National Park, and two South African researchers. A pilot test of the survey was also administered to approximately 45 undergraduate students in recreation management classes at the University of Montana. Several valuable comments and suggestions were made through this process, and a number of changes were made as a result.

The questionnaire consisted of four main sections - "About your trip," "About Kruger National Park," "Using Resources in Kruger National Park," and "About You." The first section - "About Your Trip" - was strategically featured first in order to generate a visitor's interest in the survey, the assumption being that questions regarding the personal nature of their trip to Kruger would interest the visitor, and they would be more likely to complete the survey if it was more interesting to them. In this section, questions were asked regarding the type of group the visitor was with (e.g., alone, family, friends, etc.); how many times they had visited the park; and their itinerary while in the park. This set of questions, as well as the more general demographic questions, were asked in order identify respondent bias and relationships between (a) the type of visitor and the nature of their experience and (b) their respective values regarding Kruger and their perspectives on resource use.

The second section - "About Kruger National Park" - presented respondents with a twenty-five-item "values scale," the items of which identified potential reasons why (or 
why not) a visitor might value Kruger National Park. The purpose of this section, was to gather values-related data that would permit an analysis of how values concerning the park influence perceptions of resource use. The values scale presented in the questionnaire was based largely on the scale developed by Borrie, Freimund, and Davenport (2002). In that scale respondents were asked to indicate - on Likert-type scale items from 1 (strongly disagree) to 7 (strongly agree) - whether or not Yellowstone National Park was important in terms of twenty four values ranging from "a protector of threatened and endangered species" to "a social place." After reviewing the results of the pilot test, the preliminary analysis of the interview data and then framing the individual items in a South African context, several items were added and dropped. For instance because of its ambiguity in a South African setting, the item "a place of natural curiosities," which was included in the Borrie et al. scale was dropped for the purposes of this study. Items not in the original scale, but added for this study included "a source of benefits for local communities," "a reserve of natural resources for use by local people," and "a place to view the 'Big 5' (i.e., lion, rhino, elephant, leopard, and buffalo). After adapting the Borrie et al. scale, the scale used for this study included twenty-five items. I employed the same Likert-type scale as Borrie et al. with one exception - respondents were allowed to select ' $\mathrm{X}$ ' for "do not know" in their responses.

\section{Sampling}

Eight-hundred questionnaires were distributed to visitors throughout Kruger National Park. Because of Kruger's complexity - in terms of geography and 
infrastructure - sampling visitors in order to offer them a questionnaire was an equally complex enterprise. In addition to the qualities of representativeness that are associated with simple random sampling, representativeness was also sought in terms of Park geography. In preparing the questionnaire, several staff members commented that I would likely receive different responses depending on which part of the Park the surveys were distributed. Visitors, for instance, who entered through the remote Punda Maria gate in the far north might value "solitude" and "wildness" more than those visitors who entered through the frequently traveled Skukuza gate in the south. Consequently, their perceptions concerning resource use might be different as well - would, for instance, those who value "solitude" and "wildness" be less sympathetic to resource use, which might upset those values?

There are nine principal gates through which visitors enter Kruger National Park, and all are situated along the northern, western, and southern borders. ${ }^{28}$ I sought to sample at all nine gates, but because of scheduling and logistical conflicts, Pafuri was not sampled. Initially, I also sought to distribute all 800 samples at the gates. However, after sampling began, it became apparent that I would not be able to distribute all of the surveys in the time I had available - particularly since most of the sampling period overlapped with a relatively slow time of the year in terms of Park visitation. ${ }^{29}$ As such, 500 surveys were administered at gates and 300 were administered by reception desk

\footnotetext{
${ }^{28}$ Giriyondo, along the eastern border could arguably be labeled a major gate if based on infrastructure alone, but it receives very few visitors and was not sampled.

${ }^{29}$ While I am not aware of any empirical evidence describing the differences between visitors across different seasons, I was told by a number of staff that during summer, there are far more local South Africans that visit than during the winter when most international visitors visit (i.e., the northern hemisphere's summer).
} 
attendants at all major rest camps throughout the Park on random days and times. In retrospect, this approach might have given rise to a more representative sample than simply administering surveys at gates since this method assured a certain level of representativeness across two dimensions (i.e, gates and camps) rather than just one (i.e., gates).

In terms of the surveys administered at the gates and by attendants at the reception desks, two important choices had to be made:

1. the number of questionnaires to be administered at each gate and camp and 2. the day and time at which those questionnaires would be administered.

Table 4- 3: Survey Distribution at Entry Gates

\begin{tabular}{lcccc}
\hline Gate & Entry $\%$ & Surveys Dist. & Survey & \# Dist. Days \\
\hline Malelane & $18.20 \%$ & 90 & $11.25 \%$ & 3 \\
Crocodile Bridge & $10.60 \%$ & 50 & $6.25 \%$ & 2 \\
Numbi & $11.70 \%$ & 60 & $7.50 \%$ & 3 \\
Phabeni & $12.40 \%$ & 60 & $7.50 \%$ & 3 \\
Paul Kruger & $19.70 \%$ & 100 & $12.50 \%$ & 3 \\
Giriyondo & $0.00 \%$ & 0 & $0.00 \%$ & 0 \\
Phalaborwa & $13.30 \%$ & 70 & $8.75 \%$ & 2 \\
Punda Maria & $3.80 \%$ & 20 & $2.50 \%$ & 0 \\
Pafuri & $0.70 \%$ & 0 & $0.00 \%$ & 2 \\
Orpen & $9.00 \%$ & 50 & $6.25 \%$ & 19 \\
& & & & \\
\hline
\end{tabular}


Table 4- 4: Survey Distribution at Rest Camps

\begin{tabular}{|c|c|c|c|c|}
\hline Camp & $\mathrm{BN}$ & Surveys Dist. & Survey $\%$ & \# Dist. Days \\
\hline Berg-en-dal & $10.27 \%$ & 30 & $3.75 \%$ & 1 \\
\hline Crocodile Bridge & $2.25 \%$ & 10 & $1.25 \%$ & 1 \\
\hline Lower Sabie & $10.40 \%$ & $50(80)^{*}$ & $6.25 \%$ & 3 \\
\hline Skukuza & $22.80 \%$ & $70(40)^{*}$ & $8.75 \%$ & 1 \\
\hline Satara & $15.15 \%$ & 60 & $7.50 \%$ & 2 \\
\hline Orpen & $4.75 \%$ & 10 & $1.25 \%$ & 1 \\
\hline Olifants & $9.30 \%$ & 0 & $0.00 \%$ & 0 \\
\hline Mopani & $7.27 \%$ & 20 & $2.50 \%$ & 1 \\
\hline Letaba & $11.31 \%$ & 30 & $3.75 \%$ & 1 \\
\hline Shingwedzi & $4.65 \%$ & 10 & $1.25 \%$ & 1 \\
\hline Punda Maria & $1.84 \%$ & 10 & $1.25 \%$ & 1 \\
\hline Private Lodge & $?$ & 0 & $0.00 \%$ & 0 \\
\hline Primitive Bush Camp & $?$ & 0 & $0.00 \%$ & 0 \\
\hline Other & $?$ & 0 & $0.00 \%$ & 0 \\
\hline Total & $100.00 \%$ & 300 & $37.50 \%$ & 13 \\
\hline
\end{tabular}

In terms of the first choice, I employed a quota sampling technique based on gate entry and bed-night data for the respective camps gathered from a Kruger National Park Tourism Assessment $(2006,80,180)$. In each of Tables 4-3 and 4-4, the second columns - Entry $\%$ and BN \% - indicate, based on the Kruger Tourism Assessment, the percentage 
share of gate entry and bed-nights ${ }^{30}$ for each respective location. I then administered that percentage of surveys at each location across what I deemed to be a feasible number of distribution days. The distribution days were randomly selected as well as the time of day the questionnaires were to be administered (eligible times were 5:00 am, 8:00 am, 10:00 am, 12:00 pm, and 2:00 pm).

Once a location, date, and time were selected, I then employed methods of randomly sampling visitors that I would present a survey to, depending on the type of location they were being sampled. For visitors sampled at gates, I used a systematic random sampling approach where sampling intervals are typically spaced depending on a calculation of the total population divided by the number of questionnaires to be administered. Because I did not have access to data that would have indicated how many people would pass through a particular gate for a given day and time, it was not possible to calculate the precise sampling interval. Nevertheless, after a random start, I chose to sample every third visitor passing through the gate. For the most part, this proved to be an acceptable interval. In terms of questionnaires administered at the camps, having randomly selected the day and time the camp would be sampled, I simply asked the receptionist to ask every visitor to complete a questionnaire until no questionnaires were left. While no sampling interval was used, this method is still mathematically equivalent to a simple random sampling framework.

\footnotetext{
${ }^{30}$ Bed nights for a particular camp are calculated by totaling the number of nights stayed in a particular camp among all visitors who stayed at that camp.
} 


\section{A brief description of the questionnaire sample}

A total of 273 responses were received from the 800 questionnaires that were distributed throughout the Park for a response rate of $34.12 \% .{ }^{31}$ Of the visitors who did not return a completed survey, $15.18 \%$ were from South Africa within $150 \mathrm{~km}$ of Kruger, 44.59\% were from South Africa at a distance greater than $150 \mathrm{~km}$ from Kruger and $40.23 \%$ were international visitors. Visitors from Japan exhibited the highest nonresponse rate at $15.57 \%$, perhaps due to a language barrier. The non-response rate for men was $52.88 \%$ versus $47.12 \%$ for women.

Among those visitors that did return a completed survey, a number of descriptive statistics could be calculated. There was a statistically significant difference between the number of males $(n=153 / 56.04 \%)$ and females $(n=119 / 43.59 \%)$, and the mean age of respondents was 42.09 years. While the country of South Africa - known as the "Rainbow Nation" - is a diverse one, nearly $90 \%$ of the respondents were white, whereas only roughly $6 \%$ were black. Among South African visitors, $88.5 \%$ were white compared to $9.1 \%$ who were black. Most of the respondents $(56 \%)$ were from South Africa at a distance of $150 \mathrm{~km}$ or greater from Kruger; $34.60 \%$ of the respondents were international visitors. In terms of education, approximately $80 \%$ had at least a four-year college degree. While the types of community respondents grew up in were fairly evenly distributed across community types ranging from a farm to a major city, $61 \%$ of the respondents lived in medium (50,000-1 million) or major cities (over 1 million) at the time they completed the questionnaire.

\footnotetext{
31 The limitations associated with this response rate will be discussed in the "Limitations to research" section of this Chapter.
} 
In terms of the nature of respondents' trips to Kruger, most (71.40\%) were visiting with family members, whereas only $(4.00 \%)$ of the respondents were on a lodgeor guided-tour. Almost half of the visitors (46.5\%) had visited Kruger more than ten times. This figure was not surprising since a portion of the sampling time period was during the South African holiday or vacation season. Staff members at Kruger commented that during the Christmas and New Year season, fewer international visitors visit the Park, and perhaps as a result, South African residents see this period as an opportune time to visit the Park.

The length of stay in the Park ranged from a day-visit to 22 days in the Park, with a mean of 5.19 days. The large majority of visitors (87.9\%) did stay overnight somewhere in the Park, but roughly $30 \%$ of the respondents also stayed outside the Park during their visit. The three most popular camps in the Park (in terms of average stay and bed-nights) among respondents were Lower Sabie, Skukuza, and Satara with Letaba, Berg-en-dal, Shingwedzi and the others coming in distantly behind.

\section{$\underline{\text { Analysis - multivariate statistical analyses }}$}

The four sections of the questionnaire yielded four different classes of data that were statistically analyzed in a variety of ways. The analysis included (1) calculating descriptive statistics, (2) logistic regression, and (3) contingency tables. Generally speaking, each of these analyses - summarized below and described in more detail in Chapter 7-9 - were designed to address the second fundamental research question for this study, 
Research question \#2: How do different groups - i.e., Park managers, local residents, and visitors - conceptualize the legitimacy of resource use?

The insight that these analyses provided concerning how visitors conceptualized the legitimacy of resource use, though, did contribute to a better understanding of how different views concerning resource use might be reconciled in order to resolve the resource use issue, which is central to the third research question,

Research question \#3: Are there possible strategies for resolving competing or conflicting conceptualizations of legitimacy?

For all classes of data - i.e. data regarding the visitor's trip, their values, their thoughts on resource use, and their demographics - general descriptive statistics (e.g., means, standard deviations, frequencies, confidence intervals, etc.) were calculated. In terms of the questions pertaining to nature of the visitor's trip (questions 1 through 5) and their demographics (questions 12 through 18), descriptive statistics were calculated primarily in order to identify potential bias. For instance, as discussed above, the descriptive statistics reveal that a smaller proportion of black South Africans were surveyed than what Kruger's visitor data suggest visit the Park. Descriptive statistics were also calculated for questions pertaining to the visitor's values (question 7) and their thoughts related to resource use (question 9). For example, as I will discuss in Chapter 9, a comparison of the means of the value scale items indicates that, on average, visitors agreed with statement "I believe Kruger National Park is particularly important as a protector of threatened and endangered species" more strongly than any other item on the values scale. This item also had the lowest standard deviation of any of the values scale 
items, which suggests that there was more agreement on this item's value than any other item's value.

The primary purpose of the visitor survey was to generate data that could provide insight into (1) the extent to which visitors believe resource use is a legitimate activity and (2) why they feel that way. To directly address this objective, I employed the items from the resource use scale as independent variables in a logistic regression with question 11(a) - which asks whether or the visitor believes resource use should be allowed - as the dependent variable. Through this analysis, which I will discuss in more detail in Chapter 7-9, I was able to identify how specific considerations (e.g., the belief that "Kruger is an area that should remain pristine with as little human impact as possible) influenced determinations that resource use either should or should not be allowed. Then, I was able to statistically explore the varying substantive considerations ${ }^{32}$ that contribute to visitors' conceptualizations of the legitimacy of resource use.

The final analysis conducted concerned Question 11. For each of the four subquestions, I calculated $2 \times 2$ contingency tables with the response to the questions as column variables and whether or not the respondent was a South African or international visitor as the row variable. Chi-square statistics, which indicate whether or not there is a significant difference between the distribution of the observed table and the expected table, were also calculated. Beyond its descriptive utility, this analysis allowed me to identify how views concerning whether or not resource use should be allowed, who

\footnotetext{
${ }^{32}$ A similar scale could have been developed for strictly procedural questions, but doing so would have dramatically increased the length of the survey, which would have very well resulted in fewer completed surveys. Nevertheless, question 11(b) did address procedural concerns by asking respondents to indicate whether they believed only Park managers should decide how and what resources are to be used or if visitors should help decide.
} 
should decide how and what resources are used, and whether or not the Park should

provide other benefits to local residents (e.g., a community levy) varied between South African and international visitors.

In summary, I employed a three-prong approach to analyzing the visitor survey data:

1. calculating descriptive statistics for all questions and variables,

2. employing a logistic regression model to analyze how specific substantive considerations concerning resource use influence visitors' assessment of the legitimacy of resource use, and

3. crafting contingency tables to identify how two different visitor groups (i.e., South African and international visitors) compare in their assessments of resource use and benefit provision.

In the next section, I discuss how both the interview and survey data served as a test of the broader ideas that have been discussed throughout this dissertation thus far.

\section{Testing logic: connecting the data and theory}

One of the features that distinguishes a scientific study, such as this, from other forms of inquiry is the existence of a testing logic - i.e., a system of principles that illustrate and guide the way in which data function as a test of ideas (Schrader-Frechette and McCoy 1994; Patterson and Williams 2001). A testing logic, then, connects the normative commitments and research questions to the data. As Patterson and Williams $(2001,6)$ comment, "choosing a testing logic depends on judgments about the research goals and assumptions about the nature of the phenomenon being studied." Data, for instance, obtained through research grounded in a psychometric, positivistic approach, where research is designed to be representative and generalizable, will serve a different 
function and connect to ideas in a different way than, say, idiographic data obtained through a hermeneutic research design.

\section{The abductive logic of a critical theory approach}

At its most basic level, the testing logic of a critical theory approach, which I loosely adopted for the purposes of this study, can be summarized as involving "intensive explication" and "comparative generalization" (Morrow 1964, 211-212). In terms of "comparative generalization," data and results are taken to be highly contextual but also valuable in terms of comparing similar phenomenon across multiple contexts. Conversely, researchers are encouraged to utilize scholarship beyond the context of their own as a means to formulate initial, broad understandings of the phenomena being studied. This study of the legitimacy of resource use in Kruger National Park, for instance, might be informative (but not deterministic) when studying, for example, the legitimacy of wildfire policies in western Montana. And, conversely, preceding studies and scholarship related to legitimacy were instrumental in crafting a general framework through which the concept of legitimacy was explored in this study.

The comparative generalization element of the logic is an important one, but the thrust of the critical theory testing logic is its call for "intensive explication." By intensive explication, Morrow refers to a logic that is grounded in hermeneutic principles of intersubjectivity that is empirically "lifted" into view with the manifest socio-political structures. In other words, the critical theory testing logic posits that the intersubjectively defined realities of a society must be taken together with the material observable reality 
that acts upon that society in the process of analyzing and understanding human phenomenon. Habermas in On the Logic of Social Science $(1988,73)$ further describes this defining element as the interplay between interpretivism and positivism where researchers "must resolve the tension between [interpretivism and positivism], bring them under one roof, ... and reflect on the relationship between analytic and hermeneutic procedures." For the purposes of this study, and consistent with the critical theory research tradition, the interplay Habermas describes served to

1. reveal inconsistencies between what is intersubjectively desired - i.e., a legitimate policy for resource use (of course, perhaps defined differently across social groups ) - and what manifestly and materially exists - i.e., the current resource use policy and the policy that is to be adopted; and

2. identify ways in which those inconsistencies are resolved - i.e., how legitimate policies for resource use are crafted for different social groups, and how competing or conflicting perceptions of legitimacy are reconciled.

In some cases, ideas and theories concerning these two goals or purposes were formulated before the data was collected. For instance, in Chapters 2 and 3 I discussed background information that I had become familiar with prior to data collection that included observations on the historical development of the relationship between Kruger National Park and local residents, as well as theoretical and philosophical treatments of legitimacy. The familiarity that I had acquired with this information allowed me to offer tentative ideas concerning, for instance, a possible structure to the conceptualization of legitimacy. However, because some dimensions of the research were, what I judged to be, almost entirely contextually-dependent or little research existed upon which to base tentative propositions - e.g., ways in which inconsistent perceptions of the legitimacy of 
resource use might be resolved - I did not offer preliminary thoughts or hypotheses in these cases.

Where ideas or tentative theories were put forward before data was collected, the data served to re-fine and re-shape those ideas or tentative theories. My ex ante framework and analysis of the related data provides an excellent example of how the data served as a test of these tentative ideas. Before data were ever collected, I adopted a tentative framework for understanding legitimacy (illustrated in Figure 3-1) that provided, in essence, a framework concerning the factors that contribute to perceptions of legitimacy. Rather than begin the research by deductively testing the components of that framework, though, I adopted an "abductive logic" - what Peirce referred to as a "logic of discovery" - whereby the range of themes that emerged from the analysis enriched my a priori framework (Peirce 1998). Thus, I took my initial understanding of the Kruger context and my synthesis of the legitimacy scholarship as a point of departure and modified that conceptual understanding in response to the data I collected. In the case of Park visitors, following a preliminary analysis of the interview data, I was able to deductively test the validity of those refinements and modifications through the visitor survey. $^{33}$

This abductive approach differed from a purely inductive approach in that tentative theory (in this case, my framework for understanding legitimacy) preceded the data and differed from a purely deductive approach in so far that the data served to generate theory and enrich the framework I adopted, rather than simply accepting and/or

\footnotetext{
${ }^{33}$ The survey was not conducted with the Park staff because, as I will discuss later, I felt the validity of the refinements could be more effectively determined through in-person discussions following the analysis.
} 
rejecting theory. With this approach, then, which has also been labeled as "inference to the best explanation," questions of validity are rarely problematic, since interpretations and conclusions are so firmly rooted in the raw data itself; the more significant question, rather, concerns the reliability of those interpretations and conclusions (Snyder 1998). In short, given the same a priori theories, will those theories converge to the same conclusive theories in both context A and context B? Recognizing this challenge to the reliability of an abductive logic, I chose this approach over a more purely inductive or deductive approach because I aimed to put forward a tentative conceptualization of legitimacy, to build on existing theory, but do so within a contextual and situational account of resource use in Kruger National Park.

\section{The function of the interview data}

With this approach, the relationship between the data and its theoretical interpretation was necessarily dynamic. Considering again my framework for understanding legitimacy, prior to analyzing the qualitative results, three separate electronic documents containing the framework in model form (see Figure 3-1) were created - one for Park staff, Park visitors, and local residents. As I analyzed the data, I would make corresponding refinements, additions, and comments in each respective model (depending on what group the data came from). In short, I created somewhat of a continual dialogue between the data, the theory, and myself as the researcher. ${ }^{34}$ In this way, the data had an evolutionary effect on the interpretation of results and the broader understanding of the legitimacy of resource use in Kruger.

\footnotetext{
${ }^{34}$ See Patterson and Williams 2001 and Mishler 1990 for a discussion of this approach.
} 
Even when theories, hypotheses, or ideas concerning certain dimensions of the research were not put forward prior to data collection, the data still served as an evolving "test of ideas" in so far that the ideas, themes, and interpretations that emerged from the results evolved as I analyzed the data, and in the end, they could be "tested" against the data. In presenting the results of my qualitative analysis, my goal was to represent the variation of views (in terms of both diversity and magnitude) manifest in the data and present a persuasive justification for the interpretations drawn from the data. ${ }^{35}$ For instance, in terms of the qualitative data related to the factors contributing to perceptions of legitimacy, the data was presented in order to illustrate the range of such factors, as well as the range of those factors' importance to different groups. In some cases, there was a preponderance of qualitative evidence suggesting that some factors figured more strongly for particular groups in the conceptualization of legitimacy than did others. When this was the case, the validity of these interpretations could be "tested" against the qualitative data.

\section{The function of the survey data}

In the spirit of "intensive explication," the survey data did not serve exclusively as a test of a priori theories or postulations, but was also an extension and refinement of the data derived through the interviews with Park visitors. For instance, a number of visitors commented in the interviews that they felt resource use was an illegitimate activity in the Park because it went against the principles upon which Kruger was founded and exists. Taking this consideration (among others) as a point of departure in the questionnaire, I

\footnotetext{
${ }^{35}$ For a discussion of the goals of presenting qualitative results, see Patterson and Williams 2001.
} 
was then able to statistically describe how this consideration related to others, such as whether or not they felt resource use was legitimate if it would improve the livelihoods of local residents, and then how all of the considerations I measured manifested in tandem with the various values I measured.

In short, the survey data collected from Park visitors functioned as an extension of the interview data and as evidentiary enrichment of the framework presented in the latter part of Chapter 3.

\section{Summary}

In summary, there are four main points that illuminate how the interview and survey data I collected functioned as a test of ideas related to the legitimacy of resource use in Kruger. First, in accordance with the critical theory research tradition, the data served to

1. allow for "comparative generalizations" to research that has already been conducted or will be conducted, and

2. provide an "intensive explication" that reveals any inconsistencies between what is viewed as a legitimate policy for resource use in Kruger (i.e., intersubjective meanings) and the current policy for resource use (i.e., the material, observable reality).

Second, as a test of my interpretations and conclusions - including those ideas and theories offered ex ante - the data facilitated an evolving refinement and reshaping of those interpretations and conclusions to the point where the data, in part, would come serve as evidence of their validity. Third, the data presented as evidence was chosen based on the extent to which it demonstrated variation of the data (both in terms of 
diversity and magnitude) and justified possible explanations for that variation. Finally, in an effort to further ensure that the connection between the data and my interpretation was valid, I engaged in a number of "checks" with my committee and members of the populations I sampled where we discussed the interpretation of my findings.

\section{Limitations to this research design}

Even with the most thoroughly articulated design, unforeseeable circumstances arise that may impact the research in important ways. In this section, I discuss what I believe to be the primary limitations to this study that are a result of such factors. Most significantly, language and intercultural differences likely impacted the study in important ways. Some interviews, for example, required translators, giving rise to potential misinterpretation and loss of meaning through translation, and questionnaires were offered only in English. Despite the limitations associated with this research, as I will discuss in the results and discussion chapters of this dissertation, I feel that the insight gained through a relatively complex research design - while perhaps giving rise to certain limitations - allowed me to meaningfully respond to all of the research questions and meet all of the research objectives.

\section{Limitations associated with the interview data}

There were at least two important considerations associated with the sampling procedure and data collection, and they relate primarily to interviews conducted with local residents. First, the initial informants were selected based on either (1) the 
recommendation of the community facilitator or (2) through contacts made at Kruger Community Forum meetings. At the risk of over generalizing, I found those local residents recommended by the Park to be more sympathetic to the Park than those that I had initially contacted at the Forum meetings. Aside from mere chance, the observation could be attributed to: (a) many of the local residents who attended the Forum meetings were attending because they were disgruntled with the Park, whereas those who were satisfied with the Park chose to not attend because they had no recommendations to offer, or (b) the Kruger staff intentionally identified local residents who would be sympathetic in order to illustrate the acceptability of Park policies among local residents. Irrespective of any potential biases introduced through the initial identification of informants, collectively speaking, the informants provided very diverse and meaningful perspectives. As a result, and consistent with the purposes of qualitative data and snowball sampling, this feature of the data is merely a consideration of note rather than a crippling limitation. Subsequent interviews with local residents that were identified by the initial local residents I interviewed demonstrated no particular pattern in terms of their perspectives on the Park or the issue of resource use.

A second important consideration concerning the sampling procedure and collection of data was the use of translators when interviewing local residents. The large population of local residents living along the western boundary of Kruger National Park speaks a diverse array of languages and associated dialects including, primarily, Xhosa, Shangaan, Venda, Afrikaans, and limited English. For the most part, local residents who were neither leaders within their communities or who had little formal education did not 
speak English. As a result, I employed the expertise of translators for approximately onethird to one-half of the interviews with local residents. The use of translators can be problematic for a variety of reasons, but as Hoffman (1989) commented, the main limitation is that meanings become "lost in translation." ${ }^{36}$ Interestingly, the loss of meaning through translation can be both intentional and unintentional.

In many languages there is simply no equivalent English word for capturing the meaning that an interviewee expresses (Strauss and Corbin 1997, 285). As such, translated interviews might lack coherence and depth in some instances. It may be the case that the translator a researcher is working with has a political agenda of their own with respect to the issue in question and chooses to selectively interpret or intentionally mis-translate an interviewee's response in order to advance a particular agenda (Esposito 2001; Temple 1997). Despite these challenges there are ways to minimize their effects. In terms of the unintentional loss of meaning, questions can be re-asked and re-phrased in order to triangulate meaning - whereas a precisely asked question in one's native language may normally be sufficient to elicit meaning, in a non-native language and when translated, a particular question may need to be asked repeatedly and in several different ways (Esposito 2001; Temple 1997). To the extent that this was possible without frustrating the interviewee, I employed this tactic. In terms of the intentional mis-representation of what an interviewee stated, I utilized a number of different translators, the assumption being that not all translators would have a political agenda to advance. Using different translators introduces problems of its own, though, since every

\footnotetext{
${ }^{36}$ For a good overview of some of the difficulties encountered when employing the assistance of a translator, see Esposito (2001) and Temple (1997).
} 
time a new translator is used, they and I would have to start from scratch in familiarizing ourselves with one another and the purposes of the research.

\section{Limitations associated with the survey data}

There are at least three main limitations associated with the survey data. First, as discussed earlier in the chapter, the $34.12 \%$ response rate is low in comparison to that of other visitors studies in protected areas in the United States, which might often exceed $80 \%$ or $90 \%$. Recognizing that a sample size of $n=273$ is statistically sufficient under most circumstances and considering the close alignment of the sample profile with certain dimensions of Kruger's baseline visitor data, the response rate did not severely cripple the analysis of the survey data. However, given the low response rate and as mentioned earlier, it cannot be assumed that the data is representative of those visitors sampled when considered along other dimensions (e.g., values assigned to Kruger or perceptions of resource use). More specifically, it might be argued, for instance, that the only visitors who went to the trouble of returning a survey were those that felt particularly strong about the issues discussed in the survey. If true, the magnitude of perceptions or beliefs expressed in the results may be more extreme than if a higher percentage of the visitors sampled had responded. As I will discuss with the third limitation of this study (see below), in the absence of a non-response bias test, this proposition cannot be established.

While, indeed, $34.12 \%$ is a low response rate compared to intercept surveys where respondents are asked to complete a questionnaire on-site (often yielding response 
rates in excess of $80 \%$ ), the same may not be true when compared to other distribution modes, such as mail or web-based surveys, where response rates may range from 2$30 \%{ }^{37}$. In fact, in similarly designed surveys, Kruger's Tourism and Marketing director commented to me in an informal discussion that they were pleased to obtain $10 \%$ response rates (which makes the response rate better than typical, but not necessarily "generalizable"). This is not to say that by virtue of the distribution mode any potential bias must be discounted, but to rather highlight that response rates are frequently a function of the mode of distribution. Consequently, because the length of the questionnaire for this study precluded on-site completion, the distribution mode for this study (which may be considered analogous to a mail-back survey) did not give rise to an unexpectedly low response rate.

The second important limitation of the survey data is that it fails to account for non-English reading visitors. While I do not have exact data, some visitors - both South Africans (e.g., Afrikaans and Xhosa speaking South Africans) and international visitors did not accept a questionnaire because they did not speak English. ${ }^{38}$ While the number of visitors who declined to accept a survey was less than 10 , it could very well be true that sampled visitors who were somewhat fluent accepted a survey but failed to complete it on account of the length of time associated with completing the questionnaire or the difficulty in grasping some of the nuanced concepts that are discussed in the questionnaire. In this way, the language format might have impacted the response rate.

\footnotetext{
${ }^{37}$ For a discussion of response rates associated with different modes of distribution, see, e.g., Kaplowitz, Hadlock, and Levine (2004),

${ }^{38}$ In these cases, the survey they were intended to receive was distributed to the next visitor in the sampling interval. In retrospect, I recognize the value of tracking the exact number of these occurrences.
} 
It might be true for instance that if the survey were offered in a variety of languages (e.g., Afrikaans, German, etc.) that a higher response rate would have been gained. This, however, would introduce a different set of challenges, due to the cost of translation and the potential inconsistencies in the meanings conveyed across languages.

The third limitation, one which could have been avoided if it were not for an organizational oversight on my part, concerns the inability to calculate certain dimensions of potential non-response bias. Before the questionnaires were distributed, each was assigned an identification number that when recorded on a postcard completed by the respondent, would allow me to identify the response rate by gate and camp at which the questionnaire was distributed. For each date, location, and time - a distribution event, if you will - at which the questionnaires were distributed, the event was assigned a range of surveys. For example, if 30 questionnaires were to be distributed at Kruger gate at 2:00 p.m. on December $19^{\text {th }}$, that event might be assigned questionnaires 1 through 30 . With this arrangement, it would have then been possible to calculate how many successful responses were collected for each event. Unfortunately, at some point during the survey period, I somehow disorganized the sequencing and did not realize I had done so until approximately $2 / 3$ of the way through the distribution process. Such a misstep would not have been a problem if I had only distributed questionnaires at the gates, but because they were also distributed at camps, that a respondent indicated they entered through Kruger gate would not necessarily imply the questionnaire was distributed at that gate (e.g., it could have been distributed at the Pafuri camp but the respondent entered through the Kruger gate). Notwithstanding the inability to measure this potential source of non- 
response bias, I was able to assess possible non-response bias in terms of where the sampled visitors lived and whether they were male and female (though, admittedly, the latter assessment was a bit fuzzy, since this determination was made on the basis of names alone).

\section{Conclusion}

The study of complex issues and topics almost necessarily gives rise to complex research designs, and this study is no exception. Framing this as a scientific study provides a structure to the research design that requires the articulation of normative research commitments I have adopted, as well as the logic that guides the way in which the data serves as a test of ideas. Because of the nature of my research questions and the goals of this study, I adopted an approach closely aligned with the critical theory research tradition. Attentiveness to this tradition allowed me to both sharpen my research questions and more thoroughly refine this mixed-method case-study. The data provided a rich source of insight, but there were important limitations to its utility - most significantly those challenges associated with language. Nevertheless, as I discuss in the next four chapters, a number of themes and ideas emerged that could inform the philosophy and decision-making processes associated with resource use in Kruger. 


\section{AUTHOR'S NOTE}

The results and discussion of the analysis described in the preceding chapters is divided into four chapters that follow this note (Chapters 5-10). Generally speaking, each chapter is designed to address the three fundamental research questions for this study:

Research question \#1: What are the resources in demand among residents living near the western boundary of Kruger National Park?

Research question \#2: How do different groups - i.e., Park managers, local residents, and visitors - conceptualize the legitimacy of resource use?

Research question \#3: Are there possible strategies for resolving competing or conflicting conceptualizations of legitimacy?

\section{Organization of results and discussion}

Chapter 5: Insight into the Context: Local Resident Perspectives on the Evolving Park-People Relationship (Research questions 1, 2, \& 3)

Chapter 6: Contemporary Resource Use in Kruger National Park and Resources in Demand Among Local Residents (Research question 1)

Chapter 7: Conceptualizing the Legitimacy of Resource Use in Kruger National Park - Kruger Staff (Research question 2)

Chapter 8: Conceptualizing the Legitimacy of Resource Use in Kruger National Park - Local Residents (Research question 2)

Chapter 9: Conceptualizing the Legitimacy of Resource Use in Kruger National Park - Park Visitors (Research question 2) 
Chapter 10: Towards a Resolution of the Resource Use Issue in Kruger National Park (Research question 3)

While not directly addressing any of the three questions above, Chapter 5 sets the stage for a significant portion of the discussion that follows in Chapters 610 by exploring the evolving relationship between the Park and local residents from the perspective of local residents. As will be discussed throughout the next four chapters, this relationship has had an important impact on the resources and other benefits that are of interest to local residents, the manner in which they conceptualize the legitimacy of those interests, and potential resolutions for the resource use issue.

Chapter 6 addresses the first research question by describing the current policy for resource use, as well as the resources that are currently of interest to local residents. In Chapters 7 through 9, I respond to question 2 by discussing the various ways that Park staff, local residents, and Park visitors conceptualize the legitimacy of resource use. In Chapter 10, I present an analysis of how the various conceptualizations of the legitimacy of resource use might be reconciled in order to resolve the resource use issue. 


\title{
CHAPTER 5
}

\author{
INSIGHT INTO THE CONTEXT: \\ LOCAL RESIDENT PERSPECTIVES ON \\ THE EVOLVING PARK-PEOPLE RELATIONSHIP
}

\begin{abstract}
Introduction
To a large extent, current debates concerning the relationship between Kruger and local residents - including the provision of benefits, such as access to resources - are a function of the historic relationship between the two. For instance, because local residents or their families were forcefully removed from the Park before and during the Apartheid era, many now express a sense of moral entitlement to receive benefits derived from the Park. Claims to land in the Park, employment opportunities, revenue sharing, and development aid are all among the set of benefits local residents have staked an interest in as a result of democratization and the changing nature of the Park-people relationship.
\end{abstract}

Because issues concerning local residents and the Park, such as resource use, are fundamentally shaped by the historic and evolving relationship between the two, it is important to explore that relationship from a variety of perspectives. For the most part, the history of the Park-people relationship has been documented by Park staff and academics rather than those living along the Park boundary. In Chapter 2, for instance, I presented a brief history of the Park and it's relationship with people who lived in or near the Park largely from the perspective of those who worked in the Park or were employed 
by South Africa National Parks (e.g., Mabunda, Pienaar, and Verhoef 2003; Moore and Masuku van Damme 2002).

In this Chapter, and based on the results of my interviews with local residents and staff, I present a brief account of this relationship primarily from the perspective of local residents (though I do include some results from staff interviews). It's important to note that such a perspective is but one of many. It is entirely possible, that - told from the perspective of Kruger staff or visitors - the account of the historical relationship between local residents and Kruger might be very different. Nevertheless, local residents are in a very useful position to provide a significant understanding of their historical relationship with the Park. Many residents I spoke with, for instance, were able to provide firsthand accounts of life inside the Park, as well as removal from the Park and the way in which the relationship with the Park has changed following democratization in 1994. As I will discuss at times throughout the next few Chapters, the Park-people relationship is an important contextual consideration in exploring the issue of resource use.

\section{Historic populations in Kruger}

One feature common to nearly all accounts of life in the Park prior to removal was the belief that life was essentially "good" and "peaceful" in the Park prior to the protracted removals that took place from the beginning through the middle of the twentieth century and that there was abundant access to nearly all of the resources that were in need,

... they were living very peacefully between themselves and the animals and also within themselves they were living in a very peaceful way. So, it 
is not true that there were problems and illness amongst them... even though there were no clinics, no hospitals, they were staying in a very peaceful way. (LC21)

It was good, because they were plowing. The soil was fertile - lots of fruits were there. We are having something, we call it African chocolate, from peanuts. They were eating it and other things. And, there are peanuts from marulas as you know. Marula beer. Things were good... Long before, there was no permission... If you wanted an impala, it was free you could choose that today I want an impala. Or, I could kill a warthog. We would be happy if we could go to Kruger and they would welcome us with all different kinds of meat as we used to be able to get. (LC30)

They were enjoying staying in the Kruger NP because if they wanted something, they could have access to it and no one would disturb them and say "no, you're not allowed to do this." They were having the rights. (LC5)

They were having enough space to plow if they wanted to plow, and if they wanted their stock to be able to go very far, they can be able to do that. But, now we are close and we are packed in one place. (LC15)

When speaking with the local residents, it was at times evident that they experienced a sense of frustration in not being able to verbally express the meaning or enthusiasm associated with a particular question or statement. However, it was clear from many of the interviewee's statements and body language that they viewed life in the Park in a very idyllic, almost Edenic, way compared to their current livelihoods. Most significantly, missing from all accounts of the life in the Park was the element of poverty, while, as will be discussed later in this chapter, it figured very strongly in the contemporary account of life outside the Park. As illustrated in the quotes above, the favorable view among local residents of life in the Park was rooted in liberal access to resources, access to fertile soils to plow and plant, and abundant grazing lands. As the last excerpt describes, the abundance and availability of resources might have been 
attributed to low population densities in the Park in comparison to the now high population densities on communal lands outside the Park that some say has led to land degradation. While there was a general consensus regarding the quality of life in the Park, though, there were discrepancies in details related to aspects such as the number of inhabitants who lived in the Park prior to removal.

The number of inhabitants who lived in the Park and were later removed is more important than one might think in terms of the contemporary management and governance of Kruger. If, for instance, it is true that, rather than being sparsely populated by scattered families, there is evidence that a large number of people inhabited the Park prior to removal, then stronger cases could, perhaps, be made for the broad provision of benefits to current local residents as a form of redress. Some local residents, for instance, argued that there were "thousands" of people living in Kruger that were later removed,

I think there were thousands of people living in the Park, because Kruger is a very large area. (LC11)

There were many, many people living in the Park... uncountable. (LC16)

There were thousands and thousands of people, I can say. That's why I say when they chased us out and took us out, there were so many of us that some went to Komatipoort [near the Mozambiquan border], some to Mozambique, and eastern Transvaal. (LC17)

$\ldots$ it is not true that there were few people here before the Europeans arrived. There were lots of people staying there. All of the people who are today around the park were actually staying in the Park. (LC21)

Others, however, offer the impression that only a very low number of people actually lived in the Park, "There were few people, because if you want to visit your neighbor, you were to take 15-20 kilos to visit your neighbor" (LC28). But, as other interviewees 
illuminated, the impression that Kruger was not highly populated might be confused with low population densities,

Kruger was sparsely populated. It was not dense... You might find that there was about 500 meters in between houses or 200 meters in between or even a kilo in between. So, they were very scattered... People used to stay away from each other.... They knew each other, though. They made visits to each other. (LC7)

Even, then, if Kruger were sparsely populated, at two million hectares, a low population density could have still resulted in thousands of people living in the Park.

Most staff were very guarded in discussing historic populations in the Park, including their size, perhaps because they believed that such information if it ever became public, could have a bearing on land claims in the Park. Nevertheless, as one staff member commented, there is at least some level of suspicion among some staff regarding the accounts of local residents related to historic populations in the Park,

There are a lot of older or elderly people out there that remember how it was like. The name "Skukuza" in fact came from the sweeping clean of people from the park. It was not a pleasant thing. When you go around here and talk about land claims, though, that's when you really see people's eyes light up as they 'remember' how it used to be, where they used to be, how they used to go down to collect water, how they used to run out in the fields, how there were thousands of people living in the Park. (S24)

Irrespective of how many people inhabited Kruger, though, the fact that they were later forcefully removed from the Park (which no one - either local residents or staff contests) and the circumstances under which they were removed has had an important impact on the contemporary relationship between the Park and local residents. 


\section{"Skukuza": the forced removal of Park inhabitants}

As discussed in Chapter 2, populations living inside the Kruger were removed

from the Park throughout the first half of the twentieth century. Initially, these removals, instituted by the Park's first warden - Colonel James Stevenson-Hamilton, who earned the dubious nickname Skukuza, or "he who sweeps clean" - were part of a strategy to protect dwindling game populations. But, as the Apartheid regime gained strength throughout the mid-twentieth century, removals were more closely aligned with the efforts to segregate blacks into concentrated "homelands" (Moore and Masuku van Damme 2002; Meskell 2005).

While the principle of removal obviously strained the relationship between the Park and its former inhabitants, the comments of local residents seem to suggest that the most traumatic aspects of the removal were the circumstances and manner under which removal occurred. A number of interviewees discussed how the removal happened almost instantaneously without notice,

...what makes them even today not feel good is the day it was said they must get out without even 24 hours. Some of their things or their properties, they left there, because if you do not have enough transport, you cannotafford to take everything. (LC30)

...we soon became aware that these people are moving us even though they do not explain it or say why, they are doing it. They were giving us a mandate to be out in 24 hours. (LC35)

They said to us, 'they do not want any person because it's not for people, it's for animals.' So, this is what they told us. But, as you know, you cannot tell me now and then I pack and off I go. I have to plan and decide where I'm going to go. Because of time, we were forcefully removed and they killed our animals. They vandalized us. We were plowing a lot of things, but we had to leave them. (LC36) 
While LC35 mentions above that they were not offered an explanation as to why they

were being removed from the Park, many who discussed the removals claimed that the

Park inhabitants had been told they were being removed in order to protect them from

Malaria or because their cattle were inflicted with disease that might be communicable to

wildlife. Almost all of the interviewees, though, viewed these rationales with skepticism,

They chased them out. They first killed their cattle... Black people have a lot of cattle, and they destroyed them bit by bit until one day at 11 o'clock when soldiers destroyed all the cattle of the people... They were not having any diseases. It was a sign showing them that no one was welcome there anymore. (LC35)

Let me tell you this, before they removed the people there, they claimed that there is a breakout to our livestock, that they were sick. They killed so many cattle saying that they were sick and burned them. After that, they removed all the people. (LC9)

... certain people were actually hired to come and check the diseases of the cattle. But I worry that there was no report given to them as to what type of disease these cattle had. They were only killed, and they lost their livestock, and they were not compensated out of the loss that they had. (LC17)

They are saying that even though they had no hospitals and no clinics at all, they never experienced any problems of illness. It is not true that there was malaria in the area. Again, it is not true that those cattle, which were killed in that year were actually ill or sick. (LC23)

The claims of disease and Malaria are stories. If someone wants to move you away, they can just tell you stories and even if they say there are Malarias, the people who were living there were able to control that because they were having these trees and all the roots and they would mix them. They were not having doom or being killed. They were using certain trees and they are still there those trees. They were also using the dung from the elephants and the dung from the hippos. You just burn them and the mosquitoes just go away. Sometimes they use a certain small tree and I do not remember the name of it. In our language we call it the babazan. They took it and they would just rub it on their body. They smell nicely, 
but the mosquitoes, they do not like it. So, those things were being used. (LC5)

Some of the people, if they are clever and do not want you to have something, they will tell you that there is a certain disease and that they have to kill all of the animals. They used to say there is a disease foot and mouth, which is there and we have to kill all the animals, but they did not kill their animals - the kill those that were with the black people. That was the problem. If they were having the certain medicine they could use to prevent that, why do not they give it to the people so that they can prevent it? They just decided that it's better if they kill all of them. (LC5)

Beyond being viewed as a strategy to legitimate the removal of inhabitants of the Park, some local residents that I spoke with believed the killing of cattle to be a direct attempt to impoverish the inhabitants and subjugate them to menial labor in the farms,

In fact, they were weakening a black person, because that is our wealth. According to our culture, you see, livestock is our wealth. If you have got cattle, goats, sheep, chickens, you are rich. So, in order to make us poor, that's why that came out with that strategy of claiming that our livestock are sick, and they started shooting them. (LC9)

When they took away our cattle, they forced us to work for the farmer. Before that, they were refusing because they were rich and having cattle, they were farming and stuff like that. And, then, it was a strategy to weaken them. If they burned those cattle, the people will remain poor and they will go and work for the farmer. So, that was the strategy. (LC10)

Only two interviewees I spoke with agreed with the assertion that disease was, indeed, a challenge that inhabitants of the Park faced,

Malaria yes, previously, it was killing a lot of people. (LC11)

There was a lot of disease in the Park. Malaria was a problem because you cannottreat Malaria in a traditional way. So, they were drinking the water from the rivers. It was another thing that was causing a lot of diseases during those times. So, yes, diseases were there, but there were those that were healed traditionally. (LC25)

Setting aside any questions concerning the validity of local residents' accounts, 
their views concerning historical populations that inhabited and were later removed from the Park have framed their contemporary relationship with the Park in important ways. More specifically, and as I will discuss in more detail in Chapter 8, many of the local residents felt that they were morally entitled to receive compensatory benefits from the Park as redress for the loss of land, livestock, and other property. With the fall of Apartheid, this feeling of entitlement has successfully materialized through land claims, employment opportunities, and other benefits associated with tourism. As some local residents commented, though, the transformation has, in many ways, been realized imperfectly.

\section{Before and after Apartheid}

It would be only half true to say that the forced removals of the first half of the twentieth century have been the most important factor that has shaped the contemporary relationship between the Park and local residents. As discussed above, the removals that occurred under Apartheid engendered, at best, a deep suspicion of the Park, and at worst, a fervent resentment for having been robbed of a better life. Since the fall of Apartheid in 1994, though, the relationship between the Park and local residents has ostensibly

undergone a transformation. As one Park staff member commented,

Well, I have to say that the past imbalances of our country whereby the local or black people were not necessarily recognized as people per se might have created the perception that we cannotallow these people to come in. So, the Park was just seen as something that needed to be protected. Actually, the people outside were mainly viewed as a threat rather than as people that can contribute towards the establishment of the Park. That created the no-touch type of perspective. Eventually, as things started changing, as we moved to our era of democracy, a lot of people 
started having different thinking. They started realizing that, no, the local people are not really a threat. They can actually contribute towards building the park. (S3)

Democratization not only ushered in "different thinking," but also introduced an entirely new management regime to the Park. David Mabunda became the Park's first black warden in 1998, and many white, senior-level staff were replaced by black South Africans. In keeping with the "different thinking," and as discussed in Chapter 2, the Park established a Social Ecology unit in 1995 (which would later morph into the People and Conservation department) and Community Forums in 2005 in an effort to forge cooperative relationships with local residents. As evident, though, in my interviews with local residents, some changes have been more pronounced than others.

The dramatic change in the management structure of Kruger was among the most noticeable changes for some of the interviewees. As they commented, before 1994, blacks were relegated only to back-breaking labor in the Park, but following the fall of Apartheid, blacks were put in positions of considerable power within Kruger's management structure,

... there is a vast difference between what is happening now and what was happening in the past. In the past, before Apartheid, we were repressed. We were given hard labor to be done. My brothers and I were once given a task to make a road using a hoe. That was very hard to do. But, now we're actually seeing some changes - black people are the ones managing the Park and occupying the higher positions in the park. We can see that change. (LC22)

Now it is better than before Apartheid because in the Apartheid days, black people were just working as if they were slaves, but now they have their rights. They can stand and say whatever they feel. That is the difference which I see in KNP. (LC6) 
It would be reasonable to expect that democratization and the rise of blacks into Kruger's upper-level management positions would translate to an increased attentiveness to interests of the local, black residents. For some, this assumption has proven true.

In terms of access to the Park, some interviewees commented that, whereas before Apartheid, they were simply not allowed to enter the Park, they now enjoy the same access rights that anyone would. And, for many local residents, access is not important only for the purposes of visiting the Park, but for traveling through the Park to visit family members who were dislocated to Mozambique, as a result of forced removals in the Park,

Before 1994 and after 1994, there is a change, of course, yes, because before 1994, we were not having access to even go in or pass through the Park to go to Mozambique so that we could visit our families. Maybe you want to take your family to just visit the Park and go and observe the wildlife there. It was not possible there before, but now they allow it. (LC27)

Before 1994, we were not considered anywhere by the protected areas. Look, now our schoolchildren are able to visit KNP free of charge, as long as you make pre-arrangements. There are half-entry permits for the community. For instance, if you visit KNP you are paying half price. You will only pay R15 [approx. \$2]. That was not happening before. (LC9)

Indeed, local residents have been given access to the Park that they never had during Apartheid, and programs have been introduced that are designed to make Park visitation more affordable to the local residents. Nevertheless, many of those that I spoke with, in some cases despite wanting to visit the Park, cannot afford to do so,

Since that place was ours before, we would like to go to our place, but then it is difficult for us now because you are supposed to pay when you get there. It's not that easy for us to pay that money at the gate. But, we do 
want to go there and see our old places, because it was ours before. (LC19)

Sometimes I use it, but not every time. It's tough to visit. You have to pay for transport, you have to pay for a permit. It becomes expensive. Sometimes, the kids or children go with schools, but I do not. It is too much money. (LC32)

I go there often, but that is not typical for the people from my village. As chief, I am able to go, but most of the people are too poor to go. The Park started a program to charge the communities only 30 Rand [approximately $\$ 4.25$ ] to enter, while they charged the tourists 120 Rand [approximately $\$ 17.00]$, I think. Thirty Rand is a good start, but it means nothing if you want to stay overnight in the Park. If people in my village want to stay in the Park, it costs 200, 300, 400 Rand. They do not have that money. The Park likes to say that they're helping our communities go into the Park, but they're only half helping - we need them to lower the rates for accommodation. (LC3)

For at least one of the local residents I spoke with, though, cost was not as much of a limiting factor as was what might be identified as a lost sense of place,

I no longer have any interest in going there, because things have changed. I could not easily identify the places where we were staying, and it seems that someone else took over and that it is no longer our place. It's someone else's place, and I would not be free to walk there. (LC 20)

As Park historians have commented, Apartheid effectively destroyed feelings of ownership towards the Park among local residents (see, e.g., Mabunda, Pienaar, and Verhoef 2003, 14; Meskell 2005). But, despite being a necessary step in the establishment of that ownership, the current, democratized framework for providing access to local residents has not automatically translated to large numbers of local residents visiting the Park. For instance, on a national level, while black South Africans constitute $80 \%$ of the national population (South Africa Census 2001), Park staff estimate that fewer than $20 \%$ of South African 
visitors are non-white (Kruger National Park 2007). ${ }^{39}$ Of the visitors randomly sampled for the purpose of this study's survey, only $8.8 \%$ of the South African respondents were black, and only $1.7 \%$ were local, black residents. ${ }^{40}$ In this way, despite being identified as a central stakeholder to the management and governance of Kruger, local residents do not enjoy the same opportunities to experience Kruger other stakeholders do, which might be one factor contributing to what is sometimes perceived to be very different views concerning the management and governance of the Park.

The views and opinions of local residents are ostensibly gaining import with the newfound interest in "community involvement." Increasingly, for instance, public meetings are held where Park managers present potential Park policies for comment, as was the case with drafting of the 2006 Management Plan. For some of those I spoke with, these meetings and the fact that the perspectives of the local residents are even entertained constitute a dramatic shift,

There is a great change. Let us be open. We cannot keep on criticizing even when things are good. There is a change already. We are able to talk about Kruger National Park unlike before, when we were not even allowed. We are able to meet the managers of the protected areas, unlike before. For instance, the public hearing about the Management Plan that we recently had at the Protea hotel, to us it's very important. We highly appreciated what they have done. That was not happening. They were not consulting the public. Just because we have a meeting with them, that's a very big change. We understand. Change is a growth. It's a process.

There is already a big change. (LC9)

\footnotetext{
${ }^{39}$ No data are available on specific demographics by race. In the 2007 study, visitors were only categorized as "white" or "non-white," which would include black, Asian, Indian, coloured, etc.

${ }^{40}$ The percentage of blacks (including local blacks) might be higher than these percentages, since the nonresponse rate among blacks could, for a number of reasons including language barriers, be higher among blacks than whites.
} 
I think our involvement is good because now we cannot just look into what happened in the past, we do not want to scratch on healing wounds by saying we're not being considered for our feelings - we are. Now, everyone is involved in making the plan something that is sustainable. (LC7)

I think that the steps taken in involving all the stakeholders is a giant step in the good management of the Park, because everyone must see the Park as his own asset, so I think that it has been a good step. (LC8)

For some residents I spoke with, though, democratization and the rise of blacks to senior management positions in the Park has not automatically translated to effective involvement of local residents in decision-making processes,

Since Mabunda came into power, even as a black manager, there has not been any communication with the communities. There is no more good communication. After Apartheid, after 1994, it is very much worse. We do not know why, maybe it is the management. You just cannotget anything from the Park. It's very very bad. (LC12)

... it's still a passive participation. I think we have to fight against that because, in fact, they just come and consult you and you make inputs, but when they go, they throw it away and make their own decision. They say, 'no, there are decision makers elsewhere.' I think it is important to involve us in the process of decision making. (LC10)

I think Kruger has to do much more consultation now and then with the community. If there is a relationship or communication now and then between the community leaders and Kruger, that will help Kruger National Park to be more successful and to have good relationships with the community. People will see that as a benefit... after 1994, there has been a bit of improvement in terms of communication, but it is still a problem that started after 1994 when the whole of national parks started to be in the process of privatizing some of the camps, and that has limited the involvement of the people. So just after 1994 they were just about to get the people involved, but because of privatization, it disturbed what Kruger was planning to do in terms of involving the community. (LC14)

As illustrated in the excerpts, local residents offered a number of views concerning why the nascent efforts to involve communities have not been effective. For some (see, e.g., 
LC12 above), communication between Park managers and local residents has been more of a problem than what they expected with black managers in the Park and, perhaps, even worse than before democratization. As LC14 comments, the perception that communication is degrading might be attributed to the Park's seemingly prioritized attentiveness to concessionaires rather than local residents. Even when Park managers and local residents are communicating, though, the value of that communication might be diminished in the eyes of local residents when their input is perceived to be discarded by managers (see, e.g., LC10 above).

At least on the surface, it is apparent that efforts to involve local residents have increased since the fall of Apartheid, but the challenges that these emerging processes face have been exacerbated and, perhaps the processes have even undermined, by the aggressive efforts of surrounding private game reserves to provide benefits to and interact with local residents,

We are surprised because the Park seems to not be interacting with us. It is only these newly-developed private game lodges that are coming on board to assist community members. But, the park is doing nothing at all. We would like to be on board with the Park, and they should actually come out and assist and make sure there is a very good relationship between themselves and community members around the park. (LC19)

[The private game reserves] are doing something very important. Like Londolozi through the Africa Foundation, they are building classes. They are busy building kitchens with all the equipment in the schools. They are plowing back. They are really doing something. There at the clinic ... there is a garden there. That was introduced by the Londolozi people. It means they are plowing something back to the communities. (LC5)

I do not see a very serious change because, big as the Park is, there is nothing that it is doing for the communities. The local game reserves are involving and helping us much better. For instance, Londolozi, Singita, they've built some blocks at the school and that is very important. So, for 
the big park, we expected better than that, but they have done nothing. (LC25)

While a number of local residents I spoke with viewed the current relationship with the Park in a negative way, no one I spoke with harbored negative feelings concerning the relationship with local, private game reserves. In fact, all of the residents I spoke with who had past and continuing interactions with the private reserves felt that they were providing an extraordinary level of benefits to the local residents including the development of infrastructure, access to natural resources, and employment opportunities. As I will discuss in more depth in the Chapter 10, the provision of these benefits may not always be purely altruistic, but it has, nonetheless, contributed to shaping the current Park-local resident relationship by giving rise to expectations among local residents of similar interactions with and benefit provision from the Park.

\section{Conclusion}

The evolution of the relationship between the Park and local residents illustrates that democratization, while ostensibly engendering legitimacy, also introduces layers of complexity un-encountered under more oppressive regimes, such as Apartheid. In the post-Apartheid era, local residents possess the freedom to seek redress for the consequences of Apartheid policies that included forced removals from the Park, to access the Park on the same footing as other visitors, and to be involved in decisionmaking processes of which they were once disenfrachised. While, in part, legitimating 
the Park, the introduction of local residents as a new constituency has introduced a complex set of challenges that must be addressed.

Based on my interviews with local residents, the most important issues that need to be resolved concern (1) the level and way in which local residents are involved in decision-making processes and (2) the provision of Park-derived benefits to local residents. Both of these issues come to head in questions concerning the legitimacy of resource use in Kruger among local residents. In the next Chapter, I discuss contemporary resource use in Kruger, including the types and levels of use currently allowed, as well resources that are not permitted to be harvested but are of interest to local residents. 


\section{CHAPTER 6}

\section{CONTEMPORARY RESOURCE USE IN KRUGER NATIONAL PARK AND RESOURCES IN DEMAND AMONG LOCAL RESIDENTS}

\section{Introduction}

As seen from the perspective of local residents, their historical relationship with Kruger has been frequently characterized by contention. Resulting from what is perceived to be an often troubled past, the Kruger staff has increasingly aimed to provide for many of the demands that local residents place on the Park. Such demands include the allowance for increased participation in decision-making processes, assistance with eco-tourism development, access to cultural sites in the Park, revenue sharing, and access to natural resources in the park for subsistence purposes, among others.

A lot has changed in Kruger over the past several decades, but one feature that has remained constant is that resource use has been a contentious issue for the Park. This is particularly true when "resource use" is defined broadly to include the use of natural resources by Park staff and visitors, in addition to local residents. As a senior ranger discussed in a 1957 memo to the Park Warden, the use of firewood by tourists and staff in the Park had escalated out of control to where nearly 5,130 tons of firewood annualy were being utilized by tourists alone (Kruger National Park 1957). This, combined with the firewood used by "native labourers," rangers, and other staff, had resulted in an area of 254 square miles being “denuded completely” (Kruger National Park 1957). According to the ranger, 
To sum up the disadvantages of wood fuel collected in the Park, it can be seen that excessive mileage and collection costs make it an expensive luxury, there is the wear and tear of the vehicles to be considered and above all the overiding fact that we are robbing nature.

The Park's first Warden, Stevenson-Hamilton, also wrestled with the issue of resource use when the National Parks Board ordered him to discontinue the sale of thatching grass (used for constructing rooftops and other household items) harvested in the Park. Stevenson-Hamilton believed the cutting, harvesting, and sale of the grass to be an important and practical strategy in the Park's management portfolio,

...it has long been the established custom of the Board to derive a small annual income from the sale of skins of animals killed by the staff in the Park, which it might be considered is one less in accordance than the mere sale of grass... The presence of long rank grass over hundreds of morgen is inimical to the interests of grazing animals which refuse to remain in such country, and moreover this 4 or 5 feet long grass near the road sides blocks the view of the country and any game which may happen to be in sight of visitors. Therefore, the only alternative to cutting would have been to burn; a gratuitous waste of a valuable asset. (Kruger National Park 1943)

Over the course of the next fifty years, biodiversity protection became a higher priority for the Park and the sale of resources to the public was discontinued (firewood in the Park, for instance, is now brought into the Park from outside sources). However, despite the evolution of Park objectives, as late as 1994, there were at least discussions of abandoning the policy to harvest resources only when doing so would increase biodiversity and adopting a market-oriented approach to harvesting resources, such as grass and game, that could be sold to the public in order to generate operating funds 
(Novellie and Randall 1994). Discussed as it was, the market-driven policy was never adopted, and instead the Park's policy remained grounded in the logic that, ... the policy that many of us would feel comfortable with is never to introduce consumptive utilization of any organism in a national park if it may have a negative effect on biodiversity, however slight. (Novellie and Rarndall 1994)

For the most part, this policy has been effectively enforced in terms of the local residents. With only a couple of rare exceptions, all extractive resource use (e.g., collection of firewood, thatch grass, medicinal plants, meat, etc.) among local residents is currently prohibted. The same, though, has not necessarily been true in terms of Park staff who, at varying levels, have been either officially or unofficially permitted to harvest thatch grass, fruits, limited firewood, mopane worms, fish, impala, and building materials such as sand and rock. Over the past couple of decades, the use of some of these resources (e.g., impala) has been scaled back, but a considerable amount of use among the staff still exists.

If the 2006 Kruger Management Plan is any indication, though, the Park's no-use policy among local residents might be changing. According to a "statement of intent" issued in the Plan,

SANParks recognise that they have been established to protect and conserve areas of biological diversity. This is its primary mandate and all other activities must be regulated by this goal. However, it also recognises that as a national agency, SANParks must provide for the needs of all citizens by generating an array of tangible and intangible benefits and resources. (Kruger National Park 2006) 
The statement of intent in the Management Plan is consistent with the broader Protected Areas Act of 1994 and a new SANParks policy, which in effect sanctions resource utilization as a potential use of a national park. According to the statement of intent, Kruger will craft a policy for resource use over the course of the next few years that will "provide resources that are truly sustainable in the long-term, without compromising any of the organizations biodiversity or other values" (Kruger National Park 2006). The development of this policy will follow 14 "feasibility" and "implementation" principles (see Appendix 3) that incorporate [a] "precautionary approach," "cost-benefit analysis," “adaptive management," "co-management," and "redress for past inequalities," among others (Kruger National Park 2006). Reflective of the "adaptive management" approach, the Park will experiment with the use of various resources over the next few years in order to determine the mechanics of sustainable use. As the Park enters that adaptive phase, and begins to construct a policy for resource use, there is a recognition that it will be critical to understand precisely what resources are of interest to local residents, as well as how the policy can be constructed in a legitimate way.

\section{Resources currently of interest to local residents}

While a policy for resource use is currently being developed in Kruger, as of right now, there is nearly a blanket prohibition on any extractive resource use in Kruger among local residents. According to Park staff,

As far as the communities go, [resource use] has been stopped. There is no outside community that is allowed to come into the park to collect anything. The only utilization that occurs is within the Park itself in the 
Skukuza community. That's going to be maybe for sedges to make mats and then fishing. That's about it. (S24)

I would describe [the resource use policy] as a policy that really has not been put into action yet. The stuff that's happening at the moment is more ad hoc where the outside people do not really have legal access yet to the resources. It's more of the internal stuff where we let our people use things like sand, gravel, and so on. For the outside people, the policy has not really been put in place yet... I do not think [resource use] happens that often. (S27)

In the next chapter, I discuss in more depth the reasons why resource use has not been viewed as a legitimate activity in the Park, but for now, suffice it to say that from a Park staff perspective, resource use has historically been viewed as an activity that runs counter to the Park's interest in preserving biodiversity. Despite this view, though, and as S27 comments above, there have been and are certain ad hoc and infrequent requests for resources that are granted.

Ad hoc requests for resources are typically made to a Park ranger who then passes it along to the head of the Conservation Services department, who either approves or denies the request. In the past, small groups were permitted to harvest thatching grass (used for hut roofs) and firewood on a very limited basis, but these activities later became a safety concern after several local residents who were collecting thatching grass were killed in a wildfire in 2000. As a result, thatch and firewood collection were immediately halted pending an investigation that has yet to be finalized. Despite this prohibition, local residents do have access to firewood in the Park under very special circumstances according to the Park staff I spoke with, the only current request for resource use consistently granted is a bakke-load (i.e., a pick-up truck-load) of firewood provided to 
the family of Park staff when either that staff member or someone from the staff

member's immediate family passes away,

At the moment, it's only focused on our own internal staff. We have supplied firewood to local communities adjacent to Kruger specifically when a staff member dies and a family is arranging the funeral. They often request a bakke load of firewood. So, you often have these night vigils beforehand and they would like to have a fire going, etc. That's not the odd one that I can think of now. I cannotreally think of any other resource use from outside the Park. (S9)

Anytime we give out firewood to communities like we have done in the past, is when our own staff members have died, then there is a funeral in the community, we give a bakke load of firewood. That's few and far between, but it's getting more and more because of the HIV/AIDS epidemic there are much more deaths than usual. (S23)

... the main use that occurs is for staff who have some family member that has passed on, and they use quite a bit of wood. It's like a week of mourning, and then they cook meat and they need fires. Basically, it's mainly wood. (S21)

... there are requests by staff members or their families where the staff member or someone from their family has died and they request wood. As a goodwill gesture from our side, we've allowed them wood in the past, but then it became associated family members that died and do not work in the Park. And, then a request comes through and eventually we had to draw the line and said that it can only be for immediate family members. They're also limiting it to a bakke load, but then you also have to stipulate what type of bakke load, otherwise they'll pile it way up. Every meeting with our rangers, that is one of the issues that came up - concerns from the Rangers for firewood. (S9)

The extent to which the provision of firewood occurs throughout the Park is not recorded, but the rangers I spoke with indicated that they receive and grant such requests for firewood three to six times per year, though that number continues to increase with the rampant HIV/AIDS infection rate. 
A significant, but infrequent, request for resource use in the Park that has been granted was a request made by Chief Mdluli - whose community successfully claimed a large chunk of land in the southwestern area of the Park, but is situated outside the Park for impala meat,

We also get requests from Chief Mdluli. He came last week with a request that he wants something like 18 impalas or something like that for a celebration. (S10)

Well, we've had requests for impala for some kind of festival or to do that Chief Mdluli has arranged. And, he felt like he is entitled to it because his land forms part of Kruger. The requests have been granted, but it's highly debatable. (S9)

The occasional bakke-load of firewood for a funeral and Chief Mdluli's requests for impala are the most notable instances where local residents have been allowed to utilize resources from within the Park, but as my interviews with staff and local residents demonstrated, there might be interest among local residents in much broader access.

The perception among staff regarding demands for resources among local residents is by no means uniform and appears to depend heavily upon a staff member's day-to-day interaction with local residents. For instance, as a staff member who had infrequent contact with local residents commented,

There is not that much pressure... we've had requests from guys that are on the Crocodile river, and they want to build something there - a house or whatever - and they request some loads of sand from the river. It's not a commercial thing. My impression is that it has been limited. Even the requests for fishing, it has been fairly limited. (S27)

However, as another staff member who interacts with local residents on a regular basis stated, 
Since I work with local communities, I hear a number of there requests and the types of products that they want. You find that whenever you've got a meeting, even if the meeting is not necessarily about resource utilization, they will come to you and approach you of the things that they want to use in the Park. I constantly hear requests for firewood, the thatch grass, mopane worms, lala palm leaves, skin hides... especially the Xhosas are often asking if we can get a leopard skin, can get a lion skin. Tradtional healers I know are interested in medicinal plants and animals like hyenas. Let me tell you that each and every part in a hyena is intended for medicinal purposes. Things like vultures, elephant dung, hippo dung, baboons, all for medicinal purposes. (S3)

Based on my interviews with local residents, it would seem that the latter assessment is most likely correct. Primarily speaking, local residents expressed a great deal of interest in utilizing four main types of resources - firewood, meat, medicinal plants, and thatching grass (See Table 6-1). There were, though, a number of other "secondary" resources of interest that included fruit and mopane worms for consumption, sand for building materials and construction, and water. Below, I discuss the views of local residents and Park staff concerning each of the four primary resources currently of interest to local residents.

\section{Wood}

Nearly all of the resources of interest to local residents were available outside the Park at some point in time. However for a variety of reasons - including Apartheid-era efforts to concentrate blacks in "homelands" - many resources became exhausted to the point they can no longer be sustainably utilized (Pollard, Shackleton, and Carruthers 2003, 434-436). In certain respects wood is one such example. As Rademan (2004) found, there is not a significant difference in the types of woody species that are found 
Table 6- 1 Primary Resources of Interest to Local Residents

\begin{tabular}{|c|c|c|c|c|}
\hline & Wood & Medicinal Plants & $\begin{array}{c}\text { Thatching } \\
\text { Grass }\end{array}$ & Meat \\
\hline Uses & $\begin{array}{l}\text { Firewood for } \\
\text { cooking \& } \\
\text { heating } \\
\text { (replacing or } \\
\text { supplementing } \\
\text { electricity in } \\
\text { some cases) } \\
\text { Building } \\
\text { materials } \\
\text { Ceremonial use }\end{array}$ & $\begin{array}{l}\text { Used by } \\
\text { sangomas to } \\
\text { treat local } \\
\text { residents }\end{array}$ & $\begin{array}{l}\text { Roofing } \\
\text { material } \\
\text { Mats/rugs }\end{array}$ & $\begin{array}{l}\text { Food } \\
\text { Ceremonial } \\
\text { use }\end{array}$ \\
\hline $\begin{array}{c}\text { Challenges } \\
\text { to Access }\end{array}$ & $\begin{array}{l}\text { Disruptive to } \\
\text { the Park's } \\
\text { nutrient cycle } \\
\text { Inability to } \\
\text { provide enough } \\
\text { wood to } \\
\text { meaningfully } \\
\text { satisfy demand }\end{array}$ & $\begin{array}{l}\text { Medicinal plants } \\
\text { and materials are } \\
\text { often endangered } \\
\text { or threatened. }\end{array}$ & $\begin{array}{l}\text { Collection } \\
\text { might } \\
\text { facilitate } \\
\text { spread of } \\
\text { veterinary } \\
\text { diseases }\end{array}$ & $\begin{array}{l}\begin{array}{l}\text { Disease } \\
\text { transmission } \\
\text { through raw } \\
\text { meat }\end{array} \\
\text { Inability to } \\
\text { provide } \\
\text { enough meat } \\
\text { to } \\
\text { meaningfully } \\
\text { satisfy } \\
\text { demand }\end{array}$ \\
\hline
\end{tabular}

inside and outside the Park, but there is a substantial difference in the structure of forests

- there are far more large trees inside the Park compared to outside the Park. As two

chiefs commented, because of the scarcity of wood, they are now having to resort to cutting down trees to use and/or using small wood, which requires considerable labor to collect, 
Actually, we have a large piece of land, but presently it's not that sufficient for firewood because it has been exhausted. You'll find people chopping those that are still wet, whereas we used to only use wood that was dry. We do not have large trees like you find in the Park. (LC7) We need big sticks for firewood. Right now, the women must collect many, many little sticks, and they burn up quickly and not as hot. We need big sticks. The big sticks get hotter, and they will last longer. Collecting the firewood takes so much time because you have to collect many sticks. If we could go in with trucks and get the firewood, the women would not have to spend so much time collecting the little sticks. (LC2)

Despite the dwindling availability of wood, it continues to be in demand for a variety of reasons. As described above, firewood is of considerable importance for cooking, heating homes, and even keeping away insects,

It's winter it's cold. You remember in that time that if it was winter you got whatever firewood you wanted. It was strong, then you burned it, and you felt warm. So, if it can be possible for us to collect firewood, we would want it. When we lived in the Park, we used those firewoods. (LC31)

The wood for burning, because people need it to survive. People here use wood every day, it's a necessity. We need it. People within our villages use it to heat themselves and to cook or boil water. (LC4)

The firewood is very important. We need it to cook, to make water with, and we use it to keep mosquitos away. (LC1)

On the surface, at least, it might seem odd that local residents would be dependent on firewood, given that so many households - particularly in the southern region - are electrified. As some local residents noted, though, access to electricity does not guarantee that it can be widely used,

Most of our communities are electrified; however, firewood is something very important for them because not all of them are electrified. And, even when they are electrified, the cost of electricity is so high that they cannot afford to use it for all tasks. So, what you might find is that people use 
electricity for lighting, but use wood for cooking and heating their homes. (LC7)

Nowadays, you have to use electricity and money. We do not always have it, and we must use wood. It is not that we feel we must use wood or that we want to use wood; we just have to use wood. (LC30)

Beyond wood for firewood, some local residents expressed an interest in utilizing wood for other purposes, such as building materials,

there is no wood here in Welwerdiend. [My husband] is making the handle of an ax right now, but it's not that strong compared to wood that can be found in the Park. (LC31)

I need wood for the poles for roof of this house. It's a kitchen. I need the indigenous trees from the park because they are stronger and last longer. And, I do not have to pay or have money to use them. The indigenous trees in the park are good. You just take your ax and go to work. I could choose the wood I want. (LC35)

For the most part, the Park staff did not view the collection of wood in the Park in a favorable way. In fact, only two members of the staff that I spoke with even entertained the prospect of wood collection beyond what is already permitted in terms of firewood for funerals,

Collecting of wood, to a certain extent, we can allow that, and we could allow that in certain areas of the Park where there is an abundance of wood. We could allow people to harvest the wood, especially in the northern part of the Park, we've done that and we could do it in the southern part of the Park, as well. Although it is not enough as far as the demand from the people is concerned. (S10)

We used to let communities come into the Park to collect wood from the edges of roads. Over years you get this curtain effect alongside roads. We've had that in the past where communities came and collected that wood and made charcoal and so on. Unfortunately, it fell flat because of a problem with contractors and so on. But, that is definitely something that we can look at again. (S11) 
Both of these respondents were managers who are forced to balance the multiple demands being placed on the Park. In contradistinction to these two views, most of the staff members I interviewed felt that wood harvesting would be a problem for a variety of reasons. Most importantly, interviewees felt that harvesting wood would upset the nutrient cycle, which is dependent on decomposing wood, that harvesting would be very difficult to control, and the fear that wood could not be harvested in a sustainable way,

Firewood harvesting could be a really problematic thing. People really need it, but certainly I think it is a very important part of the nutrient cycle. And, it's very important habitat for a lot organisms. So, if you allow firewood harvesting over vast areas, it's going to change the whole system. The wood on the ground plays lots of other roles. It's not like it's just lying there and you think, 'oh well, it will just burn.' It does not just burn. The problem with allowing that is that it will be very difficult to allow it selectively enough so that it does not affect the system. I would be very hesitant to allow it. (S20)

I do not think it's a good idea, because as human beings, the minute they say, 'yeah, it's fine,' it's not going to be controlled and it's going to be out of hand. It's going to be out of hand. I know that. (S28)

They would obviously like to get a hold of firewood. I mean you know what the area looks like outside. The amount of wood extraction that has taken place is completely unsustainable. Kruger is kind of this big reservoir of wood that they think they can just harvest. (S9)

Irrespective of whether or not wood harvesting is appropriate in the Park, one staff member that I spoke with commented that if, indeed, there is high demand for wood among the local residents, then the Park would simply not be able to meet that demand.

Instead, allowing local residents to collect wood would only be a token gesture, ... everyone says, "people should be allowed to harvest things like firewood and thatch grass inside the park. That would solve the problem.' [studies] have shown that there would not even be enough to be harvested 
inside the park to provide for the amount of people living outside. That was important in that it showed that the Kruger Park is not going to be, or these conservation areas are not going to be a solution for the poverty problem. So, that's important. (S14)

For a variety of reasons, wood appeared to be a resource in the Park that local residents have an expressed interest in. Even in communities with electricity, firewood provides a cheap alternative for cooking and heating, and the large, indigenous trees found inside the Park might serve as more effective building materials than the wood found outside the Park. Nevertheless, while some of the staff are willing to entertain the collection of wood, most are not. And, even if the Park allows for the collection of wood, it might not be possible to meet the level of demand among local residents.

\section{Medicinal plants and materials}

Traditional healers, or sangomas, continue to play an important role in the communities surrounding Kruger. Even though western-medicine clinics can be found in many of these communities, treatment might often be too expensive, or some might not place a great deal of faith in western medicine. As populations along the Park continue to increase, and as the interest in traditional medicine remains steadfast, there remains an interest in collecting medicinal plants and materials,

What he is saying that, of course, in the park there is a lot of important medicinal plants that they would really need to get if that can be the case, because a lot trees are in the park, and outside here people are cutting down and chopping down trees for wood, for cooking, because we use wood for cooking here. So, they do not have the medicine plants that they would like to have for the sake of the health of the people, because a lot of people have different problems and different diseases that could maybe be 
healed with a lot of trees that they do not have access to. There are a lot of them in there. (LC25)

What is very important with the Park is that they can access the elephant dung. The elephants have eaten almost each and every tree, which is very important. That dung is very important. He can make medicine out of it. Even mixing it with the oil of the lion. Mixing that together he can make that. So, if somebody is mad, mentally disturbed, by that thing - mixing it - he can be able to treat somebody who has been mentally disturbed. (LC27)

There are some trees. We have got some sangomas. They were using those trees to cure people in Welwerdiend with different diseases, but because those trees are inside, they are failing to teach the young generation that these trees cure these types of diseases. So, it's difficult. They would like a chance to go inside with their kids or the new sangomas to show them all of those types of trees for curing people. (LC30)

There are a variety of plants and materials that are of interest to the local sangomas, but most of those that I spoke with were very guarded or vague in discussing specific plants and materials of interest. For the most part, this was because they did not know the English word for the plants and materials or those plants and materials were deliberately kept secret. Nevertheless, as might be expected, the plants in the highest demand were those that are rare and difficult to find outside the Park. One interviewee commented that a square-inch of bark from the pepperbark tree, used to treat heart and lung diseases, could fetch R300 (approximately \$50) among sangomas.

In the case of plants and materials that are rare or endangered in the Park (e.g., the pepperbark tree), there is little interest among Park staff in allowing sangomas to harvest those plants and materials inside the Park,

... the one concern I have is medicinal plants from the wild, because even though Kruger is big, there are some populations that are really tiny. I know the gingers are quite sought after and the populations that we knew 
of, I do not know if they even exist anymore. Then there is the pepperbark trees, and they are now under threat in Punda Maria. To me, it would be a huge loss if we loss some of those due to overuse. We cannot let people collect those species for medicinal purposes or any other purposes. (S2)

... there is two most sought after plants in the country, and both of them occur in the park. Wild ginger and pepperbark. They're both very scarce in the park, but we most certainly cannotallow them to collect them. (S13)

The possibility of further threatening already rare or endangered species is not the only aspect of harvesting that worries some staff members. As some commented, the local market for traditional plants and materials is small in comparison to the larger markets in Johannesburg and Durban, and when valuable plants and materials, or muti as they are called among sangomas, are in demand in those markets, there may be little interest in conserving the resources,

The big medicinal plant demand is in Jo'burg. There have been a couple of studies that show what the demand is for at the muti market in Jo'burg. It's huge. The problem is, yeah, those guys are coming here to look for those resources - especially in the far north - but it's not local people looking for those resources. It's a commercial market driven by Jo'burg. (S8)

The problem is that what has happened now is that there is a huge demand for these type of plants and there are big markets in Johannesburg and in Durban. The people that market those things could not care less where they come from. They are not doing it the way that the old ritual requires from them, which means they're not even trying to look after the resource. Apparently, if the people from the local communities come to try and protect those resources, they actually just get shot... But, that is the biggest problem - yes, we actually have the resources, and it could actually be one of the things that we did offer, but only if you can offer it to people that will use it responsibly and that really need it. It would be much nicer than trying to actually provide to a huge market in Jo'burg. That's why they started the nurseries. Originally, the sangomas would not use the nurseries because they collect it from certain areas, but now the guys in Jo'burg could not care less where it comes from. (S20) 
As S20 discusses, separating the large-scale commercial use of medicinal plants and materials from the local use would be an important concern if medicinal plants and materials were allowed to be harvested from the Park. One of the more promising and prominently discussed alternatives for accommodating local demand while not furnishing other markets is to utilize the Park's nursery located in Skukuza to supply local sangomas with medicinal plants. According to some local residents,

From the traditional point of view, it could be very important if the issue of medicinal plants can be addressed, because there are a lot of people dying. But, if they could get those medicinal plants, which are in the park, they can be able to heal them. But, now they do not have an access to that. But, if they could make it a point to grow those plants in the nursery, that would be very helpful. (LC3)

We channel [the sangomas] to where they go and see the nursery, because we are having the nursery at Skukuza. So, the nursery is the one where they are going to get all the trees that they want. That really helps them most. (LC5)

Nurseries are also a good idea. They can give them access so that they can go and have those products. Then, also, they make sure they get those plants they need to make sure they have a project outside where they plant them, so that they can plant those trees and they look after them so that in the future they can have what they need from that orchard. (LC9)

As LC9 discusses in the last excerpt, nurseries might serve not only as a supply for immediate use, but also as a source for establishing "medicinal orchards" in lands outside the Park. While nurseries do provide some promise for resolving demands related to medicinal plants and materials, there are some sangomas who reject the idea. According to these sangomas, plants grown for medicinal purposes in nurseries are devoid of the spiritual qualities that make them effective as medicines, 
In terms of the nursery, they are saying it's not good because it's not the same. You may have to go like maybe 20 kilos to get to that very tree that you need. It sometimes comes as a dream to say, 'go and get this kind of tree, in this direction, in this place.' You never know about that tree before, but then as a dream, it comes to you and tells you the use of that tree and you go straight to it and get it as you've been directed by the dream. So, for nursery, it can be another option, but what they think is important is to get access and if they can ... go in there and dig for the plants... (LC25)

Beyond beliefs concerning the spiritual potency of nursery-raised plants, sangomas may

also scoff at the idea of a nursery, since the establishment of a nursery would require identifying plants that are used in their medicines, which some sangomas are unwilling to do,

It seems that there are big scares of sharing their knowledge in terms of these medicinal plants because they say 'no, no - this is my stuff and you must know your stuff'. So, they are a bit scared of sharing such information... (LC8)

Park staff, while recognizing the apprehensions of some sangomas concerning the establishment of nurseries, are skeptical of the validity of those apprehensions and believe that attitudes among sangomas are changing,

Nurseries seem to work. It's bullshit that you have to get this stuff from nature. The people cross a threshold and they're quite happy with nursery plants. They're becoming acceptable. (S1)

Attitudes are changing. You see there is an understanding now that whether this thing has been grown in the nursery or it has been grown in the wild, it is still the same. There is no difference. But, in the past, there was always that belief that no it's not genuine if it has been grown in a nursery. They would like to get it in the wild, but at the end of the day, the mechanism and composition is still exactly the same. It does not make any difference, and there is a realization. The good thing now is that traditional healers have got their associations. In these associations, there are people who are very much enlightened in terms of the medicinal plants and all of 
the other stuff that pertains to these plants. It makes our work easier to work through their associations than to work with individual traditional healers. Individual traditional healers might have their own beliefs, but when they come together as a collective, then it's easier to deal with them. (S10)

From what I've read in literature, [the argument concerning the spiritual potency of nursery plants is] a poor argument. That's a perception on their side, but where guys have looked at the chemical constituents and so on, there is no difference. So, their argument is poor. It's poorly motivated. It's a perception, but I'm sure if you could convince them that this stuff grown in a nursery, artificially propagated, is as good as what you get in the bush, I'm sure they'll swing. It's in their interest. It's easier to get then and there is no risk of getting caught or doing something illegally. Or having the struggle of searching and searching and searching. You search the whole day and you find two specimens, whereas you go to a nursery and you say, 'I want five of that.' Finished. Done. You see what I mean. The ease of access. (S13)

Perhaps unlike what is the case with the collection of wood from Kruger, there does seem to be a possibility that Kruger is willing to allow access to medicinal plants and materials, if only vis-à-vis a Park nursery. However, in doing so, they will likely exclude use among those who maintain that only "wild" plants or materials can supply the potency that they expect. Moreover, little has been done to understand how demand for medicinal materials other than plants, such as elephant dung, mentioned above, might be supplied.

\section{Thatching grass}

Grass for thatching rooftops, rugs, and other household items, as well as for burning, was mentioned less frequently as a resource in demand compared to firewood and medicinal plants, but is still an apparent demand, 
We would really like to have the long grass. When you burn it, is good for keeping mosquitos away. You see, we're in a risk[y] Malaria area. I've been here for 14 years, but I've never had it. My family has, but I have not. I'm lucky. (LC1)

We need thatching grass because we have got people who are poor and cannot afford to pay for grass from other places. We've got refugees from Mozambique living here, although they are no longer refugees because they have been here for more than ten years. They started arriving here in 1986 and they are very poor. They have no jobs. You will see them pushing wheel barrows filled with grass over long distances because the thatching grass is very hard to find here. They want grass for thatching. (LC9)

The thatching grass - we use it for many things. We make mats out of it; we build our rooftops with it. Some people burn it to keep away mosquitos. It is really important to us, but we do not have much of it here anymore. We have use it all, but the Park still has some, and it would be very good if we could get some of that. (LC10)

As briefly discussed above, at one time, local residents had been allowed to come into the Park and gather thatching grass, but those activities were halted in the wake of a fire that swept through the Park killing some of those harvesting grass,

... they got an agreement once, but it was probably not very well documented. They said, yeah, it's fine as long as the ranger organizes it... people would come... They would not even actually come in through the gate. They would come in through a separate entrance... they were given permission to camp out in the bush, in the Pretoriuskop area, and then they had a whole lot of thatch that they would collect. I think they would come back for three or four nights and then go back and a truck would come back and get all of the thatch and take them all out again. Then there was a big fire... That's the one where I think there were about 19 people killed in the Park... There is been a huge, big investigation about it, actually. (S14)

Some staff believe, though, that the harvesting of thatch can resume in the Park and that it would actually be easy to manage if properly organized, 
I suppose harvesting of grass, traditionally, has been done in the Pretoriuskop area for centuries. It's really quite easy to manage it. (S25)

Probably what you would do is rotational cropping and not just use the same area. And, apparently, in Nduma [a local private game reserve], the community was involved in setting up the park, and one of the things that they offered them was thatch grass. So, they're utilizing that now and they're forcing them to utilize the same patch all the time. And, that will decrease production. So, as long as you a rotational cutting, I really cannot see that it can be bad. (S20)

I think for them to use thatch grass, it must actually be very good. It's either humans cutting it or fire is burning it. So, I do not think it's bad. How you handle it or whatever, you've got to think about, but I really cannotsee that it will be detrimental at all. It's just another resource that's removed in any other way. (S19)

At least one other staff member, though, maintains that it is naïve to believe that thatch grass harvesting will ever be allowed in Kruger again. Rather than being prohibited on the basis of immediate safety in the Park, veterinary concerns may be a more serious concern,

I suggested a while ago, before this foot and mouth outbreak up in the northern part of the park - outside actually - which originated from the buffalo inside the park... I had a suggestion going well until, as I said, that outbreak - instead of burning our western boundary sage like we do every year, we should allow the community members to come in and harvest the grass. Cut it, and they can use the grass either for fodder for their cattle or to build houses, depending on the species that they would cut. It would kill two flies with one stone. But, because of the possibility of transmitting foot-and-mouth through the grass to livestock outside the Park, it is impossible for any such things to happen. It would have worked well I think... The veterinary services are very strict. I mean if you talk of foot and mouth, you see their faces change in a second from being friendly to being very serious. Foot and mouth is no joke to domestic cattle. They can close down your exports for a country completely if that gets out of hand, costing the country, of course, unnecessarily a huge loss. (S17) 
While in principle, then, some staff are amenable to the possibility of harvesting thatching grass from the Park, it may not be feasible to do so based on the veterinary risks.

Meat

Most of the more prevalent requests for resources in the Park are for resources that are used for household purposes (e.g., building materials, firewood, grass for mats, etc.) or medicinal purposes, but there was also significant interest in more directly consumptive resources, such as meat. For the most part, there is very little wildlife outside of the Park that can be hunted for meat, and there is not enough livestock raised to supply meat to all of those who want it. As a result, the Park is seen by some local residents as a bountiful reserve of meat,

We're very hungry man. Did you drive to Punda Maria? It's a very hungry place. The need the meat and they need the wood to cook their food, and they need the thatch for their houses or plants for illness. The Park has so much, but we have so little. Cannotthey help us? We need it bad - we are starving. We know that the Park is thinking about culling the elephants. Could not they let us have the meat? Elephant will feed a lot of people. Impala would also be good. We need the meat. (LC1)

So, to mention meat. We do not have access to meat. We used to live through hunting some years back. Grey duiker meat, impalas, even the kudu - it was a very nice meat to us. But, then at this time, we do not have access to that, and you cannoteven get it from the shop. So, that is another very important thing that the community can benefit from. (LC25)

Long before, there was no permission... If you wanted an impala, it was free - you were to choose that today I want an impala. Or I could kill a warthog. I would be happy if I could go to KNP and they would welcome me with all different kinds of meat I used to be able to get. The meat is very good, and we would enjoy to have it. (LC30) 
People do go and buy the meat because they like it. They grew up and they know that this one is very nice. If someone does not give that access, they do not understand it. If that can be done, I think it will eliminate poaching because people will have access. (LC9)

For some local residents, the need for meat or for financial gain, as described below, has driven them to poach wildlife inside the Park. As the second excerpt below illustrates, though, poaching may not necessarily be viewed as a crime among local residents.

Instead, it may be viewed as a practical strategy that both provides for the needs of the local residents and assists in controlling what is perceived to be burgeoning wildlife populations,

Sometimes, people who live near the fence go in to get the meat anyway. They get them, and then they drag them through the tunnels. They also get firewood and other plants, but they mainly get meat. It's very dangerous to go inside the Park, and people will only risk it for meat... You see, it is very dangerous to go into the Park under the fence. There are the animals, but there are also the rangers. It is true that the rangers can be more dangerous than the animals. It's dangerous, and people are not able to take out very much impalas. And, only a few people do it. So, when they come out with the meat, they are the ones who eat it. Sometimes, they sell it to other people for money. But, only people with money can get the impalas. So, you either have to have money or you have to go into the Park to get the impalas. Most people do not do these things, so they do not get meat. (LC2)

In our tradition, we believe that if I go hunting, it's not a crime, because the animals do not belong to anybody. As long as I go and hunt and then use the meat, it's not a crime. But, when I come and steal your pen, it's a crime, because you bought it, you own it, you have ownership of that. So, but, to manage your natural resources sustainably, there must be a mechanism of controlling that. Let us have access for game meat like some other private nature reserves. (LC10)

There are too many impala in the Park - we could use that impala. The Park likes to claim that it is natural, but the impala entirely unnatural. Allowing us to kill the impalas for meat would make it more natural. The 
park does not want to let us do that. Instead, they let the lions come out and kill our cattle instead of the impala. (LC4)

Access to meat, then - particularly from impala and other antelope in the Park - would be highly valued among some local residents. And, for many, it's valued enough already that they choose to harvest it illegally. Notwithstanding the expressed desire to have meat from the Park, there were very different views among Park staff regarding such use. According to one staff member,

If you ask people, they've seemed to have changed their ideas around meat. So, a couple of years ago, this was the place that there was meat. They do not see it that way anymore and that's probably largely to do with the fact that we do not cull and sell meat anymore. So, now people do not recognize this as a source of meat, which is a bit of an irony. What that shows us is historically, we are actually creating the demands and creating the perceptions by what we do. So, as soon as we stopped culling and stopped selling meat, all of a sudden we're not the place where their's meat. (S8)

According to this excerpt, the demand for meat is purely a function of supply - if it is supplied, then it will be demanded; cut off the supply, and it is no longer demanded. The views of other staff, however, more closely parallel the responses I received from local residents,

You go to town, though, and there is loads of people - they work at the bank, they work anywhere - they will ask you where they can get meat. They see your [SANParks] clothes on and they want meat. They even work, but they want meat from us. They do not see anything else in Kruger than meat. Even medicinal plants, thatch, sand, wood, it's small in demand, but meat... They do not care. They do not even think of thatch or medicinal, or nothing. They see Kruger as one big cow. (S5)

One of my colleagues used to joke, but I saw in his joke that he was quite serious, he saw impala as fresh meat. It was not that he saw that he had a right to come into Kruger and get impala - he just saw it as fresh meat walking around. 'I'm hungry and I want fresh meat type of thing.' That was one insight that he gave to me in that sort of way. (S2) 
I remember once at Makuleke, very near Punda Maria, outside the Park. An elephant had got out of the Park and I shot it there and the official there with me told me that chop the tusks and get the hell out here, because when the people get in here with their knives and things, you will not have enough field rangers to protect the carcass. Low and behold, six people ended up in the hospital that day. I start cutting and you start cutting the same piece of meat, so I just give you a bit of my knife in your arm to get you out of my way and that type of thing. It becomes very serious. The magic word is, 'nyama' - meat. (S17)

Most of the staff who viewed meat as being in high demand among local residents interact with them on a regular basis and claimed to be familiar with the types of resources that were of interest to them, whereas the staff who were unfamiliar with meat as a demand among local residents or did not believe it to be in high demand occupied positions where interaction with local residents was infrequent. Consequently, it seems likely that - based on the assessments of those who regularly interact with local residents - meat is an important resource of interest. As with thatching grass, though, providing meat to local residents raises serious veterinary concerns. Meat has been provided to a local chief for ceremonial purposes, but because diseases can be transmitted through raw meat, it cannot be distributed uncooked to the local residents, ... the veterinary laws do not allow fresh meat to go out of the park - it has to be cooked. In fact, in the days of elephant culling, they used to have huge pots in Park where they would cook, boil the meat because of the veterinary requirements to give to adjoining communities - not raw meat no animal product is allowed to go out. Bugs or skins or anything - it has to processed inside the park according to veterinary specifications because of the danger of taking diseases out... you could allow meat to go outside the Park, but it would have to be slaughtered in the Park and processed at the processing plant and then passed out, unless the agricultural department changes their laws, which I cannot see them doing because its... especially a source of foot and mouth. (S13) 
It is reasonable to assume that a processing operation, where wildlife in the Park are slaughtered and cooked, would require a significant amount of financing and would require a large number of animals being harvested for the operation to, perhaps, even meet the overhead of their costs. But, even if wildlife were harvested as a source of meat, there is some doubt among the staff that enough meat could be provided to satisfy the demands of local residents,

If the need for meat is really demand-driven, we will not be able to meet it. Even if we go on, say for instance let's use the elephant culling as an example, even if we go full out and we cull 1,500 elephant per year, if you take all of the people that live on our boundaries, it will just provide a little bit of meat for everybody. (S11)

We should not come out and shoot two hundred impala a month to give to everyone on the boundary, because they're going to eat it and they're still going to be saying, "more, more, more." I do not think you're going to satisfy their needs. (S23)

I do not think you can resolve it. There are just too many people. Even if we cull 90 percent of the wildlife population... it will not provide for the need that's out there. (S25)

Perhaps, then, as is the case with firewood, the need for meat is significant enough that any provision - with the exception of isolated requests - would only be a token gesture.

As a consequence, the benefits of establishing a processing operation in the Park may not outweigh the costs. And, even if the benefits did outweigh the costs, hunting - whether by staff or local residents - in order to provide meat might not be allowed simply because some staff feel that hunting should not occur in a national Park,

In a national park, we do not hunt at all. Hunting is out of the question, we cannot allow hunting in a national park. Killing of animals definitely is a no-go. (S10) 
People do not understand the economics of hunting. I'm totally against hunting within the National Park. There is nothing wrong with drinking, but you do not go drinking in the church. There is nothing wrong with hunting, but do not go hunting in the National Park. But, along our boundaries, utilize it... . When you've got no wealth, how do you uplift the poverty? Then, you've got to go to desperate measures like hunting your national parks and the rest of it. I do not believe we need to hunt at this stage, though. There will always be people who are not entirely happy, and there will always be poor people in the world. (S23)

\section{Conclusion}

Based on my interviews with local residents, there appear to be four primary types of resources that are of interest to local residents - wood, medicinal plants and materials, thatching grass, and meat - and a number of secondary resources of interest, such as water, fruit, fishing access, sand and gravel, etc. In terms of wood, some local residents would like access to the resource for cooking and heating, as well as for building materials. Medicinal plants and materials were of interest primarily among local sangomas for both local use and potentially and for selling to urban markets. Some residents would like to collect thatching grass for roofing material. Meat (e.g., impala or buffalo) for consumption was an important resource of interest for a number of local residents that I spoke with. Notwithstanding local residents' interests in collecting resources from the Park, there were, as illustrated in Table 6-1 and discussed in this Chapter, several potential challenges to implementing access to those resources.

Resource use has been an important and challenging issue in Kruger since the Park was first established more than eighty years ago. While resource use has always occurred in varying forms among Park staff and visitors, it has been permitted only sparingly among the residents in surrounding areas. With democratization and new 
protected area legislation in place, though, the Park must entertain a host of new demands - including those related to resource use - expressed by the local, black constituency. While some staff believe that local residents have little interest in collecting resources, most, and in particular those who work closely with local residents on a regular basis, believe the interest to be significant. As such, the Park has crafted a "statement of intent," included in the 2006 Management Plan, that will serve as the foundation for the resource use policy. One important task in the further development of this policy is to gain an understanding of the resources of interest.

Just as important as identifying what resources are of interest to local residents, it is equally critical to understand why local residents, as well as other stakeholders, believe it is appropriate (or inappropriate) to collect and utilize those resources. In other words, how do different groups conceptualize the legitimacy of resource use? The case of medicinal plants provides a case-in-point. As an important initial step in confronting the resource use issue, medicinal plants have been identified as a resource of interest. To understand how that interest or need may be satisfied, it's necessary to understand how the different stakeholders legitimate its use. For instance, some Park staff and sangomas maintain that a Park nursery would provide a pragmatic source of medicinal plants for surrounding communities, but others argue a nursery might be morally unsuitable insofar that it does not align with their belief that medicinal plants must come from natural settings. Thus, what might have been initially viewed as an effective, well-intended resolution to demands for medicinal plants might, in fact, be perceived as illegitimate among local sangomas. 
The history of the Park-people relationship is a testimony to the assumption that legitimacy may be an important determinant of a regime or policy's robustness over the long-term. As discussed in Chapter 2, for example, the Apartheid-era policy of excluding blacks from the Park fell precisely because of its illegitimacies on a number of levels. In the next chapter, I discuss how Park staff, Park visitors, and local residents conceptualize the legitimacy of resource use. Based on the interview and survey data, it is evident that different groups legitimize resource use in different ways, and that those varying conceptualizations have important implications for Kruger's developing resource use policy. 


\section{CHAPTER 7}

\section{CONCEPTUALIZING THE LEGITIMACY OF RESOURCE USE IN KRUGER NATIONAL PARK - KRUGER STAFF}

\section{Introduction}

Like many issues concerning the management and governance of protected areas, the complexity of resource use is compounded by both the number of groups with a stake in the issue and their varied conceptualizations of its legitimacy. While local residents are the primary group with an interest in utilizing resources from the Park for subsistence purposes, the views of Park staff (as the implementing agency) and Park visitors (whose experiences in the Park might be impacted by resource use) are equally important. As a result, in this Chapter, I organize my discussion of the legitimacy of resource use into three parts - one each for Park staff, local residents, and Park visitors. Within each part, I present the results of the data analysis concerning the underlying values that each group assigns to Kruger, their conceptualizations of the substantive and procedural legitimacy of resource use, and the connection between the groups' assigned values and those conceptualizations.

As evident in this Chapter and illustrated in Figure 7-1, Park staff, whether through an interview or survey, conceptualized the legitimacy of resource in very different ways. For most staff members their values were heavily rooted in corporate (SANParks) value, Park mandates, and Park objectives. These values, though, gave rise do different rationales for either legitimating or illegitimating resource use. Substantively speaking, many Park staff felt that resource use would be a legitimate activity because it 


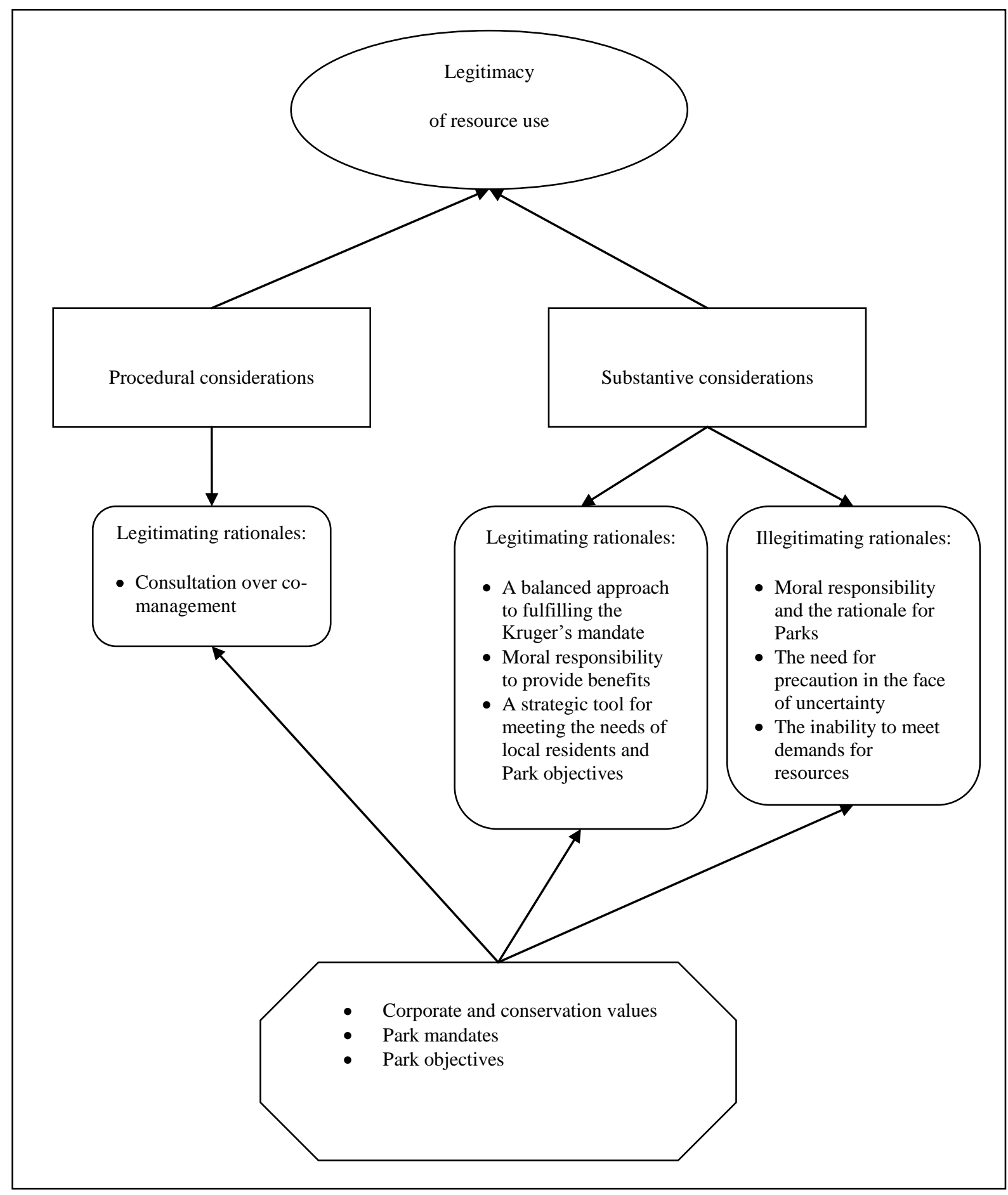

Figure 7- 1: A model of Park staff conceptualizations of the legitimacy of resource use 
would provide a balanced approach to fulfilling their mandate, and it would provide a strategic tool for meeting the needs of local residents. Other staff, though, felt that resource use would be illegitimate because utilizing resources in the Park was morally irresponsible. In terms of procedural considerations, most all of the staff that I spoke with favored a consultative approach over a co-management approach. However, as I will discuss in this and the following two chapters, the substantive conceptualizations of legitimacy and others are not necessarily irreconcilable, and there might exist opportunities for developing and implementing a policy for resource use that is generally conceived to be legitimate.

\section{Kruger staff and the legitimacy of resource use}

It is reasonable to assume that, for most issues concerning the governance and management of protected areas, it is unlikely that all groups with a stake in those issues will conceptualize the legitimacy of any related actions or policies in the same way. But, as demonstrated in my interviews with the Kruger staff, the same is also true for what, on the surface at least, might appear to be a relatively homogenous group. Perhaps more than either of the other two groups I interacted with the Kruger staff were somewhat divided in terms of their perceptions of the legitimacy of resource use. It is true that much of this division might be attributed to the after-effects of South Africa's democratization, including both the rise of black South Africans to senior level management positions in the Park and the incorporation of more benefit-oriented Park values. If anything, the results of interviews with Park staff illustrate that conceptualizations of legitimacy are 
complex and are fundamentally shaped by underlying values and contextual

considerations.

\section{A brief look at Kruger's integrated conservation-values}

As discussed in Chapter 3, the judgment or perception of an action as legitimate is likely to be fundamentally rooted in the congruence of that action with the judging or perceiving entities' system of "values, norms, and beliefs" broadly defined and more narrowly defined in terms of the specific issue and action in question. Consequently, if an action is to be viewed as legitimate by those groups with an interest in that particular action, then to a degree, it must comport with their respective systems of "values, norms, and beliefs." Values ${ }^{41}$, though, provide not only the basis for a framework against which the legitimacy of an action is evaluated, but also an explanation for how legitimacy is constructed. The biodiversity values (in addition to others) that SANParks espouse, for instance, explain why governance and management actions geared towards enhancing biodiversity in the Parks they administer are viewed as legitimate. In terms of both Kruger and SANParks, there are a number of values that govern their administration. In Chapter 2, I discussed how the contemporary management and governance of Kruger is driven not only by biodiversity values, but also by "transformation values" or "people values" that emphasize the importance of such ideals as entrenching democracy in Kruger, equity, stakeholder engagement, and benefit-provision, among others. These sets

\footnotetext{
${ }^{41}$ For the sake of brevity and to avoid a prolonged discussion of the contested (and sometimes circular) distinguishing factors of values, norms, and beliefs, I refer to this collective system throughout the remainder of the dissertation as simply "values." From a sociological perspective, values as I refer to them in this dissertation, may be thought of as abstract ideals that represent beliefs about ideal modes of conduct and goals (Rokeach 1968).
} 
of values, then - e.g., biodiversity values, people values, tourism values, etc. - come together to form the system of values, which "guide the formation of principles for decision-making and action" (South African National Parks 2006).

That these value-sets form a system does not automatically imply they do not compete or conflict with one another. Some values that drive the Veterinary Science department in Kruger (e.g., preventing the spread of communicable diseases), for example, might clash with values espoused by the People \& Conservation department where, for instance, distributing meat from the Park to local residents may be deemed a desirable activity. In a Park such as Kruger, then, where there are numerous departments, each with it's own set of explicit or implicit values, the system of values is inherently complex, and at times, contradictory. Consequently, it is, perhaps, difficult for the Kruger administration to act in such a way that is viewed as legitimate from the perspective of all its staff and departments (not to mention its diverse constituencies).

As a micro-society in and of itself, the Kruger administration is just as susceptible to issues of power - and hence the domination of certain value sets - as the broader society is. Historically, the scientific services and conservation services departments, which oversee scientific and ranger activities in the Park, have wielded considerable power in shaping the governance and management of the Park. The People \& Conservation department, though, as an emerging department arguably exercises less power, but their clout seems to be increasing in the current, transformative management era, as more "people-oriented policies" are adopted and/or considered. Notwithstanding its progressive import in the administration, there have been efforts to safeguard the 


\title{
values associated with the Department by developing a set of "integrated" values for
}

\section{Kruger that incorporate a spectrum of values into sets of corporate and conservation}

\author{
values (see Table 7-1), thus unifying people-values with other values associated with
}

\section{biodiversity and tourism.}

\section{Table 7- 1: SANParks Corporate and Conservation Values}

Corporate Values
1. We shall demonstrate leadership in all we do
2. We shall embrace, and be guided by environmental ethics in
all we do
3. We shall promote transformation within, and outside of the
organisation

4. We shall strive for scientific and service excellence at all times

5. We shall act with professionalism at all times

6. We shall adopt, and encourage initiative and innovation by all

7. We shall treat all our stakeholders with equity and justice

8. We shall exercise discipline at all times

9. We shall show respect to all

10. We shall act with honesty and integrity

11. We shall strive for transparency and open communication at all times

\begin{abstract}
1. Respect the complexity, as well as the richness and diversity of the socioecologicalsystems making up each national Park and the wider landscape and context. Respect the interdependency of the formative elements, the associated biotic and landscape diversity, and the aesthetic, cultural, educational and spiritual attributes. Leverage all these for creative and useful learning.
\end{abstract}

2. Strive to maintain natural processes in ecosystems, along with the uniqueness, authenticity and worth of cultural heritage, so that these systems and their elements can be resilient and hence persist.

3. Manage with humility the systems under our custodianship, recognising and influencing the wider socio-ecological context in which we are embedded.

4. Strive to maintain a healthy flow of ecosystem and cultural goods and services (specifically preserving cultural artefacts), and to make these available, also through access to national Parks, thereby promoting enjoyment, appreciation and other benefits for people

5. When necessary, intervene in a responsible and sustainable manner, complementing natural processes as far as possible, using only the level of interference needed to achieve our mandate.

6. Do all the above in such a way as to preserve all options for future generations, while also recognizing that systems change over time.

7. Finally, acknowledge that conversion of some natural and cultural capital has to take place for the purpose of sustaining our mandate, but that this should never erode the core values above. 
The interest in integrating the diversity of values held throughout Kruger's administration might be explained by a number of rationales, but, based on discussions with Park staff, most likely it would seem that (a) the assumption was made that a holistic approach to conservation would require a holisitc framing of values and (b) that the compartmentalization of values might pit values, and hence departments, against one another to where the stronger of the departments would inevitiably see their policies or actions put into place at the expense of other values,

Just recently, we put pressure on those guys to work on a corporate, integrated set of core values. That was after some pressure, because there was just an assumption that core values would be biodiversity values, and we have to work against that assumption. In terms of the corporate picture of the organization, the understanding is that there must be a balance. (S16)

Now, we've just revised the values... [T] here were tourism values... There were biodiversity values. We went into the Executive Committee meeting, the People \& conservation group argued that they did not want their own set of values anymore. They did not want People $\&$ conservation values. They did not think it served our interest if there were biodiversity values, tourism values, and People \& Conservation values. They just wanted one set of integrated values. So, we met... and actually came up with these seven [conservation] values, which are the underlying values which we think drive us. (S1)

We had a very smart man sitting at head office, and he said 'you cannothave different values and different principles for different functions.' What you need is organizational values, because if you have biodiversity values and People \& Conservation values, and tourism values, they're going to clash. And, we saw that, but did not have any kind of power to do anything about it. So, we said we'll just create the values and sort out afterwards the hierarchy of values. How do you pit two values against each other when they're conflicting and they do not integrate. So, we're also trying to work away from talking about balancing, because balancing implies a fulcrum where there is two positions and you're compromised and there is no winner. (S8) 
The corporate values developed by SANParks are intended to be general values that all organizations should espouse (e.g., professionalism, leadership, respect, etc.), and it is, rather, the conservation values that are likely to have the most significant impact on the management of Kruger. If those values are any indication, social considerations will play an important role in that management - almost all of the seven conservation values contain a social element. Conservation values 1 and 3, for instance, posit that Kruger is part of a much broader social-ecological system, where the interdependency of the elements (e.g., local residents, visitors, the Park itself, the broader South African citizenry, etc.) must be respected, and as a result of the inherent complexity, the Park must be managed with "humility." Conservation value 4, moreover, states that there should be a healthy flow of goods and services to Park constituencies in order to promote enjoyment and appreciation of the Park. Taken together, the values are a refinement of Kruger's broader mission,

to maintain biodiversity in all its natural facets and fluxes, to provide human benefits and build a strong constituency and to preserve as far as possible the wilderness qualities and cultural resources associated with the Park. (Kruger National Park 2006)

Under this rubric, it would seem that resource utilization - as a good and service made available to a local constituency - would be a legitimate activity in Kruger. That is, resource use is congruent or comports with the values that Kruger has adopted (see, e.g., conservation value 4) and might further the pursuit of its mandate (i.e., providing human benefits and building a strong constituency). At the same time, though, it is, perhaps, just as legitimate to prohibit resource use if it is possible that resource use would upset the 
sustainability of natural processes in Kruger (see, e.g., conservation values 2, 6, and 6 and the "maintenance of biodiversity" in the mandate).

For Kruger, issues such as resource use, present a complex challenge to the Park's values and mandate - what is the (yet to be articulated) hierarchy of values that S8 discusses in the excerpt above? When the Kruger administration's values conflict, what takes precedence - biodiversity values or people values? Should some biodiversity or "natural processes" be infringed upon in order satisfy people-oriented values and objectives, such as beneift provision and constituency building? If, indeed, resource use were practiced in an entirely sustainable way among local residents, such questions would be moot, but when benefit- and constituency-oriented values conflict with biodiversity or other values, Kruger's values and mandate are sufficiently ambiguous (and perhaps conflicted themselves) to preclude a clear resolution. The seventh and final conservation value suggests that in some circumstances it is permissible for "natural capital" (i.e., natural resources and its attendant diversity) to be "converted" to "cultural capital," (which, in the absence of a definition, we are left to assume is tantamount to the provision of opportunities for realizing one's culture). But, there is little guidance as to the conditions or circumstances under which such a conversion (including its magnitude) is permissable. Further confounding these value judgments is that Kruger's espoused values and mandate have translated to all of the Park's principle objectives - including its biodiversity and people objectives - being situated at an equivalent level in terms of importance (Kruger National Park 2006). 
It is, perhaps, true that the specious "integration" of values will insure that decisions made in the Kruger administration will be guided by the same set of values, but what might be more appropriately termed a "concatenation" of values will not always translate to harmonious decisions. In the brief discussion and presentation of the values above, it is apparent that even with the integrated conservation values, trade-offs might need to be made in some circumstances. One Kruger staff member illustrated this point with a hypothetical example,

Will those principles and values guide you in decision-making for every eventuality? No. One of the examples is if there is a demand for boxing matches, and it brings people into the Park, so it gives people exposure to the Park, is it a nature-based tourist activity? What is nature-based tourism? So, then should you have a boxing match, or should not you? No principle or value on the planet is going to answer that question. It depends on who is sitting at the desk at the day that you make the decision. We get fortunes of those type. It's just like the resource use question. The decision becomes somebody's best guess on the day... It becomes somebody's call. I think most of the resource utilization issues are at that scale and complexity. It's going to be the same thing. How much firewood? Who the hell knows? You do not know until you tip it over into a different state, whether you've taken off too little or too much. You do not know when it's too little, but you sure as hell know when it's too much. But, you do not know whether 1 bundle of firewood is too many or 20 is too much. (S8)

Kruger's conservation values, as S8 discusses, can only go so far in resolving complex issues. At some point value trade-offs might need to be made (e.g., would an unorthodox activity such as a boxing match be acceptable if it promoted nature-based tourism?). Moreover, further complicating the assessment of trade-offs is the uncertainty concerning when values have been unacceptably compromised (e.g., sustainability in S8's discussion of firewood harvesting). Consequently, the Kruger administration's various perceptions 
of the legitimacy of resource use are accordingly as complex (and at times, conflicted) as the values it espouses as an organization.

\section{Kruger staff and the substantive legitimacy of resource use among local residents}

When interviewing Kruger staff, I asked if they believed resource use among

local residents was an appropriate activity in the Park and why they felt the way they did. Having spoken with staff from a number of different departments and at a variety of levels within the organizational hierarchy, it is no surprise that several substantive considerations emerged from the interview data as rationales that, for the respective interviewees, either legitimated or illegitimated resource use in Kruger. In this section, I present the Kruger-staff interview data that illuminates their varied substantive conceptualizations of legitimacy.

\section{Resource use as legitimate}

With democratization in 1994 and the associated transformation of many sectors of the South African society, activities - in many aspects of society - that were once conceived as illegitimate are being reconsidered. In terms of protected area governance and management, one of the most revolutionary changes has been the metamorphosis of the Park-people relationship. As discussed below, for a variety of reasons, activities, such as resource use, that were once prohibited might now be considered legitimate in the face of Kruger's nascent "people-objectives" and the responsibility to redress historical wrongs. 


\section{$\underline{\text { Fulfilling Kruger's mandate }}$}

The system of values that Kruger has espoused, the resultant objectives they have adopted, and the underpinning legal framework provided by the Protected Areas and National Parks Acts give rise to a complex mandate that Kruger must fulfill. As summarily stated in the Park's mission, this mandate directs Kruger to (1) "maintain biodiversity," (2) "provide human benefits and build constituencies," and (3) "preserve wilderness and cultural resources." Despite how ambitious or over-extended such a mandate may be, allegiance to and compliance with this mandate - including legislation, such as the Protected Areas Act, which requires Parks to promote resource use (see

Chapter 1, section 2(e)) - played an important role in staff assessments of the legitimacy of resource use,

What makes [resource use] right, I suppose, is whether or not it addresses our mandate as an organization. What's our legal mandate as an organization - are we addressing that? Are we achieving the mandate, and to what degree? (S9)

You'd have to look at our current legislation, which I guess you'll have to go into and see if you agree with, but I think it's fairly clear that it is amenable to resource use. (S1)

We've had workshops... And, a lot was said and what, but for some other reason, nothing is finalized. Luckily, now, with this new legal requirement that we have to comply with, we are bound to push this matter to an end. [Resource use] should have been [implemented] a long time ago, but now we have the legal tools in hand to see it through. (S17)

I will also say that we have a civilized and well-transformed management in the Park. They basically now understand that SANParks is not an isolated entity. It has to be governed by the Protected Areas Act. It has to be managed by the laws of our current government, and obviously that means that the transformation of the country will affect the transformation of SANParks and how the resources are actually distributed and used. (S4) 
As addressed, in particular, in the last two excerpts, whereas historic mandates that placed biodiversity protection at a premium precluded the use of resources, the Park's "transformed" management and mandate have gone a long way to legitimate resource use. Of course, there are certainly underlying rationales that have given rise to the creation of legislation and mandates that allow for resource use, but the very fact that such a provision is codified is a significant influence on perceptions of legitimacy. For some, a policy's alignment with Kruger's mandate is a sufficient guarantor of that policy's legitimacy (see S9 above). Satisfying the Park's mandate is no trivial enterprise, though. As several Park staff commented, alignment with the Park's mandate is an important factor in assessing the legitimacy of resource use, but all elements of that mandate must be carefully considered,

If you can see how [a policy for resource use] flows from legislation and you can show that it has that good legal basis - that it's not against that then, that is already one step in the right direction. Also, if it's integrated and takes into consideration multiple views - not just conservation - but you can see that the benefits will be to communities and on multiple pathways. That is also something that SANParks considers favorably. (S27)

I would definitely say that resource use is legitimate if it is clear that the policy is there to help you fulfill your mandate. So, if part of our mandate is biodiversity conservation in the first place, which it is, then any policy must take that into consideration, but if one of our core policies or mandates are also to make sure that people like us, that we have the constituency to support us, then you have to take that into consideration, as well. If you can make a trade off in terms of biodiversity conservation and, I'm not saying in terms of losing that, but in terms of utilizing it in such a way that you do not actually lose it and at the same time you build your constituency and actually build your support base that's going to help you to survive in the future, then you have to do that. (S11)

[O]ur resource use policy will be a policy that's written for the Kruger Park and the main objective of the Park is conservation and biodiversity. 
So, I mean that's got to be. I mean, you cannot put like solving poverty as the main issue or mission statement. It is going to be conservation of biodiversity, but then you've got a whole lot of other things that tie into that, like building constituencies. (S14)

If resource use clearly satisfied all components of the Park's mandate, then there would likely be few who would question its legitimacy, but as S14 alludes, it may be true that benefit-oriented policies could become improperly aggrandized to the extent that their objectives broaden beyond the "conservation and biodiversity" prong of the mandate to include "poverty alleviation." Notwithstanding this possibility, the Kruger administration has placed "people objectives" at the same level of importance of biodiversity and conservation objectives and has acknowledged that, while integrated, there might need to be trade-offs in achieving these objectives (see "conservation value" number 7). According to some staff, the most difficult task in assessing the legitimacy of a policy is determining whether or not the policy is appropriately balanced,

We need to balance that biodiversity mandate with some of the local issues, because I do not think either of them should have complete overriding authority. In the past, we've always actually used the biodiversity perspective to override a lot of that local stuff, but I think we are more and more recognizing that's not going to make us successful in the long term. It's going to just lead to our demise, ultimately. So, I think that's probably our biggest challenge in trying to determine whether a policy really legitimate - are we really able to address those, sometimes very conflicting, views or not, and how do we actually try and find that balance? I think that's probably about our biggest challenge. (S18)

It's really getting that balance right that is quite difficult. I think it is a balance. You do not want to cut them out completely, but you've got to be responsible about the resource that you are protecting, and how do you do that efficiently. (S20)

As discussed earlier, compounding the difficult task of assessing a policy's alignment with Kruger's multi-pronged mandate is that the importance of each prong 
(again, despite being placed on equal footing from an objectives point of view) might be viewed differently depending on the department making the assessment,

Certain departments have different mandates. The People \& Conservation department's mandate is to please people with conservation. But, they do not come from a wildlife management or wise-management background. So, it should be [the conservation services department's or scientific services department's] responsibility to dictate what is wise management. They're always going to say, 'that's not enough,' but at some point you're compromising the integrity of this place by taking out so much more. The other people are tourism, and they are only interested in taking photos, but at some point we've got to stop putting in camps in this place, because we do not have the water resources to fuel those camps. We do not have the ability to deal with the sewage and the rest of it. Whatever you're going to do, it's got to be sustainable in terms of not degrading this resource. It is our mandate to dictate. (S23)

Because of the possibility that elements of the mandate might be viewed with varying import throughout Kruger's administration, it's correspondingly true that differing perceptions of legitimacy exist. Whereas one department may believe that allowing resource use at the expense of some degree of biodiversity is acceptable, other departments might vehemently disagree. In the face of some lack of a shared understanding of the mandate among Kruger's administration, even if alignment with the mandate could sufficiently legitimize resource use, it would be difficult to make this assessment, given the varying interpretations of the mandate and the challenge of determining how the elements should be balanced.

Indeed, at an abstract level, it may be very difficult to determine whether resource use is universally aligned with the Park's mandate. With this recognition, many staff recommended that this assessment should be made at a much lower unit of analysis. More specifically, some staff recommended that the acceptability or legitimacy of 
resource use should be determined on a resource-by-resource basis across different

resource-use zones throughout the Park. In doing so, they argued, it would be much

easier to make determinations of whether or not resource use would be a legitimate activity,

What I would do is say let us see the resource. How much do we have? Which can be used? How can it be used so that it does not negatively affect the management inside the Park? I believe in that. (S5)

I think what one has to do is take each and every specific species or item and look at that on its own. To look at everything globally is impossible. You have to look at it per species and per item. (S25)

I think it's best in my mind to categorize different types of resources and then allow it where we have abundance. (S2)

[resource use] will depend on whether or not those uses are going to adversely affect conservation or mildly affect conservation. For instance, if you talk about endangered species, we cannot allow communities to use the resources that are endangered. And, they've got to understand that they cannot have access. It does not matter what their needs are. They cannot have access to endangered species. There are other species that are not really endangered, and even if we allow limited use of those resources, it would not adversely affect conservation. We will allow them to do that... Generally, what's going to happen, as a policy, we are not going to say, 'we are not going to allow resource use.' We'll categorize the resources and say, 'these are the resources that we can allow the communities to use, these are the resources that we cannot allow the communities to use.' So, the whole idea of categorization of resources is what is going to guide our resource use policy. But, we are not going to say, 'as a policy of

SANParks, we do not allow communities access to the resources.' We'll categorize the resources together with the communities so the communities can understand why certain resources cannot be utilized and why others can be utilized. This goes back to what I said earlier on that we have got to create an awareness among the communities as to why certain resources can be utilized and why others cannot be utilized. (S10)

You would be very selective with the medicinal plants about who you would allow. Probably, you would have a zone where you would allow collection and in other zones you would not allow collection at all. That might even fall in the same zones that we have lower and higher elephant 
levels. So, when we've got high elephant levels, you can allow harvesting. Whether humans or elephants harvest it, it does not matter. In areas where we have very low or no elephants, we do not allow any harvesting. That's an area that we look after plants, not humans and elephants. (S20)

[Resource use] would happen in certain zones. I can imagine that some of my colleagues would resist resource use in the wilderness areas. I think that would probably get quite a bit of sympathy. Some of the other zones, though, it would be quite feasible. (S27)

As discussed in these excerpts, determinations of the legitimacy of resource use become sharper when considered on smaller scales. The harvest of endangered species from the Park might likely be viewed as illegitimate, just as utilizing resources from wilderness areas might also be. Conversely, in areas where resources are abundant, use may be viewed as legitimate. Categorization and zoning might not only facilitate easier judgments of legitimacy among staff, but as S10 discusses, doing so might allow staff to more effectively reason and communicate with local residents.

\section{$\underline{\text { A moral responsibility to provide benefits }}$}

In some respects laws and mandates serve to legitimate resource use (or any action for that matter) transitively. That is, laws and mandates are a medium through which other legitimating rationales are expressed. What, for instance, are the rationales that make the mandate to provide benefits legitimate, which, in turn, legitimates the use of resources among local residents? For some Park staff, moral responsibilities and duties to local residents were underlying rationales that render resource use among local residents a legitimate activity in the Park, 
We are morally obliged to provide benefits, such as resource use, to surrounding communities - especially in our case - because most of the guys that live outside the boundary of the Kruger National Park are people that were removed from the Park itself. So, they have a got a genuine claim to what is happening in the Park. (S10)

I think, despite the issue of social responsibility in terms of the law, it is a moral obligation [to allow for resource use]. Given the fact that this land belonged to certain people before it was established and people were removed and marginalized, I think for moral reasons we should try our best to assist through such things as access to resources. (S22)

As illustrated in the excerpts, some staff maintain that the Kruger administration should be compelled to redress the dislocation and marginalization of local residents through benefits, such as access to resources. Beyond, though, the purely altruistic morality of framing resource use as a making of amends for historical wrongs, there is also a veiled pragmatism in the Park administration's moral legitimation of resource use. By framing their legitimation of resource use on moral grounds, the administration illustrates their attentiveness to past wrongs, and as a result, ameliorates the Park-people relationship. In this way, the adopted morality serves the pragmatic interest of potentially reducing conflict with local residents,

We are morally obliged to give them some limited access to the resources in the Park within the confines of conservation, of course. But, whatever opportunities are there for us to give them access to some of the resources, we are morally obliged to do that. Otherwise, you sit with a conservation area that is surrounded by hostile communities, and you do not want to do that. You really want to be friends with the people that live in your neighborhood, because at the end of the day you want them to be able to help you conserve the environment. (S10)

Morally, they have a right to perhaps benefit from the Park. They need to see that the Park is going to benefit them, and they need to realize they need the Park. (S21) 
I worked for People \& Conservation for quite a time, and I'm one of the first officers in that department. It was very tough when we first started going into the communities. I think we need to move away from that cocoon - us and them, us and them. We need to get out of that cocoon, because we need to realize that the resource we are managing is not ours it's a national asset. Those people sitting outside, they also own this resource. We are managing this resource on their behalf and on the country's behalf. What that means is if we do not move out of that cocoon, we will still have a lot of criticism and still have fingers pointing at us by the communities. That is not how we should operate. We should say, 'look we understand that people have certain needs, but we are not an institution that can offer certain needs or meet certain needs. But, we can contribute. That's basically the direction we need to take - we can contribute.

For instance, if you go to Phalaborwa, you have these mines, Phalborwa mining company, Four Score, and the like. You go to those communities there and there are simple things that the mines can go out and point to and say they have done. You go there, and they will show you a clinic that they built for that community, because that was a need that the government could not meet during that time. The communities appreciate that. You go to this other community, and they have built a school, or they built a fruit market. Those things shows you that particular organization is responsible. There is no serious clashes between them and the communities living nearby because there is that type of interaction. But, if we put up the barrier and say, 'whoa, nobody comes in here. This place stays as it is,' then we are looking for problems. Also, when we open up and say, 'let's see how to utilize the resources,' we need to be able to come up with management strategies as to how we control these processes. What kind of resources are we going to say, 'yes, we can offer these to the communities'? We need to come up with all those sort of measures. To say, 'no' to me is morally wrong. (S27)

As I will discuss later in Chapter 11, the excerpts above illustrate that it is not always possible to compartmentalize the rationales that shape perceptions of legitimacy into neat packages, such as "morality," "pragmatism," "rationality," or "conventionality." They are not necessarily mutually exclusive and, on the contrary, might be dependent on one another or even indistinguishable. For instance, it could be the case that the morality of the staff excerpted above is contingent on the pragmatic consequences of that morality. 
If their morality - and the attendant access to resources - did not result in less conflict with local residents or local residents "realiz[ing] they need the Park" (S21), would these staff still maintain that there exists a moral obligation to provide benefits to local residents? Whether, though, purely motivated by moral considerations or put forward in the interest of reducing conflicts and building constituencies, the Park's responsibility and duty to local residents are significant rationales in Park staffs' legitimation of resource use.

\section{A strategic tool}

Adherence to the Park's mandate and moral considerations are each important rationales in the legitimation of resource use that some Park staff have put forward. In both cases, there is also the implication that certain interests would be pragmatically served through resource use - a "killing of two birds with one stone," if you will. The pragmatic legitimation of resource use exists independently of those two rationales, though, too. Some staff, for instance, view resource use as legitimate because it might satisfy the needs and interests of local residents. This view is notnecessarily rooted in moral responsibility or commitment to the Park's mandate, but rather is simply an attempt to meet an expressed need,

I would add that if they need the resource to survive, then I agree, they need access to the resources, and we should work with them to provide access. (S6)

I think people want to have some sort of a benefit from the Park, and from that angle, I can see resource use as appropriate. For certain resources, say, elephant management if we ever get to cull elephant again, there will actually be quite a lot of resources in terms of meat becoming available. 
So, it could actually make a bit of a difference in terms of protein or meat outside the Park. I think the main thing is just to show commitment from our side that we are prepared to accommodate some of these needs from neighboring communities (S11)

As previously discussed, it's not clear that access to resources will meet the needs of local residents or if the resources that are perhaps needed most (e.g., meat, firewood, etc.) would be permitted to be collected. Nevertheless, for some staff, the perception that many resources can be found in Kruger and often much less can be found outside the Park leads to the belief that the Park can fill at least part of resource gap among local residents.

The needs or interests that legitimate resource use among Park staff are not only those of local residents - resource use could also serve some Parks objectives, such as "building constituencies,"

I think we will benefit by buying goodwill from the people by allowing resource use. I think the only way to go for us to keep the Park recognized and to build a constituency like we've talked about is for outside communities to be interested in the Park. We've got to be able to supply, we've got to see the needs of people outside, and we've got to be able to supply for them, but I do not believe that we've got to carry on with this thing that we've done so much wrong in the past and everything. (S19)

[Resource use] will buy the goodwill from the community, and that is what we would like to see. I think that the majority of people here realize that it is important for us to co-exist with the neighboring communities, and one way in which we can foster that co-existence is by allowing the communities to have access to the resources that we have, especially those resources that do not really go against the grain of conservation. (S10)

I think the resource is appropriate in the Park because for people to be able to be associated with the Park, they must see the benefits, which the World Parks Congress has just deliberated on, in terms of benefits beyond boundaries. How do you say people are benefiting when people do not actually see the benefits? (S4) 
Clearly, based on the values the Kruger administration has espoused, building constituencies is an important objective for the Park. As discussed in the excerpts above, rather than an instrument of redress, resource use can contribute to constituency building by engendering goodwill and making the Park relevant and of interest to local residents. The underlying assumption, then, is that for constituencies to be built and relationships between local residents and the Park to be strengthened, there must be a delivery of tangible benefits.

By delivering tangible benefits through access to resources, there is also a possibility that some of Kruger's biodiversity objectives might also be met,

Kruger National Park and SANParks has got an important role that they need to play in the communities - to change the minds of the community to support conservation, to support natural resources, and teach them how to use them sustainably. So, this can be achieved through benefit sharing, such as resource use. If we conserve nature, but they do not share the benefits with us, with the community, there is no conservation - there will always be fights between the communities and the protected areas or Park management over things like poaching meat or plants. If we allow resource use in a sustainable way, that can be a teaching instrument to help them understand why they should not do things like poach. They know how to help us conserve the Park. (S9)

We will benefit by almost creating a buffer for the Park. For certain things like elephant, we'll benefit... not a real reduction of population, but it can make some difference. We will also benefit if the community is better - if resource use takes some of the financial pressure off of the communities. It will be to our benefit because the pressure will... there will not be such a huge pressure to come and collect or poach certain things from the Park. Yeah, I definitely think that will cut both ways (S11)

For some staff, then, resource use is legitimated, in part, on the basis that it could provide an opportunity for Park staff to educate local residents in sustainable practices that might ultimately reflect back on the Park through decreased poaching. Moreover, if indeed, 
resource use was permitted to the extent that it met expressed needs, it might relieve some financial pressures put on local residents that lead them to illegally pursue resources in the Park. As discussed in Chapter 6, the illegal collection of firewood to supplement costly electricity might be one such example.

Resource use might be legitimated on the basis of a number of pragmatic interests - whether of the Park, local residents, or both - but there is no assurance that all interests will be commensurate. Meeting the interests of local residents through resource use to the extent that it would, indeed, satisfy expressed needs, such as those associated with firewood or meat, might translate to some biodiversity values and objectives being infringed upon. As discussed earlier in terms of the Park's mandate, this realization gives rise to a challenging tension in the legitimation of resource use,

I think good guidelines that give benefits to the community must also consider the sustainable management of the Park. Both need to be taken into consideration by whoever is drafting or drawing the guidelines, because at the end of the day, you do not want to see the community has benefited much, and yet the Park is actually falling. (S4)

... you've got try to win their favor and support to help our ability to protect the Park. Allowing resource use may be one way to do that, and in that respect, I think it would be appropriate. We'll do that, but really we'll mess around at the edges. We cannotallow it so much that we're not meeting the rest of our mandate or objectives (S8)

Indeed, the Park's adopted values and objectives serve, in many respects, to legitimate resource use. Objectives geared towards building a constituency among local residents might be more easily achieved by providing benefits such as access to resources. And, for some staff, the history of the Park-people relationship engenders a moral responsibility or duty to make amends for past wrongs. It is not immediately clear, 
though, that these objectives and responsibilities can be clearly harmonized with the Park's other long-standing precepts.

\section{Resource use as illegitimate}

Notwithstanding South Africa's democratic transformation and the resultant shift in Kruger's objectives as a national park, the protection of biodiversity and the historic purposes that national parks have served continue to resonate very strongly with many Park staff. Activities, then, such as resource use, that are perceived by some to be inimical to the mission of a national park do not enjoy the support of all Kruger staff.

\section{Moral responsibilities and the rationale for protected areas}

A fundamental tension in the management and governance of many protected areas, such as Kruger, is that their guiding morality - their rightness and virtue - is characterized by what might be construed as conflicting tenets. As such, for contested issues like resource use, morality might serve as the antecedent for claims to both legitimacy and illegitimacy. Discussed above, for instance, the moral responsibility to redress surrounding communities for historical wrongs and the belief that protected areas should provide tangible benefits were both rationales that contributed to some Kruger staffs' belief that resource use among local residents was a legitimate activity in the Park. Conversely, other staff implied that resource use in Kruger is inherently immoral,

Kruger Park is here today because a lot of people cared about it. I have aesthetic reasons for loving the Park. I do not love it because I've got a job here, but some people do. I love it because I love Kruger National Park. I do not love it because they gave me a job. I could get a job at many other 
places... I love Kruger because of the aesthetics of it. Some people love it because they have a job there, and it provides a bit of meat here and there. It's their need for Kruger National Park. But, what is our responsibility in Kruger National Park and what are our goals with Kruger National Park? The goals of Kruger National Park is biodiversity and all of its fluxes. We want it to flourish. I do not think we should compromise the ecology in any form just to utilize a resources. This is my personal belief... What I love about the Kruger Park is the wide open space where the natural processes are allowed to operate peacefully. I would not like to see us go and treat this place like a farm and go and compromise our wilderness, aesthetics, and everything. (S23)

In my opinion, I see a national Park as someplace that should be left alone. Some staff would be sick to hear this, but our concessions is something that I cannotbelieve was allowed. I mean you've got these pieces of wilderness, and now you put this concession in and they have all the new roads, and they're just using, using, using, and screwing up the whole place. That's how I feel with people coming in and utilizing - even the medicinal plants - I do not think it's the right way to go. Leave the place as this undisturbed, unutilized place. I do not think it's a good thing. Just leave it. (S5)

For some, then, rather than benefit provision, the "wilderness," "aesthetic," and "undisturbed" qualities of Kruger form the foundation of their moral framework for assessing the legitimacy of resource use. And, these qualities are particularly key in comparing the Park's condition to those lands beyond its boundary,

For a lot of the people living outside the Park, their land was just like this place. What have they done to it? They've got to realize that responsibility is theirs. Not only theirs now today, but it was from their forefathers. That land is the same. (S19)

I do not think it's good enough to say 'well, they used up all of their resources outside the Park, therefore we must give them.' It's true that they were forced to use up a lot of the resources outside the Park, but perhaps we should be trying to help rebuild some of the environment outside the Park, instead. (S2)

I can predict that within 50 years, unless there is some complete radical change with what happens outside the Park, we will have a $20 \mathrm{~km}$ sterilized boundary, because of what happens outside the Park. Already 
from Crocodile Bridge to Malelane, there is a $20 \mathrm{~km}$ zone that's sterile. You can still do tourism activities, and there are still animals, but it's not a game reserve anymore. It's now become a theme Park kind of drivethrough zoo. You know you've got the train and the noise of the mines and you've got the ash from the sugar cane farms and it's actually very cock. There is nothing wild, or wilderness, or 'sense of place' about it anymore. Is that reversible? Not really. (S8)

As these excerpts illustrate, there is a fear among some staff that if resource use were to occur, the well-distinguished boundary between the Park and surrounding lands would become fuzzier (and not in a good way).

In fact, the exhaustion and use of resources outside the Park functioned, for some staff, as the very rationale for why Kruger should exist in the first place.

The IUCN [World Conservation Union] says that a minimum of 7\% of a country should be covered by Kruger National Park. I love the stuff, so I would say more, but I do not know where they came up with that number. If I look at the whole of South Africa, we've literally destroyed wild lands over the whole of South Africa, and we have two million hectares in the top corner and a couple of little postage stamps all around. From a moral obligation, lets leave Kruger National Park. Plus we're learning more and more that we are actually quite reliant on these places. It's not my specialty, but there are a lot of things associated with the benefit of having a Park. If the South Americans destroy the Amazon, then we are all going to go under, because there is the oxygen for the planet. That's a world resource - the world uses the oxygen from the Amazon and from algae in the sea, and it is all sustainable. I do not believe we should be using resources because we're trying to make everyone happy along the boundary. There are many benefits associated with the Park, and let's not compromise what's going on in here. (S23)

I think the big thing is that if you look at South Africa and we have, say, 3 or $4 \%$ of South Africa protected inside national Parks and the reason why there is a need to utilize those resources from within the Park is mainly because those resources have been completely depleted outside the Park. I think the big fear is that if you do not control it, maybe you could control it now, but future generations lose that control, but you've given that concession and people will just continue to utilize it and you actually risk... there is a risk that you go the same route outside the Park. And, that obviously, we do not want to do. because of the scarcity, and if you look at 
other parts of the country, the history of these species, what's happened is that they've just about been wiped out. They've disappeared. So, this is a last or one of the very few remnants of natural populations, which in my opinion, and that would go for other rare plants, we must not utilize directly in the sense of allowing people to go and collect. (S11)

For me, if you look at Kruger, well forget about Kruger, take the whole South Africa. I think national Parks take up about 3.5-4\% of the land services in this country. Conservation areas in total in the country are at about $8 \%$. Now there is $92 \%$ out there, why cannotthose resources be used. Focusing on these protected areas, I mean protected areas were proclaimed specifically for the purpose of protecting the environment. (S9)

As discussed earlier in Chapter 2, protected areas are often construed to be the last bastions or strongholds for biodiversity that simply cannot be compromised in the interest of "mak[ing] everyone happy." Instead, and because society is reliant on the renewable environmental services (e.g., clean air) that protected areas offer, the relatively small land base must be centrally protected and controlled to prevent resource depletion.

Even if, in principle, one's moral framework did not preclude the utilization of resources, there might be concerns with the distributive equity of resource use,

[L]ooking at the educational processes that we've gone through as People $\&$ conservation with the community - creating an awareness that the Park belongs to us all - we have reached a stage where people understand that as South Africans, yes, they've got the rights to the resources, but they cannot actually keep it for themselves. It's a resource that belongs to all of the nation. (S4)

Despite having "rights to resources," S4 argues that those rights are not exclusive and that the resources of the Park belong to all South Africans. Allowing local residents to collect resources, such as firewood, meat, and medicinal plants, disenfranchises the broader South African society from their corresponding entitlement to those resources. 
In such an instance, the only morally legitimate resource use policy might be to either treat Kruger as a commons where all South Africans enjoy access to natural resources or to prohibit it entirely.

The need for precaution in the face of uncertainty

Complexity breeds uncertainty. And, for many Kruger staff, that resource use is saturated with uncertainty is unsettling and an important factor in assessing its legitimacy. In no small part, it may be argued that the apparent lack of knowledge concerning what levels of use are sustainable or what resources are of interest can be attributed to historical prohibition of resource use in the Park - no use, no knowledge of use. Acknowledging that resources were utilized by indigenous peoples in the Park before it was established as such, though, might even now be immaterial in estimating how resources might be sustainably utilized,

It's not that easy to be certain what the effect of those communities was on those populations at that stage and if we actually simulate that, or just allow a certain amount of use, in sort of a new era. I do not think we really can or want to simulate it, because at that stage you had little populations living inside the Park and they were living in areas where they actually depleted the resources in that area and then moved to another area. (S11)

In essence, circumstances have fundamentally changed. Millions of people now live along Kruger's boundary and shifting cultivation (at least to the point of depletion) is not likely to be acceptable in the Park. Compounding the complexity of societal change and its implications for resource use is that resource use presents challenging questions from 
both social and biophysical perspectives. Unfortunately, as one staff member

commented, the Kruger administration has been ill-prepared to confront this combination,

When it's strictly biophysical, the decision making becomes so much easier and simpler. If this, then that and if not then something else, whereas a lot of the resource utilization issues are intertwined between the social and biophysical realm. It gets quite hard to make judgment calls when you know that there is all of these social issues revolved around it. Who is going to finally say that it is right or is not right? So, we've always just felt uncomfortable I guess in that rather uncomfortable zone. And, because most of us have biophysical types of training, we've always leaned towards the easier ones to resolve. (S18)

Based on my interviews with Park staff, whether morally and legally acceptable or not, the lack of "comfort" with the issue of resource use appears to stem from two main rationales: (1) uncertainty concerning the resources in demand and how they might be appropriately used and (2) how such use could be effectively controlled. In terms of the former there is a lack of understanding concerning what resources are in demand and how the utilization of those resources might impact the Park ecosystem,

We need studies where people are actually testing the theory and going out and testing how resource use would work. We do not even know... I do not think we even have a quantitative idea (S1)

What I have said in the past I said, 'listen, you must think about this thing, it's coming like a storm upon the horizon, we must preempt this. It's going to jump on us and we're not prepared for it, because we have not got the information.' We need to know what species are needed, whether it's plants or animals, but we do not know. We have not done our homework to where we can say, 'you can have so much of this, so much of that, and none of that.' We just do not know. What I was trying to get going is that we do studies, research, whether it's done by us or staff or students or whatever, but to have the information and be ready for it. When the request comes, we can say, 'okay, you cannothave any of that, it's too scarce, but you can have so much of this.' Now, we do not know. It's guessing (S13) 
Where to "draw the line" - i.e., recognize when resource use is being practiced unsustainably - is an important feature of this missing knowledge. Because sustainability and maintaining biodiversity are so key to the Park's espoused values and their mandate, not having the knowledge to know where to draw the line makes resource use an illegitimate enterprise to some,

We do not know enough about it, so I'd rather be conservative than... I'd rather make my errors on the side of being conservative than on the other side. When they ask for wood, how much do you give away, and where do you stop? No one knows and no research has been done to my knowledge. Where do you draw the line then? I would rather err on the conservative side at this point in time and not allow it. (S23)

I then thought again further that some things can be used but we have to be very cautious and maybe overly cautious. I do not think that there are ways of doing it without damaging the environment on our side, and we cannotbe certain of the effects of resource use. (S2)

It was mopane worms in the northern part of the Park. If you look in our staff policy, staff can collect 2-liter bottles of so many mopane worms. We had a guy doing work and he was looking at the outbreaks that occur of mopane worms. They are huge, but do you allow that to be utilized by local communities? Is that resource big enough? We have to understand the resource before we can actually utilize it wisely. And, I think very often that we do not. We simply do not know enough. We do not have enough information or knowledge. Things like elephant, we know and we understand. We know we could control them through culling and we could supply meat - whether we give it away or sell it, I do not know. Yes, you have to err on the side of caution and say that, 'I'm not sure.' Honestly, we would like to help, but we cannot because we're not sure. (S25)

One staff member further illustrated this point by describing a 1992 incident where thousands of buffalo died as a result of drought,

With the buffalo population, half of them died in the 1992 drought. Now, were we supposed to harvest them before they died and give them to the communities? The answer according to our values is 'No,' because we're running a natural system and we're trying to get the nutrients back into the ground. Otherwise, you will not run a natural system and you're back at 
the bottom of the slope. It's quite clear that when you run these things, the risks are very high. So, now those buffalo, if you want the nutrients from that 12,000 or 15,000 buffalo that died to go back into your system, because that's part of your values, and that's why society created a KNP, not for a farm, then how many of these buffalo could you take off. Can you take away a quarter of them without disturbing them, or an eighth, or none or half? How many nutrients do you want to take out? That's why issues like resource use are a slippery slope. (S1)

As with the hypothetical distribution of buffalo meat, the broader utilization of resources is, to some, a risky enterprise in the absence of knowing how it might be practiced in such a way that allows other Park values and purposes to be realized.

Uncertainty concerning the demands and ecological impacts of resource use is not the only impetus for a precautionary, conservative approach. Even if the impacts and types of resources of interest were known, some staff I spoke with were not sure that resource use could be effectively controlled and enforced,

I think it's very dangerous to allow people to go directly into the bush to harvest. We've got no control. (S13)

I guess it's this whole thing about who should be allowed to use it and I guess a lot of it is a concern that if you open this gate, it's just going to come flooding in and you're not going to be able to control it. We've always been like control freaks, and we still sort of are. We'd just rather keep the gate closed and then you're not going to have to worry about that problem. I think that's also been quite a big driver is this thing that if you start it, it's just going to take over and you' re not going to be able to control it. It's linked to who are those communities and how many thousands of people are there. (S18)

I do not think it's a good idea, because as human beings, the minute they say, 'yeah, it's fine,' it's not going to be controlled and it's going to be out of hand. It's going to be out of hand. I know that. If we can allow those other guys from outside in, it's going to be a disaster. I do not think it's going to be a good idea, because a human being, you tell today that we'll agree, but tomorrow they break that agreement. After some time, I think we would regret it. I can see from only staff members, which is less than a 
hundred people, that it is tough to manage these resources - even in one section. If they could come up with some way to watch over them and be strict, then maybe it would be okay. Or, maybe the security company at the gate could check. There will also be bribes involved, though. (S28)

It's going to be a heck of a difficult. First of all, how do you regulate it effectively? At the moment, everyone says, 'yeah, but local section level will do it.' Local section rangers are way understaffed as it is at the moment. There is no way we can do effective monitoring or regulation on resource use within the Kruger National Park - not with the current staff you can forget about it. With a growing population out there, is notthe mass going to be just increasing, increasing, increasing on an annual basis? Consumptive use, yeah, I'm not for it. (S9)

In some respects, then, some staff feel that control over resource use is important because they do not trust local residents and their capacity to consider the broader interests of the Park (e.g., maintaining biodiversity). Admittedly, this mistrust might, at least in part, be attributed to instances of poaching and vandalism that were discussed by some staff. ${ }^{42}$ Nevertheless, in the absence of an assurance that resource use would be carried out in a tightly controlled way, such access would ultimately be illegitimate in the eyes of some staff.

The inability to meet demands for resources

Just as the needs of local residents are a factor that some staff point to in their legitimation of resource use, the nature of local residents' needs might also undermine the legitimacy of resource use. Recognizing that poverty is rampant in many of the areas

\footnotetext{
${ }^{42}$ One staff member, for instance, described a cooperative program where local residents were contracted to build and repair the western boundary fence. Unfortunately, the equipment supplied by the Park and the fence itself were repeatedly stolen. The staff member commented that this generated a lot of general mistrust of the communities among those staff who were involved in the project. Another staff member commented that local authorities' unwillingness to punish poachers has strained relationships with local residents.
} 
surrounding the Park, some of the Kruger staff believe that the need for resources and

local residents' demands for resources are and would be too high for the Park to

accommodate if other conservation objectives are to also be met,

There are certain resources that we can allow the communities to use, but those resources will not satisfy the needs of the community. The community will always want more, and that's the dilemma we are faced with. With us here, we are the custodians of biodiversity conservation. We've got to create that balance. We'll satisfy some of the needs of the community, but at the same time, we've got a responsibility to insure that we conserve. There will be limited use of resources, definitely. The crux of the matter is 'limited.' We're not saying we're not going to allow them to use the resources, but we'll allow limited use of resources in a controlled manner. (S10)

If the need for meat is really demand-driven, we will not be able to meet it. Even if we go on, say for instance let's use the elephant culling as an example, even if we go full out and we cull 1,500 elephant per year, if you take all of the people that live on our boundaries, it will just provide a little bit of meat for everybody. (S11)

I would in a way say, 'listen, this is a conservation area and the job of this place is to conserve all the different resources as responsibly as possible.' Not that we're always that good at it, but at least we try. The resource that you provide to the communities outside must not be dependent on the resources that we have inside the Park, it must be experiences inside the Park, work opportunities, education, things like that. It must not be a little bit of thatch grass or things like that. What good will that do? (S20)

I do not think you can resolve it. There are just too many people. Even if we cull 90 percent of the wildlife population and go back to the huntergatherer system, it will not provide for the need that's out there. With all the modern medicines and all the clinics and all this stuff, I think there are too many people and the need is too big. (S25)

As S20 suggests, if resource use is intended to serve the pragmatic interests of local residents, and access cannot be permitted to the extent that such interests can be met, resource use might be an inappropriate activity in the Park. Instead, as S20 further offers, 
local residents might be better served through other benefits such as "experiences in the Park," "work opportunities," or "education." As discussed earlier in this Chapter, though, resource use is not intended to only serve the pragmatic interests of local residents - it may also serve the Park's interest in generating "goodwill” among local residents (even if the provision of resources will not their needs),

The one thing that I'm trying to grapple with is that we cannotsupply the needs of everyone outside, so I guess it is a token gesture that will hopefully develop goodwill towards the Park and good neighborliness. I do not think we can supply everything that they need. (S2)

Still, others maintain that local residents will recognize resource use as a "token gesture" and, as a result, rather than generating "goodwill," the provision may give rise to unrealistic expectations that, if not met, might actually damage the relationship with local residents,

In fact, I do not think resource use will bring about any goodwill or will be good idea at all. One of the concerns I've got is that it might create undue expectations among some of them - 'they've given us this, but maybe if we keep on pushing, they'll give us more or expand it.' It's difficult to say. For me, the whole thing about resource use in Kruger National Park is that it's only tokenism. There is no way we can supply for the demands and the needs of the people on the borders; we just cannotdo it. We just should not go down that road. (S9)

The pragmatic interest that local residents might have in collecting resources from the Park might, indeed, be a factor contributing to the legitimacy of resource use for some staff. But, as others suggested, if resource use is legitimated solely on the basis of need and the Park is not able to provide access at a level that meets that need, then what was crafted in the interest of legitimacy might translate to illegitimacy. 
Substantively speaking, whether pronounced legitimate or illegitimate, resource use is a thorny issue for Park staff. Perhaps what is particularly vexing and what might make resource use a difficult issue to reconcile among the staff is that there are very fundamental differences regarding the bases upon which resource use is legitimated and illegitimated. Some staff, for instance, regard resource use as legitimate because of what they perceive to be a moral responsibility or duty to rectify the Park's relationship with local residents. Others hold, though, that moral considerations - more specifically, the responsibility to protect resources - are precisely why resource use is an illegitimate activity in the Park. Similarly and from a pragmatic perspective, some believe that resource use would serve the interests of the Park, whereas others believe it would undermine them. These substantive points of disagreement notwithstanding, the Park staff must also come to terms with procedural considerations in resolving the issue of resource use.

\section{Kruger staff and the procedural legitimacy of resource use among local residents}

Establishing the legitimacy of even trivial actions, not to mention actions as nuanced as resource use, is an inordinately difficult undertaking. Not only must the substantive elements of an action be legitimated, but so, too, must the procedural manner in which the action is developed and implemented. In my interviews with Park staff, I asked interviewees to discuss how a policy for resource use might be developed and implemented in a legitimate way. 
In terms of the legitimacy of developing actions or policies, most staff I spoke with chose to discuss legitimacy in terms of protected area actions or policies in general terms, rather than within the narrow context of resource use. That is, the approach to developing legitimate actions or policies did not seem to depend on the substantive nature of the action or policy in question. Fundamentally, most staff I spoke with suggested that procedural legitimacy is achieved by establishing "buy-in" or agreement among both the Park staff and other stakeholders interested in a particular action or policy. In terms of buy-in among the staff, one interviewee discussed that, indeed, legitimacy is tantamount to buy-in, even in the face of substantive disagreement on a policy,

You've got legitimacy when you've got buy-in. So, for example, the biodiversity stuff developed by the Park - I do not buy into it. Why? Because I was not consulted up front... It's not legitimate. I was not part of that process that decided... My perspective was not on the table. I did not change my thinking in terms of being exposed to other perspectives. Therefore, I do not buy into that biodiversity methodology. Now have I accepted it because we need to move forward? Yes. Have I bought into it? No. Does that mean that I might be an activist for change of that methodology? Absolutely... Legitimacy is when people buy into it. (S8)

Staff buy-in is but one side of the coin, though, stakeholders other than staff must also buy-into an action or policy for it to be legitimated,

The process has to be something that everyone buys into, as well as the values and mission and all of that. Then, from that, the policies are just helping the managers and the lower levels implement actions to achieve those in the long term. (S2)

You've got to talk to people about it and it must be discussed at meetings and workshops. You've got to get feedback from those people and then take it from there. If it's a given that it will have a negative effect - taking this particular resource in the long term will have a negative effect on the biodiversity in any way - you have to make people see that, and they've 
got to buy into it. Then, start implementing it from there. Communication is important. (S21)

You do not just go to [the stakeholders] with preconceived ideas and impose things on them, because if you do it that way, it's going to boomerang, and when it boomerang's you're going to be in trouble. There'll be no buy-in from the people that you want to implement that policy and for whom you have developed that policy. If there is no buy-in, there is no policy, because nobody is going to abide by them. The next thing that all you'll have to do is run after all of these people trying to make sure that they obey the policy, and nobody will obey the policy because they will be distancing themselves from the policy - they do not buy into it. (S10)

If we do not get buy in from the local community, then we might as will give up because it will be over-taken. The rangers can only defend the Park so much. We need the communities to help us - giving us information about poachers and things like that. They have to buy into the fact that Kruger is there for them, too. With 26 senior rangers, we cannot protect the Park, but the communities can. (S25)

An important feature of the process of developing policies aimed at implementing particular actions, then, is convincing or persuading both staff and stakeholders that the policy and action are legitimate. This would seem to imply that while the substantive legitimacy of a policy or action might go a long way in the process of persuading or establishing buy in, it might not be necessary. For instance, if in the process of a developing a resource use policy, local residents felt they were morally entitled to liberal access to resources in the Park, but Park staff were able to effectively persuade local residents that access must be very limited, then local residents may believe the policy to be morally illegitimate but still "buy into" the policy and ultimately believe it to be legitimate. According to some staff, then, it may be the case that substantive legitimacy, while important but not necessary, is ultimately employed as an instrument of persuasion 
in the more critical effort to establish buy-in.

As implied in the excerpts above, unless an individual or group "buys into" a policy or action by default, based on their values or interests, they must be consulted or involved in the development process in some way to establish buy-in for that particular policy or action. S8 commented above that having his/her perspective heard and having the opportunity to have that perspective changed was a necessary condition for buyinginto the "biodiversity methodology." Similarly,

[I]t's important to consult internally and externally, and then you put all of those ideas together and you go back to the people and say this is the policy I've developed, this the draft of the policy, I want you to comment on this draft. Then they comment on the draft and at the end of the day, although you cannot please everybody, you are able to say people had an opportunity to comment, and I did explain to them as to why I think the policy should be like this. (S10)

I think any policy or any law that actually developed through people's involvement, it's always sound and healthy. You look at the current constitution that we're using in South Africa, it's actually made by people for people and was contributed to by people for people. Obviously, in terms of conservation policies, where people are involved - as I've said to you - the stakeholder participation process is going to be going on for Park management plans. I think if the people can be involved in that, they will feel that they are good policies, because they have contributed in that. It's like setting a race for yourself, and you know that you'll run that and then obviously you'll have some strategy on how to reach the last arena for your race. Otherwise, if someone comes up with the policies he has designed for you, then you'll feel that you've never been part of the process, and it's not a good policy for you. (S4)

I think the challenge within SANParks is to try and have space for people to engage on issues and understand the transformation and its implications so that there is serious buy in. It's not just your corporate ideas coming down and having to be implemented. You want to find situations where people are workshopped and people actually debate and engage on these things and explore implications on a Park-to-Park basis. Then, people get 
to understand that [resource use] is not really a threat to Park management. It's actually a way of getting people to understand. I do not think a community will be confused to an extent that they think a Park is really becoming theirs because they are involved in the management. People can still see that this is a SANParks management, but they appreciate moments of involvement and participation and a sense of ownership, as well. (S16)

The realization that stakeholders must be involved in decision-making processes for them to buy into policies and actions is not ground-breaking by any stretch "stakeholder involvement" materializes in almost every dimension of contemporary protected area theory and practice. The extent, though, to which stakeholders, or certain sectors of protected area administration for that matter, are involved is by no means uncontested. Whereas some stakeholders might want to increase their decision-making clout by being more involved, some protected area organizations would rather maintain as much power or control over the process as they feasibly or legitimately can. "Consultation," for instance, might be preferred by protected area organizations over a more power-sharing framework, such as "co-management," because with such an arrangement, there is the risk that the organization's agenda will not be realized or there might be no assurance that decisions are actually made,

We'll take into consideration what the local communities want, but we cannot use that to decide what is best for the Park. (S25)

I think it is better off to know whose responsibility it is to develop the policy, ultimately. The question of co-management can create a lot of problems, because what happens is if you do not agree completely on a particular matter, then nothing is going to happen. But, if it is now that the buck stops with SANParks, after consultation the buck stops with SANParks, then the responsibility is that of SANParks to make sure that things happen. If you co-manage, then nothing would happen. (S10) 
I think internally, we have to decide what is the way forward before we go and talk outside. You go outside, and you create all of these expectations that you cannotmeet, and then you make enemies. We need to have a clear policy and understanding. And, if it must be, 'at this point we do not know enough, therefore we cannotdo it,' it has to be that. As a managing agency who is responsible for this protected area, we have to make some type of decision sometimes. We have to say, 'sorry, we're not happy with this because we do not know enough, and therefore, we're not going to allow utilization for $\mathrm{a}, \mathrm{b}$, and c reasons.' There might be areas where we think we will be comfortable with - like the elephant meat. But, obviously, we're not comfortable with it, because we're not going to cull them due to the public opinion. (S25)

S8, who discussed above the importance of buy-in in terms of Park staff offered a lengthy

explanation of how, because of the Park's mistrust of local residents, they are actually being very "brave" in even consulting local residents throughout decision-making

processes,

The second part of legitimacy [beyond having buy-in] is a very active policy that I'm promoting - it's the consultative process. Now, the problem with the consultative process is that it's high risk, and what you get out might not be what you personally want. It's a leadership technique that I've adopted, in a mostly supportive environment. Is that true for everywhere else in the organization? It's not. What happens in the rest of the organization is what Kevin Rogers calls the D.A.D. approach Decide, Announce, Defend. What they do is at even the simplest scale, they will draft something and send it out for comment, then maybe someone has got a good idea and you'll make some small comments. Essentially, it's getting done your way. That's a very safe approach.

What Kruger is doing, which [local residents] are not actually getting and why they're not getting it is a different issue, is saying we're here to ask you what you want in the plan. The best way we can do it. What would be a better way? A better way would be to actually have all those people jointly work-shopping the plan or the principles or the issues. Why do not we follow that approach? Because it's too high risk right now; because, yes, we would have a shared understanding, but we do not buy into co-management.

Fundamentally, we are starting from we do not trust our stakeholders right now - that they're not at a level of capacity that we 
would adopt a comprehensive, integrated approach, because we're not trusting what might come out. And, if we create the illusion of comanagement (which is not in the law, we do not have to do comanagement, so we're not going to, or shared management) we could expose ourselves to extremely high risk, because what comes out might be the most wacky load of nonsense. And, we've had examples of that.

So, we're like, 'let's not be that brave.' That's what communitybased natural resource management approach was supposed to do. What's happened is all of the studies have shown is that all of community-based natural resource management is a failure of immense proportions... We accept - or I accept - that we do not do co-management. Upfront, we do not do co-management. But, what we do is recognize alternative forms of knowledge. And, upfront, we will be a little brave and ask you to give us that information, but we reserve the ultimate decision-making power... At least upfront, we've said you put in your knowledge, we will integrate it so it's an integrated approach versus a singular approach that we defend and there is stuff coming out of people and out of the process that we are going to use. It's actually quite smart, cool. There is also crap, which is why we reserve the right to say, 'that's crap - no - based on our values and principles.' (S8)

As S8 seems to imply, not all staff "buy-into" processes that might be, as I will discuss in the next section of this Chapter in terms of local residents' conceptualization of legitimacy, necessary for local residents to buy-into Park actions or policies. In this way, however substantively legitimate a policy might be, fundamental disagreements concerning procedural legitimacy could engender a broader perception of illegitimacy. This certainly seemed to be apparent in a three-day series of "stakeholder-participation meetings" held along the western boundary of the Park prior to the Park's release of their 2006 management plan. In attending all of those meetings, I observed ${ }^{43}$ that the Park's notion of consultation was not entirely different from the DAD process S8 describes above. The stakeholder participation meetings consisted of two parts - (1) a several-hour

\footnotetext{
${ }^{43}$ All three stakeholder participation meetings were digitally video-recorded and are available on request from South Africa National Parks. (The Promotion of Access to information Act, 2000 (Act 2 of 2000))
} 
long series of PowerPoint presentations offering stakeholders a detailed look at what the management plan would consist of (including policies related to resource utilization), and (2) a thirty-minute period after the presentation to ask questions. In two of the three meetings, disgruntled residents of nearby communities accused Kruger's administration of coming to the meeting with the Plan already decided upon and that, as a result, their comments would be irrelevant.

The stakeholder participation meetings and interviews with staff illustrated that creating a sense of "buy-in" is an important feature of the procedural legitimation of policies or actions. Nevertheless, there may be different views as to how far decisionmaking power should be shared or conceded in an effort to achieve "buy in," and hence, to engender a perception of legitimacy among a particular stakeholder. Trust clearly plays an important role in this decision. S8 describes above how, because some staff do not trust local residents, there is a hesitancy to yield decision-making power to local residents. Conversely, as demonstrated in the stakeholder participation meetings, local residents might not trust Kruger's administration, because they do not believe that the Park has made a good-faith effort to effectively involve them in the decision-making process. In this way, the lack of trust between Kruger and some of its stakeholders give rise to a troubling cycle imbued with hues of illegitimacy. These challenges are by no means unique to Kruger - protected areas around the globe struggle with these precise issues - but what this example does illustrate is that the procedure through which a policy or action is developed can have an important bearing on conceptualizations of legitimacy. 
The legitimate implementation of a resource use policy

Beyond the development of a policy or action, many of Park staff that I

interviewed commented that the legitimacy of implementation is an important procedural consideration, as well. As discussed in Chapter 2, adaptive management is an important feature of Kruger's governance and management, and for many of the staff I spoke with, the framework is a guiding philosophy for the legitimate implementation of Park policies,

I'm very much in favor of starting to do some practical stuff. That's one of the ways you learn. You do not tie yourself into precedents forever. You can delineate some part of the Park and we can start using something. Set up some rules. Try to make them work on a prototype basis, check how it goes, and commit yourself to re-deciding what you've learned and how well it's worked five years from now. But, make sure you've learned five years from now. Otherwise we're not going anywhere. Part of the learning is practical prototypes. Then, empirical data is part of the learning and theory is part of the learning. We actually need to somehow integrate all of those and have a process of doing those things and we might get somewhere. If we go on doing what's been happening ... I feel like we're just going around in circles. They've really delineated the governance part of this stuff, but if you do not understand on what basis you're making the decision, then you're governance can be excellent, but you've got nothing to support it. (S1)

For it to work right, we need to set up resource use in an adaptive way so that you say to any of the village people or any of the chiefs, 'okay, this is what we think now, we're sort of thinking of this. Will this give us the answers we need or what do you guys think? Will this help you? If eventually, we find this out, will this be useful?' (S14)

The policies have to be flexible or adaptive. In that sense, they are living. That's the most important thing for our conservation policies, goals, and ideals. It has to be something that can be re-visited and not static. It cannotbe something that someone has done once and that's the gospel truth. The fact that is being re-visited, re-hashed, that is the most important thing about our policies. That's like with this resource use policy, it has to be able to change because the needs of the community might change. There could be a decrease in demand over time. We cannotput it in a box or a bottle - we need to work with it. (S24) 
We've got an adaptive management framework that we work from, and I would say if they consider consumptive use within Kruger, within national Parks, then rather than doing nothing, make a concerted effort, say, 'let's do a trial run here, here, and there' - a sort of localized. See how it goes. Are we capable of monitoring it or regulating it? We will not know unless we try it. (S9)

We are prepared to investigate the possibility on a trial basis for certain selected areas and see how it goes... I think one will only know that if you do a couple of trials, try it out, and see how it goes. But, at the moment we can only guess. We might be very skeptical and pleasantly surprised or vice versa. We could be very optimistic and then end up being quite disappointed. (S9)

There are a number of reasons, then, why an adaptive approach might be important to the legitimacy of implementing a resource use policy. In the absence of an adaptive approach, for instance, the fear of being bound by a comprehensive resource use policy might prevent the Kruger administration from adopting a resource use policy. As discussed earlier in this Chapter, the uncertainty of the ecological impacts of resource use and whether or not resource use can be effectively monitored and regulated were important rationales shaping the substantive legitimacy of resource use. The excerpts above, though, offer the contention that uncertainty must be confronted and that a failure to confront is a failure to learn. For some, then, uncertainty is an insufficient basis from which to deem resource use illegitimate - speculations regarding impacts and the ability to monitor or regulate resource use can only be confirmed by experimenting with resource use. As S9 points out in the last excerpt, through the adaptive process, those who were originally skeptical of resource use might be "pleasantly surprised," or those who were supportive and optimistic might be disappointed. Nevertheless, the adaptive management process may be an important procedural step in mitigating uncertainty. 


\section{An overview of Park staff conceptualizations of the legitimacy of resource use}

Up to this point in the Chapter, I have offered an overview of the Park staff's complex conceptualization of legitimacy. Figure 7-1, presented earlier in this Chapter, graphically represents a holistic snapshot of their conceptualization. As illustrated in the Figure and discussed earlier in the Chapter, the values that Park staff identify appeared to have a direct bearing on what staff felt were rationales that either legitimate or illegitimate resource use. Broadly speaking these rationales were either substantive or procedural in nature. Substantively speaking, some staff felt that resource use was legitimate because (1) resource use is part of a broader, balanced approach to fulfill the Park's mandate, (2) there is a moral responsibility to provide benefits to local residents, given, in particular, that so many of them were forcefully removed from the Park, or (3) resource use could provide a strategic means to both meet the needs of local residents and build a strong constituency for the Park.

On the other hand, some staff felt that resource use was substantively illegitimate because (1) there was a moral responsibility to protect the Park from the type of degradation that resource use would bring about, (2) the uncertainty associated with resource use (including its impacts and the ability to monitor and regulate it) necessitates a very conservative, precautionary approach, (3) the inability to control access and/or utilization, or (4) there demand would likely be to high to where the provision of resources would have any practical impact in the lives of local residents.

In addition to substantive considerations, Park staff also pointed to the procedural elements of resource use that contributed to its legitimacy. Obtaining "buy-in" among 
both staff and other stakeholders through consultative processes were critical legitimating rationales in the development of a resource use policy. In terms of implementation, many staff maintained that implementing resource use adaptively could go a long way in legitimating resource use and mitigating some of the challenges faced with the uncertainty surrounding resource use.

While drawing generalizable conclusions was not the purpose of the qualitative analysis I performed, in terms of the twenty-eight rangers and senior staff I spoke with, most felt that a resource use policy could be drafted that was legitimate from their perspective. Some staff, for instance, concerned about the uncertainty of resource use felt that small-scale pilot projects undertaken in an adaptive way could alleviate their concerns. While some spoke passionately about the moral responsibility to protect Kruger from degradation, only a few felt that such a responsibility implied the absolute prohibition of resource use. Finally, the inability to satisfy the demands was a factor that contributed to some perceptions of illegitimacy, but most staff who discussed this aspect felt that such a perception of illegitimacy would likely be expressed by local residents rather than staff - the object of tokenism, that is, is more likely to experience malcontent than the provider of a token gesture. Undoubtedly, the legitimacy of resource use is a multifarious domain, but the complexity is only exacerbated when considering the conceptualizations of other groups (admittedly heterogeneous) groups, such as local residents and Park visitors. 


\section{CHAPTER 8}

\section{CONCEPTUALIZING THE LEGITIMACY OF RESOURCE USE \\ IN KRUGER NATIONAL PARK - LOCAL RESIDENTS}

\section{Introduction}

Just as it is erroneous to view the Park staff as a homogenous group of one mind when it comes to the legitimacy of resource use, assuming that local residents (as the benerationales of access to resource in Kruger) would universally endorse resource use in Kruger would also be a mistake. Figure 8-1 presents an overview of local resident conceptualizations of legitimacy. As with the Park staff, the values local residents assign to Kruger are complex and in some instances conflicting. These values, though, along with contextual considerations relating to the historical Park-people relationship, current livelihoods, and democratization fundamentally shaped the procedural and substantive considerations that either legitimated or illegitimated resource use. It might come as a surprise to some, for instance, that many local residents see more utility in conserving resources rather than utilizing them, despite having, in some cases, an obvious need for resources. However, many local residents did feel an entitlement to resources in the Park and a pragmatic need for them. In terms of process, the local residents I spoke with were not opposed to consultative processes, but felt they needed to be improved in important ways. As I will discuss in Chapter 10, these observations and others are particularly elemental in understanding how the various conceptualizations of the legitimacy of resource use (both across and within the various groups) might be reconciled. 


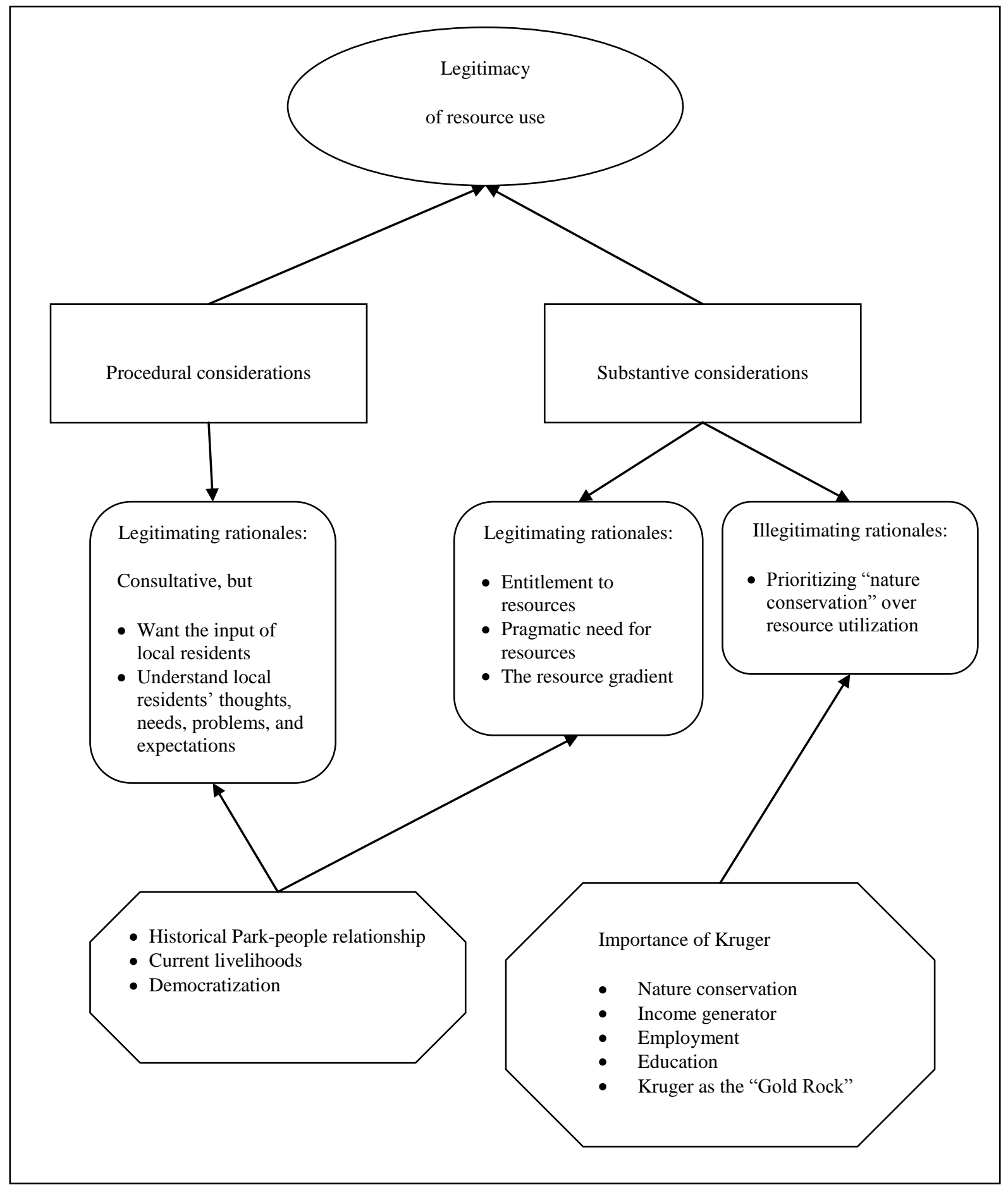

Figure 8- 1: A map of local residents' conceptualizations of the legitimacy of resource use 


\section{Local resident thoughts on the importance of Kruger National Park}

Interviews with Park staff appeared to indicate that the values they assigned to Kruger were influential in assessing the legitimacy of resource use. As articulated in the Park's conservation values, Kruger is valued as a protector of biodiviersity and other resources, but is also valued as a provider of benefits to its constituencies. These two values, among others, translated to significant rationales shaping staff perceptions of legitimacy. The value or importance of Kruger to local residents was also a contributing factor to their conceptualizations of the legitimacy of resource use. Of the 39 local residents that I interviewed, nearly all felt that Kruger was important to them in some respect. Interestingly, many deeply valued the Park despite rarely visiting it,

I see it as a very great thing. But I have never been there since we were taken out of the Park. So I have not visited the Park in a while. (LC15)

It's our treasure, because our forefathers were born there and they were staying there, so I see it as something that belongs to all of us - both ourselves and our past parents. I do not visit it, but I see it as a very important thing, because it's our part and parcel of God, because we once lived there. (LC16)

A spiritual or historic attachment that LC16 describes was by no means the only reason local residents felt that Kruger was important to them. Conservation, education, and employment opportunities were all main themes that emerged from the interviews. On

the other hand, valuing the Park as a reserve of resources for their use and as a place that they could visit were each only initially expressed as important attributes of Kruger by two separate interviewees,

All the animals. I'm a young man now, but older than you. And, it was just last year that I went to Kruger for the first time. Before then, I had 
only heard of these animals. I had seen them in books, but it was much different when I go there to them. I was afraid of them. We saw a lion right on the road. I did not want to get out of the car the whole time I was in there. I think that the Park is also important to me because when I went there, I was able to relax and rest. We went to Shingwedzi. It's a very beautiful place. I really like the Park. It's a good place (LC1)

[T]he most important thing is the fertile soils in Kruger, but it's not possible to get that soil. I remembers all those types of things that they were plowing and they were having a lot of fruits. (LC30)

Perhaps the reflection of a Kruger staff's comment that it is the Park that creates the demands of local residents ${ }^{44}$, all but the two local residents above that I spoke with discussed the importance of Kruger in terms of the current benefits and activities that are provided by or conducted in the Park, rather than benefits or opportunities that the Park could potentially provide (e.g., access to resources in the Park). This is not to say that local residents would not like to have more benefits provided to them, but, rather, that because activities and benefits like resource use are largely prohibited in the Park, local residents do not currently value the Park for those activities or benefits.

The Park's efforts to "conserve nature," on the other hand, figured prominently in local residents' expressions of the Park's importance,

[I]t's very much important for the resources in the Park to be looked for... it will actually attract people from outside to come and so those things inside the Park... it is a valuable thing that the resources in the Park - the animals and the trees of the Park - be looked for. (LC17)

It is good for the Park to be there and I want to see nature being conserved, but then I do not visit the Park regularly. Ever since we were expelled from the place, I have not yet visited the Park. I see it as important that the nature be conserved. I see the whole Park being great. (LC19)

\footnotetext{
${ }^{44}$ See S8's comment, p. 178.
} 
It is important because it is the only place that conserves nature. If you want to see some trees, or if you want to see wild animals, then you go to visit KNP. (LC32)

I once worked in the Park... and I realized while I was still working there that nature was actually conserved, and I see it as a very good thing. As such, I would like to see it preserved in the near future. (LC18)

As LC17 and LC23 discuss, the importance of Kruger's conservation of nature might be attributed to either conservation's ability to attract tourists or the assumption that Kruger is, indeed, a bastion of nature that cannot be found elsewhere. Contrary to what LC18 might have implied in the last excerpt, some local residents I spoke with insisted that the desire to conserve nature was not induced by the establishment of Kruger itself or the efforts of Park managers to teach local residents about conservation. Instead, they argued that there was an interest in conservation long before whites came to the area,

I was born and bred in that area, so I had experience of the past that even before the arrival of Stevenson-Hamilton we were taking care of those animals and those plantations.. (LC20)

These animals were looked for even before the arrival of the white man... it is very much important for the animals to be kept there, to be taken care of. (LC23)

As the comments of some staff suggested (see S8 on p. 209), there is a fear among some that if local residents had more liberal access to the resources in the Park that they would destroy it. One resident refuted that assumption by describing how land claimants, if they successfully claimed land in the Park, would not want to develop the area, but would rather conserve the area and use the tourism opportunities afforded through conservation to generate income, 
If you look at the process of land claims, people are busy trying to claim their land back in the sense of being part of the running or operation of the reserve - not wanting to go back and build their houses there. That shows how much important and understanding we have in terms of conservation or in terms of nature conservation. So, we see it as a place where they can generate income by having conservation areas close to their homes. (LC14)

As LC14's comments suggest, many local residents believe Kruger is especially

important as a mechanism for generating income and employment opportunities,

Well, for me, I think that the community feels that Kruger is important in terms of job creation. (LC14)

I do not see the very importance of Kruger, actually, but the importance of Kruger is... the many people from the village who have been employed there. That is the important thing I can quote. Nothing better than that. (LC24)

Kruger is good, because I will just say about the time that I was working there at KNP. I was first able to get a job. So, they taught me how to conserve nature. It is still good to me, because they are still conserving nature. It is good because it gives jobs to our young people, because we do have people who are working inside the Park. (LC28)

Yeah, it's important mainly because there are a lot of people from the local communities working in the Park (LC38)

[I]n the olden times, they were thinking that being removed from that place they want to go back to those places, but presently they understand it because Kruger National Park is putting their hands in the neighboring communities, giving them their work, and they're creating jobs so that they go and work there. So, that is why now they understand it better, and they know that what is in Kruger National Park is the one which is inviting people to come down to Kruger National Park so that they can be able to get money. If the people that are coming in, they will be able to go down there and they go and pay for certain things, and they get money from that. Most especially the tourists when they're down at Kruger National Park. (LC5) 
Indeed, as LC24 and LC38 discuss, employment might be the main or only reason why some local residents value or view the Park as important to them. Interestingly, for LC5 at least, the value of Kruger as a source of income and employment is, in a way, significant enough to justify the forced removal of historic Park inhabitants opportunities for employment are more important than the opportunity to go back to living in the Park.

In addition to employment opportunities and conserving nature, some local residents discussed that the Park is also valued for the opportunities it affords their children to learn about nature,

It is also a very good thing because most of the things which are important - especially the animals, we can take our kids to the Park and show them some of the animals which they cannot see outside. [L]earners will learn to also conserve nature even outside the Park. (LC16)

[I]n terms of conservation...[Kruger] is a very important thing because their forechildren need to know what is this in terms of animals and plants. For reference, for the future kids it's important for them. So, nature should be conserved as such. (LC21)

I do not visit the Park, but there is a great need for nature to be conserved. Our kids need to refer to whatever is inside the Park. So, they can only refer them to those things if those things are actually kept safe or safeguarded. (LC22)

I know people who want to become veterinarians and they need to be able to see the animals. It's not as good to see the animals in the books or the magazines - they need to see them in the bush in their natural surroundings. That is why we cannothunt them all. (LC2)

The protection of the resources found in the Park, then, is important to some local residents because, in the absence of protection, there is no other natural setting where their children can observe and learn about the wildlife and plants found in the Park. 
For many local residents, the Park is important to them as a conservator of nature because the Park's resources cannot be found elsewhere, and as a result, there are valuable opportunities for employment and environmental education. As a few local residents commented, though, the Park could be more important to them than it currently is if the Park sought to "empower" the surrounding communities,

Yes, I think it's important, but not as important as it could be. I mean, it is good to have the nature conservation, and it is good to have the tourists that come through here, and it is good to have some jobs available to our villages, but it could be more important. (LC4)

Let me say that it can be important - very important - as long as the KNP decides to empower the community. It's where the problem lies. I do not see anything wrong with KNP myself. We acknowledge the fact that they are conserving nature. They are looking after the animals, which, for instance, our children after twenty years. That's why I do not see anything wrong with the KNP. But, they do not empower the communities. They do not involve the communities in their management. They want to plan everything without coming to us. They go off and they decide alone. They want to take a decision together with us so that we can also be empowered, but that is what they are not doing. KNP is here just to control us so that they can run their business well. (LC9)

You might have realized that there is no factory near to this community nothing. If someone is looking for a job, they must go to Gauteng - very far from his or her family. Our only factory is KNP - this is our gold mine. That's why we think this community can be built on it. We call it a 'gold rock' on which our communities can be built. (LC10)

A lot is expected of Kruger as a National Park as the "gold rock" upon which surrounding communities might be built. Even those who demand more of the Park acknowledge that the Park's conservation efforts are important, but they also believe that beyond the employment and education opportunities that currently exist, more can be done to 
"empower" them. Whether or not resource use will serve that end, though, is a point of contention among local residents.

\section{Local residents and the substantive legitimacy of resource use}

Discussing the legitimacy of resource use with local residents was a more challenging task than discussing the same issue with the staff of Kruger. In my interviews with staff, it was clear that (as some commented to me) many of them had participated in a number of meetings and were well-versed in the pros and cons of resource use. In terms of the local residents, on the other hand, I often felt that I was the first person to have asked them about their views on collecting and utilizing resources from the Park. Perhaps as a result, the most significant difference between the interviews of local residents and Park staff was the level of detail at which they discussed the issue. Park staff, for instance, were prepared to talk at a very detailed level regarding the legitimacy of resource use, whereas local residents, forgoing the minutiae, often framed their discussions in broader terms of benefit provision in general. Even when probed for their specific views on resource use, some chose to discuss the legitimacy of broader themes, such as development, community involvement, employment, etc. Nevertheless, as the discussion in the following section and in Chapter 6 demonstrate, resource use is an important issue to local residents, but as I will discuss in the next chapter, local residents' interest in resource use might be a proxy for other benefits that they believe to be more important (e.g., developmental assistance, education and employment opportunities, etc.) 


\section{Resource use as legitimate}

Whether or not a proxy or surrogate for broader interests, local residents provided insight into rationales that both contributed to the legitimacy and illegitimacy of resource use. In terms of its legitimacy, local residents put forward three main arguments: (1) they are entitled to the resources based on their historical relationship with the Park, (2) there is a pragmatic need for resources among their communities, or (3) it's rational to expect that they should be given access, since the Park has a wealth of resources and their communities do not.

\section{$\underline{\text { An entitlement to resources }}$}

As some staff discussed, allowing local residents to utilize resources from within the Park may be conceived as a mechanism for redressing forced removals from the Park and its attendant consequences for local residents. Many local residents discussed this dimension in terms of benefits broadly defined, but several local residents also spoke more specifically in terms of resource use as both a mechanism of redress and a right resulting from their belief that the Park still belonged to them,

It is in fact our place so we have the right to [collect resources from the Park]. We should be able to getting in there and doing whatever with the place. It's ours, we should be given a chance to do that. It was a very good place for us. (LC21)

Resource use is appropriate because it is our original place, no one was supposed to be actually prohibiting us from going there and cutting down trees and cut grasses. It's our own place and we should have a right to do whatever things we would like to do with the place because it was originally ours. (LC23) 
During those past days, when we were in KNP, we were not asking, because we were residing inside. If I want to, I do not think about making a permit to tell someone that I want stuff. It was free for me. If I want marula, it was free for me. So, we feel not comfortable if we are not allowed to go and collect those things. In fact, or in short, they are owing us something. (LC28)

They destroyed and killed our cattle, so Skukuza is owing us. One other thing, the place where they were residing, the soil was better. If you see here, there is nothing. I want firewood and it's a problem because I have to pay. If she wants grass, she has to pay. For everything, it's money. So, Skukuza, in fact, is owing us something. It's not that she just needs something, it's that they owe her something. In return, if Skukuza can do something for them, maybe they may forget the issue of their cattle being destroyed by the Boers. (LC35)

For some, then, the legitimacy of resource use is deeply rooted in the historical Parkpeople relationship. As discussed in Chapter 5, many local residents felt that life was better in the Park, whether they actually lived there or were only told of life in the Park by older family members. When living in the Park, as LC28 comments, they did not have to ask for resources. Instead, it was their right to do as they pleased with the resources and not have to pay for anything they used. Because some feel this opportunity was unjustly taken from them and that the Park is still, in fact, theirs, they believe they are entitled to the resources in the Park and that the Park owes them access to those resources. If Kruger were to provide such access, as LC35 comments, doing so might go a long way towards redressing historical wrongs, including the forced removals and destruction of cattle. 


\section{$\underline{\text { A pragmatic need for resources }}$}

At least among the local residents I interviewed, the sense of moral entitlement to resources was a secondary factor contributing to the legitimacy of resource use when compared to the pragmatic need for resources. In Chapter 6, I discussed a number of resources that were of interest to local residents, and in that discussion, it was evident that many were interested in those resources because they needed them - not necessarily because they felt entitled to them,

As you see, we are forced to use the corrugated iron [for our roofs] - even though we do not have any money. But, you must devise some means to have those irons. Before it was cheap, because we were using thatching grass and poles inside the Park. Kruger is not owing us something, but when we are here, we are running short of things. So, there is a need to have these kinds of resources. We need meat. Sometimes people put traps, which is illegal, but they do it anyway. Skukuza must be aware that we are in need of meat. (LC36)

Another local resident I spoke with further commented on how the need for resources particularly food resources - is significant enough that some local residents are willing to risk entering the Park illegally to gather food,

People are starving here. Randy, you saw as you drove into Punda Maria people along the road. They are poor, hungry people. We need help, and we need food. It's difficult for people to get food here, but they find ways. Randy, you know some people get food from the Park, and the Park does not even know it. They dig tunnels under the fence - under the fence to get into the Park. I know where many of these tunnels are. People go out and they come back in with stuff. (LC2)

Meat and other food is not the only resource that some local residents have a desperate need for. As one sangoma noted, they felt if access to medicinal plants 
was provided, they might be able to heal many people in their communities that are dying,

From the traditional point of view, it could be very important when the issue of medicinal plants can be addressed, because there are a lot of people dying, but if we could get those medicinal plants, which are in the Park, we can be able to heal them. But, now they do not have an access to that. And, if they can make it a point that the nursery is established, that would be very important. (LC26)

Notwithstanding the reservations of utilizing nursery-raised medicinal plants among some sangomas (see p. 172), it is conceivable that a nursery in Kruger could go a long way in meeting demands for medicinal plants. In terms of other resources, such as firewood, meat, and other foods, it is not clear that access could be provided to an extent that would meet the needs of local residents. As discussed above, for some staff, this consideration was an important factor contributing to the illegitimacy of allowing resource use. And, the same seems to be true for at least some local residents - the legitimacy of resource use might be fundamentally dependent on whether or not access to resources will meet the needs that local residents have,

We're very hungry man. Did you drive to Punda Maria? It's a very hungry place. They need the meat and they need the wood to cook their food, and they need the thatch for their houses or plants for illness. We need these things often, but I do not think that the management plan will let us. Small amounts will help, but we need much of it. As I said, our people are hungry, they're starving man. We must be able to do something about that. Otherwise, we [are] going to keep starving. (LC1)

Yes, [I think resource use is appropriate] but only if it helps us and eliminates our starvation. Just letting our village go and get one stick here and one stick there is no help. We need wood for everything. We need it for keeping warm in the winter, we need it for cooking, we need it for boiling water, we need it for building things like fence. When the Park talks about resource utilization, are they talking about letting our villages come in and gather enough wood to meet all of these needs? Anything will 
help, but when they say they are benefiting us, they are not really benefiting us. It's like a game where they tell us we're benefiting, but we're not really benefiting. (LC3)

As the excerpts illustrate, any level of resource use might help, but the interest in resource use among some local residents is rooted in the hope that it might meet the, perhaps, lofty goal of eliminating starvation among their communities. This is, perhaps, not to suggest that these respondents and others who feel the same way are adopting an all or nothing mentality -i.e., they desire resource access to the extent that it eliminates starvation or they do not want any access at all - rather, the excepts reveal that, for many, there is a very serious, pragmatic need for material resources.

\section{The resource gradient}

The legitimacy of resource use, and the perception that resource use could meet the pragmatic needs that local residents have might, at least in part, be attributed to the comparison of resources in the Park with those outside. As discussed earlier, there is a sharp distinction in the two vegetative structures and wildlife populations. In the Park, large trees, fallen or dry wood for firewod, and wildlife for meat are all in abundance, whereas outside the Park, these resources are much more scarce. To some, then, it is rational or logical to expect that, with the abundance of resources in the Park, access to those resources would be granted,

The Park has so much, but we have so little. Cannotthey help us? We need it bad - we are starving. We know that the Park is thinking about culling the elephants. Could not they let us have them? Elephant will feed a lot of people. Impala would also be good. We need the meat. So, we know that the animals and the nature belong to all of South Africa - not just us. But, that does not mean that they could not help us. They have so much, and if they're going to be killing it, why not let us have what is killed? I do not 
understand why they cannotdo it. Like the presenter said yesterday [at the stakeholder participation meeting], we cannotjust go in and take everything. And, we would not. We know that if we take everything that there will be nothing left. We understand that. Then let the Park help us know what we can take and what we cannot take. Then we can do it better. Like the impala - I saw many, many impala and people tell me the same thing. Why cannotwe take some? (LC1)

Look at all the dry wood laying along the road when you drive through the Park. What purpose does it serve lying on the ground. The same is true for animals. There are too many impala in the Park - we could use that impala. The Park likes to claim that it is natural, but the impala entirely unnatural. Allowing us to kill the impalas for meat would make it more natural. The Park does not want to let us do that. Instead, they let the lions come out and kill our cattle... (LC4)

Collecting resources from the Park seems, then, rational or logical to some given the resource gradient that exists between the Park and surrounding lands. LC4 goes as far to state that that the impala population in the Park, for instance, is unnaturally high and that resource use - contrary to being unnatural or harmful to the Park's biodiversity - might actually "make it more natural." Whether or not resource use would influence the naturalness of the Park, the inability to collect resources from the Park might be particularly frustrating, as LC4 comments, when those abundant resources (e.g., carnivores, such as lions) impact on the comparatively scarce resources that local residents have (e.g., their cattle).

In short, the rationales that legitimate resource use for local residents are fairly intuitive in light of the historical context and their current livelihoods. Because they were forcefully removed from their land to make way for the Park, some local residents believe (as did some staff) that they are morally entitled to the resources in the Parkthat, in fact, the resources still belong to them. For others, the legitimacy of resource use 
lies not in its moral undertones but in the pragmatic need for resources that their current livelihoods have given rise to. Coupled with this is the premise that it is only rational to expect the Park - with many resources - to provide access to those whose land is far less productive. Not all local residents held resource use to be a legitimate activity. As I will discuss in the next section, whereas historical and contemporary livelihoods strongly influenced the belief that resource use is a legitimate activity, the value and importance local residents assigned to Kruger engendered beliefs of illegitimacy among several local residents I spoke with.

\section{Resource use as illegitimate}

While most local residents I spoke with felt that resource use in Kruger was a legitimate activity, there were several who did not. One individual I spoke with commented that, from a pragmatic standpoint, access to resources would be of little utility, given that they were not familiar with the Park,

Besides the question of letting us in, even if we can be given a chance to go there, we are not used to going to that place, so it will not be easy for us to go there because we are not used to the place. (LC20)

In this way, rather than resource use being illegitimate in principle, some local residents felt that resource use would be illegitimate because there was no way for them to actualize the benefits of access to resources. Assuming, then, that they became familiar with the Park and became aware of where resources were located, they might very well view access to resources as legitimate. 
Another individual suggested that resources in the Park are valuable and should

not be wasted as they believe is often the case when medicinal plants are harvested,

Those resources need to be kept, because it's like grasses - should they be harvested? Then animals are going to suffer maybe in terms of grazing. Even outside here, when there is [field] fires, we usually wake each other up to go up and try to stop that because we see it as a valuable and natural resource that needs to be kept, not used or wasted... people do not have an idea as to how best they can cut those trees for medicine. They usually cut the whole and the whole plant usually dies... they do not have skills as to how best can they cut this tree. (LC15)

Beyond the lack of skill in knowing how best to collect resources, LC15 also implies in the beginning of the excerpt that resources, such as grasses, are better left to be utilized by the wildlife in the Park than local residents. More generally, and consistent with the importance that local residents place on Kruger, "nature conservation" was an important consideration for several local residents in assessing the legitimacy of resource use,

Even if we were given a chance to go there and maybe cut down these trees and collect this grass, we will not be able to do that because we are on the side of conserving nature. (LC19)

The regulations and acts which are there in the Park, that actually control the Park, are prohibiting people from outside the Park going in there and try to cut trees for medicine or kill animals for meat. Those acts are good, because they're actually conserving nature (LC18)

...nobody has been putting more pressure into Kruger for wanting to get resources by force. People understand that you have to conserve or look after the environment. There must be some sort of control in the National Park (LC14)

Interestingly, as LC15 suggested above, it is perhaps true that some local residents place the needs of "nature conservation," which might be infringed upon through resource use, above their own need for resources. The three excerpts above offer similar perspectives 
and suggest that some local residents feel the prohibition on resource utilization is

desirable. This does not necessarily mean, though, that these same individuals do not recognize the need for resources among their communities. LC14, for instance, who above champions the "control" of National Parks, also commented that,

There is a very, very great demand for people to get the resources from Kruger, but unfortunately there is not much access... most of the people use firewood locally, and unfortunately we do not have a place where they can get it. (LC14)

When I asked LC14 how local residents had acquired this conservation ethic, s/he responded,

I think more education was happening to the staff that was working in the Park. And, by making sure that the people in Kruger National Park or other reserves get to learn, because every day they see the guests coming to see those kind of things that is not there in their country. So, people in the process get to understand why it is important to have national Parks, why it is important to have those natural resources. It generates income and job creation for the people. So, that message has spread to the people that are here in the community. (LC14)

Other local residents I spoke with offered similar explanations as to why local residents might place the interests of conservation above their own interest in the direct utilization of resources,

It will cause impact, because if we say that we can allow all the people to get inside the Kruger National Park to go and cut wood, or to chop wood, or get thatch, and all these, some of the animals depend on the dry wood where they have to live - like termites, they live on that. And, sometimes, you find that there are certain small animals, which are living on these dry woods. If we take them away, the tourists will not get any of those small animals that they like to see, because those small animals are the ones inviting the people to come down. So now if we do that, it means that you are destroying the nature again. Also, sometimes, you find that those dry woods, they decompose, they make manure for the grass to come up again. So, now, we understand that. That's why our government has just 
decided to put electricity all over, so the people can benefit from

electricity rather than going inside and chopping wood... (LC5)

Resources are one way in which the country can generate income, because people will get in [the Park] and they will have references in terms of trees and animals that are not actually found in other countries. So, they see it as a very good thing that nature should be conserved for people in the future to refer, their future kids to refer to, and even people coming from abroad. They're saying even in the time they were still staying there, they could actually combat [field] fires should it arise. (LC17)

At least in part and for some, resource utilization is illegitimized and nature conservation is legitimized on the basis that nature conservation (unlike resource utilization) contributes to the attributes of Kruger that local residents feel are especially important i.e., a source of income vis-a-vis employment and tourism and as an educational resource where people can learn about nature. In other words, for some local residents, the Park's utility lies not in its resources that might be directly utilized, but the more indirect benefits the Park yields though tourism, employment, and education.

\section{Local residents and the procedural legitimacy of resource use}

As did the Park staff that I interviewed, when asked about the appropriateness of processes for making decisions about resource use, most of the local residents I spoke with discussed the notion of procedural legitimacy in broader terms than resource use. In particular, a few local residents commented on decision-making processes within the context of the Kruger Management Plan that was being drafted at that point in time. What might be loosely labeled "stakeholder participation" was a key factor in the assessment of procedural legitimacy for Park staff, and it was an important consideration, 
as well, for local residents. Several Park staff I spoke with made an important distinction between "consultation," where the Park retains decision-making authority, and "comanagement," where decision-making power is shared between the Park and other stakeholders. As discussed above, most Park staff that I spoke with favored consultative approaches due, perhaps, as S8 (pp. 223-224) spoke of, to the inherent risks and uncertainty associated with sharing decision-making authority.

Whereas it might be expected that local residents would take a much different stance than Park staff, favoring more power in management and governance processes, the views of local residents I spoke with were not inconsistent with those of the Park staff. In fact, none of the local residents I spoke with called for decision-making processes designed to result in equitable decision-making power or even more power than what they already had. Consultation was not perceived to be an illegitimate approach, but there were some frustrations with the current way participation in decision-making processes were being realized. Some local residents I spoke with, for instance, offered optimistic - but guarded - impressions of the current decision-making framework, KNP and the community members must work together especially if KNP is having a problem. They must come to the community like what they did at the Protea Hotel and exchange some words. Improve where they are lacking. Even though they cannot solve it now, but bit by bit I believe things will become alright in the future. (LC11)

I think our involvement is good because now we cannot just look into what happened in the past, we do not want to scratch on healing wounds by saying we're not being considered for our feelings - we are. Now, everyone is involved in making the plan something that is sustainable... I think the starting point is the one that has been dealt with by looking into all stakeholders because everyone will be contributing towards one common goal of conserving the Park, because once that is not done, you'll see a deterioration in the Park. I think you can compare now how the Park 
looks and how it was some years back - maybe before 1994. It's not all about people are failing to manage the Park. It's all about being divided, saying 'we're not longer responsible.' Someone says let me just drop everything. But if that's how it should work, we are likely to see the Park deteriorating further in its status. The thing is let us all come together and work toward one common understanding and one common objective of conserving the Park... So, I think that step that has been taken in involving all the stakeholders is a giant step in the good management of the Park, because everyone must see the Park as his own asset, so I think that it has been a good step. (LC7)

It was good to have the stakeholder participation. I wish though that there would have been more time for input. Many of us, Randy, take the bus, and we could not stay very late, but it was late when we were able to give our input. That is the most important part of the stakeholder participation meeting. The presentations were good. I thought they were helpful. The Protected Areas Act is confusing though - very many objectives. (LC1)

In principle, then, these local residents view the current approach to "stakeholder participation" as legitimate. $\mathrm{LC} 7$, for instance, discusses that it is time to move on from "scratching old wounds" and recognize that local residents should embrace the opportunity to be involved in shaping the management of the Park and "contribut[e] towards one common goal of conserving the Park." But, as LC11 and LC1 briefly discuss, the implementation of consultative principles might have been "lacking." LC1 identifies, for example, more time in stakeholder participation meetings to provide input.

Others I spoke with, though, offered more general and systemic concerns related to the consultative process. One such concern was that the Kruger administration, through consultation, should make a more concerted effort to understand the people's needs, expectations, and problems they face,

Well, I think my point of view could be getting more local people involved in terms of the decision-making. Even if Kruger can come out and get to understand what people want and what people need or what 
people expect to happen in the reserve. Even if to only understand their point of view, that will help them to make decisions that will also help the community. The people of the community will feel that they've been part of the decision because they have been consulted before any kind of changes... I think Kruger has to do much more consultation now and then with the community. If there is a relationship or communication now and then between the community leaders and Kruger, that will help Kruger National Park to be more successful and to have good relationships with the community. People will see that as a benefit. (LC14)

There are regulations there. If you're here, you're not consulted. You're not involved. There is nothing you can do, even if you are having concerns that you can raise. If you're not given a platform where you can raise them, then it becomes null and void. It's useless to raise my voice to someone who will not actually interact with me and understand the problems I have. The relationship between the Park and the community is not good - no interaction. (LC20)

From the perspective of some local residents, having a "platform" where their thoughts, needs, problems, and expectations can not only be heard, but be understood, is an important feature of the consultative process. In the absence of such a platform, as LC20 discusses, the current approach might not even be considered "consultative." LC14 further suggests that the impression among local residents that they've been understood might go a long way to improving the relationship between them and the Park. Beyond understanding them, though, some local residents commented that they have to feel that their participation is not "passive" and that the Park does not merely "need" their input, but rather "wants" it,

Involving the villages and getting our input is a very good thing. We want to give our input. But, mostly, we want to have our input heard. When people are prejudice, they say you have to do 1-2-3. They only consulting us because the [Protected Areas Act] says they must. I did not even know of this act. We do not have copies of it. We're not aware of its existence. The whole [stakeholder participation] meeting disturbed me. They only ask for our input because the law tells them that they have to show they 
asked for it. How do I know my opinion is going to be heard. I'm sure they have finalized the Plan. They really are not interested in our input. They never wanted our input before. To me, whether we get what we need is just as important [as] having our input heard. The animals that get out of the Park is a perfect example. We have asked and asked them to control their animals, but they tell us that they are not the Park's anymore, and they tell us that they are Limpopo's animals. Limpopo tells us that they are Kruger's animals. We have given our input and asked them to take their animals, but they do not. They do not want to hear us. All the while, we suffer. Is it even worth going to these meetings? I do not know... the Park must not need our input, they must want it. (LC3)

It's still a passive participation. So, that I think we have to fight against that because, in fact, if they just come and consult you and you make inputs, but when they go, they throw it away and take some other things. They say, 'no, there are decision makers elsewhere.' So, I think it is important also to involve us in the process of decision making. (LC9)

As these and other excerpts illustrate, local residents' conceptualizations of a legitimate decision-making process are not necessarily inconsistent with the procedural principles that Park staff view as legitimate. There might be, though, aspects of the implementation of those consultative principles that local residents view as illegitimate. Most significantly, based on the interviews I conducted with local residents, a legitimate consultative process is one characterized by (1) active participation where the Park wants (rather than merely needs) the input of local residents and/or (2) a demonstration that the Park understands the thoughts, problems, needs, and expectations of local residents. While these thoughts were offered in a context much broader than the more narrowly defined issue of resource use, these considerations could have an important bearing on local residents' assessment of decision-making processes related to resource use. For instance, rather than crafting an a priori resource-utilization plan or policy, an expressed effort to "want" the input of local residents and understand local residents' thoughts, 
problems, needs, and expectations related to resource use might be critical rationales if local residents are to view such a plan or policy as legitimate.

\section{An overview of local residents' conceptualization of the legitimacy of resource use}

As with the Park staff that I interviewed, the underlying values assigned to Kruger by local residents, as well as a number of substantive and procedural considerations related to resource use, gave rise to a complex conceptualization of the legitimacy of resource use among the local residents I interviewed. Illustrated in Figure 8-1 is a model of those conceptualizations. Whereas with the Park staff, the values they assigned to Kruger had strong impacts on both the ways in which they legitimized and illegitimized resource use, the values local residents assigned to Kruger influenced primarily the perceptions of resource use as a substantively illegitimate activity. Many of the local residents I spoke with valued Kruger for it's "nature conservation" objectives and the concomitant ability of the Park to generate income for local residents through tourism and employment opportunities, as well as provide for environmental education. Some local residents I spoke with felt that allowing resource utilization would undermine those conservation objectives and, as a consequence, would damage education and incomegenerating opportunities. Resource use in Kruger, then, might be conceived as an illegitimate activity because it undermines the broader needs they have.

For those local residents who viewed resource use as a legitimate activity, their perceptions appeared to be driven by the historical context and their current livelihoods rather than the values they assigned to the Park. Many local residents I spoke with felt 
that resource use was legitimate because it might serve a pragmatic need they have, such as wood for cooking and heating or meat for food. Others reflected on the forced removals from the Park and maintained that they were morally entitled to the resources in the Park - that, in fact, those resources were still theirs. Beyond the pragmatic and moral rationales for legitimating resource use, some local residents commented that their resources were largely degraded and that the Park appears to have an abundance of resources; they suggest that it is only rational to expect, then, that they should have access to those resources.

Procedural considerations also featured strongly in my interviews with local residents. As with the Park staff I spoke with, the local residents tended to speak about procedural considerations in terms broader than the single issue of resource use. Interestingly, their perception of what constituted legitimate governance and management processes were not, in principle, different than the views of many Park staff I spoke with. Nearly all the Park staff felt that "consultation" provides a legitimate framework for management and governance of the Park, and for the most part, the views of local residents were not inconsistent with this approach. Many local residents did express, however, disappointment in the way in which the underlying principles of consultation have been realized. Most importantly, local residents commented that in the process of consulting them, Park staff must want - rather than legally need - their input, and they must demonstrate an effort to understand their thoughts, problems, needs, and expectations. 


\section{CHAPTER 9}

\section{CONCEPTUALIZING THE LEGITIMACY OF RESOURCE USE IN KRUGER NATIONAL PARK - PARK VISITORS}

\section{Introduction}

To present and discuss how Park staff and local residents conceptualize the legitimacy of resource use would be telling only part of the story. Just as the "protection of biodiversity" and "constituency building" are on equal footing as Park objectives, so, too, is providing for "tourism" opportunities. Visitors to Kruger, then - who are the realization of the tourism objective - constitute an important stakeholder in the resource use issue. Is it possible, for instance, that resource use could negatively impact tourism and the "visitor experience" to the extent that it would be rendered illegitimate? Recognizing that nearly all of Kruger's revenue comes from tourism (e.g., Park entrance fees, lodging, etc.), it seems likely that, at a minimum, visitor conceptualizations of the legitimacy of resource use might play a significant role in decisions concerning resource use.

Understanding Park visitors' conceptualizations present challenges and opportunities not encountered with Park staff and local residents. Perhaps the most challenging feature of attempting to capture the views of Park visitors was accounting for their extraordinary cultural diversity. Granted, there is certainly a high degree of diversity among local residents and Park staff, but Kruger - as an international destination - attracts visitors from literally hundreds of cultures and walks-of-life. As a result, while I felt the interviews with local residents and Park staff captured an adequate 


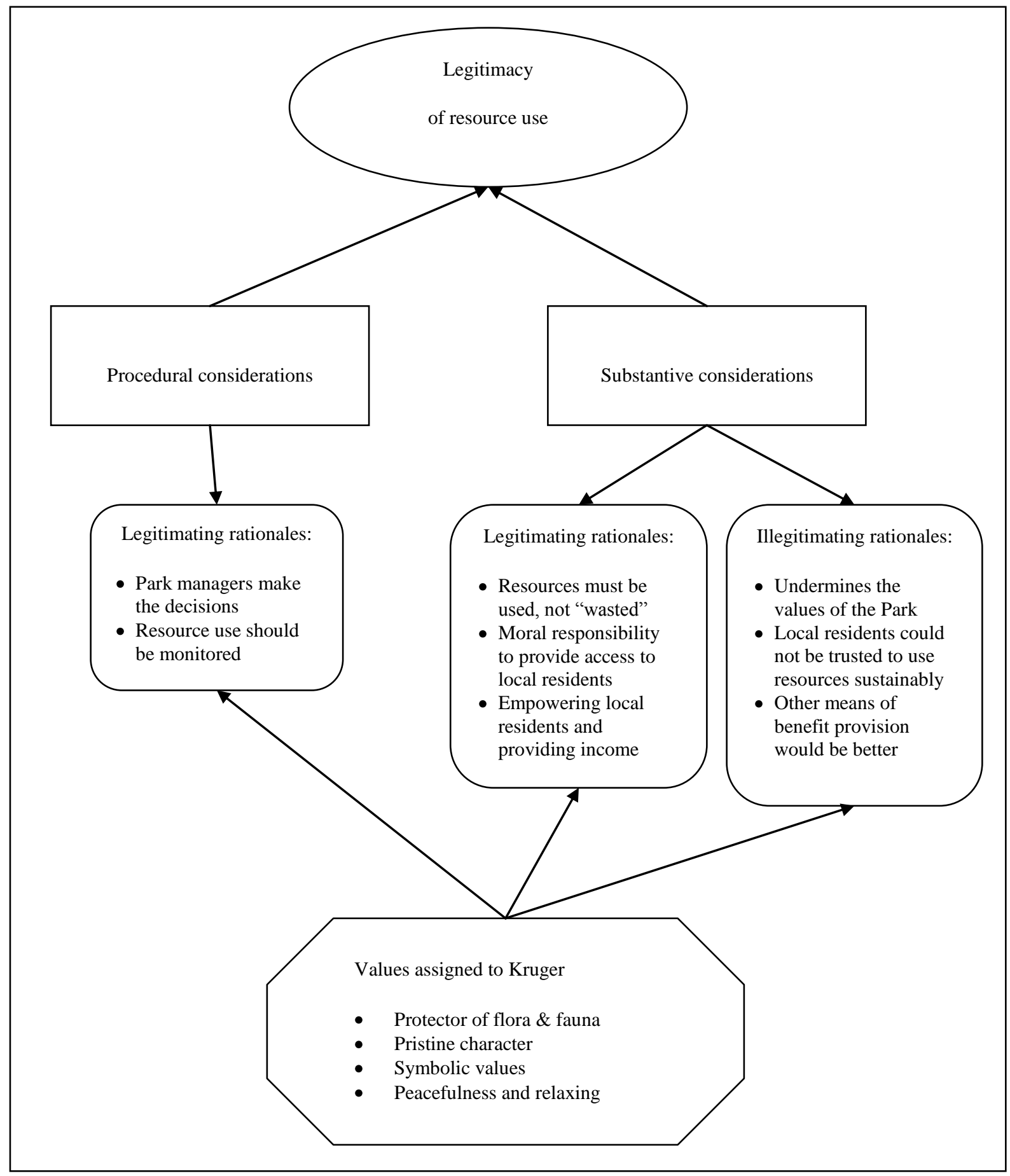

Figure 9-1: A map of Park visitor conceptualizations of the legitimacy of resource use 
and representative spectrum of views, I suspect that my interviews with visitors, while providing depthful insight, might not capture a true range of views.

In order to mitigate this challenge, I administered a visitor survey derived, in part, from my interviews with local residents, Park staff, and Park visitors. As discussed in more depth in Chapter 4 (pp. 133-136), though, there were limitations with this aspect of the research, too. In short, the data collected from visitors was, perhaps, more problematic than that collected from the Kruger staff and local residents. Nevertheless, the survey data combined with the interview data provide a useful look at visitors' conceptualizations of legitimacy.

Figure 9-1 presents an overview of these conceptualizations. As with Park staff and local residents, the underlying values that Park visitors assigned to the Park played an important role in shaping the procedural and substantive considerations that either legitimated or illegitimated resource use. Based on both the interview and suvey data, the most apparently significant values assigned to Kruger related to Kruger as a protector of the flora and fauna, Kruger's pristine character, its symbolic valus, and the opportunity for a peaceful and relaxing experience. For the most part, these values translated to resource use being widely regarded among visitors as an illegitimate activity in the Park $70 \%$ of the visitors believed resource use should not be allowed. Substantively speaking, those that felt resource use was an illegitimate activity, rationalized the illegitimacy in terms of how resource use would undermine Kruger's most important values. Moreover, many Park visitors were suspicious of local residents' ability to use the resources in a sustainable way. For those that felt resource use was a legitimate activity, they 
rationalized resource use based on the moral responsibility society has to the local residents, as well as the utilitarian perspective that resources must not be "wasted." Procedurally speaking, most Park visitors believed that Park staff should be left with power to decide how resources are used (if at all).

In this section, I retain the same organizational structure found in the preceding sections of this chapter (e.g., a discussion of values, substantive legitimacy, and procedural legitimacy), but within each of the three sub-sections, I divide my discussion and presentation of results into "interview data" and "survey data." At the end of each of the three sub-sections, though, I provide a synthesis of what - taken together - the data from both sources convey.

\section{The values visitors assign to Kruger National Park}

As with the local residents and Park staff, it was evident that the values and importance that visitors assign to Kruger contributed in important ways to their perceptions of the legitimacy of resource use. In interviewing Park visitors, I asked them if they felt Kruger was important to them and why it was or was not. No one I spoke with felt that Kruger was not important to them, and despite the diversity among the visitors, a number of common themes emerged. In addition to the interviews, I was also able to able to explore the values and importance visitors assign to Kruger through the visitor survey. 


\section{Interview data}

When asked during the interview, if they felt Kruger was important to them, every visitor I spoke with responded with a resounding “yes," as if it was almost ridiculous to ask the question in the first place. International visitors travel from around the world to experience Kruger, and many South African families have made their trips to Kruger a several-decade tradition. When asked why Kruger was important to them, nearly all visitors discussed in some form or another how the Park provides an opportunity to both conserve nature and enjoy it by being out in the "bush,"

We're just mad about the bush. Just the experience of being out in it. (V61613)

It's conserving nature for all South Africans and the country. (V6161)

It's just a great place to come and be in nature. I love it. (V6167)

I think the awareness of nature conservation in South Africa makes it important and the area that they're conserving here is one of the larger areas that you can visit. The diversity of game that you can see here. It's really important. (V823)

When I followed up these and similar responses by asking why nature conservation or the opportunity to experience nature was important to them - particularly in Kruger - many visitors had difficulty responding, commenting that the just believed it was important.

Some visitors I spoke with, though, noted that the experience and opportunities available in Kruger are important because, in the face of increasing development, it's not possible to find areas like Kruger where wildlife, the bush, and its wildness are protected,

Well, whatever else is in the suburbs and we have wildness here. Outside of the suburbs is getting eaten up by humans, so let's keep an area of the world like Kruger the way it was supposed to be. (V6277) 
Well, the conservation and the animals are important. I think it's very important. These days, the population grows and the space for animals is getting less in South Africa and all over the world. More and more species are getting extinct. We need Kruger (V6165)

As the comments of V6165 suggestion, Kruger is especially valued by visitors for its resident wildlife. Notwithstanding animals that escape the Park through the fencing, there is very little wildlife outside the Park, and Kruger provides the only opportunity to see many species in South Africa in their natural habitat. Wildlife - in particular "The Big Five" (i.e., lion, rhino, leopard, elephant, and buffalo) - are the single most important tourist attraction for a number of visitors,

It's just the wildlife and the animals basically. That's what I think is important about Kruger. (V61610)

We're all animal lovers. We love the wildlife. And especially now that my sister has a little girl. And, it's just so wonderful for her to see the animals - not in a zoo - but in their natural habitat. (V6168)

Yes, it is very important because I see a lot of animals, and I like to take animal's picture. (V61612)

The five - the Big Five - that's what's important (V6169)

The wildlife is why we come here. (V6269)

It's the bush. I love the bush. You can see animals in real life. It's not like a zoo or anything. It's quite fun. (V821)

The diversity - there is so many of everything. I do not know how to describe it. It's like being in a zoo, but not - it's wild. One of the biggest bushbok that he's ever seen and we were from here to there. Just the variety of animals. I'm still taking it in here. (V823) 
While, admittedly, a visit to Kruger can at times be best characterized as a frenetic

race to see the next leopard, at other times it can be very peaceful. And, the opportunity

to relax in the quiet of Kruger is also an important value of the Park to some visitors,

Unlike the zoo where they keep the animals, the animals are free and around, and you can drive around and see them. You're relaxed in the Park. (V6261)

I love the atmosphere. It's wonderful. It's very relaxing to be here. I love the Park. I love the animals. I love the atmosphere. It's so quiet and peaceful - it's very nice. (V62610)

Just the solitude and the peace, that's what we love about it (V6262)

At least among South African visitors, the unique experiences and opportunities (in particular those related to wildlife), not to mention its enormous size, give rise to a strong sense of pride in and identity with the Park,

I think it's one of the South African icons - a world icon, I suppose. It's very, very important that we do have it. (V61614)

I think the fact that it is our heritage. The animals have got somewhere to live and it's unspoiled. It's a place to escape. It's a natural environment. It's there - it's important just to know it's there. (V6262)

I think [Kruger] is important because it is a part of Africa that is so unspoiled, and I can say unequivocally that it is undoubtedly is the finest National Park that we have, and I've been to all of them. Within subSaharan Africa, it's probably up there with Serengeti, Masai Mara and Chobe in Botswana. But, as far as South Africa goes, it's the finest Park, and it should be kept as such. Once this goes, there is no other Kruger. (V6265)

As Mabunda, Pienaar, and Verhoef (2003) have commented, though, this heritage exists most strongly among white South Africans, and one of the Park's three principle objectives - building a constituency - is designed to engender this same sense of identity and pride among black South Africans, both locally and nationally. 
In summary, the interview data revealed that, as one might expect, Park visitors do place a lot of value on Kruger. Most significantly, Park visitors discussed the important role that the Park fulfills in conserving nature and providing opportunities for visitors to experience the Park through activities, such as wildlife viewing. For some, though, the Park is also valued as an area that visitors can come to relax and enjoy the peacefulness of Kruger. In any case, and in particular for South Africans, the role that Kruger serves, as well as the experiences and opportunities it affords, give rise to a strong identification with Kruger as a symbol of national heritage. In the next section, I discuss how visitors' values may be viewed from the perspective of the survey data I collected.

\section{Survey data}

As described in Chapter 4, the value or importance that visitors placed on Kruger was assessed through a twenty-five item, seven-point, likert-type scale preceded by the following question,

"Please indicate, for each of the following items, how important they are to the overall value of Kruger National Park (1 being "strongly disagree" 7 being "strongly agree"):

A response of "Do not know" was also permitted by circling the value "X" placed next to each item (see question 7 of the survey in Appendix 1). Descriptive statistics for responses to the scale items are displayed in Table 9-1. As illustrated in the Table, the survey data related to the value or importance of Kruger to visitors is largely consistent 
Table 9-1: Descriptive statistics for values scale items (visitor survey question 7) Likert-type scale: 1 - "strongly disagree" to 7 - "strongly agree"

\begin{tabular}{|c|c|c|c|c|}
\hline $\begin{array}{c}\text { Item } \\
\text { no. }\end{array}$ & Values scale items & Mean & $\begin{array}{l}\text { 95\% Confidence } \\
\text { Interval }\end{array}$ & $\begin{array}{l}\text { Standard } \\
\text { Deviation }\end{array}$ \\
\hline 1 & A protector of threatened and endangered species & 6.73 & {$[6.64,6.82]$} & 0.64 \\
\hline 5 & a place where the wildlife and plants of the region can live & 6.65 & {$[6.54,6.77]$} & 0.84 \\
\hline 24 & A place for scenic beauty & 6.58 & {$[6.47,6.70]$} & 0.84 \\
\hline 9 & A place for education about nature & 6.41 & {$[6.28,6.54]$} & 0.93 \\
\hline 17 & A symbol of South Africa's identity and heritage & 6.37 & {$[6.22,6.52]$} & 1.07 \\
\hline 18 & A place for a peaceful experience & 6.36 & {$[6.21,6.52]$} & 1.1 \\
\hline 6 & A place to view birds & 6.36 & {$[6.21,6.50]$} & 1.06 \\
\hline 12 & A place for wildness & 6.24 & {$[6.05,6.43]$} & 1.37 \\
\hline 23 & $\begin{array}{l}\text { a place to view the "Big } 5 \text { " (i.e., lion, rhino, elephant, leopard, } \\
\text { and buffalo) }\end{array}$ & 6.23 & {$[6.06,6.40]$} & 1.23 \\
\hline 4 & a place that everyone should see at least once in their lives & 6.18 & {$[5.99,6.37]$} & 1.34 \\
\hline 8 & A place for people of all cultures & 6.12 & {$[5.95,6.28]$} & 1.19 \\
\hline 3 & A place for scientific research & 6.05 & {$[5.86,6.24]$} & 1.34 \\
\hline 2 & A tourist destinatinon & 5.86 & {$[5.67,6.06]$} & 1.37 \\
\hline 13 & A place that belongs to everyone & 5.78 & {$[5.55,6.00]$} & 1.62 \\
\hline 15 & a place without most types of human development & 5.64 & {$[5.41,5.87]$} & 1.66 \\
\hline 20 & a place without most types of commercial development & 5.63 & {$[5.37,5.89]$} & 1.87 \\
\hline 10 & A place to be away from other people & 5.38 & {$[5.16,5.60]$} & 1.56 \\
\hline 11 & A sacred place & 4.92 & {$[4.64,5.21]$} & 2.04 \\
\hline 21 & an economic resources & 4.78 & {$[4.52,5.04]$} & 1.88 \\
\hline 14 & A source of benefits to local communities & 4.71 & {$[4.44,4.97]$} & 1.89 \\
\hline 16 & A place for family or individual traditions & 4.51 & {$[4.21,4.81]$} & 2.14 \\
\hline 22 & a place to be free from society and its regulations & 4.48 & {$[4.20,4.77]$} & 2.03 \\
\hline 7 & A place for recreational activities & 4.15 & {$[3.89,4.10]$} & 1.81 \\
\hline 19 & a reserve of natural resources for use by local people & 3.76 & {$[3.47,4.05]$} & 2.06 \\
\hline 25 & A social place & 3.7 & {$[3.44,3.95]$} & 1.82 \\
\hline
\end{tabular}


with the interview data. According to the survey data, the most important value of Kruger is its role as a "protector of threatened and endangered species." Valuing the Park as "a place where the wildlife and plants of the region can live" came in a close second, though. Responses to both items exhibited relatively small standard deviations indicating that there was general agreement across all respondents that these two features of the Park were very important. Valuing the Park as "a place for a peaceful experience" and "as a symbol of South Africa's identity" also emerged as important values in the survey data, just as they did in the interview data.

While items related to wildlife, wildness, heritage, education, and scenic beauty were all characterized by high means and relatively small standard deviations, there were items that exhibited less importance and more disagreement. Valuing Kruger as "a social place" was the lowest valued item; the $95 \%$ confidence interval for the mean, in fact, is below the scale mid-point. Interestingly, the second most least-valued feature of Kruger among the twenty-five items was Kruger as a "reserve of natural resources for use by local people," where the upper bound of the $95 \%$ confidence interval for the mean barely exceeded the scale midpoint. While having the second lowest mean score, responses to the item had the second highest standard deviation with the average response being just over plus-or-minus two scale points from the mean, meaning that there was a relatively high level of disagreement concerning that item compared to the others. In the last latter part of this chapter, I will discuss in more depth how these values - expressed both qualitatively and quantitatively - related to Park visitors' perceptions of the legitimacy of resource use in the Park. 


\section{Park visitors and the substantive legitimacy of resource use}

In terms of both the interview and survey data, it was evident that the values visitors assigned to Kruger had an important bearing on their conceptualizations of legitimacy. Most significantly both sources of data illustrate that the wildlife and conservation values which figured strongly in the broader set of visitors' values, rendered resource use as illegitimate for most visitors I spoke with. For the minority of visitors who maintained that resource use would be a substantively legitimate activity in the Park, the judgment was grounded in the belief that local residents should reap benefits from the Park and that there is a responsibility to use resources, lest they be wasted. Having an important stake in the issue of resource use, these substantive considerations expressed by visitors are particularly important in the broader assessment of the legitimacy of resource use.

Interview data and qualitative survey data

The interviews I conducted with Park visitors and the comments offered in the visitor surveys provided for very diverse perspectives concerning the substantive legitimacy of resource use among local residents. In terms of both the interviews and visitors surveys, most of the data spoke to the substantive illegitimacy of resource use. There were a handful of visitors, though, that I spoke with or surveyed who felt that resource use would be a legitimate activity in the Park. A few visitors I interviewed commented that the Park is a place that people should be able to use, and that as V6161 suggests below, the failure to use resources in the Park would be a waste, 
People cannotget stuff from somewhere else. I think they should be able to come and get things on their own here. The Park should even provide some of those things. (V6261)

Yes, I think resource use is okay...This is a place that people can use, and they must come here. (V61612)

Definitely, [resource use] is good, but I think within the boundaries. They must not abuse it. If they do not use the resources, it will definitely disappear, because you have to use what nature gives you. But, you must not abuse it. (V6271)

I think that to conserve the nature, you have got to use what God has given you. And, if you do not use it, you're just going to waste it. (V6161)

One visitor I spoke with simply felt that because many resources outside the Park have been exhausted, allowing local residents to utilize resources from the Park is the responsible thing to do (provided they do not exhaust the resources in the Park),

I think allowing the people that live next to the Park to come in and use the resources is the responsible thing to do. From what I can tell, they've exhausted much of what they have, and it's just the right thing to do to let them come in and use the resources as long as they do not exhaust what's in here... I just think it's the right thing to do and that the people living around the Park are a part of the Park. (V6167)

Other visitors I spoke with or surveyed did not automatically assume that a Park is a place for resource use, but instead suggested that resource use in Kruger is legitimate if it provides opportunities for "empowerment" or generating income,

[Resource use] is appropriate, you must remember. Look on the eastern side; there is not so much on the side of Mozambique; it's on the South African side. You can look at night, and you will see lights that look like little cities next to the borderline. Those people are sitting there looking inward and looking at this and saying to themselves 'we do not have a part of this.' There is unused land. There is a lot of money to be made there, 
and we're not making it. So, they'll have to do something about it. I do not have a problem with it. They have to do something to get them involved and share in the riches we are generating, because we are generating riches here. I think it is a rational thing to do. Otherwise, you're going to have a build up of pressure and problems on that side. You'll have people coming in and hunting, and then you'll really have a big problem. (V6164)

If you're not uplifting the surrounding communities, then the areas that people have to travel through before they get to the Park can be in quite a bit of decline. Now, if you're uplifting the local communities, then those communities are worth more and they're something to look at when you come through. I think in that sense, [resource use] definitely goes more towards the community. But, if they need to cut grass down, they may as well let the communities use it. It's the same as supplying the craft shops with beadwork. They need to let the communities do it for community empowerment. (V6266)

It all depends also if you think of what [resources] are being collected for. Firewood, for instance - for what purpose? Is it for resale? I know some of the people will collect the wood, chop it up, and then sell it alongside the road to people like me. That, sometimes, is their only income, and I would say fine, then control it. Other people would say that they need firewood to do their own cooking for eating purposes, boiling water, or whatever. Then, I would say, consider something else as an alternative heat source. (V61611)

The comments of V6164 suggest they believe that resource use would be legitimate because by sharing resources with local residents, there would be less incentive to collect them illegally from the Park. V6164's discussion of how local residents look to the Park and recognize there is "money to be made there" is aligned with V61611's suggestion that resource use is legitimate to the extent that it provides for income generation - e.g., selling resources, such as firewood, that are collected from the Park - rather than meeting a direct need that local residents might have (e.g., using the firewood collected to heat their homes). 
Most of the visitors I spoke with were, at a minimum, skeptical of resource use. Most significantly, many visitors believed that resource use is contrary to the features of the Park for which it is most valued for (e.g., protecting wildlife, scenic beauty, etc.) and, perhaps more fundamentally, the very principles upon which the Park was founded

The changing of policies in favor of the local population on the border of Kruger is contradictory to the original ideas, spirit and aim of the founders. The benefit to the locals is definitely short term, the damages to the Park and risk for further exploitation are long term. (VS17)

Whilst uplifting the local community may be a consideration, one must consider the reason for establishing the Kruger Park in the first place. It was to protect flora and fauna. Neither I as a visitor or a member of the local community has the right to destroy that. (VS692)

The fundamental and organic purpose of the Park, then - rather than providing benefits is to protect the flora and fauna of the Park and guard against its exploitation and destruction. Resource use, according to some visitors, is counter to this objective. As other visitors commented, the provision of resource use would be tantamount to commercializing the Park and morphing its mission to social welfare rather than conservation,

Do not commercialize the Park. It is the same as making poaching legal. The Park was here first - not the people (VS92)

Kruger is a game reserve - not the department of social welfare. (VS695)

Despite the contestable validity of VS92's claim that the "Park was here first not the people," it was evident that many visitors held the same underlying sentiment that, at least in terms of priorities, the integrity of the Park far surpasses the welfare of local residents and that resource use would undermine the Park's most desirable features, 
We have to keep our Park sacred. Do not allow people to use it (VS150).

[Resource use] is inappropriate. No, we as a people do not look at a Park in that sense. We might as well close it up. Because the people they just abuse it at the end of the day. They do not look at after it, they would just abuse the Park in general. It's just totally against nature for them to do that. That's just how I feel about it. At this stage, the people come in illegally, and if they do collect stuff in the Park, it just a breaking of nature in general. The animals would move out, and everything would just die out, in general, because the humans tend to break it down... everything we touch. They need to keep people out in that sense. I'm 150\% against it. (V61610)

You know, I think what we love about this is that it is so natural, and it is so untouched, and unspoiled really. I believe that... I just do not think [resource use] should be allowed. I think it would spoil it... To me, doing that would mean that the animals would be poached or wiped out. It's the duty of the Park to protect the wildlife and its habitat. I just do not think it's a good idea. I just do not think it should be allowed. It's not consistent with what the Park should be doing. People are starving, so they're going to poach the animals and destroy the wildlife. I really do not see why we would need to allow that - it's ridiculous. Are not there other places where they could collect that stuff? It's just not a good idea... This is our place. We want to come and see everything here and to enjoy ourselves... (V6168)

I do not think [resource use] must happen, definitely not. Because they would ruin the atmosphere, the wildlife. I think it's not a good idea, definitely. (V62610)

[Resource use] is not appropriate because it is a wilderness area and it should be protected as such. It is a national Park and it's a heritage site, and it's one of the few that are unspoiled. It should remain unspoiled for the rest of the world to come and enjoy. It's one of the prime tourist attractions in the country, apart from the Western Cape. If people want to see wildlife, then they come to Kruger. I think it should be protected as such - the flora and the fauna. It should be protected for everyone to enjoy. If everybody is going to be allowed to come in... If indigenous people are going to come across the borders to come and plunder, be it for firewood, for thatch for their homes, or for food, poaching, then I think appropriate measures should be taken to stop that. That's what makes this place special - is that it is unspoiled. It's a National Park. (V6265) 
The Kruger Park must be kept a National Park - not a place for resources for local people on the western boundary. Take a look at what the local people have done on the eastern boundary. There is no wildlife. Where do you stop it? (VS540)

As evident in the excerpts above, underlying the belief that resource use would "spoil" the Park is a deeply-held mistrust of the local residents - that, left to their own volition in the Park, local residents would "abuse," "plunder," "poach," and "destroy" Park resources. The Park's "specialness" and "atmosphere," as a result, would, be irrevocably blemished. V6168 suggests above that the Park and its special features do not belong to the local residents and that, instead, "This is our place. We want to come and see everything here and to enjoy ourselves."

For some visitors, as V6168 rhetorically asks in the excerpt above, resource use is illegitimate because they believe there are "plenty of places" around the Park and throughout the country where resources could otherwise be collected,

I feel that resource use would have a devastating results on the ecology. We have a large country and plenty of places elsewhere for people to obtain their resources (VS174)

It just takes away from the Park. There is plenty of places around here where they can gather things. They must not come in here to get things. It needs to be kept in a pristine condition. [If resource use was allowed] I would not come back. Part of the beauty of this is that it is left in its natural format. The problem is that it is becoming far, far too commercialized as it is. I mean it was just fantastic before. It's a lifestyle. (V6273)

People have enough land as it is. They must use what they have more efficiently and stop thinking they have the right to use resources from a conserved area. Eventually, there will be no more boundaries to what they can take. (VS277) 
It is possible that some visitors, such as V6273, hold these beliefs so strongly that they would not return to the Park if resource use was permitted.

Beyond the impact that resource use might have on Kruger's character, some visitors posited that the provision and use of resources was a red herring distracting attention away from other, more constructive benefits or considerations,

Of course, the people in the area need to see some benefit coming out of the Park, but I think it should rather be out of tourism, though. It should rather be out of a levy where we build them homes and that type of thing. I think the Park should really be sacrosanct. I do not think anything should happen in the Park. (V6262)

Rather than simply allowing increased access to resources, local communities need to be educated as to the management of these resources in areas adjacent to where they live. The areas on the western borders are radically farmed, eroded, deforested, and badly managed. The local people need education rather than further land opportunity to exploit on an 'expectation value' system, rather than a 'responsibility' system. The education received by the locals does not always focus on sustainability and this is a serious issue throughout South Africa, not just around the Park. Allowing even managed access to plants, etc. is a form of permissible poaching in an area set aside for conservation. (VS151)

I do not think they should come to the Park at all. I do not think any of them should be coming to the Park. I think they must get out there and earn a living and not collect mopane worms - they should be more creative. (V6268)

For these visitors resource use is illegitimate because it does not serve what they believe to be more important and systemic issues (e.g., a lack of "creativity" or the need for "education") or that benefits could be more appropriately provided through tourism activities.

In summary, while some visitors did view resource use a legitimate activity on the basis of the Park's responsibility to the local residents or the assumption that not using 
resources would be a waste, most visitors I spoke with viewed resource use in the Park as illegitimate. Most notably, many visitors maintained that the provision of resources would undermine the fundamental purposes (e.g., protection of the Park's flora and fauna) the Park was founded upon and serves. Moreover, resource use was also viewed as inappropriate, since some visitors believed that the resources of interest could be gathered from elsewhere. Finally, as discussed above, others felt that local residents would be better served through education, tourism revenue, or becoming "more creative" in mechanisms they employ to meet their needs. In the next subsection, I continue to explore the rationales that contributed to visitors' perceptions of the substantive legitimacy of resource use, but do so from the perspective of the survey data I collected.

Survey data

The survey data are generally aligned with the interview data, suggesting that most respondents did not view resource use as a legitimate activity in the Park. Of the 257 visitors who responded to survey question 11(a), which reads,

If managed by Kruger National Park, should people living near the western boundary of the Park be allowed to collect resources from the Park that are not endangered or rare (e.g., firewood, thatch grass, some medicinal plants, etc.)? (see Appendix 1),

27.2\% responded "Yes," resource use should be allowed, and 72.8\% responded "No," resource use should not be allowed. ${ }^{45}$ Interestingly, though, as Table 9-2 illustrates, there

\footnotetext{
${ }^{45}$ In terms of responses by population group, $86.7 \%(\mathrm{n}=13)$ of black visitors felt that resource use should be prohibited compared to $72.4 \%(n=168)$ of white visitors. However, because of the small number of black visitors surveyed, it was not possible to identify any differences with statistical significance.
} 
was a statistically significant difference in the way international visitors responded to the question compared to South African visitors. International visitors were more than twice

Table 9-2: Should resource use be allowed in Kruger? (survey question 11(a))

\begin{tabular}{lcc}
\hline Nationality & No & Yes \\
\hline South African visitors & 132 & 31 \\
& $(81.0 \%)$ & $(19.0 \%)$ \\
International visitors & 55 & 39 \\
& $(58.5 \%)$ & $(41.5 \%)$ \\
Total & 187 & 70 \\
\hline$\chi^{2}=15.19 ; \mathrm{df}=1 ; \mathrm{p}<.001$ & $(72.7 \%)$ & $(27.3 \%)$ \\
\hline
\end{tabular}

Note: Percentages in parentheses represent within-group percentages

as likely to believe that resource use should be allowed (41.5\%) than South African visitors $(19.0 \%)$.

To identify how various rationales or considerations influenced visitor perceptions of the legitimacy of resource use among local residents in Kruger, visitors were asked to respond to eleven resource-use-related scale items (see survey question 9 in Appendix 1). The scale items were derived from qualitative data obtained from Park

Table 9-3: Descriptive statistics for resource-use scale items (survey question 9) Likert-type scale: 1 - "strongly disagree" to 7 - "strongly agree"

\begin{tabular}{lllcl}
\hline Item ID Resource use scale items & Mean $\begin{array}{c}95 \% \\
\text { Confidence } \\
\text { Interval }\end{array}$ & $\begin{array}{l}\text { Standard } \\
\text { Deviation }\end{array}$ \\
\hline
\end{tabular}




\begin{tabular}{|c|c|c|c|c|}
\hline 1 & $\begin{array}{l}\text { Kruger National Park (Kruger NP) is an area that should } \\
\text { remain pristine with as little human impact as possible. }\end{array}$ & 6.44 & {$[6.28,6.60]$} & 1.13 \\
\hline 3 & $\begin{array}{l}\text { Allowing people living near Kruger NP to gather } \\
\text { resources from the Park should not be allowed if there } \\
\text { are other places where they can gather those resources. }\end{array}$ & 6.09 & {$[5.85,6.32]$} & 1.66 \\
\hline 10 & $\begin{array}{l}\text { Resource use would disturb the wild or natural features } \\
\text { of Kruger NP. }\end{array}$ & 6.06 & {$[5.83,6.28]$} & 1.6 \\
\hline 5 & $\begin{array}{l}\text { Policies and strategies for managing Kruger NP should } \\
\text { not change over time. }\end{array}$ & 4.27 & {$[3.95,4.59]$} & 2.28 \\
\hline 4 & $\begin{array}{l}\text { Access to resources in Kruger NP should only be granted } \\
\text { to people living near the Park when the law requires that } \\
\text { it be granted. }\end{array}$ & 4.01 & {$[3.65,4.36]$} & 2.54 \\
\hline 2 & $\begin{array}{l}\text { For conservation to be effective, Kruger NP, resources } \\
\text { (such as firewood, thatching grass, etc.) must be used } \\
\text { occasionally. }\end{array}$ & 3.88 & {$[3.59,4.18]$} & 2.12 \\
\hline 11 & $\begin{array}{l}\text { Resource use is acceptable because Kruger NP must } \\
\text { experiment with different ways of conserving and using } \\
\text { natural resources. }\end{array}$ & 2.93 & {$[2.65,3.21]$} & 2 \\
\hline 6 & $\begin{array}{l}\text { Allowing people living near Kruger NP to gather } \\
\text { resources from the Park is rational if the Park has many } \\
\text { resources. }\end{array}$ & 2.85 & {$[2.58,3.13]$} & 1.97 \\
\hline 8 & $\begin{array}{l}\text { Allowing people living near Kruger NP to gather } \\
\text { resources from the Park is a good idea if it will improve } \\
\text { the lives of people living near the Park. }\end{array}$ & 2.85 & {$[2.57,3.13]$} & 2.02 \\
\hline 7 & $\begin{array}{l}\text { If laws state that access to Park resources must be } \\
\text { granted to people living near Parks, then resource use by } \\
\text { people living near Parks would be appropriate. }\end{array}$ & 2.82 & {$[2.54,3.10]$} & 2.02 \\
\hline 9 & $\begin{array}{l}\text { It is morally right to allow people living near Kruger NP } \\
\text { to have access to resources within the Park. }\end{array}$ & 2.33 & {$[2.07,2.59]$} & 1.85 \\
\hline
\end{tabular}

staff, Park visitors, and local residents. Visitors were asked to indicate the extent to

which they agreed (on a seven-point likert-type scale) with statements such as,

For conservation to be effective in Kruger NP, resources (such as

firewood, thatching grass, etc.) must be used occasionally, and

Allowing people living near Kruger NP to gather resources from the Park is a good idea if it will improve the lives of people living near the Park. 
Displayed in Table 9-3 are descriptive statistics for the responses to these nine items. Consistent with the values visitors placed on Kruger, the scale item with the highest level of agreement (both in terms of a high mean and relatively low standard deviation) was the statement, "Kruger Natioanl Park (Kruger NP) is an area that should remain pristine with as little human impact as possible." Moreover, just as little value was placed on Kruger as "a reserve of resources for use by local people" (see survey question 7), the mean scores for the resource-use scale items that provided justification for resource use (e.g., "it is morally right to allow people living near Kruger NP to have access to resources within the Park") were all below the mid-point, indicating that, on average, respondents disagreed with the statements that justified resource use.

In order to identify how the various considerations described in the resource-use scale influenced visitors' perceptions of the substantive legitimacy of resource use, the scale items were employed as independent variables in a logistic regression model with the response to survey question 11(a) ("should resource use be allowed?") serving as the dependent variable (see Table 9-4). In this "full" model, with all eleven items included as independent variables, only three had statistically significant regression coefficients. Upon inspecting a correlation table for these eleven variables (see Table 9-5), it seems likely that the high number of insignificant coefficients was most likely attributed to multicollinearity among the items. Because multicollinearity inflates the variance of the Table 9-4: Logistic regression results for resource-use scale items (survey question 9) with question 11(a) as dependent variable

\begin{tabular}{cccc}
\hline $\begin{array}{c}\text { Item } \\
\text { no. }\end{array}$ & Resource use scale items & Coef. & Standard Error \\
\hline
\end{tabular}


Allowing people living near Kruger NP to gather resources from the Park is a good idea if it will improve the lives of people

For conservation to be effective, Kruger NP, resources (such as

Allowing people living near Kruger NP to gather resources from the Park should not be allowed if there are other places where

3 they can gather those resources.

Policies and strategies for managing Kruger NP should not

5 change over time.

Allowing people living near Kruger NP to gather resources from

Resource use would disturb the wild or natural features of

Resource use is acceptable because Kruger NP must experiment

Access to resources in Kruger NP should only be granted to people living near the Park when the law requires that it be granted.

Kruger National Park (Kruger NP) is an area that should remain

If laws state that access to Park resources must be granted to people living near Parks, then resource use by people living near

Likelihood Ratio: 150.17; df=11; $p<.00009$; pseudo $\mathrm{R}^{2}=0.72$

\section{* Significant at the $p<.05$ level.}


parameter estimates and, in effect, results in a less precise model, a "restricted" model was analyzed that included only three of the eleven scale items:

Item 3: Allowing people living near Kruger NP to gather resources from the Park should not be allowed if there are other places where they can gather those resources.

Item 5: Policies and strategies for managing Kruger NP should not change over time.

Item 8: Allowing people living near Kruger NP to gather resources from the Park is a good idea if it will improve the lives of those living near the Park.

These three items were selected because they were statistically significant in the full model, they had the strongest effects on the dependent variable in the full model, and the remaining eight items were all highly correlated with one or more of the three items selected.

As illustrated in Table 9-6, the strongest or most influential effect in the determination of whether or not resource use should be allowed was Item 8, which posited that resource use "is a good idea if it will improve the lives of those living near the Park." The effect of this item was more than three times as influential as the other two, which both had a negative effect on the response as to whether or not resource use should be allowed. In other words, agreeing with the two statements "allowing people living near Kruger NP to gather resources from the Park should not be allowed if there are other places where they can gather those resources" and "policies and strategies for managing Kruger NP should not change over time" tended to imply that a respondent would indicate that resource use should not be allowed. 
Table 9-5: Correlations for resource use scale items

Correlations

\begin{tabular}{|c|c|c|c|c|c|c|c|c|c|c|c|c|}
\hline & & $\begin{array}{l}\text { Little human } \\
\text { impact }\end{array}$ & $\begin{array}{c}\text { Occasional } \\
\text { use }\end{array}$ & $\begin{array}{c}\text { Other places } \\
\text { to use }\end{array}$ & $\begin{array}{l}\text { Law } \\
\text { requires it }\end{array}$ & $\begin{array}{l}\begin{array}{l}\text { No change } \\
\text { in policies }\end{array} \\
\end{array}$ & $\begin{array}{c}\text { Park has } \\
\text { many } \\
\text { resources }\end{array}$ & $\begin{array}{c}\text { Laws state it } \\
\text { must be } \\
\text { granted }\end{array}$ & $\begin{array}{l}\text { Improve } \\
\text { the lives } \\
\text { of people }\end{array}$ & Morally right & $\begin{array}{c}\text { Disturb wild } \\
\text { or natural }\end{array}$ & $\begin{array}{c}\text { Kruger must } \\
\text { experiment }\end{array}$ \\
\hline \multirow[t]{3}{*}{ Little human impact } & Pearson Correlation & 1 & $-.167^{\star \star *}$ & $.572^{\star \star}$ & -.078 & $.200^{\star \star}$ & $-.342^{\star \star}$ & $-.443^{\star \star}$ & $-.463^{\star \star}$ & $-.405^{\star \star}$ & $.509^{\star \star}$ & $-.285^{\star}$ \\
\hline & Sig. (2-tailed) & & .008 & .000 & .227 & .001 & .000 & .000 & .000 & .000 & .000 & .000 \\
\hline & $\mathrm{N}$ & 262 & 250 & 253 & 239 & 250 & 248 & 242 & 253 & 248 & 248 & 254 \\
\hline \multirow[t]{3}{*}{ Occasional use } & Pearson Correlation & $-.167^{\star *}$ & 1 & $-.164^{* \star}$ & $.283^{* *}$ & $-.214^{* \star}$ & $.519^{* *}$ & $.476^{* \star}$ & $.499^{* \star}$ & $.450^{* \star}$ & $-.244^{* *}$ & $.511^{\star}$ \\
\hline & Sig. (2-tailed) & .008 & . & .010 & .000 & .001 & .000 & .000 & .000 & .000 & .000 & .000 \\
\hline & $\mathrm{N}$ & 250 & 257 & 247 & 235 & 247 & 245 & 238 & 247 & 244 & 245 & 250 \\
\hline \multirow[t]{3}{*}{ Other places to use } & Pearson Correlation & $.572^{\star \star}$ & $-.164^{\star *}$ & 1 & .007 & $.254^{\star *}$ & $-.305^{\star \star}$ & $-.469^{* \star}$ & $-.416^{* *}$ & $-.451^{* *}$ & $.507^{\star \star}$ & $-.305^{\star}$ \\
\hline & Sig. (2-tailed) & .000 & .010 & & .914 & .000 & .000 & .000 & .000 & .000 & .000 & .000 \\
\hline & $\mathrm{N}$ & 253 & 247 & 258 & 235 & 247 & 248 & 238 & 251 & 246 & 247 & 253 \\
\hline \multirow[t]{3}{*}{ Law requires it } & Pearson Correlation & $\begin{array}{l}.078 \\
\end{array}$ & $283^{* *}$ & .007 & 1 & .000 & $.358^{* *}$ & $.422^{* *}$ & $.307^{* *}$ & $.258^{* *}$ & -.110 & $.221^{\star}$ \\
\hline & Sig. (2-tailed) & .227 & .000 & .914 & . & .995 & .000 & .000 & .000 & .000 & .095 & .001 \\
\hline & $\mathrm{N}$ & 239 & 235 & 235 & 245 & 241 & 235 & 233 & 236 & 231 & 233 & 240 \\
\hline \multirow[t]{3}{*}{ No change in policies } & Pearson Correlation & $.200^{\star *}$ & $-.214^{* \star}$ & $.254^{\star *}$ & .000 & 1 & $-.331 * \star$ & $-.307^{\star \star}$ & $-.280 * \star$ & $-.311^{\star \star}$ & $.316^{\star \star}$ & $-.186^{\star}$ \\
\hline & Sig. (2-tailed) & .001 & .001 & .000 & .995 & . & .000 & .000 & .000 & .000 & .000 & .003 \\
\hline & $\mathrm{N}$ & 250 & 247 & 247 & 241 & 257 & 246 & 238 & 248 & 242 & 244 & 251 \\
\hline \multirow[t]{3}{*}{ Park has many resources } & Pearson Correlation & $-.342 * *$ & $.519^{* \star}$ & $-.305^{\star *}$ & $.358^{* *}$ & $-.331^{* *}$ & 1 & $.649^{\star \star}$ & $.733^{* *}$ & $.683^{* *}$ & $-.410 * *$ & $.576^{*}$ \\
\hline & Sig. (2-tailed) & .000 & .000 & .000 & .000 & .000 & . & .000 & .000 & .000 & .000 & .000 \\
\hline & $\mathrm{N}$ & 248 & 245 & 248 & 235 & 246 & 253 & 239 & 248 & 244 & 243 & 251 \\
\hline \multirow{3}{*}{$\begin{array}{l}\text { Laws state it must be } \\
\text { granted }\end{array}$} & Pearson Correlation & $-.443^{* *}$ & $.476^{* *}$ & $-.469 *$ & $.422^{* *}$ & $-.307^{\star *}$ & $.649^{* *}$ & 1 & $.833^{* *}$ & $.777^{\star *}$ & $-.469 * *$ & $.640^{*}$ \\
\hline & Sig. (2-tailed) & .000 & .000 & .000 & .000 & .000 & .000 & . & .000 & .000 & .000 & .000 \\
\hline & $\mathrm{N}$ & 242 & 238 & 238 & 233 & 238 & 239 & 245 & 241 & 237 & 233 & 242 \\
\hline \multirow{3}{*}{$\begin{array}{l}\text { Improve the lives of } \\
\text { people }\end{array}$} & Pearson Correlation & $-.463^{* \star}$ & $.499^{* \star}$ & $-.416^{* \star}$ & $.307^{* \star}$ & $-.280^{\star \star}$ & $.733^{* *}$ & $.833^{* *}$ & 1 & $.829^{* *}$ & $-.499 * \star$ & $.679^{*}$ \\
\hline & Sig. (2-tailed) & .000 & .000 & .000 & .000 & .000 & .000 & .000 & . & .000 & .000 & .000 \\
\hline & $\mathrm{N}$ & 253 & 247 & 251 & 236 & 248 & 248 & 241 & 258 & 249 & 247 & 254 \\
\hline \multirow[t]{3}{*}{ Morally right } & Pearson Correlation & $-.405^{\star \star}$ & $.450^{* *}$ & $-.451^{\star *}$ & $.258^{* *}$ & $-.311^{\star \star}$ & $.683^{* *}$ & $.777^{\star \star}$ & $.829^{* \star}$ & 1 & $-.546^{\star *}$ & $.588^{\star}$ \\
\hline & Sig. (2-tailed) & .000 & .000 & .000 & .000 & .000 & .000 & .000 & .000 & . & .000 & .000 \\
\hline & $\mathrm{N}$ & 248 & 244 & 246 & 231 & 242 & 244 & 237 & 249 & 253 & 243 & 249 \\
\hline \multirow[t]{3}{*}{ Disturb wild or natural } & Pearson Correlation & $.509^{\star \star}$ & $-.244^{* *}$ & $.507^{\star *}$ & -.110 & $.316^{\star \star}$ & $-.410 * \star$ & $-.469^{\star \star}$ & $-.499 * *$ & $-.546 * \star$ & 1 & $-.338^{*}$ \\
\hline & Sig. (2-tailed) & .000 & .000 & .000 & .095 & .000 & .000 & .000 & .000 & .000 & . & .000 \\
\hline & $\mathrm{N}$ & 248 & 245 & 247 & 233 & 244 & 243 & 233 & 247 & 243 & 255 & 250 \\
\hline \multirow[t]{3}{*}{ Kruger must experiment } & Pearson Correlation & $-285^{* *}$ & $.511^{* *}$ & $-.305^{\star *}$ & $.221^{\star *}$ & $-.186^{\star *}$ & $.576^{\star \star}$ & $.640^{* \star}$ & $.679^{\star \star}$ & $.588^{\star \star}$ & $-.338^{* *}$ & 1 \\
\hline & Sig. (2-tailed) & .000 & .000 & .000 & .001 & .003 & .000 & .000 & .000 & .000 & .000 & . \\
\hline & $\mathrm{N}$ & 254 & 250 & 253 & 240 & 251 & 251 & 242 & 254 & 249 & 250 & 261 \\
\hline
\end{tabular}

${ }^{* \star}$. Correlation is significant at the 0.01 level (2-tailed). 
At the mean for Item 8 (2.85) which had the most substantial influence in legitimating resource use, the probability of responding "Yes" to whether or not resource use should be allowed was 0.11 . Increasing that value by 1 unit (i.e., to 3.85) increased the probability of responding "Yes" to 0.23 . At the means of the two items which had a negative effect on respondents' determination of whether or not resource use should be allowed, the probability of responding "Yes" was 0.23 for Item 3 and 0.24 for Item 5. An increase from the mean of one unit decreased the probability of responding "Yes" to whether or not resource use should be allowed by 0.10 and 0.08 , respectively.

Table 9-6: Restricted logistic regression model for resource use scale with question 11(a) as the dependent variable

\begin{tabular}{lcccc}
\hline \multicolumn{1}{c}{ Item } & Coef. $\begin{array}{c}\text { Standard } \\
\text { error }\end{array}$ & $\begin{array}{c}\text { Probability of } \\
\text { responding } \\
\text { "Yes" at the } \\
\text { mean }\end{array}$ & $\begin{array}{c}\text { Marginal } \\
\text { effect at the } \\
\text { mean }\end{array}$ \\
\hline $\begin{array}{l}\text { Item 3: Allowing people living near } \\
\text { Kruger NP to gather resources from } \\
\text { the Park should not be allowed if } \\
\text { there are other places to where they } \\
\text { can gather those resources. }\end{array}$ & -0.43 & 0.16 & 0.23 & -0.10 \\
$\begin{array}{l}\text { Item 5: Policies and strategies for } \\
\text { managing Kruger NP should not } \\
\text { change over time. }\end{array}$ & -0.53 & 0.15 & & \\
$\begin{array}{l}\text { Item 8: Allowing people living near } \\
\text { Kruger NP to gather resources from } \\
\text { the Park is a good idea if it will } \\
\text { improve the lives of those living near } \\
\text { the Park. }\end{array}$ & 1.48 & 0.23 & & -0.08 \\
\hline
\end{tabular}


A synthesis of the interview and survey data

Taken together, the interview and survey data provide rich insight into visitors' perceptions of the substantive legitimacy of resource use. Based on both the interview and survey data, those who viewed resource use as a legitimate activity in the Park while in the minority (particularly among South African visitors) - frequently held that belief because they perceived resource use as a valid tool if it improved the lives of local residents or they felt that it was morally responsible to provide access to resources. The majority of visitors, though, did not believe that resource use should be allowed and that it is an illegitimate activity in the Park. For these visitors, the primary consideration was the assumption that resource use would spoil the pristine character of the Park and undermine efforts to protect the flora and fauna of the Park. While perhaps secondary, both the interview data and survey data, indicate that resource use might be viewed as an illegitimate activity if there are areas other than the Park where resources can be collected. In the next section, again employing both interview and survey data, I explore the rationales that contributed to Park visitors' views concerning the procedural legitimacy of resource use.

\section{Park visitors and the procedural legitimacy of resource use}

As discussed in terms of the Park staff and local residents, the substantive legitimacy of resource use - the rightness of principles upon which resource use is based - is only one part of the broader conceptualization of the legitimacy of resource use. The

process through which a policy or approach to resource use is crafted and/or implemented 
also plays an important role in the overall perception of legitimacy. In this sub-section, I discuss Park visitors' thoughts on the procedural considerations associated with resource use in Kruger. I do not, however, offer separate discussions of the interview and survey data, though, since only one question concerning procedural considerations was posed in the survey (survey question 11(b)). ${ }^{46}$

The one procedurally-oriented question that appeared in the survey presented visitors with the question,

Should the managers of Kruger National Park decide among themselves how and what resources will be gathered, or should people living near the Park help decide how and what resources will be gathered? (see survey question 11(b), Appendix 1)

Of the 244 visitors who responded to the question, $187(68.5 \%)$ believed that only manages should decide. As with question 11(a), though, which asked visitors if resource use should be allowed, there was a statistically significant difference in how South African visitors responded ( $18.8 \%$ believing local residents should help decide) compared to international visitors ( $31.1 \%$ believing local residents should help decide) (See Table 9-7).

Only a few visitors I interviewed commented on the decision-making process associated with resource use. One visitor, consistent with some of the visitor responses concerning the substantive legitimacy of resource use, felt that if decisions and the

\footnotetext{
${ }^{46}$ A separate discussion of interview and survey data was presented in the sub-section regarding the substantive legitimacy of resource use because the resource-use scale was substantively oriented. As such, it was possible to employ analytic techniques such as logistic regression using question 11(a) as a dependent variable. Because of space limitations in the survey, a procedurally-oriented scale was not developed. However, the question of who should decide how and what resources should be gathered was put forward to the visitors surveyed in question 11(b).
} 
Table 9-7: Who should decide how and what Resources will be gathered? (survey question 11(b))

\begin{tabular}{lcc}
\hline Nationality & $\begin{array}{c}\text { Only } \\
\text { managers }\end{array}$ & $\begin{array}{c}\text { People living } \\
\text { near the Park } \\
\text { help }\end{array}$ \\
\hline South African visitors & 121 & 28 \\
& $(81.2 \%)$ & $(18.8 \%)$ \\
International visitors & 62 & 28 \\
\hline Total & $(68.9 \%)$ & $(31.1 \%)$ \\
\hline$\chi^{2}=4.76 ; \mathrm{df}=1 ; \mathrm{p}<.05$ & 183 & 56 \\
\hline
\end{tabular}

Note: Percentages in parentheses represent within-group percentages

management of resource use were not left to Park staff, then Kruger would be "destroyed,"

Let us not start building \destroying this one very special place. Leave the management of the Park to the conservationists who I am sure would be qualified to retain its natural beauty (VS60)

Other visitors I spoke with, though, believed that it would be beneficial to involve local residents, since doing so might engender a sense of appreciation and a better understanding of how resource use can be implemented in a sustainable way, I think it is quite important, though, for people living around here to be involved in this. Otherwise, they will not appreciate it and want to protect it. (V824)

Not only will they become aware of what's inside the Park, but they'll also know how to conserve it, as well. I think that, in a sense, they will be 
monitored as to what they take out of the Park. They'll understand the benefits they can get from it and not over-utilize it. (V823)

When most of the visitors I interviewed spoke about processes associated with resource use, they discussed the process of implementing resource use rather than who should be involved in the decision-making process. Perhaps most important to the visitors I spoke with was ensuring that monitoring programs and controls were in place to prevent the over-utilization of resources,

Well, I don' think it matters... All things... I think If you overdo it, let me put it that way, it will have impact. If you do not do it, in other words, because man has already intervened, that might have an impact, as well. So, you need to manage it carefully and make sure that you keep a balance. I think as long as you do not disturb the ecological balance to such an extent that is more harmful than good, then [resource use] is okay... If you control it and manage it correctly, then I'm good. Yeah, I think if you manage it correctly, then why not. (V6161)

I think [resource use] is fine, but if it is limited. I think it would ruin the Park if you saw people harvesting all over the show. The sad thing is that it then opens the Park up to other illegal uses. Once the people are in, they have to be monitored all the time. It becomes very, very expensive to make sure that they're only doing what they're supposed to do. If one's certain that they're only going to take the Mopane worms and the grass great. But, who knows what they might actually do. That's the danger of that. So, I think that it would have to be limited to certain areas only. (V6262)

Allowing locals to use materials from the Park would not necessarily be a bad thing provided it is closely monitored and managed correctly. If it affects the wildlife, flora, and fauna, it should be halted immediately and leave it up to nature to fix. (VS115)

I think that [resource use] is fine as long as they do it in a sustainable way. The last thing I would want is for the Park to allow people to come in and utilize resources and then destroy the bush. (V6167) 
While the visitors excerpted above were not opposed to resource use, provided it is monitored and carried out in a sustainable way, many visitors, as discussed earlier, did not believe that local residents would be effectively controlled as they collect resources and would only "plunder" and "poach" resources.

Kruger's staff will not likely implement any broad-scale resource use policy without first running pilot projects and adaptively modifying use levels in response to demands and impacts on the natural environment. For one visitor I spoke with, an adaptive approach is critical to the process of developing and implementing a resource use policy,

Kruger must be proactive by implementing a test program. This test will allow the impact to be studied and controlled by Park conservation professionals. The data can be used to shape any future laws in the best interests of the Park. The best scenario is to avoid having laws passed by lawmakers which do not fully understand the impact of their decisions. I have confidence that Kruger officials are the best persons to formulate resource sharing policies. (VS796)

Both the interview and survey data I collected suggest that most visitors who provided their thoughts on the procedural considerations associated with resource use felt that a legitimate approach would be characterized by Park staff retaining decision-making authority and implementing monitoring programs if resource use were permitted. A minority of the visitors who shared their thoughts felt that it would be beneficial to involve local residents in the decision-making process, since, for example, it might give rise to an appreciation of the resources in question that might ultimately motivate visitors to practice resource use in a sustainable way. 


\section{An overview of Park visitor conceptualizations of the legitimacy of resource use}

Displayed in Figure 9-1 is a mapping of Park visitors' conceptualizations of the legitimacy of resource use. As discussed above, the value that visitors place on the protection of the Park's flora and fauna, the pristine character of Kruger, its symbolic values, and the opportunities for a peaceful and relaxing experience have a considerable impact on visitors' perceptions of the legitimacy of resource use. Many visitors, for instance, discussed in detail how resource use undermines these values of the Park and that, as a result, resource use would be an inappropriate or illegitimate activity. The assumption that local residents could not be trusted to use resources in a sustainable manner was also a substantively illegitimating consideration for Park visitors. Finally, some visitors I interviewed believed that resource use was not legitimate because other benefits (e.g., infrastructure development) would be more beneficial to local residents.

A minority of the visitors I interviewed and surveyed believed that resource use was a legitimate activity in the Park. Some visitors, for instance, believed that resources must be used because they would otherwise "disappear" or "go to waste" Others felt that the Park had a moral responsibility to provide benefitis to local residents. Finally, some visitors thought resource use to be a legitimate activity provided it resulted in community empowerment or was a means to generate income.

Procedurally speaking, most of the visitors surveyed indicated that the decision of what and how resources should be used is best left entirely to Park staff rather than being informed, in part, by local residents. Some visitors, though, did believe that local residents should be involved in the decision-making process, and interviews with visitors 
indicated that the development of an appreciation for the resources might be a factor influencing why some visitors felt this way. Most of the interview data concerning the procedural elements of resource use were related to implementation and suggested that an important legitimating factor would be the creation of strong controls and monitoring programs.

The data I collected, whether through interviews or surveys, provided a nuanced look at how different groups conceptualize the legitimacy of resource use. Fundamental to the perceptions of legitimacy that Park staff, local residents, and Park visitors held were the values they assigned to Kruger and the contextual elements that defined both historic and contemporary relationships between the Park and its local residents. In terms of the Park staff, their organizational values gave rise to the belief among some that resource use was a morally responsible service to the local residents that might, in turn, ultimately help in forging better relationships between the Park and local residents. Some staff countered that the organizations values implied the important moral duty in question was to protect the Park from any activities - such as resource use - that might degrade the Park's integrity and undermine the interests the Park was established to serve. Beyond illustrating that, from a structural perspective, similar ethoi might be employed in both the legitimation and illegitimation of resource use, the Park staffs' conceptualizations of legitimacy also demonstrate that the line between elemental considerations (e.g., morality and pragmatism) cannot always be clearly drawn. In other words, what might ostensibly be moral considerations are sometimes expressed contingent upon the consequences of that morality. 
Another important lesson learned from the data is that generalizations regarding conceptualizations of legitimacy are not easily made. While one might initally expect that local residents, often in dire need for resources, would almost always view resource use as a legitimate activity, this assumption was by no means valid. Many local residents I spoke with simultaneously expressed a need for resources but viewed the collection and use of those resources from the Park as an illegitimate activity, because doing so would undermine their long-term and more important interests that hinge upon the preservation of resources in the Park.

Given the exceptionally diverse conceptualizations of the legitimacy of resource use, which might often be conflicting or competing (both within and between groups), the most important question at hand is how those conceptualizations will be reconciled. In the next Chapter, I turn to this very question. As I will discuss, notwithstanding the diversity of views, the underlying values and factors that give rise to those views might provide for a resolution to the resource use issue that is held to be legitimate by Park staff, local residents, and Park visitors alike. 


\section{CHAPTER 10}

\section{TOWARDS A RESOLUTION OF THE RESOURCE USE ISSUE IN KRUGER NATIONAL PARK}

\section{Introduction}

Resource use, like any other complex issue that parks and other protected areas are confronted with, is characterized by competing and/or conflicting views concerning its legitimacy. But, as Table 10-1 illustrates, there were also commonalities in the way Park staff, local residents, and Park visitors conceptualized the legitimacy of resource. Resolving contested, nuanced issues such as resource use is by no means a trivial task. Nevertheless, reflecting on how different groups conceptualize the legitimacy of resource use and how resource use fits within the broader collection of benefits that are of interest to local residents might offer considerable insight into understanding how the issue might be resolved.

From the perspective of the Park staff that I interviewed, resource use was substantively legitimated on the grounds that providing access (1) would be a strategic tool to fulfill their mandate to "provide human benefits" and "build constituencies" or (2) would be one way of meeting a moral obligation to provide benefits. In either case, it is conceivable that benefits other than access to resources could be provided in order to meet these objectives. This is, perhaps, an especially important observation when considering that some Park staff were passionately opposed to the principle of resource use because (1) it might threaten the Park's biodiversity, (2) the belief that resource use is 
Table 10- 1: Conceptualizing the legitimacy of resource use - a summary

\begin{tabular}{|c|c|c|c|}
\hline & Kruger staff & Local residents & Park visitors \\
\hline Values & $\begin{array}{l}\text { corporate and } \\
\text { conservation values, } \\
\text { park mandates, park } \\
\text { objectives }\end{array}$ & $\begin{array}{l}\text { historic context, } \\
\text { nature conservation, } \\
\text { income generator, } \\
\text { employment, } \\
\text { Education, Kruger } \\
\text { as the "Gold Rock" }\end{array}$ & $\begin{array}{l}\text { protector of flora } \\
\text { and fauna, pristine } \\
\text { character, symbolic } \\
\text { values, peacefulness } \\
\text { and relaxing }\end{array}$ \\
\hline \multicolumn{4}{|l|}{$\begin{array}{l}\text { Substantive } \\
\text { considerations }\end{array}$} \\
\hline $\begin{array}{r}\text { Legitimating } \\
\text { rationales }\end{array}$ & $\begin{array}{l}\text { fulfilling a mandate, } \\
\text { moral responsibility, } \\
\text { strategic tool }\end{array}$ & $\begin{array}{l}\text { entitlement to } \\
\text { resources, } \\
\text { pragmatic need for } \\
\text { resources, the } \\
\text { resource gradient }\end{array}$ & $\begin{array}{l}\text { resources must be } \\
\text { used not wasted, } \\
\text { moral responsibility, } \\
\text { empowering local } \\
\text { residents }\end{array}$ \\
\hline $\begin{array}{r}\text { Illegitimating } \\
\text { rationales }\end{array}$ & $\begin{array}{l}\text { moral responsibility, } \\
\text { need for precaution, } \\
\text { inability to meet } \\
\text { demands }\end{array}$ & $\begin{array}{l}\text { prioritizing nature } \\
\text { conservation over } \\
\text { resource utilization }\end{array}$ & $\begin{array}{l}\text { undermines the } \\
\text { value of the Park, } \\
\text { cannottrust local } \\
\text { residents, other } \\
\text { benefits are better }\end{array}$ \\
\hline \multicolumn{4}{|l|}{$\begin{array}{l}\text { Procedural } \\
\text { considerations }\end{array}$} \\
\hline Legitimating factors & $\begin{array}{l}\text { consultation over } \\
\text { co-management }\end{array}$ & $\begin{array}{l}\text { Park must want } \\
\text { input of local } \\
\text { residents and } \\
\text { understand their } \\
\text { thoughts, needs, } \\
\text { problems, and } \\
\text { expectations }\end{array}$ & $\begin{array}{l}\text { park managers } \\
\text { decide and resource } \\
\text { use should be } \\
\text { monitored }\end{array}$ \\
\hline
\end{tabular}

a morally unacceptable activity in a national park, or (3) that access could not be provided at a level to meet the demand for resources. For Park staff, then, while the judgment that resource use was a legitimate activity was not a function of the act of resource use per se (i.e., it was a function of broader objectives to provide benefits more 
generally), resource use was viewed as illegitimate precisely as a result of its potential, substantive consequences.

At least from the perspective of Park staff, then, an important question is whether or not a particular benefit or set of benefits (that might not even include access to resources) can be provided to local residents that would meet the objectives of those staff who viewed resource use as a legitimate activity while also minimizing the concerns expressed by those who viewed it as illegitimate. Understanding how local residents conceptualize the legitimacy of and prioritize resource use provides some insight into responding to this question. Several local residents, for instance, did not view resource use as a legitimate activity, because they felt it would have a negative impact on the Park and ultimately undermine more important benefits derived from the Park (e.g., employment and tourism opportunities). And, while it was evident that most local residents viewed resource use as a legitimate activity because they had a pragmatic need for resources, the need for resources, as I discuss below, was not as immediate as broader developmental needs. Consequently, it seems likely that from both the perspective of Park staff and local residents, the provision of access to resources could be supplanted by a different set of benefits (e.g., developmental assistance) and effectively (if not more effectively) satisfy the interests and needs of local residents and Park staff. At the same time, access to resources might still be legitimately (from the perspective of Park staff and local residents) provided to local residents if it were done in a small-scale and experimental way (to address the concerns that some staff had regarding potential impacts). Such a provision, though, might need to be coupled with the provision of other 
benefits if both the local residents broader needs and interests are to be met and the Park's objective to "build a constituency" is to be achieved.

The views of Park visitors - who are also impacted by resource use - are consistent with these observations. As discussed in Chapter 9, only $27.3 \%$ of the visitors surveyed felt that resource use should be allowed in the Park. When asked, though, "Should the Park provide any other types of benefits to people living near the western boundary of the Park?" (survey question 11(3)), twice as many visitors (55.0\%) responded "Yes" (see Table 10-2). Assuming the validity of these results, it would seem that fewer visitors would support the provision of access to resources than other benefits.

Table 10-2: Should the Park provide other benefits to local residents?

\begin{tabular}{lcc}
\hline Nationality & No & Yes \\
\hline South African visitors & 87 & 80 \\
& $(52.1 \%)$ & $(47.9 \%)$ \\
International visitors & 30 & 63 \\
& $(32.3 \%)$ & $(67.7 \%)$ \\
Total & 117 & 143 \\
\hline$\chi^{2}=9.50 ; \mathrm{df}=1 ; \mathrm{p}<.01$ & $(45 \%)$ & $(55 \%)$ \\
\hline
\end{tabular}




\section{The future of resource use in Kruger National Park}

Subsistence-based resource use has a long history as a contentious issue in Kruger, but the Park and its constituencies appear to be moving closer to a resolution. Most significantly, Kruger's recent Management Plan (2006) contains a "Statement of Intent" outlining how decisions related to resource use will be made. The Statement of Intent, as with the Management Plan in whole, is the result of research in the Park, a number of staff workshops, and consultative meetings with a variety of constituencies. ${ }^{47}$

The decision making framework outlined in the Statement of Intent consists of both "feasibility principles" and "implementation principles." The underlying message conveyed through these principles is that the Park recognizes that "past inequalities must be addressed through benefiting the poor," but that the Park ultimately reserves the right to choose - through a precautionary, adaptive process - what types and quantities of resources will be made available. Moreover, despite being the final arbiter, the Park has committed itself to consultative and transparent decision-making. Based on informal discussions with Park staff, Kruger will proceed with this approach by experimenting with a variety of resources over the next five years. Possible resources that might be made available to local residents on an experimental basis include firewood, medicinal plants from nurseries, sand from rivers, and, perhaps, impala meat. More resources would likely be added to this list as the experimentation continues to develop.

For the most part, the approach that Kruger has outlined in its Statement of Intent comports with the way in which Park Staff, local residents, and Park visitors

\footnotetext{
${ }^{47}$ As discussed earlier, though, some local residents did not view the public meetings as procedurally or substantively sound.
} 
conceptualized the legitimacy of resource use. In other words, most of the individuals that I spoke with or surveyed might find this approach to be "legitimate." First, many of those in all three groups, for instance, felt that decision-making should be consultative, but that, as a large number of Park visitors suggested, the Park should ultimately reserve decision-making authority. Second, while experimental resource use will not likely satisfy all of the pragmatic needs that local residents have, it is conceivable that resource use could someday reach a level that satisfies a substantial portion of that need (provided such levels were supported by the findings from experimental use). Third, at least in part, resource use will be implemented as a mechanism for redressing past inequalities, which was an important consideration for local residents (of course, whether it effectively achieves this goal will remain to be seen). Fourth, consistent with the Park staff's and Park visitors' conceptualizations of legitimacy, the precautionary, adaptive, and experimental approach provides the Park with the opportunity to withdraw use if it threatens biodiversity or other Park values.

Of course, the true assessment of whether or not this approach will be perceived as legitimate by the Park staff and its constituencies may only be determined after the Park has begun to allow resource use through the experimental process. Only then, for instance, will it be possible to assess whether consultation is embraced, whether the types and levels of use are redressing historical wrongs, and whether other Park values will ultimately usurp the value that local residents place on utilizing resources in the Park. 


\section{Resource use within the broader collection of local residents' interests}

Indeed, as discussed in Chapter 5, local residents do have an interest in accessing resources in Kruger, such as firewood, thatch grass, medicinal plants, and meat. Understanding, though, how interests in access to resources in the Park fit within the broader benefits of interest is likely to have an important bearing on the legitimacy of resource use and, perhaps more significantly, the broader legitimacy of the relationship between the Park and local residents. If, for instance, the Kruger administration were to frame its constituency building efforts and the provision of benefits primarily in terms of some form of access to resources, might it be possible that local residents would view such efforts as illegitimate if they did not generally view access to resources as the most pressing issue or need at hand? In other words, it is conceivable that providing access to resources could fail to generate goodwill, or even worse, damage the relationship with local residents if local residents view such provision as the Park's way of either ignoring or avoiding more fundamental interests.

\section{The "most important" benefits}

In order to better understand those fundamental interests, I asked local residents to discuss the most important benefits that the Park could provide. Interestingly, access to resources for subsistence purposes was never mentioned. Instead, local residents suggested that the most important and fundamental benefit that the Park could provide would be tangible and direct assistance in developing the surrounding communities,

We were supposed to be gaining more from that land. The park is not assisting us in anyway, and we would like the Park to come on board and 
try to assist us with all of those progressive things that we need as a community. (LC20)

The main thing we want the Park to help us with, though, is development. We want them to help us make our lives better, and perhaps tourism and education can do part of that, but it cannotdo it all. People on this side of the boundary are still starving. There are riches on the other side - riches on the inside of the Park, but there is much starvation and poverty on this side. You know Randy, we've talked and talked about benefits to the community for so many times, but we're still poor. Will this [Management Plan] take us to the point where we'll see development on both sides? Development on this side is good not only for this side but it is also good for the other side. Development is a heartache, but it is a necessary heartache - we need something. (LC3)

More than access to resources, many of the local residents I spoke with want the Park to help them "make [their] lives better" (as LC3 suggests above). Despite a relative shortage of resources immediately outside the Park, local residents were more interested in assistance from the Park that facilitates progressive development rather than subsistence. For some staff that I spoke with, that developmental assistance would be more important to local residents than access to resources was not a surprise,

These days, communities are not as primitive as they would have been 200 years ago, 100 years ago, where they would make a lot more use of natural resources for building and utensils, traditional domestic stuff. They're more likely to go and buy stuff. I think it's more a case of life does not revolve around natural resources that much anymore. It's more about money. Everybody has progressed and it's not as rural as we think out there. A lot of people still think that people deal in cattle out there, but that's not the case. They've all got big accounts with [retailers], with getting furniture, and it's not about resources now, it's not about cattle anymore, it's about your house, how big your fridge is, and how many rooms you've got in your house. So, there is definitely a shift. (S13)

For the last five years that I've been here, there has been an incredible amount of social growth. The area has grown exponentially. Also, the use of electricity - you find there are more lights popping up around Mkhuhlu, Lilydale, Huntington, and surrounding areas. So, the next five years or so, 
what we perceive as being essential needs might change. It actually is changing. (S24)

If the interviews with local residents are any indication, it is very likely that developmental assistance is well within the realm of "essential needs" that S24 mentions above. Infrastructure, such as schools, churches, clinics, and other buildings, was mentioned by several local residents as the most important benefit the Park could provide,

Most importantly, we need schools. There are some villages that do not have schools and learners have to walk a long way every day to get to them. Every village should have a school. The park could help us with this. They could help us build the schools - churches, too. Like schools, churches are often spread far apart and people have to rely on public transportation - which costs money - or they have to walk a long way, just like the learners. People in our villages would be much happier with the Park if they could help us with these small things. The Park is very wealthy and very powerful - surely they can do these things - we need them. (LC4)

The Park should assist us in terms of building schools and maybe building certain things that can bring progress to the community wherein we live. We contributed to the Park while working there. So, the Park is supposed to be doing something progressive to these communities which are next to the Park. One of the common things that we need is the question of schools, libraries, anything that can be progressing the community. (LC15) Yes, we are interested in the meat, but we are more interested in assistance. We need to keep people from being hungry, but we need things like schools and churches more. (LC2)

Beyond the financial assistance needed to construct schools or churches many local residents I spoke with felt that the Park could have a valuable impact on the opportunities afforded to their children through bursaries (i.e., scholarships) for secondary and post-secondary education, 
If I had to say what the most important thing we need is, I would request to provide bursaries for the young ones, because [the Park] is not assisting them in terms of taking them to schools. (LC17)

I want to see my kids assisted financially for studies in the form of bursaries... That is the basic thing that I would like the Park to assist with. (LC24)

I would like to see KNP helping the young generations - getting them to school... because if they do not... they wander around here. They are not doing anything. With the old people, there is nothing which I can say they want from KNP because they are old. We are thinking about the young generations. (LC6)

Children and the "young generation" figured strongly for local residents in terms

of the most important benefits that the Park could provide. And, this was true not only in terms of educational opportunities, but employment opportunities, as well,

My concern is a question of employment. My kids are not actually employed in the park, whereas that is their home land. That is the land of their forefathers, but now, our kids are not getting employed in the park. So, we are very much concerned about that. Maybe in a way, we would like our kids to be employed in a way of compensating them, because it is the land of their forefathers... (LC15)

The big thing that the Kruger National Park should provide to the village is jobs... We feel not happy if we see some of our young people not getting jobs [with the Park] ... that is not good for our relationship with the Kruger National Park. The important thing that can make a good relationship is if everyone can say that there is jobs. I'm old, but I'm the one who is taking the responsibility of the house. I'm the one who is going to pay school fees. I'm the one who's going to buy food. So, if young people are working and getting something, they are able to buy something for me, because now, as you see, I'm not having power to work. I'm just waiting for that patient day. Even if I want to buy something or I want to send a kid to school for tertiary education, I'm afraid because I do not have money. If they give jobs, things will go smoother... If the Kruger National Park can help solve that problem, the relationship will be good. (LC28)

The excerpts above reflect the general sentiment among the local residents I interviewed that infrastructure, education, and employment were of more interest than 
access to resources in the Park. But, rather than being entirely unrelated to developmental needs, one Park staff member that I spoke with commented that resource use might function as a proxy for those higher priority interests,

I really think that a lot of it really is about what benefits flow to those communities - not necessarily the physical resources - but what are the benefits of you being my neighbor - you the national park? I do not see any, in fact, it's just exclusion at this stage. So, then it gets turned into a negative leveraging issue quite often where the communities have no other sort of negotiation mechanism, so they use the resource thing I think to try and get some dialog going. It always ends up them being quite negative because the Park just is notable to come with anything, whereas really what they are saying is not necessarily the plant - it's about the bigger issues. (S18)

If true, this observation is an important one - demands or interests expressed by protected area constituencies might not always be as obvious as they seem on the surface. If it's possible that expressing an interest, such as that for resource use, might lead to or allow a constituency to negotiate or start a dialog for broader, more fundamental interests, then merely responding to those superficial interests might not be viewed as legitimate in the absence of a response to the more fundamental and underlying interests.

Just as the question of legitimacy is an important feature of the resource use issue, so, too, may the same questions be asked of any other types of benefits to be provided to local residents - including developmental assistance.

\section{Local residents' legitimation of developmental assistance}

That developmental assistance - such as infrastructure development, educational support, and employment opportunities - is, perhaps, more valued than access to resources among local residents does not sufficiently establish its legitimacy. Just 
because a benefit is in demand does not necessarily imply that it should be provided.

Providing limited, sustainable access to natural resources in the Park is a much different enterprise than improving social welfare and might be viewed by many in the broader citizenry as an inappropriate task for a conservation agency to embark on. For the local residents I spoke with, though, both their historical relationship with the Park and their contemporary relationship with other surrounding game reserves serve to legitimize broad, developmental assistance.

\section{$\underline{\text { Moral and historical considerations }}$}

When asked about the legitimacy of resource use, many local residents viewed it as a legitimate activity because they had a pragmatic need for resources. And, while some felt morally entitled to the resources, morality did not appear to be the most significant legitimating factor. When commenting, though, on developmental assistance, its legitimacy hinged considerably on moral factors. More specifically, because of the historical forced removals from the Park, local residents maintained that the Park has a responsibility to share the "wealth" that has and continues to accumulate at the expense of removal and to compensate local residents for the losses that they sustained as a result,

It is a question of sharing the wealth jointly. It's a question of sharing the wealth or having a stake in the actual wealth, which was getting to the place that was originally ours. We are worried that there is a huge amount of money getting there and the original owners of the place are not getting anything. As long as we get something or a stake out of the money that is getting in there, then we will be satisfied as a community. (LC21)

The Park is supposed to be assisting in a way. I grew up in the very same Park as my father; his forefathers grew up there. But, there are no benefits that we are getting as people who were there before the Park was actually 
found. I am very much concerned about that. I would like to extend a concern that the park should do something to assist us. (LC17)

I am in need of compensation in a way of assisting us in terms of taking our kids to school, and also compensation in the form of money. Our parents suffered a lot and they were earning too little. Somehow, I suggest they allow the community members to be given compensation for the hardship they experienced in the park while still working there. Some of them were transferred to Komatipoort, some of them to Mozambique, some of them to the north, and we come to the Transvaal, having nothing. You could only take your blanket, your trousers, your dress, and off you go. We should get something, or they do something for us. We were removed by force and we were not compensated after being removed from that area - we were scattered without any benefit at all. (LC18)

The concern is that there are quite a number of things that we want the Kruger National Park to do for us, but then to our surprise and dismay, nothing is actually going to us. The Kruger National Park is doing nothing - no employment for our kids, nothing at all to assist our kids. It is actually a concern that the Park is not living up to assist us as community members or to develop this area where we live. Yet, it is our original place that the Park is actually located in. (LC23)

As the "original owners" of the Park's land base, many local residents that I spoke with believed the Park owes them some form of assistance. Because the developmental assistance that local residents are looking to the Park for are typically provided by other government agencies (e.g., departments of education, utility services, or labor), the moral undertones of the local residents' interests are particularly important. Typically, for instance, it might not seem logical for a protected area management organization (such as SANParks) to be charged with tasks that other development-oriented agencies are designed to address. However, because local residents directly identify many of their developmental shortcomings with the historical actions of the Park, local residents maintain that the Park is morally culpable and, perhaps, it alone has the responsibility to provide assistance. If developmental assistance were, indeed, provided by other 
government or non-government agencies, some local residents might still look to the Park with disdain for not having justly compensated them. Thus, while the protected area organization-cum-development agency might not normally be viewed as legitimate, historical circumstances might require the organizations to practice beyond their areas of expertise (i.e., to assist with some developmental needs) in order to improve relationships with local residents or other constituencies.

\section{Contemporary relationships with surrounding private game reserves}

Moral considerations were not the only factors that contributed to local residents' expectations that the Park should provide assistance with development initiatives. Situated along or near the western boundary of Kruger are several private game reserves that have established important relationships with adjacent communities and have, perhaps, led local residents to reconsider their relationship with Kruger. From the perspective of benefit provision, many private game reserves in the area have been very active in providing for some needs of the surrounding communities. Some, for instance, allow local residents to enter the reserves to collect resources. According to some game reserve owners and managers that I spoke with,

[local residents] collect medicinal plants here... Twice a week, people from the local communities are allowed to enter. They do collect medicinal plants. They collect firewood for fuel - especially if there is a wedding or funeral. We do allow them to come in and collect in bulk for the community - not just firewood for this or that person, but for the community. They do harvest some of the animals, as well. When there is a big event, the nduna [i.e., a local traditional leader] will say we need two buffalo, three kudu, and one whatever. (GR1) 
I think resource use is a good idea. It's necessary in order to keep the community in support of the area. Yes, resource use is necessary and important. There is a lot of legitimate resource use that goes on here, but it's the few bad apples that make it seem like a bad idea. (GR2)

I frequently refer people to Ndumu game reserve where a chap... started a sustainable resource use program when he took it over from KwaZulu Bureau of Natural Resources. When he took over Ndumu... he introduced the sustainable use of natural resources. He allowed people to come into the reedbeds - areas which had traditionally been used before the fence went up. Within three years, the reedbeds were healthier than they had ever been in the entire history of the reserve, which was about 30 years old. There are ways of allowing for resource use among local communities that also benefit the ecosystem. (GR3)

In many respects, the game reserve owners and managers that I spoke with appear to have adopted a much different mentality concerning resource use and, more broadly, their relationship with local residents. Rather, for instance, than viewing resource use and the needs of local residents as a threat to a reserve's biodiversity, resource use might be seen as both an important tool for building community support for the area and as a means to increase or maintain the ecological health of a reserve.

Access to natural resources is not the only benefit that private game reserves in the area have actively provided. On a short walk through many of the surrounding communities, one will readily find placards posted on schools, community halls, or community gardens identifying that a particular lodge donated funds to help establish those buildings or projects. In one community I visited, the nearby private game reserve had provided a "hippo roller" (i.e., a large, rolling container for transporting water over long distances) to every family that requested one. Such efforts have by no means gone unnoticed by local residents, 
There is not any resentment among the local residents towards the private game reserves because the private game reserves have been involved, although it's not all of the private game reserves. But, some of the private game reserves have been willing to come out and understand what is the social and economic needs of the people, and they are willing to assist in one way or another to improve the lives of people living outside the reserve. (LC14)

That many private game reserve owners and managers have been willing (and, perhaps, even enthusiastic) to understand and contribute to the "social and economic needs" of surrounding communities has only engendered further misgivings concerning why the Park (which is considerably larger and generates more gross revenue than the surrounding reserves) provides far less direct assistance than the surrounding reserves. For many local residents I spoke with, it was only rational to expect that the Park would be prepared and willing to provide just as much if not more benefits as the private game reserves,

Londolozi [a private game reserve] builds schools. The Park could do that.Yes, even better than Londolozi, because the Park is a very big thing. We were expecting a lot from the Park. But, they do nothing. (LC12) The Park can do much better than [private game reserves]. Why? Because they are collecting a lot more money. How many guests do they have from Malelane to Pafuri? In one hour they are collecting a lot of money. There was a section ranger at Orpen. I once had a time with him and asked how much he thought they were making in an hour at all gates. He did not hesitate to say R50,000, especially during the holidays. (LC39)

The Kruger National Park is not doing enough to assist people who are staying here. Sabi Sand [a private game reserve] is assisting us compared to Kruger National Park. They even assisted with the market across here. The Park is not assisting us as compared to the other game lodges, because the other game lodges are building classes, they are giving bursaries, but the Kruger National Park people are giving nothing in terms of bursaries, no assistance in terms of building schools. The Park is not doing enough to assist them. They need to plow back what they did in the past. (LC17) 
We want a very good relationship to exist between the Park and the community. We are surprised because the Park seems to not be interacting with us. It is only these newly-developed private game lodges that are coming on board to assist community members. But, the Park is doing nothing at all. (LC20)

The other [private game] reserves are actually doing lots of things for the communities and the Kruger National Park is doing nothing - no employment for their kids, nothing at all to assist their kids. It is actually a concern that the Park is not living up to assist them as community members or to develop this area where they live. (LC24)

There is nothing that has changed since 1994. It's bad because the private game lodges have done much more than the Park has after 1994. The Park has not changed at all... There are a lot of things [the private reserves] have done. They have bought a primary school, they have built rooms for schools. There are computers that they have purchased for the schools. They have a computer lab at the high school. It's all from the private game lodges. We've got a pre-school that has been built through Londolozi Game Lodge and CCAfrica [a corporation that owns several private game reserves in the area]. There is a lot of equipment that Singita [a private game reserve] has purchased for our schools. They bring in guests here to the community. From the private lodges part of it, they have done much better... Why is it that the Park has done nothing for us, when the small private game reserves have done so much? The Park is very big, but the private game reserves are doing much better. (LC38)

As demonstrated in these and other excerpts above, the local residents I spoke with had very favorable impressions of surrounding game reserves, and in fact, the relationships they have forged with one another has, to an extent, only exacerbated some of the ill-will that some local residents harbor towards the Park. Local residents aside, though, not all of the individuals I spoke with believed that the efforts of some private game reserves owners and managers are entirely altruistic. Some Park staff commented that such activities are likely to, at least in part, be effective marketing tools aimed at attracting sympathetic (and wealthy) tourists. Others remarked that, given more than $50 \%$ of Kruger is subject to pending land claims, private game reserve owners and 
managers might have an ulterior motive to establish amicable relationships with surrounding communities in order to later secure potential operating rights for successfully claimed land. For instance, if a surrounding community's current land claim in the Park were successful and they were to acquire certain land rights to a portion of Kruger, they would likely be more willing to grant exclusive, usufruct operating rights (e.g., tourism operations) to a private game reserve that they had friendly relations with rather than one they did not,

The private [game reserves] adapt really quickly because it's in the interest of their business. And, they see things changing in the government and the community, and they find ways of adapting and reaching out to the community. They see threats of land claims, and they see by extending a local hand with the local chief and provide assistance for other things... Even some of the land claims that we're getting, some of the guys that are backing them are the private [game reserves]. They go into the community and talk to the chief and talk about possibilities of jobs and so on if we got that portion of land. Then, they provide assistance for lawyers and so on, then you get a land claim and you think it is a community, and yet there is a powerful guy behind it because they know if they get that portion, the [game reserve] will develop and have something... Although we are business oriented, we are not all the way. We're just business minded. We're not really too into strategy around social issues and how we can encounter them for our own benefit. (S16)

Moreover, by establishing favorable relationships with local residents, some Park staff believe that private game reserves have their sights set on laying the groundwork for efforts to lease surrounding communal lands outside the Park and thereby expand their reserves,

I think one really needs to be really careful when considering the benefits that private game reserves provide local residents because you can very easily, through a potential financial beneficiation to the community, actually completely hoodwink them. You can say, 'listen, I've actually got my ulterior motives and I want you to sign a ninety-nine-year lease. 
Just look, though, at all this money that you're going to get.' Actually, you might be dis-benefiting them in some way. Potentially, I think some of those communities are really vulnerable to that, because they are poor. Any promise of money suddenly becomes quite attractive to them. But, you might actually be robbing them of a source of livelihood. Where maybe you get a 99 year lease for their property for whatever reason, you're actually giving them a whole lot of money, but they cannot sustain their livelihoods. Because they can no longer eat the fruits or graze the cattle or whatever it is. So, suddenly, they've got this money, but they've got to spend even more of it just to try and get food or whatever, and then it can lead to the whole breakdown of the community. (S18)

None of the local residents I spoke with (including game reserve owners and managers) suggested or discussed any long-term arrangements geared at leasing lands or contracting for tourism services. And, anecdotes aside, there appears to be little tangible evidence supporting the concerns of some Park staff described above. Whether or not those concerns are valid, though, perhaps the more important impact of the relationships that local residents have established with surrounding private game reserves is the legitimation of developmental assistance provided by conservation areas. Because most of the local residents I spoke with did not necessarily differentiate between the underlying philosophy of national parks versus that of private game reserves, local residents expect the much larger Kruger National Park to provide as much if not more tangible, developmental assistance than the comparatively smaller private game reserves.

The relationships that communities have forged with private game reserves is instructive not only in terms of the reasons why local residents expect broader benefit provision from the Park, but also for understanding how access to resources is prioritized within the broader collection of benefits that local residents are interested in. When I asked local residents in nearby communities to describe the type of benefits they received 
from local private game reserves (which provided access to natural resources), no one mentioned access to natural resources. Just as no local residents described resource use as the "most important" benefit they would like to derive from the Park, resource use also appears to be of less importance compared to the other developmental assistance provided by private game reserves. Whether access to resources in private game reserves is either of little significance to local residents or is enjoyed by a subset of local residents that I did not interview, it was clear that benefits such as assistance with constructing schools, classrooms, clinics, community gardens, or transporting water were widely recognized and appreciated.

Understanding how local residents prioritize access to natural resources within the broader collection of benefits they are interested in is likely to be an important consideration is resolving the resource use issue. If, indeed, resource use is of secondary interest compared to developmental assistance, providing some level of access to resources without addressing (not necessarily meeting) the broader interests that local residents have in the Park might not help "build a constituency," as some staff hope that it will do. Moreover, if resource use is not a high priority among local residents and only a relatively small number would be interested in accessing resources in the Park, the time, money, and energy spent by the Park administration in an effort to understand the sustainability and impacts of resource use might be better spent on understanding how to address (again, not necessarily satisfy) the more fundamental interests of local residents.

Allowing certain levels of access to resources based on the resource in question is likely to be a logical and intuitive component of a resolution to the resource use issue. 
Park staff have commented that over the course of the next five years they will experiment with various levels and types of resource use to better understand the impacts and sustainability of use. But, as discussed above, access to resources might not sufficiently satisfy the underlying interests that either the Park staff or local residents have. Instead, access to resources might need to be augmented with other forms of benefit provision that address some of the needs discussed above if the relationship between local residents and the Park is to be improved. One possible strategy, among others, is the implementation of a "visitor community levy."

\section{Community levy and financial benefits: an example of a supplementary approach}

I attended a series of three "public participation meeting" during my fieldwork that were hosted by Kruger in order to solicit public input regarding the management plan that was being drafted. Residents from surrounding communities were invited to come and share their thoughts, and in particular, to discuss the types of benefits that they would like the Park to provide. Consistent with the discussion above, resource use was never high on the list of priorities, while developmental benefits (e.g., construction of schools, churches, clinics, etc.) were. Assuming that even if in principle the provision of such benefits is an legitimate activity for a national park to engage in (which I will discuss at greater length in the next chapter), generating the necessary funds for such initiatives is a difficult task for parks and protected areas that are typically underfunded as it is (see, e.g., de la Harpe and others 2004).

One individual who spoke passionately at the last of the three public participation meetings regarding the provision of benefits commented that the Park need not provide 
the necessary funds from its own coffers. Instead, as he suggested, the funds could be raised and maintained by implementing a "community levy" where a nominal fee is added to the Park visitor entry fee. The money generated through the levy could then be channeled to surrounding communities through a "Park-community trust" where Park administrators, together with representatives from surrounding communities, determine how the funds are disbursed and spent. According to one local resident I spoke with,

One Rand could be added to the admission and then set aside for such developmental needs [of the surrounding communities]. It would relieve the Kruger National Park of saying "what is it that we can do for the communities'? You see, it would not require an extra budget or more money that the Park would use - it would simply say 'of all the guests that have paid, we have accumulated so much, and this is the budget that we're going to work off of. What is it then, that you want us to focus on.' But, then they must for the management of such funds, Kruger must be there, the community leaders must be there to see what the money is going to be used for. Then, Kruger - maybe the head office or someone of higher authority above the People and Conservation Department - must monitor whether the money is being used properly or not. Then, I think we will see a lot of development. (LC7)

If, as LC7 suggests, one Rand (approximately \$0.14) were collected per visitor, approximately one million Rand (roughly $\$ 142,857$ ) would be generated per year through the levy. ${ }^{48}$

All of the local residents that I spoke with regarding a community levy either explicitly or implicitly described such a program as being more useful than access to resources in the Park alone,

I think that a community levy would be more useful [than access to resources] and I think that can make a huge impact in terms of the peoples lives in the community, because that kind of funding or money that they

\footnotetext{
${ }^{48}$ According to data gathered by the Park, Kruger received 1,008,716 visitors from March 2006-March 2007 (SANParks 2007).
} 
can generate will not go to individuals. There will be something tangible that Kruger can say, 'this is what we've done with the funding,' and the community will feel happy about it. (LC14)

I want to see the community benefiting directly. For instance, to each and every tourist, why cannotthey give one Rand to the community? We could have a member from our community monitoring that. That's a little amount per person, but we would be very satisfied with that. I'm not worried that if they took that money to the community that the community would not use that money very well. We are going to build schools. The problem is classrooms. They are overcrowded. We would build classrooms. We have a problem of water. It's very dry here. You'll find a drop of water in one tap. So, we can use this money to do all that and do everything that we want. (LC9)

As LC14 discusses in the first excerpt, whereas access to natural resources might service a relatively narrow segment of the population surrounding the Park (e.g., those who are willing to travel to the Park to access those resources), a community levy might provide for the needs of a larger segment. Moreover, while some local residents did feel that access to natural resources in the Park would be beneficial, when local residents spoke of such access they did not express the belief - as they did when speaking of a community levy and corresponding developmental benefits - that it would "relieve" or satisfy Kruger's responsibility to surrounding communities.

Generally speaking, most Park staff spoke favorably of a community levy, as well, and commented that, while such an initiative would have to be safeguarded against corruption, it could provide for tangible benefits that are readily apparent to local residents,

I personally think that could be a very good thing. I think whenever we embark on that thing that it is well-managed, we have to ensure that there is no corruption or that you do not have a situation where the chief is enriched and the local community does not get anything. (S11) 
It will be something tangible, something concrete, something that they can see. They can see, 'geez this place supplied R50,000 or whatever for whatever we want to do with it.' Which will last for... Well nothing lasts forever but...So this year they give money, they need this building, it's five years due for maintenance, and we're going to use the money to maintain the building that the park paid to put up. Whereas something that you put in your mouth is gone. A couple of days and it's finished. (S13)

Some Park staff I spoke with further described how, indeed, the idea of a community levy is not a new one - even to South Africa. Since 1998, KwaZulu Natal Wildlife (KZNW), which administers the provincial protected areas of South Africa's KwaZulu Natal province, has instituted a "community levy" that is structurally similar to the initiative described above. In its first two years, the levy - placed on both the entry fee and the first night's accommodation in protected areas administered by KZNW generated more than $\$ 1.2$ million and sponsored a number of projects ranging from the construction of school classrooms (including equipment) to electrification and the establishment of a poultry farm (KZNW 2007).$^{49}$ One hundred percent of the funds are channeled to communities through a board of trustees with $90 \%$ contributing to local community projects and $10 \%$ to non-local community projects.

As one, staff member commented, she felt the SANParks organization has been "crazy" not to have considered such an effort,

Personally, I think that we - SANParks - are crazy to have not looked into gate levies. It seems to be working so well in KwaZulu Natal. I'm sure there is probably the odd hiccup, but in general, it has bought them a lot of goodwill from the communities and it's brought a lot of better understanding. I just cannotunderstand why SANPark's has not yet tried. We could have even tried it at a smaller park. It's not like we only have one park that's really big and scary to manage, but we have a lot of

\footnotetext{
${ }^{49}$ For more detail on KwaZulu Natal Wildlife's community levy program, see http://www.kznwildlife.com/coast_conslevy.htm and http://www.kznwildlife.com/CommunityLinks.htm
} 
smaller parks that we could have done on a trial basis ten years ago and seen what had happened. (S18)

KwaZulu Natal Wildlife is doing that already and I think that is much better than to use the natural resources. (S20)

Like S20 above, many staff I spoke with appeared to be more amenable to a community levy than providing access to resources, but several staff I spoke with (despite, perhaps, agreeing in principle with a levy) raised concerns regarding the finer points of implementation.

An important philosophical question concerning a community levy for Kruger (or any protected area for that matter) regards the extent to which a national asset (such as a national park) should serve local interests while not providing those same services to the broader, national constituency. As one staff member I spoke with commented, I think the devil is in the details. It's how the money is disseminated. On one hand, you're saying that the neighboring communities have a financial stake or a rewarding stake in Kruger Park. Some of them feel that way because they feel they were moved out. We need to look at the details, though. Ultimately, the Park is a shared resource of the nation. If I was a community in Bushbuck Ridge [approximately $40 \mathrm{~km}$ from the Park's western boundary], I would quite legitimately ask why the hell communities near the Park are getting benefits, and I'm not? Is it just because of geography. Bushbuck Ridge is just as disadvantaged as the communities around the Park, it just so happens that the communities here are near the Park. It's a national resource, and we should all benefit from it. Where do you put the line to decide who would get financial benefits. Infrastructure and development should come from taxes, not the Park. The government should be doing it. On the face of it, I like the idea of a levy, but I wonder if that levy is national or local? (S1)

It is, perhaps, here where private game reserves differ most significantly from national parks. Whereas private game reserves are not compelled to serve the public interest and may focus their efforts at benefit provision on immediately surrounding communities, 
national parks - as a national asset - must be attentive to the concerns of public equity. To a certain extent, the KZNW model has attempted to resolve this issue by directing $10 \%$ of the community levy funds to "non-local" communities or organizations. Even this proportion, though, might be reasonably challenged.

As S1 initially discusses in the above excerpt, though, the hardships that local residents encountered at the expense of the Park's establishment and administration serve as compelling justifications for the admittedly imbalanced delivery of benefits. In effect, the forced removals and marginalization that local residents experienced prior to the fall of Apartheid amount to an economic externality where local residents endured the costs accompanying removal and marginalization without arguably enjoying the benefits of the Park's establishment and administration. As a result, proponents of a community levy might likely argue that the Park should internalize this imbalance by providing benefits to local residents - albeit in a different form than enjoyed by the public-at-large. Nevertheless, even if one subscribed to this argument, determining what constitutes "local" presents a difficult question. While it is clear that many residents living immediately on the boundary can reasonably stake a claim to have been impacted by forced removals and marginalization, so, too, may some individuals living 50, 100, or even 500 kilometers away from the Park boundary who might have moved further away from the Park once removed or who would have visited the Park but were otherwise denied access on racial grounds.

Philosophical concerns notwithstanding, some Park staff I spoke with mentioned a number of potential practical challenges to the implementation of a community levy. 
Most notably these concerns included the potential for corruption, the framework for

deciding what projects will be funded (and those that will not), and the possibility that by

raising the cost of entry to subsidize those formerly excluded from the Park, some who

currently visit the Park might, in turn, be excluded,

The problem with those kind of strategies is how, then, do you insure that the money is utilized for what it is meant for. You can establish a community trust, get trustees, and then you are not sure that those communities are going to use the money for what it is meant for. You get trustees from the community and you've got to take into consideration that some of those trustees do not have the interest of the community at heart. They have got their own interests at heart. They are sitting here with millions, living in a mud house, what are you going to do? You're going to see some of those millions and see how you can improve your lot. There will need to be some kind of administration that will go along with that. (S10)

There are projects that will have to be identified by the community itself. But, dealing with the communities is not easy, because who do you ask in the communities what is it that you need, and how do you determine what those people tell you are representative of what everybody else in the community wants. We've got structures in the communities - the chieftanships. We've got those chiefs and you would say the chiefs represent the community, but my experience is that they do not really represent the community, they represent themselves. At the end of the day, you end up with the situation where the chief has enriched himself at the expense of the whole community. They are supposed to be traditional leaders, but that's exactly where the problem is. (S10)

Looking at the South African community, SANParks is seen as the "people's park." We say that we're just watching it for you. There is a point somewhere where you start increasing the cost to where you're excluding people from the park. We're just making it the playground of the wealthy. That's something we have to guard against. Sometimes increases are good, but we need to be aware of that. Otherwise we will not be living up to our motto. (S24)

S24's implication above is that a community levy places a burden on one of the

Park's constituencies (i.e., the visitor) in order to benefit another (i.e., local residents). 
Park visitors' views concerning a community levy, then - in addition to those of local residents and Park staff - are an important consideration. As illustrated in Table 10-2 above, $55 \%$ of the visitors surveyed believed that the Park should provide benefits (other than access to resources) to local residents. When asked whether or not they would support a community levy as a benefit to local residents (see survey question 11(d)), visitors responded in the precisely same manner that is illustrated in Table 10-2. In other words each visitor who felt that benefits should be provided to local residents supported a community levy, and the converse was true, as well (i.e., question 11(c) and 11(d) were perfectly, positively correlated). If, then, providing benefits (other than access to resources) is deemed to be a legitimate activity, then every visitor surveyed who agreed with this assumption supported a community levy. Not all visitors are likely to support the provision of benefits to local residents ( $45 \%$ of those surveyed did not), but among those that do, a community levy might garner substantial support. ${ }^{50}$ As illustrated in Table 10-3, even among those who did not believe that local residents should be provided with access to resources, $43.6 \%$ supported a community levy as an alternative form of benefit provision. ${ }^{51}$

In summary, while directly addressing the resource use issue by providing for

\footnotetext{
${ }^{50}$ Of course, the support that Park visitors exhibit for a community levy is likely to be a function of how much the levy is. A one Rand levy (approx. \$0.14) is likely to be more supported than, say, a thirty-five Rand levy (approx. \$5.00). For the sake of brevity and at the request of the Kruger administration, I did not present questions concerning willingness-to-pay in the visitor survey. Park officials preferred that no levy amounts be discussed since, from their perspective, doing so might give rise to an expectation that the Park was, indeed, on the cusp of implementing such a levy. In the survey, however, the levy was described as "small" and "nominal."

${ }^{51}$ Since the responses to the question concerning a community levy (survey question 11(d)) are perfectly correlated with the responses to the question concerning whether other benefits should be provided to local residents (survey question $11(\mathrm{c})$ ), this result also implies that $46.2 \%$ of those believed that access to resources should not be provided felt that some other form of benefits should be provided.
} 
Table 10-3: Access to resources and a community levy - responses from Responses from Park visitors who felt benefits should be provided

\begin{tabular}{lcc}
\hline & $\begin{array}{c}\text { Would you support a } \\
\text { community levy? }\end{array}$ & Yes \\
& & \\
\hline Should resource use be allowed? & 106 & 82 \\
No & $(56.4 \%)$ & $(43.6 \%)$ \\
& 12 & 57 \\
Yes & $(17.4 \%)$ & $(82.6 \%)$ \\
& 118 & 139 \\
Total & $(45.9 \%)$ & $(54.1 \%)$ \\
\hline$\chi^{2}=30.90 ; \mathrm{df}=1 ; \mathrm{p}<.001$ & & \\
\hline
\end{tabular}

certain levels of use for specific resources - that may range from no use to unlimited access - might seem to be the logical or intuitive response to the issue, it might be the case that an indirect response is more legitimate. Because (1) access to resources might not be as high of a priority for local residents as other developmental needs and (2) recognizing that demands for access to resources could be a proxy for demands related to developmental needs, focusing benefit dprovision efforts on developmental rather than resource use needs might be more appropriate. There are not likely to be any panaceas for the question of resource use, but a community levy designed to address some of the developmental needs of local residents deserves closer attention if it is judged that the 
Park should address such needs. It is, for instance, important to note that based on the data collected in this study, local residents, Park staff, and Park visitors alike all appeared to be more amenable to a community levy than they did the provision of access to resources in the Park.

\section{Conclusion}

I have aimed to illustrate in this chapter that an understanding of how and why various stakeholders legitimize complex issues and their potential responses can play a significant role in resolving those issues and selecting responses. In the initial, scoping interviews I conducted with Park staff in 2005 (before any of the data presented in this dissertation were collected), resource use was described as a "hot issue" and one that required immediate, extensive research to help Park managers decide how they would directly respond. Based on the data I collected, it would seem that there might only be a mild interest among local residents in gaining access to resources (e.g., a considerable number of local residents I interviewed believed that resource use was actually an illegitimate activity). Instead, as S18 might have correctly observed (see p. 298), local residents' perceptions of the legitimacy of resource use could hinge on the issue's ability to serve as a proxy for broader developmental needs that they might have. Even if not a proxy, it was evident that developmental needs were a higher priority to local residents than access to natural resources. And, because the Park staff who viewed resource use as legitimate did so primarily because it would satisfy the organization's mandate and objective to provide benefits and build a constituency, providing benefits other than access to resources (which many Park staff viewed as illegitimate) might be a viable 
option. A visitor community levy designed to finance some developmental needs of local residents could serve as such an option and was generally viewed favorably by all three groups I collected data from. While a community levy has been instituted in South Africa at the provincial level, there are important challenges that the Kruger administration must confront if it considers a community levy or other approaches designed to exclusively benefit local residents. Perhaps most importantly, it must address the legitimacy of such an action - is it, for instance, legitimate for a national park to offer exclusive benefits to local residents?

Questions of legitimacy run deep in the governance and management of protected areas and those questions, as illustrated here, may be fundamentally connected - an exploration of the legitimacy of resource use might lead to the need to understand the broader legitimacy of how and why parks and other protected areas provide exclusive benefits to local residents at the expense of the public-at-large (e.g., through a community levy). If, in fact, protected area management organizations, such as SANParks and the Kruger administration, are to build stronger relationships with their constituencies, it is almost certain that they must address these fundamental questions of legitimacy. The issue of resource use, as I have discussed it thus far, provides merely one case study of how legitimacy may be understood, but broader lessons can be gleaned from this study. In the next chapter, I re-visit the preceding Chapters and discuss how these results might contribute to the conceptual understanding of legitimacy and how competing or conflicting legitimations might be resolved. 


\section{CHAPTER 11}

\section{CONTRIBUTIONS TO A FRAMEWORK FOR UNDERSTANDING LEGITIMACY IN PROTECTED AREA GOVERNANCE AND MANAGEMENT}

\section{Introduction}

In the first few chapters of this dissertation, I argued that the concept of "legitimacy" is becoming increasingly important to the governance and management of protected areas. Democratization, decentralization, and a concern for human rights are but a few factors that have contributed to this importance. In South Africa, for instance, the historical management and governance of protected areas was best characterized as a technocratic and centralized approach that, at times, embraced the marginalization of those whom were, perhaps, most affected by the existence of those areas (Mabunda, Pienaar, and Verhoef 2003; Moore and Masuku van Damme 2002). With democratization in 1994, though, Kruger became a park-in-transition. The ascent to power of the black majority meant that the existence of protected areas like Kruger would fundamentally depend on the extent to which the new regime viewed their purpose, management, and governance of protected areas as legitimate.

This realization meant that the grounds upon which protected areas in South Africa were legitimated would change in significant ways. Most notably, the centralized, exclusionary, and bio-centric management and governance philosophies (which, in fact, were symbols of historic oppression to blacks) gave way to decentralization, inclusiveness, and human-oriented objectives. The emergent interest in access to Park 
resources for subsistence purposes, which was prohibited under historic protected area regimes, is but one derivative of this transition. But, while recognizing that a shift from the historic approach was in order, many of the constituent elements of a new, legitimate approach remain contested. In part, this is, perhaps, attributable to the fact that despite the evident interest in changing the way protected areas are governed and managed, there are also continuities that transcend the transition (e.g., the belief that protected areas should, to some extent, serve to protect biodiversity). Not all of the local residents I interviewed for this study, for example, felt that access to resources was legitimate, since they believed that collecting resources might damage Kruger's biodiversity. Protected areas worldwide, recognizing both the need for change and some continuity, are confronted with two very basic, but crucial, questions: (1) what actions and/or policies are legitimate in protected areas? and (2) how are competing or conflicting views of legitimacy resolved? These questions resonate strongly not only with Kruger and other protected areas in transitional societies, but any protected area subjected to multiple points of view and complex issues (i.e., almost all protected areas worldwide).

The purpose of this study was to respond to these two questions. I adopted a case-study approach by exploring the concept of legitimacy through resource use in Kruger, but I believe the lessons learned have applicability well beyond South Africa's boundaries. For instance, at a foundational level, this study might offer insight into the way legitimacy is conceptually understood in the context of protected areas. As I discussed in Chapter 2, the import of legitimacy appears to have grown considerably in protected area scholarship over the past few years, but to date, the concept has arguably 
been under-theorized and loosely employed. With this study, I attempted to respond to this knowledge gap by first exploring and synthesizing existing scholarship and then empirically investigating how legitimacy materializes in the context of a specific, important protected area issue. The findings of this study demonstrate that, if anything, legitimacy is a complex, multi-dimensional concept.

Rather than either a simple perception or a normative absolute (as some scholars might seem to have suggested), legitimacy may be conceptualized as being an indivisible coalescence of both perceptions and norms. Indeed, as the findings of this study illustrate, legitimacy is a construct that varies considerably depending on whom one is talking to. Just as some of the scholars discussed in Chapter 3 equated legitimacy with a particular normative edict, such as deliberative democracy or adherence to a constitution, each individual I spoke with offered their own brand of legitimacy. But, while the rationales upon which actions were deemed legitimate varied, the building blocks of those legitimations (or illegitimations, as the case may be) were often common across the different individuals I interviewed or surveyed. Context, for instance - whether historical or contemporary - was an important factor in determinations of legitimacy, as was the distinction between procedural and substantive considerations and how those considerations were filtered through moral, rational, pragmatic, conventional, and other factors. Legitimacy, while a widely varied and nuanced belief, was defined by a relatively small, common set of elements. In the next section, I discuss how these elements might contribute to a framework for understanding the legitimacy of protected area management and governance. 


\section{A Framework for Understanding Legitimacy}

In the latter part of Chapter 3, I articulated a conceptual framework for understanding legitimacy that I derived, in part, as a result of synthesizing a number of insights from the existing legitimacy-related scholarship (see Figure 11-1). Rather than a hypothesis per se, the framework offered one way of organizing my thoughts on the legitimacy of protected area management and governance. To a certain extent, this framework guided the questions I asked. "Context," for instance, is an important feature of the framework, and I asked questions in my interviews and surveys concerning the context within which different social actors exist (see, e.g., Chapter 5). Moreover, I asked Park staff, local residents, and Park visitors specific questions concerning "procedural legitimacy" versus "substantive legitimacy" - two other important elements of the framework. But, there were also a number of features of the framework that I did not ask about, opting to allow insights related to those elements to emerge from the data. For example, in the interviews I conducted, I did not ask respondents to comment on the legitimacy of resource use in terms of "morality, rationality, pragmatism, or conventionality" in an effort to deductively test the importance or merit of each. Instead, recognizing the exploratory dimension of this research, I asked respondents to speak freely as to why they believed resource use to be either a legitimate or illegitimate activity in the Park. In short, the framework served as a well-grounded, but unproven, means to conceptualize legitimacy that - in conjunction with the empirical insights from this study - might be a useful tool for understanding legitimacy in other protected area settings. 


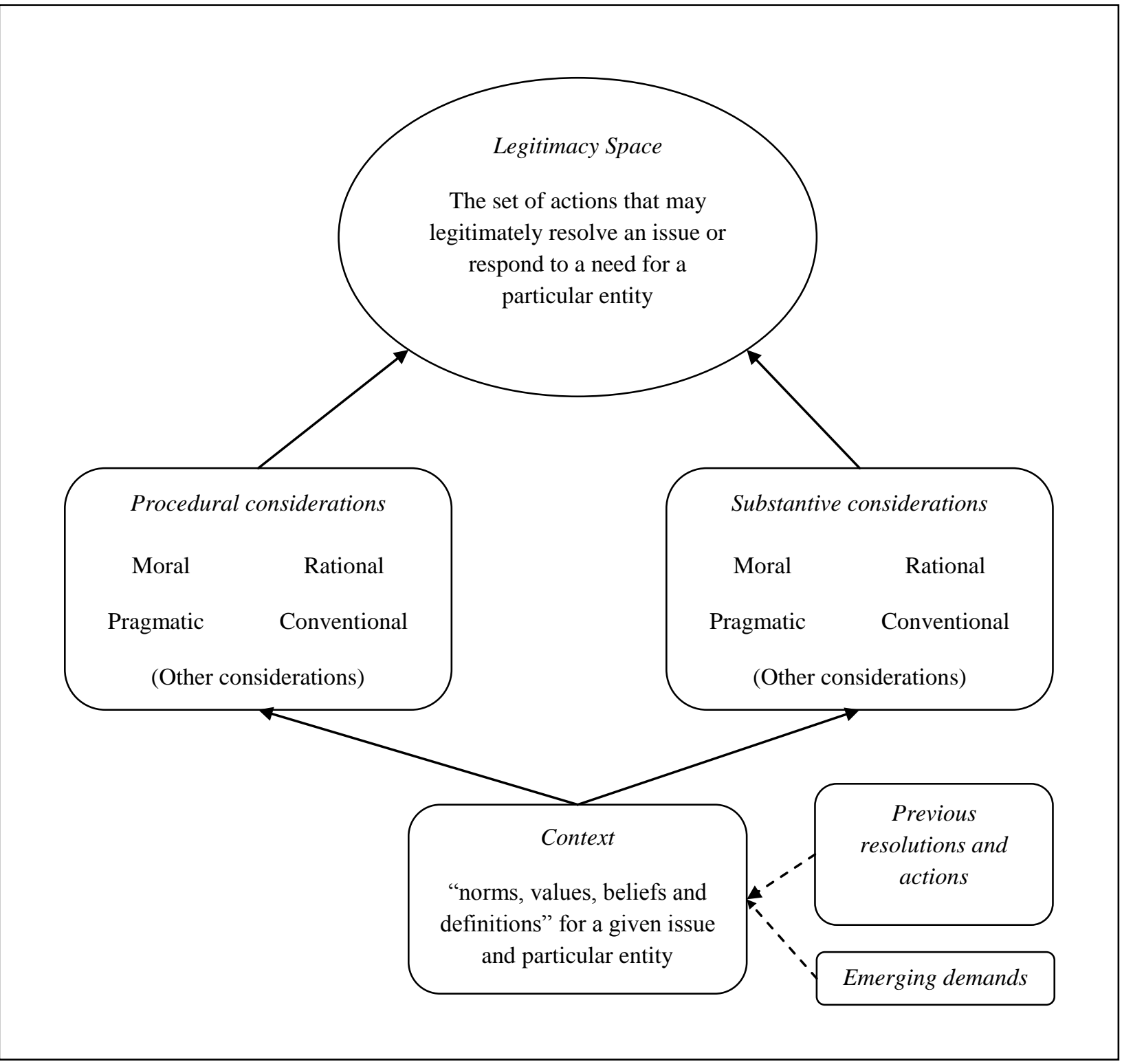

Figure 11- 1: A synthetic, conceptual framework for understanding legitimacy

\section{Legitimacy and context}

In social science research, it almost goes without saying that context matters. In our own personal lives, the values and beliefs that we espouse - indeed, our very essence - are products of our upbringing and surroundings, both historical and contemporary. 
And, if we accept, as Suchman (1995) contends, that legitimacy is a perception rooted in socially constructed norms, values, beliefs, and definitions, then context is, perhaps, the foundation of legitimacy. As illustrated in Figure 11-1, this becomes particularly apparent when recognizing the ways in which contextual factors contribute to the procedural and substantive considerations that ultimately shape the legitimacy of actions for a given issue.

As depicted in Figure 11-1, previous actions and resolutions taken in the course of managing and governing protected areas can shape the contexts within which social actors exist. Resource use among local residents for subsistence purposes has been, with few exceptions, effectively prohibited in Kruger since the Park's establishment. The view that resource use was inimical to the park ethic (i.e., an illegitimate activity) was a product of the power held by Dutch and British colonialists and their underlying norms, values, beliefs, and definitions that led them to establish parks. Because colonialists had a monopoly on power within South Africa (of which they maintained until democratization in 1994), they reserved the right to adopt and implement their brand of legitimacy. Needless to say, their "legitimacy space," as it is described in Figure 11-1, did not likely overlap in any significant way with that of the groups living near Kruger who were forcefully removed and marginalized from governance and management of the Park. As such, the contextual factors that defined the colonial and Apartheid era gave rise to a very particular definition of what activities were considered legitimate in Parks, and more specifically, Kruger. 
As I've discussed at length throughout this dissertation, though, with democratization, the context within which parks in South Africa exist changed dramatically. Over the span of less than a decade, resource use went from being an absolute prohibition to an issue high on the agenda of parks in South Africa. In effect, this transition was the result of contextual changes concerning the societal balance of power. New norms, values, beliefs, and definitions were recognized and so, too, were different conceptualizations of legitimacy.

Prior to democratization, the societal context gave rise a number of procedural and substantive considerations that shaped the legitimacy of protected area governance and management. From a procedural perspective, governance and management were legitimated to the extent that they aligned with the technocratic and rational approach driven by scientific management. Coupled with this procedural element were substantive considerations that, for instance, deemed actions legitimate when they reflected the moral axiom to preserve nature as a symbol of national heritage. Following democratization, these considerations were joined by the emerging procedural and substantive considerations of previously marginalized groups. Because, for example, local, black residents had been excluded from governance and management, involvement and consultation have become important procedural considerations when assessing the legitimacy of any action taken by the Park. Moreover, from the perspective of local residents, the changing context has translated to the delivery of benefits being an important substantive consideration of any action which involves the relationship between the Park and local residents. In other words, because of forced removals and 
exclusion, the legitimacy of Park actions affecting local residents is, in part, substantively dependent on the extent to which local residents benefit from the Park (and, in effect, are compensated for past actions taken by the Park administration).

Contextual factors are also important when considering the types of benefits that local residents hope or expect to derive from the Park. Without, for instance, the benefit of having explored the contextual factors surrounding the provision of access to resources, many Park staff that I spoke with before I collected data suspected that such a benefit would be in high demand among local residents and that they would view resource use in the Park as an entirely legitimate activity. As I interviewed local residents, though, it became apparent that while many local residents did have an interest in accessing resources in the Park, the contemporary livelihoods of local residents led them to place a higher premium on developmental assistance than resources use. Moreover, many felt that resource use was, in fact, illegitimate because it undermined what they believed to be the more important benefits associated with eco-tourism and employment opportunities. Not only do these contextual considerations provide insight into how local residents legitimize resource use, but they present important opportunities resolving the resource use issue.

When it comes to the management and governance of protected areas, then, it is critical to understand the context in order to understand how various groups conceptualize the legitimacy of particular actions. For the purposes of this study, contextual factors were explored through interviews and surveys, but this is by no means the only way to arrive at an understanding of context. The deliberative democracy 
championed by Habermas, Valadez, and others (see Chapter 3) provides a procedural approach to governance and management that is designed to elicit the underlying norms, values, beliefs, and definitions that constitute the social contexts for a variety of groups. Irrespective of the means by which decision-makers arrive at an understanding of contextual factors, it is the exploration of these factors that provides the rationale for the more refined procedural and substantive considerations that directly shape assessments of legitimacy.

\section{Dimensions of legitimacy}

Few scholars who have studied the concept of legitimacy make the explicit distinction between procedural and substantive considerations. Barnard (2001) being a notable exception, most have characterized legitimacy as either an almost exclusively procedural concept (see, e.g., Habermas) or a clouded mix of process and substance (see, e.g., Rawls and Arneson). As this study illustrates, though, the distinction between procedural and substantive considerations, as well as the way in which the respective considerations can be further deconstructed (e.g., in terms of morality, rationality, pragmatism, conventionality, etc.) provide important insights into how legitimacy is conceptualized and how protected area issues are resolved.

The manner in which some Park staff conceptualized the legitimacy of resource use provides an example of why it is important to recognize both substantive and procedural considerations. If viewed from purely substantive perspective, the data I collected from Park staff would suggest that resource use is largely viewed as an 
illegitimate activity among Park staff. Many Park staff maintained that there is a moral responsibility to protect biodiversity and that there is simply not enough evidence to suggest that resource use could proceed without infringing upon that biodiversity. On these grounds alone, many felt that resource use was an illegitimate activity. If, however, the process through which resource use was implemented was carefully considered and implemented in a way that was consistent with the principles of adaptive management (e.g., small-scale experimentation), it appeared that many staff who viewed resource use as substantively illegitimate would more generally render resource use a legitimate activity on the basis of these procedural considerations.

The manner in which local residents conceptualized the legitimacy of resource use and benefits more broadly defined also reveal the importance of explicitly identifying the considerations associated with both process and substance. Recognizing the contextual factors surrounding local residents' historic role in the governance and management of Kruger, their contemporary role in such processes has become exceedingly important to them. With democratization came the expectation that decision-making in the Park would be open, consultative, and inclusive. As such, even if a resource use policy or plan for providing developmental assistance were crafted that heavily favored the interests of local residents, they might ultimately be viewed as illegitimate if the policy or plan were not developed and implemented in what local residents judged to be an appropriate manner. Indeed, the local residents I spoke with felt that any decision-making process concerning their relationship with the Park should be consultative, but perhaps most importantly, the Park must demonstrate that they "want" 
the input of local residents rather than merely "needing" it to satisfy some legal requirement.

Of course, the converse is true, as well - it might not be possible to legitimate a policy or action solely on procedural grounds. Even if, for instance, Park staff engaged local residents in a truly consultative decision-making process concerning resource use that local residents widely held to be legitimate, the broader legitimacy of the way in which the issue was resolved would likely substantially depend on the substantive nature and consequences of the resolution. This is a particularly important observation in terms of resource use. If the Kruger staff earnestly engaged local residents and truly "wanted" their input on the resource use issue, and as a result, developed a resource use policy, it is possible that the policy might still be viewed as illegitimate. As I discussed in Chapter 10 , this possibility might be attributable to the contextual and substantive considerations that render developmental assistance a higher priority than resource use. Parks and protected areas can implement progressive and inclusive processes as they engage stakeholders, but if those processes do not address the issues that are most important to those involved, then those processes and any associated outcomes might very well be deemed illegitimate.

Beyond the distinction between procedural and substantive considerations, another important element of this framework is a more refined deconstruction aimed at identifying the bases upon which those considerations are made. To merely say that resource use is illegitimate or that the process for developing a resource use policy is legitimate is only marginally informative. If competing and/or conflicting views of 
legitimacy are to be reconciled and complex issues resolved, there is a need to know why individuals harbor particular procedural or substantive beliefs. At the end of Chapter 3, I discussed how, on the basis of a synthetic reflection on the existing scholarship, judgments of procedural and substantive legitimacy may be described in terms of moral, rational, pragmatic, conventional, or other dimensions. And, while I did not ask respondents to comment on the legitimacy of resource use in terms of these factors, the data suggest that they were important in the conceptualizations of legitimacy.

Morality, for example, played an important role in the procedural and substantive considerations for all three groups that I spoke with. A number of visitors and managers alike commented that resource use is a morally illegitimate activity in the Park, as it goes against the very value and purpose of the Park. Local residents on the other hand argued that, in light of their historical relationship with the Park, the Park has a moral responsibility to provide benefits to local residents as a form of compensation, whether in the form of access to resources or otherwise. Moreover, as discussed above, the belief that decision-making processes should be consultative and inclusive is, in part, a reflection of the assumption that Parks are morally obligated to involve local residents who are often impacted by Park-related decisions.

Pragmatism - whether or not the procedural or substantive features of an action meet a specific interest - also featured strongly in the various conceptualizations of legitimacy. Frequently, that is, individuals or groups might believe an action to be appropriate because it satisfies some need or interest they have. Rather than being based on the moral belief that Kruger should provide access to resources as a form of 
compensation, many local residents that I spoke with felt resource use was legitimate primarily because it served a practical need they had for firewood, medicinal plants, thatching grass, etc.

Rationality - the extent to which the procedural or substantive elements of an action are logical or "make sense," was an important dimension for some that I spoke with. In terms of procedural rationality, many staff that I spoke with felt that resource use was a legitimate activity as long as the process for its implementation followed the logic of adaptive management. In short, adaptive management has come to be the framework by which the rationality of the management process in Kruger is defined. If management actions follow the logic of adaptive management then they are likely to be construed as procedurally legitimate. Rationality also played a key role for some local residents in their substantive assessments of the legitimacy of resource use. Some, for instance, argued that the provision of access to resources was legitimate precisely because it was rational or logical to expect that, since the Park has numerous resources compared to what is found outside its boundaries, the Park would share those resources with surrounding communities.

Conventionality - the degree to which the process and substance associated with an action comport with laws, policies, or other informal guidelines - is another dimension that emerged in the various conceptualizations of legitimacy. This dimension was most evident in some Park staffs' substantive legitimations of resource use. For these individuals, resource use was substantively legitimate because the Protected Areas Act provides that parks must consider allowing resource use and that by allowing resource 
use, Kruger would fulfill its mandate to both provide human benefits and build constituencies for the Park.

In employing this framework for understanding the legitimacy of protected area governance and management, care must be taken to not over-simplify the dimensionality of procedural and substantive considerations. It, for instance, might often not be possible to reduce these considerations in terms of purely moral, pragmatic, rational, conventional or other dimensions. Instead, it is likely that the considerations giving rise to assessments of legitimacy are a complex composite of these dimensions. Consider the following statement paraphrasing a commonly held sentiment among local residents: "It is legitimate for Kruger to provide developmental assistance to local residents, because we need that assistance." On the surface, there is a clear pragmatic dimension to this consideration - there is a practical need or interest that local residents are looking to meet through assistance (i.e., livelihood improvement). But, there is also a latent, moral dimension to this statement. As many local residents suggested, they need the assistance from Kruger in particular because it is Kruger who - on account of the nature of the historical relationship between the Park and surrounding peoples - is morally obligated to provide those benefits as a means of compensation. In essence, benefit provision serves a pragmatic need for livelihood improvement (which could be provided by any number of government agencies) and a pragmatic need to redress moral wrongs (which, arguably, can only be provided by Kruger). Legitimacy might be established on pragmatic grounds, but the pragmatic interests or needs could be both instrumental and moral (or, for that matter, rational or conventional) in nature. 
Perhaps too often, actions are characterized as "legitimate" or "illegitimate" without explicitly identifying the bases on which those claims are made. If anything, though, legitimacy is a nuanced concept that requires an examination of its contributing context, considerations, and dimensionality if it is to be properly understood. The exercise of this deconstruction is not only useful from a descriptive perspective, but it is also instructive for efforts to identify the suite of actions that might legitimately resolve protected area issues.

\section{Legitimacy and the resolution of protected area issues}

As illustrated in Figure 11-1, context, procedural, and substantive considerations, as well as their attendant dimensionality, may be thought of as the principle factors that contribute to perceptions of legitimacy. One important value of understanding legitimacy in this way is that it facilitates the identification of a set of actions that might legitimately resolve an issue for a group or individual (i.e., that group or individual's "legitimacy space").

\section{Deciding which legitimations to recognize}

To say that this approach to understanding legitimacy "facilitates the identification of a set of actions that might legitimately resolve an issue for a group or individual" implies at least two assumptions worth mentioning. First, legitimacy's unit of analysis is two-dimensional - one dimension being the issue and the other being the constituency (whether a group or individual). This assumption communicates that "the 
legitimacy of a protected area" is more of an issue-by-issue and constituency-byconstituency assessment than a global truth.

Second, the legitimacy of a protected area organization's actions is not tantamount to its comprehensive responsiveness to the demands of all its constituencies. In fact, the failure or unwillingness to respond to certain demands or strive for particular outcomes may be the most legitimate course of action. For instance, within Kruger there are no fences alongside the road that prevent wildlife from crossing the roads or threatening tourists while they're in their vehicles (e.g., sometimes elephants on the Park's roadways will charge at vehicles). One visitor I spoke with remarked they wished the Park would construct fencing alongside all of the roads in Kruger to (1) prevent wildlife from coming on the roads and (2) enable visitors to get out of their vehicles and walk along the road. Should Kruger respond to such a demand? If the Park is to be viewed legitimately by that visitor, then, perhaps. On the other hand, one might reasonably expect that most other visitors view the failure to respond to such a demand as legitimate. In this respect, legitimacy, like beauty, is in the eye of the beholder. The question protected area organizations must ask themselves is - who's view of legitimacy matters?

The question of "whose version of legitimacy matters" and its corollary, "when is it okay to marginalize a particular group," points to the value of a critical understanding of legitimacy. As discussed in Chapter 4, critical theory calls attention to the resolution of inconsistencies between what is intersubjectively desired among a group and the existent, but socially constructed, reality. From a critical theory perspective the question may be 
re-framed as - are there circumstances in which certain inconsistencies among certain groups or individuals are okay? The answer is most certainly "yes," but the question of whether or not the response should be "yes" for a particular group and a given issue is not as easily answered.

Whether or not the response should be "yes" for a particular group and a given issue depends on whether the way in which that group conceptualizes the legitimacy of the given issue comports with the values promoted by the broader, socially constructed reality. It is important to note, though, that broader, socially constructed reality is by no means static, which implies that what failed to comport with the reality yesterday may comport with it today. What was illegitimate yesterday, then, may be legitimate today.

Consider the issue of resource use in Kruger and the group of local residents who felt that resource use is a legitimate activity in the Park. Their legitimation of resource use was frequently characterized by (1) a morality dimension that highlighted redress for past wrongs, (2) a pragmatic dimension that highlighted a practical need for resources, and (3) a rational need that highlighted the imbalance of resources existing in the Park as compared to outside the Park. At the risk of overgeneralizing, we might posit that the broad, socially constructed reality promotes the values of redress for past wrongs, the provision of basic livelihood needs, and, perhaps, the equitable (but not necessarily equal) distribution of goods. Thus, at least on those points, the manner in which those local residents conceptualize the legitimacy of resource use may be said to comport with the values promoted by the broader, socially constructed reality. However, there are also other values that the broader, socially constructed reality promotes, such as the protection 
of endangered species, that might conflict with the legitimations of those local residents. In such a situation, deciding whether or not local residents should be marginalized (i.e., taking no steps to resolve the inconsistency between what they desire and what exists) is, perhaps, a balancing act. Will, for instance, the values promoted by the broader, socially constructed reality be undermined or well-served by failing to resolve the inconsistency?

Two points are worth raising regarding the balancing of legitimations against the values promoted by the broader, socially constructed reality. First, the more dimensions that an issue is legitimated (or illegitimated) upon and the more well-developed those legitimations (or illegitimations) are, the easier it is to balance the collective legitimation of an issue against the values promoted by the broader, socially constructed reality. For instance, that the local residents discussed above conceptualize the legitimacy of resource use in at least three relatively well-developed dimensions makes it easier to balance their legitimation of resource use against the broader, socially constructed reality than if their legitimation was based solely on the dimension of morality. Then, the question would be which moral is of more value to the broader, socially constructed reality - redress for historical wrongs or the protection of endangered species. In short, the more information that is available regarding how and why a group legitimates an issue, the easier it is to understand whether that legitimation comports with the values promoted by the broader, socially constructed reality.

As alluded to above, though, understanding legitimacy in this way requires that one constantly re-evaluate the values that the broader, socially constructed reality seeks to promote. Currently, it would appear that the values promoted by the socially 
constructed South African reality are changing in a way that is tending to be more aligned with resource use than it was in the past. This recognition means that not only must society critically examine the manner in which legitimations comport with the values promoted by the broader, socially constructed reality, but society must also critically reflect on those promoted values, as well.

\section{$\underline{\text { Reconciling multiple legitimations: "legitimacy spaces" }}$}

When a particular issue involves multiple groups or individuals, it is possible that their respective legitimations may promote the values of the broader, socially constructed reality and, yet, still conflict or compete with one another. Given that this is, perhaps, the norm rather than the exception, it is important to understand how those competing or conflicting legitimations are resolved. Every group or individual that is able to articulate a conceptualization of the legitimacy of a particular action has an associated "legitimacy space" within which legitimate actions exist. For instance, the legitimacy space of local residents who believe resource use is legitimate has, at least as one point, the action of allowing resource use (see Figure 11-2). On the other hand the action of forbidding resource use is not in their legitimacy space. For some, though, an express prohibition of resource use is the sole point in their legitimacy space. When the legitimations (or illegitimations as the case may be) of several groups comport with the broader, socially constructed reality but, yet, conflict or compete with one another, resolving a particular issue involves locating where their respective legitimacy spaces intersect. 


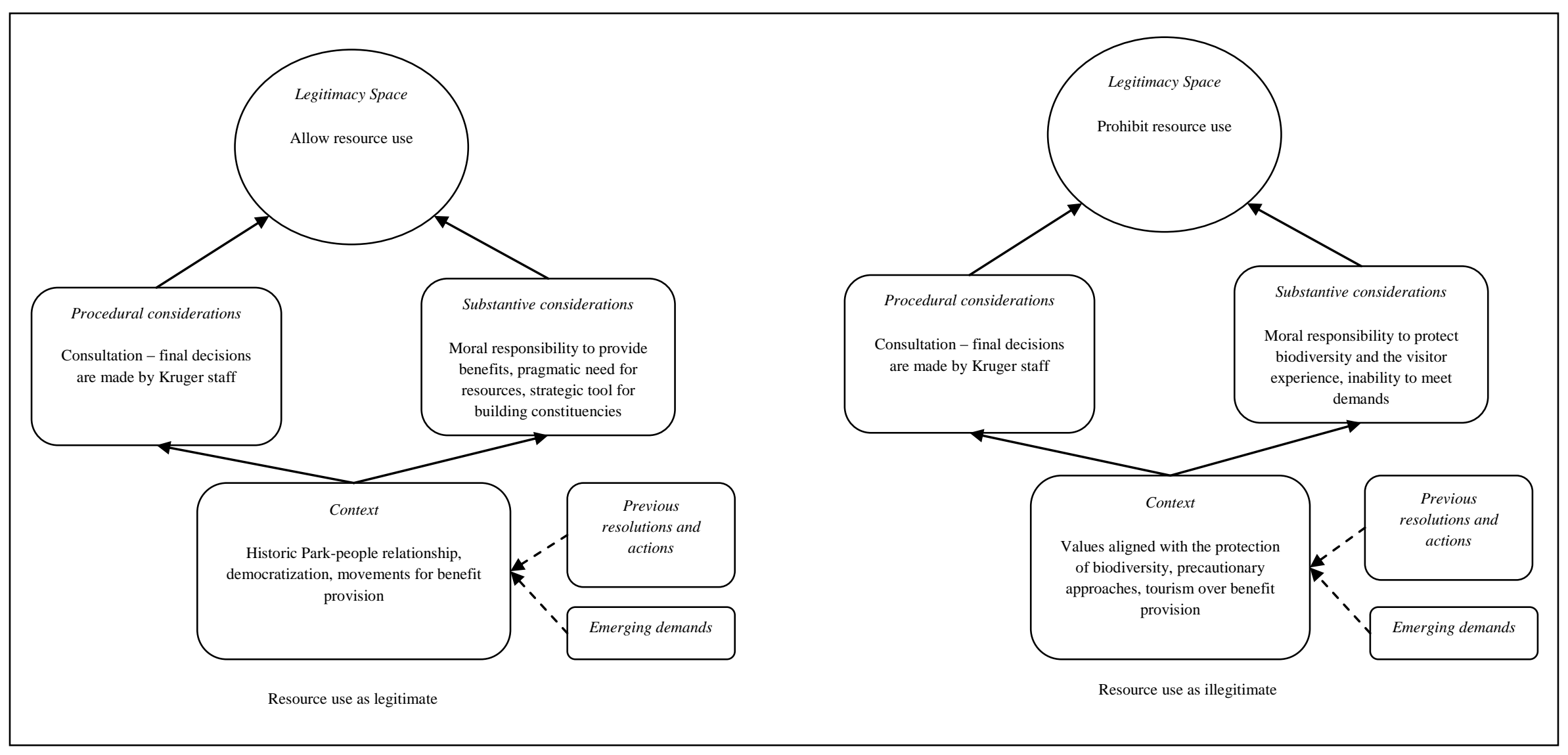

Figure 11-2: Divergent conceptualizations of the legitimacy of resource use 
Resource use in Kruger provides an excellent example of an issue where attentiveness to the concept of legitimacy spaces can facilitate the identification of resolutions that are believed to be legitimate by a diverse set of social actors. Among the Park staff, local residents, and Park visitors I spoke with, it would seem that there are three main, direct responses to the resource use question - access can either be (1) prohibited as it has in the past, (2) provided liberally to local residents with few restrictions, or (3) provided on an experimental basis where appropriate levels of use are determined through adaptive management processes.

As discussed earlier in this dissertation, while these three responses provide the anchor points of a spectrum of approaches that were deemed legitimate, the data I collected suggests that most do not define their conceptualization of legitimacy simply by a single point. ${ }^{52}$ Rather, while some believe that prohibiting resource use is a legitimate response, they might also believe that adopting an adaptive approach to permitting resource use is legitimate, as well. Similarly, those who felt that a liberal provision of access to resources is legitimate also felt that an adaptive approach was legitimate, too.

Nevertheless, if resolving the resource use issue were to be undertaken merely by responding directly to the issue itself, then there is not likely an opportunity to resolve the issue in a way that immediately or ultimately meets a substantial share of local residents' needs. As discussed in the previous chapter, the demand for access to resources among some local residents might be a proxy for broader developmental needs, which are of

\footnotetext{
${ }^{52}$ Of course, some do hold uncompromising views on both ends, but most of those whom I spoke with considered an adaptive approach to allowing resource use, coupled with complementary or alternative strategies of providing benefits, to be a legitimate approach.
} 
more importance than access to resources. Consequently, local residents might likely view the provision of developmental assistance, which may or may not be accompanied by the provision of access to resources, as a legitimate (albeit indirect) resolution to the resource use issue. Moreover, given the Park's expressed interest in providing human benefits and building constituencies for the Park, both those staff who view the provision of access to resources as legitimate and those who do not seem willing to embrace alternative or indirect resolutions to the resource use issue (e.g., a community levy) if those resolutions serve that expressed interest. Based on the visitor survey results, a similar conclusion might be drawn for Park visitors who seemed to view a community levy, for instance, more favorably than the provision of access to resources. In effect, by considering these underlying factors, the two legitimacy spaces are broadened to include indirect resolutions that gives rise to the possibility of an outcome that exhibits a more widely shared perception of legitimacy than if only direct responses to the issue were considered (see Figure 11-3). ${ }^{53}$

There is, of course, a range of ways in which the legitimacy spaces of groups overlap for a given issue. If, for the sake of simplicity, we consider only three groups, there are four basic scenarios concerning the way in which the associated legitimacy spaces relate to one another (see Figure 11-4). First, all three groups may be completely aligned with one another. This scenario most likely occurs when problems are technical

\footnotetext{
${ }^{53}$ These considerations do, though, give rise to a third legitimacy space where both resource use and developmental assistance are viewed as illegitimate. It's the separation between this space and the other two that highlights an important philosophical question that public protected areas, such as Kruger, must confront - namely, whether it is legitimate to provide a certain set of benefits to a sector of society at the expense of another?
} 


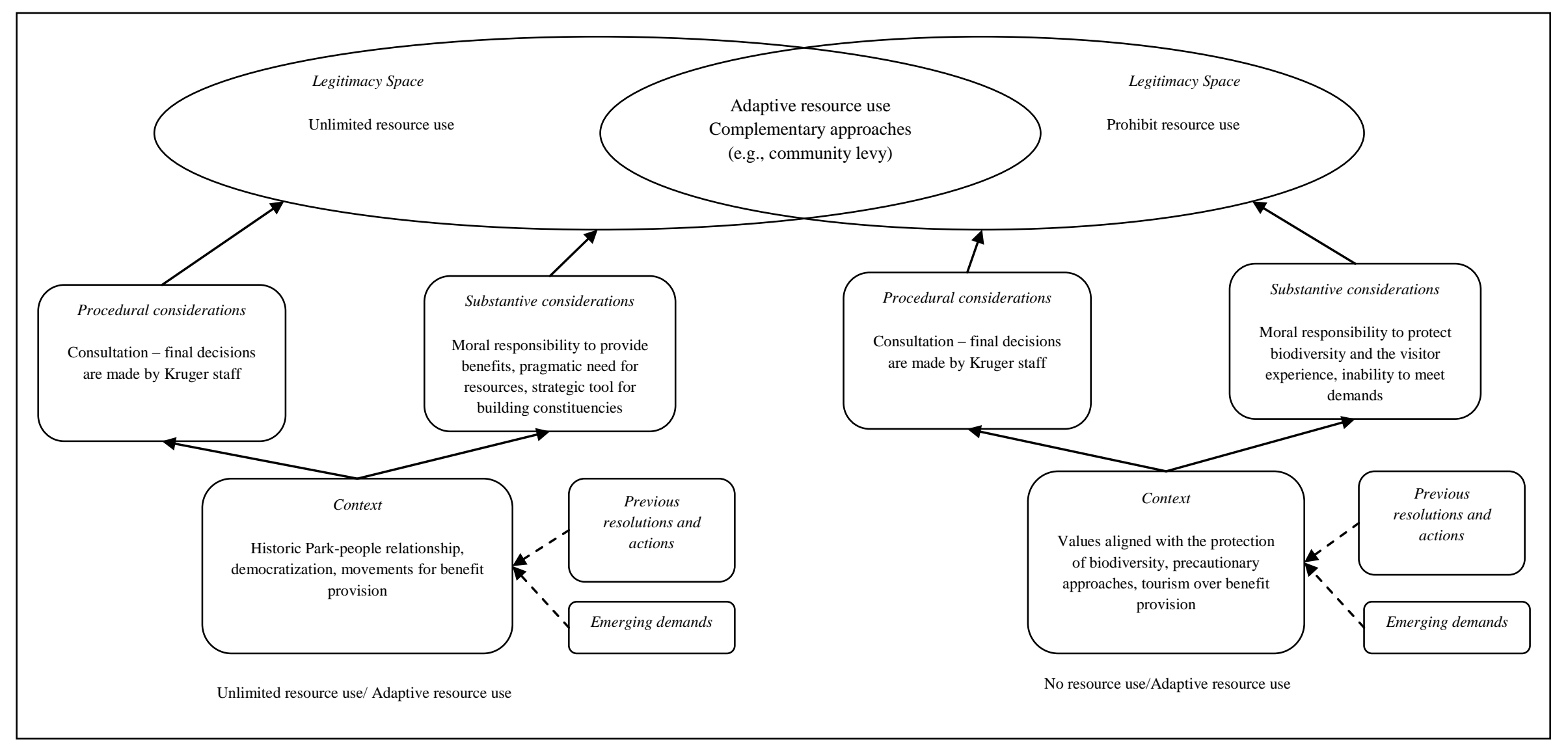

Figure 11-3: Intersecting legitimacy spaces of resource use 


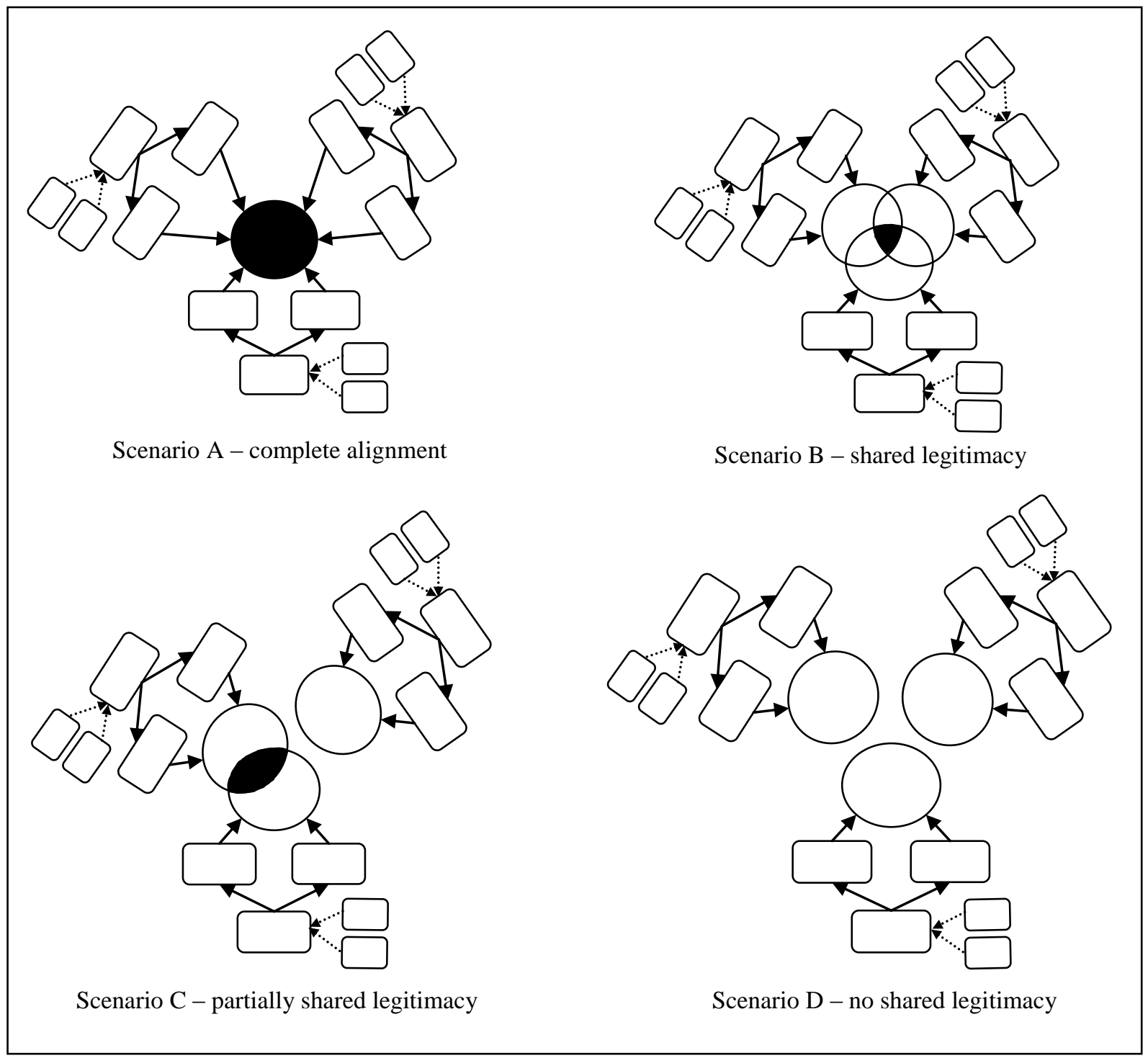

Figure 11- 4: Scenarios for shared perceptions of legitimacy

in nature and selecting a resolution is relatively straight-forward. ${ }^{54}$ Alternatively, as illustrated in Scenario B, the various actions that the three groups view as legitimate for a given issue might not be entirely aligned, but the legitimacy spaces could overlap to the

\footnotetext{
54 See, e.g., the discussion of "messy" or "wicked" problems in Lachapelle, McCool, and Patterson (2003), Allen and Gould (1986), and McCool and Guthrie (2001).
} 
extent that a resolution might be found that is viewed as legitimate by all three groups. Or, as depicted in Scenario C, it might be the case that only two groups share any common ground in terms of what actions might be legitimately responsive to a particular issue. Finally, Scenario D presents a situation where there is no overlap among any of the three groups concerning legitimate ways to resolve an issue. Here, the contextual factors for each group (including their values, beliefs, norms, and definitions) and the resultant substantive and procedural considerations related to the issue are so different that it is not likely that the issue will be resolved in a way that all (or even multiple) parties believe to be legitimate. This situation is commonly characterized by what some have called a "messy" or "wicked" problem "typified by multiple and competing goals, little scientific agreement on cause-effect relationships, limited time and resources, lack of information, and structural inequities in access to information and the distribution of power" (Lachapelle, McCool, and Patterson 2003). ${ }^{55}$

The scenario that groups find themselves in for a particular issue depends on a number of factors - one important factor being how broadly or narrowly the groups legitimacy spaces are defined. If, for example, a particular group with an interest in resource use felt that (1) substantively speaking, access to resources must be provided to local residents in order to meet their subsistence needs and that the Park was morally obliged to provide access at a level that would meet all of their needs, and (2) procedurally speaking, the Park must provide such access immediately and in conjunction with the involvement of local residents, then this group's legitimacy space is defined

\footnotetext{
${ }^{55}$ See also Allen and Gould (1986) and McCool and Guthrie (2001).
} 
relatively narrowly. If the views of other groups or individuals are even slightly different, then it is unlikely that a resolution can be crafted that results in any shared belief of legitimacy.

If, however, the goal in resolving a particular issue is to resolve it in a manner where as many groups or individuals as possible view the resolution as legitimate, then this goal is most likely achieved if the legitimacy spaces of the groups involved are broadly rather than narrowly defined. This is not to say that a resolution that is widely held to be legitimate cannot be found if the legitimacy spaces are predominantly narrow, ${ }^{56}$ but the likelihood of arriving at such a widely held belief is, perhaps, increased as the spaces are more broadly defined.

\section{Conclusion}

Of course, the analysis associated with the framework presented in this chapter will not always yield a resolution that all affected parties (or any for that matter) view as legitimate. Many complex issues concerning the management and governance of protected areas are characterized by conflicting or competing values, norms, beliefs, and definitions that ultimately give rise to legitimacy spaces that are far from intersecting. In such instances, the framework discussed above does not offer a prescription as to how the "right" or "true" conceptualization of legitimacy is identified. In such instances, the question of whose morality, interests, or logic are correct is most likely a question of both power and law. As this study demonstrates, though, it might also be true that rather than

\footnotetext{
56 This might very well be true in instances where many sectors of society share common views pertaining to the issue in question.
} 
necessitating the exercise of power and law, resolving the myriad complex issues that protected areas and their constituents are confronted with might be achieved by recognizing and appreciating the various ways that legitimacy is conceptualized. 


\section{CHAPTER 12}

\section{CONCLUSION}

In the introduction to this dissertation, I argued that protected areas are frequently confronted with the fundamental, but equally exacting and onerous, question of for whom and why do they exist? Resource use in Kruger National Park is but one issue that exemplifies both the features of this question and the inherent challenges of responding to it. Moreover, this study demonstrates that the response to this question is a function of legitimacy. In fact, the complexity of protected area governance and management is, perhaps, most firmly rooted in the difficulty of establishing or engendering the belief of legitimacy across the wide range of groups and individuals with a stake in protected areas. Such complexity, though, not necessarily insurmountable. By exploring the various ways in which different groups and individuals conceptualize the legitimacy of a particular action, it is possible to identify potential resolutions to the most challenging issues that protected areas are faced with.

This dissertation offers one of an infinite number of possible studies of legitimacy and protected areas. As a case study, this research was highly contextual, but there were key lessons learned that might be useful as the concept of legitimacy is explored in other protected areas. Summarized below are what I believe to be five fundamental lessons that this dissertation illustrates.

Lesson 1: Actions are legitimated or illegitimated on the basis of a number of factors.

This study demonstrates that different groups, and even individuals within a particular group, may conceptualize the legitimacy of actions in very different ways and based on a number of different factors. The historical relationship between the Park and local residents, for instance, has significantly shaped the manner in which local residents 
legitimate the provision of benefits from the Park. As such, it is likely that the legitimacy of a particular action will not be adequately understood without exploring the underlying factors and considerations that contribute to the perceptions of legitimacy. The framework discussed in Chapter 11 is, perhaps, one useful way in which these underlying factors may be understood.

Lesson 2: Legitimacy is dynamic.

For a variety of reasons, the way in which the legitimacy of actions are conceptualized may change in fundamental ways. For the South Africa National Parks organization, resource use is transitioning from a moral anathema to a pragmatic and legitimate means of fulfilling a Park mandate. Legitimacy, then, is not a perception that, once established, is static. As the context within which protected areas exist changes, so, too, does the manner in which legitimacy is conceptualized. Consequently, the legitimacy of protected area governance and management must be monitored and re-evaluated on a regular basis.

Lesson 3: Understanding how various social actors conceptualize the legitimacy of actions can contribute to a better understanding of how issues might be resolved.

Without articulating how Park staff, local residents, and Park visitors conceptualize the legitimacy of resource use, there would appear to be little opportunity to resolve the issue in a way that engenders a shared perception of legitimacy. By recognizing, though, the various substantive and procedural considerations that contribute to assessments of the legitimacy of resource use, possible resolution begin to materialize. Because of the contextual considerations that, for local residents, place a higher premium on developmental assistance, the underlying interests upon which resource was legitimated by Park staff, local residents, and Park visitors may be served by a greater set of possible actions. Opportunities, then, for resolving issues in ways that are widely viewed as legitimate are either constrained or expanded by the way in which legitimacy is conceptualized.

Lesson 4: Multi-dimensional and well-developed conceptualizations of legitimacy make it easier to determine whether or not a group or individual's legitimation of an action should be recognized. 
Deciding whose conceptualization of legitimacy matters depends in part on whether or not a group or individual's conceptualization of legitimacy should be acknowledged in the first place. A critical approach to understanding legitimacy can assist in such determinations. An important question is whether the legitimation of a group or individual comports with the values promoted by the broader, socially constructed reality. If they do, then groups or individuals subscribing to such legitimations should not be marginalized. However, it must be recognized that the values promoted by the broader, socially constructed reality are dynamic and should be critically assessed, as well.

Lesson 5: Direct responses to issues might not always be the most legitimate responses.

Related to Lesson 3 above, by recognizing the various ways in which legitimacy is conceptualized, it may be true that some issues can be legitimately resolved through indirect responses rather than direct responses. In the case of resource use, rather than either simply prohibiting resource use or providing for it, indirectly responding to the underlying interests in question by providing some other form of developmental assistance may constitute a resolution that is more widely believed to be legitimate.

Lesson 6: Assessing whose conceptualization of legitimacy matters requires decision-makers to marginalize some constituencies.

For almost every complex protected area issue, it is highly unlikely that decision-makers will elect a course of action that is universally held to be legitimate. For instance, while many would likely deem an adaptive approach to resource use, coupled with complementary or alternative strategies, to be a legitimate resolution to the resource use issue, there are those who would not (e.g., those who believe only unlimited access should be provided or that access should be entirely prohibited). Thus, decision-makers are forced with making the difficult decision of marginalizing some constituencies.

In no small part, the validity and ultimately the merit of these lessons are a function of the strengths and limitations of the manner in which this research was undertaken. In terms of 
strengths, this study incorporated both an exhaustive review of how legitimacy has been understood across a wide array of disciplines and an expansive set of empirical data that, through rigorous and systematic analysis, provides new insights into how legitimacy may be understood. The findings and discussion of this analysis are of utility not only from a conceptual perspective but also from a practical perspective, as resource use - the lens through which legitimacy was explored in this study - is an issue of great importance to Kruger and many other protected areas worldwide.

Study limitations are a reality of research and while the limitations discussed in Chapter 4 likely impacted this study in some way, I believe the strengths overshadow those possible impacts. Nevertheless, with the luxury of hindsight, there are changes to the approach and design if this research if I were able to do it again. First and foremost, if I had the luxury of time, I would have benefited enormously from language training in Venda, Shangaan, Xhosa, and Afrikaans. Mutli-cultural research is difficult even if one speaks the language in question, and in the absence of any familiarity with the languages of those one is, for instance, interviewing, that difficulty is further compounded. A basic knowledge of the languages spoken by local residents (e.g., Venda, Shangaan, and Xhosa) would have allowed me to, perhaps, have a richer understanding of the interview data. Similarly, while all but a few of the Park visitors I spoke with were fluent in English, familiarity with the Afrikaans language would have likely engendered a higher level of rapport with many of the South African visitors.

If I were to conduct another visitor survey in Kruger, the most significant change that I would make to the design would be to implement measures to increase the response rate. For instance, rather than providing questionnaires to visitors at gates or camps and then asking them to drop the survey off at a camp, I would likely ask sampled visitors to fill out a postcard with 
their name and address and then I would send them a survey to be mailed back (postage paid) to a central location in Kruger. Of course, there is no guarantee that this strategy would ultimately result in a higher response rate, but mailing back the survey might be more convenient for visitors than trying to remember to drop it off at a rest camp.

Finally, provided I had the time to do so, it would be beneficial to distribute the questionnaires at various times throughout the year (rather than only during the winter) in order to reduce any seasonal bias. As many Park staff commented, during the winter season, there was likely a disproportionately high number of domestic visitors compared to international visitors. Recognizing the dramatically different ways in which international visitors responded to some of the survey questions, it is likely that some of the statistical analyses (e.g., the logistic regression) would have different outcomes.

An important lesson learned from this study not presented above is that there are still many important lessons to be learned regarding the legitimacy of protected area governance and management. Legitimacy is a relatively nascent area of interest to protected area scholars and there remains a considerable amount of conceptual and practical ground to cover. First, it would be valuable to study just how the robustness, efficiency, and/or effectiveness of actions widely perceived as legitimate compare to that of actions widely believed to be illegitimate. Is it possible, for instance, that because of the complexity involved in crafting a legitimate resolution to an issue that there are (1) more "stress points" where things can go wrong or (2) because of inevitable compromises made in crafting resolutions that engender a shared belief in legitimacy, the resolution is "watered-down" to the extent that it fails to meet its objectives?

Second, longitudinal studies of legitimacy would be extraordinarily valuable. In terms of resource use in Kruger, it would be very instructive to document the implementation of a 
resource use policy and any other corresponding actions (e.g., a community levy) to see whether or not the response to the resource use issue is, in fact, widely perceived as legitimate.

Moreover, with such a study, it would also be helpful to develop a framework for understanding how the legitimacy of a resolution may be monitored. As discussed throughout this dissertation, as contextual factors change so, too, do perceptions of legitimacy. With longitudinal studies, it might be possible to identify those factors and considerations that most substantially influenced changes in the perceptions of legitimacy.

Third, from both a practical and conceptual perspective, it would be useful to explore the legitimacy of actions designed to provide developmental assistance to those living near protected areas. "Benefits beyond boundaries" was the mantra of the last World Parks Congress in South Africa, but the legitimacy of providing publicly derived benefits to private entities is likely to be contested. For instance, $43.6 \%$ of those visitors surveyed believed that Kruger should not provide benefits to local residents. Admittedly, the provision of access to resources is effectively the provision of a public good to local, private entities (though, if a resource use policy were implemented, it might very well be open to the public-at-large), but actions such as a community levy might likely raise concerns that the provision of access does not. It could, for instance, as suggested in this study be perceived as a more legitimate benefit, or because of the financial nature of a community levy, it is possible that such actions could be perceived as a dangerous precedent. In either case, such a study would provide valuable insight into the broader understanding of the legitimacy of protected area governance and management.

Finally, the conceptual framework for understanding legitimacy that I have presented in this dissertation should be further explored in other contexts and issues. Legitimacy is an incredibly complex concept that protected area scholars and practitioners - whether they realize 
it or not - have likely struggled with since the first protected area was established. Given the diverse array of protected areas that can be found across the globe, there are likely more elements to the conceptual framework that have yet to be articulated and/or different ways of situating the elements of legitimacy that I have discussed.

With this dissertation, I have attempted to offer a rigorous examination of a concept that is of paramount importance to protected areas. As new constituencies for protected areas emerge and the management and governance of protected areas continue to morph in the face of increasing societal complexity and change, the question of legitimacy correspondingly becomes more clearly central to the very existence of protected areas. Because of the contextual nature of protected area issues, we must come to the realization that there will not likely be a particular approach to management or governance that universally engenders legitimacy. Instead, protected area staff and other constituencies must be committed to evaluating the legitimacy of governance and management on an issue-by-issue basis. While this clearly complicates the practice of governance and management, it is also an honest reflection of the uniqueness of protected areas and the humility they command. 
Appendix A

Visitor questionnaire with summary statistics

\section{Kruger National Park}

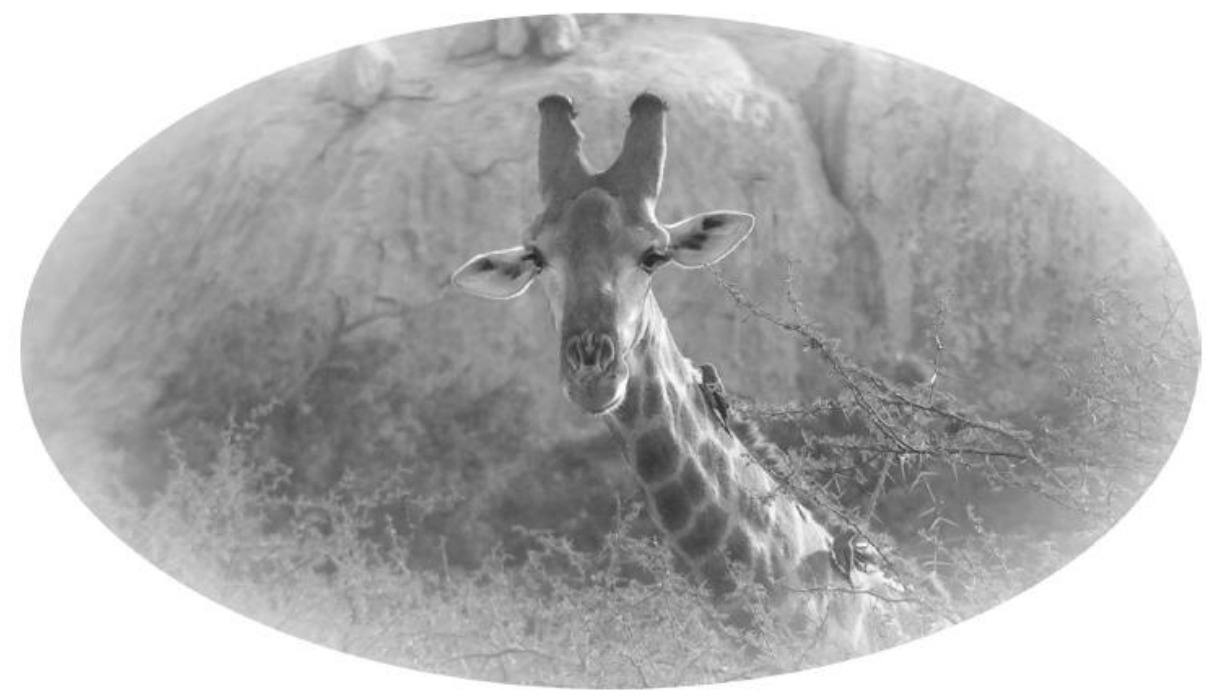

\section{Visitor Survey}

Cooperating institutions: South African National Parks University of Montana, USA

University of KwaZulu-Natal, South Africa

Please return your completed survey by post with the enclosed envelope or return it to one of the following Kruger NP reception desks:

$\begin{array}{lll}\begin{array}{l}\text { Berg-en-Dal } \\ \text { Lower Sabie }\end{array} & \begin{array}{l}\text { Crocodile Bridge } \\ \text { Pafuri } \\ \text { Shingwedzi }\end{array} & \begin{array}{l}\text { Letaba } \\ \text { Popani }\end{array} \\ \begin{array}{l}\text { Skukuza } \\ \text { Prpen }\end{array} & \begin{array}{l}\text { Satara Maria } \\ \text { Pretoriuskop }\end{array} \\ & \end{array}$




\section{About Your Trip}

1. What type of group are you with on this trip? (mark with an ' $\mathrm{X}$ ' all that apply)

[ ] Alone $(\mathrm{n}=29 / 10.6 \%)$

[ ] Family $(195 / 71.4 \%)$

[ ] Friends (38/13.9\%)

[ ] Lodge Tour or Guided Tour (11/4.0\%)

[ ] Organization or Club (please specify) :

2. How many times have you visited Kruger National Park (including this trip)? (mark with an ' $\mathrm{X}$ ")

[ ] 1 time $(\mathrm{n}=53 / 19.4 \%)$

[ ] 2-4 times $(59 / 21.6 \%)$

[ ] 5 -10 times $(36 / 13.2 \%)$

[ ] More than 10 times $(125 / 45.8 \%)$

3. How long is/was this visit to Kruger National Park? day $(\mathrm{s})\left(\right.$ mean $\left.=5.2 / \mathrm{S} \cdot \mathrm{D}^{1}{ }^{1}=3.7\right)$

4. Through which gate did you enter and leave the Park for this visit? (mark with an ' $\mathrm{X}$ ')

$\begin{array}{lcccc} & \text { Enter } & \text { Leave } & & \\ \text { Malelane } & {[\text { ] }} & {[\text { ] }} & \text { (n enter }=54 / \mathrm{n} \text { exit }=48) & (\% \text { enter }=19.8 / \% \text { exit=17.6) } \\ \text { Crocodile Bridge } & {[\text { ] }} & {[\text { ] }} & (35 / 33) & (12.8 / 12.1) \\ \text { Numbi } & {[\text { ] }} & {[\text { ] }} & (28 / 11) & (10.3 / 4.0) \\ \text { Phabeni } & {[\text { ] }} & {[\text { ] }} & (23 / 35) & (8.4 / 12.8) \\ \text { Paul Kruger } & {[\text { ] }} & {[\text { ] }} & (63 / 66) & (23.1 / 24.2) \\ \text { Giriyondo } & {[\text { ] }} & {[\text { ] }} & (1 / 0) & (11.7 .4) \\ \text { Phalaborwa } & {[\text { ] }} & {[\text { ] }} & (32 / 26) & (2.6 / 0.5) \\ \text { Punda Maria } & {[\text { ] }} & {[\text { ] }} & (7 / 2) & (3.3 / 1.5) \\ \text { Pafuri } & {[\text { ] }} & {[\text { ] }} & (9 / 4) & (8.1 / 14.3) \\ \text { Orpen } & {[\text { ] }} & {[\text { ] }} & (22 / 39) & \end{array}$

1 S.D. = Standard deviation 
5. Did you or will you be staying overnight in the Park for this visit?

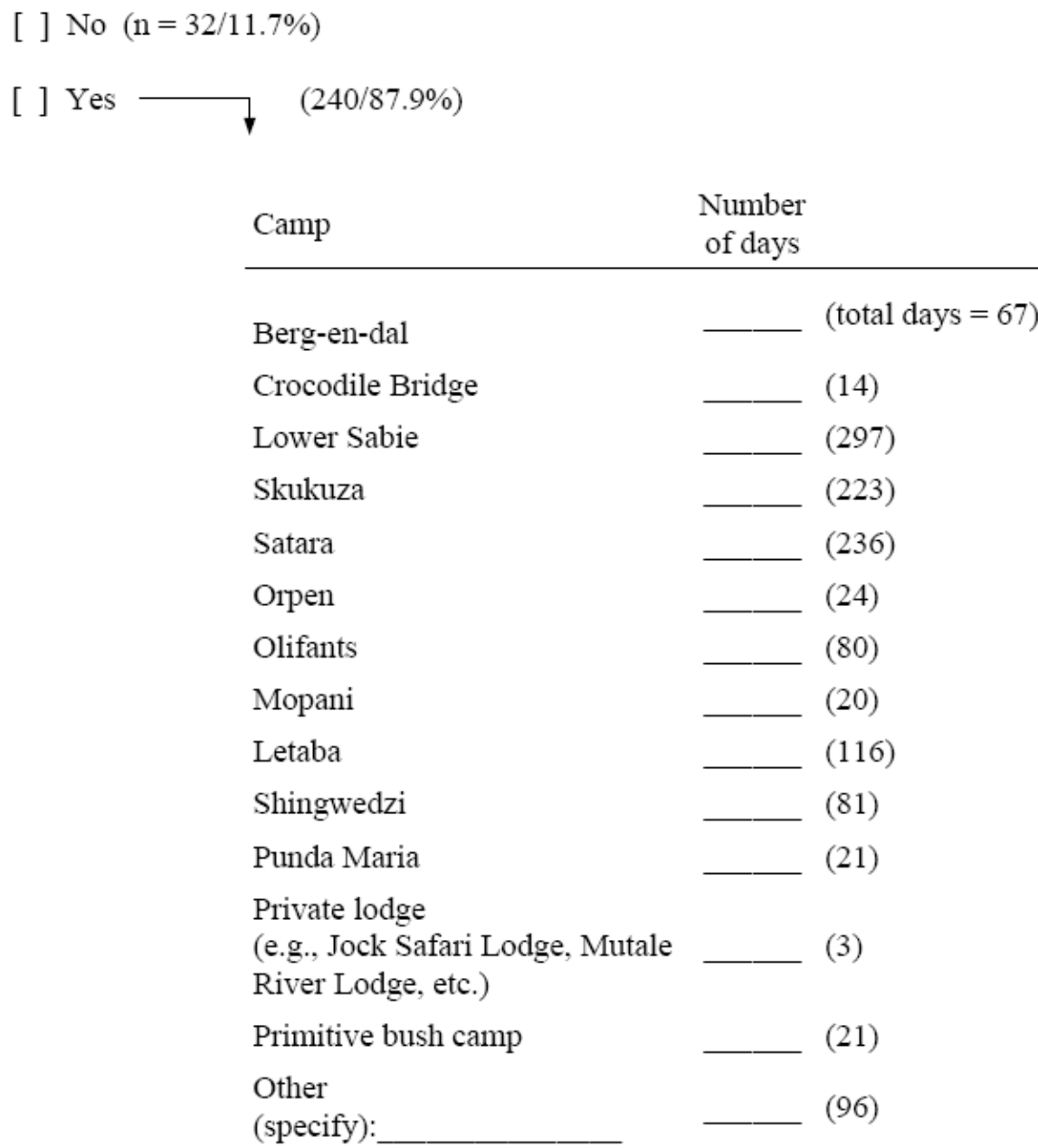

6. During this holiday/trip to Kruger National Park, did you stay overnight outside the Park?

[ ] No $(\mathrm{n}=185 / 65.8 \%)$

[ ] Yes $\longrightarrow(84 / 30.8 \%)$

a) Where did you stay? (please specify)

b) How many nights did you stay outside the Park? 


\section{About Kruger National Park}

7. We are interested in your opinions about the values of Kruger National Park. Please indicate, for each of the following items, how important they are to the overall value of Kruger National Park ( 1 being "strongly disagree" and 7 being "strongly agree"):

\section{I believe Kruger National Park is particularly important as:}

a protector of threatened and endangered species a tourist destination

a place for scientific research

a place that everyone should see at least once in their lives

a place where the wildlife and plants of the region

can live
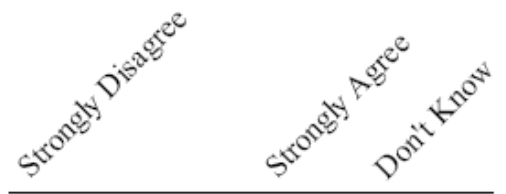

$\begin{array}{lllllll}1 & 2 & 3 & 4 & 5 & 6 & 7\end{array}$

$\begin{array}{lllllll}1 & 2 & 3 & 4 & 5 & 6 & 7\end{array}$

$\begin{array}{lllllll}1 & 2 & 3 & 4 & 5 & 6 & 7\end{array}$

$\begin{array}{lllllll}1 & 2 & 3 & 4 & 5 & 6 & 7\end{array}$

$\begin{array}{lllllll}1 & 2 & 3 & 4 & 5 & 6 & 7\end{array}$

$\begin{array}{lllllll}1 & 2 & 3 & 4 & 5 & 6 & 7\end{array}$

$\begin{array}{lllllll}1 & 2 & 3 & 4 & 5 & 6 & 7\end{array}$

$\begin{array}{lllllll}1 & 2 & 3 & 4 & 5 & 6 & 7\end{array}$

$\begin{array}{lllllll}1 & 2 & 3 & 4 & 5 & 6 & 7\end{array}$

$\begin{array}{lllllll}1 & 2 & 3 & 4 & 5 & 6 & 7\end{array}$

a place for education about nature

a place to be away from other people

a sacred place

$\begin{array}{lllllll}1 & 2 & 3 & 4 & 5 & 6 & 7\end{array}$

$\begin{array}{lllllll}1 & 2 & 3 & 4 & 5 & 6 & 7\end{array}$

a place for wildness

a place that belongs to everyone

a source of benefits for local communities

a place without most types of human development

$\begin{array}{lllllll}1 & 2 & 3 & 4 & 5 & 6 & 7\end{array}$

$\begin{array}{llllll}1 & 2 & 3 & 4 & 5 & 6\end{array}$
$\mathrm{X}(\bar{x}=6.7 / \mathrm{S} . \mathrm{D} .=0.7)$

$\mathrm{X}(5.9 / 1.4)$

$\mathrm{X}(6.1 / 1.3)$

$\mathrm{X}(6.0 / 1.5)$

$\mathrm{X}(6.7 / 0.9)$

$\mathrm{X}(6.3 / 1.1)$

$\mathrm{X}(4.2 / 1.8)$

$\mathrm{X}(6.1 / 1.3)$

$\mathrm{X}(6.4 / 0.9)$

$\mathrm{X}(5.2 / 1.7)$

$\mathrm{X}(4.9 / 2.1)$

$\mathrm{X}(6.3 / 1.3)$

$\mathrm{X}(5.6 / 1.7)$

$\mathrm{X}(4.8 / 1.9)$

$\mathrm{X}(5.6 / 1.7)$

a place for family or individual traditions

$\begin{array}{lllllll}1 & 2 & 3 & 4 & 5 & 6 & 7\end{array}$

$\mathrm{X}(4.5 / 2.1)$

a symbol of South Africa's identity and heritage

$\begin{array}{lllllll}1 & 2 & 3 & 4 & 5 & 6 & 7\end{array}$

$\mathrm{X}(6.3 / 1.1)$

a place for a peaceful experience

$\begin{array}{lllllll}1 & 2 & 3 & 4 & 5 & 6 & 7\end{array}$

$\mathrm{X}(6.3 / 1.1)$

a reserve of natural resources for use by local people

$\begin{array}{lllllll}1 & 2 & 3 & 4 & 5 & 6 & 7\end{array}$

$\mathrm{X}(3.7 / 2.1)$

a place without most types of commercial development

$\begin{array}{lllllll}1 & 2 & 3 & 4 & 5 & 6 & 7\end{array}$

$\mathrm{X}(5.7 / 1.8)$

an economic resource

$\begin{array}{lllllll}1 & 2 & 3 & 4 & 5 & 6 & 7\end{array}$

$\mathrm{X}(4.9 / 1.9)$

a place to be free from society and its regulations

$\begin{array}{lllllll}1 & 2 & 3 & 4 & 5 & 6 & 7\end{array}$

$\mathrm{X}(4.3 / 2.1)$

a place to view the "Big 5" (i.e., lion, rhino elephant,

leopard, and buffalo)

a place for scenic beauty

a social place $\begin{array}{llllllll}1 & 2 & 3 & 4 & 5 & 6 & 7 & \mathrm{X}(6.2 / 1.3) \\ 1 & 2 & 3 & 4 & 5 & 6 & 7 & \mathrm{X}(6.5 / 0.9) \\ 1 & 2 & 3 & 4 & 5 & 6 & 7 & \mathrm{X}(3.7 / 1.8)\end{array}$ 
8. Please list the values that, to you, make Kruger National Park unique (compared to other parks in southern Africa):

a)

b)

c) 


\section{Using Resources in Kruger National Park}

9. People living near Kruger National Park have requested to use resources from the Park such as firewood. thatching grass, and medicinal plants for personal and/or household use (but not for commercial use). In the past, people living near the Park have not been allowed to gather resources from the Park, except under very rare circumstances. Currently, though, the managers of Kruger National Park are considering whether or not people living near the Park should have more access to resources. If more access is allowed, it will be managed and monitored by the staff of Kruger National Park.

Based on your personal values and beliefs, please indicate whether you agree or disagree with the following statements ( 1 being "strongly disagree" and 7 being "strongly agree"):

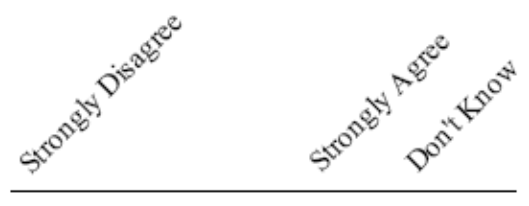

Kruger National Park (Kruger NP) is an area that should remain pristine with as little human impact as possible. $\quad \begin{array}{lllllllll}1 & 2 & 3 & 4 & 5 & 6 & 7 & \mathrm{X} & (\bar{x}=6.3 / \mathrm{S} . \mathrm{D} .=1.3)\end{array}$

For conservation to be effective, Kruger NP, resources (such as firewood, thatching grass, etc.) must be used occasionally.

Allowing people living near Kruger NP to gather resources from the Park should not be allowed if there are other places where they can gather those resources.

$\begin{array}{llllllll}1 & 2 & 3 & 4 & 5 & 6 & 7 & \mathrm{X}(5.9 / 1.7)\end{array}$

Access to resources in Kruger NP should only be granted to people living near the Park when the law requires that it be granted.

$\begin{array}{llllllll}1 & 2 & 3 & 4 & 5 & 6 & 7 & \mathrm{X}(4.0 / 2.5)\end{array}$

Policies and strategies for managing Kruger NP should not change over time.

$\begin{array}{llllllll}1 & 2 & 3 & 4 & 5 & 6 & 7 & \mathrm{X}(4.14 / 2.3)\end{array}$

Allowing people living near Kruger NP to gather resources from the Park is rational if the Park has many resources.

$\begin{array}{llllllll}1 & 2 & 3 & 4 & 5 & 6 & 7 & \mathrm{X}(2.98 / 1.9)\end{array}$

If laws state that access to park resources must be granted to people living near parks, then resource use by people living near parks would be appropriate.

Allowing people living near Kruger NP to gather resources from the Park is a good idea if it will improve the lives of people living near the Park.

$\begin{array}{llllllll}1 & 2 & 3 & 4 & 5 & 6 & 7 & \mathrm{X}(3.1 / 2.1)\end{array}$

It is morally right to allow people living near Kruger NP to have access to resources within the Park.

$\begin{array}{lllllllll}1 & 2 & 3 & 4 & 5 & 6 & 7 & \mathrm{X}(2.5 / 1.9)\end{array}$

Resource use would disturb the wild or natural features of Kruger NP.

$\begin{array}{llllllll}1 & 2 & 3 & 4 & 5 & 6 & 7 & \mathrm{X}(5.9 / 1.7)\end{array}$

Resource use is acceptable because Kruger NP must experiment with different ways of conserving and using natural resources.

$\begin{array}{llllllll}1 & 2 & 3 & 4 & 5 & 6 & 7 & \mathrm{X}(3.1 / 2.0)\end{array}$ 
10. Please list any other reasons that describe why you feel resource use should or should not be allowed

\section{a)}

b)

c)

11. There are a variety of strategies that Kruger National Park can choose to manage the use of Park resources among people living along the western boundary of the Park. Based on what you would like Kruger National Park to be like in the future, please respond to the following questions.

a) If managed by Kruger National Park, should people living near the western boundary of the Park be allowed to collect resources from the Park that are not endangered or rare (e.g., firewood, thatch grass, medicinal plants, etc.)?

[ ] No $(\mathrm{n}=191 / 70 \%)$

[ ] Yes $(72 / 26.4 \%)$

b) Should the managers of Kruger National Park decide among themselves how and what resources will be gathered, or should people living near the Park help decide how and what resources will be gathered?

[ ] Only the Park managers should decide. (187/68.5\%)

[ ] People living near the Park should help decide. (57/20.9\%)

c) Should the Park provide any other type of benefits to people living near the western boundary of the Park?

[ ] No (119/43.6\%)
[ ] Yes

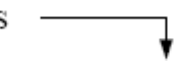

d) One way to provide benefits to local communities is through financial assistance for development projects, such as the construction of classrooms, water installations, and clinics. If this type of assistance was provided, it would be monitored and managed by the staff of Kruger National Park. Money for this program would be raised by charging visitors up to an additional 2 Rand for entry into Kruger National Park. Please check one box below.

[ ] I would not support this program. ( $0 / 0 \%)$

[ ] I would support this program. (147/100\%) 


\begin{abstract}
About You
Finally, to understand our sample, we are interested in the characteristics of the people who have taken this survey. All information provided will be kept confidential.
\end{abstract}

12. What is your gender?

[ ] Female (n=119/43.6\%) [ ] Male (153/56.0\%)

13. What is your age? years $($ mean $=42.1 / \mathrm{S} . \mathrm{D} .=12.6)$

14. Please indicate the population group(s) you belong to? (multiple answers are possible)

[ ] Asian ( $\mathrm{n}=3 / 1.1 \%)$

[ ] Black $(15 / 5.5 \%)$

[ ] Indian $(3 / 1.1 \%)$

[ ] White $(241 / 88.3 \%)$

[ ] Other (please specify):

15. Where are you from?

[ ] South Africa - within $20 \mathrm{~km}$ of Kruger National Park ( $\mathrm{n}=4 / 1.5 \%)$

[ ] South Africa - between 20 and $150 \mathrm{~km}$ of Kruger National Park (18/6.6\%)

[ ] South Africa - greater than $150 \mathrm{~km}$ of Kruger National Park (153/56.0\%)

[ ] Southern Africa (excluding South Africa) (3/1.1\%)

[ ] The continent of Africa (excluding southern Africa) (0/0.0\%)

[ ] International (excluding the continent of Africa)(specify): $(94 / 34.4 \%)$

16. What is the highest level of education you have completed?

[ ] No schooling $(0 / 0.0 \%)$

[ ] Some primary schooling (Grades 1-7) $(0 / 0.0 \%)$

[ ] Some secondary schooling (Grades $8-11)(8 / 2.9 \%)$

[ ] Matriculation certificate or High school diploma (17/6.2\%)

[ ] Some college or university studies (not completed) $(25 / 9.2 \%)$

[ ] College studies completed (certificate or diploma) $(61 / 22.3 \%)$

[ ] University studies completed (first degree or honors) $(95 / 34.8 \%)$

[ ] Advanced university studies completed (masters, doctoral, law degree, etc.) (66/24.2\%)

17. In which of the following kinds of places did you spend the most time while growing up (to age 18)?

[ ] On a farm or ranch $(n=42 /$ S.D. $=15.4 \%)$

[ ] Rural or small town (under 1,000 population) $(19 / 7.0 \%)$

[ ] Town (1,000-5,000 population) $(47 / 17.2 \%)$

[ ] Small city $(5,000-50,000$ population) $(49 / 17.9 \%)$

[ ] Medium city (50,000-1 million population) $(49 / 17.9 \%)$

[ ] Major city or metropolitan area (over 1 million population) $(66 / 24.2 \%)$ 
18. In what type of community do you now live?

[ ] On a farm or ranch $(\mathrm{n}=8 / 2.9 \%)$

[ ] Rural or small town (under 1,000 population) $(25 / 9.2 \%)$

[ ] Town (1,000-5,000 population) (32/11.7\%)

[ ] Small city (5,000-50,000 population) (36/13.2\%)

[ ] Medium city (50,000-1 million population) $(61 / 22.3 \%)$

[ ] Major city or metropolitan area (over 1 million population) (107/39.2\%)

We welcome any other comments you might have concerning the management of Kruger National Park. Please use the space below.

Thank you for your assistance. We appreciate your thoughts and opinions! 


\section{For inquiries related to this survey, please contact:}

Wayne Freimund

Department of Society and Conservation

University of Montana

32 Campus Drive

Missoula, MT USA

e-mail:wayne.freimund@umontana.edu

\section{To return the completed survey by post, please send it to:}

Patricia Khoza

Scientific Services

Kruger National Park

Private Bag X402

Skukuza 1350

This information will be used by park managers to better serve the public. Response to this request is voluntary. No action may be taken against you for refusing to supply the information requested. When analysis of the survey is completed, all name and address files will be destroyed. Thus, the permanent data will be anonymous. Please do not put your name or that of any member of your group on the survey. 


\section{Appendix B}

\section{Visitor questionnaire cover letter}

\section{Kruger National Park Visitor Survey}

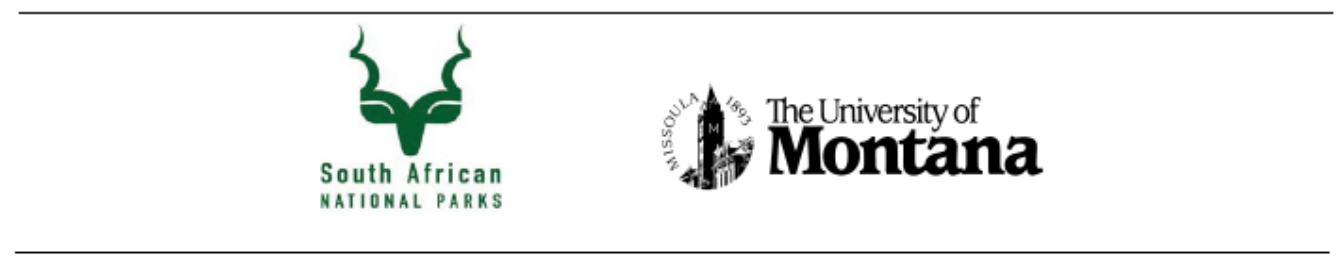

Dear Participant,

Thank you for agreeing to participate in our survey of visitors to Kruger National Park. We appreciate your thoughts and opinions concerning the challenging issues that Park managers and local residents confront on a daily basis. Knowing how visitors view these issues - and what kind of actions should be considered - is vital to Kruger National Park and those who make decisions about the management of the Park.

As you were entering Kruger, you agreed to participate in this survey. You were randomly selected from all the visitors to the Park on that day. For the results of the study to truly represent the thinking of all visitors to Kruger National Park, it is important that each survey be completed and returned in the envelope provided by post or to one of the Kruger reception desks listed on the cover of the survey.

You may be assured of complete confidentiality. The survey has an identification number for tracking purposes only. Any contact information you choose to provide will be used only for the purposes of this survey. This survey is voluntary, and your name will never be placed on the survey itself, nor associated with your answers.

If you would like to receive a summary of the results of this survey, please send an e-mail to randy.j.tanner@gmail.com. The summary will likely be distributed during June-August, 2007. Your e-mail address will not be used for any purposes other than sending you the summary of results.

Thank you very much for your assistance. If you have any questions or concerns about this study, please write or e-mail us at randy.j.tanner@gmail.com

Sincerely,

Randy Tanner

Project Leader

University of Montana
Stefanie Freitag-Ronaldson

Scientific Services

Kruger National Park 


\section{Appendix C \\ Sustainable Use - Statement of Intent (from the Kruger National Park Management Plan)}

\subsubsection{Sustainable Use - Statement of Intent}

SANParks recognise that they have been established to protect and conserve areas of biological diversity. This is its primary mandate and all other activities must be regulated by this goal. However, it also recognises that as a national agency, SANParks must provide for the needs of all citizens, by generating an array of tangible and intangible benefits and resources. Subject to guidance from SANParks corporate principles (SANParks 2006), KNP has developed the following statement of intent on sustainable natural resource utilisation.

The KNP regards any action that utilises or impacts on the scenery, sense of place, soil, water, air and nutrient cycles, habitats, heritage resources, flora and fauna, and the interrelatedness between these, as a resource use. Furthermore, KNP recognises that they have a responsibility to ensure that natural and cultural resources which are not harvested from within the park boundaries, but are used in the park, are collected and harvested in an ethical way that conforms to SANParks' policies. The KNP is aware of the demand for resources by its various stakeholders (including both neighbouring communities and SANParks) as well as the role it needs to play in developing opportunities in this regard. While natural resources have been used by humans for millennia the balance between available resources and demands has become distinctly disproportional. The exhaustion of resources outside of national parks is one of the reasons for the increasing need and demand for resources inside national parks.

This statement of intent is the first step in the development of a sustainable resource management plan. Therefore, the KNP commits to investigating natural resource use in terms of past and present practice as well as future opportunities, in order to provide resources that are truly sustainable in the long-term, without compromising any of the organisations biodiversity or other values. All resource use in KNP should be considered, implemented, managed and monitored in accordance with the corporate policy which includes a comprehensive synthesis of international and national legal issues pertaining to resource use. KNP-specific regulations for resource use should follow an adaptive approach, based on the following 14 feasibility and implementation principles:

\section{Feasibility principles}

1. Precautionary approach - The 'precautionary approach' must apply. This is interpreted as:

- leaving an appropriate 'margin of error' where information is inadequate;

- prohibiting or preventing use of resources in instances where the consequences of erring could be severely negative for species, heritage resources, cultural landscapes and/or ecosystems;

- terminating resource use activities if doubt arises as to the sustainability or impacts on the KNP. 
2. Maintenance of system integrity - The ecological, aesthetic, socio-cultural, archaeological and spiritual integrity of protected areas must not be jeopardised in the long-term in order to satisfy short-term needs/demands. System integrity, composition and function are defined as the desired state and are represented by the KNP objectives hierarchy.

3. Cost-benefit analysis - The benefit-cost ratio to SANParks must be positive.

4. Determination and evaluation of potential influence of utilising resources - The thresholds of concern for use on affected species, heritage resources, cultural landscapes and ecosystems must be determined and evaluated using methodology that is appropriate for this purpose. This must take into account the effects of resource use on population dynamics, ecosystem functioning and social and cultural values. This must be achieved in an integrated manner, incorporating all relevant scientific, formal and informal information and knowledge (including traditional knowledge).

5. Cost recovery - Costs must be recoverable from resource users who are able to pay, and it should be possible to leverage 'contributions in kind' from users who are unable to pay. Cost recovery also includes the costs of monitoring programmes that are required to manage resources in a sound manner.

6. Adequate capacity - Appropriate human and financial resources must be available to manage, monitor and regulate resource use.

\section{Implementation principles}

7. Adaptive management - Resource use must be managed adaptively, accompanied by constant learning based on monitoring, information gathering and research.

8. Incentives - Incentives for sustainable resource use and disincentives for unsustainable or wasteful use must be put in place.

9. Ethics - Accepted ethical norms and standards must be adhered to.

10. Redress - Past inequalities must be addressed through benefiting the poor, but without undermining the diversity of people's livelihood strategies.

11. Respect for rights - Intellectual property rights and historical claims to resources must be respected.

12. Co-management - Decision-making must be consultative and transparent. All stakeholders involved in resource use should accept responsibility for sustainable use.

13. Enforcement - Illegal resource use must be prevented through law enforcement.

14. Rights and responsibilities: While SANParks acknowledges the responsibilities outlined above, it also has the right to choose which resources to make available and how much, as 
well as the right to withdraw use if necessary (i.e. the use of a resource does not automatically constitute the source as being permanent). 


\section{Bibliography}

Abbot, J. I. O., and K. Homewood. 1999. A history of change: cause of miombo woodland decline in a protected area in Malawi. Journal of Applied Ecology 36: 422-33.

Abbot, J. I. O., and R. Mace. 1999. Managing protected woodlands: fuel-wood collection and law enforcement in Lake Malawi National Park. Conservation Biology 13: 418-21.

Abbot, Joanne I. O., David H. L. Thomas, Anne A. Gardner, Sama E. Neba, and Mbony W. Khen. 2001. Understanding the Links Between Conservation and Development in the Bamenda Highlands, Cameroon. World Development 29, no. 7: 1115-36.

Abelson, Julia, Pierre-Gerlier Forest, John Eyles, Patricia Smith, Elisabeth Martin, and FrancoisPierre Gauvin. 2003. Deliberations about Deliberative Methods: Issues in the Design and Evaluation of Public Participation Processes. Social Sciences \& Medicine 57: 239-51.

Abercrombie, Nicholas, Bryan S. Turner, and Stephen Hill. 2001. Penguin Dictionary of Sociology. New York: Penguin Group.

Abrahamsson, Hans. 1995. The international political economy of structural adjustment: the case of mozambique. European Journal of Development Research 7, no. 2: 297-319.

Achard, Frédéric, Hugh D. Eva, Hans-Jurgen Stibig, Philippe Mayaux, Javier Gallego, Timothy Richards, and Jean-Paul Malingreau. 2002. Determination of Deforestation Rates of the World's Humid Tropical Forests. Science 297: 999-1002.

Acharya, K. P. 2005. The Face of Forestry Research in Developing Countries: The Case of Nepal. Forests, Trees and Livelihoods 15: 41-53.

- 2002. Twenty-Four Years of Community Forestry in Nepal. International Forestry Review 4, no. 2: 149-56.

Ackoff, Russell L. 1981. The Art and Science of Mess Management. Interfaces 11, no. 1: 20-28.

Adams, Brian. 2004. Public Meetings and the Democratic Process. Public Administration Review 64, no. 1: 43-54.

Adams, Jonathan S., and Thomas O. McShane. 1992. The Myth of Wild Africa: Conservation Without Illusion. Berkeley, CA: University of California Press.

Adams, Mike. 2001. Planting Ideas. ITTO Tropical Forest Update.

Adams, Mike, and Emmanuel Ze Meka. 2002. Policy Failure: The Accomplice of Illegal Trade. ITTO Tropical Forest Update December 1: 18-20.

Adams, William, and Mark Infield. 2001. Park Outreach and Gorilla Conservation: Mgahinga Gorilla National Park. African Wildlife and Livelihoods. editors D. Hulme, and M. Murphree, 131-47. Oxford: James Currey. 
Adams, William M. 2004. Biodiversity Conservation and the Eradication of Poverty. Science 306: 1146-49.

Adepoju, Aderanti. 2003. Continuity and changing configurations of migration to and from the republic of south africa. International Migration 41, no. 1: 3-28.

African National Congress. 1994. The Reconstruction and Development Programme, Umanyano, Johannesburg.

Agger, Ben. 1991. Critical Theory, Poststructuralism, Postmodernism: Their Sociological Relevance. Annual Review of Sociology 17: 105-31.

Agrawal, Arun. 2000. Adaptive management in transboundary protected areas: The Bialowieza National Park and Biosphere Reserve as a case study. Environmental Conservation 27, no. 4: 326-33.

- 2001. Common Property Institutions and Sustainable Governance of Resources. World Development 29, no. 10: 1649-72.

Agrawal, Arun Clark C. Gibson. 1999. Enchantment and Disenchantment: The Role of Community in Natural Resource Conservation. World Development 27, no. 4: 629-49.

Agrawal, Bina. 2001. Participatory Exclusions, Community Forestry, and Gender: An Analysis for South Asia and a Conceptual Framework. World Development 29, no. 10: 1623-48.

Agresti, Alan. 2002. Categorical Data Analysis. John Wiley \& Sons.

Albers, Heidi J., Amy W. Ando, and Daniel Kaffine. 2004. Land Trusts in the United States: Analyzing Abundance. Resources Spring: 9-13.

Albright, Horace. 1956. Personal communication: H. Albright to M.K. Gilstra; Conrad Wirth Papers Box 2.

Alden, Chris. 1995. The UN and the Resolution of Conflict in Mozambique. Journal of Modern African Studies 33, no. 1: 103-28.

Aldrich, H. 1999. Organizations Evolving. London: Sage.

Alford, C. Fred. 1985. Is Jürgen Habermas's Reconstructive Science Really Science? Theory and Society 14, no. 3: 321-40.

Ali, A. 2002. A Siachen peace park: The solution to a half-century of international conflict. Mountain Research and Development 22, no. 4: 316-19.

Alkadry, Mohamad G. 2003. Deliberative Discourse Between Citizens and Administrators: If Citizens Talk Will Administrators Listen? Administration \& Society 35, no. 2: 184-209.

Alkire, Carolyn. 2000. Funding Strategies for Wilderness Management. In Wilderness science in a time of change conference - Volume 2: Wilderness within the context of larger systems, 
Comps. Stephen F. McCool, David N. Cole, William T. Borrie, and Jennifer

O'LoughlinOgden, UT: United States Department of Agriculture, Forest Service, Rocky Mountain Research Station.

Allen, Gerald M. \& Gould Ernest M. Jr. 1986. Complexity, Wickedness, and Public Forests. Journal of Forestry 84, no. 4: 20-24.

Allenby, B. R., and D. J. Richards. 1994. The greening of industrial ecosystems. Washington, D. C.: National Academy Press.

Allin, Craig W. 1982. The Politics of Wilderness Preservation. Westport, CT: Greenwood Press.

Allin, Craig W. 2000. The Triumph of Politics over Wilderness Science. In Wilderness Science in a Time of Change Conference - Volume 2: Wilderness within the context of larger systems, Comps. Stephen McCool, David N. Cole, William T. Borrie, and Jennifer O'LoughlinOgden, UT: U.S. Department of Agriculture, Forest Service, Rocky Mountain Research Station.

Allina-Pisano, Eric. 2003. Borderlands, boundaries, and the contours of colonial rule: african labor in manica district, mozambique, c. 1904-1908. International Journal of African Historical Studies 36, no. 1: 59-82.

Alpert, Peter. 1996. Integrated Conservation and Development Projects: Examples from Africa. BioScience 46, no. 11: 845-55.

Anaya, James. 2000. Indigenous Peoples in International Law. New York: Oxford University Press.

Anaya, S. J. 2005. Divergent Discourses about International Law, Indigenous Peoples, and Rights over Lands and Natural Resources. Colorado Journal of Environmental Law and Policy 16, no. 2: 237-58.

Anderies, John M., Marco A. Janssen, and Elinor Ostrom. 2004. A Framework to Analyze the Robustness of Social-ecological Systems from an Instituional Perspective. Ecology and Society 9, no. 1: 18 .

Anderson, D., and R. Groves, Editors. 1987. Conservation in Africa: People, Policies, and Practice. Cambridge: Cambridge University Press.

Anderson, Jeremy, and Steven Yaffee. 1998. "Balancing Public Trust and Private Interest: Public Participation in Habitat Conservation Planning: A Summary Report." Balancing Public Trust and Private Interest: Public Participation in Habitat Conservation Planning, research team Peter Aengst, Jeremy Anderson, Jay Chamberlin, Christopher Grunewald, Susan Loucks, Elizabeth Wheatley, and Steven Yaffee. University of Michigan School of Natural Resources and Environment, Ann Arbor, Michigan.

Anderson, Paul Nicholas. 2001. Community-based conservation and social change amongst South Indian honey-hunters: an anthropological perspective. Oryx 35, no. 1: 81-83. 
Andrade, Gérman I. 2003. National parks versus Protected Landscapes? Legitimacy, Values, and the Management of the Colombian Tropical Wildlands. In The Full Value of Parks: From Economics to the Intangible. Eds. David Harmon, and Allen D. Putney, 169-84. Lanham, MD: Rowman \& Littlefield.

Ansell, C. K. 2001. Legitimacy: Political. In International Encyclopedia of the Social and Behavioral Sciences. Eds. N. J. Smelser, and P. B. BaltesNew York: Elsevier Science Ltd.

Anthony, Brandon P. 2006. "A View from the Other Side of the Fence: Tsonga Communities and the Kruger National Park, South Africa." Doctoral Dissertation, Central European University.

Antonio, R. J. 1983. The origin, development, and contemporary status of critical theory. Sociological Quarterly 24, no. Summer: 325-51.

Antypas, A. 1995. The dynamics of legitimation and the case of the US Forest Service: a theoretical and historical discussion. Seattle: Institute for Resources in Society, University of Washington.

Appelstrand, Marie. 2002. Participation and Societal Values: the Challenge for Lawmakers and Policy Practitioners. Forest Policy and Economics 4: 281-90.

Archard, Frederic, Hugh D. Eva, Hans-Jurgen Stibig, Philippe Mayaux, Javier Gallego, Timothy Richards, and Jean-Paul Malingreau. 2002. Determination of Deforestation Rates of the World's Humid Tropical Forests. Science 297: 999-1002.

Arendt, Hannah. 1998. The Human Condition. $2^{\text {nd }}$ ed. Chicago: University of Chicago Press.

Armitage, Derek. 2004. Nature-Society Dynamics, Policy Narratives, and Ecosystem Management: Integrating Perspectives on Upland Change and Complexity in Central Sulawesi, Indonesia. Ecosystems 7, no. 7: 717-28.

Armitage, Derek. 2002. Socio-institutional dynamics and the political ecology of mangrove forest conservation in central sulawesi, Indonesia. Global Environmental Change 12: 203-17.

Arndt, Channing, and Henning Tarp Jensen. 2000. Marketing margins and agricultural technology in mozambique. Journal of Development Studies 37, no. 1: 121-35.

Arndt, Channing, and Finn Tarp. 2000. Agricultural technology, risk, and gender: a cge analysis of mozambique. World Development 28, no. 7: 1307-27.

Arneson, Richard J. 2003. Debate: Defending the Purely Instrumental Account of Democratic Legitimacy. The Journal of Political Philosophy 11, no. 1: 122-32.

Arnold, J. E. M. 1991. Community Forestry: Ten Years in Review. 1-31. Rome: Food and Agriculture Organization. 
Arnold, Stephen J., and Eileen Fischer. 1994. Hermeneutics and Consumer Research. The Journal of Consumer Research 21, no. 1: 55-70.

Arnstein, Sherry R. 1969. A ladder of citizen participation. American Institute of Planning Journal 35, no. 4: 216.

Ascher, William, and Robert Healy. 1990. Natural Resource Policymaking in Developing Countries. Durham, N.C.: Duke University Press.

Ashenafi, Zelealem, and N. Leader-Williams. 2005. Indigenous Common Property Resource Management in the Central Highlands of Ethiopia. Human Ecology 33, no. 4: 539-63.

Ashley, Caroline, Charlotte Boyd, and Harold Goodwin. 2000. Pro-Poor Tourism: Putting Poverty at the Heart of the Toursim Agenda. Natural Resource Perspectives 51: 1-6.

Attwell, C. A. M., and F. P. D. Cotterill. 2000. Postmodernism and African Conservation Science. Biodiversity and Conservation 9: 559-77.

Audi, Robert, Ed. 1995. The Cambridge Dictionary of Philosophy. New York: Cambridge University Press.

Australian Government Delegation. 1991. Speaking Notes on Self Determination.

Awanyo, Louis. 2001. Labor, Ecology and a Failed Agenda of Market Incentives: The Political Ecology of Agrarian Reforms in Ghana. Annals of the Association of American Geographers 91, no. 1: 92-121.

Babbie, Earl R. 2003. Practice of Social Research. Belmont, CA: Wadsworth.

Baber, Walter F. 2004. Ecology and Democratic Governance: Toward a Deliberative Model of Environmental Politics. The Social Science Journal 41, no. 3: 331-46.

Backus, Perry. 13 January 2006. Missoula ski area looking at adding more terrain, lifts. The Missoulian.

Baden, John, and Richard Stroup, Eds. 1981. Bureaucracy vs. Envrionment: The Environmental Costs of Bureaucratic Governance. Ann Arbor, MI: University of Michigan Press.

Badie, B. 2001. Sociology of Legitimacy. In International Encyclopedia of the Social and Behavioral Sciences. Eds. N. J. Smelser, and P. B. Baltes, 8706-9. New York: Elsevier Science, LTD.

Baird, Vanessa A. 2001. Building Institutional Legitimacy: The Role of Procedural Justice. Political Research Quarterly 54, no. 2: 333-54.

Baker, M., and J. Kusel. 2003. Community Forestry in the United States: a summary. Washington, D.C.: Island Press.

Baker, Randall. 1984. Protecting the Environment Against the Poor: the Historical Roots of Soil 
Erosion Orthodoxy in the Third World. The Ecologist 14, no. 2: 53-60.

Baranga, Deborah. 2007. Observations on resource use in Mabira Forest Reserve, Uganda. African Journal of Ecology 45: 2-6.

Barker, Rodney. 1990. Political Legitimacy and the State. New York: Oxford University Press.

Barnard, Frederick M. 2001. Democratic Legitimacy: Plural Values and Political Power. Montreal: McGilll-Queen's University Press.

Barnes, Marian, Janet Newman, Andrew Knops, and Helen Sullivan. 2003. Constituting the 'Public' in Public Participation. Public Administration 81, no. 2: 379-99.

Barnes, Sam. 1998. Ngos in peace-keeping operations: their role in mozambique. Development in Practice 8, no. 3: 309-22.

Barnett, Randy E. 2003. Constitutional Legitimacy. Columbia Law Review 103, no. 1: 111-48.

Barret, Scott. 1994. Self-enforcing International Environmental Agreements. Oxford Economic Papers 46, no. SPEISS: 878-94.

Barrett, C. B., and P. Arcese. 1998. Wildlife Harvest in integrated conservation and development projects: linking harvest to household demand, agricultural production, and environmental shocks in the Serengeti. Land Economics 74: 449-65.

Barrett, Christopher B., and Peter Arcese. 1995. Are Integrated Conservation-Development Projects (ICDPs) Sustainable? On the Conservation of Large Mammals in Sub-Saharan Africa. World Development 23, no. 7: 1073-84.

Barrow, E., and M. Murphree. 2001. Community Conservation from Concept to Practice: A Framework. African Wildlife and Livelihoods: The Promise and Performance of Community Conservation. Editors D. and M. Murphree Hulme. Heinemann, New Hampshire: James Currey.

Basadur, Min, Pam Pringle, Gwen Speranzini, and Marie Bacot. 2000. Collaborative Problem Solving Through Creativity in Problem Definition: Expanding the Pie. Creativity and Innovation Management 9, no. 1: 54-76.

Bassett, Thomas J., and Koli Bi Zueli. 2000. Environmental Discourses and the Ivorian Savanna. Annals of the Association of American Geographers 90, no. 1: 67-95.

Batisse, Michel. 2001. World Heritage and Biosphere Reserves: Complementary Instruments. Parks 11, no. 1: 38-43.

Baumann, Pari, and Subir Sinha. 2001. Linking Development with Democratic Processes in India: Political Capital and Sustainable Livelihoods Analysis. Natural Resource Perspectives 68: 1-4. 
Baumeister, Andrea T. 2003. Habermas: Discourse and Cultural Diversity. Political Studies 51: 740-758.

Bawa, K., R. Seidler, and P. Raven. 2004. Reconciling Conservation Paradigms. Conservation Biology 18, no. 4: 859-60.

Baynes, Kenneth. 2004. The transcendental turn: Habermas's "Kantian pragmatism". In The Cambridge Companion to Critical Theory. Ed. Fred Rush, 194-218. New York: Cambridge University Press.

Bedunah, Donald J., and Sabine M. Schmidt. 2004. Pastoralism and protected area management in mongolia's gobi gurvansaikhan national park. Development and Change 35, no. 1: 1163-87.

Beetham, David. 1993. In Defence of Legitimacy. Political Studies 41, no. 3: 488-91. 1994. Legitimation of Power. Brill Academic Publishers, Incorporated.

Beetham, David. 1992. Liberal Democracy and the Limits of Democratization. Political Studies 60: 40-53.

Beetham, David. 1985. Max Weber and the Theory of Modern Politics. Cambridge, MA: Blackwell.

Beierle, Thomas C. 1999. Using Social Goals to Evaluate Public Participation in Environmental Decisions. Policy Studies Review 16, no. 3/4.

Beierle, Thomas C., and David M. Konisky. 2000. Values, Conflict, and Trust in Participatory Environmental Planning. Journal of Policy Analysis and Management 19, no. 4: 587-602.

Beinart, William. 2003. The Rise of Conservation in South Africa: Settlers, Livestock, and the Environment, 1770-1950. New York: Oxford University Press.

Belcher, Brian. 2007. Commercialisation of Non-timber Forest Products: A Reality Check . Development Policy Review 25, no. 3: 355-77.

Bell. 1999. CBNRM and Other Acronyms: An Overview and Challenges in the Southern African Region. Paper presented at the inaugural meeting of the CASS/PIASS Programme on Community-Based Natural Resource Management.

Bell, H. 1987. Conservation with a human face: Conflict and reconciliation in African land use planning. In Conservation in Africa: People, Politics, and Practice. Eds. D. Andrew, and R. Grove, 79-101. Cambridge: Cambridge University Press.

Belli, Brita. 2007. Getting Rich on Public Land. E Magazine 18, no. 2: 22-24.

Belsky, Jill M. 2002. Beyond the Natural Resource and Environmental Sociology Divide: Insights from a Transdisciplinary Perspective. Society and Natural Resources 15: 269-80. 
- 1999. Misrepresenting Communities: The Politics of Community-Based Rural Ecotourism in Gales Point Manatee, Belize. Rural Sociology 64, no. 4: 611-66.

Bendix, Reinhard. 1977. Max Weber: An Intellectual Portrait. Berkeley, CA: University of California Press.

Bengsten, D. N. 1994. Changing forest values and ecosystem management. Society \& Natural Resources 7: 515-33.

Bengston, David N., and David P. Fan. 1999. An Innovative Method for Evaluating Strategic Goals in a Public Agency: Conservation Leadership in the U.S. Forest Service. Evaluation Review 2, no. 1: 77-100.

Benhabib, Seyla. 2002. Claims of Culture: Equality and Diversity in the Global Culture . Princeton, N. J.: Princeton University Press.

-1994. Deliberative Rationality and Models of Democratic Legitimacy. Constellations 1, no. 1: 26-52.

Bentler, P. M., and David G. Weeks. 1980. Linear Structural Equations with Latent Variables. Psychometrika 45, no. 3: 289-308.

Bentrupperbaumer, Joan M, Tara Day, and Joseph Reser. 2006. Uses, Meanings, and Understandings of Values in the Environmental and Protected Area Arena: A Consideration of "World Hertigage" Values. Society and Natural Resources 19, no. 8: 723-41.

Berger, J., C. L. Ridgeway, M. H. Fisek, and R. Z. Norman. 1998. The legitimation and delegitimation of power and prestige orders. American Sociological Review 63: 379-405.

Berkes, and Folke. 1998. Linking Social and Ecological Systems. Cambridge: Cambridge University Press.

Berkes, F. 1989. Common Property Resources: Ecology of Community-Based Sustainable Development. London: Belhaven Press.

Berkes, Fikret. 2004. Rethinking Community-Based Conservation. Conservation Biology 18, no. 3: 621-30.

Berlin, Isaiah. 2002. Liberty. New York: Oxford University Press.

Berlin, Isaiah. 2002. Two Concepts of Liberty . in Liberty. Isiah BerlinNew York: Oxford University Press.

Berman, Helene, Marilyn Ford-Gilboe, and Jacquelyn Campbell. 1998. Combining Stories and Numbers: A Methodologic Approach for a Critical Nursing Science. Advances in Nursing Science 21, no. 1: 1-15. 
Bernard, H. Russell. 2002. Research Methods in Anthropology. Walnut Creek, CA: AltaMira Press.

Bernstein, Richard J. 1988. Fred Dallymar's Critique of Habermas. Political Theory 16, no. 4: 580-593.

Best, C., and L. Wayburn. 2001. America's Private Forests. 75-95. Washington, D.C.: Island Press.

Bethell, Tom. 2005. The Politically Incorrect Guide to Science. Washington, D. C.: Regnery Publishing, Inc.

Bhat, Mahadev G., Ray G. Huffaker, and Suzanne M. Lenhart. 1996. Controlling transboundary wildlife damage: modeling under alternative management scenarios. Ecological Modelling 92, no. 2/3: 215-24.

Bhattarai, Keshav, Dennis Conway, and Nanda R. Shrestha. 2002. The Vacillating Evolution of Forestry Policy in Nepal: Historically Manipulated, Internally Mismanaged. International Development Planning Review 24, no. 3: 315-38.

Biggs, Harry C. 2004. Promoting Ecological Research in National Parks - A South African Perspective. Ecological Applications 14, no. 1: 21-24.

Biggs, Harry C., and Kevin H. Rogers. 2003. An Adaptive System to Link Science, Monitoring, and Management in Practice. In The Kruger Experience: Ecology and Management of Savanna Heterogeneity. Eds. Johan T. du Toit, Kevin H. Rogers, and Harry C. Biggs, 5980. Washington, D.C.: Island Press.

Biggs, Stephen D., and Don Messerschmidt. 2003. The Culture of Access to Mountain Natural Resources. Stephen D. Biggs, and Don MesserschmidtNepal: Food and Agriculture Oganization: Livelihood Support Programme.

Bigley, Gregory A., and Jone L. Pearce. 1998. Straining for Shared Meaning in Organization Science: Problems of Trust and Distrust. The Academy of Management Review 23, no. 3: 405-21.

Bilgili, Ertugrul. 2003. Stand Development and Fire Behavior. Forest Ecology and Management 179: 333-39.

Bingen, Jim, Alex Serrano, and Julie Howard. 2003. Linking farmers to markets: different approaches to human capital development. Food Policy 28, no. 4: 405-20.

Bingham, Gail. 2003. When the Sparks Fly: Building Consensus when the Science is Contested. Gail BinghamWashington D.C.: Resolve.

Bird, Jeremy, Larry Hass, and Lyla Mehta. 2005. 'Rights, Risks and Responsibilities' Approach to Implementing Stakeholder Participation, IUCN. 
Black, Richard, and Elizabeth Watson. 2006. Local community, legitimacy, and cultural authenticity in postconflict natural resource management: Ethiopia and Mozambique. Environment and Planning 24, no. 2: 263-82.

Blaikie, Piers. 1985. The political economy of soil erosion in developing countries. A new approach - with new problems. Piers Blaikie, 81-106. Harlow, Essex, England: Longman.

- 1999. A review of Political Ecology : Issues, Epistemology and Analytical Narratives. Z. Wirtschaftsgeographie 43, no. 3-4 : 131-47.

Blaikie, Piers, and Harold Brookfield. 1987. Defining and debating the problem. Land Degredation and Society. Blaikie Piers, and Harold BrookfieldLondon: Methuen.

Blaustein, Richard J. 2007. Protected Areas and Equity Concerns. BioScience 57, no. 3: 216-21.

Block, Walter. 1998. Environmentalism and Economic Freedom: The Case for Private Property Rights. Journal of Business Ethics 17: 1887-99.

Blythe, M. 2006. Interdisciplinary criticism: analyzing the experience of riot! a location-sensitive digital narrative. Behaviour \& Information Technology 25, no. 2: 127-39.

Bøås, Morten. 2003. Weak States, Strong Regimes: Towards a 'Real' Political Economy of African Regionalization. in The New Regionalism in Africa. eds. J. Andrew Grant and Fredrik Söderbaum. Burlington, VT: Ashgate.

Bobbio, Luigi. 2003. Building Social Capital Through Democratic Deliberation: The Rise of Deliberative Arenas. Social Epistemology 17, no. 4: 343-57.

Bohman, James. 2003. Explorations of Deliberative Democracy: Deliberative Toleration. Political Theory 31, no. 6: 757-79.

- 1996. Public Deliberation: Pluralism, Complexity and Democracy. Cambridge, MA: MIT Press.

- 2004. Realizing Deliberative Democracy as a Mode of Inquiry: Pragmatism, Social Facts, and Normative Theory. Journal of Speculative Philosophy 18, no. 1: 23-43.

— 1998. Survey Article: The Coming Age of Deliberative Democracy. The Journal of Political Philosophy 6, no. 4: 400-425.

Bookbinder, Marnie P., Eric Dinerstein, Arun Rijal, Hank Cauley, and Arup Rajouria. 1998. Ecotourism's Support of Biodiversity Conservation . Conservation Biology 12, no. 6: 1399.

Booth, John A., and Mitchell Seligson. 2005. Political Legitimacy and Participation in Costa Rica: Evidence of Arena Shopping. Political Research Quarterly 58, no. 4: 537-50. 
Bornstein, Lisa. 2000. Politics and district development planning in mozambique. Journal of Contemporary African Studies 18, no. 2: 243-64.

Borrie, William T., Neal Christensen, Alan E. Watson, Theron A. Miller, and Daniel W. McCollum. 2002. Public Purpose Recreation Marketing: A Focus on the Relationship Between the Public and Public Lands. Journal of Parks and Recreation Administration 20, no. 2: 49-68.

Borrie, William T., Stephen F. McCool, and George H. Stankey. 1998. Protected Area Planning Principles and Strategies. Ecotourism: A Guide for Planners and Managers. editors K. Lindberg, M. E. Wood, and D. Engeldrum, 133-54. Vol. 2. North Bennington, VT: The Ecotourism Society.

Borrie, William T. Wayne A. Freimund and Mae A. Davenport. 2002. Winter Visitors to Yellowstone National Park: Their Value Orientations and Support for Management Action. Research in Human Ecology 9, no. 2: 41-8.

Botha, J., E. T. F. Witkowski, and C. M. Shackleton. 2004. The impact of commercial harvesting on Warburgia salutaris ('pepper-bark tree') in Mpumalanga, South Africa. Biodiversity and Conservation 13: 1675-98.

-2003. Important medicinal plants of the lowveld, South Africa - a resource users' perspective, . Restoration \& Conservation Biology Research Group, Johannesburg, South Africa .

- 2001. An inventory of medicinal plants traded on the western boundary of the Kruger National Park, South Africa. Koedoe 44, no. 2: 7-46.

- 2004. Market profiles and trade in medicinal plants in the Lowveld, South Africa. Environmental Conservation 31, no. 1: 38-46.

Botha, Jenny. 1998. Developing an understanding of problems being experienced by traditional healers living on the western border of Kruger National Park: foundations for an integrated conservation and development programme. Development South Africa 15, no. 4: 621-34.

Boyle, H. 2001. The Land Problem: What Does the Future Hold for South Africa's Land Reform Program? Indiana International and Comparative Law Review 11: 665.

Bradburn, Norman, Seymour Sudman, and Brian Wansink. 2004. Asking Questions. San Francisco: John Wiley \& Sons.

Brandon, K., L. J. Gorenflo, A. S. Rodrigues, and R. W. Waller. 2005. Reconciling biodiversity conservation, people, protected areas, and agricultural suitability in Mexico. World Development 33, no. 9: 1403-18.

Brandon, K., K. H. Redford, and S. E. Sanderson. 1998. Parks in peril: People, politics, and protected areas. Washington, D.C.: Island Press. 
Brandon, Katrina, Kent H. Redford, and Steven E. Sanderson. 1998. Introduction. In Parks in Peril. Eds. Katrina Brandon, Kent H. Redford, and Steven E. Sanderson, 1-23. Washington, D.C.: Island Press.

Brannen, Julia. 2005. Mixing Methods: The Entry of Qualitative and Quantitative Approaches into the Research Process. International Journal of Social Research Methodology 8, no. 3: $173-84$.

Bray, David Barton, Leticia Merino-Perez, Patricia Negreros-Castillo, Gerardo Segura-Warnoltz, and Juan Manuel \& Vester Henricus F. M. Torres-Rojo. 2003. Mexico's CommunityManaged Forests as a Global Model for Sustainable Landscapes. Conservation Biology 17, no. 3: 672-77.

Braybrooke, David. 1987. Philosophy of Social Science. Englewood Cliffs, NJ: Prentice Hall.

Brechin, Steven R., Peter R. Wilshusen, Crystal L. Fortwangler, and Patrick C. West. 2002. Beyond the Square Wheel: Toward a More Comprehensive Understanding of Biodiversity Conservation as a Social and Political Process. Society and Natural Resources 15, no. 1: 41-64.

Brehm, John, and Wendy Rahn. 1997. Individual-Level Evidence for the Causes and Consequences of Social Capital. American Journal of Political Science 41, no. 3: 9991023.

Brewer, Gene A. 2003. Building Social Capital: Civic Attitudes and Behavior of Public Servants. Journal of Public Administration Research and Theory 13, no. 1: 5-26.

Briggs, J., M. Badri, and A. Mekki. 1999. Indigenous knowledges and vegetation use among Bedouin in the eastern desert of Egypt. Applied Geography 19: 87-103.

Bright, A. D., Michael J. Manfredo, and D. C. Fulton. 2000. Segmenting the public: An application of value orientations to wildlife planning in Colorado. Wildlife Bulletin 20: 219-26.

Brockington, David. 2006. Conservation, Human Rights, and Poverty Reduction. Conservation Biology 20, no. 1: 250-252.

2001. Exploring AgroDiversity. HC Brookfield, and H. Brookfield, 270-280. New York, NY: Columbia University Press.

Brosius, J. Peter. 2004. What Counts as Local Knowledge in Global Environmental Assessments and Conventions? Bridging Scales and Epistemologies: Linking Local Knowledge and Global Science in Multi-Scale Assessments.

Brosius, J. Peter, and Diane Russell. 2003. Conservation from Above: An Anthropological Perspective on Transboundary Protected Areas and Ecological Planning. Journal of Sustainable Forestry 17, no. 1/2: 39-65. 
Brosius, Peter J. 1999. Analysis and Intervention: Anthropological Engagements with Environmentalism. Current Anthropology 40, no. 3: 277-310.

- 2004. Indigenous Peoples and Protected Areas at the World Parks Congress. Conservation Biology 18, no. 3: 609-12.

Brosius, Peter J., Anna L. Tsing, and Charles Zerner. 1998. Representing Communities: Histories and Politics of Community-Based Natural Resource Management. Society and Natural Resources 11, no. 2: 157-68.

Brown, David, Yam Malla, Kate Schreckenberg, and Oliver Springate-Baginski. 2002. From Supervising 'Subjects' to Supporting 'Citizens': Recent Developments in Community Forestry in Asia and Africa. Natural Resource Perspectives 75: 1-4.

Brown, G., and P. Reed. 1999. Validation of a Forest Values Typology for Use in National Forest Planning. Forestry Science 46: 240-247.

Brown, Greg, and Charles Harris. 2000. The U.S. Forest Service: Whither the New Resource Management Paradigm? Journal of Environmental Management 58: 1-19.

Brown, Katrina. 2000. Environmentalists, Rubber Tappers and Empowerment: the Politics and Economics of Extractive Reserves. Development \& Change 31, no. 1.

Brown, Katrina. 2002. Innovations For Conservation and Development. The Geographical Journal 168, no. 1: 6-17.

- 1998. The Political Ecology of Biodiversity, Conservation and Development in Nepal's Terai: Confused Meanings, Means and Ends. Ecological Economics 24: 73-87.

- 2003. Three Challenges For a Real People-Centered Conservation. Global Ecology \& Biogeography 12: 89-92.

Brown, Perry L., Norman L. Jr. Christensen, Hanna J. Cortner, Thomas C. Kiernan, William H. Meadows, William Reffalt, Joseph L. Sax, George Siehl, Stewart Udall, and Deborah L. Williams. 2001. Ensuring the Stewardship of the National Wilderness Preservation System: A Report to the USDA Forest Service, Bureau of Land Management, US Fish and Wildlife Service, National Park Service, and US Geological Survey, Pinchot Institute for Conservation, Washington, D.C..

Bruch, C. 2001. Constitutional Environmental Law: Giving Force to Fundamental Principles in Africa. Columbia Journal of Environmental Law 26: 131.

Brugue, Quim, and Raquel Gallego. 2003. A Democratic Public Administration: Developments in Public Participation and Innovations in Community Governance. Public Management Review 5, no. 3: 425-48.

Brulle, Robert. 2000. Agency, Democracy, and Nature: The U. S. Environmental Movement from a Critical Theory Perspective. Cambridge, MA: MIT Press. 
Brulle, Robert J. 2002. Habermas and Green Political Thought: Two Roads Converging. Environmental Politics 11, no. 4: 1-20.

Bruner, Aaron G., Raymond E. Gullison, Richard E. Rice, and Gustavo A. B. da Fonseca. 2001. Effectiveness of Parks in Protecting Tropical Biodiversity. Science 291: 125-28.

Brunner, R. D. 1982. The policy sciences as science. Policy Sciences 15: 115-35.

Brunner, Ronald D. 2002. Problems of Governance. In Finding Common Ground: Governance and Natural Resources in the American West. Ed. Ronald D. BrunnerNew Haven, CT: Yale University Press.

Brunson, M. W. 1996. "A definition of "social acceptability" in ecosystem management." Defining social acceptability in ecosystem management: A workshop proceedings, Eds. M. W. Brunson, L. Kruger, C. Tyler, and S. Schroeder. General Technical Report PNW369. USDA Forest Service.

Brunson, Mark W., and Bruce A. Shindler. 2004. Geographic Variation in Social Acceptability of Wildland Fuels Management in the Western United States. Society and Natural Resources 17: 661-78.

Bruzzese, M. Lynne. 1993. Defining and regulating "subsistence use" of resources among Alaska natives . Natural Resources Journal 33, no. 2: 461-93.

Bryan, Todd A. 2004. Tragedy Averted: The Promise of Collaboration. Society and Natural Resources 17: 881-96.

Bryant, Raymond L. 2002. Non-governmental Organizations and Governmentality: 'Consuming' Biodiversity and Indigenous People in the Phillipines. Political Studies 50: 268-92.

- 1998. Power, Knowledge and Political Ecology in the Third World: A Review. Progress in Physical Geography 22, no. 1: 79-94.

Bryman, Alan. 2006. Integrating quantitative and qualitative research: how is it done? Qualitative Research 6, no. 1: 97-113.

Buchan, Bruce. 2002. Explaining War and Peace: Kant and Liberal IR Theory. Alternatives 27: 407-28.

Buchanan, Allen. 1999. The Internal Legitimacy of Humanitarian Intervention. The Journal of Political Philosophy 7, no. 1: 71-87.

—. 2002. Political Legitimacy and Democracy. Ethics 112: 689-719.

Buchecker, Matthias, Marcel Hunziker, and Felix Kienast. 2003. Participatory Landscape Development: Overcoming Social Barriers to Public Involvement. Landscape and Urban Planning 973: 1-18. 
Buckley, Ralf. 2003. Pay to Play in the Parks: An Australian Policy Perspective on Visitor Fees in Public Protected Areas. Journal of Sustainable Tourism 11, no. 1: 56-73.

- 2002. Public and private partnerships between tourism and protected areas: the Australian situation. Journal of Tourism Studies 13, no. 1: 26-38.

Bunn, David. 2001. Comaroff Country. Interventions 3, no. 1: 5-23.

Bunn, David. 2003. An Unnatural State: Tourism, Water \& Wildlife Photography in the Early Kruger National Park. In Social History \& African Environments. Eds. William Beinart, and Joann McGregor, 199-220. Athens, OH: Ohio University Press.

Burawoy, Michael. 1998. The Extended Case Method. Social Theory 16, no. 1: 4-33.

- 2003. Revisits: An Outline of a Theory of Reflexive Ethnography. American Sociological Review 68: 645-79.

Burby, Raymond J. 2003. Making Plans that Matter: Citizen Involvement and Government Action. Journal of the American Planning Association 69, no. 1: 33-49.

Burchfield, Jim. 2001. Finding Science's Voice in the Forest. Across the Great Divide. editors Philip Brick, Donald Snow, and Sarah Van De Wetering.

Burgiel, Stas. 2004. Convention on Biological Diversity: A Progress Report. Science and Development Network.

Burkhalter, Stephanie, John Gastil, and Todd Kelshaw. 2002. A Conceptual Definition and Theoretical Model of Public Deliberation in Small Face-to-Face Groups. Communication Theory 12, no. 4: 398-422.

Burns, Sam, Chuck Sperry, and Ron Hodgson. 2003. People and Fire in Western Colorado: Methods of Engaging Stakeholders. USDA Forest ServiceUSDA Forest Service.

Buse, A. 1982. The Likelihood Ratio, Wald, and Lagrange Multiplier Tests: An Expository Note. The American Statistician 36, no. 3: 153-57.

Busenberg, George. 2004. Wildfire Management in the United States: The Evolution of a Policy Failure. Review of Policy Research 21, no. 2: 145-56.

Busenberg, George J. 1999. Collaborative and adversarial analysis in environmental policy. Policy Sciences 32: 1-11.

Busumtwi-Sam, James. 2002. Sustainable peace and development in africa. Studies in Comparative International Development 37, no. 3: 91-118.

Butler, Jessica S., James Shanahan, and Daniel J. Decker. 2003. Public attitudes toward wildlife are changing: a trend analysis of New York residents. Wildlife Society Bulletin 31, no. 4: 1027-36. 
Buttum, Mark, and Kevin Mattson. 1999. Deliberative Democracy in Practice: Challenges and Prospects for Civic Deliberation(*). Polity 31, no. 4: 609-26.

Buyukdamgaci, Guldal. 2003. Process of Organizational Problem Definition: How to Evaluate and How to Improve. Omega 31 31: 327-38.

Cairns, John. 2002. Environmental monitoring for the preservation of global biodiversity: the role in sustainable use of the planet. International Journal for Sustainable Development \& World Ecology 9, no. 2: 135-50.

Callahan, Daniel, and Bruce Jennings, Eds. 1983. Ethics, the Social Sciences, and Policy Analysis. New York: Plenum.

Callicot, J. Baird. 1991. The Wilderness Idea Revisited: The Sustainable Development Alternative. The Environmental Professional 13: 235-47.

Callicott, J. Baird. 2000. Contemporary Criticisms of the Received Wilderness Idea. In Wilderness science in a time of change conference, Comps. David N. Cole, Stephen F. McCool, Wayne A. Freimund, and Jennifer O'LaughlinOgden, UT: U.S. Department of Agriculture, Forest Service, Rocky Mountain Research Station.

Campbell. 2001. Challenges to Proponents of Common Property Resource Systems: Despairing Voices from the Social Forests of Zimbabwe. World Development 29, no. 4.

Campbell, B. M., M. Luckert, and I. Scoones. 1997. Local level evaluation of savanna resources: a case study from Zimbabwe. Economic Botany 51: 59-77.

Campbell et al. 2002. Community-Based Conservation via Global Legislation? Limitations of the Inter-American Convention for the Protection and Conservation of Sea Turtles. Journal of International Wildlife Law and Policy, no. Spring: 121.

Campbell, J. C., and S. Bunting. 1991. Voices and paradigms: Perspectives on critical and feminist theory in nursing. Advances in Nursing Science 13, no. 3: 1-15.

Campbell, Lisa M., and Arja Vainio-Mattila. 2003. Participatory Development and CommunityBased Conservation: Opportunities Missed for Lessons Learned? Human Ecology 31, no. 3: 417-37.

Carmin, JoAnn, Nicole Darnall, and Joao Mil-Homens. 2003. Stakeholder Involvement in the Design of U.S. Voluntary Environmental Programs: Does Sponsorship Matter? The Policy Studies Journal 31, no. 4: 527-43.

Carpenter, Steve, Brian Walker, J. Marty Anderies, and Nick Abel. 2001. From Metaphor to Measurement: Resilience of What to What? Ecosystems 4, no. 8: 765-81.

Carr, C. and G. Scott. 1999. Multilateral Treaties and the Environment: A Case Study in the Formation of International Law. Denver Journal of International Law and Policy 27, no. 2: 313 . 
Carraro, Carlo and Domenico Siniscalo. 1998. International Environmental Agreements: Incentives and Political Economy. European Economic Review 42: 561-72.

Carruthers, Jane. 2005. Changing Perspectives on Wildlife in Southern Africa, C. 1840 to C. 1914. Society and Animals 13, no. 3: 183-200.

Carruthers, Jane. 1989. Creating a National Park, 1910 to 1926. Journal of Southern African Studies 15, no. 2: 188-216.

Carruthers, Jane. 1996. Defending Kruger's Honour? A Reply to Professor Henni Grobler. Journal of Southern African Studies 22, no. 3: 473-80.

Carruthers, Jane. 1994. Dissecting the Myth: Paul Kruger and the Kruger National Park. Journal of Southern African Studies 20, no. 2: 263-83.

Carruthers, Jane. 1995. A Social and Political History of Kruger National Park. Pietermaritzburg: University of Natal Press.

Carruthers, Jane. Wildlife and Warfare.

Carson, Hartwell H. 2005. "Access tradeoffs vs. Social Preferences: Upper Missouri River Breaks National Monument." Unpublished Master's Thesis, University of Montana.

Cartwright, John. 1991. Is There Hope for Conservation in Africa? The Journal of Modern African Studies 29, no. 3.

Casella, George, and Roger L. Berger. 1999. Statistical Inference. Brooks/Cole.

Cashore, B. 2002. Legitimacy and the Privatization of Environmental Governance: How NonState Market-Driven (NSMD) Governance Systems Gain Rule-Making Authority . Governance 15, no. 4: 503-29.

Cashore, Benjamin. 2004. Governing Through Markets: Forest Certification and the Emergence of Non-State Authority. New Haven, CT: Yale University Press.

Cauley, Laura. 2004. "Integrating Social Equity into the Measurement of Human Values in Outdoor Recreation." Unpublished Master's Thesis, University of Montana.

Cawley, R. Mc. 2001. Everything is hitched to everything else: environmentalism, govermentality, and legitimacy. Administrative Theory and Praxis 23, no. 1: 83-98.

Cestero, Barb, and Jill M. Belsky. 2003. Collaboration for Community and Forest Well-Being in the Upper Swan Valley, Montana. Forest Communities, Community Forests. editors J. Kusel, and E. Adler, 149-70. Lanham, MD: Rowman \& Littlefield.

Chalmers, A. F. 1990. Introducing Falsification. What Is This Thing Called Science?Queensland: University of Queensland Press. 1999. What is this thing called Science. 3rd ed. Indianapolis, IN: Hackett Publishing 


\section{Company.}

Chambers, R. 1997. Whose reality counts? Putting the last first. London: Intermediate Technology.

Chambers, R., and M. McBeth. 1992. Community Encouragement: Returning to the Basis for Community Development. Journal of Community Development Society 23, no. 2: 20-38.

Chambers, Simone. 2003. Deliberative Democracy Theory. Annual Review of Political Science 6: 307-26.

- 2004. Democracy, Popular Sovereignty, and Constitutional Legitimacy. Constellations 11, no. 2: 153-73.

- 2004. The politics of Critical Theory. In The Cambridge Companion to Critical Theory. Ed. Fred Rush, 219-47. New York: Cambridge University Press.

Chance, Norman A. 1987. Subsistence research in Alaska: premises, practices, and prospects. Human Organization 46: 85-89.

Chapin, Mac. 2004. A Challenge to Conservationists. 17-31. Washington D. C.: World Watch Institute.

Charmaz, K. 2000. Grounded theory: Objectivist and constructivist methods. In Handbook of qualitative research. 2nd ed. Eds N. K. Denzin, and Y. S. Lincoln, 509-36. Thousand Oaks, CA: Sage.

Chase, Alston, and Debra Shore. 1992. Our National Parks. Outside June: 53-56.

Chase-Dunn, Christopher K., and Thomas D. Hall. 1997. Ecological Degradation and the Evolution of World-Systems

. Journal of World-Systems Research 3, no. 3: 403-31.

Cheng, Antony. 2003. Fire Social Science Research: Opening Remarks. Treatment-Social Issues. USDA Forest Service Proceedings RMRS-P-29, USDA Forest Service.

Cheng, Antony, and Steven E. Daniels. 2003. Examing the Interaction Between Geographic Scale and Ways of Knowing in Ecosystem Management: A Case Study of Place-Based Collaborative Planning. Forest Science 49, no. 6: 841-54.

Chennells, Roger. 2002. The Khomani San Land Claim. Paper Presented at the Indigenous Rights in the Commonwealth Project Africa Regional Expert Meeting.

Chester, Charles C. 2003. Responding to the Idea of Transboundary Conservation: An Overview of Publics Reaction to the Yellowstone to Yukon (Y2Y) Conservation Initiative. Journal of Sustainable Forestry 17, no. 1/2: 103-25.

Chew, Sing C. 1997. For Nature: Deep Greening World-Systems Analysis for the 21st Century 
. Journal of World-Systems Research 3, no. 3: 381-402.

Chhatre, Ashwini, and Vasant Saberwal. 2005. Political Incentives for Biodiversity Conservation. Conservation Biology 19, no. 2: 310-317.

Child, Brian. 2004. Innovations in Park Management. In Parks in Transition: Biodiversity, Rural Development, and the Bottom Line. Ed. Brian Child, 165-88. London: Earthscan.

— Ed. 2004. Parks in Transition: Biodiversity, Rural Development, and the Bottom Line. London: Earthscan.

Chimatiro, S. K. 1998. Aquaculture production and potential for food safety hazards in subsaharan africa: with special reference to malwai*. International Journal of Food Science \& Technology 33, no. 2: 169-76.

Chirwa, Wiseman Chijere. 2002. Land use and extension services at wovwe rice scheme, malawi. Development Southern Africa 19, no. 2: 307-27.

Chitere, O. 1994. Community Development: Its Conceptions and Practice with Emphasis on Africa. Nairobi: Gideon S. Were Press.

Christensen, Jon. 2004. Win-Win Illusions. Conservation in Practice 5, no. 1: 12-27.

Cinner, Joshua E., Michael J. Marnane, Timothy R. McClanahan, Tracy H. Clark, and John Ben. 2005. Trade, Tenure, and Tradition: Influence of Sociocultural Factors on Resource Use in Melanesia. Conservation Biology 19, no. 5: 1469-77.

Cisneros, Jose A. and Valerie G. Naylor. 1999. Uniting La Frontera: the ongoing efforts to establish a transboundary park. Environment 41, no. 3: 12.

Clapham, Christopher. 1996. Africa and the International System. Cambridge: Cambridge University Press.

Clark, M. J. 2002. Dealing with Uncertainty: Adaptive Approaches to Sustainable River Management. Aquatic Conservation: Marine and Freshwater Ecosystems 12: 347-63.

Clark, T. W. 1993. Creating and using knowledge for species and ecosystem conservation: science, organizations, and policy . Perspectives in Biology and Medicine 36: 497-525.

Clark, Tim W. 2002. The Policy Process: A Practical Guide for Natural Resource Professionals. New Haven, CT: Yale University Press.

Clawson, M. 1975. Forests for whom and for what? Baltimore, MD: Johns Hopkins University Press.

Cleaver, Francis. 2001. Institutions, Agency, and Limitations of Participatory Approaches to Development. in Participation: The New Tyranny. eds. Bill and Uma Kothari Cooke. New York: Zed Books. 
Cline-Cole, Reginald A. 1996. African and Africanist Biodiversity Research in a Neo-Liberal Context. Africa 6, no. 1: 145-58.

Cock and Fig. 2000. From Colonial to Community-Based Conservation: Environmental Justice and the National Parks of South Africa. Society in Transition 21, no. 1: 22-35.

Coggins, George C. 1999. Regulating Federal Natural Resources: A Summary Case against Devolved Collaboration. Ecology Law Quarterly 25: 602-10.

Cohen, Jacob. 1994. The Earth is Round ( $<$.05). American Psychologist 49, no. 12: 997-1003.

Colchester, M. 2000. Self-determination or environmental determination for indigenous peoples in tropical forest conservation . Conservation Biology 14: 1365-67.

Colchester, M. 2001. This Park is No Longer Your Land. UNESCO Courier, no. July: 12.

Cole, David N. 1983. Campsite Conditions in the Bob Marshall Wilderness, Montana. Ogden, UT: U.S. Department of Agriculture, Forest Service, Intermountain Forest and Range Experimental Station.

. 1996. Ecological manipulation in wilderness - an emerging management dilemma. International Journal of Wilderness 2, no. 1: 15-19.

-1983. Monitoring the Condition of Wilderness Campsites. Ogden, UT: U.S. Department of Agriculture, Forest Service, Intermountain Forest and Range Experimental Station.

- 1997. Recreation Management Priorities are Misplaced - Allocate More Resources to Low-Use Wilderness. International Journal of Wilderness 3, no. 4: 4-8.

-1989. Wilderness campsite monitoring methods: a sourcebook. Ogden, UT: U. S. Department of Agriculture, Forest Service.

Cole, David N., and George H. Stankey. 1997. Historical Development of Limits of Acceptable Change: Conceptual Clarifications and Possible Extensions. In Proceedings - Limits of Acceptable Change and related planning processes: progress and future directions, Eds. Stephen F. McCool, and David N. Cole, 5-9no. INT-GTR-371. Ogden, UT: U.S. Department of Agriculture, Forest Service, Rocky Mountain Research Station.

Coleman, James S. 1964. Introduction to Mathematical Sociology. London: The Free Press of Glencoe Collier-Macmillan Limited.

Collar, N. J. 2003. Beyond value: biodiversity and the freedom of the mind. Global Ecology and Biogeography 12: 265-9.

Collins, Randall. 1994. Weberian Sociological Theory. New York: Cambridge University Press.

Comaroff, John L., and Jean Comaroff. 1997. Postcolonial politics and discourses of Democracy in Southern Africa. Journal of Anthropological Research 53, no. 2: 123-47. 
Conley, Alexander, and Margaret A. Moote. 2003. Evaluating Collaborative Natural Resource Management. Society and Natural Resources 16, no. 5: 371-86.

Connor, Teresa K. 2003. Crooks, Commuters and Chiefs: Home and Belonging in a Border Zone in Pafuri, Gaza Province, Mozambique. Journal of Contemporary African Studies 21, no. 1: 93-120.

- 2005. Place, Belonging and Population Displacement: New Ecological Reserves in Mozambique and South Africa. Development Southern Africa 22, no. 3: 365-82.

Conover, Michael R. 2001. Resolving Human-Wildlife Conflicts: The Science of Wildlife Damage Management. CRC Press.

Conover, Pamela Johnston, Donald D. Searing, and Ivor M. Crewe. 2002. The Deliberative Potential of Political Discussion. British Journal of Political Science 32: 21-62.

Conway, G., and E. Barbier. 1990. Indicators of Agricultural Performance. After the Green Revolution., 37-43. London: Earthscan.

Cook, Jonathan. 1997. Empowering people for sustainable development. In Managing Sustainable Development in South Africa. Eds. P. Fitzgerald, A. McLennan, and B. Munslow, 275-92. Cape Town, South Africa: Oxford University Press.

Cooke, Bill, and Uma Kothari, eds. 2001. Participation: The New Tyranny. New York: Zed Books .

Cooke, Fadzilah M. 2002. Vulnerability, Control and Oil Palm in Sarawak: Globalization and a New Era? Development and Change 33, no. 2: 189-211.

Cooke, M. 1994. Language and Reason: A Study in Habermas' Pragmatics. Cambridge, MA: MIT Press.

Cooren, Francois. 2000. Toward Another Ideal Speech Situation: A Critique of Habermas' Reinterpretation of Speech Act. Quarterly Journal of Speech 86, no. 3: 295-318.

Copland, Michael Aaron. 2000. Problem-Based Learning and Prospective Principals' ProblemFraming Ability. Educational Administration Quarterly 36, no. 4: 585-607.

Corbet, A., and B. Jones. 2000. The Legal Aspects of Governance in Community-Based Natural Resource Management in Namibia. Paper Presented at the 2nd Annual CASS/PLAAS Regional Meeting.

Cordell, H. Ken, Michael A. Tarrant, and Gary T. Green. 2003. Is the Public Viewpoint of Wilderness Shifting? International Journal of Wilderness 9, no. 2: 27-32.

Corner, Jessica. 1991. In search of more complete answers to research questions. Quantitative versus qualitative research methods: Is there a way forward? Journal of Advanced Nursing 16: 718-27. 
Cornter, H. J., M. Shannon, M. Wallace, S. Burke, and M. A. Moote. 1996. Institutional barriers and incentives for ecosystem management: A problem analysis, General Technical Report PNW-354. USDA Forest Service, Portland, OR.

Cortner, Hanna J., Sam Burns, Lance R. Clark, Wendy Hinrichs Sanders, Gus Townes, and Martha Twarkins. 2002. Governance and Institutions: Opportunities and Challenges. Understanding Community-Based Forest Ecosystem Management. editors Gerald J. Gray, Maia J. Enzer, and Jonathan Kusel, 65-96. Binghamton, NY: Haworth Press, Inc.

Cortner, Hanna J., and Donald R. Field. 2004. Introduction to the Special Issue: Humans, Fire, and Forests: The Reemergence of Research on Human Dimensions. Society and Natural Resources 17: 473-75.

Costanza, Robert. 2004. Visions of Alternative (Unpredictable) Futures and Their Use in Policy Analysis. Conservation Ecology 4, no. 1.

Coulombe, Mary J. 2004. Excercising the Right to Object: A Short History of the Forest Service Appeals Process. Journal of Forestry March: 10-13.

Cousins, and Hornby. 2000. Leaping the Fissures: Bridging the Gap Between Paper and Real Practice in Setting up Common Property Institutions in Land Reform in South Africa. Paper Presented at the Paper presented at the inaugural meeting of the CASS/PlASS Programme on Community-Based Natural Resource Management.

Cox, Thomas R. 1988. The Northwest and the Nation: A Parks Movement in the Making. The Parks Builders: A History of State Parks in the Pacific Northwest. Thomas R. Cox, 3-13, 165-76. Seattle: University of Washington Press.

Crespo de Nogueira, Eduardo, and Consuelo Martínez Flores. 2003. Aesthetic Values and Protected Areas: A Story of Symbol Preservation. in The Full Value of Parks. Eds. David Harmon, and Allen D. Putney, 115-27. Lanham, MD: Rowman \& Littlefield.

Critchley, W. R. S., C. Reij, and T. J. Willcocks. 1994. Indigenous Soil and Water Conservation: A Review of the State of Knowledge and Prospects for Building on Traditions. Land Degredation \& Rehabilitation 5: 293-314.

Cronon, William. 1995. The Trouble with Wilderness; or, Getting Back to the Wrong Nature. in Uncommon Ground: Toward Reinventing Nature. Ed. William CrononNew York: W. W. Norton \& Company.

Crosby, M. P., A. Abu-Hilal, A. Al-Hamoud, J. Erez, and R. Ortal. 2000. Interactions Among Scienctists, Managers and the Public in Defining Research Priorities and Management Strategies for Marine and Coastal Resources: Is the Red Sea Marine Peace Park a New Paradigm? Water, Air and Soil Pollution 123: 581-94.

Culhane, Paul J. 1981. Public Lands Politics. Baltimore, MD: Johns Hopkins University Press. Curd, Martin, and Jan A. Cover, Eds. 1997. Philosophy of Science: Central Issues. New York: 
Norton, W. \& W. Company.

Cvetkovich, G. T., and R. Werner. 1994. How can Psychology Help Save the Planet: A Research Agenda on Environmental Problems. Washington, D. C.: American Psychological Association.

Cvetkovich, George, and Patricia L. Winter. 2003. Trust and Social Representations of the Management of Threatened and Endangered Species. Environment and Behavior 35, no. 2: 286-307.

Czech, Brian, and Paul R Krausman. 1999. Public opinion on endangered species conservation and policy. Society \& Natual Resources 12, no. 5: 469-79.

Dahlberg, A. 2005. Local resource use, nature conservation and tourism in Mkuze wetlands, South Africa: A complex weave of dependence and conflict. Geografisk Tidsskrift 105, no. 1: 43-56.

Dana, S. T., and S. K. Fairfax. 1980. Forest and Range Policy. 2nd ed. New York: McGraw-Hill.

Daniels, Steven E., Rick L. Lawrence, and Ralph J. Alig. 1996. Decision-making and Ecosystem-based Management: Applying the Vroom-Yetton Model to Public Participation Strategy. Environmental Impact Assesment Review 16: 13-30.

Daniels, Steven E., and Gregg B. Walker. 1996. Collaborative Learning: Improving Public Deliberation in Ecosystem-Based Management. Environmental Impact Assessment Review 16: 71-102.

Danielsen, Finn, Danilo S. Balete, Michael K. Poulsen, Martin Enghoff, Cristi M. Nozawa, and Arne E. Jensen. 2000. A simple system for monitoring biodiversity in protected areas of a developing country. Biodiversity and Conservation 9: 1671-705.

Danks, Cecilia. 2000. Community Forestry Initiatives or the Creation of Sustainable Rural Livelihoods: A Case From North America. Unasylva 51, no. 202: 53-63.

Chapter 6: Conclusion: Japan's Ecological Shadow of Tropical Timber in Southeast Asia. 1995. Shadows in the Forest: Japan and the Politics of Timber in Southeast Asia. P. DauvergneVancouver, BC: University of British Columbia Press.

Introduction: Ecological Shadows. 1995. Shadows in the Forest: Japan and the Politics of Timber in Southeast Asia. P. Dauvergne, 1-19. Vancouver, BC: University of British Columbia.

Davalos, Liliana M. 2001. The San Lucas Mountain Range In Columbia: How Much Conservation is Owed to the Violence? Biodiversity and Conservation 10: 69-78.

Davenport, Mae A., William T. Borrie, Wayne A. Freimund, and Robert E. Manning. 2002. Assessing the Relationship Between Desired Experiences and Support for Management Actions at Yellowstone National Park Using Multiple Methods. Journal of Parks and 
Recreation Administration 20, no. 3: 51-64.

Davidson, Carlos. 2000. Economic Growth and the Environment: Alternatives to the Limits Paradigm. BioScience 50, no. 5: 433-40.

Davison, A. C. 2003. Statistical Models. New York: Cambridge University Press.

de Beer, F. 2006. The roots and complexity of the land issue and of land claims in South Africa. Anthropology Southern Africa 29, no. 1/2: 24-34.

de Beer, F. C. 1999. Mountains as Cultural Resources: values and management issues. South African Journal of Ethnology 22, no. 1: 20-25.

De Boer, W. F., and D. S. Baquete. 1998. Natural resource use, crop damage and attitude of rural people in the vicinity of the Maputo Elephant Reserve, Mozambique. Environmental Conservation 25: 208-18.

de Haan, Jakob and Jan-Egbert Sturm. 2003. Does more democracy lead to greater economic freedom? New evidence for developing countries. European Journal of Political Economy 19, no. 3: 547-63.

de Haan, Leo, and Annelies Zoomers. 2005. Exploring the Frontier of Livelihoods Research. Development and Change 36, no. 1: 27-47.

de la Harpe, Derek, Peter Fernhead, George Hughes, Richard Davies, Anna Spenceley, Jonathan Barnes, Jenny Cooper, and Brian Child. 2004. Does 'Commercialization' of Protected Areas Threaten Their Conservation Goals? In Parks in Transition: Biodiversity, Rural Development, and the Bottom Line . Ed. Brian Child, 189-216. London: Earthscan.

De Souza, Roger-Mark, John S. Williams, and Frederick A. B. Meyerson. 2003. Service Delivery Efforts Forge Links Between Population, Health and Environment. Population Bulletin 58, no. 3.

Dear, Chad E. 2003. Understanding Wilderness and Subsistence in Gates of the Arctic National Park and Preserve, Alaska. in Science and Stewardship to Protect and Sustain Wilderness Values: Seventh World Wilderness Congress Symposium, Comps. Alan Watson and Janet Sproull, 90-93Ogden, UT: U.S. Department of Agriculture, Forest Service, Rocky Mountain Research Station.

Dear, Chad E., and Olin Eugene Myers. 2005. Conflicting Understandings of Wilderness and Subsistence in Alaskan National Parks. Society and Natural Resources 18: 821-37.

Dearden, Philip, Michelle Bennett, and Jim Johnston. 2005. Trends in Global Protected Area Governance, 1992-2002. Environmental Management 36, no. 1: 89-100.

Delanty, Gerard. 1997. Habermas and Occidental Rationalism: The Politics of Identity, Social Learning, and the Cultural Limits of Moral Universalism. Sociological Theory 15, no. 1: 30-59. 
Delbecq, A. L., A. H. Van de Ven, and D. H. Gustafson. 1986. Group techniques for program planning: a guide to nominal group and Delphi processes. Middleton, WI: Green Briar.

Delli Carpini, Michael X., and Scott Keeter. 1993. Measuring Political Knowledge: Putting First Things First. American Journal of Political Science 37, no. 4: 1179-206.

Denzin, Norman K., and Yvonna S. Lincoln, Eds. 2005. The Sage Handbook of Qualitative Research. 3rd. Ed. ed. Thousand Oaks, California: Sage Publications.

Der Derian, James. 2003. War as Game. Brown Journal of World Affairs 10, no. 1: 37-48.

Dery, David. 2000. Agenda Setting and Problem Definition. Policy Studies 21, no. 1: 37-47.

Dev, Om Prakash, Oliver Springate-Baginski, Nagendra Prasad Yadav, and John Soussan. 2003. Hamlet-Based Micro-Level Action Planning: A Tool for Improving FUGs' Planning, Decisionmaking and Implementation. Journal of Forest and Livelihood 3, no. 1: 51-63.

Devlin, Vince. 14 June 2003. Reluctant developer. The Missoulian.

deWet, Chris. 2002. Can Everybody Win? Economic Development and Population Displacement. Anthropology Southern Africa 25, no. 1 \& 2: 28-38.

Dews, Peter. 1999. Communicative paradigms and the question of subjectivity: Habermas, Mead, and Lacan. In Habermas: A Critical Reader. Ed. Peter Dews, 87-117. Malden, MA: Blackwell.

Dews, Peter. 1999. Habermas: A Critical Reader. Malden, MA: Blackwell Publishers.

The Rise of the Coffee Trade. 1999. The Coffee Book. G. Dicum, and N. Luttinger, 73-98. New York: New York Press.

Dietz, Thomas. 2003. What is a Good Decision? Criteria for Environmental Decision Making. Human Ecology Forum 10, no. 1: 33-39.

Dietz, Thomas, and Elinor \& Stern Paul C. Ostrom. 2003. The Struggle to Govern the Commons. Science 302.

Dilsaver, Lary M., and William Wyckoff. 1999. Agency culture, cumulative causation and development in Glacier National Park, Montana. Journal of Historical Geography 25, no. 1: 75-92.

DiStefano, Christine. 2002. The Impact of Categorization with Confirmatory Factor Analysis. Structural Equation Modeling 9, no. 3: 327-46.

Dixon, John A., and Paul B. Sherman. 1990. Economics of Protected Areas: A New Look at Benefits and Costs. Washington, D.C.: Island Press.

Doamekpor, Francois K. 2004. Civic Engagement and Public Policy Making in America. Public Administration Review 64, no. 1: 113-17. 
Dobrev, S. D. 2001. Revisiting organizational legitimation: cognitive diffusion and sociopolitical factors in the evolution of Bulgarian newspaper enterprises, 1846-1992. Organizational Studies 22: 419-44.

Dobson, Andrew. 2003. Citizenship and the Environment. New York: Oxford University Press.

Dobson, T. 1998. Human Rights and the Environment: Community Participation in Natural Resource Management in Malawi: Charting a New Course for Sustainability. Colorado Journal of International Environmental Law and Policy, no. 1998 Yearbook: 153.

Dodani, Mahesh H. 2006. Who Took the Cooking from the Cookie Jar? Journal of Object Technology 5, no. 4: 6.

Dodds, Walter K. 2005. The Commons, Game Theory, and Aspects of Human Nature that May Allow Conservation of Global Resources. Environmental Values 14, no. 4: 411-25.

Dodson, Andrew, and Paul Lucardie, Eds. 1995. Politics of Nature. New York: Routledge.

Dopson, Sue. 2003. The Potential of the Case Study Method for Organizational Analysis. Policy and Politics 31, no. 2: 217-26.

Doremus, Holly. 2004. The Purposes, Effects, and Future of the Endangered Species Act's Best Available Science Mandate. Environmental Law 34: 397-450.

Doremus, Holly. 2005. Science Plays Defense: Natural Resource Management in the Bush Administration. Ecology Law Quarterly 32: 249-305.

Douglas, M. 1986. How Institutions Think. Syracuse, NY: Syracuse University Press.

Dovie, Delali B. K., E. T. F. Witkowski, and Charlie M. Shackleton. 2003. Direct-use value of smallholder crop production in a semi-arid rural South African village. Agricultural Systems 76, no. 1: 337-57.

Dowding, Keith. 2001. Rational Choice and Trust. Critical Review of International Social and Political Philosophy 4, no. 4: 207-20.

Dowie, Mark. 2003. In Law We Trust: Can Environmental Legislation Still Protect the Commons. Orion July/August: 1-11.

Doyle, T. 1998. Sustainable development and Agenda 21: the secular bible of global free markets and pluralist democracy. Third World Quarterly 19, no. 4: 771-86.

Draper, Malcom. 1998. Zen and the art of Garden Province maintenance: the soft intimacy of hard men in the wilderness of KwaZulu-Natal, South Africa, 1952-1997. Journal of Southern African Studies 24, no. 4: 810-828.

Driver, B. L., Perry J. Brown, George H. Stankey, and Timothy G. Gregoire. 1987. The ROS Planning System: Evolution, Basic Concepts and Research Needs. Leisure Sciences 9: 
201-12.

Driver, Bev L., and S. Ross Tocher. Toward a behavioral interpretation of recreational engagements, with implications for planning. Elements of outdoor recreation planning. Ed. Bev L. DriverAnn Arbor, MI: University of Michigan Press.

Dryzek, John S. 2001. Legitimacy and Economy in Political Democracy. Political Theory 29, no. 5: 651-69.

Dryzek, John S. 2004. Pragamatism and Democracy: In Search of Deliberative Publics. Journal of Speculative Philosophy 18, no. 1: 72-79.

du Toit, Johan T., Kevin H. Rogers, and Harry C. Biggs, Eds. 2003. The Kruger Experience: Ecology and Management of Savanna Heterogeneity. Washington, D. C.: Island Press.

Duarte, Mafalda. 2003. Institutionalizing development policies and resource strategies in eastern africa and india: developing winners and losers (book). Progress in Development Studies 3, no. 4: 352-53.

Duffus, James III. 1991. Forest Service Wilderness Management Funding. Committee on Interior and Insular Affairs, House of Representatives: Subcommittee on National Parks and Public Lands.

Duffy, Rosaleen. 1997. The Environmental Challenge to the Nation-State: Superparks and National Parks Policy in Zimbabwe. Journal of Southern African Studies 23, no. 3: 44151.

- 2001. Peace Parks: The Paradox of Globalisation. Geopolitics 6, no. 2: 1-26.

- 2005. The politics of global environmental governance: the powers and limitations of transfrontier conservation areas in Central America . Review of International Studies 31, no. 2: 307-24.

Duhem, Pierre. 1954. The Aim and Structure of Physical Theory. Princeton, N. J.: Princeton University Press.

Duncan, Mryl L. 2002. Reconceiving the Bundle of Sticks: Land as a Community-Based Resource. Environmental Law 32: 773-807.

Duraisamy, Jeevanandhan. 2003. Bamboo resources, enterprises and trade development opportunities for livelihood development and poverty reduction in mozambique. Journal of Bamboo \& Rattan 2, no. 4: 429-39.

Durant, Robert F., Chun Young-Pyoung, Kim Byungseob, and Lee Seongjong. 2004. Toward a New Governance Paradigm for Environmental and Natural Resources Management in the 21st Century? Administration and Society 35, no. 6: 643-82.

Durning, Patrick. 2003. Political legitimacy and the duty to obey the law. Canadian Journal of 
Philosophy 33, no. 3: 373-90.

Durst, Patrick B., Wulf Killmann, and Chris Brown. 2004. Asia's New Woods. Journal of Forestry June: 46-53.

Dustin, Daniel L., Thomas A. More, and Leo H. McAvoy. 2000. The Faithful Execution of Our Public Trust: Fully Funding the National Parks Through Taxes. Journal of Park and Recreation Administration 18, no. 4: 92-103.

Dye, Thomas. Englewood Cliffs, NJ. Models of Politics: Some Help in Thinking about Public Policy. Understanding Public Policy. Thomas Dye, 11-31. 2002: Prentice Hall.

Dyzenhaus, David. 2001. Hobbes and the Legitimacy of Law. Law and Philosophy 20, no. 5: 461-98.

Dzingirai, Vupenyu, and Charles Breen, Eds. 2005. Confronting the Crisis in Community Conservation: Case Studies from Southern Africa. Pietermaritzburg, South Africa: Centre for Environment, Agriculture, and Development, University of KwaZulu-Natal.

Eagles, Paul F. J., Stephen F. McCool, and Christopher D. Haynes. 2002. Sustainable Tourism in Protected Areas: Guidelines for Planning and Management. Best Practice Protected Area Guidelines Series, ed.Adrian Phillips, Gland, Switzerland and Cambridge, UK: IUCNThe World Conservation Union.

Easton, David. 1979. A Systems Analysis of Political Life. Chicago: University of Chicago Press.

Eckersley, Robyn. 1990. Habermas and green political thought. Theory and Society 19, no. 6: 739-77.

Eckhardt, H. C., B. W. Wilgen, and H. C. Biggs. 2000. Trends in woody vegetation cover in the Kruger National Park, South Africa. African Journal of Ecology 38, no. 2: 108-15.

Eddy, U. 2005. State Management of Careers, Workplace Conflict, and Regime Legitimacy in Socialist China. Sociological Quarterly 46, no. 2: 359-83.

Ehler, Charles N. 2003. Indicators to Measure Governance Performance in Integrated Coastal Managment. Ocean and Coastal Management 46: 335-45.

Ehlers, E. 1997. Traditional environmental knowledge and conciousness and the problem of sustained agricultural development. Applied Geography and Development 49: 79-95.

Ehrenfeld, David. 2005. The Environmental Limits to Globalization. Conservation Biology 19, no. 2: 318-26.

Ehrenfeld, David. 2005. Sustainability: Living with the Imperfections. Conservation Biology 19, no. 1: 33-35.

Ellemers, N., H. Wilke, and Van Knippenberg A. 1993. Effects of the legitimacy of low group or 
individual status on individual and collective identity enhancement strategies. Journal of Personality and Social Psychology 64: 766-78.

Ellis, F. 1998. Household strategies and rural livelihood diversification. Journal of Development Studies 38: 161-78.

.2000. Rural livelihoods and diversity in developing countries. Oxford: Oxford University Press .

Ellis, Stephen. 1994. Of Elephants and Men: Politics and NAture Conservation in South Africa. Journal of Southern African Studies 20, no. 1: 53-69.

Elsbach, Kimberly D., and Robert I. Sutton. 1992. Acquiring Organizational Legitimacy through Illegitimate Actions: A Marriage of Institutional and Impression Management Theories. Academy of Management Journal 35, no. 4: 699-738.

Emden, Christian J. 2005. Legality and Legitimacy. Reviews in the Humanities \& Social Sciences: $1-8$.

Empson, Laura. 2001. Knowledge management in professional service firms. Human Relations 54, no. 7: 811-17.

Endicott, Eve. 1993. Land Conservation Through Public/Private Partnerships. Washington, D.C.: Island Press.

EndterWada, J. and D. W. Levine. 1996. Comparison of subsistence activities among natives and non-natives in Bristol Bay, Alaska. Society and Natural Resources 9, no. 6: 596-609.

Engel, S., R. Lopez, and C. Palmer. 2006. Community-Industry Contracting over Natural Resource Use in a Context of Weak Property Rights: The Case of Indonesia. Environmental and Resource Economics 33, no. 1: 73-93.

English, Donald B. K., David W. Marcoullier, and H. Ken Cordell. 2000. Tourism Dependence in Rural America: Estimates and Effects. Society and Natural Resources 13: 185-202.

Erasmus, Johan. "Ecotourism can yield a crop of new jobs if communities will only wait for the harvest." Web page, [accessed 28 November 2004]. Available at C:Documents and Settings|randy.tannerlMy Documents $\backslash$ Dissertation $\backslash$ Literature $\backslash A$ frican ConservationlErasmus.doc.

Escobar, Arturo. 1998. Whose Knowledge, Whose Nature? Biodiversity, Conservation, and the Political Ecology of Social Movements. Journal of Political Ecology 5, no. 1: 53-82.

Esposito, Noreen. 2001. From Meaning to Meaning: The Influence of Translation Techniques on Non-English Focus Group Research. Qualitative Health Research 11, no. 4: 568-79.

What is Social Research? Some practical and theoretical concerns. 2002a. Qualitative Methods in Social Research. K. G. Esterberg, 1-24. New York: McGraw-Hill. 
Estes, Carroll L. 2001. Social Policy and Aging: A critical perspective. Thousand Oaks, CA: Sage.

Ethier, Wilfred J. 1998. Regionalism in a Multilateral World. Journal of Political Economy 106, no. 6: 1214-31.

Etzioni, A. 1996. Positive Aspects of Community and the Dangers of Fragmentation. Development and Change 27: 301-14.

Evans, Julian. 2001. How to Be Successful in Plantation Development. ITTO Tropical Forest Update November 3.

Evers, Adalbert. 2003. Social Capital and Civic Commitment: On Putnam's Way of Understanding. Social Policy and Society 2, no. 1: 13-21.

Fabricius, C., M. Burger, and P. A. R. Hockey. 2003. Comparing biodiversity between protected areas and adjacent rangelands in xeric succulent thicket, South Africa: arthropods and reptiles. Journal of Applied Ecology 40, no. 2: 392-403.

Fairfax, Sally K. 1999. The Federal Forests Are Note What They Seem: Formal and Informal Claims to Federal Lands. Ecology Law Quarterly 25: 630-646.

Fairfax, Sally K., Lauren Gwin, and Mary Ann King. 2005. Buying Nature: The Limits of Land Acquisistion as a Conservation Strategy, 1780-2004. Cambridge, MA: MIT Press.

Fairhead, James, and Melissa Leach. 1995. False Forest History, Complicit Social Analysis: Rethinking Some West African Environmental Narratives. World Development 23, no. 6: 1023-35.

Fakir, Saliem. 2002. The Challenges of Addressing Poverty and Environment Linkages in South Africa. IUCN Policy Think Tank Series 14.

Fakir, Saliem. 2001. Is There a Paradigm Shift in Conservation? Policy Think Tank Series No. 6 , IUCN.

— 2001. Where to From Here: Is Community-Based Natural Resource Management a Thing of the Past? Think Tank Series No. 5, IUCN.

Falk, Ian, and Lesley Harrison. 1998. Indicators of Social Capital: Social Capital as the Product of Local Interactive Learning Processes. CRLRA Discussion Paper Series, Launceston, Australia: Center for Research and Learning in Regional Australia.

Falk, Ian, and Sue Kilpatrick. 1999. What Is Social Capital? A Study of Interaction in a Rural Community. CRLRA Discussion Paper Series, Launceston, Australia: Center for Research and Learning in Regional Australia.

Fallding, Harold. 1965. A Proposal for the Empirical Study of Values. American Sociological Review 30, no. 2: 223-33. 
Fallon Jr., Richard H. 2005. Legitimacy and the Constitution. Harvard Law Review 118, no. 6 : 1789-853.

Farmbry, Kyle, and Raina Harper. 2005. Institutional Legitimacy Building in a Context of Transition: The South African Land Claims Court. Public Administration Review 65, no. 6: 678-86.

Farnham, Timothy J. 1995. Forest Service Budget Requests: What do Analyses of Trends Reveal? Policy Studies Journal 23, no. 2: 253-67.

Fassinger, Ruth. 2005. Paradigms, Praxis, Problems, and Promise: Grounded Theory in Counseling Psychology Research. Journal of Counseling Psychology 52, no. 2: 156-66.

Favre, David S. 1989. International Trade in Endangered Spcies: A Guide to CITES. Boston, MA: Brill Academic Publishers.

Feeney, Mary K. 2003. Questions of Democracy. Science and Public Policy December: 467-68.

Feld, Lars P. and Marcel R. Savioz. 1997. Direct democracy matters for economic performance: An empirical investigation. Kyklos 50, no. 4: 507-38.

Feldman, Tine Rossing, and Susan Assaf. 1999. Social Capital- Conceptual Frameworks and Empirical Evidence: An Annotated Bibliography. Social Capital Working Paper Series, Washington, DC: World Bank.

Ferraro, Paul J., and Agnes Kiss. 2002. Direct Payments to Conserve Biodiversity. Science 298: $1718-19$.

Ferrell, B. J. A. G. 2002. Community development and health project: a 5-year (1995-1999) experience in mozambique, africa. International Nursing Review 49, no. 1:27-37.

Festenstein, Matthew. 1997. Habermas on Legitimacy and Rights. In Contemporary Political Studies. eds. G. Stoker and J. Stanyer, 373-83. Nottingham, U.K.: Political Studies Association.

Few, Roger. 2001. Containment and Counter-Containment: Planner/Community Relations in Conservation Planning. The Geographical Journal 167, no. 2: 111-31.

Feyerabend, Paul. 1965. Problems of Empiricism. In Beyond the Edge of Certainty. Ed. R. G. ColodnyEnglewood Cliffs: Prentice Hall.

Field, Donald R., Perry J. Brown, and Rabel J. Burdge. 2004. Coming in from the Dark: The Evolution of ISSRM and Social Science Research in Resource Management. Society and Natural Resources: A Summary of Knowledge. Eds. Michael J. Manfredo, Jerry J. Vaske, Brett L. Bruyere, Donald R. Field, and Perry J. Brown, 1-8. Jefferson, MO: Modern Litho.

Figgis, Penelope. 2003. The Changing Face of Nature Conservation: Reflections on the 
Australian Experience. Decolonizing Nature: Strategies for Conservation in a Postcolonial Era. editors William M. Adams, and Martin Mulligan, 197-219. London: Earthscan Publications Ltd.

Finlayson, James Gordon. 2005. Habermas: A Very Short Introduction. New York: Oxford University Press.

Finney, Carolyn, and Ruth E. Polk. 1995. Developing Stakeholder Understanding, Technical Capability, and Responsibility: The New Bedford Harbor Superfund Forum.

Environmental Impact and Assessment Review 15: 517-41.

Firey, Walter. 1960. Man, Mind, and Land. Glencoe, IL: The Free Press.

Fischer, F. 2000. Citizens, Experts, and the Environment: The Politics of Local Knowledge. Raleigh-Durham, N.C.: Duke University Press.

Fishbein, M., and I. Ajzen. 1975. Belief, Attitude, Intention and Behavior: An introduction to theory and research. Reading, MA: Addision-Wesley.

Sampling Strategies. 2002. Introduction to Qualitative Research. Uwe Flick, 61-72. Thousand Oaks, CA: Sage Publications.

Florini, Ann. 2003. A Time of Transition? The Coming Democracy: New Rules for Running a New World. Ann Florini, 1-18. Washington, DC: Island Press.

Flyvbjerg, Bent. 1998. Habermas and Foucault: Thinkers for Civil Society? British Journal of Sociology 49, no. 2: 210-233.

Foggin et al. 2000. Enhancing Linkages Between Rural Communities and Protected Areas in Kwa-Zulu Natal through Tourism - Abantu Bayasizana (People Helping People). Journal of Tourism Studies 11, no. 1: 2.

The community tool box: the idea, methods and tools for participatory assessment, monitoring, and evaluation in community forestry. 1990. In Community Forestry Field Manual 2. Food and Agriculture OrganizationThailand: Food and Agriculture Organization.

Foreit, Karen F., Avertino T. L Barreto, P. Antonio Noya, and Isabel Nhatave. 2001-2002. Population movements and the spread of hiv/aids in mozambique. Journal of Health \& Human Services Administration 24, no. 3/4: 279-94.

Foreman, Dave. 1998. Wilderness Areas for Real. The Great New Wilderness Debate. editor J. Baird Callicot, and Michael P. Nelson, 395-407. Athens, Georgia: University of Georgia Press.

Foresta, Ronald A. 1984. America's National Parks and Their Keepers. Washington, D. C.: Resources for the Future.

Forester, John. 1993. Critical theory and planning practice: toward a critical pragmatism. 
Albany: State University Press of New York.

Forester, John. 1989. Planning in the Face of Power. Berkeley, CA: University of California Press.

Forsyth, Timothy. 1996. Science, Myth and Knowledge: Testing Himalayan Environmental Degredation in Thailand. Geoforum 27, no. 3: 375-92.

Fortmann, Louise. 1996. Bonanza! The Unasked Questions: Domestic Land Tenure Through International Lenses. Society and Natural Resources 9: 537-47.

Fortmann, Louise, and Emery \& Van Eeten Michel Roe. 2001. At the Threshold Between Governance and Management: Community-Based Natural Resource Management in Southern Africa. Public Administration and Development 21: 171-85.

Forty-Second Congress. Session II. United States Congress. 1872. An Act to set apart a certain Tract of Land lying near the Head-waters of the Yellowstone River as a public Park. Ch. 24.

Foster, John Bellamy. 1993. The Limits of Environmentalism Without Class: Lessons from the Ancient Forest Struggle in the Northwest. New York, NY: The Monthly Review Press.

. 2003. The New Age of Imperialism. Monthly Review 55, no. 3: 1-14.

Fotopoulos, Takis. 2003. Inclusive Democracy and Participatory Economics. Democracy \& Nature 9, no. 3: 401-25.

Foucalt, Michel. 1991. Governmentality. The Foucalt effect: Studies in governmentality. Eds. G. Burchell, C. Gordon, and P. Miller, 87-104. Chicago: University of Chicago Prese.

Foucault, Michel. 1972. The Archaeology of Knowledge. New York: Pantheoon.

Foweraker, Joe and Todd Landman. 2004. Economic Development and Democracy Revisited: Why Dependency Theory is Not Yet Dead. Democratization 11, no. 1: 1-19.

Fox, Helen E., Caroline Christian, J. Cully Nordby, Oliver W. Pergams, Garry D. Peterson, and Christopher R. Pyke. 2006. Perceived Barriers to Integrating Social Science and Conservation. Conservation Biology 20, no. 6: 1817-20.

Fraser, Nancy. 1981. Foucault on Modern Power: Empirical Insights and Normative Confusions. Praxis International 1, no. 3: 272-87.

Frechtling, Joy, and Laure Sharp. 1997. User-Friendly Handbook for Mixed Method Evaluations. Washington, D. C.: Directorate for Education and Human Resources, Division of Research, Evaluation and Communication, National Science Foundation.

Fred-Mensah, Ben K. 2004. Social capital building as capacity for postconflict development: the UNDP in mozambique and rwanda. Global Governance 10, no. 4: 437-57. 
Freedman, Eric. 2002. When Indigenous Rights and Wilderness Collide. American Indian Quarterly 26, no. 1: 378-92.

Freemuth, John, and R. McGreggor Cawley. 1998. Science, Expertise and the Public: The Politics of Ecosystem Management in the Greater Yellowstone Ecosystem. Landscape and Urban Planning 40: 211-19.

Freitag-Ronaldson, Stefanie, and Llewellyn C. Foxcroft. 2003. Anthropogenic Influences at the Ecosystem Level. in The Kruger Experience: Ecology and Management of Savannah Heterogeneity. Eds. Johan T Du Toit, Kevin H. Rogers, and Harry C. BiggsWashington, D.C.: Island Press.

Frentz, I. C., D. E. Voth, S. Burns, and C. W. Sperry. 2000. Forest Service-Community relationship building: recommendations. Society and Natural Resources 13: 549-66.

Freyfogle, Eric T. 1998. Owning the Land: Four Contemporary Narratives. Journal of Land Use \& Environmental Law 13, no. 2: 279-307.

Fried, Stephanie Gorson. 2003. Writing for their Lives: Bentian Dayak Authors and Indonesian Development Discourse. Culture and the Question of Rights. editor C. Zerner, 142-83. Durham and London: Duke University Press.

Friedmann, John. 1993. Toward a Non-Euclidian Mode of Planning. American Planning Association Journal 59, no. 4.

Friedrich, Carl J. 1963. Man and His Government: An Empirical Theory of Politics . New York: McGraw Hill.

- 1940. Public Policy and the Nature of Administrative Responsibility. In Public Policy. Ed. Carl J. Friedrich, 221-46. Cambridge, MA: Harvard University Press.

Frome, Michael. 1997. Battle for the Wilderness. Salt Lake City: The University of Utah Press.

—. 2000. For A United States Wilderness Service. Wilderness Watcher 11, no. 3.

- 2005. A Wilderness Challenge. International Journal of Wilderness 11, no. 1: 7.

Fromm, Erich. 1994. Escape from Freedom. New York: Henry Hold and Company.

Fukuyama, Francis. 2001. Comment and Analysis: The West Has Won: Radical Islam CannotBeat Democracy and Capitalism. We're Still at the End of History. The Guardian, sec. Guardian Leader Pages, p. 21.

Fulton, David C., M. J. Manfredo, and J. Lipscomb. 1996. Wildlife value orientations: a conceptual and measurement approach. Human Dimensions of Wildlife 1, no. 2: 24-47.

Fung, Archon, and Erik Olin Wright. 2001. Deepening Democracy: Innovation in Empowered Participatory Governance. Politics and Society 29, no. 1: 5-41. 
Gadd, M. E. 2005. Conservation outside of parks: attitudes of local people in Laikipia, Kenya. Environmental Conservation 32, no. 1: 50-63.

Gadgil, M, F. Berkes, and C. Folke. 1993. Indigenous knowledge for biodiversity conservation. Ambio 22, no. 2/3: 151-56.

Gadgil, Madhav, Per Olsson, Fikret Berkes, and Carl Folke. 2003. Exploring the Role of Local Ecological Knowledge in Ecosystem Management: Three Case Studies. Navigating Social-Ecological Systems. Editors Fikret Berkes, J. Colding, and Carl Folke, 189-209. Cambridge: Cambridge University Press.

Gannet, Robert T. Jr. 2003. Bowling Ninepins in Tocqueville's Township. American Political Science Review 97, no. 1: 1-16.

Garber-Yonts, Brian, Joe Kerkvliet, and Rebecca Johnson. 2004. Public Values for Biodiversity Conservation Policies in the Oregon Coast Range. Forest Science 50, no. 15: 589-602.

Garrett, James L., and Marie T. Ruel. 1999. Are determinants of rural and urban food security and nutritional status different? Some insights.. World Development 27, no. 11: 1955-75.

Gauli, Kalyan, and Parul Rishi. 2004. Do the Marginalised Class Really Participate in Community Forestry? A Case Study from Western Terai Region of Nepal. Forests, Trees and Livelihoods 14: 137-47.

Geach, Bev. National Biodiversity Strategy and Action Plan: Stocktaking Report, Department of Environmental Affairs and Tourism, Republic of South Africa.

Gearey, Mary, and Paul Jeffrey. 2006. Concepts of legitimacy within the context of adaptive water management strategies. Ecological Economics 60, no. 1: 129-37.

Geist, Helmut J., and Eric F. Lambin. 2002. Proximate Causes and Underlying Driving Forces of Tropical Deforestation. BioScience 52, no. 2: 143-50.

Gelpi, Christopher. 2003. The Power of Legitimacy: Assessing the Role of Norms in Crisis Bargaining. Princeton, N.J.: Princeton University Press.

Gerard, David. 2000. The Origins of the Federal Wilderness System. In Political Environmentalism: Going Beyond the Green Curtain. Ed. Terry L. AndersonPalo Alto, CA: Hoover PressHoover Institute.

Gerring, John. 2004. What is a Case Study and What is it Good for? American Political Science Review 98, no. 2: 341-54.

Ghimire, K. B., and M. P. Pimbert. 1997. Social change and conservation: environmental politics and impacts of national parks and protected areas. London : Earthscan.

Gibb, Richard. 1997. Regional Integration in Post-Apartheid Southern Africa: The Case of Renegotiating the Southern African Customs Union. Journal of Southern African Studies 
23, no. 1: 67-86.

Gibson, Clark C. 1999. Politicians and Poachers: The Political Economy of Wildlife Policy in Africa. Cambridge University Press.

Gibson, Clark. C., and C. Dustin Becker. 2000. A Lack of Institutional Demand: Why a Strong Local Community in Western Ecuador Fails to Protect Its Forests. People and Forests. editors E. Ostrom, Clark C. Gibson, and Margaret A. McKean, 135-61. Cambridge: MIT Press.

Gibson, Clark C., and Stuart A. Marks. 1995. Transforming Rural Hunters into Conservationists: An assessment of Communtiy-Based Wildlife Management Programs in Africa. World Development 23, no. 6: 941-57.

Gibson, Clark C., Margaret A. McKean, and Elinor Ostrom. 2000. Explaining Deforestation: The Role of Local Institutions. People and Forests. editors Clark C. Gibson, Margaret A. McKean, and Elinor Ostrom, 1-26. Cambridge: MIT Press.

Gibson, Clark C. \& Koontz Tomas. 1998. When "Community" Is Not Enough" Institutions and Values in Community-Based Forest Managmement in Southern Indiana. Human Ecology 26, no. 4: 621-47.

Gibson, James, and Gregory A. Caldeira. 2003. Defenders of Democracy? Legitimacy, Popular Acceptance, and the South African Constitutional Court. The Journal of Politics 65, no. 1: $1-30$.

Gibson, James L., Gregory A. Caldeira, and Lester Kenyatta Spence. 2005. Why Do People Accept Public Policies They Oppose? Testing Legitimacy Theory with a Survey-Based Experiment. Political Research Quarterly 58, no. 2: 187-201.

Giddens, Anthony. 1972. Politics and Sociology in the Thought of Max Weber. New York: Macmillan.

Gilley, Bruce. 2006. The determinants of state legitimacy: Results for 72 countries. International Political Science Review 27, no. 1: 47-41.

Gilligan, James P. 1953. "The Development of Policy and Administration of Forest Service Primitive and Wilderness Areas in the western United States." Ph.D. Dissertation, University of Michigan Press.

Gillingham, Sarah \& Lee Phyllis C. 1999. The impact of wildlife-related benefits on the conservation attitudes of local people around the Selous Game Reserve, Tanzania. Environmental Conservation 26, no. 3: 218-28.

Gilmour, D. A., and R.J. Fisher. 1998. Evolution in Community Forestry: Contesting Forest Resources. Bangkok, Thailand: RECOFTC.

Glaesel, Heidi. 1999. Imposing Wilderness: Struggles over Livelihood and Nature Preservation 
in Africa; Voices from the Rocks: Nature, Culture and History in the Matopos Hills of Zimbabwe. African Studies Review 42, no. 3: 120-122.

Glaser, Barney G., and Anselm Strauss. 1967. The Discovery of Grounded Theory. New York: Aldine de Gruyter.

Gleditsch, Nils Peter. 1998. Armed Conflict and the Environment: A Critique of the Literature. Journal of Peace Research 35, no. 3: 381-400.

Goebel. 1999. Then it's clear who owns the trees? Common property and private control in the social forest in a Zimbabwean resettlement area. Rural Sociology 64, no. 4: 624-40.

Goeschl, Tim, and Danilo Camargo Igliori. 2004. Property Rights Conservation and Development: An analysis of Extractive Reserves in the Brazilian Amazon. Note De Lavaro 60.2004, NRM- Natural Resource Management.

Goldman, Mara. 2003. Partitioned Nature, Privileged Knowledge: Community-Based Conservation in Tanzania. Development and Change 34, no. 5: 833-62.

Goldschmidt, M. 2002. The role of transparency and public participation in international environmental agreements: The North American Agreement on Environmental Cooperation. Boston College of Environmental Affairs Law Review 29: 343.

Goodman, S., W Seabrooke, and S. Jaffry. 1998. Considering Conservation Value in Economic Appraisals of Coastal Resources. Journal of Environmental Planning and Management 41, no. 3: 313-36.

Goulding, Christina. 1999. Grounded Theory: some reflections on paradigm, procedures, and misconceptions, Management Research Centrem, University of Wolverhampton.

Government Accountability Office. 1991. Wilderness Management: Accountability for Forest Service Funds Needs Impovement, GAO-RCED-92-33. Government Accountability Office, Washington, D.C..

-1989. Wilderness Preservation: Problems in Some National Foests Should be Addressed, GAO/RCED-89-202. Government Accountability Office, Washington, D.C..

Gowans, Christopherr, Ed. 2000. Moral disagreements: classic and contemporary readings. New York: Routledge.

Grace, Marcus M., and Mary Ratcliffe. 2002. The science and values that young people draw upon to make decisions about biological conservation issues. International Journal of Science Education 24, no. 11: 1157-69.

Grafstein, Robert. 1981. The Failure of Weber's Conception of Legitimacy: It's Causes and Implications. The Journal of Politics 43: 456-72.

Graham, John, Bruce Amos, and Tim Plumptre. 2003. "Governance Principles for Protected 
Areas in the 21st Century." Paper presented at the Fifth World Parks Congress, Durban, South Africa, June 30, 2003.

Gray, Barbara. 2003. Framing of Environmental Disputes. In Making Sense of Intractable Environmental Conflicts: Concepts and Cases. Eds. Roy J. Lewicki , Barbara Gray, and Michael Elliott, 11-34. Washington, D. C.: Island Press.

Greenberg, Daniel S. 2003. Science, Money, and Politics: Political Triumph and Ethical Erosion. Chicago: Chicago University Press.

Greider, Thomas, and Lorraine Garkovich. 1994. Landscapes: The Social Construction of Nature and the Environment. Rural Sociology 59, no. 1: 1-24.

Greiff, Pablo De. 2000. Deliberative Democracy and Group Representation. Social Theory and Practice 26, no. 3: 397-415.

Greisman, Harvey C., and George Ritzer. 1981. Max Weber, Critical Theory, and the Administered World. Qualitative Sociology 4, no. 1: 34-55.

2002. Mugged: Poverty In Your Cup. C. Gresser, and T. Ticknell, 1-4. Oxford: Oxfam.

Grey, Ramona J. and Theodore L. Putterman. 2002. The fiddler's prerogative: J.W. Krutch and the "class wars". The Antioch Review 60, no. 2: 250-266.

Grobler, Hennie. 1996. Dissecting the Kruger Myth with Blunt Instruments: A Rebuttal of Jane Carruther's View. Journal of Southern African Studies 22, no. 3: 455-72.

2002. World Atlas of Biodiversity. B. Groombridge, and M. D. JenkinsBerkeley, CA: University of California Press.

Grove, Richard. 1985. Incipient Conservationism in the Cape Colony an dthe Emergence of Colonial Environmental Policies of South Africa 1846-1890. Paper presented to the Conference on Conservation in Africa, April 1985..

Grove, Richard. 1989. Scottish Missionaries, Evangelical Discourses and the Origins of Conservation Thinking in Southern Africa 1820-1900. Journal of Southern African Studies 15, no. 2: 163-87.

Groves, Craig R., Mary L. Klein, and Thomas F. Breden. 1995. Natural heritage programs: public-private partnerships for biodiversity conservation. Wildife Society Bulletin 23, no. 4: 784-90.

Guba, E. G., and Y. S. Lincoln. 1994. Competing paradigms in qualitative research. In Handbook of qualitative research. Eds. N. K. Denzin, and Y. S. Lincoln, 105-17. Thousand Oaks, California: SAGE.

Guba, Egon G., and Yvonna S. Lincoln. 2004. Competing Paradigms in Qualitative Research. Approaches to Qualitative Research: A Reader on Theory and Practice. editors Sharlene 
Hesse-Biber, and Patricia Leavy, 17-38. New York: Oxford University Press.

Guha, R. 1998. Deep ecology revisited. In The great new wilderness debate. Eds. Callicott and Nelson, 271-79. Athens, GA: University of Georgia Press.

Gunderson, Lance H., and C. S. Holling. 2001. Panarchy: Understanding Transformations in Human and Natural Systems. Washington, D. C.: Island Press.

Guston, David H. 2000. Between Politics and Science: Assuring the Integrity and Productivity of Research. New York: Cambridge University Press.

Guthman, Julie. 1997. Representing Crisis: The Theory of Himalayan Environmental Degredation and the Project of Development in Post-Rana Nepal. Development and Change 28, no. 1: 45-69.

Gutmann, Amy, and Dennis Thompson. 2002. Deliberative Democracy Beyond Process. The Journal of Political Philosophy 10, no. 2: 153-74.

Gutmann, Amy, and Dennis Thompson. 1998. Democracy and Disagreement. New York: Belknap Press.

Guyer, Jane \& Richards Paul. 1996. The Invention of Biodiversity: Social Perspectives on the Management of Biological Variety in Africa. Africa 66, no. 1: 1-13.

Guyot, Sylvain. 2005. Political dimensions of environmental conflicts in Kosi Bay, South Africa: significance of the new post-apartheid governance system. Development Southern Africa 22, no. 3: 441-58.

Görg, Christoph. 2004. The construction of societal relationships with nature. Poiesis \& Praxis 3, no. 1/2: 22-36.

Haag, Fredrik, and Flora Hajdu. 2005. Perspectives on Local Environmental Security, Exemplified by a Rural South African Village . Environmental Management 36, no. 4: 483-94.

Haas, E. 1958. The Challenge of Regionalism. International Organization 12, no. 4: 441.

- 1975. Is There a Hole in the Whole? Knowledge, Technology, Interdependence, and the Construction of International Regimes. International Organization 29, no. 3: 827-76.

Habermas, Jürgen. 1996. Between Facts and Norms: Contributions to a Discourse Theory of Law and Democracy. Cambridge, MA: MIT Press.

— 1998. The Inclusion of the Other: Studies in Political Theory. Cambridge, Massachusetts: MIT Press.

1971. Knowledge and Human Interests. Boston, MA: Beacon Press.

1975. Legitimation Crisis. New York: Beacon Press. 
- 1976. Legitimation problems in the modern state. In Communication and the evolution of society. trans. T. McCarthy J. Habermas, 178-205. Boston: Beacon.

. 1988. On the Logic of the Social Sciences. Cambridge, MA: MIT Press.

- 1987. The Philosophical Discourse of Modernity: Twelve Lectures. Cambridge, MA: MIT Press.

- 1997. Popular Sovereignty as Procedure. In Deliberative Democracy. Eds. J. Bohman, and W. RehgCambridge, MA: MIT Press.

— 1992. Postmetaphysical Thinking. Cambridge, Massachusetts: MIT Press.

-1988. Theory and Practice. New York: Beacon.

- 1985. The Theory of Communicative Action, Volume I: Reason and the Rationalization of Society. Boston, MA: Beacon Press.

— 1970. Toward a Rational Society. Boston, MA: Beacon Press.

Hackel, Jeffrey D. 1999. Community conservation and the future of Arica's wildlife . Conservation Biology 13, no. 4: 726-29.

Hagen, Richard L. 1997. In Praise of the Null Hypothesis Statistical Test. American Psychologist 52, no. 1: 15-24.

Hamilton, A., A. Cunningham, D. Byarugaba, and F. Kayanja. 2000. Bwindi Impenetrable Forest, Uganda. Conservation Biology 14, no. 6: 1722-25.

Hamlin, Catherine, and Jan Salick. 2003. Yanesha Agriculture in the Upper Peruvian Amazon: Persistence and Change Fifteen Years Down the 'Road'. Economic Botany 57, no. 2: 16380.

Hanberger, Anders. 2003. Public Policy and Legitimacy: a historical policy analysis of the interplay of public policy and legitimacy. Policy Sciences 36, no. 3/4: 257-78.

Hanlon, Joseph. 2004. Renewed land debate and the 'cargo cult' in mozambique. Journal of Southern African Studies 30, no. 3: 603-25.

Hannah, L., G. F. Midgley, T. Lovejoy, W. J. Bond, M. Bush, J. C. Lovett, D. Scott, and F. I. Woodward. 2002. Conservation of Biodiversity in a Changing Climate. 16, no. 1: 26468.

Hanssen, Bjorg Lien. 2001. Ethics and Landscape: Values and Choices. Ethics, Place \& Environment 4, no. 3: 246-52.

Hardin, Garret. 1968. The Tragedy of the Commons. Science 162, no. 1243-1248.

Hardin, Garrett. 1968. The Tragedy of the Commons: The Population Problem Has No Technical 
Solution; it Requires a Fundamental Extension in Morality. Science 162: 1243-48.

Harmon, David. 2003. The Source and Significance of Values in Protected Areas. in The Full Value of Parks. Eds David Harmon, and Allen D. Putney, 13-25. Lanham, MD: Rowmand \& Littlefield .

Harmon, David, and Allen D. Putney, Eds. 2003. The Full Value of Parks. New York: Rowman \& Littlefield Publishers, Inc.

Harrington, Austin. 2000. Value-Spheres or 'Validity-Spheres'?:Weber, Habermas, and Modernity. Max Weber Studies 1, no. 1: 84-103.

Hartwick, Elaine, and Richard Peet. 2003. Neoliberalism and Nature: The Case of the WTO. The Annals of the American Academy 590: 188-211.

Hasenclaver, Andreas, Peter Mayer, and Volker Rittberger. 1996. Intersts, Power, Knowledge: The Study of International Regimes. Mershon International Studies Review 40, no. 2: 177-228.

Hatton, John, Mia Couto, and Judy Oglethorpe. 2001. Biodiversity and War: A Case Study of Mozambique. Washington, D.C.: Biodiversity Support Program.

Hauptmann, Emily. 1999. Review: Deliberation=Legitimacy=Democracy. Political Theory 27, no. 6: 857-72.

Hayek, F. A. 1944. The Road to Serfdom. Chicago: The University of Chicago Press.

Hayes, T., and E. Ostrom. 2005. Conserving the World's Forests: Are Protected Areas the Only Way? Indiana Law Review 38, no. 3: 595-618.

Heath, Anthony W. 1997. The Proposal in Qualitative Research. The Qualitative Report 3, no. 1.

Heath, Joseph. 1998. What is a validity claim? Philosophy \& Social Criticism 24, no. 4: 23-41.

Heckenberger, Michael J, J. Christian Russell, Joshua R. Toney, and Morgan J. Schmidt. 2007. The legacy of cultural landscapes in the Brazilian Amazon: implications for biodiversity. Philosophical Transactions: Biological Sciences 362, no. 1478: 197-208.

Helliwell, John F. 1994. Empirical linkages between democracy and economic growth. British Journal of Political Science 24, no. 2: 225-48.

Helm, C. and D. Sprinz. 2000. Measuring the effectiveness of international environmental regimes. Journal of Conflict Resolution 44, no. 5: 630-653.

Henderson, Karla A. 1991. Dimensions of Choice: A Qualitative Approach to Recreation, Parks, and Leisure Research. State College, PA: Venture Publishing Inc.

Hendricks, Brent. 1996. Postmodern Possibility and the Convention on Biological Diversity. New York Environmental Law Journal 5, no. 1. 
Hennenberger, J. 1996. Transformations in the concept of the park. Trumpter 13: 127-33.

Herbst, Susan. 2006. Legitimate Power in a Mediated Age: Revisiting Carl J. Friedrich's

"Authority, Reason, and Discretion". Political Communication 23, no. 3: 285-90.

Hetherington, J., T. C. Daniel, and T. C. Brown. 1994. Anything goes means everything stays: The perils of uncritical pluralism in the study of ecosystem values. Society \& Natural Resources 7: 535-46.

Hewlett, D. A. Fyall and J. Edwards. 2004. Beyond the Rhetoric of Visitor Management in Transboundary Protected Areas: The Case of Peneda-Geres. International Journal of Tourism Research 6, no. 6: 381-96.

Hiley, David R. 1984. Foucault and the Analysis of Power: Political Engagement without Liberal Hope or Comfort. Praxis International 4, no. 2: 192-207.

Hill, David, Matthew Fasham, Graham Tucker, Michael Shewry, and Philip Shaw, Eds. 2005. Handbook of Biodiversity Methods: Survey, Evaluation, and Monitoring. Cambridge, MA: Cambridge University Press.

Hill, Kevin A. 1996. Zimbabwe's Wildlife Utilization Programs: Grassroots Democracy or an Extension of State Power? African Studies Review 39, no. 1: 103-21.

Hitchcock, R. K. 1995. Centralizations, resource depletion and coercive conservation among the Tyua of the Northeastern Kalahari. Human Ecology 23, no. 2: 169-98.

Hiwasaki, L. 2005. Toward Sustainable Management of National Parks in Japan: Securing Local Community and Stakeholder Participation. Environmental Management 35, no. 6: 75364.

Hockings, Marc. 1998. Evaluating Management of Protected Areas: Integrating Planning and Evaluation. Environmental Management 22, no. 3: 337-45.

Hockings, Marc, Sue Stolton, Fiona Leverington, Nigel Dudley, and Jose Courrau. 2006. Evaluating Effectiveness: A framework for assessing management effectives of protected areas. Gland, Switzerland: IUCN.

Hoffman, E. 1989. Lost in Translation: Life in a New Language. New York: Penguin.

Hofstatter, Stephan. 16 August 2005. Fences not the only barrier for cross-border park . Mail \& Guardian Online.

Holdgate, M. 1999. The Green Web - A Union for World Conservation. London: Earthscan.

Hollander, E., and J. W. Julian. 1970. Studies in leader legitimacy, influence, and innovation. In Advances in Experimental Social Psychology. Ed. L. Berkowitz, 34-69. New York: Plenum. 
Hollander, E. P. 1992. Leadership, followership, self, and others. The Leadership Quarterly 3: 43-54.

Holling, C. S. 1978. Adaptive environmental assessment and management . London: John Wiley.

Holling, C. S. 2001. Understanding the Complexity of Economic, Ecological, and Social Systems. Ecosystems 4: 390-405.

Hollinger, David A. 1973. T. S. Kuhn's Theory of Science and its Implications for History. The American Historical Review 78, no. 2: 370-393.

Holmes, Christopher M. 2003. Assessing the perceived utility of wood resources in a protected area of Western Tanzania. Biological Conservation 111: 179-89.

Holmes, Stephen. 1982. Two Concepts of Legitimacy: France after the Revolution. Political Theory 10: 165-83.

Holt, Dan G., and Colleen Willard-Holt. 2000. Let's Get Real: Student Solving Authentic Corporate Problems. Phi Delta Kappan : 243-46.

Holt, Flora Lu. 2005. The Catch-22 of conservation: indigenous peoples, biologists, and cultural change. Human Ecology: An Interdisciplinary Journal 33, no. 2: 199-215.

Holter, I. M., and H. S. Kim. 1995. Methodology for critical theory: Critical action research. In In search of nursing science. Eds. A. Omery, C. E. Kasper, and G. G. Page, 220-232. Thousand Oaks, California: Sage.

Homer-Dixon, Thomas. 2002. The Rise of Complex Terrorism . Foreign Policy 128: 54.

Honneth, Axel. 1991. The Critique of Power: Reflective Stages in a Critical Social Theory. Cambridge, Massachusetts: MIT Press.

Horkheimer, Max, and Theodor Adorno. 1976. Dialectic of Enlightenment. New York: Continuum International Publishing Group.

Hornsey, Matthew. 2003. Relations between high and low power groups: the importance of legitimacy. Personality \& Social Psychology Bulletin 29, no. 2: 216-27.

Hoschild, Jennifer L. 2000. Book Reviews. Journal of Policy Analysis and Management 19, no. 3: 483-513.

Hough, J. L. 1988. Obstacles to effective management of conflicts between national parks and surrounding human communities in developing countries. Environmental Conservation 15: 129-36.

Hrubes, Daniel, Icek Azjen, and John Daigle. 2001. Predicting Hunting Intentions and Behavior: An Application of the Theory of Planned Behavior. Leisure Sciences 23, no. 3: 165-78. 
Hu, L. and P. M. Bentler. 1999. Cutoff criterion for fit indexes in covariance structure analysis: conventional criteria versus new alternatives. Structural Equation Modeling 6: 1-55.

Hudson, Barclay M. 1979. Comparison of Current Planning Theories: Counterparts and Contradictions. Journal of the American Planning Association October: 387-97.

Hudson, Laurel Anderson, and Julie L. Ozanne. 1988. Alternative Ways of Seeking Knowledge in Consumer Research. Journal of Consumer Research 14: 508-21.

Huff, A. 2005. Indigenous Land Rights and the New Self-Determination. Colorado Journal of International Environmental Law and Policy 16, no. 2: 295-332.

Hughes, David McDermott. 2001. Cadastral Politics: The Making of Community-Based Resource Management in Zimbabwe and Mozambique. Development and Change 21: 741-68.

Hughes, R., and F. Flintan. 2001. Integrating Conservation and Development Experience: A Review and Bibliography of the ICDP Literature. London: International Institute for Environment and Development.

Hughes, Ross, and Fiona Flintan. 2001. Integratingd Conservation and Developing Experience: A Review and Bibliography of the ICDP Literature. London: International Institute for Environment and Development.

Hulme, D., and M. Murphree. 1999. Communities, wildlife, and the "new conservation" in Africa. Journal of International Development 11:277-86.

Hulme, David, and Marshall Murphree. 1999. Policy Arena. Journal of International Development 11: 277-85.

Humphrey, C. R., Tammy L. Lewis, and F.H. Buttel . 2002. Social Theory and the Environment. Environment, Energy and Society: A New Synthesis. C. R. Humphrey, Tammy L. Lewis, and F.H. Buttel, 34-55. Florence, KY: Wadsworth Publisher.

- 2002. The Sociology of Sustainable Development. Environment, Energy and Society: A New Synthesis. C. R. Humphrey, Tammy L. Lewis, and F.H. Buttel, 220-264. Florence, KY: Wadsworth Publishers.

Humphrey, Craig R., Tammy L. Lewis, and Frederick H. Buttel. 2002. Environment, Energy, and Society: A New Synthesis. Belmont, CA: Wadsworth/Thomson Learning.

Hunt, S. D. 1991. Positivism and paradigm dominance in consumer research: Toward critical pluralism and rapprochement. Journal of Consumer Research 18: 32-44.

Hunter, M. L. 1996. Benchmarks for managing ecosystems: Are human activities natural? Conservation Biology 10: 695-97.

Huntington, Samuel P. 1996. The West: Unique, Not Universal. Foreign Affairs 
November/December: 28-46.

Hurtado-Gonzales, Jorge Luis, and Richard E. Bodmer. 2004. Assessing the sustainability of brocket deer hunting in the Tamshiyacu-Tahuayo Communal Reserve, northeeastern Peru. Biological Conservation 116, no. 1: 1-7.

Hutchcroft, Paul D. 2001. Centralization and Decentralization in Administration and Politics: Assessing Territorial Dimensions of Authority and Power. Governance 14, no. 1: 23-53.

Hutton, Jon, William M. Adams, and James C. Murombedzi. 2005. Back to the Barriers? Changing Narratives in Biodiversity Conservation. Forum for Development Studies 2: 341-70.

Igoe, Jim. 2004. Conservation and Globalization: A study of national parks and indigenous communities from East Africa to South Dakota. Belmont, CA: Wadsworth.

Ikenberry, John. 2001. Getting Hegemony Right. National Interest Spring, no. 63.

Illgner, P., and E. Nel. 2000. The geography of edible insects in Sub-Saharan Africa: a case study of the Mopane caterpillar. The Geographical Journal 166, no. 4: 336-51.

Infield, Mark. 1988. Attitudes of a rural community towards conservation and local conservation areas in Natal, South Africa. Biological Conservation 45, no. 1: 21-46.

Infield, Mark. 2001. Cultural Values: A Forgotten Strategy for Building Community Support for Protected Areas in Africa. Conservation Biology 15, no. 3: 800-802.

Ingalsbee, Timothy. 2001. Fire Process Research Natural Areas: Managing Research and Restoration of Dynamic Ecosystem Processes. USDA Forest Service Proceedings RMRS-P-22.

- 2003. From Analysis Paralysis to Agency-Community Collaboration in Fuels Reduction for Fire Restoration: A Success Story. USDA Forest Service Proceedings RMRS-P-29.

Innes, Judith E. 1996. Planning Through Consesus Building: A New View of the Comprehensive Planning Ideal. Journal of American Planning 62, no. 4: 460-472.

International Labour Organization. 1989. Convention No. 169 concerning Indigenous and Tribal Peoples in Independent Countries .

Inyang, Hillary I. 1999. Emergence of transboundary problems. Journal of Environmental Engineering 125, no. 11: 995.

Irvin, Renee A., and John Stansbury. 2004. Citizen Participation in Decision Making: Is It Worth the Effort? Public Administration Review 64, no. 1: 55-65. 
Irwin, Frances, and Carl Bruch. 2002. Information, Public Participation, and Justice. Environmental Law Review 7: 10784-811.

Isaacman, Allen. 2005

. Displaced people, displaced energy, and displaced memories: the case of cahora bassa, 1970-2004. International Journal of African Historical Studies 38, no. 2: 201-38.

IUCN. 1994. Guidelines for Protected Areas Management Categories. Gland, Switzerland: IUCN.

-1980. World conservation strategy, International Union for the the Conservation of Nature and Natural Resources, Gland, Switzerland.

IUCN, UNEP, and WWF. 1980. World Conservation Strategy: Living Resource Conservation for Sustainable Development, IUCN/UNEP/WWF, Gland, Switzerland.

Jacobs, Harvey M. 2003. The Politics of Property Rights at the National Level. Journal of the American Planning Association 69, no. 2: 181-90.

Jafry, Tahseen. 2000. Women, Human Capital and Livelihoods: An Ergonomics Perspective. Natural Resource Perspectives 54: 1-4.

Jain, Theresa B. 2004. Tongue-Tied. Wildfire July/August: 22-26.

Jain, Theresa Benavidez, and Russell T. Graham. 2004. Is Forest Structure Related to Fire Severity? Yes, No and Maybe: Methods and Insights in Quantifying the Answer. USDA Forest Service Proceedings RMRS-P-34: 217-34.

James, Alexander, Kevin J. Gaston, and Andrew Balmford. 2001. Can We Afford to Conserve Biodiversity? Bioscience 51, no. 1: 43-52.

Janssen, Marco A., John M. Anderies, and Elinor Ostrom. 2007. Robustness of Social-Ecological Systems to Spatial and Temporal Variability. Society and Natural Resources 20, no. 4: 307-22.

Jeanrenaud, Sally. 2002. People-Oriented Approaches in Global Conservation: Is the Leopard Changing its Spots? London

Brighton: International Institute For Environment and Development Institute for Development Studies.

Jenkins, Paul. 2001. Strengthening access to land for housing for the poor in maputo, mozambique. International Journal of Urban \& Regional Research 25, no. 3: 629-48.

Jenkins, Paul, and Peter Wilkinson. 2002. Assessing the growing impact of the global economy on urban development in southern african cities: case studies in maputo and cape town. Cities 19, no. 1: 33-48.

Jennings, William. 2004. South Africa and the Region: Hegemonic Domination or Altruistic 
Integration. Paper Presented at the Annual Meeting of the American Political Science Association.

Jensen, Stig. 2002. Wildlands for a living: Local communities and protected areas in the age of globalization. presented at "The Commons in an Age of Globalisation," the Ninth Conference of the International Association for the Study of Common Property.

Jeon, Yun-Hee. 2004. The application of grounded theory and symbolic interactionism. Scandanavian Journal of Caring Sciences 18, no. 3: 249-56.

Jepson, P., and R. J. Whittaker. 2002. Histories of Protected Areas: Internationalisation of Conservationists Values and their Adoption in the Netherlands Indies (Indonesia). Environment and History 8, no. 2: 129-72.

Jepson, Paul, and Robert J. Whittaker. 2002. Ecoregions in Context: A Critique With Special Reference to Indonesia. Conservation Biology 16, no. 1: 42-57.

Johnson, Cathryn, Timothy J. Dowd, Cecilia L. Ridgeway, Karen S. Cook, and Douglas S. Massey. 2006. Legitimacy as a Social Process. Annual Review of Sociology 32, no. 1: 5378.

Johnson, James. 1991. Habermas on Strategic and Communicative Action. Political Theory 19, no. 2: 181-201.

Johnson, Jerald B., and Kristian S. Omland. 2004. Model Selection in Ecology and Evolution. Trends in Ecology and Evolution 19, no. 2: 101-8.

Johnson, Phyllis. 2002. New technology tools for human development? Towards policy and practice for knowledge societies in southern africa. Compare: A Journal of Comparative Education 32, no. 3: 381-89.

Johnston, Eilidh, and Chris Soulsby. 2002. Gaining 'Ecological Legitimacy': the development of sustainability consciousness in the Flow Country, northern Scotland. Local Environment 7, no. 1: 81-95.

Jones, Brian T. B., and Marshall W. Murphree. 2004. Community-Based Natural Resource Management as a Conservation Mechanism: Lessons and Directions. in Parks in Transition: Biodiversity, Rural Development and the Bottom Line . Ed. Brian Child, 63103. London: Earthscan.

Jones, Elise S., and Cameron P. Taylor. 1995. Litigating Agency Change: The Impact of the Courts and Administrative Appeals Process on the Forest Service. Policy Studies Journal 23, no. 2: 310-336.

Jones, Peter J. S. 2002. Marine Protected Area Strategies: Issues, Divergences and the Search for Middle Ground. Review in Fish Biology and Fisheries 11: 197-216.

Jones, Samantha. 2006. A political ecology of wildlife conservation in Africa. Review of African 
Political Economy 33, no. 109 : 483-95.

Joseph, Jonathan. 2003. Social Theory: An Introduction. New York : New York University Press.

Jost, John T., and Brenda Major. 2001. The Psychology of Legitimacy: Emerging Perspectives on Ideology, Justice, and Intergroup Relations. Cambridge: Cambridge University Press.

Kagoro-Rugunda, Grace. 2004. Crop raiding around Lake Mburo National Park, Uganda. African Journal of Ecology 42, no. 1: 32.

Kaiser, Jocelyn. 2001. Bold Corridor Project Confronts Political Reality. Science 293, no. 5538: 2196-99.

Kajembe, G. C., A. J. Mbwilo, R. S. Kidunda, and J. Nduwanmungu. 2003. Resource use conflicts in Usanga Plains, Mbarali District, Tanzania. International Journal for Sustainable Development and World Ecology 10: 333-43.

Kala, Chandra Prakash. 2005. Indigenous Uses, Population Density, and Conservation of Threatened Medicinal Plants in Protected Areas of the Indian Himalayas. Conservation Biology 19, no. 2: 368-78.

Kalleberg, Arthur E. 1966. The Logic of Comparison: A Methodological Note on the Comparative Study of Political Systems. World Politics 19, no. 1: 68-82.

Kalu, Kalu N. 2003. Of Citizenship, Virtue, and the Administrative Imperative: Deconstructing Aristotelean Civic Republicanism. Public Administration Review 63, no. 4: 418-27.

Kangalawe, Richard Y. M., and Emma T. Liwenga. 2005. Livelihoods in the Wetlands of Kilombero Valley in Tanzania: Opportunities and Challenges to Integrated Water Resource Management. Physics and Chemistry of the Earth 30, no. 11-16: 968-75.

Kangas, Jyrki, and Ron Store. 2003. Internet and Teledemocracy in Participatory Planning of Natural Resource Management. Landscape and Urban Planning 62: 89-101.

Kanji, Nazneen. 2004. Corporate responsibility and women's employment: the case of cashew nuts. Gender \& Development 12, no. 2: 82-87.

Kanji, Nazneen, Carla Braga, and Winnie Mitullah . 2002. "The Development of the 1997 Land Law In Mozambique." Promoting Land Rights in Mozambique and Kenya: How Do NGOs Make a Difference?, International Institute for Environment and Development.

Kant, Immanuel. 1998. Critique of Pure Reason. New York: Cambridge University Press.

Kanyamibwa, Samuel. 1998. Impact of War on Conservation: Rwandan Environment and Wildlife in Agony. Biodiversity and Conservation 7: 1399-406.

Kaplan, B., and D. Duchon. 1988. Combining qualitative and quantitative methods in 
information systems research: a case study. MIS Quarterly 12: 571-88.

Kaplowitz, Michael D., Timothy D. Hadlock, and Ralph Levine. 2004. A Comparison of Web and Mail Survey Response Rates. Public Opinion Quarterly 68, no. 1: 94-101.

Karkkainen, Bradley C. 2002. Toward a Smarter NEPA: Monitoring and Managing Government's Environmental Performance. Columbia Law Review 102: 903-72.

Karlberg, Michael. 1997. News and Conflict: How Adversarial News Frames Limit Public Understanding of Environmental Issues. Alternatives Journal Winter: 22-27.

Kassarjian, H. H., and T. S. Robertson. 1990. Perspectives in Consumer Behaviour. The role of attitude theory in marketing. 4th ed., Richard J. Lutz, 317-39.

Kate, Kerry Ten, and Sarah A. Laird. 2000. Biodiveristy and Business: Coming to Term with the 'Grand Bargain'. International Affairs 76, no. 1: 241-64.

Kaufman, Alexander. 1997. Reason, Self-Legislation and Legitimacy: Conceptions of Freedom in the Political Thought of Rousseau and Kant. Review of Politics 59, no. 1: 25-52.

Kaufman, H. 1960. The Forest Ranger: A Study in Administrative Behavior. Baltimore, MD: Johns Hopkins University Press.

Keeley, James F. 1990. Toward a Foucaldian Analysis of International Regimes. International Organization 44, no. 1:83-105.

Kellert, Stephen R., Jai N. Mehta, Syma A. Ebbin , and Laly L. Lichtenfeld. 2000. Community natural resource management: Promise, rhetoric, and reality. Society and Natural Resources 13, no. 8: 705-15.

Kelly, Micahel, Ed. 1994. Critique and Power: Recasting the Foucault/Habermas Debate. Cambridge, MA: MIT Press.

Kelly, Terrence. 2004. Unlocking the Iron Cage: Public Administration in the Deliberative Democratic Theory of Jurgen Habermas. Administration \& Society 36, no. 1: 38-61.

Kemmis, Daniel. 2001. This Sovereign Land: A New Vision for Governing the West. Washington, D. C.: Island Press.

Kennedy, James J., and Thomas M. Quigley. 1998. Evolution of USDA Forest Service organizational culture and adaptation issues in embracing an ecosystem management paradigm. Landscape and Urban Planning 40: 113-22.

Kent, S. 1996. Cultural diversity among twentieth-century foragers: the African perspective. Cambridge: Cambridge University Press.

Keohane, Robert O. 1982. The Demand for International Regimes. International Organization 36, no. 2: 325-55. 
_. 2001. Governance in a Partially Globalized World: Presidential Address, American Political Science Association, 2000. American Political Science Review 95, no. 1: 1-13.

Kepe, T, Saruchera M., and W Whande. 2004. Poverty alleviation and biodiveristy conservation: a South Africa perspective. Oryx 38: 143-45.

Kepe, Thembela. 2001. Clearing the ground in the Spatial Development Inititives (SDIs): analysing 'process' on South Africa's Wild Coast. Development Southern Africa 18, no. 3.

- 1999. The problem of defining 'community': challenges for the land reform programme in rural South Africa. Development Southern Africa 16, no. 3.

Kepe, Thembela, and Ben \& Turner Stephen Cousins. 2001. Resrouce Tenure and Power Relations in Community Wildlife: The Case of Mkambati Area, South Africa. Society and Natural Resources 14: 911-25.

Kepe, Thembela, and Ian Scoones. 1999. Creating Grasslands: Social Institutions and Environmental Change in Mkambati Area, South Africa. Human Ecology 27, no. 1: 1-29.

Kincheloe, Joe L., and Peter McLaren. 2005. Rethinking Critical Theory and Qualitative Research. In The Sage Handbook of Qualitative Research . 3rd. ed., Eds. Norman K. Denzin, and Yvonna S. Lincoln, 303-42. Thousand Oaks, CA: Sage .

King, Cheryl Simrell, and Kathryn M. \& Susel Bridget O'Neill Feltey. 1998. The Question of Participation: Toward Authentic Public Participation in Public Administration. Public Administration Review 58, no. 4.

King, Loren A. 2003. Deliberation, Legitimacy, and Multilateral Democracy. Governance 16, no. $1: 23-50$.

Kingsbury, B. 1998. "Indigenous peoples" in international law: A constructivist approach to the Asian controversy. The American Journal of International Law 92: 414.

Kirkland, Tracy, Lori M. Hunter, and Wayne Twine . 2007. "The Bush is No More": Insights on Institutional Change and Natural Resource Availability in Rural South Africa. Society \& Natural Resources 20, no. 4: 337-50.

Kiss, A. 1990. Living with Wildlife: Wildlife Resource Management with Local Participation in Africa. Washington, D.C.: The World Bank.

Kiss, Agnes. 2004. Is community-based ecotourism a good use of biodiversity conservation funds? Trends in Ecology and Evolution 19, no. 5.

Kleiss, Melanie E. 2003. NEPA and Scientific Uncertainty: Using the Precautionary Principle to Bridge the Gap. Minnesota Law Review 87, no. 1215: 1215-45.

Kline, Rex B. 1998. Principles and Practice of Structural Equation Modeling. New York: Guilford Press. 
Kloeck-Jenson, Scott. 2000. Locating the Community: Administration of Natural Resources in Mozambique. Madison, Wisconsin: Land Tenure Center.

Klopf, S. L. 2004. Developments in Biodiversity in 2004. Colorado Journal of International Environmental Law and Policy 15, no. SPI: 133-42.

Kloppenburg, Jack Jr. 1991. Social Theory and De/Reconstruction of Agricultural Science: Local Knowledge for an Alternative Agriculture. Rural Sociology 56, no. 4: 519-48.

Knight, Jack, and James Johnson. 1994. Aggregation and Deliberation: On the Possibility of Democratic Legitimacy. Political Theory 22, no. 2: 277-96.

Knox, John H. 2002. The Myth and Reality of Transboundary Environmental Impact Assessment. The American Journal of International Law 96, no. 2: 291-319.

Kohn, Margaret. 2000. Language, Power, and Persuasion: Toward a Critique of Deliberative Democracy. Constellations 7, no. 3: 408-29.

Kollmair, M., and U. Mullerboker. 2002. Forests and Trees: Changing Perspectives on a Natural Resource in the Nepal Himalaya. Global Environmental Research 6, no. 1: 73-84.

Koontz, Tomas M. 2003. The Farmer, the Planner, and the Local Citizen in the Dell: How Collaborative Groups Plan for Farmland Preservation. Landscape and Urban Planning 66: 19-34.

Koontz, Tomas M. 2002. Federalism in the Forest: National Versus State Natural Resource Policy. Washington, D. C.: Georgetown University Press.

Kopecky, Petr, and Cas Mudde. 2003. Rethinking Civil Society. Democratization 10, no. 3: 114.

Kramer, R. A., C. P. van Schaik, and J. Johnson. 1997. The last stand: Protected areas and the defense of tropical biodiversity. New York: Oxford University Press.

Kramer, Roderick M. 1999. Trust and Distrust in Organizations: Emerging Perspectives, Enduring Questions. Annual Review of Psychology 50: 569-98.

Krasner, Stephen D. 1981. Transforming International Regimes: What the Third World Wants and Why. International Studies Quarterly 25, no. 1: 119-48.

Krieckhaus, Jonathan. 2004. The Regime Debate Revisited: A Sensitivity Analysis of Democracy's Economic Effect. British Journal of Political Science 34, no. 4: 635-54.

Krishna, Anirudh, and Norman Uphoff. 1999. Mapping and Measuring Social Capital: A Conceptual and Empirical Study of Collective Action for Conserving and Developing Watersheds in Rajasthan, India. Social Capital Working Paper Series No. 13, Washington DC: World Bank Social Development Department. 
Kruger National Park. 2006. Management Plan. Pretoria, South Africa: Department of Environmental Affairs and Tourism.

Kuchli, C. 1997. Nepal. Forests of Hope: Stories of Regeneration., 52-73. Gabriolo Island, B.C., Canada: New Society Publishers.

- 1997. Switzerland. Forests of Hope: Stories of Regeneration., 10-31. Gabriolo Island, B.C., Canada: New Society Publishers.

Kuhn, Thomas S. 1970. Logic of Discovery or Psychology of Research? In Criticism and Growth of Knowledge. Eds. Imre Lakatos, and Alan Musgrave, 4-10. Cambridge, U.K.: Cambridge University Press.

Kuhn Thomas S. 1962. The Structure of Scientific Revolutions. Chicago, IL: The University of Chicago Press.

Kull, Christian A. 2002. Empowering Pyromaniacs in Madagascar: Ideology and Legitimacy in Community-Based Natural Resource Management. Development and Change 33, no. 1: 57-78.

Kumar, Chetan. 2005. Revisiting 'community' in community-based natural resource management. Community Development Journal 40, no. 3: 275-85.

Kurtz, Rick S. 2003. Organizational culture, Decision-making, and Integrity: The National Park Service and the Exxon Valdez. Public Integrity 5, no. 4: 305-17.

Kurz, T. 2002. The psychology of environmentally sustainable behavior: Fitting together pieces of the puzzle. Analyses of Social Issues and Public Policy 2: 257-78.

Kushwah, Ram Bir Singh. 2001. Economics of protected areas and its effect on biodiversity. Delhi: APH .

Kwa-Zulu-Natal Nature Conservation Board. 2000. Use of Plant Resources from Protected Areas.

Kyle, Gerard Alan Graefe Robert Manning and James Bacon. 2004. Effects of Place Attachement on users' perceptions of social and environmental conditions in a natural setting. Journal of Environmental Psychology 24, no. 2: 213-25.

Kysar, Douglas A., and James Salzman. 2003. Environmental Tribalism. Minnesota Law Review 87: 1099-138.

Lachapelle, Paul R., Stephen F. McCool, and Michael E. Patterson. 2003. Barriers to Effective Natural Resource Planning in a "Messy" World. Society and Natural Resources 16 : 47390.

Lado, Cleophas. 1999. Environmental resources, population and sustainability: evidence from Zimbabwe. Singapore Journal of Tropical Geography 20, no. 2: 148-68. 
- 2004. Sustainable environmental resource utilisation: a case study of farmers' ethnobotanical knowledge and rural change in Bungoma district, Kenya. Applied Geography 24: 281-302.

Landres, Peter, Steve Boutcher, Linda Merigliano, Chris Barns, Denis Davis, Troy Hall, Steve Henry, Brad Hunter, Patrice Janiga, Mark Laker, Al McPherson, Douglas S. Power, Mike Rowan, and Susan Sater. 2005. "Monitoring Selected Conditions Related to Wilderness Character: A National Framework." Gen. Tech. Rep. RMRS-GTR-151. U.S. Department of Agriculture, Forest Service, Rocky Mountain Research Station, Fort Collins, CO.

Landres, Peter B., Penelope Morgan, and Frederick J. Swanson. 1999. Overview of the use of natural variability concepts in managing ecological systems. Ecological Applications 9, no. 4: 1179-88.

Lane, Marcus B., and Geoff McDonald. 2005. Community-based Environmental Planning: Operational Dilemmas, Planning Principles and Possible Remedies. Journal of Environmental Planning and Management 48, no. 5: 709-31.

Lankard, Annemarie, and William J. McLaughlin. 2003. Marketing an Environmental Issue: A Case Study of the Wilderness Society's Core Messages to Promote National Forest Conservation from 1964-2000. Society and Natural Resources 16: 415-34.

Larsen, V., and N. D. Wright. 1993. A critique of critical theory: response to Murray and Ozanne's "The Critical Imagination". Advances in Consumer Research 20: 439-43.

Lasswell, Harold. 1970. The emerging conception of the policy sciences. Policy Sciences 1: 314.

Lasswell, Harold D. 1971. A Pre-View of Policy Sciences. St. Louis, MO: Elsevier Science.

Laudan, L. 1984. Science and values. Berkeley, CA: University of California Press.

Laurance, William F. 2004. The perils of payoff: corruption as a threat to global biodiversity. Trends in Ecology and Evolution 19, no. 8: 399-401.

Laurance, William F., Thomas E. Lovejoy, Heraldo L. Vasconcelos, Emilio M. Bruna, Raphael K. Didham, Philip C. Stouffer, Claude Gascon, Richard O. Bierregaard, Susan G. Laurance, and Erica Sampaio. 2002. Ecosystem Decay of Amazonian Forest Fragments: a 22-Year Investigation. Conservation Biology 16, no. 3: 605-16.

Section IV: Plants and Plant-Animal Interactions. 1992. Tropical Forest Remnants . editors WL Laurence, and Jr. RO Bierregaard, 275-79. Chicago: University of Chicago Press.

Lavinas, Lena. 2003. Encouraging school attendance in mozambique by granting a minimum income to parents. International Social Security Review 56, no. 3/4: 139-.

Lawrence, Roderick J. 2003. Human Ecology and its Applications. Landscape and Urban Planning 65: 31-40. 
Layden, Paul C., Michael J. Manfredo, and Pat Tucker. 2003. Integrating public values toward wildlife into land use planning: a case study in La Plata County, Colorado. Wildlife Society Bulletin 31, no. 1: 174-84.

Leach, M., R. Mearns, and I. Scoones. 1999. Environmental entitlements: dynamics and institutions in community-based natural resources management. World Development 27 , no. 2: 225-47.

Leach, Melissa, and Robin \& Scoones Ian Mearns. 1999. Environmental Entitlements: Dynamics and Institutions in Community-Based Natural Resource Management. World Development 27, no. 2: 225-47.

Leach, Melissa \& Fairhead James. 2000. Fashioned Forest Pasts, Occluded Histories: International Environmental Analysis in West African Locales. Development and Change 31, no. 35-59.

Leach, William D. 2004. Is Devolution Democratic? Assessing Collaborative Environmental Management. Sacramento, CA: Center for Collaborative Policy. 202. Surveying Diverse Stakeholder Groups. Society and Natural Resources 15: 641-49.

Leach, William D, and Neil D. Pelkey. 2001. Making Watershed Partnerships Work: A Review of the Empirical Literature. Journal of Water Resources Planning and Management November/December: 378-85.

Leach, William D., Neil W. Pelkey, and Paul A. Sabatier. 2002. Stakeholder Partnerships as Collaborative Policymaking: Evaluation Criteria Applied to Watershed Management in California and Washington. Journal of Policy Analysis and Management 21, no. 4: 64570 .

Leader-Williams, N. et al. 1996. Community-Based Conservation in Tanzania, IUCN, Gland, Switzerland.

Lebel, Louis, John M. Anderies, Bruce Campbell, Carl Folke, Steve Hatfield-Dodds, Terry P. Hughes, and James Wilson. Governance and the Capacity to Manage Resilience in Regional Social-Ecological Systems. Ecology and Society 11, no. 1: 19.

Leberman, Sarah I., and John D. Holland. 2005. Visitor Preferences in Kruger National Park, South Africa: The Value of a Mixed-Method Approach. Journal of Park and Recreation Administration 23, no. 2: 21-36.

Leblang, David A. 1997. Political democracy and economic growth: Pooled cross-sectional and time-series evidence. British Journal of Political Science 27, no. 3: 453-66.

Lee, Kai N. 1995. Compass and Gyroscope: Integrating Science and Politics for the Environment. Washington, D. C.: Island Press.

Lee, Molly. 2002. The Cooler Ring: Urban Alaska Native Women and the Subsistence Debate. 
Arctic Anthropology 39, no. 1/2 : 3-9.

Lehmkuhl, J. F., R. K. Upreti, and U. R. Sharma. 1988. National parks and local development: Grasses and people in Royal chitwan National Park, Nepal. Environmental Conservation 15: 143-48.

Leigh, Raymond, and Sally K. Fairfax. 2002. The 'Shift to Privatization' in Land Conservation: A Cautionary Essay. Natural Resources Journal 42: 599-639.

Leitmann, Josef. 1998. Policy and Practice: Options for Managing Protected Areas: Lessons from International Experience. Journal of Environmental Planning and Management 41, no. 1: 129-43.

Lele, Sarachchandra, and Richard Norgaard. 1996. Sustainability and the Scientist's Burden. Conservation Biology 10, no. 2: 354-65.

Lemert, Charles. 2004. Social Theory: The Multicultural and Classic Readings. Boulder, CO: Westview Press.

Letey, J. 1999. Science and Policy in Integrated Watershed Management: A Case Study. Journal of the American Water Resource Association 35, no. 3: 603-7.

Levin R., and D. Weiner. 1997. No More Tears: Struggles for Land in Mpumalanga, South Africa. Trenton, N.J.: World Africa Press.

Li, Tania Murray. 2002. Engaging Simplications: Community-Based Resource Management, Market Processes and State Agendas in Upland Southeast Asia. World Development 30, no. 2: 265-83.

Lijphart, Arend. 1971. Comparative Politics and the Comparative Method. The American Political Science Review 65, no. 3: 682-93.

Liljeblad, Adam, William Borrie, and Alan Watson . 2005. Monitoring Trust as an Evaluation of the Success of Collaborative Planning in a Landscape-level Fuel Hazard Reduction Treatment Project in the Bitterroot Valley, Montana, RJVA No. 03-JV-1122204-330. USFS Rocky Mountain Research Station, Missoula, MT.

Lind, Jeremy. 2002. Report of the Consultative Session and Regional Conference on the Ecological Sources of Conflict in Sub-Saharan Africa: Toward Innovative Conflict Prevention and Management Strategies. Eco-Conflicts 2, no. 1: 1-4.

Lipper, L. 2000. Forest Degredation and Food Security. Unasylvia 51, no. 202: 24-31.

Lipset, Seymour. 1960. The Social Bases of Politics. Garden City, NY: Doubleday.

Lipset, Seymour Martin. 1959. Some Social Requisites of Democracy: Economic Development and Political Legitimacy. American Political Science Review 53, no. 1: 69-105. 
Lipton, Merle. 2000. White Liberals, 'The Left' and the New Africanist Elite in South Africa. International Affairs 76, no. 2.

Litfin, Karen T. 1997. Sovereignty in world ecopolitics. Mershon International Studies Review 41, no. 2: 167-204.

Little, Paul E. 1999. Political Ecology as Ethnography: The Case of Ecuador's Aguarico River Basin, Departamento de Antropologia, Universidade de Brasilia, Brasilia.

Little, Peter D. 1994. The Link Between Local Participation and Improved Conservation: A Review of Issues and Experiences. Natural Connections: Perspectives in CommunityBased Conservation. editors R. Michael Wright, David Western , and Shirley Strum, 34772. Washington D.C.: Island Press.

Locke, Harvey, and Philip Dearden. 2005. Rethinking protected area categories and the new paradigm. Environmental Conservation 32, no. 1: 1-10.

Lodge, Tom. 2003. Politics in South Africa: From Mandela to Mbeki. Bloomington, IN: Indiana University Press.

Loflund, J., and L. H. Loflund. 1995. Analyzing social settings: a guide to qualitative observation and analysis. Belmont, CA: Wadsworth.

Logan, Ikubolajeh B. \& Moseley William G. 2002. The political ecology of poverty alleviation in Zimbabwe's Communal Areas Management Programme for Indigenous Resources (CAMPFIRE). Geoforum 33: 1-14.

Longley, C., C. Dominguez, M. A. Saide, and W. J. Leonardo. 2002. Do farmers need relief seed? A methodology for assessing seed systems. Disasters 26, no. 4: 343-55.

Lorna, Philip, and Douglas MacMillan. 2005. Exploring Values, Context and Perceptions in Contingent Valuation Studies: The CV Market Stall Technique and Willingness to Pay for Wildlife Conservation. Journal of Environmental Planning and Management 48, no. 2: $257-74$.

Lovecraft, Amy L. 2004. Interlocal rules and democracy in the administration of cross-border policy communities. Administrative Theory and Praxis 26, no. 3: 383-408.

Low, S. M., and I. Altman. 1992. Place attachment: A conceptual inquiry. In Place attachment. Eds. I. Altman, and S. M. Low. New York: Plenum Press.

Lowendahl, Bente, and Oivind \& Fosstenlokken Siw M. Revang. 2001. Kowledge and value creation in professional service firms: A framework for analysis. Human Relations 54, no. 7: 911-31.

Luangaramsi, Pinkaew. Reconstructing Nature: The Community Forest Movement and its Challenge to Forest Management in Thailand. 45-55. 
Lubchenco, Jane. 1998. Entering the Century of the Environment: A New Social Contract for Science. Science 279, no. 5350.

Ludwig, Donald. 2001. The Era of Management is Over. Ecosystems 4: 758-64.

Ludwig, John A., David J. Tongway, Gary N. Bastin, and Craig D. James. 2004. Monitoring ecological indicators of rangeland functional integrity and their relation to biodiversity at local to regional scales . Austral Ecology 29, no. 1: 108-20.

Luijpen, W. A., and H. J. Koren. 1969. First Introduction to Existential Phenomenology. Pittsburgh, Pennsylvania: Duquesne University Press.

Lukanu, Gastao, Maryann Green, Peter Greenfield, and Steve Worth. 2004. Farmers' cash crop cultivation decisions in southern niassa province, mozambique. Development Southern Africa 21, no. 3: 531-54.

Lupel, Adam. 2004. Regionalism and Globalization: Post-nation or Extended Nation? Polity 36, no. 2: 153-74.

Lutz, Richard J. 1990. The Role of Attitude Theory in Marketing. Perspectives in Consumer Behavior. 4th Edition ed., editors H. H. Kassarjian, and T. S. Robertson, 317-39. Engelwood Cliffs, NJ: Prentice Hall.

Lybbert, Travis, Christopher B. Barrett, and Hamid Narjisse. 2004. Does Resource Commercialization Induce Local Conservation? A Cautionary Tale from Southwestern Morocco. Society and Natural Resources 17: 413-30.

Lyles, Marjorie A. 1981. Formulating Strategic Problems: Empirical Analysis and Model Development. Strategic Management Journal 2: 61-75.

Mabunda, David, Danie J. Pienaar, and Johan Verhoef. 2003. The Kruger National Park: A Century of Management and Research. in The Kruger Experience: Ecology and Management of Savanna Heterogeneity. Eds. Johan T. du Toit, Kevin H. Rogers, and Harry C. Biggs, 3-21. Washington, D.C.: Island Press.

MacCallum, Robert C., and James T. Austin. 2000. Applications of Structural Equation Modeling in Psychological Research. Annual Review of Psychology 51: 201-26.

MacKaye, Benton. 1918. Some Social Aspects of Forest Management. Journal of Forestry 16 , no. 2: 210-214.

Maclay, Tom. 2006. "Bitterrroot Resort." Web page, [accessed 23 February 2006]. Available at www.skibitterrootresort.com.

Macridis, Roy. 1968. Comparative Politics and the Study of Government: The Search for Focus. Comparative Politics 1, no. 1: 79-90.

Madulu, Ndalahwa F. 2005. Environment, Poverty and Health Linkages in the Wami River 
Basin: A Search for Sustainable Water Resource Management. Physics and Chemistry of the Earth 30, no. 11-16: 950-960.

Maggio, G. regory F. 1998. Recognizing the vital role of communities in international legal instruments for conserving biodiversity. UCLA Journal of Environmental Law and Policy 16, no. 1: 179-226.

Maguire, Lynn A. 1994. Science, Values and Uncertainty: A Critique of the Wildlands Project. Environmental Policy and Biodiversity. editor R. Edward Grumbine, 267-72. Washington, DC: Island Press.

Maikhuri, R. K., S. Nautiyal, K. S. Rao, K. Chandrasekhar, R. Gavali, and K. G. Saxena. 2000. Analysis and resolution of protected area-people conflicts in Nanda Devi Biosphere Reserve, India. Environmental Conservation 27: 43-53.

Maisiri, N., A. Senzanje, J. Rockstrom, and S. J. Twomlow. 2005. On Farm Evaluation of the Effect of Low Cost Drip Irrigation on Water and Crop Productivity Compared to Conventional Surface Irrigation Systems. Physics and Chemistry of the Earth 30, no. 1116: 783-91.

Majone, Giandomenico. 1989. Evidence, Argument, and Persuasion in Policy Process. New Haven, CT: Yale University Press.

Major, B. 1994. From social inequality to personal entitlement: The role of social comparisons, legitimacy appraisals and group membership. Advances in Experimental Social Psychology 26: 293-355.

Maletz, Donald J. 2002. Tocqueville's Tyranny of the Majority Reconsidered. The Journal of Politics 64, no. 3: 741-63.

Malla, Yam B., Hari R. Neupane, and Peter J. Branney. 2003. Why Are not Poor People Benefiting More from Community Forestry? Journal of Forest and Livelihood 3, no. 1: 78-93.

Mandela, Nelson. 1998. Address at the launch of the kruger National Park Centenary Celebrations, 26 March, Skukuza.

Mandle, Jon. 2006. Coercion, legitimacy, and equality. Social Theory and Practice 32, no. 4: $617-25$.

Manfredo, Michael, and Ashley Dayer. 2004. Concepts for Exploring the Social Aspects of Human-Wildlife Conflict in a Global Context. Human Dimensions of Wildlife 9, no. 4: 317.

Manfredo, Michael J., Tara L. Teel, and Alan D. Bright. 2003. Why are public values towards wildlife changing? Human Dimensions of Wildlife 8, no. 4: 287-306.

Manin, Bernard, Elly Stein, and Jane Mansbridge. 1987. On Legitimacy and Political 
Deliberation. Political Theory 15, no. 3: 338-68.

Mann, C. 2002. The Real Dirt on Rainforest Fertility. 920-923.

Mann, Charles C. 2002. 1492. The Atlantic Monthly March: 41-53.

Mann, Elizabeth. 2003. Sustainable water supply for a remote rural community in mozambique. Greener Management International 42, no. Summer: 59-66.

Manning, Nadia, and Mary Seely. 2005. Forum for Integrated Resource Management (FIRM) in Ephemeral Basins: Putting Communities at the Centre of the Basin Management Process. Physics and Chemistry of the Earth 30, no. 11-16: 886-93.

Manning, Robert, William Valliere, and Ben Minteer. 1999. Values, Ethics, and Attitudes Toward National Forest Management: An Empirical Study. Society \& Natural Resources 12, no. 5: 421-36.

Manning, Robert E., W. A Freimund, and J. L. Marion. 2004. Research to support application of the visitor experience and resource protection (VERP) framework to backcountry planning at Zion Natioanl Park: Final Report .

Manring, Nancy J. 2004. Locking the Back Door: The Implications of Eliminating Postdecisional Appeals in National Forest Planning. Society and Natural Resources 17: $235-45$.

Mansfield, Edward D. and Helen V. Milner. 1999. The New Wave of Regionalism. International Organization 53, no. 3.

Marcus, Richard R. 2001. Seeing the Forest for the Trees: Integrated Conservation and Development Projects and Local Perceptions of Conservation in Madagascar. Human Ecology 29, no. 4: 381-97.

Marcuse, Herbert. 1964. One-dimensional Man. Boston, MA: Beacon Press.

Margarita, Alario. 1994. Environmental destruction and the public sphere: On Habermas's discursive model and political theory. Social Theory and Practice 20, no. 3: 327-41.

. 2001 Is Our Project Succeeding?: A Guide to Threat Reduction Assessment for Conservation Richard Margolius, and Nick SalafskyWashington D.C.: Biodiversity Support Program.

Marion, Jeffrey L., and Scott E. Reid. 2007. Minimising Visitor Impacts to Protected Areas: the Efficacy of Low Impact Education Programmes. Journal of Sustainable Tourism 15, no. 1: 5-27.

Markus, Gyorgy. 1999. On Freedom: Positive and Negative. Constellations: An International Journal of Critical \& Democratic Theory 6, no. 4: 273-89.

Marlin, Randal. 2002. Propaganda and the Ethics of Persuasion. Orchard Park, NY: Broadview 
Press.

Mascarenhas, Michael, and Rik Scarce. 2004. The Intention was Good": Legitimacy, ConsensusBased Decision Making, and the Case of Forest Planning in British Columbia, Canada. Society \& Natural Resources 17, no. 1: 17-38.

Mascia, Michael B., Peter J. Brosius, Tracy A. Dobson, Bruce C. Forbes, Leah Horowitz, Margaret McKean, and Nancy J. Turner. 2003. Conservation and the Social Sciences. Conservation Biology 17, no. 3: 649-50.

Finding a Focus and Knowing Where you Stand. 2002b. Qualitative Researching. J. Mason, 1323. Thousand Oaks, CA: Sage Publishing Inc.

Masozera, Michel K., and Janaki R. R. Alavalapati. 2004. Forest Dependency and its implications for Protected Areas Management: A Case Study from the Nyungwe Forest Reserve, Rwanda. Scandanavian Journal of Forest Research 19, no. 4: 85-92.

Massyn, Peter John. 2004. Safari Lodges and Rural Incomes: Some Key Southern African Trends . The Center for Integrated Study of the Human Dimensions of Global Change.

Matheson, Craig. 1987. Weber and the Classification of Forms of Legitimacy. The British Journal of Sociology 38, no. 2: 199-215.

Mathews, Jessica Tuchman. 1997. Power Shift. Foreign Affairs 76, no. 1: 50-66. 1998. Redefining Security. Foreign Affairs 68, no. 2: 162-78.

Matthew, Richard A. 2002. In Defense of Environment and Security Research. ECSP Report Summer, no. 8: 109-24.

Maxwell, Nicholas. 1972. A Critique on Popper's Views on Scientific Method. Philosophy of Science 39, no. 2: 131-52.

Mayer, Margrit. 2003. The Onward Sweep of Social Capital: Causes and Consequences for Understanding Cities, Communities and Urban Movements. International Journal of Urban and Regional Research 27, no. 1: 110-132.

Mayer, Roger C., James H. Davis, and F. David Schoorman. 1995. An Integrative Model of Organizational Trust. The Academy of Management Review 20, no. 3: 709-34.

Mbile, P., M. Vabi, M. Meboka, D. Okon, J. Arrey-Mbo, F. Nkongho, and E. Ebong. 2005. Linking Management and Livelihood in Environmental Conservation: Case of the Korup National Park Cameroon. Journal of Environmental Management 76: 1-13.

Mbilinyi, B. P., S. D. Tumbo, H. F. Mahoo, E. M. Senkondo, and N. Hatibu. 2005. Indigenous Knowledge as Decision Support Tool in Rainwater Harvesting. Physics and Chemistry of the Earth 30, no. 11-16: 792-98. 
McAfee, Noelle. 2004. Three Models of Democratic Deliberation. Journal of Speculative Philosophy 18, no. 1: 44-59.

McAllister, Daniel J. 1995. Affect- and Cognition-based Trust as Foundations for Interpersonal Cooperation in Organizations. The Academy of Management Journal 38, no. 1: 24-59.

McAllister, S. 1999. Restructuring institutions to involve communities in a meaningful way. Colorado Journal of International Law and Policy 10: 195.

McCabe, J. Terrence, Scott Perkin, and Claire Schofield. 1992. Can conservation and development be coupled among pastoral people? An examination of the Maasai of the Ngorongoro Conservation Area, Tanzania. Human Organization 51, no. 4: 353-66.

McCann, Terence, and Eileen Clark. 2003. Grounded theory in nursing research: Part 2 Critique. Nurse Researcher 11, no. 2: 19-28.

McCarthy, James. 2002. First World Political Ecology: Lessons From the Sise Use Movement. Environment and Planning 34: 1281-302.

McCarthy, Thomas A. 1978. The Critical Theory of Jürgen Habermas. Cambridge, MA: MIT Press.

McCarty, Teresa L. 2003. Indigenous Languages in Homogenising Times. Comparative Education 39, no. 2: 147-63.

McClenahan, Patricia. 2004. Historic Kanataq: One Central Alaska Peninsula Community's Use of Subsistence Resources and Places. Arctic Anthropology 41, no. 2: 55-69.

McCloskey, Michael. 1999. Local Communities and the Management of Public Forests. Ecology Law Quarterly 25, no. 4: 624-29.

- 2000. Problems with Using Collaboration to Shape Environmental Public Policy. Valparaiso University Law Review 34: 423-34.

McCluskie, Ed. 2003. Replacing the Qualitative-Quantitative Distinction With the Critique of Ideological Methodological Practices. Paper presented at a non-divisional workshop held at the meeting of the International Communication Association.

McCool, Daniel. 1995. Conflict and Choice in Policy Theory. In Public Policy Theories, Models, and Concepts: An Anthology. Daniel McCool, 390-412. Englewood Cliffs, New Jersey: Prentice Hall.

McCool, Daniel C. 1995. Public Policy Theories, Models, and Concepts: An Anthology. New Jersey: Englewood Cliffs.

McCool, Stephen F. 2003. Managing Natural Disturbances and Sustaining Human Communities: Implications of Ecosystem-Based Management of Public Lands. Understanding Community-Forest Relations, General Technical Report PNW-GTR-566. technical editor 
Linda E. KrugerPortland, Oregon: U.S. Dept. of Agriculture, Forest Service, Pacific Northwest Research Station.

- 2004. Wilderness Character and the Notion of an "Unconfined" Experience. International Journal of Wilderness 10, no. 3: 15-17.

McCool, Stephen F., and David N. Cole. 1997. Experiencing Limits of Acceptable Change: Some Thoughts After a Decade of Implementation. In Proceedings - Limits of Acceptable Change and related planning processes: progress and future directions, Eds. Stephen F. McCool, and David N. Cole, 72-78no. INT-GTR-371. Ogden, UT: U.S. Department of Agriculture, Forest Service, Rocky Mountain Research Station.

McCool, Stephen F., and Kathleen Guthrie. 2001. Mapping the Dimensions of Successful Public Participation in Messy Natural Resources Management Situations. Society and Natural Resources 14: 309-23.

McCool, Stephen F., and David W. Lime. 2001. Tourism Carrying Capacity: Tempting Fantasy or Useful Reality? Journal of Sustainable Tourism 9, no. 5: 372-88.

McCool, Stephen F., Neil Moisey, and Norma P. Nickerson. 2001. What Should Tourism Sustain? The Disconnect with Industry Perceptions of Useful Indicators. Journal of Travel Research 40: 124-31.

McCool, Stephen F., and Michael E. Patterson. 2000. Trends in Recreation, Tourism and Protected Area Planning. Trends in Outdoor Recreation, Leisure and Tourism. W. C. Gartner, and D. W. LimeWallingford: CABI Publishing.

McCool, Stephen F., and George H. Stankey. 2004. Indicators of Sustainability: Challenges and Opportunities at the Interface of Science and Policy. Environmental Management 33, no. 3: 294-305.

McCoy, K. Lynn, Edwin E. Krumpe, and Stewart Allen. 1995. Limits of Acceptable Change Planning - Evaluating Implementation by the U.S. Forest Service. International Journal of Wilderness 1, no. 2: 18-22.

McCullough, R. 1995. From the Common Wood. The Landscape of Community: A History of Communal Forests in New England., 4-46. Hanover, NH: University Press of New England.

McEvoy, John G. 1975. A "Revolutionary" Philosophy of Science: Feyerabend and the Degeneration of Critical Rationalism into Sceptical Fallibilism. Philosophy of Science 42, no. 1: 49-66.

McFarlane, Bonita, and Peter C. Boxall. 2000. Factors influencing forest values and attitudes of two stakeholder groups: the case of the Foothills Model Forest, Alberta, Canada. Society \& Natural Resources 13, no. 7: 649-61.

McGuire, Kevin, and Nick Sanyal. 2005. A Human Dimensions Inquiry in Watershed Analysis: 
Listening to Constituents' Views of Contested Legitimacy on the National Forest. Society and Natural Resources (In press) .

McKinney, Matthew, and Will Harmon. 2005. Resolving natural resource disputes: A historical, analytical and prescriptive framework. Renewable Resources Journal 23, no. 2: 16-22.

McKinney, Matthew, and William Harmon. 2004. The Western Confluence: A Guide to Governing Natural Resources. Washington, D.C.: Island Press.

McMichael, P. 2004. The Development Project: International Dimensions. Development and Social Change: A Global Perspective. P. McMichael, 39-71. Thousand Oaks, Ca: Pine Forge Press.

- 2004. Implementing Globalization as a Project. Development and Social Change: A Global Perspective. P. McMichael, 39-71. Thousand Oaks, Ca: Pine Forge Press.

McNeely, J. A. 2004. Nature vs. Nurture: Managing Relationships Between Forests, Agroforestry and Wild Biodiversity. Agroforestry Systems 61: 155-65.

McSwite, O. S. 1997. Legitimacy in Public Administration. Thousand Oaks, CA: Sage.

Mehta, Jai N. \& Kellert Stephen R. 1998. Local attitudes toward community-based conservation policy and programmes in Nepal: a case study in the Makalu-Barun Conservation Area. Environmental Conservation 25, no. 4: 320-333.

Meine, C., and R. Knight. 1999. The Essential Aldo Leopold: Quotations and Commentaries. Madison, WI: University of Wisconsin Press.

Melber, Henning. 2003. Liberation and Democracy: Cases from Southern Africa. Journal of Contemporary African Studies 21, no. 2: 149-56.

Meredith, Thomas C. 2002. Democracy and Participation in Environmental Decision-Making. Human Ecology Review 9, no. 1: 62-63.

Merelman, Richard M. 1966. Learning and Legitimacy. American Political Science Review 60, no. 3: 548-61.

Merigliano, Linda, and Bryan Smith. 2000. Keeping Wilderness Wild: Increasing Effectiveness with Limited Resources. In Wilderness Science in a Time of Change Conference Volume 4: Wilderness Visitors, Experiences, and Visitor Management, Comps. David N. Cole, Stephen F. McCool, William T. Borrie, and Jennifer O'Laughlin, 236-42Ogden, UT: U. S. Department of Agriculture, Forest Service, Rocky Mountain Research Station.

Merquior, Josâe Guilherme. 1980. Rousseau and Weber: A Study in the Theory of Legitimacy. New York: Routledge.

Meskell, Lynn. 2005. Archaeological Ethnography: Conversations around Kruger National Park. Archaeologies 1, no. 1: 81-100. 
Meskell, Lynn. 2006. Deep Past, Divided Present: South Africa's Heritage at the Frontier. Western Humanities Review 60, no. 2: 101-16.

Metcalfe, Simon. 1999. " Community Perspective." Study on the Development of Transboundary Natural Resource Management Areas in Southern Africa, Jaidey Singe. Biodiversity Support Program, Washington D.C..

- 2003. Impacts of Transboundary Protected Areas on Local Communities in Three Southern African Initiatives. 1-27.

Meyer, J. W., and W. R. Scott. 1983. Organizational Environments: Ritual and Rationality. Beverley Hills, CA: Sage.

Meyer, John M. 1997. Gifford Pinchot, John Muir and the boundaries of politics in American thought. Polity 30, no. 2: 267-84.

Mill, J. E., M. N. Allen, and R. A. Morrow. 2001. Critical theory: critical methodology to disciplinary foundations in nursing. Canadian Journal of Nursing Research 33, no. 2: 109-27.

Miller, Carol, Peter B. Landres, and Paul B. Alaback. Evaluating Risks and Benefits of Wildland Fire at Landscape Scales. The Joint Fire Science Conference and Workshop. Hazard and Risk Session.

Miller, Char. 2001. Gifford Pinchot and the Making of Modern Environmentalism. Washington, D.C.: Island Press.

Miller, Kenton R. 1999. International Wilderness Provides Ecological Services for Sustainable Living. International Journal of Wilderness 5, no. 3: 35-39.

Mintzberg, Henry, Duru Raisinghani, and Andre Theoret. 1976. The Structure of "Unstructured" Decision Processes. Administrative Science Quarterly 21: 246-75.

Mislevy, Robert J. 1986. Recent Developments in the Factor Analysis of Categorical Variables. Journal of Educational Statistics 11, no. 1: 3-31.

Mistry, Jayalaxshmi, Matthews Simpson, Andrea Berardi, and Young Sandy. 2004. Exploring the links between natural resource use and biophysical status in the waterways of North Rupununi, Guyana. Journal of Environmental Management 72, no. 3: 117-31.

Mitchell, E. S. 1986. Multiple triangulation: a methodology for nursing science. Advances in Nursing Science 8, no. 3: 18-26.

Mitchell, G. Duncan. 1979. A New Dictionary of Sociology. London: Routledge \& Kegan Paul.

Mitchell, Jonathan. 1998. The maputo development corridor: a case study of the sdi process in mpumalanga. Development Southern Africa 15, no. 5: 757-69. 
Mitchell, Joseph Pershing. 2000. "The Central Bankers: Administrative Legitimacy and the Federal Reserve System." Virginia Polytechnic Institute and State University.

Mitchell, Ronald B. 1998. Sources of Transparency: Information Systems in International Regimes. International Studies Quarterly 42, no. 1: 109-30.

Mocumbi, Pascoal. 2004. Plague of my people. Nature 430, no. 7002: 925.

2001. Helping People, Saving Biodiversity: An Overview of Integrated Approaches to Conservation and Development, Kathleen Mogelgaard. Population Action International, Washington D.C..

Moir, W. H., and W. M. Block. 2001. Adaptive Management on Public Lands in the United States: Commitment or Rhetoric? Environmental Management 28, no. 2: 141-48.

Moleele, N. M., and J. Mainah. 2003. Resource use conflicts: the future of the Kalahari ecosystem. Journal of Arid Environments 54 , no. 2: 405-23.

Momberg, EleanorSA falls short of Live Earth challenge. The Sunday Independent, p. 1.

Montague, Peter. 2001. Rachel's Environment \& Health News \#727 The Importance Of VisionPart I. Environmental Research Foundation.

Moon, J. Donald. 2003. Rawls and Habermas on Public Reason: Human Rights and Global Justice. Annual Review of Political Science 6: 257-74.

Moore, Alan, and Miguel Cifuentes. 1997. Sustainable resource use and Latin American parks. Forum for Applied Research \& Public Policy 12, no. 1: 53-56.

Moore, Brooke Noel, and Robert Michael Stewart. 1994. Moral Philosophy: A Comprehensive Introduction . Mountain View, CA: Mayfield Publishing Company.

Moore, D. S. 1993. Contesting terrain in Zimbabwe's eastern highlands: political ecology, ethnography, and peasant resource struggles. Economic Geography 69, no. 4: 380-401.

- Marxism, culture, and political ecology. in Liberation ecologies: environment, development, social movements. R. Peet and M. Watts, 125-47. London: Routledge.

Moore, Donald S. 1998. Clear Waters and Muddied Histories: Environmental History and the Politics of Community in Zimbabwe's Eastern Highlands. Journal of Southern African Studies 24, no. 2: 377-403.

Moore, Kevin, and Lynette Masuku van Damme. 2002. The Evolution of People-and-Parks Relationships In South Africa's National Conservation Organisation. In Environmental Education, Ethics and Action in Southern Africa. Eds. Johan Hattingh, Heila Lotz-Sisitka, and Rob O'DonoghuePretoria, South Africa: Human Sciences Research Council.

Communities in Flames: Proceedings of an International Conference on Community 
Involvement in Fire Management. 2002. Communities in Flames, editors Peter Moore, David Ganz, Lay Cheng Tan, Thomas Enters, and Patrick B. DurstBangkok, Thailand: FAO.

Moote, Ann. 2001. Revitalizing Baltimore: Urban forestry at the watershed scale. Forest Communities, Community Forests. Editors J. Kusel, and E. Adler, 171-87. Lanham, MD: Rowman \& Littlefield.

More, Thomas A. 2002. "The Parks Are Being Loved To Death" and Other Frauds and Deceits in Recreation Management. Journal of Leisure Research 34, no. 1: 52-78.

Morgan, Douglas F. 1990. Administrative Phronesis: Discretion and the Problem of Administrative Legitimacy in Our Constitutional System. In Images and Identities in Public Administration. Eds. Henry D. Kass, and Bayard L. Catron. Thousand Oaks, CA: Sage.

Morris, Brad, Beat vonAllmen, and Robert Brandenberger. 2004. Montana Snowbowl Master Development Plan.

Morris, Joseph M., and Mark K. McBeth. 2003. The New West in Context of Extractive Commodity Theory: The Case of Bison-Brucellosis in Yellowstone National Park. The Social Science Journal 40: 233-47.

Morrow, James. 1994. Game Theory for Political Scientists. Princeton, NJ: Princeton University Press.

Morrow, R. A. 1985. Critical theory and critical sociology. Canadian Review of Sociology and Anthropology 22, no. 5: 710-747.

_. 1994. Critical Theory and Methodology. Thousand Oaks, California: Sage.

— 1991. Toward a critical theory of methodology: Habermas and the theory of argumentation. Current Perspectives in Social Theory 11: 197-228.

Morton, Rebecca B. 1999. Methods and Models: A Guide to the Empirical Analysis of Formal Models in Political Science. New York: Cambridge University Press.

Mouritsen, Per. 2003. What's the Civil in Civil Society? Robert Putman, Italy and the Republican Tradition. Political Studies 51: 650-668.

Mueller, Charles W., and Miriam J. Landsman. 2004. Legitimacy and Justice Perceptions. Social Psychology Quarterly 67, no. 2: 189-202.

Muir, Andrew. 2002. Strengthening Wilderness in South Africa. International Journal of Wilderness 8, no. 2: 4-8.

Muldoon, Paul. 2003. Reconciliation and Political Legitimacy: The Old Australia and the New South Africa. Australian Journal of Politics and History 49, no. 2: 182-96. 
Mulongoy, K. J., and S. Chape. 2005. Protected Areas and Biodiversity - An Overview of Key Issues. Journal of Environmental Assessment Policy and Management 7, no. 2: 327-28.

Mulwafu, Wapulumuka O., and Hendrina K. Msosa. 2005. IWRM and Poverty Reduction in Malawi: A Socio-economic Analysis. Physics and Chemistry of the Earth 30, no. 11-16: 961-67.

Munalula. 2000. Community-Based Natural Resource Management: Experiences of the Western Province of Zambia - Understanding the Role of Traditional Authorities. presentation at The 2nd aпnual CASS/PLAAS Regional Meeting.

Murphree, M. 1991. Communities as Institutions for Resource Management. CASS Occasional Paper Series, Harare, Zimbabwe: Center for Applied Social Science, University of Zimbabwe.

Murphree, M. 1999. Governance and Community Capacity. paper presented at The inaugural meeting of the CASS/PIASS Programme on Community-Based Natural Resource Management.

Murphree, Marshall W. 1994. The Role of Institutions in Community-based Conservation. Natural Connections. editors David Western, and R. Michael Wright, 403-27. Washington, D.C.: Island Press.

Murphree, Marshall W. 2004. Who and What Are Parks for in Transitional Societies? in Parks in Transition: Biodiversity, Rural Development and the Bottom Line. Ed. Brian Child, 21731. London: Earthscan.

Murray, Jeff B., and Julie L. Ozanne. 1991. The Critical Imagination: Emancipatory Interests in Consumer Research. Journal of Consumer Research 18, no. 2: 129-44.

Myers, Gregory W. 1994. Competitive Rights, Competitive Claims: Land Access in Post-War Mozambique. Journal of Southern African Studies 20, no. 4: 603-32.

Myerson, Joel, Ed. 2000. Transcendentalism: A Reader. New York: Oxford University Press.

Nadasdy, Paul. 2005. Hunters and Bureaucrats: Power, Knowledge, and Aboriginal-State Relations in the Southwest Yukon. Society \& Natural Resources 18: 287-97.

Nadeau, Solange, Bruce A. Shindler, and Christina Kakoyannis. 2003. Beyond the Economic Model: Assessing Sustainability in Forest Communities. Two Paths Towards Sustainable Forests. editors Bruce A. Shindler, T. M. Beckley, and M. C. Finley, 60-74. Corvallis, Oregon: Oregon State University Press.

Naeem, Shahid, Lindsey J. Thompson, Sharon P. Lawler, John H. Lawton, and Richard M. Woodfin. 1994. Declining biodiversity can alter the performance of ecosystems. Nature 368: 734-37.

Nagel, Thomas. 1991. Equality and Partiality. New York: Oxford University Press. 
_ 1987. Moral Conflict and Political Legitimacy. Philosophy and Public Affairs 17: 22737.

Napier, Victoria R., George M. Branch, and Jean M. Harris. 2005. Evaluating conditions for successful co-management of subsistence fisheries in KwaZulu-Natal, South Africa. Environmental Conservation 32, no. 2: 165-77.

Narayan, Deepa. 1999. Bonds and Bridges: Social Capital and Poverty. Washington, DC: World Bank, Poverty Group.

Nash, Roderick. 1982. The International Perspective. Wilderness and the American Mind. 3rd ed., R. Nash, 342-78. New Haven, CT: Yale University Press.

Nash, Roderick Frazier. 2001. Wildernss and the American Mind. 4th ed. New Haven, CT: Yale University Press.

Natural Resources Law Center, University of Colorado School of Law. 2004. Special Provisions in Wilderness Legislation, University of Colorado School of Law, Boulder, CO.

Naughton-Treves, Lisa, Margaret Buck Holland, and Katrina Brandon. 2005. The Role of Protected Areas in Conserving Biodiversity and Sustaining Local Livelihoods. Annual Review of Environment \& Resources 30: 219-52.

Negi, Chandra S., and S. Nautiyal. 2003. Indigenous peoples, biological diversity and protected area management - policy framework towards resolving conflicts. International Journal of Sustainable Development and World Ecology 10: 169-79.

Nelson, J. Gordon, and Lucy M. Sportza. 2000. Evolving Protected Area Thought and Practice. The George Wright Forum 17, no. 2: 59-69.

Nelson, Robert H. 2000. Burning Issue: A Case for Abolishing the U.S. Forest Service . Lanham, MD: Rowman \& Littlefield Publishers, Inc.

Nepstad, Daniel, Claudia Azevedo-Ramos, Eirivelthon Lima, David McGrath, Cassio Pereira, and Frank Merry. 2004. Managing the Amazon Timber Industry. Conservation Biology 18, no. 2: 575-77.

Nesbitt, J. Todd \& Weiner Daniel. 2001. Conflicting environmental imaginaries and the politics of nature in Central Appalachia. Geoforum 32: 333-49.

Neumann, R. P. 1998. Imposing wilderness: Struggles over livelihood and nature preservation in Africa. Berkeley, CA: University of California Press.

Neumann, Roderick P. 1997. Primitive Ideas: Protected Area Buffer Zones and the Politics of Land in Africa. Development and Change 28: 559-82.

Newmark, W. D., and J. L. Hough. 2000. Conserving wildlife in Africa: integrated conservation and development projects and beyond. BioScience 50: 585-92. 
Newton, Julianne L., and Eric T. Freyfogle. 2005. Sustainability: A Dissent. Conservation Biology 19, no. 1: 23-32.

Newton, Julianne Lutz, and Eric T. Freyfogle. 2005. All About Nature. Conservation Biology 19, no. $1: 42-44$.

Nhapi, I., W. Holch, D. Mazvimavi, D. A. Mashauri, G. Jewitt, N. Mudege, L. A. Swatuk, and R. Beukman. 2005. Integrated Water Resource Management (IWRM) and the Millenium Development Goals: Managing Water for Peace and Prosperity. Physics and Chemistry of the Earth 30, no. 11-16: 623-24.

Nickas, George, and Kevin Proescholdt. 2005. Keeping the Wild in Wilderness: Minimizing NonConforming Uses in the National Wilderness Preservation System - A Tool for Protecting Wilderness in Future Wilderness Designations, Wilderness Watch, Missoula, MT.

Nie, Martin. 2004. Administrative Rulemaking and Public Lands Conflict: The Forest Service's Roadless Rule. Natural Resources Journal 44: 687-742.

—. 2003. Drivers of Natural Resource-Based Conflict. Policy Sciences 36: 307-41.

- 2006. Governing the Tongass: National Forest Conflict and Political Decision Making. Environmental Law 36, no. 2: 1-91.

- 2004. State Wildlife Policy and Management: The Scope and Bias of Political Conflict. Public Administration Review 64, no. 2: 221-33.

- 2004. Statutory Detail and Administrative Discretion in Public Lands Governance: Arguments and Alternatives. Journal of Environmental Law \& Litigation 19, no. 2: 22391.

Nielsen, Donald A. 1987. A Theory of Communicative Action or a Sociology of Civilizations? A Critique of Jürgen Habermas. Internaitonal Journal of Politics, Culture, \& Society 1, no. 1: $159-89$.

Nieminen, Matti. The Incontestable Nature of Biodiversity. Policy Agendas for Sustainable Technology.

Nightingale, Andrea J. 2005. "The Expert Taught Us All We Know": Professionalisation and Knowledge in Nepalese Community Forestry. Antipode: 581-604.

Nilsen, Per, and Grant Tayler. 1998. A Comparative Analysis of Protected Area Planning and Management Frameworks. In Proceedings - Limits of Acceptable Change and related planning processes: progress and future directions, Comps. Stephen F. McCool, and David N. ColeOgden, UT: U. S. Department of Agriculture, Forest Service, Rocky Mountain Research Station .

Nixon, Rob. 1991. Mandela, Messianism, and the Media. Transition, no. 51: 42-55. 
Nkomo, Sakhiwe, and Pieter van der Zaag. 2004. Equitable water allocation in a heavily committed international catchment area: the case of the komati catchment. Physics \& Chemistry of the Earth - Parts A/B/C 29, no. 15-18: 1309-17.

Nordlund, Annika M., and Jörgen Garvill. 2002. Value Structures Behind Proenvironmental Behavior. Environment and Behavior 34, no. 6: 740-756.

Norgaard, Richard B. 1989. The Rise of the Global Exchange Economy and the Loss of Biological Diversity. BioDiversity. editor E. O. Wilson, 206-11. Washington, DC: National Academy Press.

Norris, Frank B. 2002. Alaska Subsistence: A National Park Service management history. Anchorage, AK: Alaska Support Office, National Park Service.

Norton, Bryan G. 2005. Sustainability: A Philosophy of Adaptive Ecosystem Management. Chicago: University of Chicago Press.

Norton, Bryan G. 1991. Toward Unity Among Environmentalists. New York: Oxford University Press.

Nowak, Pete. 1992. Of what value are values in resource management? Journal of Soil and Water Conservation 47, no. 5: 356-59.

Ntsebeza, Lungisile. 2002. Decentralisation and Natural Resource Management in Rural South Africa: Problems and Prospects. presented at "The Commons in an Age of Globalisation," the Ninth Conference of the International Association for the Study of Common Property.

Nyambe, Nyambe. 2005. "Organizational Culture and its Underlying Basic Assumptions as a Determinant of Response to Change." University of KwaZulu-Natal.

Nygren, Anja. 2000. Development Discourses and Peasant-Forest Relations: Natural Resource Utilization as a Social Process. Development and Change 31, no. 1: 11.

O'Brien, Geraldine. 2002. Participation as the Key to Successful Change- A Public Sector Case Study. Leadership and Organization Development Journal 23, no. 8: 442-55.

O'Brien, Timothy G., and Margaret F. Kinnaird. 2003. Caffeine and Conservation. Science 300: 587.

O'Connor, T. G. 2005. Influence of land use on plant community composition and diversity in Highland Sourveld grassland in the southern Drakensberg, South Africa . Journal of Applied Ecology 42, no. 5: 975-88.

O'Kane, Rosemary H. T. 1993. Against Legitimacy. Political Studies 41, no. 3: 471-87. 1994. Legitimacy and Political Science. Political Studies 42, no. 1: 103-4.

O'Laughlin, Bridget. 1996. From basic needs to safety-nets: the rise and fall of urban food- 
rationing in mozambique. European Journal of Development Research 8, no. 1: 200-224.

O'Mara, Alexandra. 2004. Procedural Fairness and Public Participation in Planning. Environmental and Planning Law Journal: 62-80.

Oates, J. F. 1999. Myth and Reality in the Rain Forest: How conservation strategies are failing in West Africa . Berkeley, CA: University of California Press.

Office of Technology Assessment (OTA). 1987. Technologies to maintain biological diversity, U.S. Government Printing Office, Washington, D.C..

Ogondo, H. O., and S. Walker. 2005. Comparison of Measured Changes in Seasonal Soil Water Content by Rainfed Maize-Bean Intercrop and Component Cropping Systems in a SemiArid Region of Southern Africa. Physics and Chemistry of the Earth 30, no. 11-16: 799808.

Ohr, D. W. 1995. The Qustion of Management. Readings From Conservation Biology. editor D. Ehrenfeld, 1-2. Cambridge, Mass.: Blackwell Science Inc.

Okasha, Samir. 2002. Philosophy of Science: A Very Short Introduction. New York: Oxford University Press.

Oksanen, Markku. Biodiversity Considered Philosophically: An Introduction. In Philosophy and Biodiversity. Eds. Markku Oksanen, and Juhani Pietarinen, 1-26. Cambridge: Cambridge University Press.

Oliver-Smith, Anthony. 2002. Displacement, Resistance and the Critique of Development: From the Grass-roots to the Global. Refugee Studies Centre Working Paper Series, Oxford: Queen Elizabeth House International Development Centre.

Olson, David M., Eric Dinerstein, Eric D. Wikramanayake, Neil D. Burgess, George V. N. Powell, Emma C. Underwood, Jennifer A. D'Amico, Illanga Itoua, Holly E. Strand, John C. Morrison, Colby J. Loucks, Thomas F. Allnutt, Taylor H. Ricketts, Yumiko Kura, John F. Lamoreux, Wesley W. Wettengel, Preshant Hedao, and Kenneth R. Kassem. 2001. Terrestrial Ecoregions of the World: A New Map of Life on Earth. Bioscience 51, no. 11: 933-38.

Olsson, E. Gunilla A., Susanne K. Hanssen, and Katrina Ronningen. 2004. Different conservation values of biological diversity? A case study from the Jotunheimen mountain range, Norway. Norwegian Journal of Geography 58, no. 4: 204-12.

Olsson, U., F. Drasgo, and N. J. Dorans. 1982. The Polyserial correlation coefficient. Psychometrika 47: 337-47.

Olwig, Kenneth R. 1995. Reinventing Common Nature: Yosemite and Mount Rushmore - A Meandering Tale of a Double Nature. In Uncommon Ground: Toward Reinventing Nature. Ed. William Cronon, 379-408. New York: Norton. 
Onwuegbuzie, Anthony, and Nancy L. Leech. 2005. On Becoming a Pragmatic Researcher: The Importance of Combining Qualitative and Quantitative Research Methodologies. International Journal of Social Research Methodology 8, no. 5: 375-87.

Orr, David W. 2003. Rachel's Environment \& Health News - Walking North on a Southbound Train- Part 1. New Brunswick, NJ: Environmental Research Foundation.

- 2003. Rachel's Environment \& Health News-Walking North on a Southbound TrainPart 2. New Brunswick, NJ: Environmental Research Foundation.

Orr, Shannon K. 2005. New Technology and Research: An Analysis of Internet Survey Methodology in Political Science. PS: Political Science and Politics 38, no. 2: 263-7.

Ostrom, Elinor. 1990. Analyzing Long-Enduring CPRs. Governing the Commons: The Evolution of Institutions for Collective Action. Elinor Ostrom, 88-101. Cambridge: Cambridge University Press.

-1990. Governing the Commons: The Evolution of Institutions for Collective Action. New York: Cambridge University Press.

- 2003. How Types of Goods and Property Rights Jointly Affect Collective Action. Journal of Theoretical Politics 15, no. 3: 239-70.

-1995. New horizons in institutional analysis. American Political Science Review 89, no. 1.

-1990. Reflections on the Commons. Governing the Commons: The Evolution of Institutions for Collective Action. Elinor Ostrom, 1-15, 17-23. Cambridge: Cambridge University Press.

- 2002. Some Thoughts about Shaking Things Up: Future Directions in Political Science. Political Science 35, no. 2: 191-92.

Ostrom, Elinor, Joanna Burger, Christopher B. Field, Richard B. Norgaard, and David Policancy. 1999. Revisiting the Commons: Local Lessons, Global Challenges. Science 284: 278-82.

Ostrom, Elinor, and Vincent Ostrom. 2004. The Quest for Meaning in Public Choice. American Journal of Economics and Sociology 63, no. 1: 105-47.

Osunade, M. A. 1994. Community environmental knowledge and land resource surveys in Swaziland. Singapore Journal of Tropical Geography 15: 157-70.

Outhwaite, William. 1994. Habermas: A Critical Introduction. Stanford, CA: Stanford University Press.

Owen, Dave. 2002. Prescriptive Laws, Uncertain Science, and Political Stories: Forest Mangement in the Sierra Nevada. Ecology Law Quarterly 29, no. 2: 747-71. 
Packer, Connie A. A. and Donald Rukare. 2002. The New African Union and its Constitutive Act. American Journal of International Law 96, no. 2: 365-79.

Padoch, Christine, and Robin R. Sears. 2005. Conserving Concepts: in Praise of Sustainability. Conservation Biology 19, no. 1: 39-41.

Paehlke, Robert. 2005. Sustainability as a Bridging Concept. Conservation Biology 19, no. 1: 3638.

Pagiola, Stefano, Agustin Arcenas, and Gunars Platais. 2005. Can Payments for Environmental Services Help Reduce Poverty? An Exploration of the Issues and the Evidence to Date from Latin America. World Development 33, no. 2: 237-53.

Paldam, Martin. 2000. Social Capital: One or Many? Definition and Measurement. Journal of Economic Surveys 14, no. 5: 629-53.

Palmer, Lisa. 2004. Bushwalking in Kakadu: A Study of Cultural Borderlands. Social and Cultural Geography 5, no. 1: 109-27.

Parkins, John R., Richard C. Stedman, and Jeji Varghese. 2001. Moving Towards Local-Level indicators of Sustainability in Forest-Based Communities: A Mixed-Method Approach. Social Indicators Research 56, no. 1: 43.

Parkinson, John. 2003. Legitimacy Problems in Deliberative Democracy. Political Studies 51, no. 1: 180-196.

Parrish, Jeffrey, David P. Braun, and Robert S Unnasch. 2003. Are we Conserving What We Say We Are? Measuring Ecological Integrity within Protected Areas. BioScience 53, no. 9: 851-60.

Parrotta, John A., John W. Turnbull, and Norman Jones. 1997. Catalyzing Native Forest Regeneration on Degraded Tropical Lands. Forest Ecology and Management 99: 1-7.

Paterson, A. 2005. Tax incentives - valuable tools for biodiversity conservation in South Africa. South African Law Journal 122, no. 1: 182-216.

Patterson, M. E., and D. R. Williams. 2001. Collecting and analyzing qualitative data: Hermeneutic principles, methods, and case examples. Champaign, Illinois: Sagamore Publishing.

Patterson, Michael E., and William E. Hammitt. 1990. Backcountry Encounter Norms, Actual Reported Encounters, and Their Relationship to Wilderness Solitude. Journal of Leisure Research 22, no. 3: 259-75.

Patterson, Michael E., Alan E. Watson, Daniel R. Williams, and Joseph R. Robggenbuck. 1998. An Hermeneutic Approach to Studying the Nature of Wilderness Experiences. Journal of Leisure Research 30, no. 4: 423-52. 
Patterson, Michael E., and Daniel R. Williams. 2005. Maintaining research traditions on place: Diversity of thought and scientific progress. Journal of Environmental Psychology 25, no. 4: 361-80.

- 1998. Paradigms and Problems: The Practice of Social Science in Natural Resource Management. Society and Natural Resources 11: 279-95.

Paulson, Susan, and Lisa L. \& Watts Michael Gezon. 2003. Locating the Political in Political Ecology: An Introduction. Human Organizatioins 62, no. 3: 205-17.

Paxton, Pamela. 1999. Is Social Capital Decling in the United States? A Multiple Indicator Assessment. American Journal of Sociology 105, no. 1: 88-127.

Payne, Rodger A. 1998. The Limits and Promise Of Environmental Conflict Prevention: The Case of the GEF. Journal of Peace Research 35, no. 3: 363-80.

- 1995. Freedom and the Environment. Journal of Democracy 6, no. 3: 41-55.

Peang-Meth, Abdulgaffar. 2002. The rights of indigenous peoples and their fight for selfdetermination. World Affairs 164, no. 3: 101-15.

Pearce, David, Francis E. Putz, and Jerome K. Vanclay. 2003. Sustainable Forestry in the Tropics: Panacea or Folly. Forest Ecology and Management 172: 229-47.

Pedynowski, Dena. 2003. Prospects for Ecosystem Management in the Crown of the Continent Ecosystem, Canda-United States: Survey and Recommendations. Conservation Biology 17, no. 5: 1261-69.

Peet, Richard. 2002. Ideology, Discourse, and the Geography of Hegemony: From Socialist to Neoliberal Development in Postapartheid South Africa. Antipode : 54-84.

Peirce, Charles S. 1998. Chance, Love and Logic: Philosophical Essays. Lincoln, NE: University of Nebraska Press.

Peluso, N. L. 1993. Coercing conservation: The politics of state resource control. Global Environmental Change 3, no. 2: 199-218.

Pennington, Mark. 2003. Hayekian Political Economy and the Limits of Deliberative Democracy. Political Studies 51: 722-39.

Percival, Robert V., Christopher H. Schroeder, Alan S. Miller, and James P. Leape. 2003. Environmental Regulation: Law, Science, and Policy. New York: Aspen Publishers.

Percival, Val, and Thomas Homer-Dixon. 1998. Environmental Scarcity and Violent Conflict: The Case of South Africa. Journal of Peace Research 35, no. 3: 279-98.

Peres, Carlos A., and John W. Terborgh. 1995. Amazonian Nature Reserves: An Analysis of the Defensibility Status of Existing Conservation Units and Design Criteria for the Future. 
Conservation Biology 9, no. 1: 34-46.

Perez-Verdin, Gustavo, Martha E. Lee, and Deborah J. Chavez. 2004. Outdoor recreation in a protected area in southern Durango, Mexico: analysis of local residents' perceptions . Society \& Natural Resources 17, no. 10: 897-910.

Perfecto, Ivette, Robert A. Rice, Russell Greenberg, and Martha E. Van der Voort. 1996. Shade Coffee: A Disappearing Refuge for Biodiversity

. BioScience 46, no. 8: 598-608.

Perrez, F. 1996. The relationship between "permanent sovereignty" and the obligation not to cause transboundary environmental change. Environmental Law 26, no. 4: 1187-212.

Perrings, Charles \& Lovett Jon. 1999. Policies for Biodiversity Conservation: The Case of SubSaharan Africa. International Affairs 75, no. 2: 281-305.

Peters, Richard G., Vincent T. Covello, and David B. McCallum. 1997. The Determinants of Trust and Credibility in Environmental Risk Communication: An Empirical Study. Risk Analysis 17, no. 1: 43-54.

Peterson, Garry D., and Graeme S. \& Carpenter Stephen R. Cumming. 2003. Scenario Planning: a Tool for Conservation in an Uncertain World. Conservation Biology 17, no. 2: 358-66.

Peterson, M. Nils. 2004. An Approach to Demonstrating the Social Legitimacy of Hunting. Wildlife Society Bulletin 32, no. 2: 310-321.

Petts, Judith. 2004. Barriers to Participation and Deliberation in Risk Decisions: Evidence from Risk Management. Journal of Risk Research 7, no. 2: 115-33.

Pfeiffer, James. 2003. Cash income, intrahousehold cooperative conflict, and child health in central mozambique. Medical Anthropology 22, no. 2: 87-130.

-2003. International ngos and primary health care in mozambique: the need for a new model of collaboration. Social Science \& Medicine 56, no. 4: 725-38.

Phillips, Adrian. 2003. Turning Ideas on their Head: The New Paradigm for Protected Areas. The George Wright Forum 20, no. 2: 8-32.

Phillips, Adrian, Sue Stolton, Nigel Dudley, and Kevin Bishop. 2003. Speaking a Common Language: An assessment of the IUCN categories of protected areas carried out for the World Commission of Protected Areas by Cardiff University and Partners, Cardiff University, Wales, UK.

Philpott, Stacy M., and Thomas Dietsch. 2003. Coffee and Conservation: a Global Context and the Value of Farmer Involvement. Conservation Biology 17, no. 6: 1844-46.

Pimm, Stuart L., Marcio Ayres, Andrew Balmford, George Branch, Katrina Brandon, Thomas Brooks, Rodrigo Bustamante, Robert Costanza, Richard Cowling, Lisa M. Curran, 
Andrew Dobson, Stephen Farber, Gustavo A. B. de Fonseca, Claude Gascon, Robert Kitching, Jeffrey McNeely, Thomas Lovejoy, Russell A. Mittermeier, Norman Myers, Jonathan A. Patz, Bradley Raffle, David Rapport, Peter Raven, Callum Roberts, John Paul Rodriguez, Anthony B. Rylands, Compton Tucker, Carl Safina, Cristian Samper, Melanie L. J. Stiassny, Jatna Sapriatna, Diana H. Wall, and David Wilcove. 2001. Can We Defy Nature's End. Science 293: 2207-9.

. 2002 An Introduction to the National Fire Plan: History, Structure, and Relevance to Communities Pinchot Institute for ConservationWashington D.C.: Pinchot Institute for Conservation.

Pitcher, M. Anne. 1996. Recreating Colonialism or Reconstructing the State? Privatisation and Politics in Mozambique. Journal of Southern African Studies 22, no. 1: 49-74.

Plumptre, Tim, and John Graham. 1999. Governance and Good Governance: International and Aboriginal Perspectives. Institute on Governance.

Poisner, Jonathan. 1996. A Civic Republican Perspective on the National Environmental Policy Act's Process for Citizen Participation. Environmental Law 26, no. 1: 53-94.

Pokorny, Benno, Guilhermina Cayres, and Westphalen Nunes. 2003. Participatory Analysis of Heterogeneity, an Approach to Consolidate Collaborative Initiatives at Community Level. Forest, Trees and Livelihoods 13: 161-75.

Pollard, Sharon, Charlie Shackleton, and Jane Carruthers. 2003. Beyond the Fence: People and the Lowveld Landscape. In The Kruger Experience: Ecology and Management of Savanna Heterogeneity. Eds. Johan T. du Toit, Kevin H. Rogers, and Harry C. Biggs, 422-46. Washington, D. C.: Island Press.

Popper, Karl. 1963. Conjectures and Refutations. London: Routledge and Kegan Paul.

Porter, Michael. 1985. Competitive Advantage. New York: Free Press.

Povilitis, Tony. 2002. What is a Natural Area? Natural Areas Journal 22, no. 1: 70-74.

Power, Marcus. 2006. Anti-racism, Deconstruction and 'Overdevelopment'. Progress in Development Studies 6, no. 1: 24-39.

Power, Thomas Michael. 1996. Thinking About the Local Economy. Lost Landscapes and Failed Economies. Thomas MIchael Power, 7-28. Washington D.C.: Island Press.

Press, Eyal, and Jennifer Washburn. 2000. The Kept University. The Atlantic Monthly March: 39-54.

Pretty, Jules. 2003. Social Capital and the Collective Management of Resources. Science 302.

Price, Edward T. 1955. Values and concepts in conservation. Annals of the Association of American Geographers 45, no. 1: 64-84. 
Pridmore, Pat, and Chris Yates. 2005. Combating AIDS in South Africa and Mozambique: The Role of Open, Distance, Flexible Learning (ODFL). Comparative Education Review 49, no. 4: 490-511.

Primm, Steven A., and Tim W. Clark. 1996. The Greater Yellowstone policy debate: What is the policy problem? Policy Sciences 29: 137-66.

Proffitt Jr., W. Trexler. 2004. Legitimacy and Adoption of a Scientific Biological Control Program: an Institutional Analysis of Hoddle. Conservation Biology 18, no. 1: 68-61.

Puchala, Donald J. 1997. Some non-western perspectives on international relations. Journal of Peace Research 34, no. 2: 129-35.

Putz, Francis E., Geoffrey M. Blate, Kent H. Redford, Robert Fimbel, and John Robinson. 2001. Topical Forest Management and Conservation of Biodiversity: an Overview. Conservation Biology 16, no. 1: 7-20.

Pyhala, Ail, Katrina Brown, and W. Neil Adger. 2006. Implications of Livelihood Dependence on Non-Timber Products in Peruvian Amazonia. Ecosystems 9, no. 8: 1328-41.

Quinn, Dennis P. and John T. Woolley. 2001. Democracy and National Economic Performance: The Preference for Stability. American Journal of Political Science 45, no. 3: 634-57.

. 2002 Public Lands and Private Recreation Enterprise: Policy Issues from a Historic Perspective Tom Quinn. General Technical Report PNW-GTR-556, Portland, OR: USDA Forest Service Pacific Northwest Research Station.

Quintana, J., and S. Morse. 2005. Social interactions and resource ownership in two private protected areas of Paraguay. Journal of Environmental Management 77, no. 1: 64-78.

Rabinowitz, A. 1999. Nature's last bastions: Sustainable use of our tropical forests may be little more than wishful thinking. Natural History 108: 70-72.

Rademan, Louise Katherine. 2004. "An ecological assessment of the sustainable utilization of woody vegetation in the Lowveld Bushveld, Mpumalanga province." Masters Thesis , University of Pretoria.

Rajabu, Kossa R. M. 2005. The Role of Participatory Problem Analysis in Performance Improvement and Sustainable Management of Rainwater Harvesting (RWH) Systems: A Case Study of Makanya Village, Tanzania. Physics and Chemistry of the Earth 30, no. 11-16: 832-39.

. 2003 The Emergence of Strong Property Rights: Speculations from History Raghuram G. Rajan, and Luigi Zingales. NBER Working Paper Series 9478, Cambridge, MA: National Bureau of Economic Research.

Rajan, Ravi S. 2002. Disaster, Development and Governance: Reflections on the 'Lessons' of Bhopal 
. Environmental Values 11: 369-94.

Ramutsindela, Maano. 2003. Land reform in South Africa's national parks: a catalyst for the human-nature nexus. Land Use Policy 20, no. 1: 41-49.

Ramutsindela, Maano F. 2002. The perfect way to ending a painful past? The Makuleke land deal in South Africa. Geoforum 33: 15-24.

Rasinski, K., T. R. Tyler, and K. Fridkin. 1985. Exploring the function of legitimacy: Mediating effects of personal and institutional legitimacy on leadership endorsement and system support. Journal of Personality and Social Psychology 49: 386-94.

Rasker, Ray. 2006. An Exploration Into the Economic Impact of Industrial Development Versus Conservation on Western Public Lands. Society \& Natural Resources 17, no. 3: 191-207.

Rasmussen, David, and James Swindal, Eds. 2004. Critical Theory. Sage Formations in Social Thought Series. Thousand Oaks, CA: Sage.

Rasmussen, David M. 1996. The Handbook of Critical Theory. Cambridge, Massachusetts: Blackwell Publishers.

Demosclerosis. 1994. Demosclerosis: The Silent Killer of American Government. Jonathan RauchNew York: Times Books.

Raustiala, K. 1997. States, NGOs, and international environmental institutions. International Studies Quarterly 41, no. 4: 719-40.

Raustiala, Kal. 1997. Domestic Institutions and International Regulatory Cooperation: Comparative Responses to the Convention on Biological Diveristy. World Politics 49, no. 4: 482-509.

Rauwald, Kimberly S., and Colleen F. Moore. 2002. Environmental Attitudes as Predictors of Policy Support Across Three Countries. Environment and Behavior 34, no. 6: 709-39.

Rawls, John. 2005. Political Liberalism. New York: Columbia University Press. 1975. Theory of Justice. Cambridge, MA: Harvard University Press.

Ray, Marcella Ridlen. 2003. An Analysis of U.S. Civil Society. The American Sociologist Spring/Summer: 104-11.

Reddy, S. R. C., and S. P. Chakravarty. 1999. Forest Dependence and Income Distribution in a Subsistence Economy: Evidence from India. World Development 27, no. 7: 1141-49.

Redford, K. H. 1991. The ecologically noble savage. Cultural Survival Quarterly 15: 46-48.

Redford, K. H., and S. E. Sanderson. 1999. Conservation of biodiversity in a world of use. Conservation Biology 13: 1246-56. 
—. 2000. Extracting Humans from nature. Conservation Biology 14: 1362-64.

Redford, Kent, Katrina Brandon, and Steven Sanderson. 1998. Holding Ground. In Parks in Peril: People, Politics, and Protected Areas. Eds. Katrina Brandon, Kent H. Redford, and Steven E. Sanderson, 455-63. Washington, D.C.: Island Press.

Redford, Kent H., and Allyn Maclean Stearman. 1993. Forest-Dwelling Native Amazonians and the Conservation of Biodiversity: Interests in Common or Collision? Conservation Biology 7, no. 2: 248-55.

Reed, Lawrence W. 1995. Environmental Rules Cost Jobs, Money, and Freedom. Human Events 51, no. 15: 18.

Refugee Research Programme. 2002. A Park for the People? Great Limpopo Transfrontier ParkCommunity Consultation in Coutada 16, Mozambique, Refugee Research Programme, Limpopo Province, South Africa.

Rehfeld, Andrew. 2005. The Concept of Constituency: Political Representation, Democratic Legitimacy, and Institutional Design. Cambridge, MA: Cambridge University Press.

Rehg, William, and James Bohman. 1996. Discourse and Democracy: The Formal and Informal Bases of Legitimacy in Habermas' Faktizität und Geltung. Journal of Political Philosophy 4, no. 1: 79 .

Reid. 2001. Contractual national parks and the Makuleke community. Human Ecology: An Interdisciplinary Journal 29, no. 2: 135.

Reitan, Marit. 2004. Multi-Level Governanace: Politicisation and professional expertise in the policy of nature conservation. Local Environment 9, no. 5: 437-50.

-2004. Politicisation and professional expertise in the policy of nature conservation. Local Environment 9, no. 5: 437-50.

Republic of South Africa. 2004. Biodiversity Act. Act no. 10.

- 2004. National Environmental Management, Biodiversity Act. Government Gazette 467: 1-43.

- 2003. Protected Areas Act. Act no. 57.

Resilience Aliance. 2005. "About RA." Web page, [accessed 12 March 2007].

Resilience Alliance. 2005. "Key Concepts: Resilience." Web page, [accessed 12 March 2007].

Reuveny, Rafael and Li Quan. 2003. Economic Openness, Democracy, and Income Inequality. Comparative Political Studies 36, no. 5: 575-601.

Ribot, Jesse C. 2002. Democratic Decentralization of Natural Resources: Institutionalizing Popular Participation, World Resources Institute. 
Ribot, Jesse C. 2004. Waiting for Democracy: The Politics of Choice in Natural Resource Decentralization, editors Martha Schultz, and Emily Yaghmour. World Resources Institute, Washington D.C..

Ribot, Jesse C., and Nancy Lee Peluso. 2003. A Theory of Access. Rural Sociology 68, no. 2: 153-81.

Rice, Tom W. and Jeffrey Ling. 2002. Democracy, Economic Wealth and Social Capital: Sorting Out the Causal Connections. Space \& Polity 6, no. 3: 307-25.

Richard, Tim, and Ellen Stein. 2001. "Kicking Dirt Together" in Colorado: Communityecosystem stewardship and the ponderosa pine forest stewardship partnership. Forest Communities, Community Forests. Editors J. Kusel, and E. Adler, 191-206. Lanham, MD: Rowman \& Littlefield.

Richards, Michael, Maksha Maharjan, and Keshav Kanel. 2003. Economics, Poverty and Transparency: Measuring Equity in Forest User Groups. Journal of Forest and Livelihood 3 , no. 1: 91-106.

Richter, Melvin. 1982. Toward a Concept of Political Illegitimacy: Bonapartist Dictatorship and Democratic Legitimacy. Political Theory 10, no. 2: 185-214.

Ridder, Ben. 2007. The Naturalness versus Wildness Debate: Ambiguity, Inconsistency, and Unattainable Objectivity. Restoration Ecology 15, no. 1: 8-12.

Rideout, Douglas B. 2003. "Social Sciences and the Economics of Moderation in Fuels Management." Fire-Economics, RMRS-P-29. USDA Forest Service Proceedings .

Riley, Patrick. 1973. Will and Legitimacy in the Philosophy of Hobbes: is he a Consent Theorist? Political Studies 21, no. 4: 500.

Ringen, Stein. 2004. A Distributional Theory of Economic Democracy. Democratization 11, no. 2: $18-41$.

Ringland, Gill. 2002. Scenarios in Public Policy. New York: John Wiley \& Sons, Ltd.

Rittel, Horst W. J., and Melvin M. Webber. 1973. Dilemmas in a General Theory of Planning. Policy Sciences 4: 155-69.

Rizzo, Ann-Marie, and Laura Lee Swisher. 2004. Comparing the Stewart-Sprinthall management survey and the defining issues test-2 as measures of moral reasoning in public administration. Journal of Public Administration Research and Theory 14, no. 3: 335-48.

Robbins, Paul. 2001. Tracking Invasive Land Covers in India or Why Our Landscapes Have Never Been Modern. Annals of the Association of American Geographers 91, no. 4: 63759.

Roberts, A. 2001. Traditional and modern approaches to customary international law: A 
reconciliation. American Journal of International Law 95, no. 4: 757-91.

Roberts, J. Timmons Bradley C. Parks and Alexis A. Vásquez. 2004. Who Ratifies Environmental Treaties and Why? Institutionalism, Structuralism and Participation by 192 Nations in 22 Treaties. Global Environmental Politics 4, no. 3: 22-64.

Robertson, J., and M. J. Lawes. 2005. User perceptions of conservation and participatory management of iGxalingenwa forest, South Africa. Environmental Conservation 32, no. 1: 64-75.

Robinson, J. C. 1993. The limits to caring: Sustainable living and the loss of biodiversity. Conservation Biology 7: 20-28.

Robinson, W. Courtland. 2003. Risks and Rights: The Causes, Consequences, and Challenges of Development-Induced Displacement. Occasional Paper, Washington, DC: The Brookings Institution-SAIS Project on International Displacement.

Robteutscher, Sigrid. 2002. Advocate or Reflection? Associations and Political Culture. Political Studies 50: 514-28.

Rocheleau, Diane, Barbara Thomas-Slayter, and Esther Wangari. 1996. Gender and Environment: A Feminist Political Ecology Perspective. Feminist Political Ecology. Diane Rocheleau, Barbara Thomas-Slayter, and Esther Wangari, 3-23. London: Rutledge.

Rocheleau, Dianne, and Barbara \& Wangari Esther Thomas-Slayter. 1996. Out On The Front Lines But Still Struggling For Voice. Feminist Political Ecology: Global issues and local experiences. Connie Campbell.

Roderick, Rick. 1986. Habermas and the Foundations of Critical Theory. New York: St. Martin's Press.

Rodrik, D. 2000. Where did all the growth go? External Shocks, social conflict, and growth collapses. Journal of Economic Growth 4, no. 4: 385-412.

Roesch, Otto. 1992. Remamo and the Peasantry in Southern Mozambique: A View from Gaza Province. Canadian Journal of African Studies 26, no. 3: 462-84.

Rogers, Kevin, and Harry Biggs. 1999. Integrating indicators, endpoints and value systems in strategic management of the rivers of Kruger National Park. Freshwater Biology 41, no. 2: 439.

Roggenbuck, Joseph W., Daniel R. Williams, and Steven P. and Dean Denis J. Bange. 1991. River Float Trip Encounter Morms: Questioning the Use of the Social Norms Concept. Journal of Leisure Research 23, no. 2: 133-53.

Rogowski, R. 1974. Rational legitimacy: a theory of political support. Princeton, N.J.: Princeton University Press. 
Rohr, John A. 1986. To Run a Constitution: The Legitimacy of the Administrative State. Lawrence, KS: University Press of Kansas.

Rokeach, M. 1968. Beliefs, Attitudes, and Values. New York: The Free Press.

Rolle, Su. 2002. Measures of Progress for Collaboration: A Case Study of the Applegate Partnership, General Tech. Report PNW-GTR-565. U.S. Department of Agriculture, Forest Service, Northwest Research Station, Portland, OR.

Rollins, Matthew, Tom Swetnam, and Penelope Morgan. 2000. Twentieth-Century Fire Patterns in the Selway-Bitterroot Wilderness Area, Idaho/Montana and the Gila/Aldo Leopold Wilderness Complex, New Mexico, RMRS-P-15-VOL-5. U.S. Department of Agriculture, Forest Service, Rocky Mountain Research Station, Fort Collins, CO.

Romzek, Barbara S., and Melvin J. Dubnick. 1987. Accountability in the Public Sector: Lessons from the Challenger Tragedy. Public Administration Review May/June: 227-38.

Rosenberg, J., and F. L. Korsmo. 2001. Local participation, international politics, and the environment: The world bank and the Grenada Dove. Journal of Environmental Management 62: 283-300.

Rosencrance, Richard. 1992. A New Concert of Powers. Foreign Affairs 72, no. 2: 64-82.

Rosendal, G. Kristin. 2006. Balancing Access and Benefit Sharing and Legal Protection of Innovations from Bioprospecting. Journal of Environment and Development 15, no. 4: 428-47.

1995. The Convention on Biological Diversity: A Viable Instrument for Conservation and Sustainable Use? Green Globe Yearbook of International Co-operation on Environment and Development 1995. editors Helge Ole Bergesen, Georg Parmann, and Oystein B. Thommessen, 69-81. Oxford: Oxford University Press.

Rosenfeld, Michel. 2001. The Rule of Law and the Legitimacy of Constitutional Democracy. Southern California Law Review 74: 1307-51.

Rotberg, Robert I. 2001. Ending Autocracy, Enabling Democracy: The Tribulations of Southern Africa. Cambridge, MA: World Peace Foundation.

Rothman, Hal K. 1989. "A Regular Ding-Dong Fight": Agency Culture and Evolution in the NPS-USFS Dispute, 1916-1937. Western Historical Quarterly 20, no. 2: 141-61.

Rothstein, Bo. 2003. Social Capital, Economic Growth, and Quality of Government:The Causal Mechanism . New Political Economy 18, no. 1: 49-71.

Rousseau, Denise M, Sim B. Sitkin, Ronald S. Burt, and Colin Camerer. 1998. Introduction to Special Topic Forum: Not So Different After All: A Cross-Discipline View of Trust. The Academy of Management Review 23, no. 3: 393-404. 
Rousseau, Jean-Jacques. 2004. The Social Contract, or Principles of Political Right. Whitefish, MT: Kessinger.

Rowe, Gene, and Lynn J. Frewer. 2000. Public Participation Methods: A Framework for Evaluation. Science, Technology and Human Values 25, no. 1: 3-29.

Rowe, Gene, Roy Marsh, and Lynn J. Frewer. 2004. Evaluation of a Deliberative Conference. Science, Technology and Human Values 29, no. 1: 88-121.

Runte, Alfred. 1997. Catalysts: Nationalism, Art, and the American West. National Parks: The American Experience. Third Edition ed., 11-32. Lincoln, NE: University of Nebraska Press.

Rush, Fred, Ed. 2004. The Cambridge Companion to Critical Theory. New York: Cambridge University Press.

Ruttan, Lore M. \& Borgerhoff Mulder Monique. 1999. Are East African Pastoralists Truly Conservationists? Current Anthropology 40, no. 5: 621-52.

Ryan, Erin. 2001. Public Trust and Distrust: The Theoretical Implications of the Public Trust Doctrine for Natural Resource Management. Environmental Law 31, no. 2: 477-96.

Ryfe, David Michael. 2002. The Practice of Deliberative Democracy: A Study of 16 Deliberative Organizations. Political Communication 19: 359-77.

Sabatier, P. A., and H. C. Jenkins-Smith, eds. 1993. Policy Change and Learning: An Advocacy Coaltion Approach. Boulder, CO: Westview Press.

Sachikonye, Llyod M. 1995. Civil society, social movements and democracy in Southern Africa. Innovation: The European Journal of Social Sciences 8, no. 4: 399-412.

Sagar, Ambuj D., and Stacy D. VanDeveer. 2005. Capacity Development for the Environment: Broadening the Scope. Global Environmental Politics 5, no. 3: 14-22.

Salafsky, N., H. Cauley, G. Balachander, B. Cordes, J. Parks, C. Margoluis, S. Bhatt, C. Encarnacion, D. Russell, and R. Margoluis. 2001. A Systematic Test of an Enterprise Strategy for Community-Based Biodiversity Conservation. Conservation Biology 15, no. 6: $1585-95$.

Salafsky, Nick. 2000. Lessons From the Field: How Can We Work Together? Biodiversity Support Program October: 1-8.

Salafsky, Nick, and Richard Margoluis. 1999. Greater Than the Sum of Their Parts. Washington DC: Biodiversity Support Program. 1999. Threat Reduction Assessment: a Practical and Cost-Effective Approach to Evaluating Conservation and Development Projects. Conservation Biology 13, no. 4: 830-841. 
Salafsky, Nick, Richard Margoluis, Kent H. Redford, and John G. Robinson. 2002. Improving the Practice of Conservation: a Conceptual Framework adn Research Agenda for Conservation Science. Conservation Biology 16, no. 6: 1467-79.

Salafsky, Nick, and Eva Wollenberg. 2000. Linking Livelihoods and Conservation: A Conceptual Framework and Scale for Assessing the Integration of Human Needs and Biodiversity. World Development 28, no. 8: 1421-38.

Sale, Joanna E. M., Lynne H. Lohfeld, and Kevin Brazil. 2002. Revisiting the QuantitativeQualitative Divide: Implications for Mixed-Methods Research. Quality and Quantity 36, no. $1: 43-53$.

Salka, William M. 2004. Mission Evolution: The United States Forest Service's Response to Crisis. Review of Policy Research 21, no. 2: 221-32.

Salman, D. H. 1963. Psychology and sociology in Weber's theories. Social Compass 10, no. 6: 536-39.

Soil Management in Shifting Cultivation Areas. 1976. Properties and Management of Soils in the Tropics. P. Sanchez, 346-49 \& 404-405. New York: John Wiley \& Sons.

Sandel, Michael J. 1984. The Procedural Republic and the Unencumbered Self. Political Theory 12, no. 1: 81-96.

Sanderson, S. 2005. Poverty and Conservation: The New Century's "Peasant Question"? World Development 33, no. 2: 323-32.

Sanderson, Steven, and Kent Redford. 2004. The defence of conservation is not an attack on the poor. Oryx 38: 146-47.

Sandomierski, David. Canadian Environmental Policy in a Post-Newtonian World. ISYP Conference "Advancing Human Security".

Saner, Mark, and Jake Wilson. 2003. Stewardship, Good Governance and Ethics, Institute on Governance, Ottawa, Canada.

Sapat, Alka. 2004. Devolution and Innovation: The Adoption of State Environmental Policy Innovations by Administrative Agencies. Public Administration Review 64, no. 2: 141 51.

Sarewitz, Daniel \& Pielke Roger Jr. 2000. Breaking the Global Waming Gridlock.

Sarkar, Sahotra. 2005. Biodiversity and Environmental Philosophy: An Introduction. Cambridge: Cambridge University Press.

Satterfield, T. 2002. In search of value literacy: suggestions for the elicitation of environmental values. Environmental Values 10: 331-59. 
Sax, Joseph L. 1980. The Compromise Called For. Mountains Without Handrails: Reflections on the National Parks. Joseph L. Sax, 61-77. Ann Arbor, MI: University of Michigan Press.

Sax, Joseph L. 1980. Mountains Without Handrails: Reflections on the National Parks. Ann Arbor, MI: University of Michigan Press.

Sayer, Jeffrey A. 1999. Globalization, localization and protected areas. In Partnerships for Protection: New Strategies for Planning and Management of Protected Areas. Eds. Sue Stolton, and Nigel Dudley, 29-40. London: Earthscan.

Sayre, Nathan. 1999. The Cattle Boom in Southern Arizona: Towards a Critical Political Ecology. Journal of the Southwest 41, no. 2: 239.

Scapple, K. 1998. Is consensus necessary for effective environmental treaties? Journal of Environment and Development 364, no. 1.

Schaar, John H. 2000. Legitimacy in the Modern State. New Brunswick, N.J.: Transaction .

Schattschneider, E. E. 1960. The Contagiousness of Conflict. The Semi-Sovergin People: A Realist's View of Democracy in America.

Schelhas, John, Ruth E. Sherman, Timothy J. Fahey, and James Lassoie. 2002. Linking Community and National Park Development: A Case From the Dominican Republic. Natural Resources Forum 26: 140-149.

Scheufele, Dietram A., and Dhavan V. Shah. 2000. Personality Strength and Social Capital. Communication Research 27, no. 2: 107-32.

Schlager, Daniel B. \& Freimund Wayne A. 1997. Integrating Social Science and Ecosystem Management: A National Challenge . Legal and Institutional Obstacles to Implementing Ecosystem Management H. Ken Linda Caldwell \& Shela Mou Cordell. USDA Forest Service Southern Research Station General Technical Report SRS-17, Asheville, NC: Southern Research Station.

Schlager, Edella, and Elinor Ostrom. 1992. Property-Rights Regimes and Natural Resources: A Conceptual Analysis. Land Economics 68 , no. 3: 249-62.

Schmidtz, David. 2000. Natural Enemies: An Anatomy of Environmental Conflict. Environmental Ethics 22, no. 4: 397-408.

Schmookler, Andrew Bard. 1993. The Illusion of Choice: How the Market Economy Shapes our Destiny. Albany, NY: State University of New York Press.

Schneider, Joseph W. 1985. Social Problems Theory: The Constructionist View. Annual Review of Sociology 11: 209-29.

Schroeder, Richard A. 1997. "Re-claiming" Land in the Gambia: Gendered Property Rights and 
Environmental Intervention. Annals of the Association of American Geographers 87, no. 3: 487-508.

Schultz, P. W., and L. Zelezny. 1998. Values and proenvironmental behavior: A five-country survey. Journal of Cross-Cultural Psychology 29: 540-558.

Schwartzman, S., A. Moreira, and D. Neptstad. 2000. Rethinking tropical forest conservation: Perils in parks. Conservation Biology 14: 1351-57.

Schwartzman, S., D. Nepstad, and A. Moreira. 2000. Arguing tropical forest conservation: People versus parks. Conservation Biology 14: 1370-1374.

Schwartzman, Stephan, and Barbara Zimmerman. 2005. Conservation Alliances with Indigenous Peoples of the Amazon. Conservation Biology 19, no. 3: 721-27.

Scodanibbio, Lucia, and Gustavo Manez. 2005. The World Commission on Dams: A Fundamental Step Towards Integrated Water Resource Management and Poverty Reduction? A Pilot Case in the Lower Zambezi, Mozambique. Physics and Chemistry of the Earth 30, no. 11-16: 976-83.

Scoones, I. 1999. New Ecology And The Social Science: What Prospects for a Fruitful Engagement? Annual Review of Anthropology 28: 479-507.

Scott, John P. 1978. Critical Social Theory: An Introduction and Critique. The British Journal of Sociology 29, no. 1: 1-21.

Scott, John Wesley. 1999. European and North American Contexts for Cross-border Regionalism. Regional Studies 33, no. 7: 605-17.

Sedano, Fernando, Peng Gong, and Manuel Ferrao. 2005. Land Cover Assessment with MODIS Imagery in Southern African Miombo Ecosystems. Remote Sensing and Environment 98, no. 4: 429-41.

Seidman, Steven. 1996. Queer Theory/Sociology. Malden, MA: Blackwell Publishers.

Sekhon, Jasjeet S. 2004. Quality Meets Quantity: Case Studies, Conditional Probability, and Counterfactuals. Perspectives on Politics 2, no. 2: 281-93.

Sellars, Richard West. 1997. Preserving Nature in the National Parks. New Haven, CT: Yale University Press.

Senge, P. M. 1990. The fifth discipline: the art and science of the learning organization. New York: Currency Doubleday.

Sengo, D. Jose, Albert Kachapila, Pieter van der Zaag, Marloes Mul, and Sakhiwe Nkomo. 2005. Valuing Environmental Water Pulses into the Incomati Estuary: Key to Achieving Equitable and Sustainable Utilisation of Transboundary Waters. Physics and Chemistry $A / B / C$ 30, no. 11-16: 648-57. 
Sezen, Uzay U., Robin L. Chazdon, and Kent E. Holsinger. 2005. Cenetic Consequences of Tropical Second-Growth Forest Regeneration. Science 307: 891.

Shabani, Omid A. Payrow. 2003. Democracy, Power, and Legitimacy: The Critical Theory of Jürgen Habermas. Toronto: University of Toronto Press.

Sharpe, Barrie. 1998. 'First the forest': Conservation, 'community,' and 'participation' in southwest Cameroon. Africa 68, no. 1: 25.

Shauri. 2000. The legal aspects of governance in community-based natural resource management in Tanzania. presented at The 2nd annual CASS/PLAAS Regional MeetingThe 2nd annual CASS/PLAAS Regional Meeting.

Shaw, Jon. 2003. Book Reviews: Land in the American West. Land Use Policy 20: 291-92.

Shelby, Bo and Vaske Jerry J. 1991. Using Normative Data to Develop Evaluative Standards for Resource Management: A Comment on Three Recent Papers. Journal of Leisure Research 23, no. 2: 173-87.

Shi, Hua, Ashibindu Singh, Shashi Kant, Zhiliang Zhu, and Eric Waller. 2005. Integrating Habitat Status, Human Population Pressure, and Protection Status into Biodiversity Conservation Priority Setting. Conservation Biology 19, no. 4: 1273-85.

Shields, D. J., I. M. Martin, and M. A. Haefele. Survey Results of the American Public's Values, Objectives, Beliefs, and Attitudes Regarding Forests and Grasslands, RMRS - GTR - 95. USDA Forest Service, Fort Collins, CO.

Shillington, K. 1993. A History of Southern Africa. Malaysia: Longman Group.

Shindler, Bruce, and K. Aldred Chee. 1999. Integrating citizens in adaptive management: A propositional analysis. Journal of Conservation Ecology 3, no. 1: 13-29.

Shindler, Bruce, Mark W. Brunson, and Kristin Aldred Cheek. Social Acceptability in Forest and Range Management. in Society and Natural Resources: A Summary of Knowledge. Eds. Michale J. Manfredo, Jerry J. Vaske, Brett L. Bruyere, Donald R. Field, and Perry J. Brown, 147-57. Jefferson, MO: International Symposium on Society and Resource Management.

Shipley, Bill. 2000. Cause and Correlation in Biology: A User's Guide to Path Analysis, Structural Equations and Causal Inference. Cambridge, U.K.: Cambridge University Press.

Shrader-Frechette, K. S., and E. D. McCoy. 1994. Applied ecology and the logic of case studies. Philosophy of Science 61: 228-49.

Siebert, S. F. 2001. Sustainable Harvesting of Wild Rattan: Viable Concept or Ecological Oxymoron? Unasylva 52: 36-45. 
Siebert, Stephen F., and Jill M. Belsky. 2002. Livelihood Security and Protected Area Management. International Journal of Wilderness 8: 38-41.

Silva, Eduardo. 2004. The Political Economy of Forest Policy in Mexico and Chile. Singapore Journal of Tropical Geography 25, no. 3: 261-80.

Simmons, A. John. 1999. Justification and Legitimacy. Ethics 109, no. 4: 739-71.

—. 1989. Locke's State of Nature. Political Theory 17, no. 3: 449-70.

Simpson, Charles R., and Anita Rapone. 2000. Community Development From the Ground Up: Social-Justice Coffee. Human Ecology Review 7, no. 1: 46-57.

Sims, David. 1979. A Framework for Understanding the Definition and Formulation of Problems in Teams. Human Relations 32, no. 11: 909-21.

Singh, Jaidev, and Henk van Houtom. 2002. Post-colonial nature conservation in southern Africa: same emperors, new clothes? GeoJournal 58, no. 4: 253-63.

Singleton, Sara. 2002. Collaborative Environmental Planning in the American West: The Good, the Bad and the Ugly. Environmental Politics 11, no. 3: 54-75.

Sinha, C. C., and R. Bushell. 2002. Understanding the Linkage between Biodiversity and Tourism: A Study of Ecotourism in a Coastal Village in Fiji. Pacific Tourism Review 6, no. $1: 35-50$.

Sist, Plinio, Rober Fimbel, Douglas Sheil, Robert Nasi, and Marie-Helene Chevallier. 2003. Towards Sustainable Management of Mixed Dipterocarp Forests of Southeast Asia: Moving Beyond Minimum Diameter Cutting Limits. Environmental Conservation 30, no. 4: 364-74.

Skolleerhorn, Erland. 1998. Habermas and nature: The theory of communicative action for studying environmental policy. Journal of Environmental Planning \& Management 41, no. 5: 555-74.

Smagadi, Aphrodite. 2006. Analysis of the Objectives of the Convention on Biological Diversity: Their Interrelation and Implementation Guidance for Access and Benefit Sharing. Columbia Journal of Environmental Law 31: 243-83.

Smeyers, Paul. 2001. Qualitative Versus Quantitative Research Design: A Plea for Paradigmatic Tolerance in Educational Research. Journal of Philosophy of Education 35, no. 3: 47795.

Smith, Eric Alden, and Mark Wishnie. 2000. Conservation and subsistence in small-scale societies. Annual Review of Anthropology 29 : 493-524.

Smith, K., and F. Biley. 1997. Understanding grounded theory: Principles and evaluation. Nurse Researcher 4, no. 3: 17-30. 
Smith, P. D., and McDonough. 2001. Beyond public participation: fairness in natural resource decision making. Society and Natural Resources 14: 239-49.

Smith, Patrick D., Bir Bahadur Khanal Chhetri, and Bimal Regmi. 2003. Meeting the Needs of Nepal's Poor: Creating Local Criteria Indicators of Community Forestry. Journal of Forestry July/August: 24-30.

Smith, Robert J., and Matthew J. Walpole. 2005. Should conservationists pay more attention to corruption? Oryx 39: 251-56.

Smith, W., T. C. Meredith, and T. Johns. 1996. Use and conservation of woody vegetation by the Batemi of Ngorongoro district, Tanzania. Economic Botany 50: 290-299.

Smith, Wynet. 2002. The Global Problem of Illegal Logging. ITTO Tropical Forest Update December 1: 3-5.

Smythe, Robert, and Caroline Isber. 2003. NEPA in the Agencies: A Critique of Current Practices. Environmental Practices 5, no. 4: 290-297.

Snow. 1996. Coming Home. Chronicle of Community 1, no. 1: 40-43.

Snyder, Laura J. 1998. Is Evidence Historical? In Philosophy of Science: The Central Issues. Eds. Martin Curd \& J. A. Cover, 460-480. New York: W.W. Norton \& Co.

Snyder, Gary. 1990. The Etiquette of Freedom. The Practice of the Wild., 3-24. Emeryville, CA: Shoemaker \& Hoard.

Society for Conservation Biology. 2005. Society for Conservation Biology Code of Ethics. Conservation Biology 19, no. 1: 3.

Sokal, Alan. 1996. A Physicist Experiments with Cultural Studies. Lingua Franca May/June : 62-64.

Songorwa, Alexander N. 1999. Community-Based Wildlife Management (CWM) in Tanzania: Are the Communities Interested? World Development 27, no. 12: 2061-79.

South Africa National Parks. 2002. Policy for the Use of Natural Resources .

South African National Parks. 2006. Coordinated Policy Framework Governing Park Management Plans, South Africa National Parks, Pretoria.

South African National Parks. 2007. Guest Demographics from Gate Access System for Year Ended March 31, 2007. Skukuza, Kruger National Park: Kruger National Park.

Southern Africa Development Community. 1992. Declaration and Treaty of the Southern Africa Development Community. Windhoek, Namibia.

Spaargaren, Gert. 2003. Sustainable Consumption: A Theoretical and Environmental Policy Perspective. Society and Natural Resources 16: 687-701. 
Spenceley, Anna. 2006. Tourism in the Great Limpopo Transfrontier Park. Development Southern Africa 23, no. 5: 649-67.

Spirn, Anne Whiston. 1995. Constructing Nature: The Legacy of Frederick Law Olmsted. In Uncommon Ground: Toward Reinventing Nature. Ed. William Cronon, 91-113. New York: Norton.

Springate-Baginski, Oliver, Om Prakesh Dev, Nagendra Prasad Yadav, and John Soussan. 2003. Community Forest Management in the Middle Hills of Nepal: The Changing Context. Journal of Forest and Livelihood 3, no. 1: 5-20.

Springate-Baginski, Oliver, Nagendra Yadav, Om Prakesh Dev, and John Sousssan. 2003. Institutional Development of Forest User Groups in Nepal: Processes and Indicators. Journal of Forest and Livelihood 3, no. 1: 21-36.

Sprinz, Detlef, and Tapani Vaahtoranta. 1994. The Interest-Based Explanation of Environmental Policy. International Organization 48, no. 1: 77-105.

Stanislav, Andreski. 1964. Method and Substantive Theory in Max Weber. British Journal of Sociology 15, no. 1: 1-18.

Stankey, G. H., D. N. Cole, R. C. Lucas, M. E. Petersen, and S. S. Frissell. 1985. The limits of acceptable change (LAC) system for wilderness planning, Gen. Tech. Rep. INT-176. U. S. Department of Agriculture, Forest Service, Intermountain Forest and Range Experiment Station, Ogden, UT.

Stankey, George H. 1989. Beyond the Campfire's Light: Historical Roots of the Wilderness Concept. Natural Resources Journal 29, no. 1: 9-24.

1997. Institutional Barriers and Opportunities in Application of the Limits of Acceptable Change. Proceedings - Limits of Acceptable Change and Related Planning Processes: progress and future directions. editors S. McCool, and D. Cole, 10-15. Portland, OR: USDA, Forest Service, General Technical Report-371.

Stankey, George H., Roger N. Clark, and Bernard T. Bormann. 2005. Adaptive Management of Natural Resources: Theory, Concepts, and Management Institutions, PNW-GTR-654. Pacific Northwest Research Station, USDA Forest Service, Corvalis, OR.

Stankey, George H., Stephen F. McCool, and Gerald L. Stokes. 1984. Limits of Acceptable Change: A New Framework for Managing the Bob Marshall Wilderness Complex. Western Wildlands 10, no. 3: 33-37.

Stea, David. 2002. Public Participation and the Active, Critical Citizen: Another View . Geography, Culture and Education., 169-78. Vol. 71. Dordrecht, Netherlands: Kluwer Academic Publishers.

Steel, Brent S., John C. Pierce, and Nicholas P. Lovrich. 1996. Resources and Strategies of Interest Groups and Industry Representatives Involved in Federal Forest Policy. Social 
Science Journal 33, no. 4: 401-19.

Steen, Harold K. 1976. The U.S. Forest Service: A History. Seattle, WA: University of Washington Press.

Stein, Stanley M., and Thomas L. Harper. 2003. Power, Trust and Planning. Journal of Planning Education and Research 29: 125-39.

Steinberg, Paul F. 2004. New Approaches to Causal Analysis in Policy Research. Paper Presented at the Annual Meeting of the Political Science Association.

Stephens, Scott L., and Jason J. Moghaddas. 2005. Experimental Fuel Treatment Impacts on Forest Structure, Potential Fire Behavior, and Predicted Tree Mortality in a California Mixed Conifer Forest. Forest Ecology and Management in press.

Stern, P. C. 2000. Psychology and the science of human-environment interactions. American Psychologist 55: 523-50.

Stern, Paul C., Thomas Dietz, and Elinor Ostrom. 2002. Research on the Commons: Lessons for Environmental Resource Managers. Environmental Practice 4, no. 2: 61-64.

Stevens, S. 1997. Conservation through Cultural Survival: Indigenous Peoples and Protected Areas . Washington, D.C.: Island Press Books.

Stevens, Sharon McKenzie. October 2003. Community Stewardship and Inclusive Decisionmaking. Science and Public Policy: 383-85.

Stevenson, Fiona, Nicky Britten, Christine A. Barry, Colin P. Bradley, and Nick Barber. 2002. Perceptions of legitimacy: the influence on medicine taking and prescribing. Health: An Interdisciplinary Journal Fo Rthe Social Study of Health, Illness \& Medicine 6, no. 1: 85104.

Stevenson-Hamilton, James. 1946. General Report on Kruger National Park.

Stevenson-Hamilton, James. 1937. South Africa Eden. London: Cassell and Co.

Stewart, M., and B. Weidema. 2005. A Consistent Framework for Assessing the Impacts of Resource Use. A focus on resource functionality. International Journal of Life Cycle Assessment 10, no. 4: 240-247.

Steyn, L. 1957. Annual Report of the Warden of Kruger National Park.

The Way Ahead. 2002. Globalization and its Discontents. Joseph E. Stiglitz, 214-29. New York: WW Norton.

Stillman, Peter G. 1974. The Concept of Legitimacy. Polity 7, no. 1: 32-56.

Stoll-Dleemann, Susanne \& O'Riordan Timothy. 2002. From Participation to Partnership in Biodiversity Protection: Experience from Germany and South Africa. Society and 
Natural Resources 15: 161-77.

Stone, G. D. 1993. Agriculture Abandonment: A Comparative Study in Historical Ecology. Abandonment of Settlements and Regions: Ethnoarchaeological and Archaeological Approaches. editors C. Cameron, and S. TomkaCambridge: Cambridge University Press.

Strauss, Anselm, and Juliet Corbin. 1998. Basics of Qualitative Research: Techniques and Procedures for Developing Grounded Theory. Thousand Oaks, CA: Sage Publications.

1990. Grounded Theory: Introduction. Anselm \& Corbin Strauss, 17-32.

Strauss, David A. 2005. Legitimacy and Obedience. Harvard Law Review 118, no. 6: 1854-66.

Strauss, Leo. 1953. Natural Right and History. Chicago: The University of Chicago Press.

Streever, W. J., and M. Callaghan-Perry. 1998. Public attitudes and values for wetland conservation in New South Wales, Australia. Journal of Environmental Management 54, no. 1: 1-13.

Struhsaker, Thomas T., Paul J. Struhsaker, and Kirstin S. Siex. 2005. Conserving Africa's rain forests: problems in protected areas and possible solutions. Biological Conservation 123: 45-54.

Stryber, R. 2001. Legitimacy. In International Encyclopedia of the Social \& Behavioral Sciences. Eds. N. J. Smelser, and P. B. Baltes, 8700-8704. New York: Elsevier Science Ltd.

Stryker, Robin. 1994. Rules, Resources, and Legitimacy Processes: Some Implications for Social Conflict, Order, and Change. The American Journal of Sociology 99, no. 4: 847-910.

Suchman, Mark. 1995. Managing Legitimacy: strategic and institutional approaches. Academy of Management Review 20, no. 3: 571-610.

Sullivan, Helen. 2003. Book Review: Public Participation and Innovation in Community Governance. Local Government Studies 29, no. 1: 130-131.

Sutter, Paul S. 2002. Driven Wild. Seattle, WA : University of Washington Press.

Svatek, M. 2004. Landscape-ecological approach to state and management evaluation of protected areas. Ecology 23, no. 1: 340-350.

Swanson, Timothy. 1999. Why is there a biodiversity convention? The international interest in centralized development planning. International Affairs 75, no. 2: 307-31.

Swatuk, Larry A. 2005. From "Project" to "Context": Community Based Natural Resource Management in Botswana. Global Environmental Politics 5, no. 3: 95-124.

- 2005. Political Challenges to Implementing IWRM in Southern Africa. Physics and Chemistry of the Earth 30, no. 11-16: 872-80. 
Swiderska, Krystyna. 2002. Implementing the Rio Conventions: Implications for the South. London: Internation Institute for Environment and Development.

Swingland, Ian R. 1995. Commercialization, structure and sustainability of biodiversity conservation. in Integrated Protected Area Management. Eds. Mike Walley, Ian Swingland, and Shaun RusselNew York: Springer.

Tabachnick, Barbara G., and Linda S. Fidell. 1996. Using Multivariate Statistics. New York: Harper Collins.

Taff, Gregory. 2005. Conflict between Global and Local Land-Use Values in Latvia's Gauja National Park. Landscape Research 30, no. 3: 415-30.

Talisse, Robert B. 2004. Introduction: Pragmatism and Deliberative Politics. Journal of Speculative Philosophy 18, no. 1: 1-8.

Tanner, Randy. 2003. Special Provisions in Federally Designated Wilderness, Wilderness Watch, Missoula, MT.

Tanner, Randy J. In review. Campsite Impacts in the Bob Marshall Wilderness Complex: An Empirical Analysis of Monitoring from 1987 through 2004. International Journal of Wilderness .

Tanner, Randy J. (In Press). Wilderness and the Paradox of Individual Freedom. In Science and Stewardship to Protecte and Sustain Wilderness Values: Eighth World Wilderness Congress Symposium, Comps. Alan Watson, Liese Dean, and Janet SproullFort Collins, CO: U.S. Department of Agriculture, Forest Service, Rocky Mountain Research Station.

Tarrant, M. A., H. K. Cordell, and G. T. Green. 2003. A scale to measure public values of forests. Journal of Forestry 102: 24-30.

Taylor, Charles. 1981. Growth, Legitimacy and the Modern Identity. Praxis International 1: 111-25.

—. 2004. Modern Social Imaginaries. Durham, N. C.: Duke University Press.

Taylor, Dorceta E. 2000. The Rise of the Environmental Justice Paradigm: Injustice Framing and the Social Construction of Environmental Discourses. American Behovioral Scientist 43, no. 4: 508-80.

Taylor, James R. 2001. The "Rational" Organization Reconsidered: An Exploration of Some of the Organizational Implications of Self-Organizing. Communication Theory 11, no. 2: 137-77.

Taylor, Michael. 1998. Governing natural resources. Society and Natural Resources 11, no. 3: 251-57.

Tebble, Adam James. 2003. Does Inclusion Require Democracy? Political Studies 51: 197-214. 
Teich, Gretchen M. R., Jacqueline Vaughn, and Hanna J. Cortner. 2004. National Trends in the Use of Forest Service Administrative Appeals. Journal of Forestry March: 14-19.

Temple, Bogusia. 1997. Watch Your Tongue: Issues in Translation and Cross-Cultural Research. Sociology 31, no. 3: 607-18.

Terborgh, J. 2000. The fate of tropical forests: a matter of stewardship. Conservation Biology 14: 1358-61.

- 2004. Reflections of a Scientist on the World Parks Congress. Conservation Biology 18, no. 3: 619-20.

- 1999. Requiem for Nature. Washington, D.C. Island Press.

Thagard, Paul R. 1978. Why Astrology is a Pseudoscience. In Proceedings of the Philosophy of Science Association. Eds. P. Asquith, and I. Hacking, 223-34. Vol. Vol. I. East Lansing, MI: Philosophy of Science Association.

The Corner House. 2004. How Northern Donors Promote Corruption: Tales from the New Mozambique. The Corner House Briefing October, no. 33: 1-12.

The New Partnership for Africa's Development . 2001. The New Partnership for Africa's Development Charter.

Theunissen, Michael. 1999. Society and history: a critique of Critical Theory. In Habermas: A Critical Reader. Ed. Peter Dews, 241-71. Malden, MA: Blackwell Publishers.

Thompson, J. L. 1987. Critical scholarship: the critique of domination in nursing. Advances in Nursing Science 10, no. 1: 27-38.

Three Pair List. 2003. " Latest News and Efforts from the Government Accountability ProjectForest Service whistleblowers vindicated after nine years!" Web page, [accessed 17 February 2006]. Available at http://three.pairlist.net/pipermail/gap-general-list/2003April/000021.html.

Tidy Jr., Stanley H. 1959. "Bureaucracy" and "Rationality" in Weber's Organization Theory: An Empirical Study. American Sociological Review 24, no. 6: 791-95.

Tiffen, M., M. Mortimore, and F. Gichuki. 1994. More people, less erosion: environmental recovery in Kenya. Chichester: John Wiley and Sons.

Timsina, Netra Prasad. 2003. Promoting Social Justice and Conserving Montane Forest Environments: A case study of Nepal's community forestry programme. The Geographical Journal 169, no. 3: 236-43.

Tisdell, Clem. 1997. Local Communities, conservation and sustainability: institutional change, alterned governance and Kant's social philosophy. International Journal of Social Economics 24, no. 12: 1361-75. 
Tisdell, Clement. 2005. Economic Incentives to Conserve Wildlife on Private Lands: Analysis and Policy. The Environmentalist 24, no. 3: 153-63.

Todd, Susan. 2002. Building Consensus on Divisive Issues: A case study of the Yukon wolf management team. Environmental Impact Assessement Review 22: 655-84.

ToppJ??rgensen, E., M. K. Poulsen, J. F. Lund, and J. F. Massao. 2005. Community-based Monitoring of Natural Resource Use and Forest Quality in Montane Forests and Miombo Woodlands of Tanzania. Biodiversity and Conservation 14, no. 11: 2653-77.

Toutain, Bernard, Marie-Noel Visscher, and Dominique Dulieu. 2004. Pastoralism and Protected Areas: Lessons Learned from Western Africa. Human Dimensions of Wildlife 9, no. 4: 287-95.

Trombulak, Stephen C., Kristian S. Omland, Julie A. Robinson, Jeffrey J. Lusk, Thomas L. Fleischner, Glenn Brown, and Meg Domrose. 2004. Principles of Conservation Biology: Recommended guidelines for conservation literacy from the education committee of the Society for Conservation Biology. Conservation Biology 18, no. 5: 1180-1190.

Tschirley, David L., and Rui Benfica. 2001. Smallholder agriculture, wage labour and rural poverty alleviation in land-abundant areas of africa: evidence from mozambique. Journal of Modern African Studies 39, no. 2: 333-58.

Tsie, Balefi. 1996. States and Markets in the Southern African Development Communtiy (SADC): Beyond the Neo-Liberal . Journal of Southern African Studies 22, no. 1.

Tsing et al. 1999. Assessing community-based natural resource management. Ambio 28, no. 2: 197.

A Consuming Passion: The United States as Exploiters of Tropical Nature. 2000. Insatiable Appetite: The United States and the Ecological Degredation of the Tropical World. R. Tucker , 1-11, 380-389. Berkeley, CA: University of California Press.

Tucker, Robert W., and David C. Hendrickson. 2004. The Sources of American Legitimacy. Foreign Affairs 83, no. 6: 18-33.

Tuler, S., and T. Weber. 1999. Voices from the forest: What participants expect of a public participation process. Society \& Natural Resources 12: 437-53.

Turner, Frederick J. 1896. The Problem of the West. Atlantic Monthly, no. September: 289-97.

Turner, Jack. 1996. The Abstract Wild: A Rant. The Abstract Wild. Jack Turner, 19-37. Tucson, AZ: University of Arizona Press.

Turner, Matthew D. 1999. Conflict, Environmental Change, and Social Institutions in Dryland Africa: Limitations of the Community Resource Management Approach. Society and Natural Resources 12: 643-57. 
Turner, Matthew W. 2000. Managing Multiple Activities in a National Park. Land Economics 76, no. 3: 474-85.

Twine, W., D. Moshe, T. Netshiluvhi, and V. Siphugu. 2003. Consumption and direct-use values of savanna bio-resources used by rural households in Mametja, a semi-arid area of Limpopo province, South Africa. South African Journal of Science 99, no. 9/10: 467-72.

Twine, W. C. 2005. Socio-economic transitions influence vegetation change in the communal rangelands of the South African lowveld. African Journal of Range and Forage Science 22, no. 2: 93-100.

Twine, Wayne, Victor Siphugu, and Dineo Moshe. 2003. Harvesting of Communal Resources by 'Outsiders' in Rural South Africa: A Case of Xenophobia or a Real Threat to Sustainability. International Journal of Sustainable Development and World Ecology 10 : 263-74.

Twyman, Chasca. 2000. Livelihood Opportunity and Diversity in Kalahari Wildlife Management Areas, Botswana: Rethinking Community Resource Management. Journal of Southern African Studies 26, no. 4: 783-806.

. 2001. Natural resource use and livelihoods in Botswana's Wildlife Management Areas. Applied Geography 21, no. 1: 45-68.

- 2000. Participatory community-based natural resource management. The Geographical Journal 16, no. 4: 323.

- 2000. Participatory conservation? Community-based natural resource management in Botswana. The Geographical Journal 166, no. 4: 323-35.

Twyman, Chasca. 1998. Rethinking community resource management: managing resources or managing people in western Botswana. Third World Quarterly 19, no. 4: 745-70.

Tyler, T. R. 1990. Why people obey the law. New Haven, C. T.: Yale University Press.

Tyler, T. R., and G. Mitchell. 1994. Legitimacy and the empowerment of discretionary legal authority: The United States Supreme Court and abortion rights. Duke Law Journal 43: 703-815.

Tyler, Tom R. 2006. Psychological perspectives on legitimacy and legitimation. Annual Review of Psychology 57, no. 1: 375-400.

- 1997. The Psychology of Legitimacy: A Relational Perspective on Voluntary Deference to Authorities. Personality and Social Psychology Review 1, no. 4: 323-45.

Ulph, Alistair. 1998. Political Institutions and the Design of Environmental Policy in a Federal System with Asymmetric Information. European Economic Review 42: 583-92.

UNCE. 1972. Declaration of the United Nations Conference on the Human Environment. 
Stockholm.

United Nations. 1992. Convention on Biological Diversity. Rio de Janeiro, Brazil.

-1995. United Nations Convention to Combat Desertification in those countries experiencing serious drought and/or desertification, particularly Africa. Text with annexes. Geneva: UNEP/CCD.

United Nations Conference on Environment and Development . 1992. Rio Declaration on Environment and Development. Rio De Janeiro: United Nations Conference on Environment and Development.

United States Congress. 1864. An Act Authorizing a grant to the State of California of the "YoSemite Valley," and of the land embracing the "Mariposa Big Tree Grove".

United States Department of Agriculture . 1987. Bob Marshall, Great Bear, Scapegoat Wildernesses: Recreation Management Direction.United States Department of Agriculture, Forest Service, Flathead, Lolo, Helena, Lewis \& Clark National Forests.

United States Forest Service. 2004. Bob Marshall Wilderness Complex LAC Monitoring Guidebook. United States Deparment of Agriculture, Forest Service.

—. 2005. National Forest System Land Management Planning. Washington, D.C..

Unruh, Jon D. 2001. Land Dispute Resolution in Mozambique: Institutions and Evidence of Agroforestry Technology Adoption. Washington D.C.: International Food Policy Research Institute.

Unruh, Jon D. 1994. The Role of Land Use Pattern and Process in the Diffusion of Valuable Tree Species. Journal of Biogeography 21: 283-95.

Unruh, Jon D., Nikolas C. Heynen, and Peter Hossler. 2003. The political ecology of recovery from armed conflict: the case of landmines in mozambique. Political Geography 22, no. 8: 841-61.

Uphoff, Norman. 1989. Distinguishing Power, Authority \& Legitimacy: Taking Max Weber at his Word by Using Resources-Exchange Analysis. Polity 22, no. 2: 295-322.

Usongo, Leonard, and Bertin Tchihangwa Nkanje. 2004. Participatory approaches towards forest conservation: The case of Lobéké National Park, Southeast Cameroon. International Journal for Sustainable Development \& World Ecology 11, no. 2: 119-27.

Valadez, Jorge. 2000. Deliberative Democracy, Political Legitimacy, and Self-Determination in Multicultural Societies. Boulder, CO: Westview Press.

van Aarde, Rudi, Ian Whyte, and Stuart Pimm. 1999. Culling and the dynamics of the Kruger National Park Elephant Population. Animal Conservation 2, no. 4: 287-94. 
van Amerom, M. and B. Buscher. 2004. Peace Parks in Southern Africa: Bringers of an African Renaissance? Journal of Modern African Studies 43, no. 2: 159-82.

van Amerom, Marloes. 2002. National sovereignty \& transboundary protected areas in southern Africa. GeoJournal 58, no. 4: 265-73.

van Amerom, Marloes, and Bram Buscher. 2005. Peace parks in southern africa: bringers of an african renaissance? Journal of Modern African Studies 43, no. 2: 159-82.

van Knippenberg, Barbara, Daan van Knippenberg, and David De Cremer. 2007. Why people resort to coercion: the role of utility and legitimacy. European Journal of Social Psychology 37, no. 2: 276-87.

1983. The Moral Fix: On the Ethics of Fieldwork. John Van Maanen, 269-87.

van Schaik, C. P., and R. A. Kramer. 1997. Toward a New Protection Paradigm. In Last Stand: Protected areas and the defense of tropical biodiversity . Eds. R. A. Kramer, C. P. van Schaik, and J. Johnson, 212-30. New York: Oxford University Press.

van, Schaik C. P., J. Terborgh, and B. Dugelby. 1997. The silent crisis: The state of rain forest nature preserves. In Last stand: Protected areas and the defense of tropical biodiversity. Eds. R. A. Kramer, C. P. van Schaik, and J. Johnson, 64-89. New York: Oxford University Press.

Vanderheiden, Steve. 2002. Rousseau, Cronon, and the Wilderness Idea. Environmental Ethics 24, no. 2: 169-88.

Vandermeer, John, and Ivette Perfecto. 1995. Rethinking Rain Forests: Biodiversity and Social Justice. Backgrounder Summer: 1-8.

Varettoni, william, and Jeremy S. Boss. 2005. Communities and Science: Paths to Sustainability in East Africa? Global Environmental Politics 5, no. 3: 125-30.

Vaske, Jerry J., and Maureen P. Donnelly. 1999. A value-attitude-behavior model predicting wildland preservations voting intentions. Society \& Natural Resources 12, no. 6: 523-37.

Vaske, Jerry J., Alan R. Graefe, Bo Shelby, and Thomas A. Herberlein. 1986. Backcountry Encounter Norms: Theory, Method, and Empirical Evidence. Journal of Leisure Research 18, no. 3: 137-53.

Vaske, Jerry J., Mark D. Needham, and Robert C. Cline Jr. 2007. Clarifying Interpersonal and Social Values Conflict among Recreationists. Journal of Leisure Research 39, no. 1: 18295.

Vaughn, Jacqueline, and Hanna Cortner. 2004. Using Parallel Strategies to Promote Change: Forest Policymaking under George W. Bush. Review of Policy Research 21, no. 6: $767-$ 82. 
Vayda, Andrew P. \& Walters Bradley B. 1999. Against Political Ecology. Human Ecology 27, no. 1: 167-79.

Veblen, Thomas T. 2003. "Key Issues in Fire Regime Research for Fuels Management and Ecological Restoration." Fire Regime Considerations, RMRS-P-29. USDA Forest Service, Rocky Mountain Research Station, Fort Collins, CO.

Victor, David. 1999. Enforcing international law: Implications for an effective global warming regime. Duke Environmental Law and Policy Forum 10, no. 1: 147.

Vining, Joanne, and Carol D. Saunders. 2004. Conservation Psychology. In Society and Natural Resources: A Summary of Knowledge . Eds. Michael J. Manfredo, Jerry J. Vaske, Brett L. Bruyere, Donald R. Field, and Perry J. Brown, 46-57. Jefferson, MO: Modern Litho.

Volkema, Roger J. 1995. Creativity in MS/OR: Managing the Process of Formulating the Problem. Interfaces 25, no. 3: 81-87.

Wadsworth, Yoland. 1998. What is Participatory Action Research?, Action Research International.

Wainwright, Carla \& Wehrmeyer Walter. 1998. Success in Integrating Conservation and Development? A Study from Zambia. World Development 26, no. 6: 933-44.

Waitzkin, Howard. 1989. A Critical Theory of Medical Discourse: Ideology, Social Control, and the Processing of Social Context in Medical Encounters. Journal of Health and Social Behavior 30, no. 2: 220-239.

Walker, Brian, Stephen Carpenter, John Anderies, Nick Abel, Graeme Cumming, Marco Janssen, Louis Lebel, Jon Norberg, and Garry \& Pritchard Rusty Peterson. 2002. Resilience Management in Social-ecological Systems: a Working Hypothesis for a Participatory Approach. Conservation Ecology 6, no. 1.

Walker, Peter A. 2003. Reconsidering 'regional' political ecologies: toward a political ecology of the rural American West. Progress in Human Geography 27, no. 1: 7-24.

Walker, Peter A., and Pauline E. Peters. 2001. Maps, Metaphors, and Meanings: Boundary Struggles and Village Forest Use on Private and State Land in Malawi. Society and Natural Resources 14: 411-24.

Walker, Peter \& Fortmann Louise. 2003. Whose Lanscape: A political ecology of the 'exurban' Sierra. Cultural Geographies 10: 469-91.

Wallace, M. G., M. A. Cortner, and S. Moote. 1996. Moving toward ecosystem management: examining a change in philosophy for resource management. Journal of Political Ecology 3: $1-36$.

Wallace, Walter. 1990. Rationality, human nature, and society in Weber's theory. Theory \& Society 19, no. 2: 199-223. 
Wallerstein, Immanuel. 1974. The Rise and Future Demise of the World Capitalist System: Concepts for Comparative Analysis. Comparative Studies in Society and History 16, no. 4: 387-415.

1993. The World-System after the Cold War. Journal of Peace Research 30, no. 1: 1-6.

Waltz, Kenneth N. 1993. The Emerging Structure of International Politics. International Security 18, no. 2: 44-79.

- 1959. Man, the State and War: A Theoretical Analysis. New York: Columbia University Press.

Warner, K. 2000. Forestry and Sustainable Livelihoods. Unasylvia 51, no. 202: 3-12.

Warren, Greg A. 1997. Recreation Management in the Bob Marshall, Great Bear, and Scapegoat Wildernesses: 1987-1997. In Proceedings - Limits of Acceptable Change and Related Planning Processes: Progress and Future Directions, Eds. Stephen F. McCool, and David N. Cole, 21-24no. INT-GTR-371. Ogden, UT: U.S. Department of Agriculture, Forest Service, Rocky Mountain Research Station.

Warren, Kenneth F. 1993. We have Debated Ad Nauseam the Legitimacy of the Administrative State - But Why? Public Aministration Review 53, no. 3: 249-54.

Watson, Alan, and David Cole. 1992. LAC Indicators: An Evaluation of Progress and List of Proposed Indicators. Ideas for Limits of Acceptable Change Process: Book Two Linda MeriglianoWashington, DC: U.S. Department of Agriculture, Forest Service.

Watson, Alan E. Why is it Important to Monitor Social Conditions in Wilderness? Managing America's Enduring Wilderness Resource.

Watson, Alan E., and Lilian \& Sproull Janet Alessa. 2002. Wilderness in the Circumpolar North: Searching for Compatiblity in Ecological, Traditional, and Ecotourism Values. Perspectives on Wilderness in the ArcticDavid R. Klein. Rocky Mountain Research Station P-26, Ogden, UT: USDA, Forest Service, Rocky Mountain Research Station.

Watson, Alan E., and Gamini Herath. 1999. Research Implications of the Theme Issues "Recreation Fees and Pricing Issues in the Public Sector" (Journal of Park and Recreation Administration) and "Societal Responses to Recreation Fees on Public Lands" (Journal of Leisure Research). Journal of Leisure Research 31, no. 3: 325-34.

Watts, Michael. 2001. Petro-Violence: Community, Extraction, and Political Ecology of a Mythic Commodity. Violent Environments. Nancy Lee Peluso, and Michael Watts, 189213. Ithaca, NY: Cornell University Press.

- 2000. Political Ecology. A Companion to Economic Geography. editors E. Sheppard, and T. J. Barnes, 257-74. Ames, IA : Blackwell Publishing.

Weatherford, M. Stephen. 1992. Measuring Political Legitimacy. American Political Science 
Review 86, no. 1: 149-66.

Weaver, David B. 1998. Ecotourism in Nepal. Ecotourism in the Less Developed World.New York, NY: CAB International.

Weber, Edward P. 1999. The Question of Accountability in Historical Perspective: From Jackson to contemporary grassroots ecosystem management. Administration \& Society 31, no. 4: 451-94.

Weber, Linda R., and Allison Carter. 1998. On Constructing Trust: Temporality, Self-Disclosure, and Perspective-Taking. International Journal of Sociology and Social Policy 18, no. 1: $7-26$.

Weber, Max. 1986. Economy and Society. Berkeley, CA: University of California Press.

Weber, Max. 1949. The Methodology of the Social Sciences. Glencoe, IL: Free Press. 1997. Theory of Social and Economic Organization. New York: Simon \& Schuster.

Weeks, John. 1996. Regional cooperation and southern African development. Journal of Southern African Studies 22, no. 1: 99-117.

Weidema, B., G. Finnveden, and M. Stewart. 2005. Impacts from Resource Use: A common position paper. International Journal of Life Cycle Assessment 10, no. 6: 382.

Weisfelder, Richard F. 1992. Lesotho and the inner periphery of the new South Africa. The Journal of Modern African Studies 30, no. 4: 643-68.

Weiss, E. and H. Jacobson. 1999. Getting countries to comply with international agreements (includes related articles). Environment 41, no. 6: 16.

Weladji, Robert B., and Martin N. Tchamba. 2003. Conflict between people and protected areas within the Benoue Wildlife Conservation Area, North Cameroon. Oryx 32: 72-79.

Wellman, Christopher. 1996. Liberalism, Samaritanism, and Political Legitimacy. Philosophy and Public Affairs 25, no. 3: 211-37.

Wellman, J. Douglas, and Dennis B. Probst. 2004. Wildland Recreation Policy. 2nd ed. Malabar, Florida: Krieger Publishing Company.

Wells, M., K. Brandon, and L. Hannah. 1992. People and Parks: Linking Protected Area Managment with Local Communities. Washington, D.C. The World Bank.

Wellstead, Adam M., Richard C. Stedman, and John R. Parkins. 2003. Understanding the Concept of Representation within the Context of Local Forest Management Decision Making. Forest Policy and Economics 5: 1-11.

West, Harry G., and Gregory W. Myers. 1996. A Piece of Land in a Land of Peace? State Farm Divestiture in Mozambique. Journal of Modern African Studies 34, no. 1:27-51. 
West, P. C., and S. R. Brechin, Eds. 1991. Resident Peoples and National Parks. Tucson, AZ: University of Arizona Press.

West, Paige, and Dan Brockington. 2006. An Anthropological Perspective on Some Unexpected Consequences of Protected Areas. Conservation Biology 20, no. 3: 609-16.

West, Patrick C., Crystal L. Fortwangler, Valentin Agbo, Micahel Simsik, and Nestor Sokpon. 2003. The Political Economy of Ecotourism: Pendjari National Park and Ecotourism Concentration in Northern Benin. Contested Nature: Promoting International Biodiversity in the Twenty-First Century. editors SR Brechin, PR Wilshusen, Crystal L. Fortwangler, and Patrick C. West, 103-15. SUNY Press.

West, William F. 2004. Formal Procedures, Informal Processes, Accountability, and Responsiveness in Bureaucratic Policy Making: An Institutional Policy Analysis. Public Administration Review 64, no. 1: 66-80.

Western, David. 2003. Conservation science in Africa and the role of international collaboration. Conservation Biology 17, no. 1: 11-19.

Westing, A. H. 1998. Establishment and management of transfrontier reserves for conflict prevention and confidence building. Environmental Conservation 25, no. 2: 91-94.

Wheeler, Brett R. 2001. Law and Legitimacy in the Work of Jürgen Habermas and Carl Schmitt. Ethics \& International Affairs 15, no. 1: 173-83.

White, Richard. 1999. "Are You an Environmentalist or Do You Work for a Living?": Work and Nature. Uncommon Ground: Rethinking the Human Place in Nature. editor William Cronon, 171-85. New York: W.W. Norton.

Whitten, Holmes D., and K. Mackinnon. 2001. Conservation Biology: A Displacement Behavior for Academia? Conservation Biology 15, no. 1: 1-3.

Whyte, Ian, Rudi van Aarde, and Stuart L. Pimm. 1998. Managing the Elephants of Kruger National Park. Animal Conservation, no. 1: 77-83.

Whyte, Ian J., Rudi J. van Aarde, and Stuart L. Pimm. 2003. Kruger's Elephant Population: Its Size and Consequences for Ecosystem Heterogeneity. in The Kruger Experience:

Ecology and Management of Savanna Heterogeneity. Eds Johan T Du Toit, Kevin H. Rogers, and Harry C. BiggsWashington, D.C.: Island Press.

Wiersum, K. F., and C. Shackleton. 2005. Rural dynamics and biodiversity conservation in Southern Africa. African Studies 81: 67-94.

Wiersum, K. F., R. Singhal, and C. Beneker. 2004. Common Property and Collaborative Forest Management: Rural Dynamics and Evolution in Community Forestry Regimes. Forests, Tress and Livelihoods 14: 281-93.

Wiggershaus, Rolf. 1994. The Frankfurt School: its history, theories, and political significance. 
Cambridge, MA: MIT Press.

Wiggins, Steve, Kofi Marfo, and Vincent Anchirinah. 2004. Protecting the Forest or the People? Environmental Policies and Livelihoods in the Forest Margins of Southern Ghana. World Development 32, no. 11: 1939-55.

Wikramanayake, Eric, Eric Dinerstein, Colby Louks, David Olson, John Morrison, John Lamoreux, Meghan McKnight, and Prashant Hedao. 2002. Ecoregions in Ascendance: Reply to Jepson and Whittaker. Conservation Biology 16, no. 1: 238-43.

Wilderness Watch. "Motorized Use: Alaska Provisions." Web page, [accessed 30 August 2005].

Wilkie, David, Gilda A. Morelli, Josefien Demmer, Malcolm Starkey, Paul Telfer, and Matthew Steil. 2006. Parks and People: Assessing the Human Welfare Effects of Establishing Protected Areas for Biodiversity Conservation. Conservation Biology 20, no. 1: 247-49.

Wilkinson, Charles F. 1997. The National Forest Management Act: The Twenty Years Behind, The Twenty Years Ahead. University of Colorado Law Review 68: 660-682.

Wilkinson, Todd. 1998. Science under Siege: The Politicians' war on Nature and Truth. Boulder, CO: Johnson Books .

Willers, Bill. 2001. The Postmodern Attack on Wilderness. Natural Areas Journal 21, no. 3: 259-65.

Williams, D., J. Roggenbuck, M. Patterson, and A. Watson. 1992. The variability of user-based social impact standards for wilderness management. Forest Science 38: 738-56.

Williams, Dan, and Michael Patterson. 1996. Environmental meaning and ecosystem management: perspectives from environmental psychology and human geography. Society and Natural Resources 9: 507-21.

Williams, Daniel R. 2002. Social Construction of Arctic Wilderness: Place Meanings, Value Pluralism, and Globalization. In Wilderness in the Circumpolar North: searching for compatability in ecological, traditional, and ecotourism values, Comps. Alan e. Watson, Lilian Alessa, and Janet Sproullno. RMRS-P-26. Ogden, UT: U.S. Department of Agriculture, Forest Service, Rocky Mountain Research Station.

Williams, Daniel R., Christine A. Vogt, and Joar Vitterso. 1999. Structural Equation Modeling of Users' Response to Wilderness Recreation Fees. Journal of Leisure Research 31, no. 3: 245-68.

Williams, Daniel R. and Jerry J. Vaske. 2003. The Measurement of Place Attachment: Validity and Generalizability of a Psychometric Approach. Forest Science 49, no. 6: 830-40.

Williams, James. 2005. Hunting and the Royal Image of Henry VIII. Sport in History 25, no. 1: 41-59. 
Willis, K. J., L. Gillson, and T. M. Brncic. 2004. How "Virgin" Is Virgin Rainforest? Science 304: 402-3.

Wilshusen, Peter R. 2003. Exploring the Political Contours of Conservation: A conceptual view of power in practice. Contested Nature: Promoting International Biodiversity and Social Justice in the Twenty-first Century . editors Steven R. Brechin, Crystal L. Fortwangler, Patrick C. West, and Peter R. Wilshusen, 41-57. Albany, NY: SUNY Press.

Wilshusen, Peter R., Steven Brechin, Crystal Fortwangler, and Patrick C. West. 2003. Contested Nature. in Contested Nature: Promoting International Biodiversity with Social Justice in the Twenty-First Century . Eds. Steven R. Peter R. Wilshusen Crystal L Fortwangler and Patrick C. West Brechin. Albany: State University of New York Press.

Wilshusen, Peter R., Steven R. Brechin, Crystal L. Forrtwangler, and West Patrick C. 2002. Reinventing a Square Wheel: Critique of a Resurgent "Protection Paradigm" in International Biodiversity Conservation. Society and Natural Resources 15, no. 1: 17-40.

Wilshusen, Peter R., Steven R. Brechin, Crystal L. Fortwangler, and Patrick C. West. 2003. Contested Nature: Consevation and Development at the Turn of the Twenty-first Century. Contested Nature: Promoting International Biodiversity and Social Justice in the Twentyfirst Century. editors Steven R. Brechin, Crystal L. Fortwangler, Patrick C. West, and Peter R. Wilshusen, 1-22. Albany, NY: State University of New York Press.

Wilshusen, Peter R., Patrick C. West, and Crystal L. Fortwangler. 2003. Contested Nature: Promoting International Biodiversity with Social Justice in the 21st Century. Albany, NY: SUNY Press.

Wilson, Randall K. 1999. 'Placing Nature': The Politics of Collaboration and Representation in the Struggle for La Sierra in San Luis, Colorado. Ecumene 6, no. 1: 1-28.

Winter, Caroline. 2005. Preferences and Values for Forests and Wetlands: A Comparison of Farmers, Environmentalists, and the General Public in Australia. Society and Natural Resources 18, no. 6: 541-55.

Winter, Patricia L., Laura J. Palucki, and Rachel L. Burkhardt. 1999. Anticipated Responses to a Fee Program: The Key is Trust. Journal of Leisure Research 31, no. 3: 207-26.

Witter, Rebecca C., and Divy Mavasa. Agroforestry, Trees, and the Cultural Landscape of the Limpopo National Park, Mozambique. World Agroforestry Center and the Transboundary Protected Areas Research Initiative.

Wittkopf, Eugene R. 1994. Faces of internationalism in a transnational environment. The Journal of Conflict Resolution 38, no. 3: 376-401.

Wobst, Peter. 2003. The impact of domestic and global trade liberalisation on five southern african countries. Journal of Development Studies 40, no. 2: 70-92.

Wohlforth, William C. 1999. The Stability of a Unipolar World. International Security 24, no. 
1: 5-41.

Wollenberg, Eva, David Edmunds, and Louise Buck. 2000. Using Scenarios to Make Decision About the Future: Anticipatory Learning for the Adaptive Co-Management of Community Forests. Landscape and Urban Planning 47: 65-77.

Wolmer, William. 2003. Transboundary Conservation: the Politics of Ecological Integrity in the Great Limpopo Transfrontier Park. Journal of Southern African Studies 29, no. 1: 261-78.

Wondolleck, Julia M., and Steven L. Yaffee. 2000. Making Collaboration Work: Lessons from Innovation in Natural Resource Management . Washington, D.C.: Island Press.

Wong, Day. 2005. Foucault Contra Habermas: Enlightenment, Power, and Critique. Philosophy Today 49, no. 1: 55-69.

Wood, B. Dan, and Alesha Doan. 2003. The Politics of Problem Definition: Applying and Testing Threshold Models. American Journal of Political Science 47, no. 4: 640-653.

Wood, E. 2001. Global Advances in Conservation Management of Marine Ornamental Resources. Aquarium Sciences and Conservation.

Woodhouse, Philip. 1995. Water rights and rural restructuring in south africa: a case study from eastern transvaal. International Journal of Water Resources Development 11, no. 4: 527 44.

World Commission on Environment and Development. 1987. Our common future: report of the World Commission on Environment and Development. Oxford: Oxford University Press.

2003. Tourism Highlights , World Tourism Organization. World Tourism Organization, Madrid, Spain.

World Watch. 2005. From Readers. 5-20. Washington, D. C.: World Watch Institute.

Wright, Geroge \& Goodwin Paul. 1999. Future-Focussed Thinking: Combining Scenario Planning with Decision Analysis. Journal of Multi-Criteria Decision Analysis 8: 311-21.

Wynne, Brian. 1996. Misunderstood Misunderstandings: social identities and public uptake of science. Misunderstanding Science: The public Reconstruction of Science and Technology. editors Alan Irwin, and Brian Wynne, 19-46. Cambridge: Cambridge University Press.

Yaffee, Steven L. 1997. Why Environmental Policy Nightmares Recur. Conservation Biology 11, no. 2: 328-37.

1997. Why environmentla policy nightmares recur. Conservation Biology 11, no. 2: 328-37.

Yaffee, Steven L., and Julia M. Wondolleck. 2000. Making Collaboration Work. Conservation 
Biology in Practice 1, no. 1: 17-25.

Yanda, P. Z., and N. F. Madulu. 2005. Water Resource Management and Biodiversity Conservation in the Eastern Rift Valley Lakes, Northern Tanzania. Physics and Chemistry of the Earth 30, no. 11-16: 71-725.

Yankelovich, Daniel. 1991. Coming to Public Judgment: Making Democracy Work in a Complex World. Syracuse, NY: Syracuse University Press.

Young, A. 1989. Agroforestry for Soil Conservation. 23-243. Wallingford, UK: CAB International.

Young, Emily. 2001. State Intervention and Abuse of the Commons: Fisheries Development in Baja California Sur, Mexico. Annals of the Association of American Geographers 91, no. 2: 283-306.

Young, Oran. 1980. International Regimes: Problems of Concept Formation. World Politics 32, no. 3: 331-56.

Young, Zoe, and Geroge \& Boehmer-Christiansen Sonja Makoni. 2001. Green aid in India and Zimbabwe - conserving whose community? Geoforum 32: 299-318.

Yu, Ching-Yun. 2002. "Evaluating Cutoff Criteria of Model Fit Indices for Latent Variable Models with Binary and Continuous Outcomes." UCLA.

Yung, Laurie, and Wayne A. \& Belsky Jill M. Freimund. 2003. The Politics of Place: Understanding Meaning, Common Ground, and Political Difference on the Rocky Mountain Front. Forest Science 49, no. 6: 855-66.

Zaag, Pieter van der. 2005. Integrated Water Resource Management: Relevant Concept or Irrelevant Buzzword? A Capacity Building and Research Agenda for South Africa. Physics and Chemistry of the Earth 30, no. 11-16: 867-71.

Zbicz, Dorothy C. 1999. The "Nature" of Transboundary Cooperation. Environment 41, no. 3: $15-16$.

Zelditch Jr., M. 2001. Theories of legitimacy. In The Psychology of Legitimacy: Emerging Perspectives on Ideology, Justice, and Inter-group Relations. Eds. J. Jost, and B. MajorCambridge: Cambridge University Press.

Zelditch, M. Jr., and H. A. Walker. 1984. Legitimacy and the stability of authority. Advances in Group Processes 1: 1-25.

Zeng, H., D. Z. Zui, and X. B. Wu. 2005. Human disturbances on landscapes in protected areas: a case study of the Wolong Nature Reserve. Ecological Research 20, no. 4: 487-96.

Zwart, Ivan. 2003. A Greener Alternative? Deliberative Democracy Meets Local Government. Environmental Politics 12, no. 2: 23-48. 